\title{
INTERFACES DOS RISCOS URBANOS NA REGIÃO METROPOLITANA DE SÃO PAULO
}
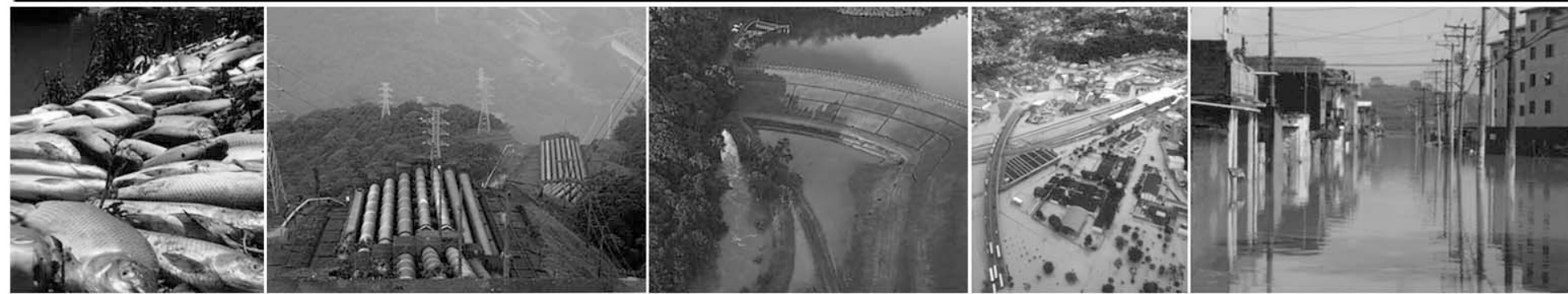

Renata M. P. Moreira

Tese apresentada ao Programa de PósGraduação da FAU-USP como parte dos requisitos para obtenção do título de Doutora em Arquitetura e Urbanismo

Área de Concentração: Habitat Orientador: Ricardo Toledo Silva

São Paulo, Outubro de 2018 
Autorizo a reprodução e divulgação total ou parcial deste trabalho, por qualquer meio convencional ou eletrônico, para fins de estudo e pesquisa, desde que citada a fonte.

Catalogação na Publicação Serviço Técnico de Biblioteca

Faculdade de Arquitetura e Urbanismo da Universidade de São Paulo

Moreira, Renata

Interfaces dos Riscos Urbanos na Região Metropolitana de São Paulo / Renata Moreira; orientador Ricardo Toledo

Silva. - São Paulo, 2018.

258 .

Tese (Doutorado) - Faculdade de Arquitetura e Urbanismo da Universidade de São Paulo. Área de concentração: Habitat.

1. Gestão de Riscos Urbanos. 2. Abordagem de Múltiplas Ameaças. 3. Região Metropolitana de São Paulo. 4.

Infraestrutura Crítica. I. Silva, Ricardo Toledo, orient. II. Título.

Elaborada eletronicamente através do formulário disponível em: 〈http://www.fau.usp.br/fichacatalografica/> 


\section{Agradecimentos}

Esta pesquisa contou com apoio de bolsa Capes-CNPq no último ano de seu desenvolvimento. Para além dessa ajuda, várias contribuições foram importantes para auxiliar na abordagem de tema tão complexo.

Inicialmente, agradeço à orientação de Ricardo Toledo Silva, que me deu confiança para manter a complexidade do objeto, e não sucumbir às simplificações tentadoras de um corte temático nos riscos a serem analisados. Esse incentivo foi alimentado com sugestões às fontes mais diversas e questões muito atuais. Obrigada aos professores da área do Habitat por terem aceitado essa orientação pontual.

Agradeço também a todos aqueles que abriram espaço e me acolheram nas discussões da Câmara Temática de Gestão de Riscos Metropolitanos, e o faço, especialmente, em nome de Fernando Nogueira, Ronaldo Malheiros e Eduardo de Macedo.

À Elaine, da Defesa Civil de Franco da Rocha, agradeço a imensa abertura, atenção e disponibilização de informações e documentos. A Claudio, Denise, Cristina e Lídia, do Instituto Geológico, o tão atencioso diálogo, que me permitiu compreender e utilizar a consolidação de informações produzidas pelo Instituto, e também a Mariana e Letícia da Emplasa, que trabalham no desenvolvimento do SIM. No Jardim Pantanal, agradeço especialmente ao Instituto Alana, que abriu contato para os moradores e representantes do bairro e da Associação AMOJAP, e um obrigada especial à Sonia. Na EMAE, aos funcionários José Luppi, Mario Oliveira e Julio Pinfari. Da Sabesp, imensa gratidão a Nagip Abraão, antiga fonte do mestrado, que me apresentou a Nilzo Fumes, quem me permitiu compreender os aspectos operacionais do reservatório Paiva Castro. A Fernanda, da Sehab, pela conversa sobre os recursos do bolsa-aluguel, e Taís Tsukumo, pela abertura aos contatos. Agradeço também às conversas com Luiz Orsini, Orlando Natale e Wagner Isaguirre, Ana Paula Bruno, Angela Pilloto, João Taqueda, Celso Carvalho, e o convívio com Angelo Fillardo, João Meyer e Caio Santamore nas disciplinas PAE.

E como não poderia deixar de mencionar, a viabilidade do esforço aqui empreendido só foi possível com a ajuda de meus pais, que, com afinco se dedicam aos cuidados dos netos João e Aurora nos momentos de trabalho mais intenso. Ajuda também inestimável de minhas irmãs, Ana e Paula, de Margarete e Bernd, e a companhia de José. Espero que o trabalho esteja à altura de todo esse apoio de vocês. 


\section{Interfaces dos riscos urbanos na Região Metropolitana de São Paulo}

Diante do crescimento de ameaças extremas, a gestão do risco de desastres é um campo em transformação. Marcos internacionais, que promovem a preparação da resiliência física e financeira nos países, e a lei que institui a Política Nacional de Proteção e Defesa Civil, orientam a mudança de foco da resposta à prevenção, exigindo desdobrar o tema em agendas urbanas variadas. Compreender fatores que amplificam riscos é um dos pontos dessa agenda: em contextos adensados, há vulnerabilidade criada pela própria complexidade e interdependência de grandes sistemas de infraestrutura urbana. Sobre ela, a precariedade urbana acumula vulnerabilidades que podem não resultar em simples soma, mas na escalada dos riscos. Situações classificadas como baixo risco por um setor, quando associadas, podem desencadear efeitos de grande escala. Contribuindo como método para análise de riscos desse contexto, esta tese aborda dimensão desafiadora: a Região Metropolitana de São Paulo como segunda natureza. Compreende desastres como falhas de sistemas urbanos, e busca analisar interfaces em risco que podem amplificar impactos. Identifica, nos conflitos entre escalas local e regional, riscos residuais, falhas sistêmicas, de interface e de desenvolvimento intersetorial. Como base empírica, levanta instrumentos de planejamento e de identificação de risco já existentes e potenciais, e desenvolve análise quantitativa de ocorrências na abrangência Metropolitana para a última década. A análise qualitativa, baseada em notícias de jornal dos períodos com eventos mais críticos, foi desdobrada por meio de entrevistas e levantamento de processos, planos, propostas e programas existentes para 3 casos emblemáticos na RMSP: inundações persistentes no Jardim Pantanal; conflitos entre ocupação, controle de inundação e o Sistema Cantareira na região Norte; e conflitos nos aproveitamentos hídricos a oeste, com impactos extrametropolitanos. As conclusões conduzem a uma agenda específica de pesquisa urbana, como campo que pode conferir visão integradora e de coordenação ao tema da gestão de riscos.

Palavras-chave: inundações, abordagem de múltiplas ameaças, gestão de riscos urbanos, Região Metropolitana de São Paulo, infraestrutura crítica.

Abstract

\section{Interfaces of urban risks in São Paulo Metropolitan Area}

As extreme weather threats rise, disaster risk management field constantly change. Both the International policy frameworks, which promote physical and financial resilience to the countries, and the Brazilian National Policy on Civil Protection and Defense, are driving the focus from response to prevention. This requires a deeper and broader understanding of risk management in urban agenda. Understanding conditions that amplify risks is one of the points of this agenda: there are vulnerabilities created by the very complexity and interdependence of large urban infrastructure systems in large cities and metropolises. On them, urban precariousness overlaps vulnerabilities that may not result in simple sum, but in the escalating of risks. Situations classified as low risk by one sector, when associated, can trigger large-scale effects. Proposing a method for risk analysis of these situations, this thesis addresses a challenging dimension: the São Paulo Metropolitan Region and its second nature. It understands disasters as failures of urban systems, and analyzes interfaces at risk that can increase impacts. It identifies residual risks, interface and systemic failures, and intersectoral development gaps in local and regional cross-scale conflicts. The research was based on surveying existing and potential urban planning instruments and risk identification instruments, and on quantitative analysis of occurrences within the metropolitan area for the last decade. The qualitative analysis was based on newspaper reports from the periods with the most critical events. It was detailed through interviews and survey of existing processes, plans, proposals and programs for 3 emblematic cases in the São Paulo Metropolitan Area: floods in Jardim Pantanal, in the east region; conflicts between urban settlements, flood control and the Cantareira Water Supply System in the north region; and water resources conflicts in the west region, with extra-metropolitan impacts. The conclusions lead to a specific research urban agenda, as a field that might integrate and coordinate actions towards a more effective urban risk management.

Key words: floodings, all hazards approach, urban risk management, São Paulo Metropolis, critical infrastructure. 


\section{Lista de quadros e tabelas}

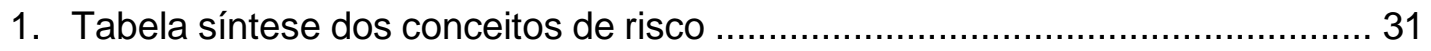

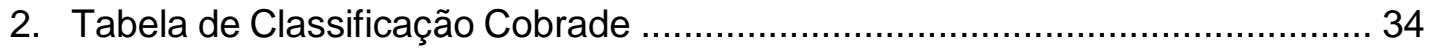

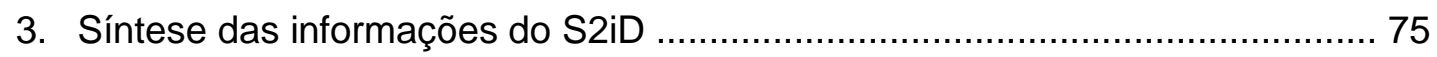

4. Tabela de Classificação dos instrumentos de diagnóstico, planejamento e ações - de riscos, urbano-ambiental ou setoriais ................... 80

5. Síntese dos sistemas de informações em desastres .................................... 107

6. Quadro de sistematização da primeira contagem dos dados de ocorrência na RMSP por ano calendário - 2007-2017

7. Quadro de sistematização e contagem dos dados de ocorrência na RMSP por ano hidrológico - 2006-2017

8. Contagem de ocorrências e mortes para na RMSP por tipo de ocorrência e por localidade para o período 2006-2017

9. Amplitude e intensidade dos efeitos das ocorrências na RMSP por ano hidrológico (2006-2017)

10. Amplitude e intensidade dos efeitos das ocorrências na RMSP por ano hidrológico e por tipo de ocorrência (2006-2017)

11. Efeitos crônicos e agudos das ocorrências na RMSP por localidade (2006-2017)

12. Efeitos crônicos e agudos das ocorrências na RMSP por localidade e por tipo de ocorrência (2006-2017)

13. Gradiente geral de ocorrências e mortes - Distribuição por ano hidrológico e localidade da RMSP entre 2006-2017

14. Gradiente de ocorrências geológicas - Distribuição por ano hidrológico e localidade da RMSP entre 2006-2017

15. Gradientes de ocorrências hidrológicas - Distribuição por ano hidrológico e localidade da RMSP entre 2006-2017

16. Gradientes de ocorrências de chuvas - Distribuição por ano hidrológico e localidade da RMSP entre 2006-2017

17. Indicadores de letalidade e proporção de ocorrências por domicílio - RMSP, por município, para o período 2006-2017

18. Gradiente do indicador de letalidade - Distribuição por ano hidrológico (2006-2017) e por localidade da RMSP

19. Gradiente do indicador de ocorrências por domicílio - Distribuição por ano hidrológico e localidade da RMSP (2006-2017) 149

20. Piores dias em quantidade de ocorrências na RMSP 
para o período 2006-2017

21. Piores dias em quantidade de mortes na RMSP

para o período 2006-2017

22. Piores dias em quantidade de localidades atingidas na RMSP para o período 2006-2017

23. Quantidade de dias críticos em cada ano hidrológico

24. Linha do tempo das notícias do período crítico de 2009-2010

25. Linha do tempo das notícias do período crítico de 2009-2010 no Jardim Pantanal

26. Esquema analítico dos sistemas setoriais urbanos envolvidos nos estudos de caso

27. Controles da calha Tietê-Pinheiros analisados no estudo EMAE

28. Matriz dos riscos identificados para a região do Jardim Pantanal

29. Matriz dos riscos identificados para o município de Franco da Rocha

30. Tabela de vazões limite de impacto e vazões de pico geradas nas sub-bacias ao longo do rio Juqueri

31. Esquema do método para determinar a cota de restrição para absorver o hidrograma com período de retorno de 10.000 anos

32. Síntese dos relatos prestados ao Ministério Público pela Sabesp e pelo NUDEC no evento de chuvas de março de 2016

33. Matriz dos riscos identificados - sistema hidráulico do rio Pinheiros 227 


\section{Lista de figuras}

1. Capa da Revista New York Magazine ......................................................... 12

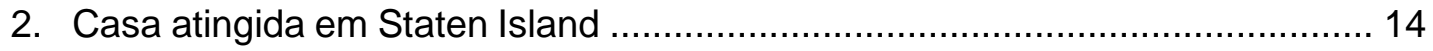

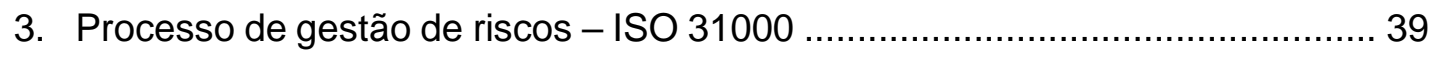

4. Análise Global do perfil de riscos e cobertura de seguros .............................. 56

5. Análise Global das perdas cobertas e não cobertas por seguros em 2016 ...... 56

6. Gráfico do crescimento de débito no Programa Nacional de Seguros Contra Inundações Americano .................................................... 60

7. Potencial de desenvolvimento soberano de seguros e proteção financeira

8. Ranking de mercados emergentes para seguros Swiss-Re............................ 63

9. Menu do site do sistema de informação S2ld .............................................. 75

10. Informações sobre Suscetibilidade a Movimentos de Massa e Inundações existentes para a RMSP disponíveis no SIM - Emplasa

11. Informações sobre Cartas de aptidão à urbanização existentes para a RMSP disponíveis no SIM - Emplasa

12. Informações sobre Setorizações de Risco existentes para a RMSP disponíveis no SIM - Emplasa

13. Fluxograma de ações, fases e agentes do PDN .

14. Espacialização das ocorrências geológicas, Boletim 67 IG

15. Mapa síntese de riscos geológicos e hidrológicos a partir de informações do IG com incorporação das manchas de inundação do PDMAT3 incorporados ao SIM - Emplasa

16. Espacialização das ocorrências do cadastro do IG e da COMDEC-SP para a RMSP. SIM-Emplasa

17. Mapa de áreas contaminadas na RMSP CETESB, 2017 - SIM-Emplasa

18. Síntese e localização dos estudos de caso 116

19. Quantidade de ocorrências por tipo e localidade ........................................... 128

20. Regionalização Emplasa ................................................................. 135

21. Infográfico: Falha no sistema de bombas do rio Pinheiros ............................. 165

22. Infográfico: Limite de armazenamento do Sistema Cantareira ........................ 170

23. Infográfico: ocorrências na RMSP nos dias 10 e 11 de março de 2016 ........... 180

24. Contagem de população suscetível a inundação na Várzea Tietê - Leste 191

25. Corte esquemático - conceito da proposta Via Parque 196 
26. Desenho de soluções ambientais propostas no projeto Renova SP Água

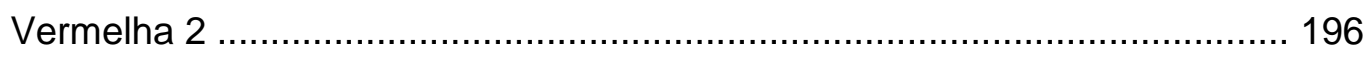

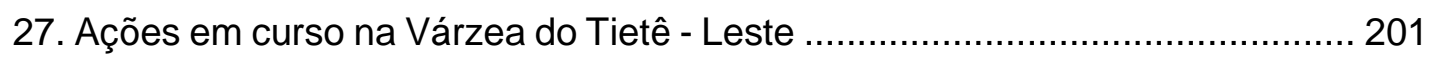

28. Perímetros e propostas para o PAI Água Vermelha ...................................... 202

29. Esquema da estrutura viária da Região Norte e zona de impacto do reservatório Paiva Castro .............................................. 208

30. Perspectiva e corte esquemático do Sistema Cantareira ............................... 210

31. Conjunto de fotos da inundação de Subestação em Franco da Rocha ........... 212

32. Cruzamento das manchas de suscetibilidade à inundação e localização de subestações elétricas - RMSP ............................................ 213

33. Manchas de inundação das manobras do Paiva Castro ................................. 221

34. Sistema hidro energético de Henry Borden - hidrografia e dispositivos .......... 224

35. Sistema hidro energético de Henry Borden - seção esquemática .................. 225 


\section{Sumário}

Introducão 12

\section{PARTE I - Conceitos e contextos em gestão de riscos e desastres}

Capítulo 1 - Transversalidade dos riscos

1.1 Contribuição da Teoria social dos riscos

para construir abordagens transversais

1.1.1 Um mundo de incertezas e riscos produzidos

1.1.2 Limites das teorias sociais dos riscos: retórica da catástrofe

e economia ausente

1.1.3 Da retórica da catástrofe aos problemas concretos

em uma sociedade de riscos 26

1.2 Atuar na interface: riscos cruzados, saberes cruzados 30

1.2.1 Terminologias dos campos da gestão de riscos e seus limites . 30

1.2.2 Sistemas fechados e riscos residuais: uma análise dos procedimentos propostos pela ISO 31000 e as lacunas para sua aplicação na gestão metropolitana .38

1.2.3 Por uma visão integrada dos riscos urbanos

I. Sobre o processo de planejamento .......................... 42

II. Sobre contextos geradores de risco ............................ 44

III. Sobre a coordenação de interfaces complexas ................. 44

Capítulo 2 - Contexto internacional das políticas para redução

de riscos: do socorro à prevenção e os princípios da diluicão de riscos ..........46 46

2.1 Principais diretrizes dos marcos internacionais ........................... 46

2.2 Redução ou diluição de risco: a política internacional de gestão

e proteção financeira a risco de desastre ..................................... 49

2.2.1 Títulos de catástrofe e Mercado de seguros: como funcionam? ................... 52

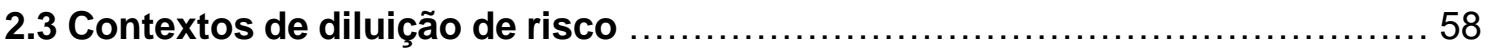

2.3.1 O Programa Nacional de Seguros

Contra Inundações norte-americano (NFIP) ............................... 58

2.3.2 Perfil das perdas e estado da arte dos mecanismos de

proteção financeira a desastres no Brasil .................................... 62

2.3.3 Mercado de seguros no Brasil ............................................ 67

Capítulo 3 - Institucionalizacão da gestão de riscos no Brasil

e na RMSP, e o desenvolvimento de informação. 70

3.1 Institucionalização da Defesa Civil e desenvolvimento de marcos regulatórios de gestão de riscos a desastres no Brasil 70 
3.1.1 Histórico das instituições de defesa e prevenção no Brasil:

origem militar de uma necessidade urbana ................................... 70

3.1.2 A Política Nacional de Proteção e Defesa Civil de 2012 .......................... 72

3.2 Níveis da gestão de riscos: arranjos e lacunas

entre as esferas local e federal

3.2.1 Instrumentos, diagnósticos e ações do

campo de gestão de riscos e desastres

3.2.2 Instrumentos de planejamento urbano e ambiental

em relação ao controle de riscos 96

3.2.3 Instrumentos de planejamento setoriais

em relação ao controle dos riscos - possíveis integrações 98

\section{PARTE II - Contexto dos riscos na RMSP e estudos de caso}

Capítulo 4 - Aspectos metodológicos e as informacõos sobre desastres ….....105

4.1 As informações sobre desastres .............................................. 105

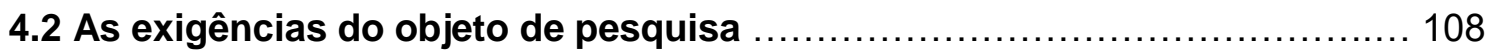

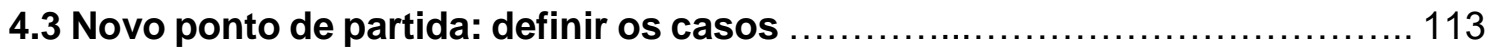

Capítulo 5 - Contexto geral dos riscos metropolitanos:

análise quantitativa das ocorrências na RMSP a partir

do Cadastro Geral do Instituto Geológico - 2006-2017 ........................ 117

5.1 Aspectos gerais da contagem e organização dos dados .................... 117

5.2 Análise geral de ocorrências no período 2007-2017 ........................ 122

5.2.1 Análise da variável tempo: anos hidrológicos ............................... 122

5.2.2 Análise da variável categoria ............................................. 124

5.2.3 Análise da dispersão especial ............................................... 126

I. $\quad$ Amplitude e intensidade .................................... 129

II. Situações crônicas e agudas ................................... 133

5.2.4 Indicadores de letalidade por localidade e registros por número

de domicílios: relativização do peso do município de São Paulo ........................ 143

5.2 .5 Análise dos piores dias ................................................. 150

5.3 Síntese geral das ocorrências metropolitanas como contexto

para os estudos de caso selecionados

Capítulo 6 - Análise do tempo: notícias de jornal

dos momentos críticos na RMSP

6.1 O ano crítico 2009-2010 e inundações duradouras no Jardim Pantanal ..... 158

6.1.1 Um período de ameaça atípica ............................................. 159

6.1.2 Principais consequências e as panes como agravantes ....................... 162 
6.2 Março de 2016: criticidade da região norte e operações

de manobras em represas

6.3 Novembro de 2014: efeitos da crise de estiagem no

sistema hídrico do Médio Tietê

Capítulo 7 - Análise do espaco: diagnóstico dos contextos

crônicos na RMSP 190

7.1 O Jardim Pantanal 190

7.1.1 Caracterização geral: riscos e interfaces ..................................... 190

7.1.2 Soluções, limitações, potencialidades ...................................... 195

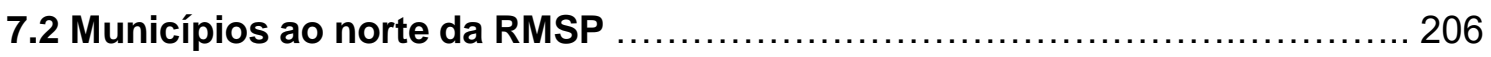

7.2.1 Caracterização geral: riscos e interfaces ................................... 206

7.2.2 Soluções, limitações, potencialidades ...................................... 214

7.3 Controles de quantidade e qualidade da água a oeste ...................... 223

7.3.1 Caracterização geral: riscos e interfaces ........................................ 223

7.3.2 Soluções, limitações, potencialidades ..................................... 228

\section{PARTE III - Conclusões}

\section{Capítulo 8 - Interfaces de escala e escopo:}

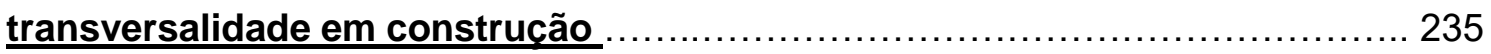

I. Mudanças de rumos e o contexto da pesquisa ............................ 235

II. Métodos utilizados, limitações de informações e desdobramentos ........ 238

III. Casos: percepção geral das falhas interconexas no contexto metropolitano

IV. Uma agenda de gestão de riscos metropolitanos que considere processos da natureza segunda ....................................... 243

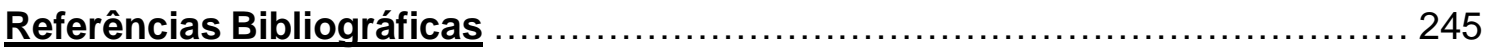

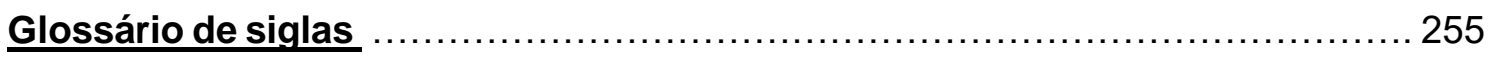




\section{Introdução}

"...what is unique about cities is that they are dense concentrations of infrastructure."

Benjamin Sims

"Diante das ameaças da segunda natureza, absorvida no sistema industrial, vemo-nos praticamente indefesos. Perigos vêm a reboque do consumo cotidiano. Eles viajam com o vento e a água, escondem-se por toda a parte, e junto com o que há de mais indispensável à vida - o ar, a comida, a roupa, objetos domésticos - atravessam todas as barreiras altamente controladas de proteção da modernidade."

Ulrich Beck

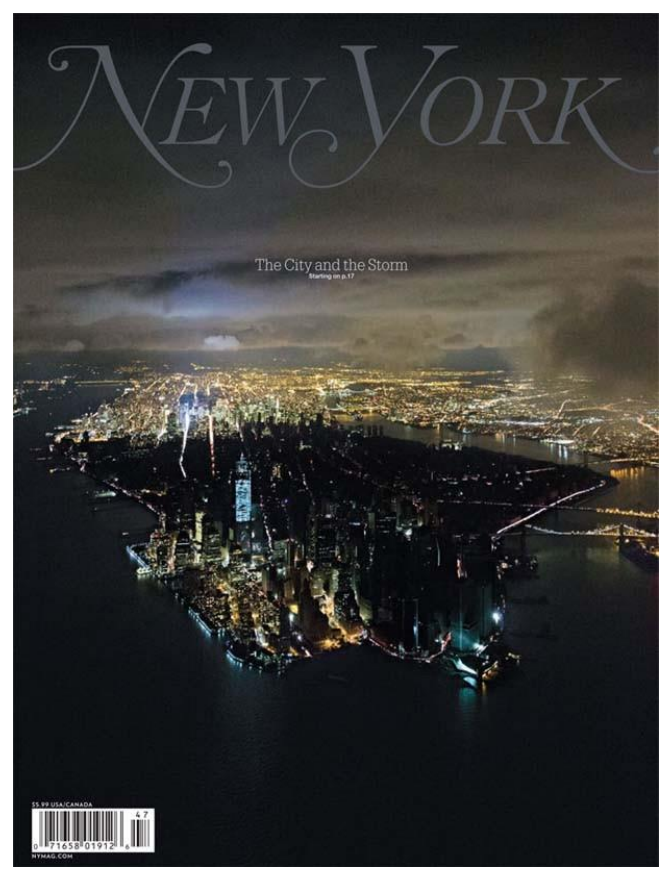

FIG 1. Capa da revista New York Magazine, com a parte sul da Manhattan sem energia.

As motivações que me levaram ao tema da gestão de risco envolvem uma experiência pessoal. Entre os anos de 2012 e 2013, morando na cidade de Nova lorque, vivenciei o impacto do Furacão ${ }^{1}$ Sandy e alguns danos causados à cidade. Para uma urbanista, o fato que primeiro chamou atenção foi a ampla comunicação imediatamente anterior ao evento, com avisos SMS e e-mails enviados a todos os residentes da cidade - inclusive turistas que estavam em visita - sem que, ao menos, tivessem sido fornecidos dados telefônicos ou cadastramento a qualquer organização específica. Os mercados ficaram superlotados e tiveram estoques esvaziados, e as mensagens solicitavam que se permanecesse dentro das casas durante a passagem do furacão. Moradores acostumados aos avisos na temporada de furacões duvidavam de consequências severas, e eram noticiadas discordâncias de moradores com maior probabilidade de serem atingidos em relação ao zoneamento de risco pré-estabelecido.

\footnotetext{
${ }^{1}$ Na mídia e nos avisos o termo frequente para o evento é 'hurricane', mas tecnicamente foi classificado como 'superstorm'.
} 
Segundo estranhamento: que zoneamento é esse? Que comunicação é essa? Havia ali alguma organização prévia e de amplo alcance com a qual, mesmo sendo urbanista, tendo experiência profissional com atuação em espaços muito vulneráveis, construídos de forma precária, e ter feito uso profissional de informações de relatórios de risco, jamais havia dirigido minha atenção: a organização preventiva de grande escala.

Estas impressões levaram às primeiras formulações das propostas de pesquisa: compreender o panorama da gestão de riscos nas cidades brasileiras em comparação com o panorama internacional, e como, em cenários com distintas ameaças, os princípios de gestão de riscos são incorporados aos instrumentos de planejamento e gestão urbanas.

Outros fatores do impacto do desastre foram melhor compreendidos após adentrar ao tema da gestão de riscos, e conduziram este trabalho a outra problematização. Apesar da grande quantidade de árvores derrubadas e ruas parcialmente alagadas, em Manhattan, a estrutura da grande maioria das habitações permaneceu em segurança. $\mathrm{O}$ que mais impactou a cidade foram efeitos em seu funcionamento, as panes e interrupções na distribuição elétrica, deixando diversos setores da cidade sem energia: mais de um milhão de economias por pelo menos 2 dias, e, em distritos mais distantes do centro dinâmico, mais de 8 mil economias ainda sem energia 60 dias após o evento. Na decretação de emergência, todo o transporte da cidade foi paralisado (ônibus, metrô, pontes e túneis), além de escolas, serviços, e mesmo a Bolsa de Valores. Com a subida do nível das águas em mais de 4 metros, o alagamento de túneis, linhas de metrô e danos a equipamentos elétricos manteve o fechamento do sistema de circulação por ao menos 4 dias, após os quais apenas os ônibus e algumas linhas de metrô voltaram a funcionar. Alguns túneis e pontes foram reabertos apenas após 15 dias, e, ainda em junho do ano seguinte, havia partes mais afetadas da cidade - justamente aquelas com maior dependência e menor redundância de conexões de transporte - que não tiveram o serviço de metrô reestabelecido, ficando desconectadas da dinâmica urbana ao longo de meses. Danos mais severos a residências e mortes (53 em todo o estado) ocorreram principalmente nessas áreas que permaneceram desconectadas, as frentes aquáticas de Rockaway Beach e Red Hook, no Brooklyn, algumas ocupações residenciais em zonas baixas em Staten Island, e Breezy Point, no Queens, além da região contígua em Long Island. Geralmente locais onde, além das zonas demarcadas como sujeitas a inundação, as casas são mais vulneráveis, construídas com sistemas mais flexíveis (estruturas e vedações de madeira). Além desses efeitos mais graves e prolongados em distritos mais distantes do centro financeiro, é fato que, por ao menos quatro dias, Manhattan parou completamente: mercados sem estoque, escolas sem aulas, alguns hospitais e parques fechados, circulação totalmente interrompida e falta de eletricidade. Características que, mais do que revelarem vulnerabilidades frente às ameaças naturais, revelam a dependência e fragilidade urbana em relação aos dispositivos não naturais, interconectados e interdependentes. 


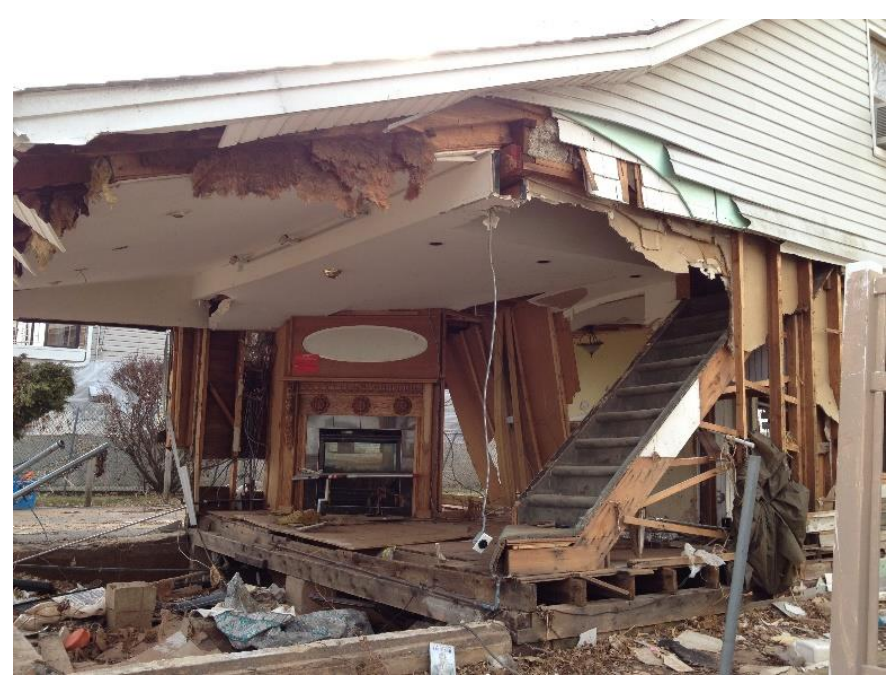

FIG. 2. casa de padrão médio destruída em Staten Island, NYC, 2012 (foto da autora).

Ao analisar outros contextos recentes, ameaças que desencadeiam impactos amplos e efeitos importantes em sistemas interdependentes têm se mostrado recorrentes. $O$ furação Harvey, que atingiu o Texas em 2017, sobretudo a cidade de Huston, causou tanto danos diretamente relacionados às tempestades e inundações (com a elevação de nível d'água agravada por processos de subsidência decorrente da densa ocupação e impermeabilização da cidade), como danos indiretos de amplo alcance: a capacidade de toda a cadeia produtiva da indústria de refino de petróleo e gás na região e no Golfo do México foi reduzida, gerando escassez de combustível e subida de preços generalizada; barragens de lagos, represas e mananciais de água tiveram que ser operadas para acomodar o volume da tempestade prevista, obrigando à evacuação e, ainda assim, o transbordamento da capacidade de um dos reservatórios fez com que o Centro Espacial da NASA fosse fechado; a subida do nível d'água interrompeu o bombeamento numa estação de abastecimento de água, interrompendo o fornecimento em algumas cidades; e a desativação do sistema de refrigeração em uma indústria química causou explosão e incêndio da planta industrial. Em 2011, o sismo e tsunami de Sendai levou, além do grande número de mortes e danos em toda a região, a efeitos de falhas nos refrigeradores das usinas nucleares de Fukushima, obrigando à evacuação de toda a cidade. O furacão Katrina em 2005 também resultou em efeitos de redução na produção de petróleo, algo recorrente na região do Golfo do México na temporada de furacões, mas o mais marcante nesse evento foi a inundação de $80 \%$ da superfície da cidade de Nova Orleans, resultante da combinação da passagem do furacão com a sequência de falhas no conjunto de barragens e diques que protegem a cidade da subida de nível d'água do rio Mississipi e do Lago Pontcharttrain. A questão das falhas nas barragens, relacionada como causa de $2 / 3$ dos efeitos desse desastre, foi objeto de diversos estudos e discussões que concluíram pela responsabilização técnica do Corpo de Engenheiros do Exército dos Estados Unidos (USACE) em virtude de decisões construtivas e premissas de projeto incorretas nas estruturas, mas é possível compreender mais amplamente as causas como de ordem sócio-técnica, pois envolvem aspectos institucionais e de gestão das estruturas, como falta de 
financiamento para execução completa do sistema projetado em 1965, além de manutenção insuficiente ${ }^{2}$.

O detalhamento de alguns dos efeitos do furacão Katrina permitem compreender um pouco melhor a relação entre encadeamento e cruzamento de causas e a ordem de grandeza dos impactos. Tão logo o olho do furacão tocou o continente na cidade de Nova Orleans, os sistemas elétricos, de telefonia e conexão com internet foram destruídos ou danificados. Torres usadas para comunicação de emergência via rádio também foram danificadas. Na mesma manhã, as barragens começaram a falhar e a cidade passou a ficar submersa. Com a inundação, a maioria das vias ficou interditada, e a rede de esgotos parou de funcionar. Pouco depois, também o abastecimento de água parou. Equipamentos públicos que poderiam prestar socorro - escolas, hospitais e instalações policiais - estavam submersos. Com a subida do nível de água, geradores de energia de segurança (backup) foram inundados, deixando de servir as poucas torres de comunicação de rádio que ainda funcionavam, e as equipes que trabalhavam na resposta ficaram sem comunicação, sem suprimentos e com pouca mobilidade ${ }^{3}$. No Estado da Louisiania foram mais de 1500 mortes, com corpos resgatados apenas depois de muitos dias. Cerca de 25 mil pessoas ficaram por dias abrigadas no estádio Superdome, que posteriormente também sofreu com alagamentos. Aproximadamente 200 mil casas ficaram alagadas por semanas. Foram necessárias evacuações a outras cidades, e a falta de solução posterior levou a migração de pessoas por todo o país.

Aquela experiência pessoal e estes exemplos mostram impactos que são sentidos e vivenciados mais amplamente não apenas pelo caráter extremo das ameaças, mas pela decorrência de efeitos das ameaças sobre infraestruturas, e de variadas interdependências entre diversos sistemas de infraestrutura urbana. Ao se atingir dispositivos de infraestruturas e suas interfaces, os efeitos dos impactos são cruzados, somados, amplificados e irradiados.

Em São Paulo, o perfil de riscos está longe de apresentar situações de danos e mortes de grandes proporções. Se compararmos o total de mortes dos últimos dez anos na RMSP (205 óbitos ${ }^{4}$ ) com eventos como o da Região Serrana no Rio de Janeiro em 2011 (com saldo de 918 óbitos), ou aos casos anteriormente mencionados de terremotos e furacões, São Paulo tem um perfil de riscos de baixo impacto, em uma região não suscetível a ameaça e processos de grande magnitude. Os riscos altos são pontuais e localizados, e poderiam ser gerenciados por uma efetiva gestão e controle urbanos. No entanto, alguns eventos recentes, como a crise hídrica de 2014-15, ou a necessidade de manobras em represas do sistema Cantareira nos anos de 2011 e 2016, mostram que aqui, em algumas situações, o gerenciamento de riscos precisa lidar com a probabilidade de impactos que podem assumir grande escala e amplitude em virtude da complexidade das funções que compõem o território urbano.

\footnotetext{
${ }^{2}$ LITTLE, 2010.

${ }^{3}$ SIMS, 2010.

${ }^{4}$ De acordo com Cadastro de Eventos Geodinâmicos e Desastres do Estado de SP - Instituto Geológico, com contagens e quantificações detalhadas nos capítulos 4 e 5.
} 
Assim, a pesquisa sofreu ajustes no objeto para identificar e compreender essas especificidades de ocorrências relacionadas a riscos cruzados, encadeamento de efeitos, falhas em dispositivos e riscos nas interfaces entre sistemas setoriais de infraestruturas, que sugeriam ser relevantes em ambientes metropolitanos complexos.

Ao analisar o desenvolvimento das políticas de gestão de riscos no Brasil e em São Paulo, a percepção foi a de que estamos em plena transformação de contexto, principalmente após a formulação da Política Nacional de Prevenção e Defesa Civil (PNPDEC, de 2012), com maior incidência do tema da gestão de riscos e adaptação a extremos climáticos na agenda urbana. No entanto, a abordagem dos riscos cruzados em contextos complexos é pouco levantada e desenvolvida dentro do tema da gestão de riscos e prevenção a desastres, tanto no cenário nacional como internacional, e também nas discussões locais de governança de riscos metropolitanos.

A fim de abordar este tema, o objeto foi redefinido para um limite em que essa problematização é relevante: a Região Metropolitana de São Paulo, por meio de eventos recentes mais significativos, com identificação de casos que pudessem ilustrar possíveis interações de riscos entre sistemas. Partindo desses pressupostos, este trabalho foi construído em diálogo com o acompanhamento das discussões de governança de riscos metropolitanos conduzidos pela Câmara Temática de Gestão de Riscos Metropolitanos - CTM-GRAU, vinculada ao Conselho de Desenvolvimento Metropolitano da RMSP.

Como visão geral, na primeira parte, no capítulo 1, são abordados aspectos conceituais sobre riscos. Na seção 1.1, os conceitos são abordados do ponto de vista sociológico das teorias críticas de grande amplitude, da sociedade dos riscos, rumo a teorias do concreto, pelo estudo de falhas e efeitos encadeados no funcionamento das cidades. Na seção 1.2, os conceitos sobre riscos são abordados do ponto de vista objetivo - dos conceitos básicos da ciência perita sobre riscos rumo a abordagens transversais, que podem ser desenvolvidas pela área de estudos urbanos, sobretudo para riscos cruzados ou na interface entre sistemas.

Nos capítulos 2 e 3 são abordados os contextos de desenvolvimento das políticas de gestão de riscos e desastres: dos protocolos internacionais, bem como o cenário de desenvolvimento de mecanismos de proteção financeira nesses cenários, no capítulo 2 , e o contexto de desenvolvimento do marco da política nacional e do contexto institucional metropolitano sobre gestão de riscos, no capítulo 3.

$\mathrm{Na}$ segunda parte, são desenvolvidos os estudos empíricos. No capítulo 5, são apresentados os resultados do trabalho quantitativo com o Cadastro Geral de Eventos Geodinâmicos e Desastres do Instituto Geológico para a abrangência do universo metropolitano e para a série histórica da última dácada. Estas análises foram desenvolvidas a fim de contextualizar o cenário dos estudos de caso e avaliar sua relevância no universo metropolitano: a amplitude e magnitude dos impactos e as localidades submetidas a efeitos crônicos e críticos.

O capítulo 4 apresenta alguns aspectos metodológicos das análises quantitativas e dos estudos de caso em relação:

- à premissa parcialmente discutida no capítulo 1, de que os métodos usuais de análise possibilitam que riscos nas interfaces entre sistemas setoriais sejam tratados 
como desprezíveis, de baixa probabilidade, ou baixo impacto dentro de determinado sistema de gestão de riscos ao qual pertence;

- e em relação à hipótese de que em contextos urbanos densos e complexos, sob ameaças extremas, riscos cruzados, entre sistemas ou em suas interfaces devem ser considerados fator de agravamento dos impactos individuais de cada ocorrência. A soma de seus efeitos pode definir categorias de riscos mais altos e potencialmente catastróficos a partir de riscos tidos como baixos pelo sistema setorial que o gerencia.

Foram selecionados 3 estudos de caso, que são analisados nos capítulos 6 e 7: as inundações recorrentes na região do Jardim Pantanal, que foram duradouras no ano de 2009-2010; as manobras no Reservatório Paiva Castro em Franco da Rocha em contextos de eventos chuvosos extremos em 2011 e 2016; e o risco residual da operação de abertura dos descarregadores do reservatório de Pirapora do Bom Jesus na Bacia do Médio Tietê, com efeitos no município de Salto, em novembro de 2014.

O capítulo 6 trata dos aspectos qualitativos dos casos, articulados com as datas e anos resultantes das análises quantitativas das ocorrências, realizadas no capítulo 5 . A análise qualitativa foi feita a partir da leitura sistemática de notícias de jornal dos períodos destacados no capítulo 5 e relacionados aos casos pré-definidos. No capítulo 7 são apresentados, para cada caso, diagnósticos das soluções, planos, protocolos operacionais entre outras medidas existentes em cada contexto, bem como conflitos e insuficiências desses instrumentos, e as potencialidades e acertos necessários para maior efetividade na articulação da gestão de riscos com mecanismos e instrumentos da gestão urbana e metropolitana.

No capítulo 8 são apresentadas as considerações finais, que se dirigem à necessária integração entre escopos e escalas, e apontam alguns desdobramentos necessários a futuras agendas de pesquisa que surgiram, principalmente, no desenvolvimento das análises quantitativas. 
PARTE I - Conceitos e contextos em gestão de riscos e desastres 


\section{Capítulo 1 - TRANSVERSALIDADE DOS RISCOS \\ 1.1 Contribuição da teoria social dos riscos para construir abordagens transversais}

\subsubsection{Um mundo de incertezas e riscos produzidos}

Enquanto áreas das ciências naturais aplicadas e ciências exatas se dedicam ao controle dos riscos pela investigação minuciosa do comportamento de determinados elementos da matéria envolvidos no processo - a coesão das partículas nos diferentes tipos de solo, suas condições de desagregação, a relação com a presença de água; ou - comportamento hidrológico em suas diversas fases, probabilidades de desencadeamento de processos pelo estudo da frequência das ameaças - ao urbanista cabe investigar a interação entre elementos construídos e o meio físico, e analisar sistematicamente, pela leitura dos efeitos dos processos indesejados, o suporte (o espaço) e a produção social das condições finais de risco, a interação entre suscetibilidades do meio e vulnerabilidades da ocupação. Ainda é preciso encontrar lugar específico para que a participação do urbanista e dos estudos urbanos possa contribuir de forma relevante ao campo da gestão de riscos - e este parece ser um momento propício, pois o cenário da gestão de riscos tem se mostrado como um campo em transição. Transição não apenas pela mudança de paradigma nos aspectos práticos, do gerenciamento do desastre à prevenção e gestão do risco. Segundo alguns teóricos, vivemos uma mudança de paradigma da própria ciência enquanto campo perito.

No final da década de 1980 e início da década de 1990, o conceito de risco passou a ocupar lugar de destaque nas teorias sociais. Considerados, sobretudo os riscos ambientais e tecnológicos de grande impacto, como chaves para o entendimento da modernidade, os principais autores dessa tendência - Ulrich Beck e Anthony Giddens buscaram novo enfoque para iluminar questões relativas a conflitos sociais, crise da ciência (no conflito entre conhecimento perito e leigo em um mundo de incertezas), novos pressupostos na forma de fazer política, e à atuação de agentes em esferas políticas derivadas das arenas de risco (GUIVANT, 1998:3).

Até a década de 1980, a literatura sobre risco refletia com certa uniformidade a crença de que riscos poderiam ser objetivamente definidos, e que essa definição era tarefa exclusiva de cientistas e engenheiros, uma comunidade "perita". Recusar essas verdades objetivas seria uma atitude leiga e irracional. Os primeiros a desafiarem esta noção foram a antropóloga americana Mary Douglas e o cientista político Aaron Widalvsky, em 1982, com a publicação do Livro Risk and Culture: an Essay on the Selection of Technological and Environmental Dangers. Neste livro, dois questionamentos - por que certos riscos são enfatizados enquanto outros são ignorados? ou, por que, em dado momento, a poluição foi escolhida e amplamente aceita como fonte de preocupação sobre riscos e ameaças? (HANNIGAN, 1995) apontam para a questão de como se escolhe, define e prioriza um risco sobre outro.

Os autores defendem que as respostas a esses questionamentos são culturais, não objetivas. Dependem de visões de mundo mais ou menos afeitas ao fatalismo, à crença no mercado, no Estado ou em ações comunitárias (HANNIGAN, 1995; GUIVANT, 1998; 
DOUGLAS, 2003). Por isso, teorizaram sobre percepções de riscos: construídas socialmente, representam a competição de definições sobre o que configura ou não configura risco, pautadas, em última instância, por julgamentos morais baseados em crenças (sejam elas da ciência tradicional, de uma 'ciência do verde', ou de premissas místicas) sobre a melhor forma de organizar a sociedade (HANNIGAN, 1995). A tendência vivida no cotidiano da pós-modernidade industrial, em que novas situações de risco são constantemente identificadas, experimentadas, suplantam as anteriores, e criam um campo relativista de conceitos em disputa, é o contexto que ilustra essa teoria e as teorias de 'Sociedade do Risco' que se desenvolveram a partir deste momento.

Por mais que se tenham acumulado críticas refutando o caráter relativista da teoria de Douglas e Widalvsky, permaneceu a abertura para o fato de que, mesmo que decisões acerca da definição de riscos sejam tomadas com base em evidências científicas, ainda assim, não são isentas de julgamentos sociais ao se aplicar critérios objetivos. E também, de que as percepções do risco diferem entre populações que vivem oportunidades de vida diferentes, e entre atores políticos e sociais com diferentes poderes e influência: moradores afetados, executivos de companhias, poder governamental e burocrático, tecnocracias. Diferentes percepções de risco encobrem diferenças na distribuição social de riscos e na exposição ao risco. Este panorama teórico mostra que é importante o papel daquele que, compreendendo processos espaciais, estabelece o diálogo entre diferentes percepções e formulações de risco, e isto pode fazer parte da construção do lugar do urbanista nas discussões sobre riscos.

O efeito desse debate é melhor percebido na formulação e uso do "princípio da precaução" no julgamento de causas que envolvem situações de risco. Na linha das contestações formuladas pela crítica ambientalista, que se avolumaram na década de 1990, a impossibilidade da ciência em fornecer provas absolutas - evidências inequívocas e seguras - sobre determinados impactos, mas apenas estimativas de probabilidades variáveis, sem consenso entre pares, fomentou um alarmismo socialmente ativo em relação às questões ambientais. Nesse cenário, o "princípio da precaução" tornou-se o argumento frequentemente aceito e praticado para ação oficial de regulação e controle em relação a riscos ambientais: se existe alguma razão para suspeitar que determinada substância ou prática está causando danos ao ambiente, então a ação deve ser suspeita e suspensa até que se prove que não produz tais danos. A razão por trás deste pressuposto é a de que possa ser tarde demais para responder efetivamente ao se aguardar pela apuração científica das situações, o que, muitas vezes, paralisa projetos socialmente úteis e necessários.

Guiddens ${ }^{5}$ explica os novos cenários de risco pelas incertezas. Muitas das mudanças que a teoria da Sociedade de Risco procura evidenciar são forjadas pelo impacto da ciência e tecnologia em atividades do nosso dia a dia mais banal, inscritas materialmente no ambiente. À medida que as inovações se aceleram, novas tecnologias penetram mais e mais em nossa vida cotidiana. Essa situação, entretanto, não tem correspondência com o aumento de certezas ou a segurança sobre a nova realidade que nos preenche - e, muito provavelmente, a correspondência é exatamente inversa.

${ }^{5}$ GUIDDENS, 1999. 
Não se trata de uma nova ciência, mas do limite das próprias bases da ciência como tal, assentada sobre um processo de constante revisão e avanço em busca de novos conhecimentos. A diferença é que, antes, esses processos eram isolados do domínio público, e hoje há contato direto com embates científicos como parte de nossa rotina ${ }^{6}$.

A característica definitiva do que Beck? define por "Sociedade de Risco" (e que Giddens define por "Riscos Produzidos" [manufactured]) é a de uma sociedade que vive além dos limites da tecnologia moderna, que vive a alta tecnologia numa fronteira ampliada, a qual não é mais possível compreender ou ter completo domínio das consequências, mas que carrega, também, um lado positivo, de possibilidades. Para Guiddens, duas transformações fundamentam o novo momento em que vivemos: o fim da natureza e o fim da tradição. Por fim da natureza, a passagem do medo de eventos naturais ao medo do que a humanidade pode causar à natureza. E pelo fim da tradição, a existência de uma realidade em que a vida não mais é vivida como destino, mas como projeto.

O que Beck caracteriza como "Sociedade de Risco", Guiddens explica por meio de termos duplos, dois momentos da sociedade aos quais correspondem diferentes tipos de percepção e objetivação de riscos. Os dois primeiros séculos da existência da sociedade industrial foram dominados pelo que ele chama de "riscos externos", riscos que podem afetar indivíduos de forma inesperada, mas que ocorrem com certa regularidade e frequência suficientes para serem previsíveis, mensuráveis e mitigáveis por um agente de segurança coletiva. O Estado de Bem-Estar Social foi o padrão predominante de segurança coletiva desse período. Entretanto, uma época que vive além da natureza e da tradição seria caracterizada pela transição dos "riscos externos" aos "riscos produzidos" [manufactured]. Riscos produzidos seriam aqueles criados na progressão do desenvolvimento humano, por meio da ciência e da tecnologia.

As incertezas criadas, produzidas [manufactured], são dissipadas socialmente entre atores diversos e em nossas vidas singulares - e não mais inscritas em nosso corpo coletivo, ou expressos claramente como riscos coletivos. Essa visão da modernidade reflexiva ${ }^{9}$ não é apenas apocalíptica, pois contém novas oportunidades para o debate político e para o engajamento político. Nossa nova relação com a ciência seria potente, não mais da forma tradicional, da ciência como entidade que se respeita e que se vive de fora. As relações com a ciência atualmente seriam mais dialógicas, e estariam longe da simples aceitação de verdades absolutas.

\footnotetext{
${ }^{6}$ As pesquisas com alimentos são tomados como exemplo: informações disponíveis na mídia ao público em geral ora trazem informações do benefício de certos alimentos à saúde, ora os mesmos alimentos podem ser submetidos à controvérsia e tornarem-se vilões.

${ }^{7}$ BECK, 2011.

8 "...somos testemunhas oculares - sujeitos e objetos - de uma ruptura no interior da modernidade, a qual se destaca dos contornos da sociedade industrial clássica e assume uma nova forma - a aqui denominada 'sociedade industrial de risco.'” (BECK, 2011: 12).

${ }^{9}$ A definição de risco apresentada por Guiddens corresponde às noções de modernização simples e modernização reflexiva, derivadas das teorias da modernidade reflexiva de Habermas, e disseminadas mais recentemente por Bauman. A ideia de 'Segunda Natureza' está indiretamente presente nas formulações de Guiddens, e mais claramente enunciada nas formulações de Beck. Nenhum dos sois autores fazem referência clara ao termo 'Segunda Natureza' como conceito do materialismo dialético, que está presente desde as formulações de Hegel sobre a natureza e produção humana, recuperado por Marx e trabalhado também por autores como Henri Lefebvre e David Harvey.
} 
Suas considerações também permitem repensar a ideia de Estado de Bem-Estar como um Estado em crise. Não se trata apenas de crise fiscal; para o autor, essa forma de Estado está em crise justamente no gerenciamento dos riscos produzidos. No Estado de Bem-Estar, a ideia de segurança a riscos externos correspondia a atores que podiam ser institucionalmente definidos e responsabilizados. Na revisão deste cenário, riscos estariam ligados também a necessidades de responsabilizações além do Estado, de atores institucionais indefiníveis, pois podem ser difusas, dificilmente imputadas, e merecerem debates a respeito de novos valores. No novo cenário, seria urgente discutir como conectar direitos com responsabilidades objetivas e difusas ${ }^{10}$.

$\mathrm{Na}$ literatura brasileira sobre riscos, essas referências estão presentes principalmente em Acselrad e Valêncio ${ }^{11}$, e nas abordagens sobre riscos em estudos da área das ciências sociais, ciências ambientais e saúde pública. Nestes casos, aborda-se, sobretudo: aspectos políticos, da comunicação de riscos (DI GIULIO et alli, 2015) e estudos empíricos sobre percepção de risco (SPINK, 2014), a caracterização de vulnerabilidades e grupos sociais sistematicamente vulneráveis (ACSELRAD, 2002), a participação de comunidades afetadas em processos de definição e gestão de riscos (DI GIULIO, 2012), a discussão dos paradigmas entre medidas estruturais e não estruturais $^{12}$ (SULAIMAN, 2014), e impacto de medidas de mitigação ou convívio com o risco em comunidades atingidas. Em geral, trazem um panorama atualizado do quadro institucional em gestão de risco no Brasil (SULAIMAN, 2014 e CABALLERO, 2005).

No campo das geociências, risco tem tratamento técnico: estudos de caracterização de processos e eventos críticos, causas e procedimentos para definição, classificação e quantificação dos riscos, ameaças e impactos (CASTRO, 2003b; MACEDO, 2013; TOMINAGA, 2015). A percepção do risco nesse campo de estudos é também abordada ao se problematizar a subjetividade inerente aos processos objetivos de definição de riscos e análises de sensibilização (CARVALHO, 1996). Os estudos que constam do banco de dados e referências do CEPED-UFSC apresentam um misto entre abordagens técnicas e aspectos da percepção, comunicação e governança de riscos ${ }^{13}$. Nas engenharias, os estudos abordam aspectos práticos de planos de contingência e logística, sobretudo de setores produtivos industriais (BERTAZZO et ali, 2013). Os estudos urbanos sobre riscos tendem às abordagens das ciências sociais, menos focados em procedimentos para redução de riscos. Quando têm sentido aplicado, tendem a isolar problemas de localidades específicas.

\footnotetext{
10 O caso 3, discutido nos capítulos 6 e 7, é particularmente representativo dessa questão dos fatores difusos na definição de riscos e da aplicação do princípio da precaução.

${ }^{11}$ ACSELRAD, 2002 e VALÊNCIO, 2010.

${ }^{12}$ Nos estudos mais próximos do campo do urbanismo e nas políticas do Banco Mundial, a dicotomia entre medidas estruturais e não estruturais é frequentemente problematizada como termos excludentes e opostos. Entendemos esse posicionamento de "novo paradigma" como um falso problema, uma vez que medidas estruturais e não estruturais são complementares, e muitas vezes os limites de sua definição não são claros. Há que se flexibilizar estes conceitos, que devem ser trabalhadas, nos planos, e, nos estudos teóricos, de forma conjunta.
}

${ }^{13}$ Banco disponível em: http://150.162.127.14:8080/biblioteca/biblioteca.html 


\subsubsection{Limites das teorias sociais do risco: retórica da catástrofe e economia ausente}

A primeira questão sobre as teorias da Sociedade de Risco como fundamento teórico à prática da gestão e governança de riscos remete à transposição da análise de realidades de plena industrialização ao contexto brasileiro.

Nos esquemas teóricos de diversos estudos em sociedades avançadas sistematizados por Hannigan ${ }^{14}$, sobre governança e arena social de risco, diversidade de atores e vieses, os atores geradores de risco em geral são categorizados no papel de executivos ou responsáveis por grandes companhias. Quando pensamos em alguns de nossos agentes geradores de risco - que não são os únicos, mas são agentes fundamentais em nossos processos de risco geológico e hidrológico - não se trata tanto de empresários de uma sociedade industrial amadurecida (que, de um lado produzem risco e de outro garantem retornos lucrativos), mas dos resíduos de nosso processo industrial incipiente - a miséria urbana que tem como única alternativa habitar áreas frágeis, e não lucra nada com os riscos que ela mesma produz. Como, então, as noções de risco como produto de uma sociedade industrial podem auxiliar na explicação de nossos riscos, produtos sociais globais, pós-industriais e ao mesmo tempo arcaicos?

$\mathrm{Na}$ chave teórica proposta por Giddens e Beck, esse questionamento também é inevitável. Quando se faz a distinção entre dois momentos - 1. de uma "sociedade industrial" onde ameaças são tipicamente formuladas como "riscos externos" controlados por um Estado de Bem-estar social, e 2. da "sociedade de risco" onde as ameaças são "riscos produzidos" (manufactured risks), e as respostas estão além da forma de resposta da sociedade industrial - fica a dúvida: como pensar o caso brasileiro e de países que não atingiram processos de Estado de Bem-Estar-Social amadurecidos? Estaríamos vivendo uma realidade apenas de "riscos externos", e não de "riscos produzidos"? A realidade parece ser mais complexa do que a dicotomia de temporalidades sucessivas. Vivemos num e noutro momento ao mesmo tempo ${ }^{15}$.

É possível apontar também outros limites que não se restringem à transposição dos conceitos de sociedades de economia avançada para o contexto brasileiro, e que podem ser questionados nos próprios contextos em que as teorias foram formuladas.

Tanto Beck como Guiddens, quando desenvolvem os conceitos de modernização reflexiva, optam por compreender como a modernidade e suas instituições - sobretudo as instituições científicas que têm por atribuição definir riscos - estão dissolvidas. $O$ possível perante a crise institucional, ou as margens de ação política prenunciadas nessas teorias, possuem tensões duplas:

- saídas políticas: que passam por elaborações em torno da democratização dos processos de definição de risco (incluindo conhecimento, reconhecimento, divulgação, comunicação, análise, mitigação, precaução e contingenciamento de riscos);

\footnotetext{
${ }^{14}$ Hannigan (1999) produz uma síntese da gênese e das principais teorias sociais de risco.

${ }^{15}$ Embora Beck mencione que é característico da "sociedade de risco" a condição global, e que algumas realidades participam do contexto de risco global como partes que servem realidades mais avançadas, isso não dá conta de explicar os processos dentro das realidades de economias menos avançadas.
} 
- saídas econômicas: oportunidades de mercado que surgem (que se formam) a partir de novos cenários de risco, e das novas formas de convívio na sociedade de riscos, que seria importante serem compreendidos pela ótica da justiça social.

Este segundo polo da tensão, o econômico, é anunciado, mas pouco desenvolvido nas preocupações dos dois principais autores da sociologia do risco. Sobre esse ponto, o trabalho de JERONIMO (2014), um ensaio de um ponto de vista mais material, permite complementar e suprir essa carência nas teorias da sociologia do risco. A autora critica a escolha do termo 'risco' para definir "Sociedade de Risco", uma vez que 'risco' pressupõe mensuração probabilística de um evento e toda a cadeia de princípios de racionalidade que decorrem do pressuposto de quantificação: redução de situações complexas, desvalorização da aceitação de processos randômicos, objetivação em avaliações custo-benefício, risco-oportunidade, na construção de argumentos para tomada de decisão, e eliminação da ideia de convívio com as incertezas.

"Futuros possíveis são antecipados, possíveis eventos desastrosos são fruto de projeção, mas a probabilidade de que cada um deles possa, de fato, ocorrer, é negligenciada, assim como a possibilidade de que algo que sequer tenha sido imaginado possa também acontecer, como resultado da inerente randomicidade do mundo natural e das contingências envolvidas no comportamento social e institucional. (...) baseado nesses instrumentos, certos eventos podem passar, (...) a fazer parte da lógica de financeirização. Seguros climáticos são um exemplo: eles incluem 'derivativos climáticos', 'hipotecas ambientais', 'seguros de áreas florestadas protegidas', 'compensações por instrumentos de segurança hídrica' e 'títulos de catástrofes' ou cat bonds. (...) O que estamos assistindo é a um processo de 'comodificação da contingência', ou ao uso do risco como 'cálculo de exposição às contingências'." (JERÔNIMO, 2014: 59 livre tradução).

Guiddens aponta como um aspecto positivo - embora desenvolva pouco - que riscos são, em princípio, energia para o mercado. Beck elabora e incorpora essas questões em suas análises e, também sem aprofundar, mantém a retórica ${ }^{16}$ catastrofista da inevitabilidade de processos econômicos descontrolados, "um barril de necessidades sem fundo, interminável, infinito, auto produzível.” (BECK, 2011: 28).

Sobre esse barril de oportunidades econômicas e a comodificação dos riscos, KEUCHEYAN (2014) traz descrições muito concretas sobre como as necessárias previsões de eventos se transformam em produtos e processos tecnológicos (sobretudo modelagens territoriais e climáticas), cuja comercialização e especulação de resultados se transmuta em títulos de mercados de seguros e resseguros.

O mercado em torno dos riscos busca mecanismos e oportunidades para diluir riscos, um processo de abstração da realidade que é o fundamento das práticas de securitização ${ }^{17}$. No horizonte dos estudos urbanos e ambientais, o que deve ser continuamente perseguido como bem-estar social, como horizonte civilizatório, são

${ }^{16}$ O termo "retórica da catástrofe" mostra-se bastante apropriado e passou a ser utilizado nesta tese depois de participação na mesa do XVII ENANPUR, a partir do artigo de MOMM et al, 2017. Até então, os materiais desta pesquisa utilizavam o termo "discurso catastrofista" para designar uma mesma percepção crítica sobre a teoria social dos riscos.

${ }^{17}$ Assunto parcialmente abordado no capítulos 2. 
processos concretos de redução e mitigação de riscos. No entanto, em contextos onde recursos públicos são cada vez mais escassos, torna-se importante entender como funcionam os mecanismos de proteção financeira e a lógica de diluição de riscos.

Tanto pelos estudos de caso desenvolvidos na segunda parte desta tese, como pela análise de contexto histórico da gestão de risco nacional e internacional, foi possível perceber que ainda estão por ser formulados ${ }^{18}$ novos pressupostos para financiar redução de riscos que considerem dinâmicas ou possibilidades de diluição de riscos. Por isso, ter como objeto de análise os riscos nos sistemas de infraestruturas ${ }^{19}$ corresponde tanto ao intuito de compreender processos pouco investigados de efeitos de ameaças que integram meio físico natural e meio construído, anunciado nas motivações iniciais, e que são relevantes na ampliação de riscos em contextos metropolitanos, como ao intuito de não perder do alcance a dimensão econômica, necessária à mitigação e adaptação às ameaças. Riscos associados a infraestruturas permitem investigar processos de escala, cruzamentos de escopo, e elementos urbanos estratégicos para pensar novas saídas que ampliem a resiliência nas cidades, sobretudo tendo em vista que estes sistemas possuem, simultaneamente: fins de serviço e fins de atividade econômica, apresentam organização institucional robusta, resiliente, com algum porte de capital e inserção nas dinâmicas financeiras globais.

Os cenários de financiamento das práticas de redução de riscos estão mudando. Ao não aceitar esse fato, nem buscar compreender aspectos da dinâmica dessa mudança, as posturas teóricas e práticas críticas ao movimento econômico, que se utilizam de retóricas alarmista focadas na escala inédita das ameaças e magnitude global de um processo sem volta, podem fornecer, por omissão, alimento a esferas econômicas de diluição de riscos sem elaborar possível aproveitamento desses retornos na redução concreta dos riscos. De fato, há ampliação dos cenários de risco. Mas, de um lado, a crença em que as soluções de gestão de risco podem ser financiadas apenas por um modelo antigo, de fundos de um Estado de Bem Estar Social, e, de outro, a ampliação do elenco de diversas situações como 'de risco' - pautada em grande parte por diretrizes e premissas da agenda internacional - reforçam o desenvolvimento crescente de uma economia global de diluição financeira de riscos que possui posições em desvantagem, ou seja, que podem não se beneficiar no processo econômico.

As teorias sociais do risco problematizam as novas ameaças como um movimento amplo e global, e caracterizam as incertezas como derivadas da segunda natureza, a natureza transformada e própria de uma sociedade pós-industrial. Para conectar com a realidade concreta, tanto dos sentidos negativos - porque alarmistas - dessas teorias, como de sua positividade utópica, são necessárias outras problematizações. Riscos cruzados e as falhas na interface entre sistemas de infraestruturas são objetos de análise que se beneficiam das noções de segunda natureza e de ameaças pósindustriais formuladas por essas teorias. Mas estas noções não são suficientes para fundamentar particularidades e vulnerabilidades, auxiliar na identificação de contextos, ou orientar medidas para uma gestão urbana eficaz na conjuntura da pós-modernidade.

\footnotetext{
${ }^{18} \mathrm{Ou}$, no mínimo, repensados, se se considerar casos, como nos EUA, em que há políticas problemáticas de securitização de zonas de risco (capítulo 2).

${ }^{19}$ São sistemas de infraestrutura as redes, atividades e setores necessários ao funcionamento urbano.
} 


\subsubsection{Da retórica da catástrofe aos problemas concretos}

\section{em uma sociedade de riscos}

A partir de bases muito mais concretas, e sem perder o domínio de processos geopolíticos amplos nem sua dimensão cultural, Graham ${ }^{20}$ problematiza alguns dos conceitos de riscos como situações propícias a uma análise da sociedade pós-industrial sem qualquer pretensão de produzir uma teoria social totalizante. Seus estudos sugerem um método de abordagem: a cidade vulnerável é vulnerável pela sua complexidade, e porque a organização dessa complexidade entra em falha. É preciso, então, abordar as complexidades enquanto tal, suas interações, suas falhas, compreender os contextos de normalidade e de anormalidade.

O autor problematiza contextos geopolíticos de desastres e situações catastróficas mantendo o foco em questões operacionais das infraestruturas. Essa postura, aparentemente um recorte nas categorias de desastres - naturais, tecnológicos, falhas em sistemas complexos - pode ser entendida como um posicionamento diante da ideia de "risco urbano". Pois desastres - naturais, tecnológicos, ambientais - são sempre urbanos, se considerarmos que mesmo as áreas protegidas e intocáveis assim o são por uma opção de planejamento ou de viabilidade e interesse da exploração econômica. Desta forma, desastres, seja qual for a categoria, são sempre sistemas humanos que entraram em situação de erro e colapso, que falharam ao servir a determinadas funções, seja de fluxos ou de proteção e distanciamento de possíveis ameaças.

Esse posicionamento pressupõe o desastre como falha de um sistema urbano, ou acúmulo de falhas no encadeamento entre sistemas urbanos - de energia, de água, fluxos de resíduos, de águas de chuva, gás, transporte, dos sistemas habitacionais, do planejamento territorial - e não como passividade frente a um evento aleatório provocado por causas externas. Pois a vulnerabilidade do elemento sob ameaça é construída, e pode ser dosada por planejamento.

O mesmo posicionamento joga alguma luz no tema da resiliência. Com frequência, resiliência é um termo utilizado nos discursos da gestão urbana como sinônimo do paradigma técnico dicotômico entre medidas estruturais e não-estruturais. Mas, quando se problematiza a vulnerabilidade de sistemas de infraestruturas setoriais, os impactos urbanos de suas falhas, por fatores internos ou diante de ameaças externas, a relação entre estrutural e não estrutural não é tanto de dicotomia, e sim de complementariedade. A manutenção e ampliação adequada dos sistemas pode depender de soluções estruturais como de saídas não estruturais.

Quando ligado aos discursos das mudanças climáticas (argumento central nas políticas internacionais de gestão de riscos e desastres) o tema da resiliência se associa ao diagnóstico de que eventos aleatórios são inevitáveis e virão em proporções inéditas; que não é mais possível prever consequências, pondo em foco eventos menos frequentes e de maior impacto. O que Graham propõe vai na direção contrária e permite até mesmo colocar a discussão de resiliência em outros termos. Pois o planejamento

${ }^{20}$ GRAHAM, 2011, professor da Universidade de New Castle Uppon Tyne, dedicou-se ao tema das falhas em sistemas urbanos, e tem uma trajetória em estudos de urbanismo militar e de defesa. 
para redução de riscos deve passar pelo controle contínuo de situações críticas frequentes, e não apenas pelo preparo para situações críticas eventuais. Por isso a proposta de estudar as falhas - das mais banais às mais complexas, a normalidade em relação a contextos de anormalidade - parece ser bastante promissora aos estudos urbanos: pois ao se estudar as grandes catástrofes, o foco permanece apenas no contexto da anormalidade.

Para o autor, a condição urbana atual é caracterizada por territórios dependentes de vastos e complexos sistemas de infraestrutura e tecnologias interdependentes. Sistemas imobilizados no espaço, mas que trazem mobilidade e circulação ao funcionamento das cidades. Energia (aquecimento e resfriamento, eletrificação e iluminação); sistemas de água, transporte e desinfecção de águas servidas, remoção de resíduos humanos do ambiente em geral, transportes.

"Nas cidades, sistemas de distribuição - de águas tratadas, esgotos, alimentos e lixo - continuamente ligam os corpos humanos e seus metabolismos a processos metabólicos mais amplos, com o objetivo de manter a saúde pública" (GRAHAM, 2011: 12 - livre tradução).

As redes de conexão digital, também elas subterrâneas, invisíveis, estão intimamente ligadas às infraestruturas elétricas, que, por sua vez, se ligam a todos os outros sistemas infra estruturais urbanos. Há vulnerabilidades nesses sistemas e em suas interconexões, mas eles são vividos na cidade como serviços cuja falha está fora de cogitação. Essa aparente segurança é forjada pela impressão da permanência e imobilidade das estruturas, e desconsidera a enormidade de atividades, serviços e trabalho fluido envolvidos na operação e manutenção dos sistemas. O crescimento geográfico e demográfico contínuo torna a humanidade cada vez mais dependente de sistemas funcionais de infraestrutura, enquanto seus funcionamentos são cada vez mais imperceptíveis, desinteressantes e banais à maioria que apenas os usa. A súbita interrupção, ou perturbação, de pequeno ou grande impacto, seriam momentos poderosos e potentes para revelar como são os procedimentos, processos, e as políticas para seu funcionamento em condições de normalidade.

"Aqui, nos deparamos com o paradoxo: estudar momentos em que as infraestruturas param de funcionar como algo 'normal' é, talvez, o caminho mais potente para penetrar realmente e problematizar a aparente normalidade de fluxos e circulação a um ponto limite em que eles podem ser submetidos ao escrutínio realmente crítico". (GRAHAM, 2011: 19 - livre tradução).

O estudo das falhas da infraestrutura são oportunidades para criar conjuntos de métodos que auxiliem na resolução de problemas, de aprendizado daquilo que não é possível problematizar quando os sistemas estão em pleno funcionamento. Panes e colapsos na geografia normal dos fluxos nos permitiria escavar as políticas e conexões usualmente escondidas. O automóvel, a auto-estrada, o avião, o telefone celular tomaram o mundo e seu design tornou-se imperceptível, sobretudo o design do intenso desenvolvimento de infraestruturas que dão suporte a eles - "quanto mais fáceis de usar, mais difíceis de ver" (GRAHAM, 2011: 20). A capacidade de compreender os processos é restrita aos engenheiros, ou aos sistemas peritos em seus segmentos. Na falha, os bastidores assumem o palco do debate público. 
Culturas em que as infraestruturas são bem estruturadas, com serviços normais e seguros, percebem a infraestrutura urbana como um conjunto fixo, de tecnologia pesada e estável, caracterizada pela ordem perfeita, completude, imanência e homogeneidade interna. E, no entanto, infraestruturas são conquistas muito precárias. Nos acostumamos a entender as redes antigas (maduras) como invulneráveis, mas elas são mais vulneráveis, menos estáveis e menos previsíveis do que supomos. São defeituosos, parciais, heterogêneos, improvisados e se deterioram, e podem até ser colocados em condição vulnerável pelo desenvolvimento posterior ao plano original.

As linhas de conexão entre os nós de uma rede não resistem por si mesmas, exigem suporte permanente de operação e manutenção. Em muitos sistemas urbanos, especialmente naqueles em contexto severo de informalidade, o alcance de padrões razoáveis de serviços corresponde a um processo de improvisação constante. Mesmo em contextos onde os serviços podem ser associados à estabilidade e permanência, uma economia de reparos e manutenção vasta e escondida opera continuamente, garantindo que circuitos de infraestrutura permaneçam funcionando.

Constituindo ao menos 10\% da economia urbana (GRAHAM, 2011), essa economia de reparos é praticamente invisível nos debates e estudos urbanos. Graham cita, por exemplo, 5,82 milhões de pessoas empregadas em serviços de instalação, reparo e manutenção no ano de 2000 nos Estados Unidos, o que significa 4\% de todos os trabalhos $^{21}$, ideia que confere brutal materialidade à gestão das falhas e dos desastres urbanos. Os estudos urbanos parecem ter dificuldade em aceitar que sistemas complexos, de grande escala e aparentemente estáveis têm natureza dinâmica, que sua normalidade é dinâmica. Usamos o conceito de "serviços públicos" para definir infraestruturas, o que não ajuda a iluminar os processos econômicos que permitem sustentar sua demanda, e que, na prática recente, já se comportam muito além do padrão de oferta de serviços do Estado de Bem-Estar Social.

A confiança continuada em sistemas grandes e complexos e a crença de que sua continuidade está garantida por fundos públicos seguros também cria vulnerabilidades. Quanto mais confiança cega nos sistemas, paradoxalmente, mais prováveis são as panes. E porque eles são cada vez mais interdependentes, o colapso menor em apenas um ponto pode se alastrar para todo o sistema e outros sistemas rapidamente, como efeito em cascata. Impactos nas infraestruturas podem atuar como agravantes em situações de crise, e amplificar efeitos de ameaças que não necessariamente são extremas em sua origem. Pois a interação e encadeamento de efeitos pode levar a impactos extremos.

Essa foi a premissa considerada para levantar os estudos de caso da parte 2 (cap. 6 e 7), que revelam situações de falhas e riscos em sistemas setoriais com função e abrangência de escala regional, ou metropolitana. Foram identificadas: situações de risco residual (externo ao sistema); falhas operacionais em dispositivos e falhas de interface, ou seja, da articulação entre sistemas diversos, sobretudo entre sistemas usuários de recursos hídricos (macrodrenagem, produção de água, geração de energia,

\footnotetext{
${ }^{21}$ DPE (Department for Professional Employees) (2003) Current Statistics on White Collar Employees. Washington DC:DPE. Apud Graham, 2011.
} 
controle da poluição hídrica). São analisadas, também, falhas no ordenamento e uso do solo, e na organização da resposta, entendidos como sistemas. A identificação da relevância de investigação dessas falhas como agravo foi avaliada a partir do cruzamento entre anormalidades em sistemas (por hipótese inicial de casos) com os anos e locais de impactos críticos. A identificação de tempo x lugar críticos resultou da análise quantitativa de ocorrências na RMSP da última d (cap. 4 e 5).

Para fundamentar abordagens urbanas sobre risco e desastre, a proposição teórica de Graham nos coloca num campo de investigação mais promissor: nos afastamos das teorias catastróficas e dos medos apocalípticos em direção ao estudo da cultura de reparos e interdependências entre sistemas. Um campo fértil para pensar e agir na redução de riscos, para construir contextos de governança.

Nossos sistemas mais banais podem estar em risco por ameaças que não estão sendo problematizadas, porque externas ou nas interfaces entre determinados sistemas. Uma gestão de riscos cuidadosa exigiria antecipar essas ameaças em relação ao impacto material e funcional nas infraestruturas e sistemas interdependentes, e possíveis efeitos desencadeados. Exigiria, também, forte desenvolvimento de comunicação institucional para o efetivo tratamento dos riscos e pleno reestabelecimento em situações de falha, uma leitura integrada dos riscos que usualmente não é realizada devido à segmentação e campos peritos apartados. 


\subsection{Atuar na interface: riscos cruzados, saberes cruzados}

\subsubsection{Terminologias dos campos da gestão de risco e seus limites}

Os fundamentos das práticas consolidadas em relação à identificação e gestão de riscos são os da ciência natural e ciência natural aplicada, áreas dedicadas a caracterizar processos baseados em histórico de registros, estimativas históricas, ou situações materiais isoladas e ensaiadas; a analisar comportamentos físicos e situações limite dos elementos e materiais-foco de cada disciplina separadamente; a definir, classificar e quantificar os respectivos processos em análise, instrumentalizar e propor medidas de respostas a cada processo ou conjunto de processos identificado individualmente.

Dentro dessa prática, alguns termos e definições são necessários para comunicar com clareza entre as diferentes áreas que atuam no campo da gestão de riscos em suas diversas fases ${ }^{22}$. Suscetibilidade, vulnerabilidade, ameaças, perigos e risco são termos com significados distintos e precisos. Sempre referenciados a um tipo de evento ou processo (sismológico, geológico, hidrológico, meteorológico, entre outros), criam correspondências específicas com diferentes instrumentos de identificação de riscos e mapeamentos, instrumentos de prevenção, contingência e preparação da resposta.

Suscetibilidade trata de características inerentes ao meio físico face à ocorrência de determinados processos e ameaças, à sua distribuição espacial e ao potencial de intensidade (magnitude). Não leva em consideração a frequência. Existem solos mais ou menos suscetíveis a movimentos de massa, terrenos mais ou menos suscetíveis (pela topografia) a alagamentos, e zonas mais ou menos suscetíveis a enxurradas em função das recorrências meteorológicas e do meio físico, independentemente da ocupação e uso que se faça do espaço ${ }^{23}$.

Quando se fala em perigo [hazard], trata-se de atribuir determinada frequência a condições de produzir consequências indesejáveis à suscetibilidade de um lugar, portanto, associado a algum possível dano ou a alguma condição de vulnerabilidade. Perigo envolve definições de probabilidades de ocorrência dentro de um certo período de tempo, a um lugar com certa suscetibilidade e com algum elemento que deve ser avaliado quanto à sua vulnerabilidade.

A vulnerabilidade, ao contrário, diz respeito à condição que a ocupação espacial (dano potencial) assume frente a determinada condição de suscetibilidade e de perigo (probabilidade de ocorrer). A transformação espacial pode exacerbar ou minimizar suscetibilidades, a forma e posição espacial podem expor ou preservar vidas e bens. A vulnerabilidade identifica o grau de perdas e danos potenciais.

\footnotetext{
22 Vários manuais e glossários de definições compõem a literatura de riscos. Atualmente, no Brasil, as definições tendem a ser uniformizadas de acordo com a Estratégia Internacional das Nações Unidas para Redução de Desastres (UNISDR), criada no ano de 2000, à qual o Brasil aderiu. Nesta breve recuperação, as definições foram cotejadas com fontes do IPT e do Instituto Geológico (MACEDO, 2013 E TOMINAGA, 2015) por representarem as duas instituições mais ativas em São Paulo relacionadas com produção de instrumentos de identificação de riscos e gestão de riscos e desastres.

${ }^{23}$ A terminologia da UNISDR (2004 e 2009) considera apenas as definições de perigo, vulnerabilidade e risco. Suscetibilidade é uma definição utilizada em metodologias de mapeamento produzidas pelo CPRM e IPT com base no manual Guidelines Suscetibility Hazard and Risk Zoning for Land use Planning.
} 
Quadro 1 - Tabela síntese dos conceitos de risco

\begin{tabular}{|c|c|}
\hline & $\begin{array}{l}\text { Ameaça - relativa a um evento deflagrador de } \\
\text { situações de risco ou a um processo ( } 1 . \\
\text { hidrológico, meteorológico, } 2 \text {. geológico, etc) que } \\
\text { pode causar distúrbios. O Estudo de sua } \\
\text { frequência pode definir probabilidades para } \\
\text { ocorrência de processos (termo usado por } \\
\text { algumas fontes também para suscetibilidade e } \\
\text { perigos). }\end{array}$ \\
\hline & $\begin{array}{l}\text { Suscetibilidade - relativa ao espaço enquanto } \\
\text { meio físico, sua configuração, mais ou menos } \\
\text { predisposta a desenvolver processos (alteração } \\
\text { de uma situação de estabilidade, } 1 \text { ou } 2 \text { ) como } \\
\text { efeito de uma ameaça. Termo também usado } \\
\text { como perigo. }\end{array}$ \\
\hline & $\begin{array}{l}\text { Vulnerabilidade - deriva de análise relativa ao } \\
\text { uso que se faz do espaço: como os elementos } \\
\text { presentes no espaço estão expostos às ameaças } \\
\text { e aos processos desencadeados por ameaças, e } \\
\text { como interagem (ampliam ou diminuem) o } \\
\text { contexto de suscetibilidade. Depende de uma } \\
\text { avaliação da qualidade da relação entre } \\
\text { elementos construídos no espaço e a } \\
\text { suscetibilidade do meio. }\end{array}$ \\
\hline quantas? & $\begin{array}{l}\text { Risco - relativo à ameaça, às características do } \\
\text { meio físico e ao uso do espaço simultaneamente. } \\
\text { É uma avaliação quantitativa de impactos } \\
\text { negativos potenciais ou gerados por processos e } \\
\text { ameaças. Associa probabilidade do evento, } \\
\text { ameaça ou processo (quando) com a magnitude } \\
\text { do impacto (quantas perdas? quantas vidas?). }\end{array}$ \\
\hline \multicolumn{2}{|c|}{$\begin{array}{l}\text { Cenários possíveis: alta suscetibilidade + baixa vulnerabilidade; baixa suscetibilidade + } \\
\text { alta vulnerabilidade (quando o uso do meio pode desencadear processos); alta } \\
\text { suscetibilidade + alta vulnerabilidade. }\end{array}$} \\
\hline \multicolumn{2}{|c|}{$\begin{array}{l}\text { Um problema desta formulação de conceitos para os urbanistas: sistemas de } \\
\text { infraestruturas podem ser considerados, em parte, como elementos do meio, e serem } \\
\text { incorporados nas análises de suscetibilidade, embora sejam, por princípio, elementos de } \\
\text { ocupação do espaço, elementos construídos e, portando, em geral, considerados do } \\
\text { ponto de vista da vulnerabilidade. }\end{array}$} \\
\hline
\end{tabular}


A noção de Risco, finalmente, envolve necessariamente alguma mensuração. É preciso quantificar a possibilidade de consequências prejudiciais de um evento, ou seja, relacionar a probabilidade de ocorrência (frequência estimada de determinada suscetibilidade) com seu efeito e severidade (impacto, magnitude do processo e intensidade das consequências, estimando a condição vulnerável). O risco associa perigo, suscetibilidade e consequências à quantificação de elementos vulneráveis. É função da ameaça (suscetibilidade e perigo) e do dano potencial (vulnerabilidade):

$$
R=A \times V .
$$

A composição dos fatores $\mathrm{A}$ e $\mathrm{V}$ podem variar nas diversas metodologias, sobretudo na caracterização da vulnerabilidade, que pode incorporar ponderações diversas.

Para cada um dos elementos de análise de risco, é possível classificar categorias - alto, médio e baixo - em função da frequência (probabilidade) e do impacto (intensidade do processo e do dano), e definir perfis de risco por tipo de ameaça e magnitude provável ${ }^{24}$.

Por envolver mensuração, esses conceitos podem ser expressos por equações matemáticas ou intervalos, gerar classes espacialmente distribuídas e serem representados em mapas com gradação de escalas: as informações sobre suscetibilidade seriam mais apropriadas ao planejamento da ocupação inicial de um território, em escalas mais distantes; sobre vulnerabilidades, no auxílio da definição de áreas prioritárias para maior controle e gestão de riscos, em escala mais próxima; e sobre risco (setorizações) para orientar ações dirigidas à mitigação de riscos já instalados, em escala de detalhes.

Apesar do esforço em definir conceitos precisos para embasar procedimentos de análise racionais e objetivos, existe, mesmo na literatura das ciências naturais e ciência aplicada, discussões relacionadas à subjetividade na definição e quantificação de riscos, e divergências com relação a metodologias e classificações dos elementos em risco de um território. Existem disputas e divergências dentro da própria comunidade perita em torno de métodos, o que leva a considerar que produzir mapas e informações sobre riscos é um mercado. A adesão aos conjuntos de estratégias elaborados pela ONU (Marco de Hyogo e de Sendai) amenizam as divergências apenas em parte.

Além da comunidade perita envolvida na fase de conhecimento do problema, há também o campo de controle dos riscos em outras fases relativas a eventos críticos, a fase do desastre. As fases da gestão de riscos podem ser classificadas em: fase preventiva (na qual se identifica os riscos e se estuda e planeja ações para mitigar ou monitorar e conviver com os riscos em segurança) anterior ao evento; a fase do atendimento emergencial, as ações durante a crise (aspectos de organização transitória e logística); e fase pós-desastre, nas ações de reconstrução, reparação de danos, indenizações e reorganização espacial que, espera-se, acumule o conhecimento da experiência da situação crítica vivida. As ênfases de atuação das diferentes fases também introduzem alguma ordem de tensão e disputa institucional no campo da gestão de desastres, principalmente devido à alocação de recursos.

\footnotetext{
${ }^{24}$ Nos estudos de caso analisados, foram produzidas avaliações síntese (apenas uma aproximação ao método, sem quantificação objetiva) em matrizes de risco que estimam probabilidade $\mathrm{x}$ impacto distinguindo o impacto em categorias de escala: efeitos locais ou regionais (metropolitanos). Capítulo 7.
} 
Com relação à classificação do tipo de processo, na classificação $\operatorname{COBRADE}^{25}$ (ver tabela a seguir) são definidas categorias pelos termos: desastres naturais - processos do meio físico que independem da ação humana (uma consideração que deve ser relativizada nos estudos do território, como visto pela ideia de segunda natureza), e desastres tecnológicos - processos resultantes de atividades de transformação, produtivas. Também são usadas expressões com qualificativos, como riscos 'ambientais', 'urbanos', 'socioambientais', com o intuito de designar o contexto dos riscos, e onde ocorrem. Esses qualificativos revelam que as categorias convencionais podem não estar dando conta de designar a complexidade dos contextos de risco.

A classificação Cobrade reforça a segmentação setorial presente na gestão urbana. Uma contribuição específica dos estudos urbanos ao campo da gestão de riscos poderia ser incorporar certos elementos estruturantes do meio urbano às noções de suscetibilidade, como dado do meio físico - uma segunda geografia - e vulnerabilidade, e trabalhar compreensões na interface entre categorias existentes.

Sistemas grandes e complexos compõem a cidade como uma segunda natureza, e arranjos de múltiplas interfaces resultam dessas interações: sistema habitacional, de controle urbano, de proteção ambiental, de saneamento, de drenagem, coleta e disposição de resíduos sólidos, de mobilidade, sistemas elétricos, sistemas de informações. A dependência funcional entre sistemas define territórios e escalas espaciais e de gestão diversas. Tanto falhas em cada um deles, como efeitos secundários de eventos externos a eles, são informações ausentes nos grandes campos de classificação de desastres. Não há entrada que oriente registro sistemático das informações de processos ou efeitos na natureza segunda, seja como dano, seja como causa. $\mathrm{Na}$ abordagem da interface entre sistemas, além do foco nos processos aleatórios da natureza e do desenvolvimento técnico individualmente, é preciso focar entre especialidades, nas falhas de interação, para melhor identificar riscos.

Nas interfaces e nos resíduos estão contidas as falhas da cidade, se entendida como expressão máxima da natureza segunda, de uma natureza transformada. Fenômenos dessa segunda natureza não podem ser expressos, simplesmente, por eventos classificados como 'tecnológicos' na codificação Cobrade (BRASIL, 2012), pois resultam de interações complexas entre meio técnico, espaço social e espaço natural. Dito de outra forma, existem desastres cujos processos são de natureza urbana: não aconteceriam na natureza, e não podem ser explicados pela descrição isolada de processos tecnológicos. Prescindem do entendimento de processos urbanos funcionamentos, normalidades e falhas, e interações complexas frente a ameaças. Também não basta compreender a adjetivação 'urbano', como delimitação administrativa, pois podem se relacionar a processos fora dos espaços delimitados oficialmente como zona urbana e serem produtos típicos da dinâmica urbana, ela mesma muitas vezes desastrosa. É preciso entender que a natureza segunda configura suscetibilidades, não apenas vulnerabilidades, e como isso ocorre. Ou seja, ela gera riscos, não apenas é suscetível a eles.

\footnotetext{
${ }^{25}$ A Classificação Cobrade foi um elemento de uniformização das definições nacionais de desastres. Anteriormente, no Brasil, a política de Defesa Civil utilizava a Classificação CODAR. Na prática, há lacunas tanto de uma como de outra para de aplicação nos processos de notificação de desastres.
} 


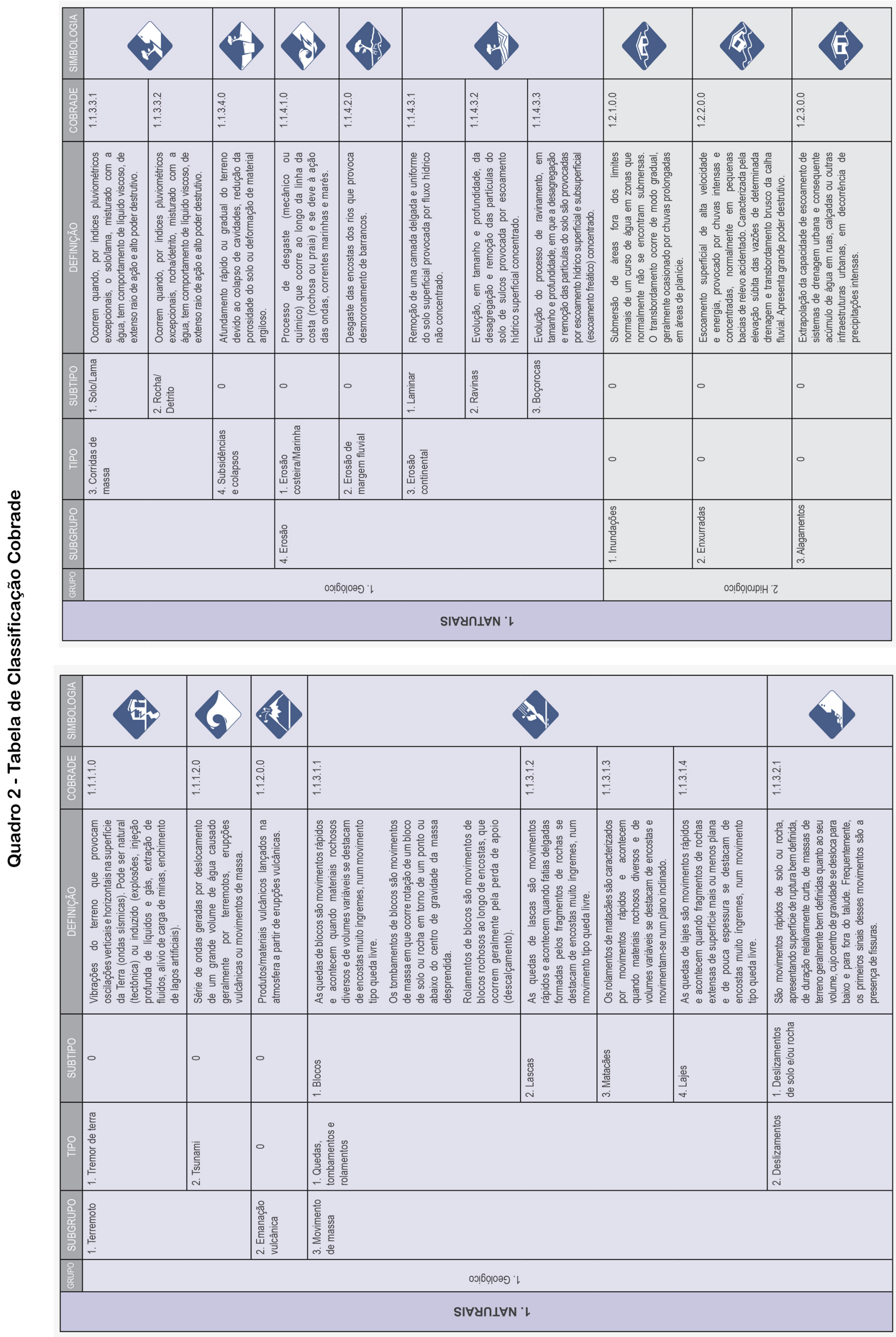




\begin{tabular}{|c|c|c|c|c|c|c|c|c|c|c|c|c|}
\hline & 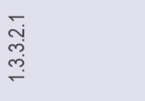 & ָָ̃ & 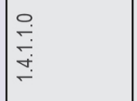 & 守 & \multicolumn{2}{|l|}{ 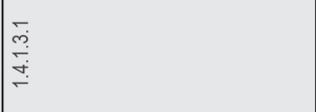 } & 舀 & 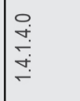 & ت. & & : & 守 \\
\hline & 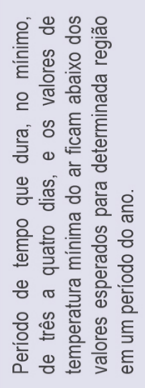 & 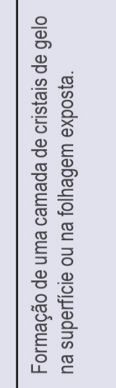 & 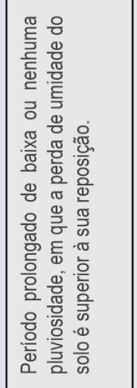 & 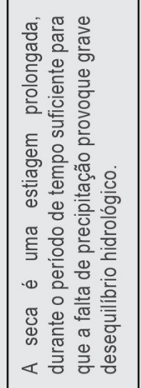 & \multicolumn{2}{|l|}{ 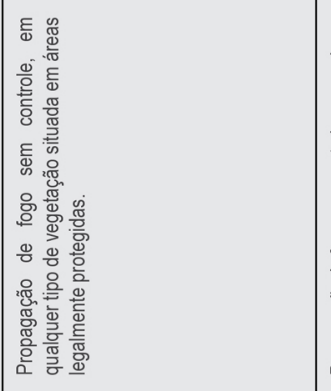 } & 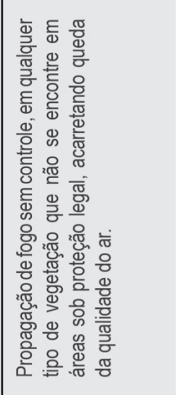 & 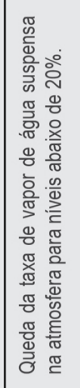 & 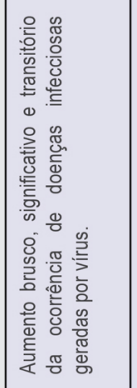 & 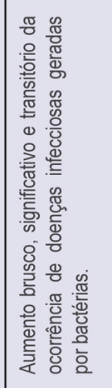 & 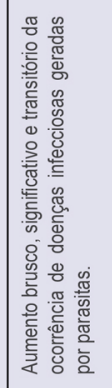 & 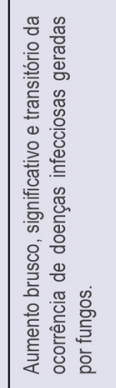 \\
\hline 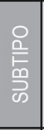 & 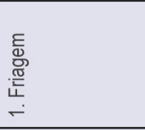 & 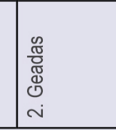 & 0 & 0 & \multicolumn{2}{|c|}{ 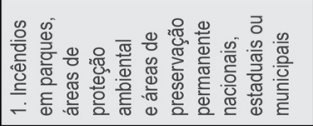 } & 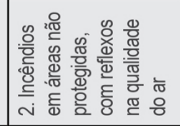 & . & 0 & 0 & 0 & 0 \\
\hline 일 & \multicolumn{2}{|c|}{ 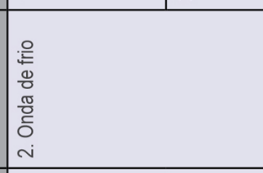 } & 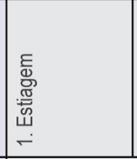 & 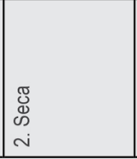 & \multicolumn{3}{|l|}{ 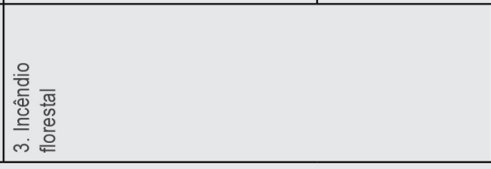 } & 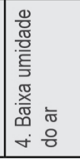 & 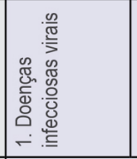 & 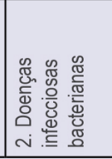 & 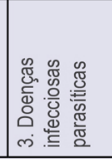 & 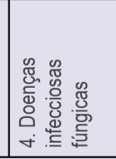 \\
\hline \begin{tabular}{|l|l}
0 \\
0 \\
0 \\
0 \\
0 \\
0 \\
0 \\
\end{tabular} & \multirow{2}{*}{\multicolumn{2}{|c|}{ 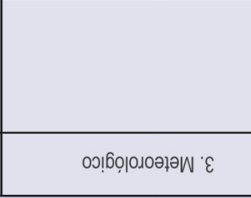 }} & \multicolumn{6}{|l|}{ 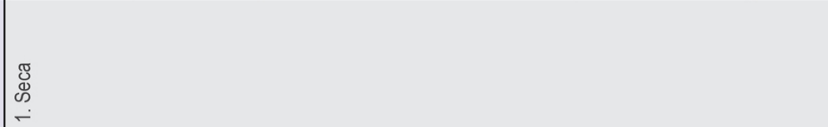 } & \multicolumn{4}{|l|}{ 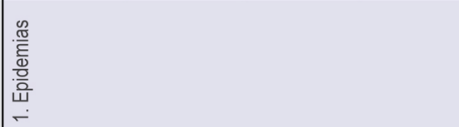 } \\
\hline 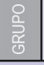 & & & \multicolumn{6}{|c|}{ 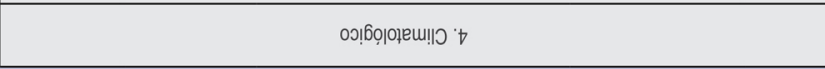 } & \multicolumn{4}{|c|}{$00,600109: 9$} \\
\hline \multicolumn{13}{|c|}{ SI YynIVN 'L } \\
\hline के & & & & & & & & & & & & \\
\hline 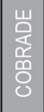 & $\varlimsup_{\bar{\infty}}^{-}$ & 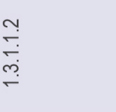 & & 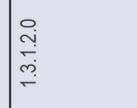 & & 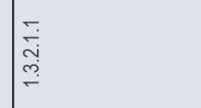 & $\underset{\substack{\dddot{j} \\
\stackrel{\sim}{\sim}}}{\stackrel{\sim}{-}}$ & 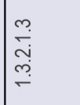 & 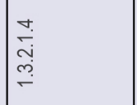 & 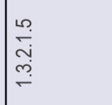 & 弚 & \\
\hline 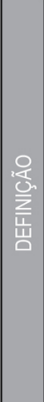 & 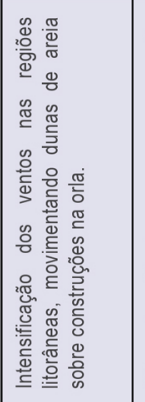 & 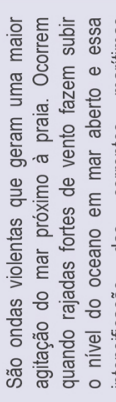 & 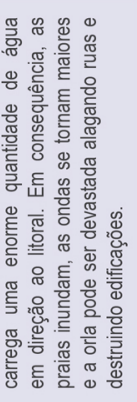 & 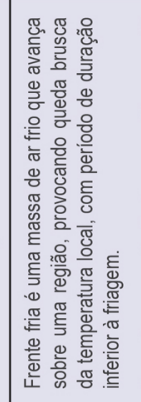 & 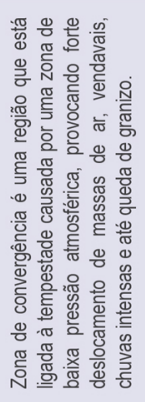 & 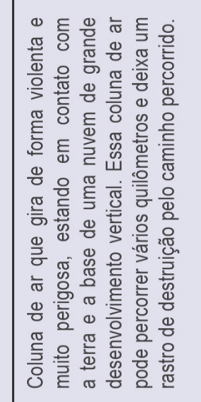 & 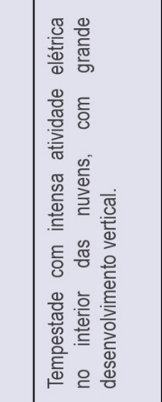 & 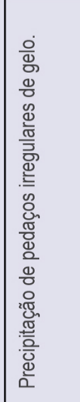 & 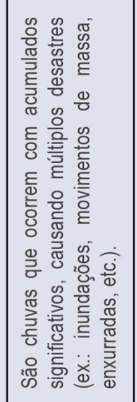 & 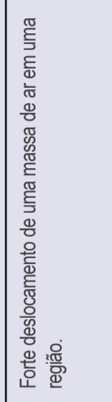 & 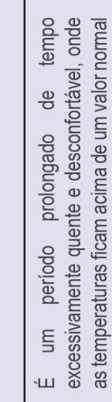 & 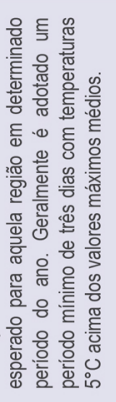 \\
\hline 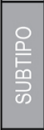 & 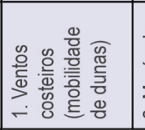 & 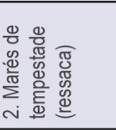 & & 0 & & 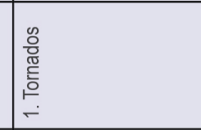 & 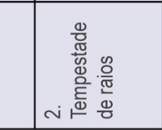 & 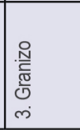 & 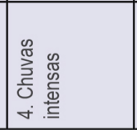 & 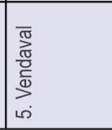 & 0 & \\
\hline 울 & 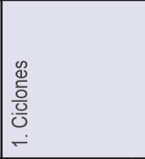 & & & 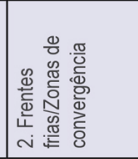 & & 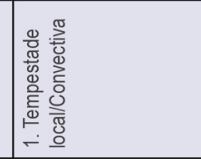 & & & & & 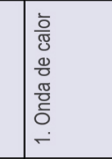 & \\
\hline 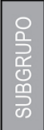 & 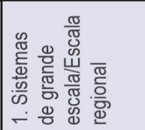 & & & & & 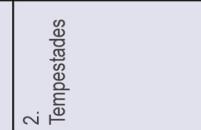 & & & & & 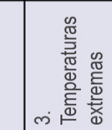 & \\
\hline \begin{tabular}{|l|l|}
0 \\
$\frac{0}{20}$
\end{tabular} & & & & & & 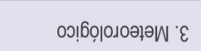 & & & & & & \\
\hline & & & & & & SI & & & & & & \\
\hline
\end{tabular}




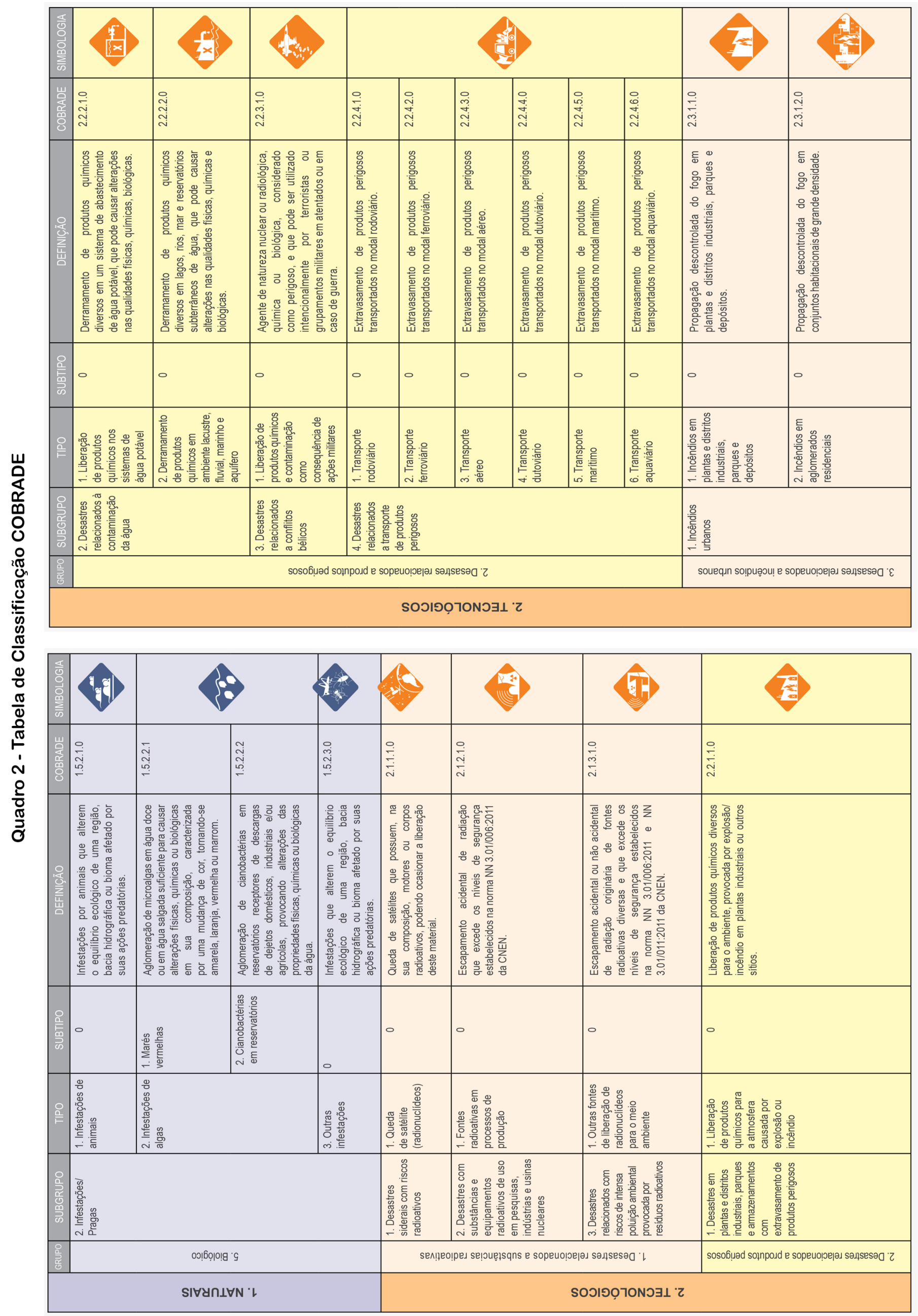


Quadro 2 - Tabela de Classificação COBRADE

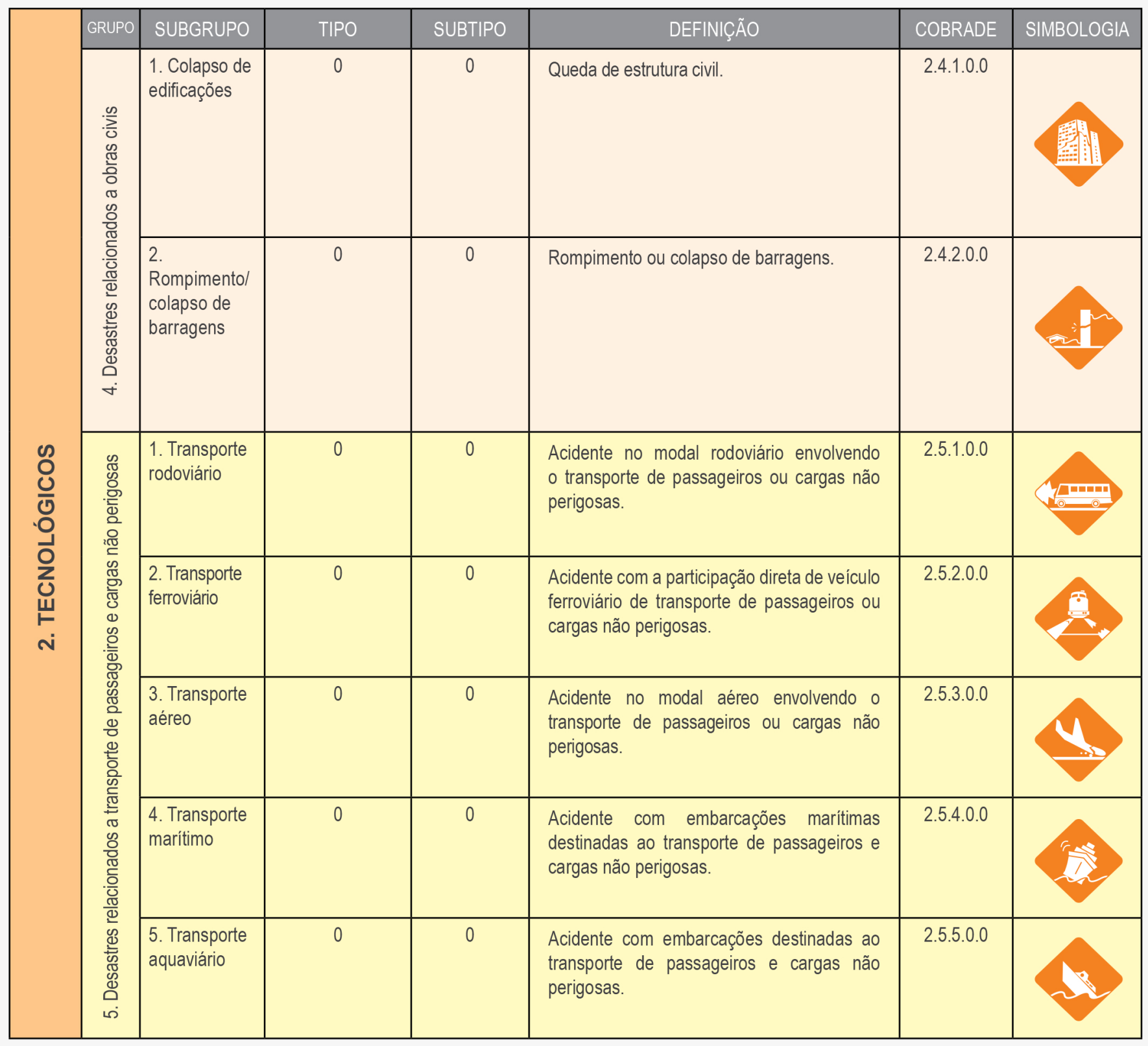




\subsubsection{Sistemas fechados e riscos residuais: uma análise dos procedimentos propostos pela ISO 31000 e as lacunas para sua aplicação na gestão metropolitana}

Além da categorização por fenômenos organizada pela Cobrade, outro elemento que pode segmentar as análises de risco é a noção de risco residual, presente na Norma ABNT-ISO 31000 - Gestão de Riscos - Princípios e Diretrizes ${ }^{26}$. Esta norma propõe um método para gerenciar riscos, independentemente do tipo de organização interessada, setor de atividade, ou tipo de risco envolvido. Sua investigação é interessante à abordagem de riscos que atravessam categorias, e também porque é utilizada em planos de gestão de risco das empresas de infraestrutura e organizações setoriais.

Os Procedimentos propostos na ISO 31000 partem da premissa de que a gestão de riscos deve ser aplicada a sistemas bem definidos, fechados, embora se defina que deve haver uma face de comunicação para lidar com contexto e elementos externos. Sobre estes sistemas, ou organizações, incidem fatores internos e externos de incertezas para que a organização que busca gerenciar seus riscos alcance seus objetivos e desempenhe suas atividades-fim. Risco é, então, definido como 'efeito de incertezas no objetivo'.

Todas as atividades de uma organização ou sistema envolvem riscos, mas apenas alguns riscos interferem nas atividades a ponto de valerem à pena serem gerenciados. Portanto, uma organização deve estabelecer critérios de significância dos riscos, baseados tanto nos objetivos organizacionais de seu contexto interno (objetivos da organização, estrutura, condições) como nas condicionantes do contexto externo (aspectos regulatórios e restritivos de toda ordem; fatores que podem ter impacto; relações com outras partes interessadas). Aqueles considerados significantes e gerenciáveis devem sê-lo com a medida mais eficiente e eficaz possível - suficiente, definida por procedimento sistemático e lógico, e por estrutura de gerenciamento de riscos associada a instâncias de decisão, planejamento e gestão de processos. Isso corresponde à formulação corriqueira nas engenharias de que atividades com risco zero, tendem a ter um custo infinito ou, inversamente, uma atividade com custo muito baixo tende a ter riscos infinitos.

No passo a passo, a primeira medida a se tomar na elaboração de uma proposta de gestão de risco é definir um contexto. Contexto, aqui, não diz respeito a uma complexidade relativa a efeitos de ameaças, situação ou lugar, e sim ao contexto de objetivos da organização e suas finalidades: o que define o sistema a ser gerenciado? Que parâmetros internos e externos devem ser levados em consideração? Qual o escopo e critério para definir risco?

Estabelecido o contexto de condicionantes internas e externas, deve-se proceder à avaliação dos riscos. Inicialmente, pela identificação das incertezas, os fatores que podem impedir o desempenho de atividades do sistema: quais são as ameaças e processos de risco externos e internos ao sistema? Posteriormente, riscos e incertezas devem ser analisados na apreciação das causas e das fontes, e em suas interações e

\footnotetext{
${ }^{26}$ A Norma ISO 31000 derivou da norma regional australiana e neozelandesa AS/NZS 4360 (2004).
} 


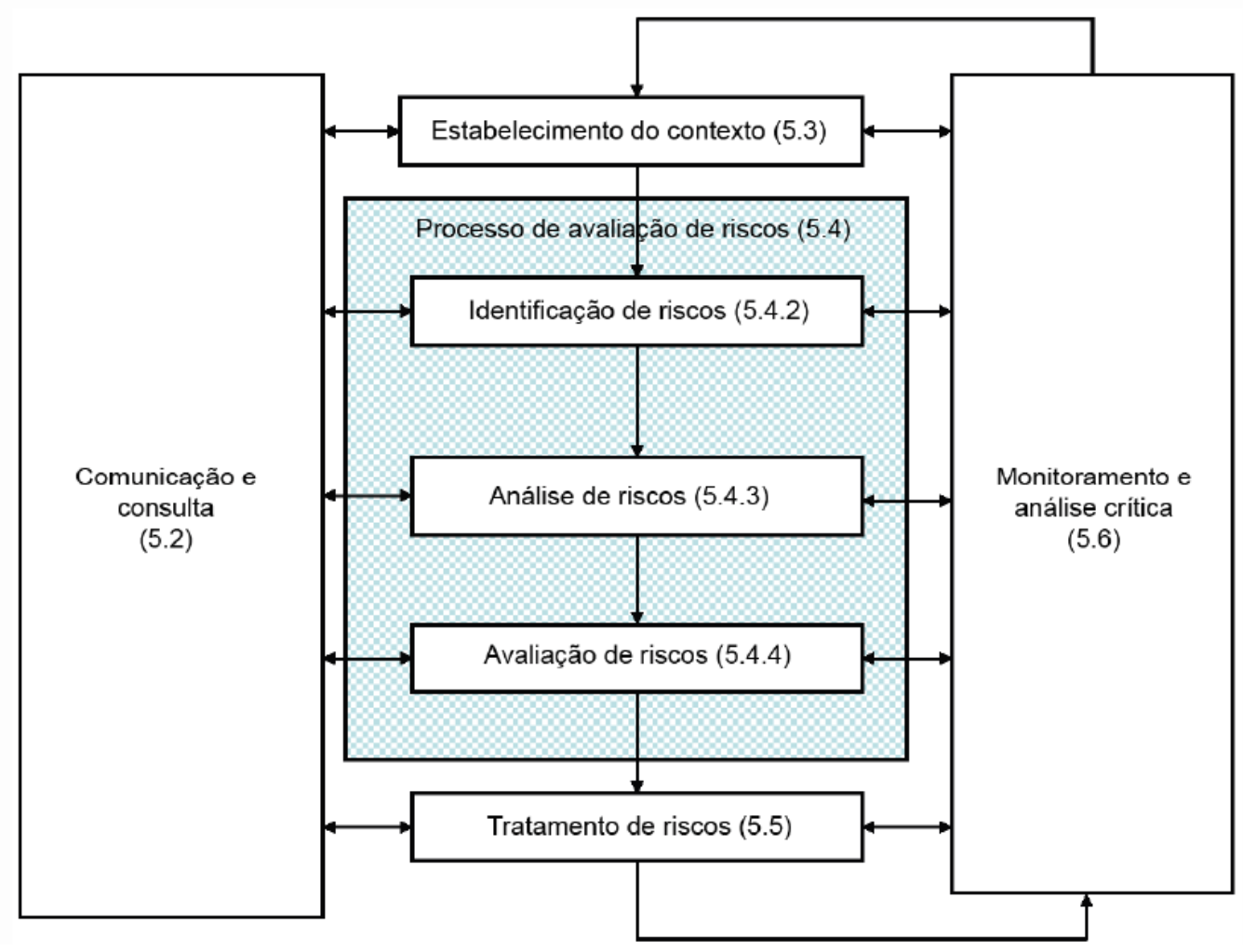

FIG. 3 Processo de Gestão de Riscos. Fonte: ABNT 31000, 2009.

complexidades. Após identificados, são finalmente avaliados: quantificados em termos de probabilidade e impacto.

Após estas etapas é possível definir o tratamento que será dado aos riscos: quais serão gerenciados e quais serão residuais no processo. O tratamento só pode ser feito mediante atribuição de valor às incertezas. Um investimento em mitigação deve compensar o custo do risco à atividade fim: é possível decidir não realizar a atividade que dá origem ao risco, ou assumir e aumentar o risco para aproveitar uma oportunidade. É possível assumir o risco com medidas para sua redução: buscando eliminar a fonte de risco, alterando probabilidades e consequências, compartilhando o risco, utilizando tratamentos que podem mitigar, modificar, ou até criar novos riscos.

O que não é tratado é considerado residual ${ }^{27}$. Mas o risco residual pode ser gerado nas etapas anteriores: pode ser um risco não avaliado, por ser insignificante à organização; não analisado por estar fora do escopo e critérios pré-definidos; ou mesmo não identificado, desconhecido. Pode ficar retido no sistema, pelo desconhecimento ou mediante avaliação de quão tolerável é assumi-lo. Pode ser transferido, o que, numa boa governança, exige processos de comunicação e consulta efetivos. Ou seja, é

\footnotetext{
${ }^{27}$ A terminologia UNISDR, 2009 traz o conceito de risco residual bastante similar ao da norma: "risco que permanece como não gerenciável, mesmo quando são tomadas medidas eficazes de redução de desastres, e para os quais possam ser mantidas capacidade de resposta a emergência e capacidades de recuperação. A presença de risco residual implica o desenvolvimento contínuo de capacidades preparação, suporte e serviços de emergência eficazes, associados a políticas sócio econômicas, como redes de apoio e transferência de riscos". Também o conceito de risco e perigo guardam similaridades com a ideia de 'efeitos de incertezas no objetivo' ao usar termos como 'perturbação à ordem', 'danos e prejuízos', 'consequências negativas' (UNISDR, 2009 e 2004).
} 
importante que, se conhecidos, tomadores de decisão e outras partes interessadas estejam cientes da natureza e da extensão do risco residual após identificação, e que a decisão seja documentada, submetida a monitoramento do resíduo e análise crítica. Não só os riscos residuais, mas todo o processo de gestão e controles estabelecidos para os riscos deve ser submetido a verificação, supervisão, observação crítica de forma contínua, ter o desempenho avaliado por um processo contínuo de monitoramento.

A atividade de comunicação e consulta ${ }^{28}$, que deve ser contínua e alimentar todas as fases do processo de gerenciamento de riscos, é fundamental e trabalha interfaces entre sistemas, entre o que é interno e externo a um sistema ou organização. No caso de riscos residuais, sobretudo se transferidos, a atividade de interface, ou comunicação é ainda mais necessária. $\mathrm{E}$, ainda, nos casos em que se defina como critério de avaliação conveniente a consideração de combinações de riscos múltiplos, identificação de reações em cadeias, efeitos cumulativos e em cascata, e outras complexidades que envolvam contextos internos e externos, o trabalho de interface é imprescindível.

Algumas questões dos procedimentos propostos na norma podem ser apontadas. A primeira delas é que, apesar de problematizar situações de riscos interdependentes ${ }^{29}$, a norma não sistematiza procedimentos para trabalhar efeitos das interdependências além de indicar a importância da tarefa de comunicação nesses contextos. Outra questão é que a premissa de estabelecer metas e desempenho para o tratamento dos riscos pode definir circunstância de vício em que quanto menos complexo o contexto de risco, mais fácil se torna o cumprimento das metas, e que quanto mais riscos são externalizados, menos problemas restam à organização. Pela regra da eficiência, poupar trabalho pode levar à negligência de um ponto chave - a comunicação.

Ao analisar situações de gestão de riscos por sistemas que aplicam princípios desta norma ${ }^{30}$, é possível notar que a identificação de contextos e fatores internos e externos tende a não são ser devidamente desenvolvida, e a frente de comunicação é incipiente. Sem o efetivo desenvolvimento da atividade de comunicação, as interfaces, essenciais à gestão de riscos complexos, os efeitos diferidos, ou riscos residuais transferidos, são os aspectos mais prejudicados.

\footnotetext{
28 "A comunicação e consulta às partes interessadas são importantes na medida em que elas fazem julgamentos sobre riscos com base em suas percepções. Essas percepções podem variar devido às diferenças de valores, necessidades, suposições, conceitos e preocupações das partes interessadas. Como os seus pontos de vista podem ter um impacto significativo sobre as decisões tomadas, convém que as percepções das partes interessadas sejam identificadas, registradas e levadas em consideração no processo de tomada de decisão". (ISO 31000:14).

29 "Convém que a identificação inclua todos os riscos, estando suas fontes sob o controle da organização ou não, mesmo que as fontes ou causas dos riscos possam não ser evidentes. Do contrário, não serão gerenciados. Convém que a identificação de riscos inclua o exame de reações em cadeia provocadas por consequências específicas, incluindo os efeitos cumulativos e em cascata. Convém que também seja considerada uma ampla gama de consequências, ainda que a fonte ou causa do risco não esteja evidente. Além de identificar o que pode acontecer, é necessário considerar possíveis causas e cenários que mostrem quais consequências podem ocorrer. Convém que todas as causas e consequências significativas sejam consideradas". (ISO 31000:17).

${ }^{30}$ O Plano de Contingência para o Abastecimento de Água da RMSP - Comitê Crise Hídrica, 2015, foi elaborado tendo por referência os procedimentos da ISO 31000, além das normas COSO ERM e WHOGuidelines for Drinking-Water Quality - além de outras organizações setoriais analisadas no cap. 7.
} 
Em relação a essas situações de maior complexidade, LITTLE (2010) desenvolve análise onde aponta que, na literatura técnica das falhas e sinistros em infraestruturas análoga ao campo de estudos de riscos em sistemas complexos - existem categorias de processos que definem tipos de interdependências entre sistemas, como:

- falhas em cascata: quando o funcionamento fora da normalidade em uma infraestrutura pode causar anormalidades em um segundo sistema de infraestrutura, e em um terceiro, e assim por diante.

- escalonamento de falhas: o funcionamento fora da normalidade em uma infraestrutura pode exacerbar anormalidades independentes de uma outra infraestrutura (por exemplo, o tempo para recuperar as linhas de metrô afetadas por determinada ameaça se estendem porque as linhas de energia não foram restabelecidas de outra ameaça);

- falhas por causas comuns: anormalidades em duas ou mais infraestruturas simultaneamente em virtude de causas comuns aos diferentes sistemas.

Little simplifica definindo que efeitos de interdependências entre sistemas ocorrem quando a falha em uma das partes aciona a falha de outras partes sucessivamente, $e$ que quando esse processo é traduzido para o caso de infraestruturas, efeitos de interdependências definem situação em que a perturbação em um sistema ou dispositivo de infraestrutura espalha, por sua capilaridade e conectividade característica, impactos consideráveis a outros sistemas ou dispositivos de infraestrutura, com ampliação considerável de impactos. A valoração do fenômeno depende de quão vitais são as consequências, da amplitude de propagação e da magnitude dos impactos. Estas dependem do grau de interdependência, do quanto as conexões entre os componentes desses sistemas são singulares, ou se existem capacidades redundantes e de segurança. Os efeitos da interrupção podem tanto desaparer à medida que se propagam a partir da interrupção de base, limitando o dano geral, como podem somar força em ondas sucessivas, mais fortes, de efeitos em cascata, até que parte ou toda a rede de infraestrutura sofra perturbações. Neste último caso, o dano em uma componente chave pode criar uma falha muito mais ampla, potencialmente desproporcional em relação à falha original. Considerando as muitas ligações entre vários sistemas de infraestrutura, as falhas em cascata podem atravessar os limites da infraestrutura (LITTLE, 2010: 29).

As discussões sobre riscos complexos encadeados e a noção de risco residual traz questões importantes para aspectos da gestão e governança metropolitana de riscos, sobretudo para adequação de escalas. Por exemplo, que organização ou agente gerencia o conjunto de riscos residuais dos diversos sistemas setoriais de infraestrutura, e possíveis efeitos combinados tanto de riscos residuais como da relação entre sistemas? A metrópole pode ser entendida como um sistema, uma organização, composta por diversos subsistemas setoriais, em que pode ser aplicado o procedimento sugerido na norma ISO 31000? Se sim, a que organização caberia gerenciar os riscos residuais da metrópole por causas difusas (situação típica do estudo de caso 3, analisado nos capítulos 6 e 7)? O ente metropolitano teria importância apenas como agente nas atividades de comunicação e consulta, nas interfaces? O mesmo raciocínio pode ser feito ao pensar a relação entre escalas administrativas locais e regionais município x metrópole. Pelos procedimentos propostos, seria possível e desejável 
distinguir riscos que devem ser gerenciados na escala local e riscos que carecem de gestão em nível regional, assim como na relação entre bacias e sub-bacias.

Os estudos de caso nos capítulos 6 e 7 ajudam a compreender alguns graus de interconexão de riscos na Região Metropolitana de São Paulo e como os contextos institucionais estão preparados e organizados para lidar com riscos internos e externos a suas organizações.

\subsubsection{Por uma visão integrada dos riscos urbanos}

A ideia de integração de escopos é própria da prática de arquitetos e urbanistas nas atividades de compatibilização de disciplinas em projetos de variadas escalas. Também a gestão de risco já está presente na atividade de planejar, embora não definida com este nome. A ruína de um edifício, os perigos do meio e a transformação dos perigos a uma forma segura são pressupostos para estabelecer limites à ocupação, coeficientes de segurança, cálculos e desígnios de um projeto. Portanto, simplificando e generalizando, pode-se dizer que qualquer desastre com dano que ocorra em meio urbano (ou em meio transformado pela dinâmica urbana) é uma falha na previsão de como melhor usar, controlar e ocupar o território, seja a ameaça natural ou tecnológica. É um desastre 'do urbanista'.

Os estudos urbanos, portanto, já contribuem, pelos seus próprios pressupostos, à gestão de riscos de desastres, mas podem ser aprimorados nesse sentido, ao explicitar seu papel na integração de ações, na leitura de situações integradas, e na comunicação das interfaces.

Três linhas de investigação podem ser considerados como elementos de uma agenda de estudos que permita organizar e fundamentar essa contribuição: I. Processos de planejamento: evidenciar que o planejamento já trabalha com pressupostos da gestão de riscos, reconhecer quais são eles e como podem ser aprimorados; II. Contextos urbanos: desenvolver estudos sobre produção do espaço que permitam abordar processos indiretos geradores de risco, considerando a dimensão social do espaço e do risco; III. Interfaces urbanas: trabalhar as complexidades de escala e de escopo dos complexos urbanos em sua totalidade, composta por sistemas espacial e funcionalmente integrados que geram efeitos não identificáveis no âmbito estrito de cada um daqueles sistemas, recompondo, ao invés de decompor, um todo complexo em partes simples.

\section{Sobre o processo de planejamento}

As atividades de planejamento já são orientadas pelo controle de riscos:

a) ao buscar orientar a ocupação (coletiva ou individualmente) para evitar a interação com prováveis riscos de desastres naturais;

b) ao estabelecer diretrizes para organizar recursos espaciais de maneira a responder aos, assim chamados, problemas urbanos, vivenciados na prática como déficits; e aos problemas ambientais, vivenciados como limites; 
c) ao ordenar fluxos e funções a fim de orientar o construído e o não construído (a paisagem protegida) de forma racional e eficiente, evitando desastres, desperdícios, ou perda de oportunidades;

d) ao ordenar todos estes elementos com sentido estético, evitando desastres tanto de forma como de significados.

Mas essas atividades podem ser melhor orientadas pela noção de controle de riscos, que envolve ações de planejamento em três momentos:

1) no momento que antecede o desastre, nas fases de prevenção, mitigação e preparação, ao estabelecer as estratégias de organização cuja tarefa inicial é identificar situações problema (e críticas), e definir contingências;

2) na momento da emergência e resposta, que exige conhecimentos de logística para preparar trabalhos de salvamento, relacionar planos de emergência a sistemas de alerta, e reorganizar o cotidiano sob condições de crise;

3) no momento da reconstrução, em que eventos anteriores devem servir de referência para uma reconstrução consciente dos processos e ameaças existentes.

Em condições ideais, a identificação de riscos deveria envolver trabalhos interdisciplinares de investigação de eventos que norteassem o planejamento da ocupação. As situações problema são recortes privilegiados de análise e as técnicas escolhidas para intervir podem resultar em operações de algum tipo de supressão nos instrumentos de planejamento:

a) pela subtração de áreas-problema da dinâmica espacial, como áreas protegidas (evitar o problema, como a ocupação na margem de um rio);

b) pela transformação estrutural da fonte geradora de problema (ex., altera-se o curso de um rio, a situação problema desaparece - ou é transferida dali);

c) pela redução da margem de segurança frente a situações problema a limites menores, incluindo e aceitando zonas críticas de convívio com o risco como dado de planejamento e organização, de onde decorrem planos para situações de emergência, sistemas de monitoramento e alarme, e se estabelecem novos limites e ponderações do risco, por meio de sistemas de informação compartilhada com o usuário. São estratégias que superam a mera proibição do uso ou a radicalização da transformação espacial, mas exigem monitoramento permanente.

Mudanças climáticas são fator de necessária renovação da linha de investigação dos processos de planejamento, pois exigem atualização de parâmetros e fatores de segurança pré-estabelecidos, maior flexibilidade para conviver com situações extremas, e o desenvolvimento de repertórios de experiências de planejamento com soluções para convívio seguro com os riscos. 


\section{Sobre contextos geradores de risco}

É necessário dedicar esforços a compreender processos que produzem vulnerabilidades e exacerbam riscos, o que implica em introduzir cenários tendenciais e dinâmicos a instrumentos de avaliação que são estáticos, ou seja, incorporar o elemento tempo às avaliações de risco.

Os contextos e cenários associados à ampliação de riscos são os mais variados possíveis, e envolvem o conteúdo social que compõe o Espaço. As dinâmicas sociais produzem localizações e deslocamentos, processos cristalizados no território como expressão física de acúmulo e de temporalidades diversas. Há fluxos diários e transições lentas, podem surgir concentrações rápidas ou cumulativas, orientadas por planejamento ou não, previsíveis e imprevisíveis.

Os estudos fundamentados teoricamente na ideia de 'Produção do Espaço' ${ }^{31}$ podem promover leitura crítica sobre os fluxos produtivos que participam da produção espacial, e a produção espacial como fluxo produtivo ela mesma. A introdução de conceitos práticos de risco, e de uma sociedade de risco (da teoria social do risco ${ }^{32}$ ) a estes estudos, poderia ampliar possibilidades de investigação, como, por exemplo, compreender de que forma os fluxos imobiliários podem ampliar e reduzir vulnerabilidades, ou promover expulsão de moradores e ocupações indesejadas - uma exemplificação que pode servir para diversos outros fluxos urbanos, sociais e técnicos.

Os processos sócio-econômicos das cidades e do território poderiam ser compreendidos até o ponto de chegada da geração de situações amplas de riscos urbanos. É uma linha de investigação cujos fundamentos teóricos poderiam estar amparados nos métodos de análise da produção do espaço e nas teorias social do risco, de um lado, e necessariamente associados a análises pragmáticas dos riscos urbanos, e de indicadores de planejamento urbano, de outro.

Nesta linha, o papel a ser desempenhado pelos estudos urbanos seria o de interligar aspectos das ciências tradicionais às teorias sociais críticas, conferindo maior concretude e possibilidade de soluções aos estudos de percepções sociais do risco.

\section{Sobre a coordenação de interfaces complexas}

Existem funcionalidades dinâmicas no espaço construído - a própria dinâmica social, mencionada acima, e a dinâmica dos fluxos, com - conteúdos naturais organizados e disciplinados para reproduzir a vida nas cidades, como água, energia, resíduos, e o deslocamento em geral de matérias e pessoas - que não podem ser compreendidas e explicadas a cada parte que compõe aquele espaço. Isto contrasta com outras

\footnotetext{
31 Para Lefebvre (2000), o Espaço compreende as dimensões social, econômica e política, além de sua própria materialidade. Compreende, ao mesmo tempo, a natureza em estado absoluto, a natureza humana e a humanização da natureza, matéria prima e produto em um processo de produção do humano, em última instância. No espaço, camadas do tempo e de diferentes temporalidades se sobrepõem.

32 Os principais autores dessa tendência - Ulrich Beck (BECK, 2011) e Anthony Giddens (GUIDDENS, 1999) e aspectos da teoria social dos riscos serão melhor desenvolvidos na seção1.1. O IPPUR, sobretudo trabalhos conduzidos por ACSELRAD, desenvolve linhas de pesquisa orientadas por este viés de investigação dos processos urbanos.
} 
disciplinas, nas quais se busca explicações mais apropriadas mediante a decomposição do todo nos menores elementos. No complexo urbano, há necessidade de compreender a interação entre os sistemas, os desdobramentos dessas interações e as soluções para os desafios delas decorrentes.

Em contextos urbanos adensados, cujo funcionamento envolve expressivos e repetidos impactos sobre o meio físico natural, não é possível estabelecer separação nítida entre riscos por causas naturais, antrópicas e falhas. Inundações, escorregamentos, colapsos em redes de saneamento e energia são desafios presentes e crescentes, e a formulação de diretrizes para sua superação requer abordagem específica e pragmática. As vulnerabilidades a desastres não se caracterizam, somente, ou necessariamente, pela exposição a processos naturais e/ou de alta magnitude. Podem estar relacionadas a eventos corriqueiros e crônicos $^{33}$ que, associados a efeitos de diversas ordens na própria infraestrutura urbana, aumentam exponencialmente os riscos, com consequências maiores que a simples soma das partes. Situações classificadas como residuais ou de baixo risco por um setor de infraestrutura, ou disciplina relacionada a certos fenômenos, quando devidamente associadas, podem desencadear efeitos de grande escala. Uma espécie de "vulnerabilidade da complexidade" é criada simplesmente pelo tamanho e interdependência entre sistemas urbanos. Regiões metropolitanas são o objeto privilegiado para estes tipos de análises.

Interações desse tipo são pouco estudadas e organizadas como método para abordar riscos urbanos, muito embora a percepção de que contextos urbanos submetidos a situações de risco desenvolvem efeitos em cascata seja frequentemente aceita entre os peritos do risco, e mencionada nas descrições sobre eventos.

Os diferentes sistemas que compõem a cidade se desenvolveram e evoluíram em suas especialidades, criando suas respectivas instituições, legislações, protocolos, normas e parâmetros. As interfaces entre sistemas carecem de desenvolvimento correspondente. São lacunas obscurecidas, que podem apresentar comportamento falho mesmo em situações de normalidade, e efeitos de grande impacto mesmo com eventos aleatórios levemente acima da normalidade.

\footnotetext{
${ }^{33}$ Por exemplo, a ruptura de redes de abastecimento de água sob pressão em áreas de urbanização em encostas. Este é um dos elementos analisados por RIBEIRO, 2007.
} 


\section{Capítulo 2 - CONTEXTO INTERNACIONAL DAS POLÍTICAS PARA REDUÇÃO DE RISCOS: DO SOCORRO À PREVENÇÃO E OS PRINCÍPIOS DA DILUIÇÃO DE RISCOS}

\subsection{Principais diretrizes dos marcos internacionais}

O Brasil, na condição de Estado-Membro da ONU, adotou a Estratégia Internacional para a Redução de Desastres (EIRD/ISDR) criada em 2000. O propósito desta estratégia é alcançar uma redução considerável das perdas ocasionadas por desastres, e construir comunidades e nações mais resistentes como condição de um desenvolvimento sustentável. O escritório da ONU responsável pela implementação da estratégia -UNISDR- oferece orientação estratégica e coerente a tais princípios por meio do estabelecimento de marcos internacionais, como os Marcos de Hyogo e de Sendai.

O estabelecimento desses marcos corresponde a um percurso de desenvolvimento de políticas e protocolos que, desde a década de 1970, reconhece a necessidade de uma interação equilibrada entre sociedade e natureza. Movimento que foi acelerado na década de 1990 - com a divulgação do primeiro Relatório do IPCC (Painel Intergovernamental de Mudanças Climáticas das Nações Unidas) em 1990; do Livro Verde na Europa; da Agenda 21 Global, em 1992; a Conferência das Partes sobre Mudanças no Clima, COP 1995; a Conferência Habitat II em 1996 - e foi consolidado nas décadas seguintes, com a Rio+10, em 2002; o estabelecimento do Protocolo de Quioto em 2005, para redução dos gases do efeito estufa; a Rio+20, em 2012, e a COP21, quando foi firmado o Acordo de Paris (SIEBERT, 2017).

Em 2005, mesmo ano em que foi firmado o Protocolo de Quioto e em que ocorreu o Furacão Katrina, foi aprovado o Marco de Ação de Hyogo (2005-2015), com as diretrizes para redução de riscos e desastres da UNISDR. O Marco de Sendai (2015-2030) foi adotado em março de $2015^{34}$, na Terceira Conferência Mundial sobre Redução do Risco de Desastre, no mesmo ano da COP 21 e do Acordo de Paris, e após o terremoto de Sendai, de 2011.

O Marco de Sendai é apresentado como uma revisão e continuação do Marco de Hyogo. Faz um diagnóstico dos avanços e lacunas deste último, sobretudo apontando a ausência de diretrizes de implementação e definição de metas e indicadores de acompanhamento. As 5 diretrizes do Marco de Hyogo podem ser sintetizadas como: 1. tornar o risco uma prioridade dos governos; 2. conhecer os riscos e tomar medidas de alerta para reduzir impactos; 3. promover a conscientização sobre os riscos; 4. reduzir fatores de riscos; 5 . desenvolver preparação para resposta eficaz em todos os níveis.

Pelo diagnóstico do Marco de Sendaij ${ }^{35}$, o cenário pós Marco de Hyogo contém avanços na redução do número de mortes em todo o mundo. No entanto, observa-se aumento generalizado de custos com perdas materiais e efeitos desproporcionais sobretudo em

\footnotetext{
${ }^{34} 2015$ foi o segundo ano de desenvolvimento desta pesquisa, o que reforça o contexto de um tema dinâmico.

35 UNISDR, 2015.
} 
populações mais vulneráveis. Em virtude dessa constatação, o Marco de Sendai apresenta claramente a associação dos propósitos de aumento da resiliência com propósitos de redução da pobreza ${ }^{36}$. Além disso, ao apontar as lacunas de diretrizes para direcionamento de ações aos governos e na orientação de investimentos no Marco anterior, o Marco de Sendai propõe 7 indicadores relacionados a metas, que devem ser avaliadas para o período 2015-2030 em relação ao período 2005-2015:
A. Reduzir número de mortes por desastres
B. Reduzir número de população afetada
C. Reduzir perdas econômicas avaliadas em relação ao PIB (perdas/PIB)
D. Reduzir danos a infraestruturas e interrupção de serviços básicos em contextos de desastres
E. Ampliar a adesão de países às estratégias de Redução de Riscos
F. Intensificar a cooperação internacional com países em desenvolvimento para os objetivos de redução de riscos
G. Disponibilizar amplamente sistemas de alerta, informações e avaliações sobre riscos de desastres.

Outro aspecto de avanço em relação ao Marco de Hyogo foi definir ampliação do escopo dos riscos, propondo avaliações mais integradas e considerando não apenas os eventos de grandes proporções, mas eventos mais frequentes e crônicos. Estes aspectos se relacionam com a meta ou objetivo "D", ao qual esta pesquisa se alinha.

Assim, os resultados esperados pelo Marco de Sendai podem ser sintetizados como: redução de perdas de vidas e de danos a meios de subsistência e de promoção da saúde, a ativos econômicos, físicos, sociais e ambientais de pessoas e empresas. Os objetivos para atingir estes resultados exigem ações de prevenção de novos riscos, redução de riscos já existentes e implementação de medidas integradas (nos aspectos econômicos, estruturais, jurídicos, sociais, de saúde, culturais, educacionais, ambientais, tecnológicos, políticos e institucionais), e inclusivas, para reduzir a exposição e aumentar a preparação para o risco.

Outra proposição que decorre do reconhecimento de lacunas ao direcionamento das ações de governo e investimentos, é que um dos princípios norteadores do Marco de Sendai passou a ser a identificação e criação de responsabilização nos processos de demarcação dos riscos. Desse princípio, decorrem outros, voltados à criação de capacidades nas burocracias e comunidades; à disponibilização de informações sobre desastres, desagregadas e de fácil acesso a todos; à ampliação da cooperação

\footnotetext{
${ }^{36}$ Essa associação de objetivos vem definindo um novo vocabulário para demandas antigas. Em novembro de 2017, foi possível participar com esta pesquisa de encontro internacional na Alemanha (Dangerous Landscape: re-thinking environmental risk in low-income communities - Leibniz University of Hannover), uma reunião de pesquisadores de diversos países que se dedicam a estudos sobre gestão de riscos e desastres. $O$ que se pôde observar é que poucos dos bolsistas selecionados apresentavam trabalhos, de fato, sobre gestão de riscos e análises de desastres. A grande maioria retratava aspectos de vulnerabilidade urbana e social, sobretudo de estudos muito localizados, que podem ser compreendidos como a antiga problematização sobre déficit e pobreza, utilizando os conceitos da gestão de risco apenas como um novo vocabulário para antigos problemas.
} 
internacional na promoção de financiamentos, transferência de tecnologias e capacitação entre países. Temas que, como veremos no capítulo 3 e 4, ainda são grandes desafios no Brasil e mesmo na RSMP, que conta com informações e sistemas de monitoramento bastante desenvolvidos se comparados ao restante do país.

Reforçando e desdobrando os princípios do Marco de Hyogo, o Marco de Sendai assume como princípios, também, a proteção de pessoas, bens e o direito de desenvolvimento, do qual decorrem princípios derivados, como a não discriminação, o engajamento amplo e participação inclusiva de afetados; a coerência entre crescimento, desenvolvimento sustentável, segurança alimentar, políticas de saúde, variabilidades climáticas e a gestão ambiental para redução de riscos e desastres, com foco nos aspectos locais dessas articulações; a noção de que investir em prevenção é mais eficiente do que investir recursos na resposta; e a importância de uma reconstrução consciente dos eventos e efeitos que levaram à perturbação e/ou destruição.

Desses princípios, objetivos e resultados esperados, resultam 4 ações prioritárias, ou frentes de ações, de certa forma afinados com o método de abordagem para gestão de risco descrito na norma ISO 31000, porém, aplicado à escala global:

1. Compreender riscos, o que envolve, sobretudo, melhorar o nível de informações sobre desastres, ampliar seu compartilhamento e promover amplamente a educação sobre riscos e desastres;

2. Fortalecer a governança de riscos, que exige também a melhoria na produção e compartilhamento de informações, educação das comunidades e capacitação das burocracias para gerenciar e adquirir responsabilidades. A ampliação da governança e do campo de informações sobre desastres permitiria construir maior embasamento para a própria estratégia internacional de redução de riscos.

3. Investir em redução de riscos com foco em resiliência, compreendida, sobretudo, do ponto de vista da vulnerabilidade dos bens produtivos, o que inclui avaliar aspectos econômico-financeiros das medidas de redução de riscos associados a objetivos distributivos (de erradicação da pobreza).

4. Melhorar as medidas de preparação para os riscos, melhorando a eficácia da resposta, e melhorar os processos de reconstrução, incorporando informações sobre efeitos dos desastres.

Em termos de método, esta tese aponta significativamente na promoção e execução da Meta $\mathrm{D}$ e da Ação Prioritária 1 do Marco de Sendai, com desdobramentos importantes também das metas 2 e 3. Na parte 2, são apresentadas análises que representam uma abordagem inovadora em direção a uma avaliação intersetorial de riscos urbanos, convergindo para uma experimentação no campo amplo que se pretende abranger pela definição de 'compreensão do risco de desastres' da Meta 1, conforme detalhamentos desta meta expostos no Marco de Sendai:

“... uma compreensão clara do risco em todas as suas dimensões de vulnerabilidade, capacidade, exposição de pessoas e bens, características dos perigos e meio ambiente". (SENDAI, 2015, parágrafo 23).

O exercício de análises foi feito para uma dimensão extremamente desafiadora e complexa, que é a de uma grande região metropolitana, especificamente a RMSP. 


\subsection{Redução ou diluição de risco: a política internacional de gestão e proteção financeira a risco de desastre}

Documentos relativamente recentes ${ }^{37}$ organizados pelo Banco Mundial para diversos países, com recomendações para políticas de gerenciamento de riscos de desastres (GRD) e proteção financeira a risco de desastres (PFD), apresentam como panorama um cenário de incerteza crescente na previsibilidade climática e, consequentemente, na previsibilidade de perigos e riscos associados às ocupações urbanas - seja pelas incertezas da ameaça climática ou pelo descontrole territorial na exposição a ela.

A política de gestão do risco de desastres (GRD) proposta pelo Banco Mundial organizase em torno do aumento da proteção física local, por meio de desenhos urbanos mais resilientes ${ }^{38}$, e melhoria dos dados sobre riscos nos países aderentes, alinhadas com os marcos da UNISDR, através das seguintes diretrizes:

- identificação do risco - avaliar e comunicar perdas e danos, estabelecer metodologias para avaliação de perdas e danos.

- redução do risco - definir medidas estratégicas de curto, médio e longo prazos, estruturais e não-estruturais.

- investimento em preparação - sistemas de alerta e planejamento de contingências (resposta).

- modernização das capacidades institucionais.

- organização da proteção financeira - redução de passivos financeiros, apropriação de processos de avaliação de perdas e danos e estabelecimento de camadas de risco; identificação de instrumentos financeiros ex-ante e ex-post utilizados e já estabelecidos; adoção de programas para aumento da capacidade financeira dos Estados para responder a emergências garantindo proteção ao equilíbrio fiscal; ampliação dos mercados de seguros e proteção social às camadas de baixa renda.

\footnotetext{
${ }^{37}$ São documentos posteriores ao Marco de Hyogo, e anteriores ao Marco Sendai: BANCO MUNDIAL, 2012 a; BANCO MUNDIAL, 2012 b; BANCO MUNDIAL, 2012 c. A síntese destes documentos desenvolvidos em 2012 compõe boa parte das análises desta seção. O ano de 2012 é crítico, reflete as reações da comunidade internacional para o acúmulo de eventos que desde 2004 (tsunami na Indonésia, Furacão Katrina, Tsunami no Japão, Furacão Sandy e, no Brasil, desastres em Santa Catarina, Região Serrana do Rio de Janeiro, Santa Catarina, Pernambuco e Alagoas) assumiram proporções catastróficas tanto nos danos e perdas causados, como na capacidade financeira de reconstrução. Os documentos indicam algumas mudanças de paradigmas no tratamento das questões de risco, principalmente na relação que se estabelece entre redução e diluição de riscos.

${ }_{38}$ Nos documentos do Banco Mundial aqui mencionados, o uso que é feito do termo "resiliente" corresponde a um paradigma tecnológico cujo foco está no estabelecimento de medidas não estruturais, de convívio com eventos críticos, promoção de conjunto urbano adaptável e com intuito de reduzir danos. No entanto, o conceito físico de resiliência refere-se à capacidade de um corpo recuperar sua forma original depois de submetido a um esforço ou carga. No caso das cidades, diz respeito à capacidade de recuperar sua funcionalidade, e isto não necessariamente se associa ao caráter não estrutural das medidas para mitigar riscos ou adaptar cidades a ameaças extremas. Esta tese incorpora este conceito mais abrangente de resiliência, sobretudo por tratar da ampliação da resiliência das infraestruturas.
} 
- promoção da reconstrução resiliente - desenvolvimento do planejamento como precaução, investimento em pesquisa de soluções alternativas.

- promoção da gestão integrada - equilibrar decisões entre medidas estruturais e não estruturais, necessariamente ligadas a políticas e práticas de gerenciamento e planejamento territorial e urbano; rever métodos de gestão tradicionais, coordenar dinâmicas de tomada de decisão em nível nacional, regional e local.

Análise do Atlas Brasileiro de Desastres Naturais (CEPED, UFSC, 2013) aponta que, a partir de 2010, os registros de inundação, secas e movimentos de massa no país concentraram-se em maior número e com maiores impactos do que os registros de todo o período entre 1990 e 2000. Segundo o EM-DAT ${ }^{39}$, o contexto apresentado é crítico no Brasil, e também é no mundo para os anos de 2010 e 2011. É difícil afirmar o quanto esse cenário é mais crítico somente como função da transformação das ameaças no contexto das mudanças climáticas e o quanto um maior fortalecimento da prevenção, com estruturação de capacidades para produzir (notificar), reunir e disponibilizar dados amplia esses números. Apesar da diminuição do registro de perdas de vidas humanas, os documentos de 2012 antecipam o diagnóstico do Marco de Sendai, de que o impacto em perdas econômicas foi ampliado, sobretudo em populações vulneráveis, indicando que a distância segura entre ocupação humana concentrada (urbana) e os perigos naturais tem diminuído, seja pela maior quantidade de bens expostos ao perigo, pelo aumento das situações de perigo ou pela ampliação da vulnerabilidade dos conjuntos urbanos (cf. BANCO MUNDIAL b, 2012). O fato de populações mais vulneráveis serem sistematicamente atingidas, no caso brasileiro, define perfil em que gastos na recuperação são sobretudo gastos públicos ${ }^{40}$. A vulnerabilidade sistemática associa-se a riscos igualmente sistemáticos em virtude das oportunidades disponíveis a esses contingentes sociais.

Mas essas análises produzem, também, outros efeitos. O aumento da incidência de desastres e a tendência de relativizar a eficiência e eficácia de medidas estruturais ${ }^{41,} \mathrm{e}$

\footnotetext{
${ }^{39}$ O EM-DAT é uma plataforma de dados sobre desastres mantida pelo Centre for Research on the Epidemiology of Disasters (CRED), criada pela Organização Mundial de Saúde e pelo governo Belga e alimentada com informações oficiais dos diferentes países. No caso do Brasil, a informação fornecida não é desagregada.

${ }^{40}$ Cf. BANCO MUNDIAL; Governo do Estado de Santa Catarina, 2012; BANCO MUNDIAL; Governo do de Alagoas, 2012, BANCO MUNDIAL; Governo do Estado de Pernambuco, 2012, BANCO MUNDIAL; Governo do Estado do Rio de Janeiro, 2012.

${ }^{41}$ Medidas estruturais são definições de projeto derivados de métodos de cálculo probabilísticos baseados em registros históricos. Em drenagem, por exemplo, as medidas estruturais são aquelas que interferem diretamente no controle do fluxo da água, ainda que não necessariamente sejam de engenharia pesada (ex.: buffers, lagoas de amortecimento de cheias). São calculadas com base em uma capacidade limite do projeto, estabelecida pela escolha de determinada probabilidade/ frequência aceitável nas estatísticas do histórico de eventos. Se um risco nunca pode ser integralmente previsto - e as tendências indicam cada vez menos capacidade de previsão - há sempre uma capacidade estabelecida em projeto (garantidora absoluta a determinada probabilidade) que poderá ser suplantada. Portanto, quando medidas estruturais são definidas, sempre há risco residual sob aparência de um controle absoluto a certa frequência prevista. Esse conceito está apresentado como justificativa, nestes documentos do Banco Mundial, para a transição da ênfase dos investimentos em medidas estruturais para as medidas não estruturais, formulação que obscurece a importância de interações existentes entre as medidas estruturais e não estruturais.
} 
relativizar a própria validade de registros históricos ${ }^{42}$, ampliam um campo de incertezas que permite, por exemplo, avaliar riscos pouco frequentes como se fossem riscos frequentes, ação fundamental como mecanismo do mercado de seguros anti-catástrofe.

A implementação de políticas nos moldes de GRD permite criar um campo de confiabilidade para implementar medidas de Proteção Financeira a Desastres (PFD), seja por interesses internos dos governos, ou por interesses dos Bancos Internacionais de desenvolvimento em promover amplamente políticas de suporte de proteção financeira e transferência de riscos. A compreensão desses processos é importante, pois permite levantar interesses duplos no desenvolvimento das estratégias internacionais para redução de desastres, o barril de oportunidades que BECK (2011) menciona e que KEUCHEYAN (2014) exemplifica.

Nas propostas de PFD apresentadas para o Brasil pelo Banco Mundial a partir da avaliação de perdas e danos de 4 eventos extremos (Santa Catarina, Região Serrana do Rio de Janeiro, Pernambuco e Alagoas), foi aplicada uma metodologia padrão de avaliação (DaLA Damage and Loss Assessment - CEPAL) que resultou em valores de perda anual média para do local (PMA). A partir da PMA, foi feita a categorização de riscos em camadas, relativas à probabilidade do risco e seu impacto, e, então, traçadas estratégias de proteção financeira para cada camada:

- camada de alto risco - baixa probabilidade e altíssimo impacto - CAT DDO ${ }^{43}$ do Banco Mundial;

- camada de risco médio - probabilidade média e alto impacto - Fundo Federal a aprimorar

- camada de risco baixo - probabilidade alta e baixo impacto - procedimentos dotação orçamentária municipais e estaduais já existentes.

Nas estratégias propostas, diferenciadas por camadas de risco, leva-se para o portfólio do banco apenas os riscos de menor probabilidade de ocorrência e maior probabilidade de dano. Se considerarmos que as perdas médias anuais foram definidas pela avaliação de perdas e danos dos últimos eventos extremos ${ }^{44}$, pode-se considerar que há possibilidade de exageros na avaliação.

Ou seja, aparentemente seriam transferidos ao banco apenas os riscos menos prováveis, ou os mais improváveis possíveis - se não improváveis de fato. Embora seja claro o real interesse do Banco Mundial em dar suporte financeiro a governos para enfrentar cenários fiscais críticos diante de desastres igualmente críticos, a quantificação e categorização de riscos empregada reproduz, em certa medida, a lógica

42 O Relatório Especial do IPCC sobre Eventos Extremos apresenta-se como o mais recente consenso científico a respeito do impacto das mudanças climáticas sobre os riscos de desastres, afirmando que mudanças do clima levam a alterações na frequência, intensidade, extensão espacial, duração e ocorrência de eventos e de condições meteorológicas extremas que podem resultar em fenômenos de efeitos sem precedentes, afirmação que relativiza a pertinência do uso exclusivo de dados históricos.

${ }^{43}$ Definições ao longo do texto.

${ }^{44}$ BANCO MUNDIAL; Governo do Estado de Santa Catarina, 2012; BANCO MUNDIAL; Governo do de Alagoas, 2012; BANCO MUNDIAL; Governo do Estado de Pernambuco, 2012; BANCO MUNDIAL; Governo do Estado do Rio de Janeiro, 2012. 
necessária ao mercado de seguros e derivativos de riscos, que busca por ampliação de adesão ou ampliação de escopo para diluir riscos mais críticos.

Os CAT-DDO propostos para as situações extremas (e muito improváveis) equivalem aos Catastrophe bonds, ou CAT Bonds. São títulos que funcionam na vinculação de seguros de riscos, e transferem determinado conjunto de riscos segurados de um promotor (que detém a gestão de uma situação de risco, como gestores de fundos anticalamidades, seguradoras ou o empreendedor de atividade de risco) a investidores.

CAT-DDO são usados como instrumentos de empréstimo de Política de Desenvolvimento. Para ter acesso a esse crédito, os países devem estar envolvidos em programas abrangentes de Gestão de Riscos de Desastres. O instrumento de desembolso rápido - Componentes Contingentes de Resposta a Emergência - permite aos fundos serem rapidamente realocados para atividades de emergência $e$ recuperação. O Banco Mundial propõe programas nacionais e regionais com o intuito de ajudar a transferir o risco de desastres do governo para o mercado financeiro por meio de serviços de consultoria financeira e seguridade, desenvolvendo estratégias de financiamento integrado de riscos de desastres com base em parcerias públicoprivadas; e pelo Mecanismo Global Índice de Seguro - um fundo fiduciário de múltiplos doadores gerido pela Corporação Financeira Internacional para apoiar o desenvolvimento de soluções de seguros agrícolas baseadas em indicadores.

“Em 2008, o BIRD e a AID introduziram derivativos intermediários do clima, um produto que a República do Malawi usou nos últimos quatro anos para gerir o risco de seca severa e catastrófica. Ambas as iniciativas representam as opções mais amplas de soluções financeiras adaptadas para ajudar a proteger os recursos de desenvolvimento e os investimentos do governo. Para responder à diversidade da demanda nessa área, pode ser necessário ampliar o escopo dos serviços de intermediação e os tipos de produtos oferecidos. " (BANCO MUNDIAL, 2012 - Sendai Report.)

\subsubsection{Títulos de catástrofe e mercado de seguros: como funcionam?}

Os CAT bonds - catastrophe bonds - surgiram da necessidade de companhias de seguros aliviarem riscos assumidos no caso de enfrentarem ocorrências simultâneas em grandes catástrofes, cujos danos podem ficar descobertos pela avaliação dos prêmios ${ }^{45}$ estabelecida, e terem retornos impossíveis.

Uma companhia de seguros emite um título através de um Banco de Investimentos, e este título é repassado a investidores. Os títulos são intrinsecamente arriscados e as condições de acionamento são vinculadas a parâmetros de catástrofes extremas. Se a catástrofe não ocorre no período determinado e dentro de parâmetros das condições de acionamento específicas estipuladas (condições de simultaneidade de eventos ou de danos), os investidores resgatam os títulos, com valores pagos pela seguradora. Se

\footnotetext{
${ }^{45}$ Prêmio é o valor pago pelo segurado ao segurador, para que assuma determinados riscos especificados na apólice.
} 
ocorre, os investidores perdem o valor, e a seguradora os usa para cobrir danos dos valores e bens segurados. Funcionam como uma alternativa aos resseguros.

Os investidores mais usuais desses títulos são ${ }^{46}$ :

- fundos de cobertura (hedge funds) que gerenciam investimentos e portfólios institucionais),

- fundos criados para a cobertura de catástrofes (de indústrias, seguradoras ou governos, que também costumam ser emissores),

- gestores de recursos.

A lógica é: quanto maior a quantidade de catástrofes de grande impacto e de baixa probabilidade, mais deve crescer a emissão de CAT bonds, e maior é o ambiente para diluição dos riscos. À medida que cat-bonds passarem a ser opção banal na diversificação de investimentos, o escopo e volume dos seguros pode ser ampliado, assim como os títulos de seguros e possibilidades de arranjos de portfólios desenvolvidos por fundos de cobertura. A estratégia de empresas de gestão de fundos e coberturas $^{47}$ é assegurar que os investidores estão sendo adequadamente compensados ao aceitar montantes apropriados de risco identificável, e evitar riscos não compensados suficientemente.

Entretanto, a diluição dos riscos dos seguros para cobertura de catástrofes tem particularidades, porque as catástrofes de grandes proporções trazem problemas além do que os meios de comercialização e precificação da indústria de seguros dispõe tradicionalmente. Para os seguros mais convencionais, o princípio é simples: nenhum acidente de carro pode ser previsto individualmente, mas o número total de acidentes de carro sobre uma determinada população é bastante previsível, considerando o conhecimento acumulado em históricos. A lógica das catástrofes aparenta ser semelhante, mas é diversa: o evento de desastre é aleatório, pode ocorrer numa cidade ou em outra, pouco mais distante; pode causar danos dentro da razoabilidade, nenhum dano, ou atingir efeitos encadeados em uma escala catastrófica para uma seguradora conseguir reestabelecer o dano aos clientes. Se houvesse um grande número de cidades no planeta, com o mesmo grau de riqueza material exposta, para as quais fosse plausível prever situações de danos em escala catastrófica, o segurador poderia diluir essa exposição às perdas vendendo seguros a todos eles, e as perdas sofridas em uma cidade seriam compensadas pelas perdas não sofridas em outras cidades, como é feito com carros. Mas o contexto de desastres naturais não é esse: riscos de terremotos e furacões, por exemplo, são extremamente concentrados em poucos locais. O grande desafio do mercado de seguros e seus derivativos é proporcionar semelhança probabilística em realidades com riscos muito diferentes ${ }^{48}$.

\footnotetext{
${ }^{46}$ US GAO, 2002; LEWIS, M, 2007.

${ }^{47}$ Os fundos de cobertura são entidades passíveis de serem entendidas como pouco transparentes, pouco sujeitas a controle regulatório ou submetidos a procedimentos de registros como outra atividade de investimento. Novas regras regulatórias estabelecidas nos EUA e Europa a partir de 2010 requerem que gestores de fundos de cobertura relatem mais informações sobre suas atividades.

48 LEWIS, M, 2007.
} 
Os Painéis de Mudanças Climáticas do IPCC - que expressam consenso na comunidade científica - embasam a percepção de aumento de probabilidades dos riscos e, sobretudo, da quantidade de desastres. A combinação de investimentos em um escopo variado de riscos é o antídoto que dilui o problema da concentração desigual de riscos. E a incerteza, que amplia probabilidades e fermenta a matéria 'risco', é um elemento poderoso para o mercado que procura diluir riscos de danos e impactos maiores.

O mistério de como se pode ganhar no mercado de seguros está em como se estabelecem as vinculações entre títulos de seguros, que, apenas em parte, corresponde ao problema da precificação. A precificação estabelece valor tanto para os prêmios quanto na avaliação do risco e dos danos prováveis (o grau de probabilidade do evento e do impacto definido para o acionamento). Em parte, o ganho pode derivar, também, das regras de flutuação dos títulos derivados dos seguros. Mas é na composição combinada de regras para acionamento das apólices, e na combinação de portfólios de investimentos, que os ganhos com esse mercado se explica melhor.

Ao tentar compreender procedimentos do mercado financeiro, de seguros, e de fundos de cobertura, foram apresentados tanto argumentos que afirmam que o controle da flutuação correspondeu a um mercado de ferramentas de previsão ${ }^{49}$ - oriundos de modelos de previsão climática, hidrometeorológica, associados a perigos geológicos ou condições da ocupação do solo urbano, por meio das ferramentas de avaliação de risco - como argumentos de que tanto a precificação quanto as flutuações independem, cada vez mais e mesmo completamente, das reais situações geradoras de riscos extremos, sendo, então, baseados em probabilidades-padrão das carteiras e portfólios dos investidores, e modelagens de estatísticas mais relacionadas aos comportamentos de troca e compensações dos mercados de títulos.

Após o furacão Andrew (Florida, 1992) ${ }^{50}$, foi fundada nos EUA a Applied Insurance Research - AIR - uma empresa de previsões e dados para previsão e seguros, que passou a comercializar não só dados na forma de resultados, mas também modelos de previsão (softwares). Outras empresas posteriormente competidoras nesse mercado Eqecat e Risk Management Solutions - permitiram ampliar a incorporação de mais áreas da ciência no mercado de previsões - meteorologistas, sismólogos, oceanógrafos, físicos, engenheiros e estatísticos - e avançaram no escopo das situações de risco - de furacões e terremotos para inundações, incêndios, tempestades de inverno extremas, tornados, tsunamis, e até mesmo terrorismo ${ }^{51}$.

\footnotetext{
${ }^{49}$ KEUCHEYAN, R. (2014) desenvolve uma análise que confere importância significativa ao papel das agências de avaliação e modelagem de riscos de desastres naturais no estabelecimento de bonds. Para MUIR-WOOD, R. (2014), o mercado de securitização de riscos cresceu e mudou seu patamar - se inseriu no circuito financeiro - apenas como resultado da confiança adquirida em modelagens de riscos de catástrofe. Para ele, seria impossível organizar transações, calcular perdas esperadas e desenvolver preços para os títulos sem modelos confiáveis. CLARKE, D. (2014) afirma que modelos são amplamente utilizados pelo setor privado, e onde quer que haja tomada de decisão acerca de riscos de desastres, eles são significativos - como exemplo, o mercado de seguros e resseguros de desastres.
}

50 LEWIS, M. (2007).

51 LEWIS, M, 2007; KEUCHEYAN, R., 2014. 
Os modelos físicos dessas empresas partem de um princípio: a aceitação do passado como uma orientação imperfeita para o futuro. Ou seja, pode ser que, de fato, nenhum furacão tenha atingido uma localidade, mas pode ser apenas que registros detalhados sobre o evento não tenham sido realizados e coletados no intervalo histórico conhecido. Ou, de fato, podem não ter ocorrido, mas simulações com extrapolações por similaridades de zonas contíguas podem indicar uma probabilidade fora dos registros da localidade - previsão que é possível se vinculada a modelos físicos. As modelagens, embora já existissem no campo da engenharia para cálculos de dimensionamento de projetos, não haviam sido associadas sistematicamente e simultaneamente a bancos de dados extensos e cruzados, incluindo valores de imóveis e dados históricos com possibilidade de extrapolações físicas e temporais. Essas ferramentas permitiram a montagem de cenários com variedades de dados e abrangência espacial e temporal em uma escala de alternativas inédita, sobretudo numa atividade profissional rudimentar, como a de seguros. Ajudaram a tornar mais confiável a atividade de precificação.

E estão tendo, cada vez mais, penetração nos processos de planejamento territorial, em diversos países e diversos setores de infraestruturas. O propósito dos modelos é prover um catálogo síntese de eventos extremos, projetando alargamento de 10.000 ou 100.000 anos de atividade, como um meio de relacionar o perigo de uma localização à perda que ela geraria de acordo com a natureza da exposição ao perigo. Podem trazer respostas a duas questões chave que rodeiam seguros de catástrofes: 1) qual é o preço técnico a cobrar pelo risco que representa o custo anual de todos os danos potenciais de uma localidade, acrescidos de taxas apropriadas? 2) Qual o capital que o segurador deveria manter contra perdas potenciais extremas em uma localidade, que ocorrem, por exemplo, a cada 200 anos? (MUIR-WOOD, 2014).

As previsões foram ferramentas importantes para promover o movimento na indústria de seguros $^{52}$, embora para os operadores de mercado possam não passar de ferramentas de comprovação do senso comum. Convergem para o fato de que furacões nos EUA, terremotos na Califórnia e no Japão constituem as situações de perigos naturais que ultrapassam qualquer habilidade das companhias de seguros de os assegurarem. A concentração de riqueza nessas áreas desafia a lógica dos seguros; e o risco econômico dos grandes desastres do século 21 não pode ser diversificado facilmente somente pelo mecanismo dos resseguros. O suporte necessário a essas exposições exige espalhar amplamente os riscos, transferindo-os do circuito da indústria de seguros ao circuito financeiro. Para serem elevados à rotina das transações de investimentos do mercado financeiro e aos portfólios de fundos de cobertura, os títulos de seguro precisam se apresentar com características de um jogo de vantagens e falhas, e tornar claras as possibilidades concretas de ganhos nesse jogo para os tomadores (compradores) do risco (LEWIS, 2007).

O mecanismo para diluir riscos nada mais é do que combinar diferentes eventos com diferentes frequências (probabilidades) numa mesma aposta para variadas condições de acionamento, ou de clientes, ou regiões. A transferência de riscos ao mercado

\footnotetext{
${ }^{52}$ As duas principais empresas que fornecem análises globais com avaliação de sinistros por ameaças naturais e da cobertura de seguros são a Swiss Re e Munich Re, que atuam com seguros, resseguros e emissão de títulos CAT.
} 
financeiro não é nova, o que é novo é a relação que se estabelece entre a avaliação de riscos a serem diluídos e as políticas recentes de redução de riscos, com difusão ampla.

Essa variabilidade de ganhos da aposta pode ocorrer na elaboração da apólice - nas condições de acionamento, combina-se o seguro de duas áreas distintas e a combinação de probabilidades diminui probabilidade, risco e custo - e na expansão dos títulos, por meio dos quais um investidor pode combinar diferentes produtos em seu portfólio. Por exemplo, ele pode comprar os títulos de risco de uma área sujeita a inundação e, ao mesmo tempo, títulos de investimento para a reconstrução daquela área, ficando coberto para ter retorno nas duas hipóteses possíveis.

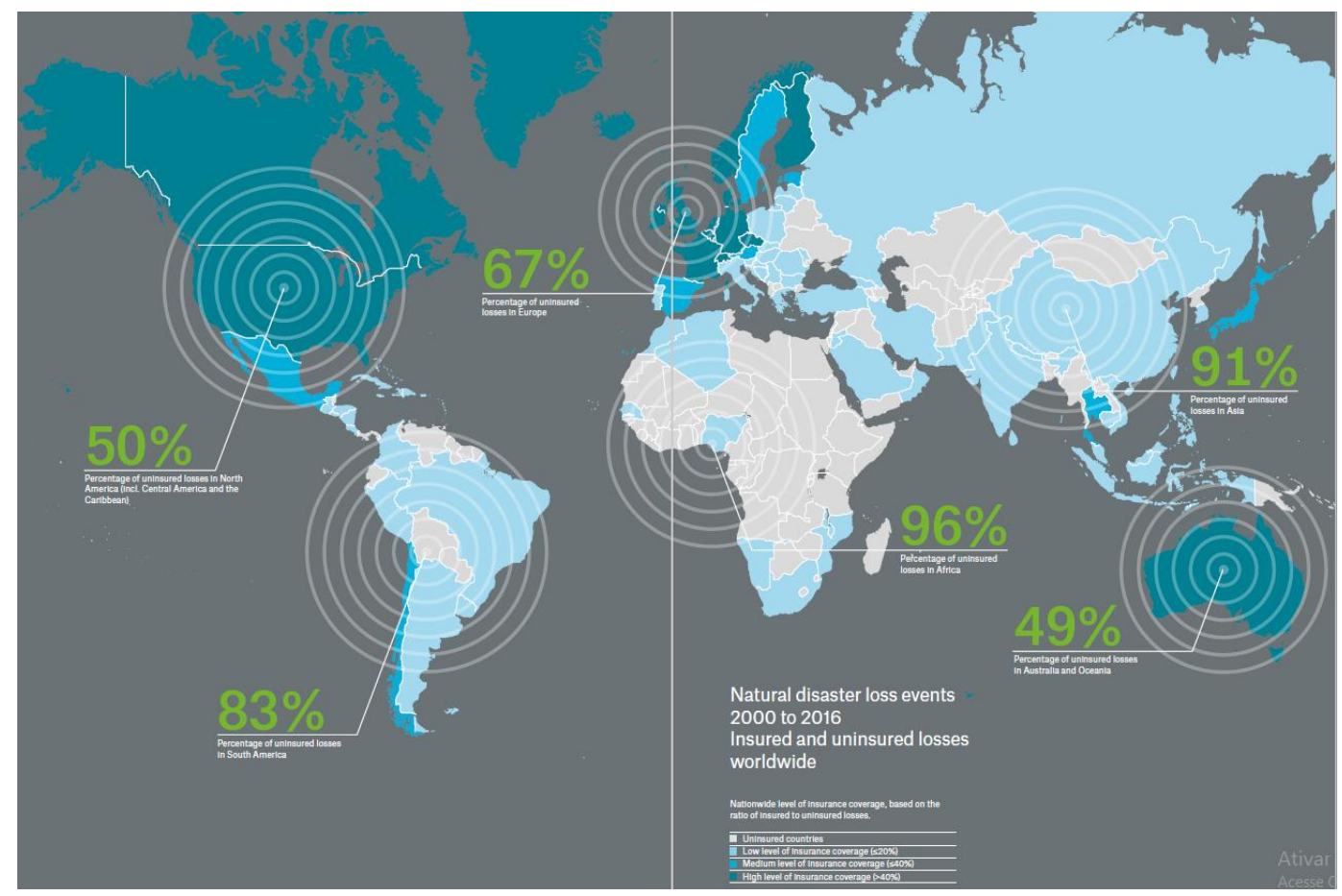

Loss events 2016 compared to 1980-2015

Breakdown of global insured losses by continent

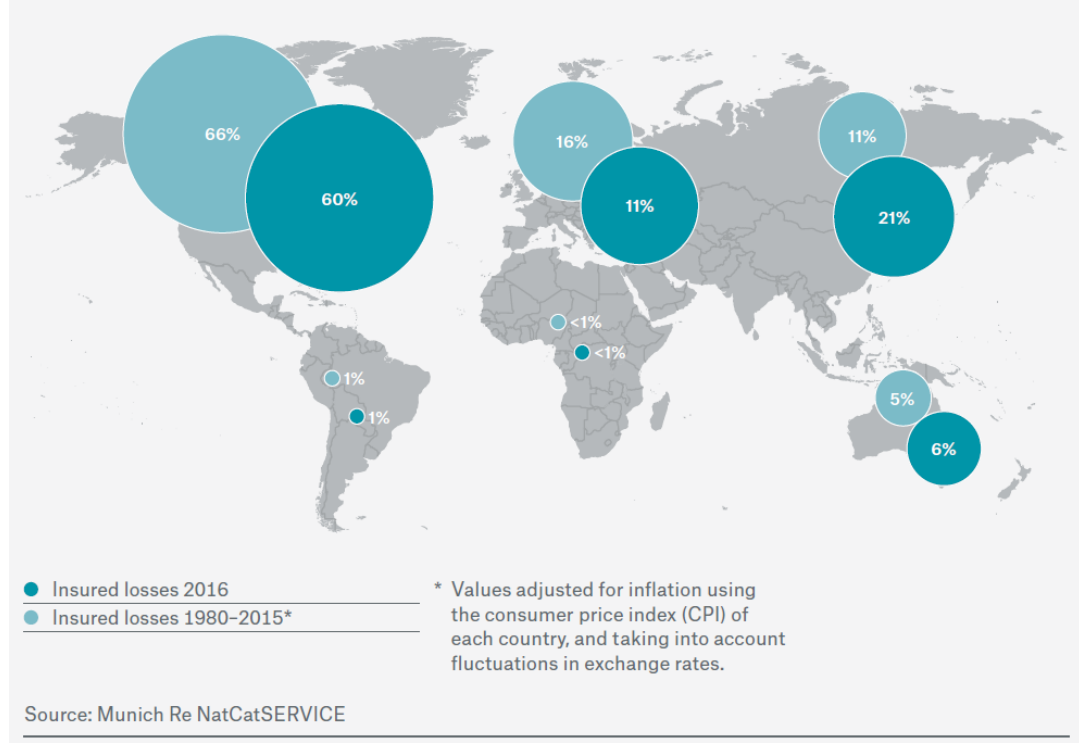

Fig. 4 Análise Global do perfil de riscos e cobertura de seguros e Fig. 5 Análise global das perdas cobertas e não cobertas por seguros em 2016 e metas para 2017. MUNICH-RE (2017: 59 e 60). 
Nas propostas das políticas do Banco Mundial, a avaliação (valoração) do risco é feita primeiro, e depois atua-se na implementação de medidas para redução dos riscos. Essa ordem é importante: diluir risco não é reduzir risco, mas a redução posterior de uma situação avaliada anteriormente amplia os ganhos possíveis da diluição.

A redução de riscos envolve principalmente (mas não necessariamente) gastos públicos; a diluição implica, geralmente, em ganhos privados no mercado de securitização e fundos de cobertura. Mas pode haver ganhos públicos também ${ }^{53}$. Considerando-se um contexto de escala global em que há interesse econômico na diluição de riscos de portfólios internacionais, um elemento de interesse da regulação nacional de países e governos cujo perfil de riscos não é tão alto, deveria consistir em uma preparação institucional que permita manter controle dos detalhes técnicos da categorização de risco, das metodologias de perdas e danos e, sempre que possível, de formas autônomas para financiar a reparação de danos. Algumas perguntas devem ser elaboradas: o que deve ser regulado por um governo que pretende assegurar-se em sua capacidade (e das capacidades do mercado privado que o serve) de cobrir suas situações catastróficas? Seria possível o desenvolvimento de um contexto interno de diluição dessas inseguranças e possíveis ganhos cruzados, sem submeter-se a um mercado maior, com riscos mais concentrados e potencialmente agressivo? Que escopos podem ser cruzados para fomentar tal contexto de diluição?

A estratégia "D" do Marco de Sendai, de garantir segurança às infraestruturas, é um ponto que permite pensar alguns aspectos de segurança financeira para situações de risco de cobertura local. Pois as infraestruturas, como objeto de análise, são estruturas de capital de uma localidade. Sua produção depende de instituições robustas, eficientes e acreditadas, que recebem investimentos financeiros e podem emitir títulos. Uma vez que essas instituições ${ }^{54}$ tenham seus riscos bem conhecidos e avaliados - mais especificamente riscos ligados a processos urbanos - seria possível jogar com sua diluição e com condições para sua redução?

Num contexto futuro hipotético em que a cobertura de seguros se torne de fato importante, seria necessário pensar em como é possível escalonar e integrar benefícios dos mecanismos de seguros desde o nível institucional até o menor nível possível, dos usuários, cidadãos em risco, ou entre sistemas diversos que podem se beneficiar mutuamente da melhoria de confiabilidade e eficiência dos sistemas, ampliando escopos. São situações complexas que exigiriam estudo mais específico, com

\footnotetext{
53 No México, CAT Bonds e outros mecanismos financeiros foram desenvolvidos para financiar a reconstrução no evento Tabasco Floods, 2007 (MUIR-WOOD, 2014), mais detalhado na próxima seção.

${ }^{54}$ A título de exemplo de ausência de mecanismos de segurança financeira, foi levantado para a Sabesp que, em 2016, foi elaborado documento de Gestão de Riscos Corporativos (SABESP, 2016a) com base na ISO 31000, que apenas estabelece procedimento e contexto de governança para instituir futuros processos de avaliação e tratamento de riscos corporativos. E também no termo de registro à Security Exchange (SABESP, 2018) consta a contratação de seguros apenas aos seguintes riscos: "a Companhia mantém seguros que cobrem, entre outros, incêndio e demais danos aos bens, edifícios de escritórios e seguro de responsabilidade contra terceiros, adicionalmente, também mantém cobertura de seguro de responsabilidade civil para conselheiros e diretores ("seguro D\&O") e seguro garantia judicial (...) e seguro garantia tradicional. A Companhia contrata seguros por meio de licitações que contam com a participação das principais companhias seguradoras brasileiras e internacionais que operam no Brasil"
} 
embasamento e ferramentas da área econômica, mas interessa aqui, pontuar que infraestruturas podem ser uma oportunidade para o desenvolver esses aspectos.

A investigação de uma política de seguros que articula a dimensão econômica com instrumentos de planejamento locais, como ocorre nos Estados Unidos para eventos de inundação, pode ilustrar uma série de desafios ao se implementar um mercado de apólices difusas, não diversificadas, concentrados em um único escopo e incentivados por imposições públicas. O exemplo de países e cidades que incorporaram mecanismos de financiamentos privados às políticas de proteção financeira a desastres, onde essa solução está mais avançada e é mais necessária, mostra que os problemas ainda estão longe de serem resolvidos. O que não quer dizer que países que ainda não fizeram esse movimento apresentem melhores soluções: o caso brasileiro sugere que o problema de lidar financeiramente com perdas em desastres sequer possui conjunto de dados suficientes e métodos próprios de avaliação para ser equacionado devidamente.

\subsection{Contextos de diluição de risco}

\subsubsection{O Programa Nacional de Seguros Contra Inundações norte- americano (NFIP)}

O contexto americano traz um cenário de desenvolvimento avançado do mercado de seguros, com políticas públicas que obrigam à adoção de soluções privadas para cobertura de danos. No entanto, conforme mostram os casos mais recentes de desastres de grandes proporções - como o Furacão Sandy, em 2012, associado à revisão da legislação de seguros contra inundação - traz também um contexto de crise desse modelo, somado a resultados indesejáveis em termos de justiça social ${ }^{55}$.

O plano de emergência a desastres vigente no Estado de Nova lorque em 2012 propunha, de acordo com os mapas de um novo zoneamento, a compra de casas atingidas nas áreas mais afetadas - Região de Rockaway Beach, distrito do Brooklyn, e em alguns loteamentos de cota mais baixa em Staten Island, e em Long Island desapropriando famílias pelo valor integral do imóvel antes do evento. Àqueles que aceitassem reconstruir suas casas em suas cidades de origem, fora de Nova lorque ou do país, seria dado um bônus de $5 \%$ sobre o valor original. Aqueles que recusassem e decidissem permanecer, estariam sujeitos a taxas de seguros maiores, em função da localização em área de alto risco. Para estes, seria oferecido auxílio para a construção de estruturas à prova de inundações - obrigatórias apenas a partir do evento - mas um auxílio não suficiente para a reconstrução total do imóvel.

Funcionando como uma ação de indução de mercado imobiliário, o plano sugeria provável resultado de gentrificação da faixa costeira e frentes aquáticas para as quais já eram previstas diretrizes de renovação no plano diretor da cidade (The City of New York, 2007): os moradores sem recursos para arcar com a reconstrução integral de suas casas, apesar do auxílio para estruturas especiais, deveriam encontrar outras localidades; os moradores com mais recursos teriam melhores condições de usufruir do

\footnotetext{
55 Não foram investigados aspectos dos seguros das infraestruturas implicadas nessa situação, mas seria um elemento de investigação importante de uma agenda de pesquisa no campo dos estudos urbanos.
} 
auxílio público para ampliar a segurança de suas residências, e permaneceriam nas áreas reconstruídas renovadas e então liberadas dos moradores sem recursos para habitar e construir em situações ambientalmente suscetíveis (ANGOTTI, 2013; MARCUSE, 2013). Famílias que ocupavam zonas historicamente delimitadas como de risco não crítico viram os limites de zoneamento de áreas consolidadas serem alterados subitamente, aproximadamente um mês antes do evento ${ }^{56}$.

É um exemplo de como situações de risco e mecanismos de proteção financeira podem ser usados a fim de alcançar determinados resultados espaciais e sociais. Pode-se considerar que estratégias de renovação urbana como esta contém sentidos sociais positivos e negativos. Positivo, ao transferir parte do custo das construções resilientes aos moradores de mais alta renda, configurando uma forma em que gastos privados são utilizados para benefício coletivo. No entanto, é coletivo apenas entre os que podem permanecer. O sentido social negativo está na expulsão de moradores sem recursos para tal intervenção construtiva. Ponderar o saldo desses sinais é papel importante de profissionais e pesquisas no campo do planejamento, e também para os que atuam na produção de cartografias que embasam zoneamento de riscos. Elas promovem resultados econômicos para os afetados, e é necessário refletir sobre possíveis compensações criativas, como operações de reinvestimento de ganhos de valorização imobiliária, para corrigir dimensões de injustiça urbana em processos dessa natureza.

O exemplo descrito resulta, em parte, dos desafios que as novas ameaças e amplitude dos impactos criaram ao Programa Nacional de Seguros Contra Inundações americano (National Flood Insurance Program - NFIP). O programa, criado em 1968 pela Lei de Seguro Inundação (National Flood Insurance Act), tinha como objetivo indenizar vítimas de inundação pelos prêmios, reduzir danos futuros de inundação por meio de planos de gestão de várzeas e frentes aquáticas, empreendidos pelo Estado com o reinvestimento, e reduzir gastos federais na assistência a desastres e controle de inundações (FEMA, 1986; NATIONAL RESEARCH COUNCIL, 2015; HANSCOM, 2014).

A lei estabelece critérios de gestão para zonas de risco e torna obrigatória a adesão a essas condições para quem ocupa tais áreas. Além do objetivo de promover seguros e reduzir danos, o NFIP identifica e mapeia áreas alagáveis em todo o país, fornecendo dados para a gestão das zonas e precificação dos prêmios de seguros (HANSCOM, 2014). Inicialmente o programa contava com adesão voluntária, que gerava baixa penetração. Dessa forma, o Estado continuava tendo prejuízos com os desastres. Em 1973 foi criada uma lei que proibia o FEMA (Federal Emergency Agency) de fornecer ajuda financeira a quem não aderisse ao programa de seguros (HANSCOM, 2014).

O Fundo Nacional de Seguro do NFIP coleta os prêmios, financia os custos operacionais e administrativos, e pode tomar empréstimos do Tesouro. A FEMA trabalha em conjunto com as seguradoras para facilitar a comercialização de apólices, que são vendidas de duas formas: 1) por concessões do Estado a empresas ou agentes de seguros que lidam com os segurados através da FEMA; 2) por empresas de seguros privados, na

\footnotetext{
${ }^{56}$ Relatos de ativistas do movimento Occupy Sandy - Rockaways - apresentados no evento Planners Network, realizado em junho de 2013, em Nova lorque, revelam que, apesar dos alertas para evacuação das zonas de maior risco (A) (The City of New York, 2007 e 2011), muitas famílias desconheciam o novo zoneamento.
} 
modalidade do programa Write Your Own, criado em 1983 (FEMA, 1985). As duas modalidades praticam os mesmos métodos de precificação. Os valores das taxas de seguros variam de acordo com a cota de implantação da edificação em relação ao nível definido na mancha de inundação estipulada nos zoneamentos de risco: abaixo, no mesmo nível ou acima da cota de inundação. Diferentemente das Diretivas Quadro Europeias, que definem dois conceitos distintos para sinistros ("inundação" como o extravasamento da calha de um curso d'água, e "alagamento" como cheias decorrentes de falhas dos sistemas de micro drenagem), no NFIP o termo "inundação" é definido, nas apólices denominadas "Standard Flood Insurance Policy Forms" (SFIP), como "condição geral e temporária de inundação parcial ou completa de dois ou mais acres de terra - seca em condições de normalidade - de duas ou mais propriedades (com pelo menos uma delas segurada), causadas pelo transbordamento de águas de maré ou águas de interiores, de acúmulo invulgar e rápido, ou pelo escoamento superficial a partir de qualquer fonte, seja de água ou lama" (FEMA, 1985).

Esse programa de subsídios passou a dar sinais de colapso a partir do Furacão Katrina, em 2005, quando se viu num contexto de débito cumulativo de 18 bilhões de dólares e com reposições anuais de apenas 3,6 bilhões (HANSCOM, 2014). Seguiu-se ao evento Katrina anos de batalhas legislativas severas, resultando no Bigger-Waters Act, em 2012, que impunha diversas restrições à FEMA para continuar subsidiando seguros contra inundação. O Congresso também recomendava à FEMA que conduzisse estudos de viabilidade econômica de forma a garantir que as novas regras não deixassem cidadãos em situação de mais vulnerabilidade, ou até sem casas (NATIONAL RESEARCH COUNCIL, 2015; HANSCOM, 2014).

Antes que pudesse empreender tais estudos, e já sob o regime das novas regras do Bigger-Waters Act tornado lei, o Furacão Sandy abateu a Costa Leste americana, exigindo enormes esforços de recuperação e levando o NFIP a acumular ainda mais débitos, tingindo a casa dos 30 bilhões de dólares (HANSCOM, 2014).

\section{National Flood Insurance Program Debt Grows}

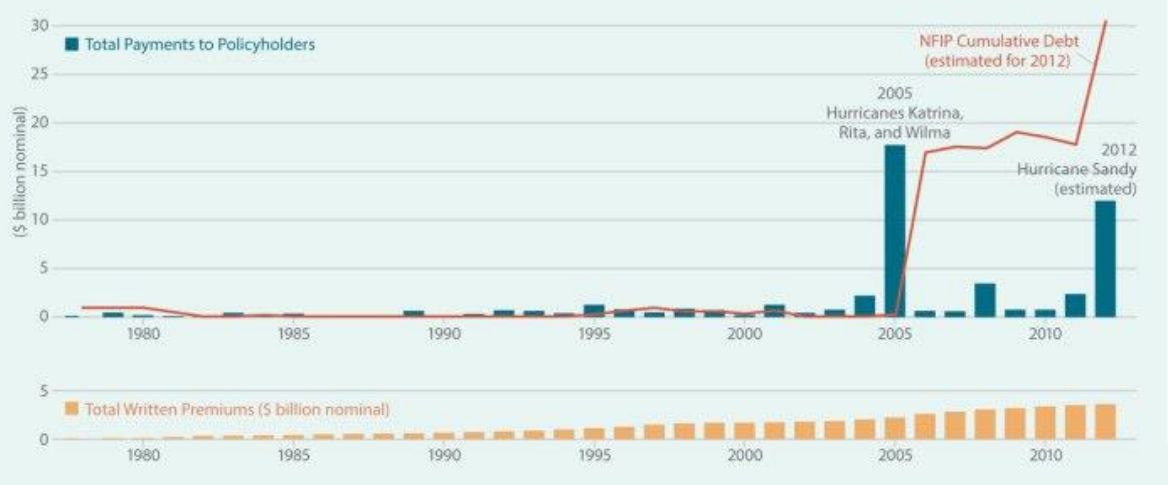

The National Flood Insurance Program has fallen deeper in debt since the payouts after Hurricane Katrina and most recently the costs of Hurricane Sandy. As of November 2012, the program was more than $\$ 20$ billion in debt to the U.S. Treasury (GAO 2013), and that figure is likely to rise once all the Sandy claims are settled.

Sources: FEMA 2013a; estimate for 2012 NFIP payments for Hurricane Sandy from King 2013; estimate for 2012 NFIP debt based on its borrowing limit of $\$ 30.4$ billion set by the Hurricane Sandy Relief Act. 
Pouco antes do furacão Sandy, os mapeamentos de risco de inundação já estavam sendo revistos, e quando o evento se abateu sobre a Costa Leste, muitos moradores não tinhas certeza sobre qual zona pertenciam, e quais medidas de alerta deveriam seguir (MARCUSE, 2012). Após o evento, as medidas de ajustamento ao Bigger-Waters continuaram em processo, e foram anunciados aumentos nos custos das apólices, em alguns casos dramáticos, com vinculação da manutenção dos prêmios anteriores a certas medidas de adequação das edificações a parâmetros resilientes.

Apesar dos efeitos dramáticos do Bigger-Waters Act sobre a população americana mais vulnerável, alguns críticos consideram que a lei traz como aspecto positivo a responsabilização no processo de novas ocupações. Isso porque, pela primeira vez, a FEMA estaria comercializando seguros da mesma forma que o mercado de seguros não subsidiado comercializa, e praticando preços efetivos em função dos riscos (HANSCOM, 2014). Isso levaria as pessoas a pesarem seus riscos (como consequência do peso dos seguros obrigatórios) ao optarem entre duas localizações, ou ao optarem entre duas soluções construtivas, mais ou menos seguras e adaptadas.

Para viabilizar economicamente as crescentes taxas de seguros às populações mais empobrecidas, foi proposto um sistema de crédito (vouchers) condicionado à tomada de medidas para tornar as edificações menos vulneráveis a eventos catastróficos. Eram oferecidos empréstimos com taxas de juros mais baixas, com o propósito de que, reduzido o risco da edificação, no futuro, os prêmios de seguros poderiam voltar ao preço mais baixo (HANSCOM, 2014). Na prática, entretanto, não há garantia de que haja reequilíbrio entre adaptação da edificação e preço do seguro.

O caso do furacão Sandy em 2012 é exemplar para demonstrar essa falta de garantia. $\mathrm{E}$, também, como o mercado do risco pode funcionar na perspectiva de implementação de projetos resilientes mas não necessariamente mais justos socialmente, ou ao objetivo de aliar resiliência à redução da pobreza, conforme proposto no Marco de Sendai. Por isso, o uso de recurso de mercado de diluição de risco não pode ser entendido como solução única, mas como instrumento de estratégias mais amplas, em que objetivos de redução da pobreza estejam presentes. Não é possível que o mercado, por si, promova justiça social; um programa público que aposte exclusivamente nisso irá fracassar. No entanto, não parece ser possível colocar-se de fora da evolução do mercado de riscos.

As inundações da região de Tabasco, no México trazem outro exemplo de utilização de seguros. Não se trata de uma política nacional, mas de um fundo local constituído em conformidade com as diretrizes das políticas internacionais, financiadas por estratégias de Programas de Desenvolvimento das Nações Unidas (UNDP). Após evento de inundação em 2007, o governo Mexicano investiu pesadamente em estruturas de defesa contra inundações no estado, para proteger propriedades agrícolas, infraestruturas e habitações contra cheias recorrentes. Em 2010, 3 anos depois, eventos de chuva similares ocorreram, mas os investimentos ajudaram a minimizar danos, com redução de perdas aproximadamente 3 vezes maior que o custo da construção de defesas. Benefícios desse tipo até então não eram visíveis, pois não eram avaliados pelo viés de um programa voltado especificamente a esse fim, mas por análise de dotações orçamentárias genéricas. Modelagens foram usadas não apenas no dimensionamento das medidas para redução de riscos, mas na elaboração de soluções de mercado para 
reorganizar o Fundo Nacional para Desastres Naturais (Fonden) do México. O fundo, criado no final dos anos 1990, traçou estratégia de resseguros em 2007 com a Swiss$R e$, lançou cat bonds no mercado de seguros, e obteve recursos que permitiram reinvestimento em prevenção e reconstrução (MUIR-Wood, 2014; WILKINSON, 2014).

Se comparado com o exemplo americano, o Fonden passou a praticar diluição mais ampla, global, a partir da emissão de debêntures, usadas tanto na reposição de danos como na reconstrução. O escritório UNISDR mantém unidades específicas para estudar essas oportunidades de estruturação e financiamento de fundos nos diversos países.

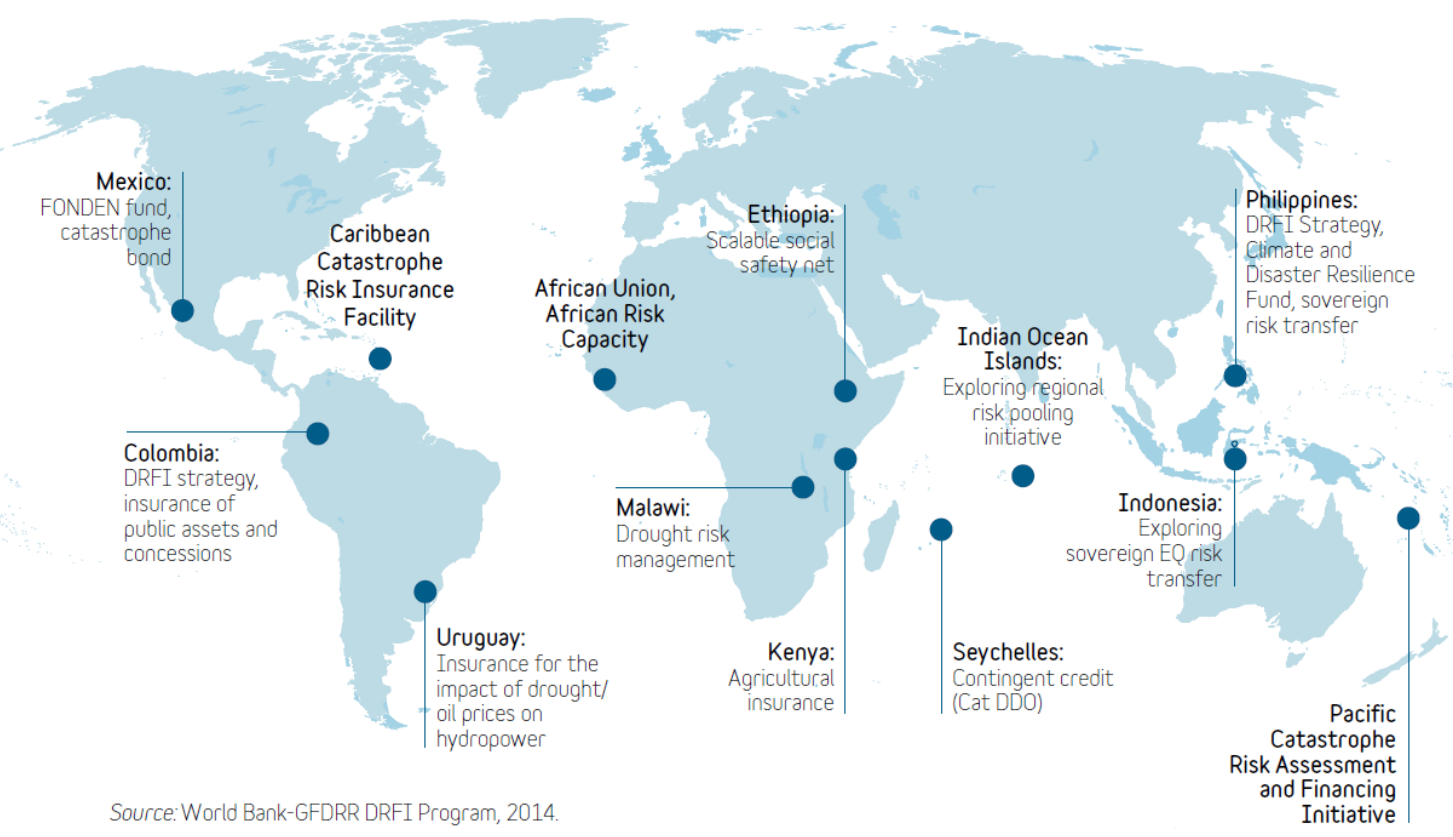

FIG. 7 Potencial de desenvolvimento soberano de seguros e proteção financeira. CLARKE, 2014.

O que a análise dessa política internacional da UNDP e das políticas da UNISDR mostram é que, uma vez criada, em âmbito global, a necessidade de se trabalhar políticas de redução de riscos e implementar governança de riscos localmente, uma provável lacuna de um futuro marco pós-Sendai será lidar, em forma de diretrizes globais, com o problema de como as políticas locais para redução de riscos podem contar com financiamentos e estruturar seus fundos para redução de riscos e recuperação de desastres. A depender de como os países vão participar nesse processo econômico global, a adesão poderá se tornar uma saída ou uma armadilha.

No Brasil, o financiamento da prevenção e recuperação dos desastres é uma lacuna evidente, como veremos a seguir. Uma hipótese, que não será trabalhada nesta tese, é a de que infraestruturas possam entrar positivamente nesse jogo de composições de internalizar, transferir e reduzir riscos.

\subsubsection{Perfil das perdas e estado da arte dos mecanismos de proteção financeira a desastres no Brasil}

No Brasil, a indústria de seguros é bastante incipiente. $O$ ambiente de informações sobre desastres também é limitado, com reflexos tanto no desenvolvimento de processos de 
diluição como no planejamento de ações para redução de riscos. Seria desejável, em nosso contexto, que o desenvolvimento de informações sobre riscos de desastres alcançasse ao menos um patamar adequado para o bom desenvolvimento de premissas de redução, com clareza suficiente para compreender como o país se insere ou se protege de um mercado de riscos possivelmente agressivo.

No ranking da seguradora Swiss $\mathrm{Re}^{57}$, o Brasil é um dos 10 países com maior probabilidade de perdas e danos por inundação. As análises do Banco Mundial (2012b) apontam para a necessidade desses países se prepararem para mitigar impactos fiscais decorrentes dos desastres, sendo que, no caso do Brasil, a implementação de instrumentos de proteção financeira seria mais desejável associada a políticas de combate a inundações.

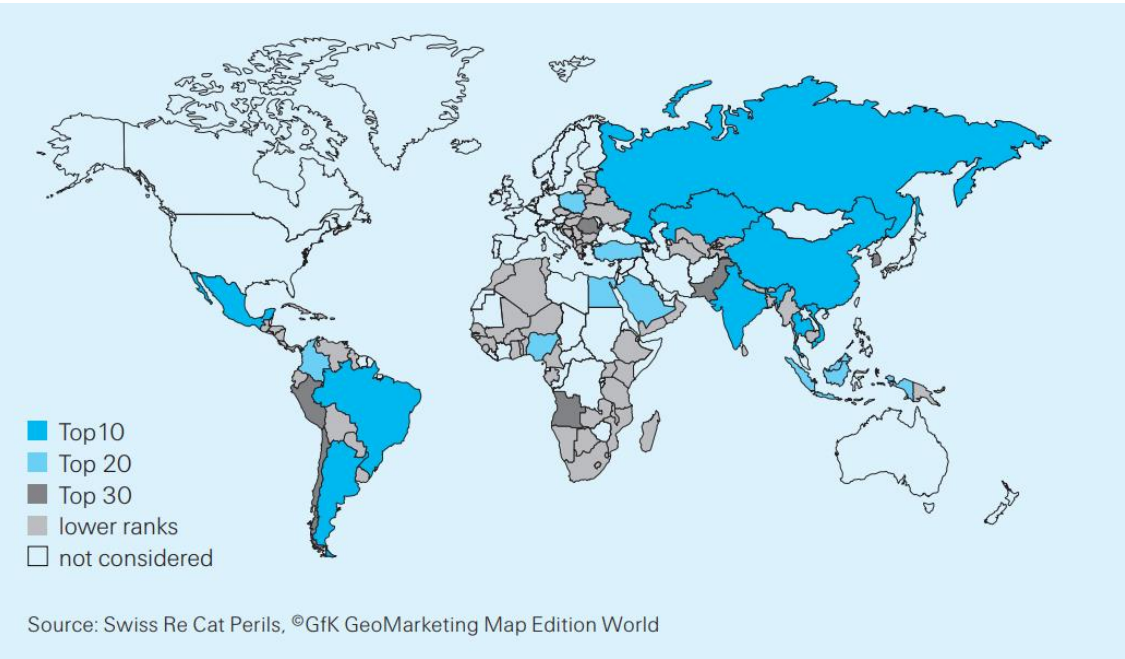

FIG. 8 Mercados emergentes do ranking "hot spot" da Seguradora Swiss-Re. SWISS-RE, 2012.

Com rotina de desastres de mais baixo impacto, o Brasil possui um perfil de riscos ocultos, com impactos negligenciados ou não contabilizados sistematicamente. São riscos extensivos, recorrentes e de pequena escala. Os impactos subestimados em desastres recorrentes são perdas cumulativas que podem até superar perdas de grandes catástrofes, pois a falta de procedimentos de avaliação leva à desconsideração da escala de danos das situações menos graves. A ocorrência de grandes catástrofes, portanto, não tem importância expressiva no perfil de risco do país, a não ser na sequência de grandes eventos em curto espaço de tempo em anos mais recentes - entre 2009 e 2012 (BANCO MUNDIAL, 2012b; 2012c, CEPED-UFSC, 2010). Outra consequência da negligência de análise das situações frequentes é que possíveis encadeamentos entre situações menos graves também deixem de ser conhecidos.

As secas correspondem a $7,6 \%$ das fatalidades, e a $51,3 \%$ da população afetada em desastres no país. As Inundações correspondem a $71,5 \%$ das fatalidades, e $32,7 \%$ dos afetados por desastres no país, mais de 1,3 milhão de desabrigados por inundações por período. Deslizamentos de terra compõe o terceiro principal risco em função da magnitude dos danos, representando $15,6 \%$ das mortes por desastres no país no período, e 1,79\% dos desabrigados. São comuns em área de grande concentração de ativos, localidades em que os índices de morte por este tipo de ocorrência assumem

${ }^{57}$ SWISS-RE, 2012. Sigma n. 2/2012. 
maior peso frente aos demais. O custo total de deslizamentos no Rio de Janeiro corresponde a 36,2\% do PIB regional; e em Alagoas, $8 \%$ do PIB do Estado, e estimativa de perda de receita fiscal no Brasil da ordem de 10 a 20\% (CEPED-UFSC, 2016).

"Um problema comum aos países com um perfil de risco extensivo é que ele pode levar os governos a negligenciarem as práticas de Gestão de Riscos de Desastres (GRD) em suas agendas nacionais. Por exemplo, como resultado, os sistemas de avaliação e gestão de dados sobre desastres acabam não sendo incorporados às políticas de resposta. Essa falta de infraestrutura básica para o desenvolvimento de mercados privados de riscos e de ferramentas de planejamento adequadas para apoiar as estratégias soberanas de proteção financeira prejudicam enormemente a capacidade de recuperação financeira dos agentes públicos e privados, causando atrasos nas operações de reconstrução $e$ ampliando os efeitos negativos dos desastres sobre o desenvolvimento econômico." (BANCO MUNDIAL, 2012c).

Os financiamentos internacionais voltados ao auxílio a desastres estão distribuídos da seguinte forma: $69,9 \%$ na resposta a emergências; $24,8 \%$ nas ações de reconstrução; $3,6 \%$ na preparação e prevenção de desastres. Dentre o volume de auxílio internacional, o auxílio a desastres corresponde a $2 \%$ do total de ajuda ao desenvolvimento (Banco Mundial, 2012b).

O estudo sobre impactos (ônus) fiscais de desastres naturais no Brasil (Banco Mundial, 2012c) apresenta elementos de diagnóstico para desenvolvimento de proposta de Proteção Financeira, listados abaixo:

1. avaliação preliminar de riscos fiscais. No Brasil, o Banco Mundial estimou as Perdas Anuais Médias em 3,9 bilhões de dólares, com impacto fiscal de 30\% a $40 \%$ dos custos totais (públicos e privados) em desastres;

2. revisão do processo orçamentário para financiamento a respostas. Não há atualmente no Brasil estratégia nacional integrada, apenas mecanismos ex-post. Alguns estados estabeleceram fundos próprios para desastres, e há debate para reinstitucionalização do FUNCAP - Federal.

3. análise constante do déficit de financiamento, que aponta que processos de recuperação e reconstrução ineficientes e ineficazes geram passivo de $30 \%$ ao montante estimado para esses fins pelo governo.

4. revisão do mercado de seguro de desastres. Houve alto grau de apoio do governo a seguros agrícolas; a partir de 2003, apenas para pequenos produtores, crescendo o seguro privado para grandes propriedades.

5. estratégias para proteção financeira a desastres no Brasil deve desenvolver estruturação por diferentes níveis de risco, com mecanismos apropriados a cada um. O país deve compreender melhor o passivo para avaliar possibilidade de transferências de risco entre os setores agrícolas e habitacional; com adoção de metodologia nacional para avaliação de perdas e danos.

O estudo sugere que, a essa organização, deve corresponder a sistematização de informações. Processos de liberação do fundo pós desastre no Brasil, que exigem 
notificação de perdas e danos em até 5 dias, prejudicam a confiabilidade das informações, pois somente municípios que pedem auxílio ao governo federal preenchem os formulários, e os dados por e para estados que não solicitam apoio financeiro não são disponibilizados em sistema nacional integrado. Daí a importância em desenvolver estudos que contribuam na melhoria do conhecimento e desenvolvimento de informações sobre riscos, que avaliem lacunas na disponibilização de dados e entraves a seu potencial analítico.

Orçamentos dispersos e fragmentados também caracterizam dificuldades de estruturação da informação, que dificultam, também, o efetivo desenvolvimento de medidas de prevenção. Só no âmbito Federal, o orçamento encontra-se dividido entre Ministério das Cidades (prevenção de riscos); Ministério da Integração (resposta), por meio da Secretaria Nacional de Defesa Civil; Minas e Energia e Ciência e Tecnologia (lei 12593 18/01/2012). Além da fragmentação no âmbito federal, há fragmentação orçamentária entre as esferas, e de acordo com as categorias de danos.

As fontes de proteção financeira a desastres previstas em lei são ex-post: realocação orçamentária, tributos e assistência internacional, sempre posteriores ao evento. Além da fonte das dotações, não há tributos específicos com receitas revertidas em prevenção a desastres. Há isenção fiscal para apoiar recuperação - no IPTU, e de impostos ao setor industrial, agrícola e comercial - sem que haja avaliação do impacto econômico ou físico (resultados espaciais) dessas medidas. A modalidade de assistência internacional não é particularmente relevante no Brasil. É mais representativa no nível local, principalmente na assistência à apoio e recuperação para as camadas de renda baixa, mas ainda nesses casos, a dependência orçamentária do governo federal é maior do que de doações internacionais (BANCO MUNDIAL, 2012c).

A dotação e realocação compõem a maior parte do orçamento para eventos de emergência. As realocações (créditos federais extraordinários diretamente aos municípios) são determinadas mediante avaliações estimativas de perdas e danos, e não incluem medidas preventivas no pedido de orçamento extraordinário (na escala federal, via Ministério da Integração Nacional). É expediente de liberação rápida para o socorro, mas o mesmo procedimento é usado para recursos de recuperação e reconstrução, indicando que as atividades de reconstrução não passam por planejamento, pois após um desastre e decretação de estado de emergência, o Governo Federal deve responder à ocorrência em questão de dias, sem análise mais detida dos impactos efetivos do desastre. A avaliação indica que uma estrutura especialmente concebida para administrar projetos de recuperação seria desejável para melhorar projetos de prevenção (BANCO MUNDIAL, 2012c).

As principais práticas de planejamento de recursos de antecipação aos desastres, no âmbito federal, são as reservas plurianuais do orçamento (PPA), assim como as reservas plurianuais do orçamento local são as principais práticas no caso de eventos frequentes e de menor impacto (BANCO MUNDIAL, 2012c). Desde 2004, a dotação nos Planos Plurianuais da União tem tido metodologia para acompanhar despesas para políticas de prevenção a desastres, além das dotações apenas à resposta. As reservas plurianuais em nível federal permanecem no FUNCAP. 
Além do planejamento plurianual de reservas, as principais práticas de proteção financeira ex-ante estão representadas na revisão regulatória do fundo nacional FUNCAP. O Fundo Especial de Calamidade, criado em 1969, regulamentado pelo decreto 66.204 de 13/02/1970 - passa atualmente por revisão de seus regramentos (apontado em alguns documentos de revisão institucional como 'sem regulamentação' - Banco Mundial, 2012a). Ele foi estruturado na forma de um fundo de doações de correspondência: para cada real transferido para o fundo por um estado ou município, o Governo Federal transfere três reais. No caso de um desastre, os governos subnacionais podem sacar recursos do Fundo até o limite de suas quotas. Mas, na prática, o fundo não recebe recursos financeiros desde 1995.

O formato original do Fonden, do México, tem funcionamento orçamentário similar, mas seu planejamento é ex-ante, e permite instrumentos de transferência de risco. Financia $100 \%$ da reconstrução de ativos federais, e $50 \%$ de ativos locais no caso de primeiro acionamento. Em 2007, foi desenvolvido um programa específico para financiar atividades de redução de riscos a desastres (por meio de mapas de risco e pequenas intervenções estruturais), e estudos para reconstrução resiliente (MUIR-WOOD, 2014).

Recentemente, o uso do FUNCAP para financiar o desenvolvimento de mapeamento de riscos para os municípios brasileiros se assemelha ao uso do Fonden. A lei 12.340 de 2010, no artigo 8으, inclui a preparação e financiamento da defesa Civil para prevenção de desastres como dependentes do FUNCAP, estabelecendo restrições para os saques: pelo menos $50 \%$ de recursos investidos pelo governo sacados do fundo devem ser alocados em medidas de prevenção e preparação, como, por exemplo, identificação de áreas de risco, reestabelecimento de áreas de risco, implementação de sistemas urbanos de drenagem, monitoramento hidrometeorológico, implementação do Plano de Contingência da Defesa Civil, formação de agentes da defesa civil (BANCO MUNDIAL, 2012c). Além dessa mudança, foram propostas novas diretrizes em Projeto de Lei 3084/2012 para o FUNCAP: participação de $2,5 \%$ da receita da loteria federal e alteração do investimento de $R \$ 5$ do governo federal para cada $R \$ 1$ obtido pela loteria.

Não há prática de empréstimos contingentes pelo Fundo; em nossa prática e perfil de riscos, os custos se acomodam nos orçamentos. Não foram desenvolvidos mecanismos de transferência de risco ou seguros tradicionais de bens públicos no Brasili ${ }^{58}$; até o momento, a prática é reter o risco no governo e assegurar-se com ativos próprios. Também não foram emitidos títulos de catástrofe no Brasil (Banco Mundial, 2012c).

Nos governos locais, as alocações orçamentárias atingem proporções maiores do orçamento do que no âmbito federal. Os expedientes de dotação orçamentária são eficientes para remediação de desastres de custos baixos, e os recursos disponibilizados não são suficientes para financiamento total da recuperação e reconstrução de comunidades afetadas, e igualmente não são planejados para programas de preparação (BANCO MUNDIAL, 2012a). Há, portanto, muito recurso em recuperação investido pela população afetada que não é contabilizado.

\footnotetext{
${ }^{58}$ Há, apenas, levantamentos de que os empreendimentos MCMV são cobertos por seguros contra desastres naturais.
} 
Os fundos municipais para desastres e emergências vêm sendo utilizados para cobrir custos, sendo transferidos para exercícios seguintes nas reservas plurianuais. Mesmo quando estes fundos estão operando, os recursos são limitados. Alguns fundos existem com receita vinculada a impostos específicos, sugerindo que no âmbito onde os impactos são significativos (em volume de eventos, e não necessariamente em criticidade do evento), identifica-se a necessidade de instrumentos aprimorados de proteção financeira contra desastres. A tributação, novamente, não é um recurso utilizado, pois há dificuldade em aumentar impostos pós-calamidades; a tendência praticada é, ao contrário, eliminá-los (BANCO MUNDIAL, 2012c).

Recentemente, a partir de 2012, o uso dos fundos na escala local passou a ser monitorado pelo cartão da Defesa Civil, com uso vinculado a fornecedores préautorizados, mas esse monitoramento não funciona para finalidades de reconstrução.

\subsubsection{Mercado de seguros no Brasil}

Até a Lei de Resseguros de 2007, no Brasil, o Instituto de Resseguros do Brasil (IRB) detinha o monopólio da atividade de resseguros, controlando as empresas seguradoras que poderiam atuar no país. A nova lei permitiu a participação de seguradoras privadas, inclusive internacionais, e possibilitou a abertura do mercado de resseguros. Atualmente existem mais de 128 seguradoras atuantes no Brasil, em mais de 130 ramos distintos, e 123 resseguradores, sendo 16 locais, 35 externos admitidos e 72 eventuais (MARSH, 2017). Pequena parte da atividade de resseguros, entretanto, é local (em torno de 1,5\% da atividade), indicando que, com a abertura, o mercado de seguros brasileiro já se tornou global. A capacidade local das seguradoras atuantes no mercado brasileiro é em torno de $\mathrm{R} \$ 10$ bilhões, sendo que $80 \%$ desta capacidade está concentrada em 10 seguradoras, das quais apenas 4 são brasileiras e, em 8 principais resseguradoras, todas estrangeiras, com exceção do IRB. A dissolução da atividade no mercado global é, inclusive, uma meta da lei de regulamentação do setor de seguros, que reduz progressivamente a porcentagem de resseguros locais.

No Decreto no 60.589, de 23.10.67 atualmente em vigor, os ramos de seguros são agrupados em três blocos: saúde, de vida e elementares; e, na prática, continuam agrupados em dois segmentos: vida (que inclui saúde) e elementares. Os seguros de vida incluem as apólices contra risco de morte e acidentes pessoais bem como os planos de previdência privada aberta (VGBL), e os seguros saúde cobrem despesas com serviços médico-hospitalares. Os dois juntos correspondem a mais de $92 \%$ das receitas totais dos seguros. Os seguros elementares são os que têm por finalidade a garantia de perdas, danos ou responsabilidades sobre objetos ou pessoas (terceiros). Dentro do ramo elementar, a modalidade agrícola é a mais desenvolvida (http://www.susep.gov.br/).

O Brasil tem o maior mercado de seguros elementares da América Latina, mas a taxa de penetração ainda é baixa (1,08\% do PIB contra 3,6\% do PIB em países de economia avançada) (Banco Mundial, 2012c). A modalidade que vem sendo recentemente fomentada no mercado de seguros é a de seguro garantia.

O Seguro Garantia é uma modalidade que existe para garantir o cumprimento de obrigações de contratos - públicos ou privados - assumidas pelo tomador perante 0 
segurado (artigo $6^{\circ}$ da lei 8666), necessidades trazidas principalmente a partir das formas de contratação das Parcerias Público Privadas, cujos arranjos se dão por intermédio de operadoras e fundos de investimentos. À seguradora cabe garantir perante o segurado, o cumprimento das obrigações do tomador dos serviços. O Seguro Garantia faz parte do projeto financeiro da Sociedade de Propósito Específico (SPE), e se desdobra em diferentes produtos para as diferentes etapas e formas de atuação do segurado. É uma modalidade de contra-garantia dos contratos, que podem ser feitos também por Fiança Bancária - definida, pelo setor de seguros, como um produto bancário, de modalidade genérica, mais cara e padrão. Apesar de estarem presentes nos contratos para produção de infraestruturas, os seguros garantia são seguros financeiros, de diluição, e não associados a propostas de mitigação de riscos de obra e operacionais (embora possa haver detalhes sobre mitigação e valor de prêmios nas apólices). Nos arranjos de elaboração dos projetos financeiros das SPEs, podem ser identificadas necessidades de seguros: de engenharia (riscos diversos de projetos e obras), operacionais, de desempenho, de reponsabilidade (erros, responsabilidade civil, ambiental), entre outros, que, lançados em uma matriz, são redistribuídos de acordo com responsabilidades, definindo quem assume o risco no arranjo: o tomador, 0 construtor, projetista, etc (MARSH, 2017).

No que diz respeito ao mercado de apólices elementares, ou seja, ligado a danos materiais e propriedades, em 2010 foi criado um Fundo de Catástrofe (Lei Complementar 137 de 2010) com o intuito de substituir o FESR - Fundo de Estabilidade do Seguro Rural - criado em 1966, e gerido pelo IRB. Sua finalidade é manter e garantir o equilíbrio das operações agrícolas no país, bem como atender à cobertura suplementar dos riscos de catástrofe, inerentes à atividade rural. Posteriormente a este marco, também foram desenvolvidos programas de subvenção e apoio ao seguro privado, como o Pronamp - Programa nacional de apoio ao médio produtor rural, entre outros (http://www.susep.gov.br/).

No seguro de propriedade do mercado brasileiro, a cobertura contra riscos de desastres naturais ocorre por meio de apólices abrangentes de riscos não especificados (Banco Mundial, 2012c), o que não permite sistematizar dados históricos de desastres cobertos por seguros de propriedade. Por isso, há incerteza sobre a capacidade das empresas de seguros precificarem adequadamente as catástrofes e garantirem reservas suficientes para indenizar sinistros relacionados a eventos futuros. Como vimos para o caso americano, a precificação desse produto é desafiadora e potencial, e além do segmento residencial, também as empresas estão submetidas à possibilidade de não serem cobertas com precificação razoável. Um gargalo importante no desenvolvimento da indústria de seguros contra desastres no Brasil é o mesmo que existe ao desenvolvimento de políticas e planejamento de Estado voltados à redução de riscos de desastres: falta de acesso a informações como perdas históricas, mapas de risco atualizados, modelagens, e ferramentas de monitoramento climático. Apesar de avanços recentes, é necessário considerar que sem elementos mais acurados para precificar, os preços das apólices tendem a ser elevados e proibitivos.

O aprimoramento dos seguros agrícola, que têm maior penetração, poderia fornecer experiência e subsídios à estruturação de uma gama mais ampla de seguros: a melhor compreensão das perdas anuais médias deste ramo poderia levar à elaboração de 
modelos de transferências financeiras entre setores agrícolas, setoriais e de habitação, e desenhos de retenção e transferência alternados (cruzados).

Outra frente de desenvolvimento no mercado do Brasil são os microsseguros. Enquanto o termo 'seguro popular' é usado para designar produtos massificados, com importâncias seguradas e prêmios de pequeno valor, 'microsseguro' é um produto específico, direcionado a necessidades das famílias de baixa renda. Os microsseguros foram regulamentados para ramos mais estruturados, como de saúde e rural. A estrutura de microsseguros contra desastres aguarda aprovação desde 2008, quando a discussão entrou na agenda da Superintendência de Seguros Privados (SUSEP).

A principal dificuldade no desenvolvimento de seguros e microsseguros contra desastres, e de programas públicos de subvenção dessas aquisições no mercado privado, está - além da falta de dados e histórico de apólices mais específicas e menos abrangentes, que permitam boa precificação dos prêmios - na precariedade dos títulos de propriedade de populações mais vulneráveis aos riscos, e sua incapacidade de constituir demanda nesse mercado.

Para além da análise do mercado de seguros propriamente, as políticas territoriais também trazem alguma discussão sobre seguros. O Plano de Macrodrenagem da Bacia do Alto Tietê PDMAT-3, de 2014, em seu volume de medidas não estruturais, traz considerações para subsidiar estudos de viabilidade de implantação de um sistema de seguro de inundação para a Bacia do Alto Tietê, em São Paulo (DAEE, 2013). Dentre estes apontamentos, sugere-se um fundo de seguros para inundação que antecipe medidas de mitigação preventivas, atuação na redução da vulnerabilidade e mitigação de danos de longo prazo viabilizados por recursos gerados na sua implantação. Na fase preventiva, caberia a elaboração de mapas para gerenciamento de riscos, manchas de inundação e curvas de prejuízo potencial, medidas que poderiam tanto ser utilizadas na formulação de leis de zoneamento e medidas de controle urbano, como na estruturação do fundo, estratégias de financiamento e transferência de riscos com reinvestimentos.

O plano aponta que, do ponto de vista do segurador, seria condição interessante num programa de seguros contra inundação a diversificação de alternativas do portfólio que permitisse a compensação de prejuízos. Esse cruzamento é sugerido não por atividades (escopo), mas por cruzamento espacial, como um fundo regional de seguros que possibilitasse compensar prejuízos de uma determinada bacia hidrográfica que sofreu inundações a outra, que não registrou danos no mesmo período (DAEE, 2013).

Críticas sobre seguros de inundações apontam para o fato de que eles poderiam servir com o sentido contrário das medidas de mitigação de risco, pois podem induzir a população a ampliar a exposição e ocupar áreas de risco, uma vez que a perda do imóvel pode ter aparente segurança pela existência da apólice. Além disso, falta garantias de que os recursos sejam aplicados de fato em medidas de prevenção, e não se percam em um mercado agressivo. 


\section{Capítulo 3 -INSTITUCIONALIZAÇÃO DA GESTÃO DE RISCOS NO BRASIL E NA RMSP, E O DESENVOLVIMENTO DE INFORMAÇÃO}

\subsection{Institucionalização da Defesa Civil e desenvolvimento de marcos regulatórios da gestão de riscos a desastres no Brasil}

\subsubsection{Histórico das instituições de defesa e prevenção no Brasil: origem militar de uma necessidade urbana}

Em diversos países, e também no Brasil, a noção de defesa civil tem origem em doutrinas e princípios de defesa militares ${ }^{59}$. As instituições brasileiras voltadas à gestão de riscos, por terem se originado nessa tradição, são focadas principalmente na fase de resposta e atendimento emergencial. Apesar do desenvolvimento institucional posterior, uma questão fundante permanece nessa trajetória institucional e na organização de uma política de Gestão de Riscos de Desastres no Brasil: como articular o sistema de defesa civil e procedimentos de emergência com instituições vinculadas ao controle do território e planejamento territorial, a fim de promover, com maior eficácia, as medidas preventivas? Impasse que só reitera a importância de contribuições específicas dos estudos urbanos ao tema.

No caso brasileiro, sem terremotos, vulcões e furacões, mas com inundações, secas e deslizamentos, as noções de defesa civil tiveram que incorporar a identificação de riscos de desastres naturais em meio urbano às concepções originais de ameaças externas.

A década de 1960, que coincide com uma fase de expansão urbana expressiva nas grandes cidades brasileiras, trouxe casos emblemáticos para a primeira inflexão nas noções da defesa civil, com reflexos institucionais. Em 1966, o município do Rio de Janeiro sofreu inundações e deslizamentos com desabamentos e mortes, resultando na criação da Comissão Estadual de Defesa Civil por iniciativa do governo do Estado. Posteriormente, outros estados também foram organizando suas defesas civis nessa esfera (CABALLERO, 2005: 37). São Paulo passou por eventos hidrometeorológicos críticos em 1967 no município de Caraguatatuba quando, em âmbito federal, no mesmo ano, através do Decreto Lei n. 200/1967, foi criado o Ministério do Interior, com competência e função de atuar em áreas e obras de proteção contra secas e inundações, e assistência a calamidades públicas (CABALLERO, 2005: 38).

$\mathrm{Na}$ década de 1970, os grandes incêndios urbanos, como dos edifícios Joelma e Andraus, foram fator determinante para o desenvolvimento de edificações mais seguras, quando se tomou consciência da ausência de procedimentos, normas e legislação preventiva das edificações para tais situações (CABALLERO, 2005: 37 e SHIMBO \&

\footnotetext{
${ }^{59}$ O primeiro decreto que trata de ações de Defesa Civil a Lei Federal 4.098/1942, sobre defesa passiva antiaérea e obrigações da Defesa Civil em tempos de Guerra.
} 
CABALLERO, 1989). A partir desses eventos é que foram estabelecidos, nos códigos de obras, princípios de segurança contra incêndio.

Institucionalizada a noção de que contextos urbanos precisavam de organização para emergências e calamidades, se desenvolveu também a necessidade de sistematização orçamentária, que resultaria na criação da FUNCAP ${ }^{60}$, com funções de financiar e orientar, em âmbito federal, atividades relacionadas à prevenção de calamidades públicas, assistência emergencial a famílias atingidas, e recuperação de perdas e danos. Para essas funções, foi criado o grupo GECAP, com representação de todos os ministérios e possibilidade de acesso ao FUNCAP - que, segundo CABALLERO 2005, mostrou-se pouco operacional, não suprindo a necessidade de um órgão para controlar e aplicar com embasamento técnico os recursos do fundo. Nesse contexto, pelo Decreto 83.839/1979, foi criada a Secretaria Especial de Defesa Civil - SEDEC - na reestruturação do Ministério do Interior - a fim de coordenar as atividades relativas a medidas preventivas, assistenciais e de recuperação em desastres para o território nacional, e fornecer apoio técnico e administrativo ao GECAP (CABALLERO, 2005).

A urbanização acelerada e precária da década de 1980 alterou a escala de danos e quantidade de eventos adversos e catastróficos em todo o país, sobretudo nas grandes cidades, extrapolando os limites orçamentários dos municípios para atender às situações de emergência, e aumentando a demanda aos orçamentos estaduais e federais para esses fins. Esse contexto conduziu à necessidade prática de integração das estruturas ligadas à defesa civil nas 3 instâncias federativas, culminando na criação do Sistema Nacional de Defesa Civil pelo Decreto 97.274/1988, durante o processo de redemocratização e da constituinte, quando se extinguiu o GECAP (CABALLERO, 2005; SULAIMAN, 2014 e VALÊNCIO et ali, 2003).

O Sistema Nacional de Defesa Civil, SINDEC, relaciona os COMDECs - Comissões Municipais de Defesa Civil; e CEDECs - Coordenadorias Estaduais de Defesa Civil - à Secretaria Especial de Defesa Civil por meio de suas Coordenadorias Regionais CORDECs, com estrutura verticalizada. Na lei de criação do sistema, Defesa Civil é definido como "conjunto de medidas destinadas a prevenir, limitar ou corrigir os riscos e danos pessoais ou materiais decorrentes de estado de calamidade pública ou de situação de emergência" (Decreto 97.274/1988).

A década de 1990 trouxe mudanças importantes nas condições institucionais e do sistema. Em 1994, o Decreto 1.080/1994 propôs nova regulamentação ao FUNCAP; em 1995, a estrutura de ministérios foi alterada pela Medida Provisória n. 913/1995 e posteriormente pela Lei 9.649/1998, e a Defesa Civil deixou o Ministério da Defesa, passando integrar o Ministério do Planejamento e Orçamento. Estas novas condições (em um ministério civil, e não militar) permitiram maior desenvolvimento em termos de procedimentos, como a aprovação do primeiro Manual para Decretação de Situação de Emergência ou de Calamidade Pública (V. I e II) em 1999. A Secretaria de Defesa Civil, posteriormente, com a Medida Provisória 1.911-8/1999, passou a ser competência do

\footnotetext{
60 O FUNCAP - fundo especial de calamidade, criado em 1969 pelo Decreto Lei n. 950/1969 e regulamentado pelo Decreto 66.204/1970 - está descrito na seção 2.3.3.
} 
Ministério de Integração Nacional que se criava, já que o Ministério do Planejamento e Orçamento possuía foco mais central e menos executivo de ponta (MARCONDES, 2003). A instabilidade nesse processo de estruturação, que tornou a lotação do SINDEC indefinida entre 1990 e 2001, passando por 7 diferentes ministérios (IBAMA, 2002 e SULAIMAN, 2014) é um fator apontado como prejudicial à eficiência do sistema.

Além disso, nesse esforço de estruturação nos três níveis, o sistema apresentava dificuldades em incorporar os princípios de preparação para desastres na prática. Valêncio (2009) aponta para problemas no funcionamento do sistema de defesa civil em função da estrutura hierarquizada. A descentralização, que funcionaria para ligar a ponta de processos à gestão central de um fundo federal, tornou deficiente a divulgação de informações centrais para instâncias executivas de gestão local, bem como a retroalimentação de informações, problema apontado também entre a ponta em relação à Coordenadoria Estadual de Defesa Civil (CEDEC).

Os procedimentos de notificação de desastres, fundamentais para estruturação de bases de dados, estimativas de perdas e danos e agilidade na decretação de emergências, também passaram por aprimoramentos. Segundo Valêncio (2003), as estatísticas disponíveis reuniam boletins de ocorrência da Defesa Civil ou Corpo de Bombeiros, feitos pelos segmentos sociais que demandavam socorro, mas que nem sempre chegavam aos órgãos públicos. Há, também, referência a informações que permaneciam restritas ao âmbito privado, familiar ou de empresas de seguros. Valêncio (2009) também aponta que muitas vezes, o registro da ocorrência não era feito pois, em muitos municípios, não havia o representante legal municipal de Defesa Civil, trazendo problemas para a contabilização oficial. Além disso, o próprio processo de notificação era problemático: manuscrito nos NOPRED - Formulário de Notificação Preliminar de Desastres, e nos AVADAN - Formulário de Avaliação de Danos. Estes procedimentos passaram a ser informatizados e integrarem automaticamente o sistema em 2012 pela plataforma S2iD pelos formulários FIDE (CEPED-UFSC, 2012 e SULAIMAN, 2014).

O período entre 2000 e 2010 foi marcado pela incorporação mais precisa da proteção como noção fundamental à gestão de riscos e defesa (SULAIMAN, 2014). O Decreto 7.257/2010 apresenta essa inflexão no paradigma de defesa, definindo defesa civil como "conjunto de ações preventivas, de socorro, assistenciais e recuperativas destinadas a evitar desastres e minimizar seus impactos para a população e restabelecer a normalidade social'. A perspectiva de incorporação da prevenção nas ações da defesa civil, articulada com instrumentos do planejamento urbano, por fim, encontrou forma vinculante na lei que institui a Política Nacional de Proteção e Defesa Civil (PNPDEC) n. 12.608/2012.

\subsubsection{A Política Nacional de Proteção e Defesa Civil de 2012}

O recente marco regulatório da Lei 12.608 de 10/04/2012, que Institui a Política Nacional de Proteção e Defesa Civil no Brasil, cria o Cadastro Nacional de Riscos a Desastres, que estabelece vinculações para os municípios que nele constarem. No artigo 26, são apresentadas regras preventivas de controles geológicos (mapeamentos) e hidrológicos (mapeamento e associação aos Planos de Recursos Hídricos) que devem ser 
obrigatoriamente incorporadas ao instrumento dos Planos Diretores dos municípios inseridos no cadastro. A lei promove essa vinculação pelo acréscimo dos artigos 42-A e 42-B à Lei Federal 10.257/2001, de diretrizes gerais da política urbana.

O Artigo 42-B estabelece que, na ampliação dos perímetros urbanos dos municípios, deve-se delimitar trechos de urbanização restrita submetidos a controle especial em função de ameaças de desastres naturais. O Artigo 42-A obriga que os municípios inscritos no "cadastro nacional de municípios com áreas suscetíveis à ocorrência de deslizamentos de grande impacto, inundações bruscas ou processos geológicos ou hidrológicos correlatos" incluam em seus planos diretores:

II - mapeamento contendo as áreas suscetíveis à ocorrência de deslizamentos de grande impacto, inundações bruscas ou processos geológicos ou hidrológicos correlatos;

III - planejamento de ações de intervenção preventiva e realocação de população de áreas de risco de desastre;

IV - medidas de drenagem urbana necessárias à prevenção e à mitigação de impactos de desastres; $e$

$V$ - diretrizes para a regularização fundiária de assentamentos urbanos irregulares, se houver, observadas a Lei no 11.977, de 7 de julho de 2009, e demais normas federais e estaduais pertinentes, e previsão de áreas para habitação de interesse social por meio da demarcação de zonas especiais de interesse social e de outros instrumentos de política urbana, onde o uso habitacional for permitido.

No artigo 42-A, é estabelecido que a identificação e o mapeamento das áreas de risco devem "levar em conta a produção de Cartas Geotécnicas". Um produto base, ou mínimo, é sugerido sem maiores definições ou referência a escopo, escala ou método. Estabelece, ainda, que os Planos Diretores devem estar compatibilizados com os planos de Recursos Hídricos, sem maiores detalhamentos de como ou por meio de quais instrumentos essas duas políticas se vinculam - como as outorgas, planos de bacia, de macrodrenagem ou o instrumento de enquadramento. A lei carece de regulamentação, o que poderia trazer detalhamento às vinculações e instrumentos que estão apontados sem maiores definições.

Em 2012 foi lançado, também, o "Plano Nacional de Gestão de Riscos e Resposta a Desastres Naturais", que organizava a distribuição de recursos na escala federal para prevenção e melhora da resposta a ocorrências, com seleção de 821 municípios prioritários (atualmente 827 municípios prioritários, variando até 849 em certas fontes), cuja soma dos dados de ocorrências correspondiam a 94\% das mortes por desastres e $88 \%$ do total de desalojados e desabrigados no país, de acordo com sistematizações do Atlas de Desastres. A lista desses municípios não consta da publicação disponível do plano, e nem é de acesso direto pelo site do Ministério da Integração. Além disso, os critérios que definiram como os municípios foram considerados prioritários também não 
foram disponibilizados com metodologia aberta. Em conversa informal ${ }^{61} \mathrm{com}$ técnicos do Ministério da Cidade e técnicos do IPT, foi possível compreender que os critérios de seleção foram baseados em um ranking geral oriundo das sistematizações do Atlas, mas que manteve abertura para incorporar e extrair certos municípios, de modo a não enrijecer processos, pois, caso fossem estabelecidos indicadores muito rígidos para corte, poderiam gerar distorções, deixando situações sabidamente críticas de fora. Também em conversa com alguns agentes de Núcleos Municipais, foi levantada a percepção de "falta de transparência no critério". A opção de flexibilidade que, por uma fonte, serve a propósitos objetivos de planejamento, para outras, pode ser entendida como servindo a propósitos de favorecimento no acesso aos recursos federais. $O$ estabelecimento de uma política de indicadores para tornar as priorizações de recursos mais transparentes e bem direcionadas, adequada às diferenças no território nacional, é uma tarefa complexa, necessária e ainda a ser feita.

A institucionalização da gestão do risco nesta década de 2010 foi, sem dúvida, um campo em franco movimento que, a partir de 2016, viu recrudescer seu processo de regulamentação - descontinuidade preocupante para avançar nas lacunas que já se faziam presentes mesmo nos anos mais vigorosos. Os esforços na institucionalização da lei refletiram em grande avanço na organização de informações, como a unificação da codificação de desastres com base na Cobrade; pela criação do Sistema Integrado de Informações sobre Desastres (S2id) e a primeira sistematização de informações no Atlas Brasileiro de desastres naturais 1991-2010, desenvolvido pelo Centro Universitário de Estudos e Pesquisas sobre Desastres da Universidade Federal de Santa Catarina (CEPED-UFSC, 2012). O CEPED-UFSC estabeleceu o método e editou o primeiro perfil de risco de cada estado, cuja edição dos anuários brasileiros de desastres naturais posteriores foi feita pelo CENAD. Destaca-se, ainda, a sistematização de dados sobre desastres no Censo IBGE "Perfil dos Municípios Brasileiros 2013"; o desenvolvimento de Planos Municipais de Redução de Riscos, com realização de conferências e fóruns nacionais de defesa civil e, mais recente, o esforço na sistematização do perfil de perdas e danos (CEPED, 2016) por estados.

A produção e disponibilização de dados oferecida pelo CENAD através do sistema S2id, entretanto, apresenta problemas tanto devido à desaceleração do processo institucional como por elementos estruturantes do próprio sistema. Falta uniformização de registros e disponibilização de informação (parte da plataforma é de acesso restrito). Faltam sistematizações abertas: os dados disponíveis no acesso a 'série histórica', com início em 2003, são apenas arquivos com lista de municípios que tiveram decretação de emergência reconhecida naquele ano, sem informações quantitativas. As quantidades de decretação de situação de emergência não correspondem à realidade das ocorrências; os municípios na listagem de decretações para São Paulo, por exemplo, é

\footnotetext{
61 Juntamente com o lançamento do Plano, foi inaugurado o CENAD (Centro Nacional de Gerenciamento de Riscos e Desastres), ligado ao Ministério da Integração. Foi feito contato com o CENAD, por meio de indicação dirigida diretamente a técnicos responsáveis pelo S2id e envolvidos com os critérios para seleção dos municípios; e também pela lei de acesso à informação, ambos sem sucesso. A conversa informal foi o meio de maior resultado.
} 
muito menor do que a que aparece em qualquer cadastro de ocorrência que pode ser obtido por outras fontes ${ }^{62}$.

\section{Quadro 3 - Síntese das informações do S2iD}

\begin{tabular}{|c|c|c|c|c|c|c|c|c|}
\hline 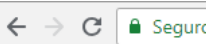 & https://s2id.mi.gov.br/paginas/series/ & & & & & & & 它 \\
\hline B. BRASIL & Serviços & & Simplifique! & Participe & Acesso à informação & Legislação & Canais & 被 \\
\hline $\begin{array}{l}\text { Sisten } \\
\text { Inforn }\end{array}$ & $\begin{array}{l}\text { tegrado de } \\
\text { es sobre Desastres }\end{array}$ & & & Inicic & Acessibilidade $\mathrm{A}^{+}$Aumentar & f Fonte $\mathbf{A}$ Tamanho Nu & $A^{-} \mathrm{Dm}$ & it Fonte Altw Contraste \\
\hline Série histórica & & Sobre & Série Histónica & Relatórios & Arquivo Digital & Atlas Brasileiro & Ouvidoria & Suporte técnico \\
\hline
\end{tabular}

No S2ID é possível:

- Registrar desastres ocorridos no município/estado;

- Consultar e acompanhar os processos de reconhecimento federal de situação de emergência ou de estado de calamidade pública;

- Consultar e acompanhar os processos de transferência de recursos para ações de resposta;

- Consultar e acompanhar os processos de transferência de recursos para ações de reconstrução;

- Buscar informações sobre ocorrências e gestão de riscos e desastres com base em fontes de dados oficial.

Dados abertos do sistema:

- Série Histórica: consulta por estado e por ano (desde 2003). Fornece listagem de reconhecimentos realizados agregados por ano e município.

- Relatórios: apresentam dados por estado (lista de municípios) relacionados aos registros de danos e prejuízos, reconhecimento federal de situação de emergência, ações de resposta e obras de reconstrução realizadas pela SEDEC. Informam tipo de evento e danos (não informa perdas materiais) agregados por ano e por município. Somente a partir de 2013

- Arquivo Digital: documentos em pdf do registro ou histórico dos desastres informados. Busca por estado, tipo de documento e ano.

- Atlas: arquivos dos 27 volumes (por estado e o geral Brasil), com sistematização de registros de 1991 a 2012.

FIG. 9 - Menu do site S2iD ${ }^{62}$ Ex.: Cadastro do Instituto Geológico, analisadas no capítulo 5, Banco do IPMET, fontes do CGE, ou
cadastro de óbitos do IPT. 
As informações do S2id disponíveis no acesso a 'relatórios', apresentam dados quantitativos relacionados aos registros de danos e prejuízos, reconhecimento federal de situação de emergência, ações de resposta e obras de reconstrução realizadas pela SEDEC. Mas só são disponíveis para consulta por estado na forma de relatório a partir do ano de 2013, agregados por município e para todo um ano. Para obter as informações dos municípios de uma região metropolitana para vários anos, seria preciso gerar um relatório do estado por ano e separar os metropolitanos, um trabalho que logo pareceu mostrar pouco resultado para análises quantitativas, pois apresentava quantidade de municípios afetados muito aquém de outros registros de ocorrências. Além disso, a agregação de informações (mortes, desabrigados, afetados) por ano não permite identificar quantas vezes no ano uma localidade sofreu (identificar recorrências).

No acesso a 'arquivos digitais', é possível buscar informações por ano (somente até 2013) e por município, mas o resultado oferecido não é um dado, e sim um arquivo pdf de notícia de jornal, ou portaria no diário oficial, ou cópia de ofícios de declaração de danos (AVADANs e NOPREDs), também em quantidade aquém das notícias ou registros existentes em outros bancos. As informações disponíveis não têm circularidade ou formas correspondentes e complementares, e não há um sistema de acesso que permita obter e trabalhar os dados de forma desagregada. Não há estudos de indicadores disponíveis, e as sistematizações desenvolvidas estão longe de trazer problematizações da integração dos riscos, e visão ampla de efeitos. Este é um aspecto da informação consideravelmente importante para a área de planejamento e para a gestão urbana, pois permitiria compreender qualitativamente o comportamento dos riscos nos diferentes municípios, a compreensão dos diferentes efeitos das ocorrências. E também quantitativamente, pois o impacto é um dos dois fatores da equação que define risco objetivamente.

Com relação aos mapeamentos sugeridos na lei, já em 2011, o Serviço Geológico do Brasil (CPRM) passou a realizar o mapeamento de suscetibilidades dos municípios prioritários apontados no ranking do Atlas, iniciando pelas regiões sul e sudeste, gravemente afetadas por desastres desde 2008, até a situação mais crítica na Região Serrana do Rio, em janeiro de 2011. Esse trabalho consistia em uma avaliação expedita e qualitativa, relacionada aos riscos de inundações, enxurradas e movimentos de massa (deslizamentos, queda de blocos e solapamentos), que depois se tornou uma metodologia nacional ${ }^{63}$, com gradação de escalas e detalhamentos em função da ação de planejamento pretendida (para planejamento da ocupação, para definição de restrições à ocupação ou ações de mitigação a riscos já instalados). A ampliação desse diagnóstico foi programada no Projeto Mapeamento de Riscos de Desastres do Governo Federal, realizado através da Secretaria Nacional de Proteção e Defesa Civil pelo CENAD, e com participação de algumas Universidades.

Diversas são as lacunas e frentes abertas no processo institucional mais recente. Embora a vinculação de instrumentos de identificação de risco aos Planos Diretores propostos pela lei seja um passo muito importante, sobretudo para o tipo de risco que causa mais mortes - o risco geológico - a lei não criou vinculações mais detalhadas com

63 CPRM, 2014. Cartas de suscetibilidade a movimentos gravitacionais de massa e inundações 1:25.000. Nota Técnica Explicativa. 
outros instrumentos que já existem, e não foram produzidos elementos de informação suficientemente consistentes para embasar critérios de prioridade no território nacional. Além disso, criou um instrumento de vinculação novo, dependente de metodologias para identificação de risco que se sobrepõe parcialmente a instrumentos de outros campos de identificação de riscos que não o geológico, sem estabelecer parâmetros para tratamento dessas interfaces.

Por exemplo, o mapeamento desenvolvido a partir das exigências do artigo 26, as Cartas de Suscetibilidade a Movimentos Gravitacionais de Massa e Inundação do CPRM-IPT, a metodologia faz uma avaliação para zonas de inundação muito mais genérica do que as modelagens que foram aplicadas no diagnóstico do Plano de Macrodrenagem da Bacia do Alto Tietê (PDMAT3). Também metodologias para escalas mais detalhadas, como as Cartas Geotécnicas de Aptidão à Urbanização, trabalhadas pela UFABC, apresentam procedimentos não compatibilizados com os da área da hidráulica-hidrologia para definir o risco à inundação. Estes aspectos sugerem que a lei tem viés do olhar geológico em sua raiz.

A lei ainda carece de decreto de regulamentação, e as pontas abertas podem servir para não engessar processos que, no território nacional, são muito diversos. Em contextos onde os instrumentos de planejamento são menos desenvolvidos, a lei é um avanço inegável, mas nos contextos onde os instrumentos são mais desenvolvidos, pode trazer situações de conflitos e disputas na validação dos instrumentos de identificação de risco, que precisarão ser equacionadas entre os diferentes agentes envolvidos sem que haja uma arena institucionalmente definida para essa arbitragem.

A recente publicação da Plataforma do IBGE, 2018, de populações em áreas de risco no Brasil, representa um novo avanço das informações sobre riscos, ao transformar os mapeamentos de risco (probabilidades) existentes em informação, mas não avança em termos de informações sobre desastres (o passado de ocorrências e impactos). A plataforma reuniu e homogeneizou todas as informações espaciais (independentemente do detalhamento de escala) sobre riscos existentes no país, e procedeu a adequações nas divisões (delimitações) dos setores censitários de forma a permitir que se quantifique, dentro dos perímetros de risco, a população ali inserida. Além disso, desenvolveu procedimento para identificar vulnerabilidades por extrapolação analítica do padrão da ocupação, o que permite ampliar a contagem de população exposta ao risco em função do perfil da ocupação e das características de suscetibilidade. São análises estatísticas sobre probabilidades geradas a partir da soma de métodos de identificação de riscos diversos e desiguais (que contém ponderações subjetivas inerentes ao processo de identificação de risco), e pela comparação de formas de ocupação precárias similares. Mas não são informações que permitem desenvolver análises estatísticas sobre desastres.

\subsection{Níveis da gestão de riscos: arranjos e lacunas entre a esfera local e federal}

A dificuldade de incorporar na prática e amplamente às esferas de planejamento territorial os princípios de precaução e as sistematizações de informações sobre 
desastres, dificulta o desenvolvimento efetivo de um planejamento de redução de riscos que parta do reconhecimento das vulnerabilidades, suas transformações e interações com aspectos da produção do espaço urbano. Para investigar essa questão, é necessário identificar o que foi incorporado ou já existe nas práticas de planejamento territorial e setorial com objetivos de prevenir riscos, e cotejar com procedimentos de análises de risco - instrumentos, planos, ações para identificação, prevenção, monitoramento e mitigação de riscos.

Durante o desenvolvimento desta pesquisa, na fase em que se buscava identificar os instrumentos de planejamento relacionados com controle de riscos - uma espécie de mapeamento das ações institucionais mais recentes nos níveis estaduais e municipais - foi possível iniciar o acompanhamento das atividades Câmara Temática de Gestão de Riscos Ambientais Urbanos CTM-GRAU, vinculada ao Conselho de Desenvolvimento Urbano da Região Metropolitana de São Paulo. Na Câmara, participam representantes dos municípios e consórcios municipais, departamentos da gestão pública ligados ao planejamento (Emplasa e representantes de órgãos e secretarias municipais), pesquisadores de universidades (USP, UFABC) e institutos de pesquisa (IPT e Instituto Geológico IG) ligados ao tema dos riscos, representantes da área da saúde, do DAEE, CETESB, representações da defesa civil das escalas estadual (CEDEC) e municipal (COMDEC-SP e de outros municípios e consórcios). Não há representantes de concessionários de serviços públicos.

Durante os anos de 2017 a 2018, a CTM-GRAU discutiu a elaboração da política de governança de riscos metropolitanos e o plano de gestão de riscos metropolitanos como parte das diretrizes do Plano de Desenvolvimento Urbano Integrado conduzido pela Emplasa - PDUI-RMSP (“0”, na tabela a seguir). No mesmo período, foi organizado o "Seminário Metropolitano sobre Governança de Riscos e Adaptação a Mudanças Climáticas", para avançar o debate em comunidade ampliada voltada à gestão de riscos.

O PDUI é um instrumento obrigatório trazido pelo Estatuto da Metrópole (lei 10257 de 2015) para todas as regiões metropolitanas brasileiras ${ }^{64}$, cujo prazo de finalização, para permitir a vinculação das Regiões Metropolitanas ao Fundo Metropolitano e não imputar improbidade administrativa aos municípios, era janeiro de $2018^{65}$. As atividades da Câmara, de elaborar uma política metropolitana de riscos, trabalhavam sob as exigências desse prazo, o que limitava as discussões de tema tão complexo embora o contexto de reunião dos agentes fosse muito favorável a uma discussão aprofundada.

Das discussões, resultou a proposta de associar aspectos da gestão de riscos a desastres naturais à gestão de riscos tecnológicos, um avanço à própria formulação do marco legal PNPDEC, por consenso entre contribuições de representantes de diversos campos e esferas. A demanda da Emplasa viabilizou o esforço de somar a identificação de vulnerabilidades dos diversos municípios, produzidas por diversos agentes, e a

\footnotetext{
${ }^{64}$ A constituição de 1967 e posteriormente a LC 14/1973 instituiu o sistema Metropolitano, definindo as Funções Públicas de Interesse Comum FPICs. O Estatuto da Metrópole recupera o princípio das FPICs com o objetivo de criar regras para a governança compartilhada de grandes aglomerados urbanos que envolvam mais de um município, como fato e como demarcação institucionalizada.

${ }^{65}$ Esse prazo foi alterado no final do ano de 2017 para 2021; atualmente o Estatuto da Metrópole passa por revisão da lei.
} 
proposição de contextos a serem mapeados com critérios homogêneos, que deverão ser incorporados em um sistema de informação integrado, com atualização constante - SIM. O SIM reúne diversas informações úteis aos processos de planejamento, e incorporou camadas de informação para os instrumentos de identificação de riscos existentes. O sentido maior das propostas, na discussão da política de riscos da CTMGRAU, foi criar cooperação entre localidades para atuar na prevenção e resposta por meio de instrumentos de informação semelhantes e uniformes.

O objetivo principal da Emplasa, a partir dessas discussões, é (trata-se de um trabalho ainda em andamento) delimitar zonas metropolitanas com restrição à urbanização, para as quais os municípios devem, obrigatoriamente, grafar em seus planos diretores como zonas sujeitas a controles especiais pelos riscos, ou como prioritárias para ações de mitigação de riscos já instalados. O objetivo da CTM-GRAU foi traçar as diretrizes gerais de uma política. As discussões na CTM-GRAU sobre o objetivo da Emplasa (a demarcação de zonas) foram e têm sido pautadas, sobretudo, por uma leitura que soma espacialmente contextos de riscos, pela superposição de mapeamentos já realizados. Integrar análises de risco geológico às análises de manchas de inundação definidas no PDMAT3 foi um grande avanço, mas o prazo limitado não permitiu fazer discussões qualitativas sobre o que seriam riscos específicos da escala metropolitana, ou riscos específicos relacionados a funções públicas de interesse comum, que diretrizes podem ser extraídas daí, ou chegar a aspectos específicos da espacialização desses riscos.

Este trabalho, portanto, se propõe a adentrar essas lacunas menos desenvolvidas, e ensaiar os primeiros passos para análises de risco integradas, na transição entre escala local e regional, e na interface entre funções setoriais. O primeiro passo para isso é compreender o contexto dos agentes e instrumentos de gestão urbana e de riscos, apresentado a seguir. O segundo passo, é a construção de contexto quantitativo de ocorrências para o universo metropolitano, feito a partir do Cadastro de Eventos e Desastres do Instituto Geológico ${ }^{66}$, com identificação de criticidades espaciais e temporais, a fim de embasar casos de interesse. O terceiro passo, é o levantamento de situações típicas de riscos associados a funções setoriais, e sua análise qualitativa.

Por isso, na seção a seguir, se empreendeu o esforço de uma leitura ampla de todos os agentes, ações e instrumentos que podem estar relacionados a uma gestão integrada de riscos metropolitanos. Esta leitura será guiada pela tabela 4, a seguir, que é uma tentativa preliminar de mapear e classificar instrumentos de planejamento e de gestão dos riscos segundo a finalidade dos agentes: controle dos riscos, controle urbano e ambiental e controles setoriais. Foram classificados, também, segundo a escala de abordagem dos instrumentos: pontual (limitada a demarcações ou dispositivos específicos de sistemas urbanos); local na escala do bairro ou sub-bacia; local na escala do município; regional, na escala metropolitana ou de conjunto de municípios. Este mapa, a seguir, é apresentado e desenvolvido no texto como um glossário, onde se traça a contextualização dos agentes e de produção dos instrumentos listados.

\footnotetext{
${ }^{66}$ Cadastro de Eventos Geodinâmicos e Desastres do Estado de São Paulo. Instituto Geológico, SMA, Estado de São Paulo. Disponível em: https://goo.gl/8UjEi2
} 


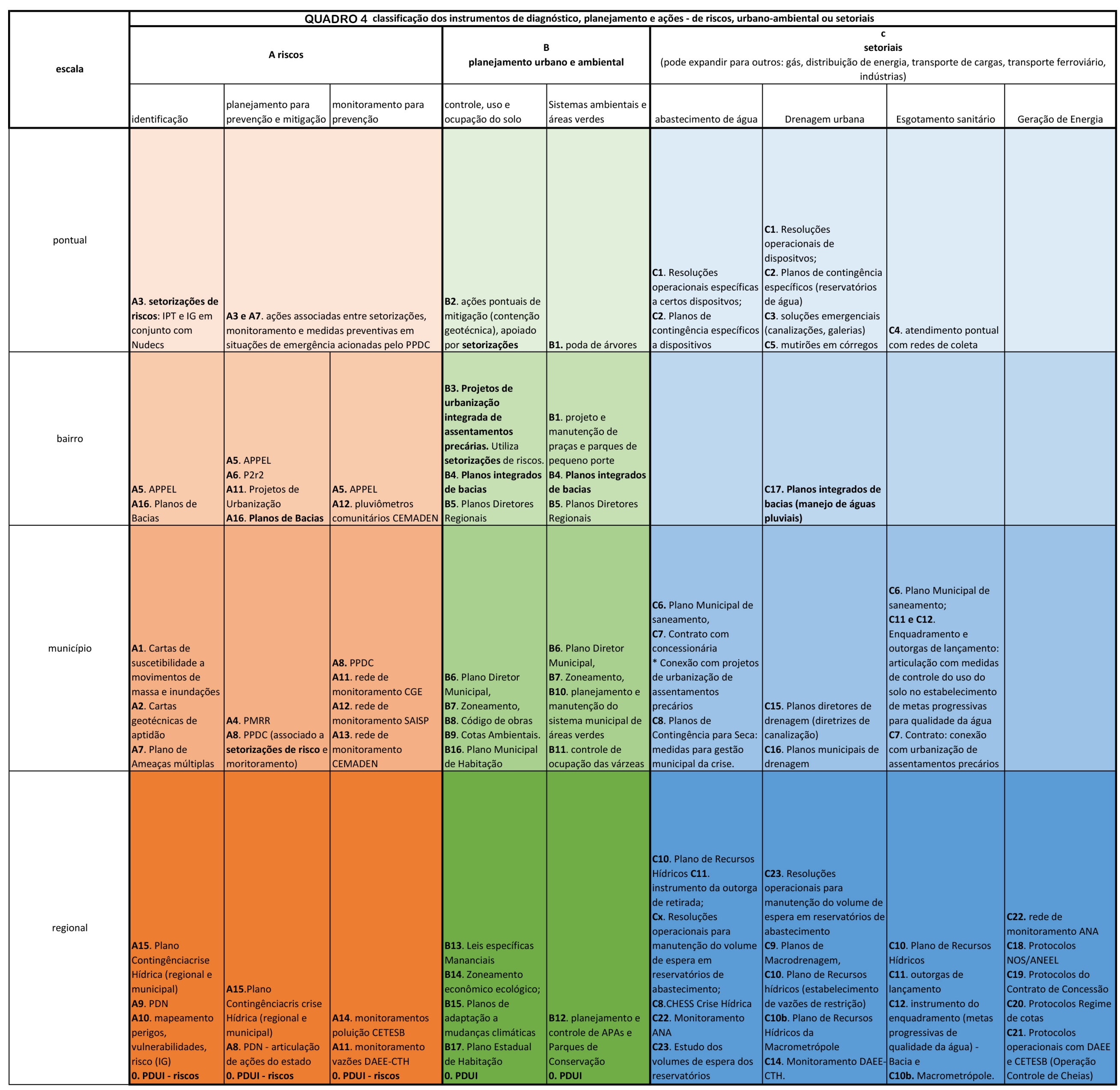

Elaboração: da autora, com base nas informações das diversas instituiçoes envolvidas. 


\subsubsection{Instrumentos, diagnósticos e ações do campo de gestão de riscos e desastres}

Segundo o atlas de desastres, os riscos de desastres avaliados para o Brasil concentram-se em 3 situações: inundação, deslizamentos e secas, estas últimas concentradas no semi-árido nordestino. Na região sudeste, concentram-se as situações de inundações e deslizamentos, que são, em geral, eventos vinculados pelos aspectos hidrológicos e meteorológicos. Por isso, a maior parte dos instrumentos de identificação de riscos são orientados por métodos do campo da geologia, mesmo na identificação de processos hidrológicos. A seguir, os instrumentos de risco levantados e seus contextos são apresentados individualmente nesta seção.

\section{A1. Cartas de suscetibilidade a movimentos de massa e inundações}

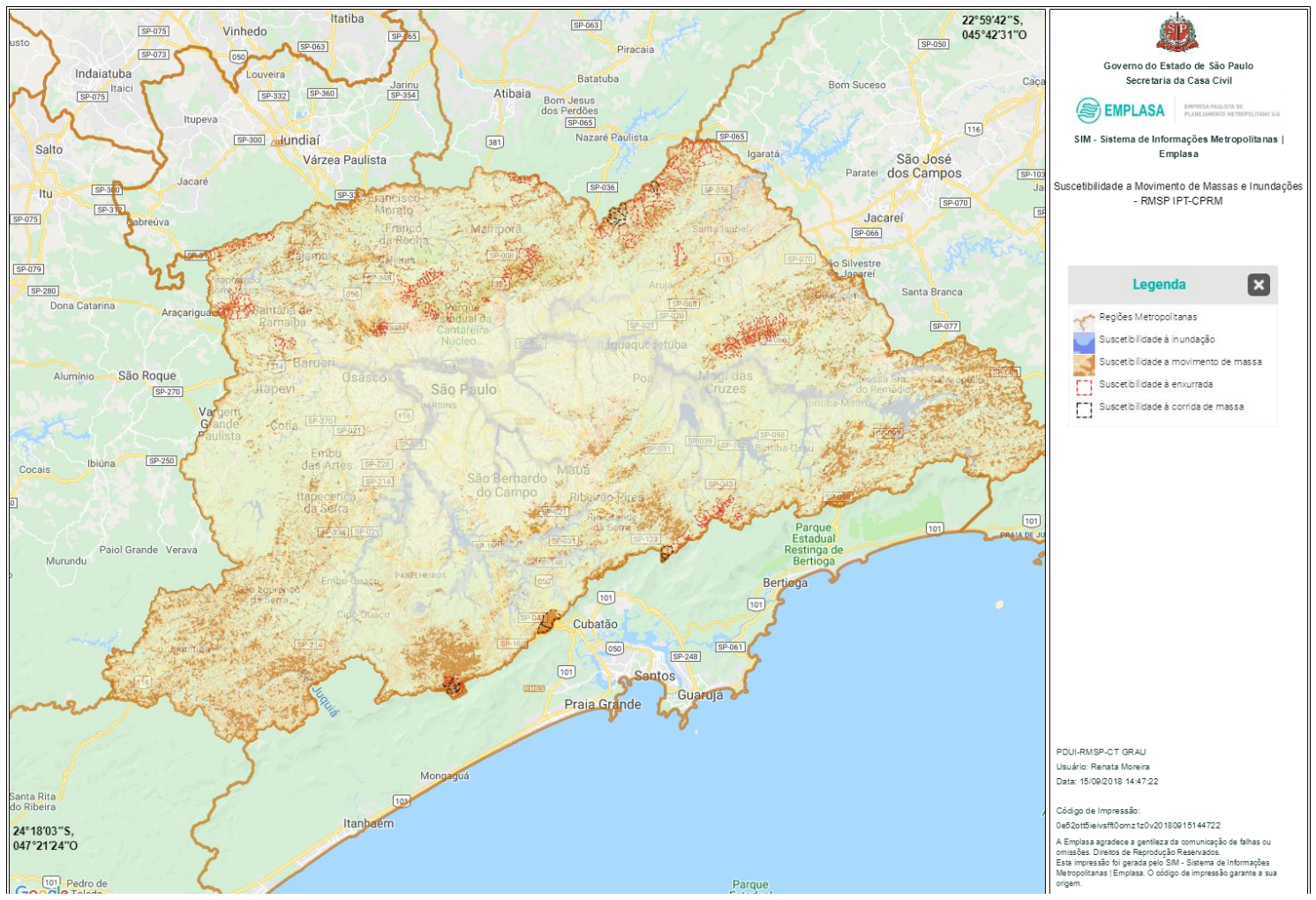

FIG. 10 Informações sobre Suscetibilidade a Movimentos de Massa e Inundações RMSP - CPRM-IPT (produzidas entre 2014 e 2018). Disponibilizadas no SIM - precisão 1:25.000

Abrange a área total de municípios, incluindo zonas urbanas e rurais, áreas de unidades de conservação e outras incidências. Identificam fatores naturais predisponentes, gerando classificação (alta, média e baixa) espacializada quanto à predominância do processo do meio físico que pode gerar desastres - no caso, movimento de massa, com caracterização de tipos específicos dos processos, ou inundação. Para gerar a classificação são analisados tipo dos solos (geologia), declividades e feições do relevo, associados a precipitações médias (com base em isoietas, hietogramas e equações IDF) como fator predisponente, bem como histórico de processos e aspectos gerais da ocupação (apenas distinguindo se urbanizado ou não urbanizado). As cartas são em escala 1:25.000 ou 1:50.000 (em São Paulo, a escala usada é 1:25.000). Por isso, o 
zoneamento das classes não pode ser entendido e utilizado para avaliar a estabilidade dos terrenos, o que dependeria de estudos mais detalhados em nível local, que é a recomendação para áreas de suscetibilidade alta e média. Nas áreas urbanizadas/edificadas, as classes indicadas podem estar alteradas, para mais ou para menos, a depender do grau de influência da ocupação existente, que, no caso da RMSP, corresponde a quase toda a área analisada. A principal função das cartas é orientar o ordenamento territorial macro, sobretudo em áreas ainda não urbanizadas (expansão), ou, indicar a necessidade de estudos específicos pela incidência de suscetibilidade alta em áreas urbanizadas, que pressupõe condições com potencial de risco maior. Após aprovação da PNPDEC, este instrumento passou a ser o nível zero de informações de risco entre os municípios prioritários do Plano Nacional, que contaram com financiamento federal para os mapeamentos. Em 2018 se completou o mapeamento de suscetibilidade de todos os municípios da RMSP. A metodologia foi desenvolvida pelo Serviço Geológico do Brasil - CPRM e IPT; as cartas foram desenvolvidas pelo IPT em São Paulo, e pelo CPRM no restante do Brasil. Estas informações estão lançadas no SIM da Emplasa.

\section{A2. Cartas Geotécnicas de Aptidão à Urbanização}

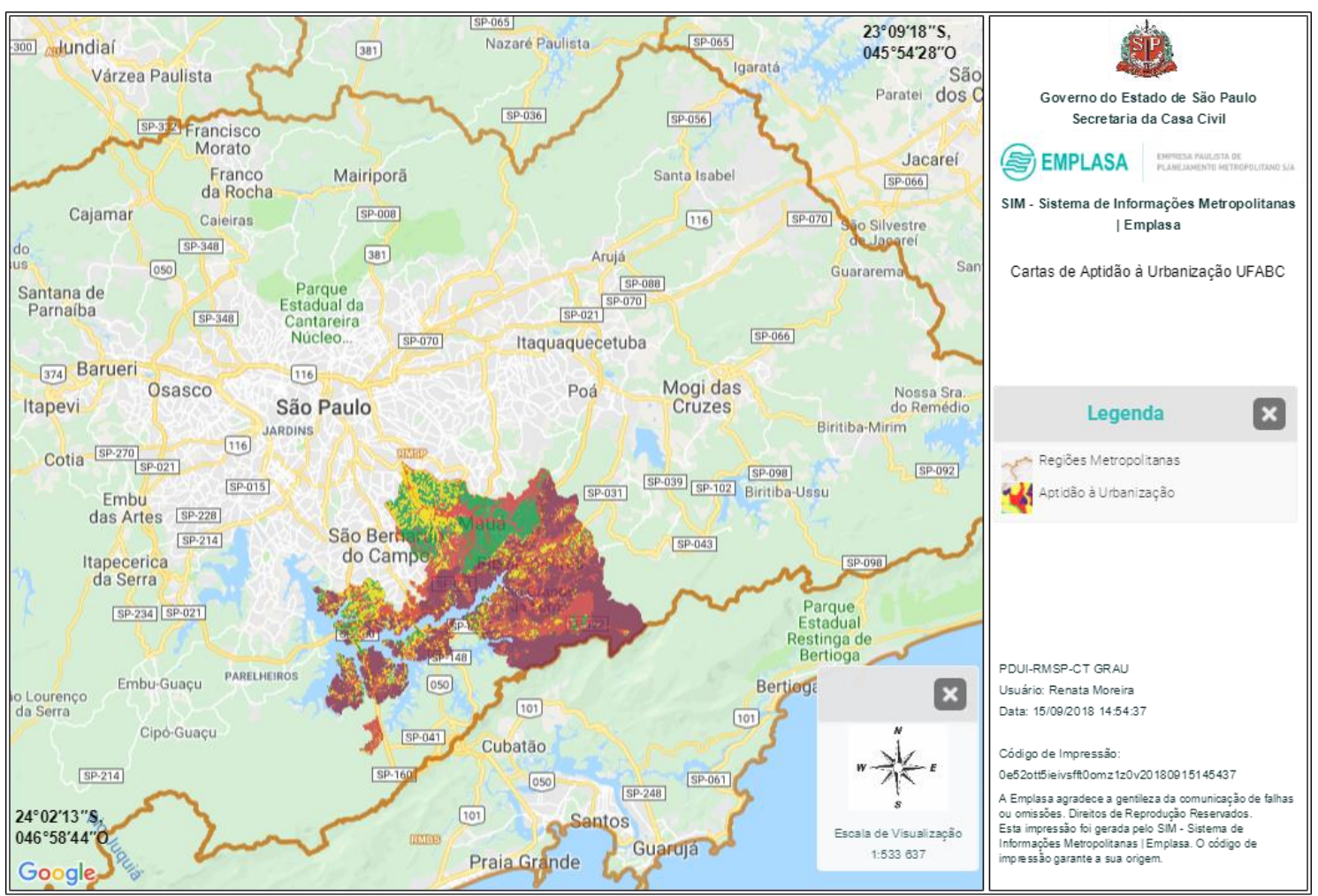

FIG. 11 Informações Aptidão à Urbanização RMSP - UFABC. Disponibilizadas no SIM - Precisão 1:10.000

"Abrange áreas desocupadas ou com urbanização incipiente situadas dentro do perímetro urbano legal dos municípios, bem como no domínio da zona de expansão urbana prevista no Plano Diretor municipal, incluindo recomendações para 0 parcelamento do solo" (BITAR, 2015). São produzidas em mais detalhe que as cartas de suscetibilidade, na escala 1:10.000 ou maior. Contém o resultado da avaliação dos perigos associados a processos do meio físico, com recomendações ao uso urbano do 
solo de acordo com as limitações e potencialidades de cada unidade geotécnica delimitada. Para sua produção, é necessário classificar os terrenos em unidades geotécnicas (caracterização; potencialidades e limitações; diretrizes para ocupação), e avaliar perigos em áreas ocupadas com riscos potenciais a desastres naturais. As classes podem se associar a normas para loteamentos e ocupação nas áreas de média suscetibilidade, que necessitam de estudos de avaliação geotécnica, e as cartas devem conter informações detalhadas para orientar a expansão urbana (NOGUEIRA e CANIL, 2017). Servem a instrumentos de planejamento urbano, como planos diretores. $\mathrm{Na}$ RMSP, esses tipos de Cartas foram desenvolvidos pela UFABC para os municípios de Rio Grande da Serra, São Bernardo do Campo, Ribeirão Pires, Mauá e Santo André, e em fase de finalização para Franco da Rocha. Estes materiais estão na plataforma SIM. Além dos processos de movimento de massas e inundações, as cartas não consideram outros aspectos que podem representar perigos, por exemplo, relacionados à proximidade e contiguidade a dispositivos de infraestrutura urbana.

\section{A3. Setorizações de risco}

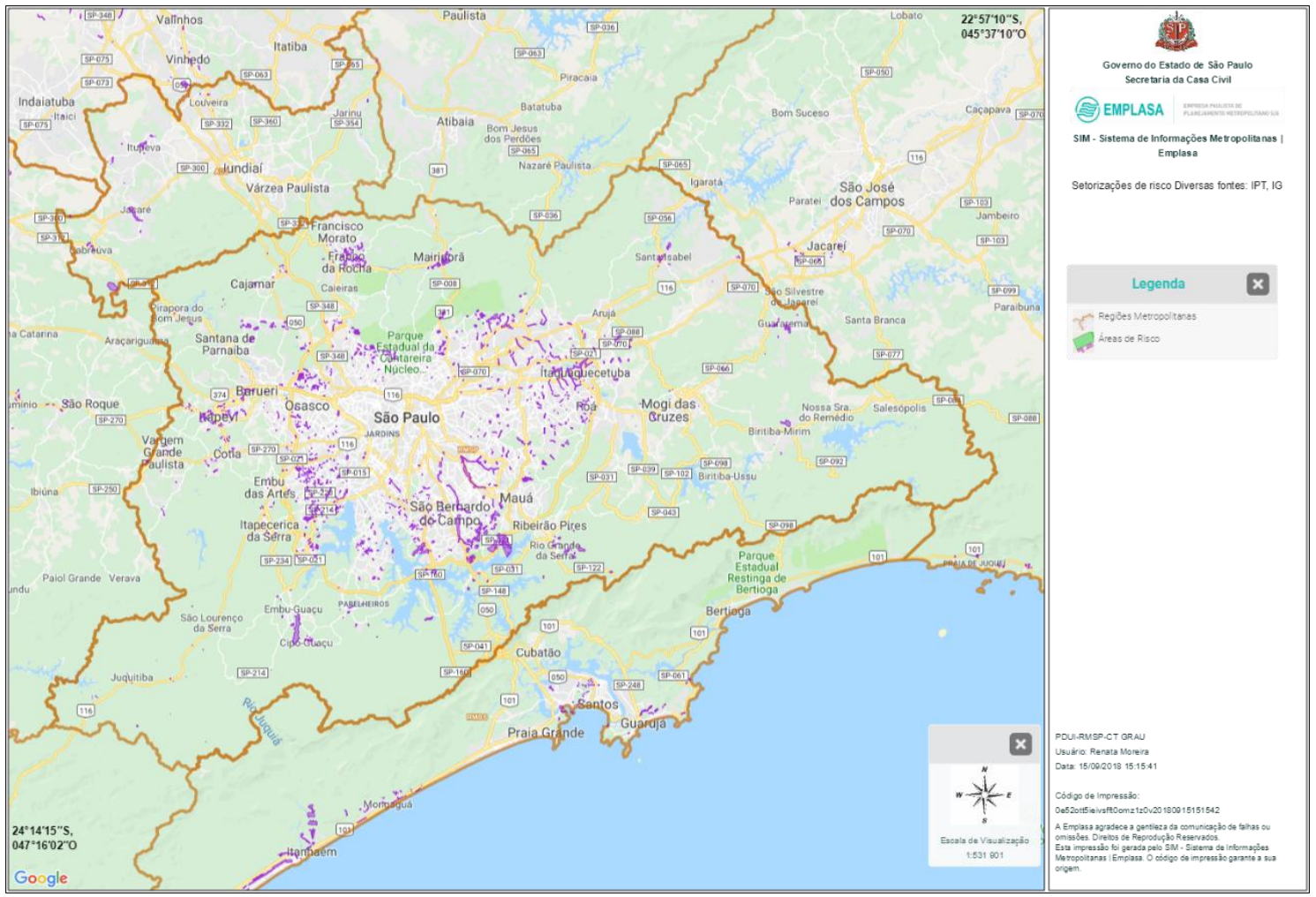

FIG. 12 Setorizações de Risco existentes para a RMSP disponíveis no SIM - Emplasa. IG e IPT.

São delimitações específicas, em escala 1:2000 ou mais próxima, que abrangem áreas urbanizadas do município - distritos, bairros e, em geral parte deles, sobretudo residenciais - geralmente com alta incidência de assentamentos precários. Resulta de análise de riscos, com indicação de setores e edificações em situação de maior ou menor risco (baixo, médio e alto risco a deslizamento ou inundação). Envolve avaliação de perigo, vulnerabilidade e consequências (perdas e danos). São elemento de base em diagnósticos dos projetos de urbanização de assentamentos precários (B2) e orientam gestores, também, nas ações emergenciais de remoções, obras de contenção 
ou, eventualmente, canalização. São elementos de identificação de risco muito importantes no procedimento do PPDC, Plano Preventivo da Defesa Civil, que será apresentado adiante. No PPDC, as informações de monitoramento de chuvas (fator predisponente) são utilizadas como gatilho e alerta para disparar ações de vistoria e trabalho emergencial em áreas foco, mais vulneráveis e conhecidas de cada regional, ou município, oficialmente representadas nos setores de risco. O ideal é que sejam atualizadas com frequência, preferencialmente anualmente. Em São Paulo, são produzidas setorizações de risco pelo IPT e pelo Instituto Geológico, IG. Muitos municípios estão com setorizações desatualizadas, e parte do trabalho continuado dos Núcleos de Defesa Civil locais é manter atualizações desses setores por meio de trabalho social continuado. Estão lançadas no SIM.

A4. Plano Municipal de Redução de Risco (PMRR): Embora o Plano Municipal de Redução de Riscos possa ser um importante instrumento de articulação ao planejamento urbano, o que se observa de sua aplicação é que, em geral, é utilizado apenas como instrumento garantidor de recursos para auxiliar os municípios a mapearem (setorizações) suas áreas de risco e realizarem obras. Seus prognósticos apenas orientam prioridades que justificam intervenções estruturais de prevenção e mitigação em áreas de ocorrência - em geral de deslizamentos nas encostas e solapamento de margem de suas áreas urbanas. As informações de diagnóstico dos PMRRs não são utilizadas em uma chave de leitura das tendências de crescimento ou predominância de precariedade, a fim de orientar ações amplas não só de remediação (pontual ou mesmo de projetos de urbanização integrada) mas: de um planejamento estruturado e de longo prazo para urbanização de áreas precárias, de reorientação do crescimento e controle do déficit habitacional, da estruturação viária que fornece condições de penetração indesejáveis ou mesmo de dificuldades logísticas ao socorro, a orientação de controles ambientais e limites de atuação setoriais. Também os diagnósticos não ampliam o escopo dos riscos. No site da defesa civil, na busca por instrumentos de identificação de riscos, somente os municípios de Guarulhos e Embu têm PMRRs disponibilizados. Além desses, pela organização dos Consórcio do ABC, os sete municípios da região contam com PMRRs (NOGUEIRA, CANIL, 2017).

A5. APELL: APELL é um programa e uma metodologia (Awareness and Preparedness for Emergencies at Local Level) desenvolvidos e promovidos pela Organização das Nações Unidas (ONU). O objetivo do programa é intensificar a conscientização e preparar as comunidades para situações de emergência, sobretudo de desastres tecnológicos (PNUMA, 1988), numa espécie de arena de governança de riscos organizada localmente em função de um cenário de risco (definido pela existência, por exemplo, de zona portuária, de mineração, atividades que envolvem agentes públicos e privados com um ou mais riscos associados). A metodologia propõe a criação de um Grupo Coordenador (gestor), composto por representantes de indústrias, do poder público e das comunidades, que deve elaborar um plano de ação e Planos de Resposta à Emergência com efetivo envolvimento das comunidades e agentes. A análise em uma abrangência espacialmente delimitada permite identificar contextos integrados de riscos. Um dos pilares do APELL é a definição de atribuições e de responsabilidades 
aos atores envolvidos, reafirmando papéis como de comunicação dos riscos associados a atividades produtivas, tomada de medidas de proteção e identificação das já existentes, estabelecimento de planos, mecanismos de alerta, etc. É uma proposta de governança local continuada. No Brasil, a Associação Brasileira da Indústria Química (ABIQUIM) disseminou o APELL a partir de 1988 (DUTRA, 2018). Foi incorporado à legislação no estado de Alagoas. A CETESB utilizou essa metodologia, cuja aplicação é marcada por atividades de exercícios simulados, no Terminal da Alemoa, com previsão para posterior ampliação da região portuária; integração do Plano de Área com o Plano de Auxílio Mútuo do Porto de Santos e com o Plano de Contingência para Vazamento de Produtos Químicos no Mar.

A6. P2R2: o P2R2 um Plano Nacional de 2007, direcionado ao aperfeiçoamento do processo de prevenção, preparação e resposta rápida a emergências ambientais com produtos químicos perigosos. Em face do histórico de ocorrência de eventos emergenciais em todo o país, e da inexistência de um planejamento nacional de caráter preventivo e de ação em caso de acidentes envolvendo produtos químicos perigosos, o Ministério do Meio Ambiente iniciou o processo de formulação do Plano P2R2 tendo como premissa a parceria dos governos estaduais e processo de consulta, além de Declaração de Compromisso firmada entre Ministério do Meio Ambiente, Secretarias de Meio Ambiente dos Estados e Associação Nacional de Municípios para o Meio Ambiente - ANAMMA, para elaboração e implementação do Plano Nacional de Prevenção, Preparação e Resposta Rápida a Emergências Ambientais com Produtos Perigosos P2R2. O Plano conta com as seguintes frentes trabalhadas em âmbito local: 1. mapeamento de áreas de risco - elaboração de propostas técnicas para a identificação, caracterização e mapeamento de áreas/atividades que efetiva ou potencialmente apresentem risco de ocorrência de acidente de contaminação ambiental; 2. criação de banco de dados; 3 . desenvolvimento estratégico - planejamento para orientação de processos decisórios referentes a sua implantação e manutenção; 4. Planejamento de recursos financeiros.

A7. Plano e mapeamento de ameaças múltiplas: recentemente (2018) o IPT foi contratado para desenvolver o projeto-piloto de um mapa de ameaças múltiplas para o município de Cubatão, que contém diagnóstico de ameaças naturais e tecnológicas no município, com os principais pontos geradores de ameaças de risco: deslizamento de terras, corridas de massas, quedas de blocos, erosões, inundações e enxurradas, localização de indústrias e postos de gasolina, transporte de substâncias perigosas e acidentes rodoviários. O mapeamento não chega a detalhar riscos, com raios de alcance, mas localiza geograficamente os locais geradores de ameaças. Um avanço metodológico à abordagem transversal do risco (Informações site IPT).

A8. Planos Preventivos da Defesa Civil e Operação Chuvas de Verão: (informações extraídas da apostila de procedimentos do PPDC e site do Instituto Geológico) O PPDC (Plano preventivo da defesa civil) é uma medida não-estrutural que tem como objetivo dotar as COMDEC (coordenadorias municipais) com procedimentos preventivos para 
reduzir perdas (vidas humanas e bens) decorrentes de escorregamentos e processos correlatos. Foi estabelecido pelo Decreto Estadual no 30.860 de 1989, redefinido pelo Decreto Estadual no 42.565 de 1997, e passou a ser operado desde 1988/1989 nos municípios da Baixada Santista e Litoral Norte, após acidentes de grandes proporções ocorridos no verão de 1987-1988, na região da Serra do Mar. Vigora anualmente entre 1 de dezembro a 31 de março, podendo ser prorrogado de acordo com características meteorológicas do período. O PPDC foi inicialmente implementado em 8 Municípios do Litoral de São Paulo (na Baixada Santista), e em 2003 o Instituto Geológico passou a operar Planos Preventivos de Defesa Civil também nos municípios das regiões do ABC e de Sorocaba. Atualmente abrange um total de 175 municípios em diversas regiões do estado. Conta com a participação do Instituto Geológico, a Defesa Civil Estadual e IPT.

O PPDC está organizado em 4 níveis de alerta-ação: 1. Observação: acompanhar índices pluviométricos; 2. Atenção: realizar vistoria de campo nas áreas previamente identificadas em cadastro; 3 . Alerta: realizar remoção preventiva de população em área de risco iminente indicadas nas vistorias; 4. Alerta máximo: remover toda a população moradora de áreas indicadas como de risco.

As áreas de risco são definidas por setorizações de risco. O PPDC contem um roteiro para renovar e ampliar essas informações, que consiste em um cadastro de risco a ser atualizado por agentes que não necessariamente sejam da área técnica da engenharia ou geologia. O roteiro propõe o levantamento de parâmetros relacionados a uma escala de risco simplificada, que permite concluir sobre o grau de risco da situação em análise.

A operação do PPDC é baseada no entendimento dos processos de escorregamentos e seus condicionantes. Os condicionantes indicam quando e onde podem ocorrer os escorregamentos. O quando é definido pelos índices pluviométricos (números calculados a partir da quantidade de chuvas e seus limiares) e previsão meteorológica. O onde é definido pelas vistorias de campo, os cadastros e as setorizações.

Pelo acompanhamento das chuvas, as vistorias de campo e a implementação das medidas preventivas de remoção, cada COMDEC tem condição de avaliar a situação do seu município e a necessidade de mudança de nível. Diariamente são coletados dados de chuva nos postos pluviométricos determinados para cada município. Por estes dados, são calculados os parâmetros 'acumulado de chuvas de 3 dias' (que, pela experiência, indicam alta possibilidade de ocorrência de escorregamentos), 'Coeficiente de Ciclo Móvel-CCM' e 'Coeficiente de Precipitação Crítica'. É feito monitoramento da previsão do tempo pelo Centro de Gerenciamento de Emergências (estadual), com dois boletins diários para as localidades, e com boletins emergenciais no caso de 3 dias consecutivos de chuvas.

No município São Paulo, a Operação Chuvas de Verão é semelhante. A operação é um plano preventivo da Prefeitura (PPCV), coordenado pela Defesa Civil Municipal (Comdec) com apoio do monitoramento do CGE (do município de São Paulo). O objetivo é reunir recursos de órgãos e secretarias municipais para realizar ações de caráter preventivo, de socorro, assistencial e recuperativo. O plano vigora de novembro a abril de cada ano ou conforme necessidade. O trabalho de integração promovido pela Coordenadoria Municipal de Defesa Civil (Comdec) articula: Secretaria Municipal de Coordenação das Subprefeituras, Secretaria Municipal dos Transportes, Secretaria de 
Infraestrutura Urbana, Secretaria Municipal de Assistência Social e a Secretaria da Habitação e Desenvolvimento Urbano. Esses órgãos realizam operações de desobstrução de bueiros e limpeza de ruas, transporte e alojamento de desabrigados, preparação de acampamentos e abrigos de emergência, suprimentos para desabrigados e assistência social a vítimas de emergência.

Nos meses que antecedem o período chuvoso na Capital paulista, é feito um ciclo de reuniões de elaboração do PPCV, onde o CGE e representantes de secretarias municipais, Defesa Civil, membros do Corpo de Bombeiros, entre outros, discutem os procedimentos de cada órgão em condições de precipitação intensa. As informações do monitoramento meteorológico e precipitações iniciam e determinam o ciclo de mobilização dos demais. No período de vigência do plano, o monitoramento é intensificado, e o CGE exerce a função de notificar e manter informados os órgãos participantes sobre estados de criticidade decretados, condições meteorológicas previstas, acumulado das chuvas, entre outros. Os estados de criticidade decretados pelo CGE são: 1. observação: quando a condição do tempo permanece sem mudanças significativas; 2 . atenção: quando as chuvas possuem potencial para a formação de alagamentos (precipitação intermitente, contínua, ou moderada a forte); 3. alerta: deflagrado após a confirmação do transbordamento de córregos e rios; 4. alerta máximo: quando constatado estado de calamidade pública, que depende de intervenção das esferas estadual e federal. O mapa da Capital exibido na página principal do website do CGE apresenta uma coloração específica para diferenciar os estados decretados entre as regiões da Cidade. Passada a temporada de chuvas, a equipe do CGE foca o monitoramento e comunicação nas condições meteorológicas características das estações mais frias, principalmente as baixas temperaturas e a baixa umidade relativa do ar (informações obtidas no site da Prefeitura de São Paulo e do CGE-MSP).

\section{A9. Programa Estadual de Prevenção de Desastres Naturais e de Redução de Riscos Geológicos (PDN)}

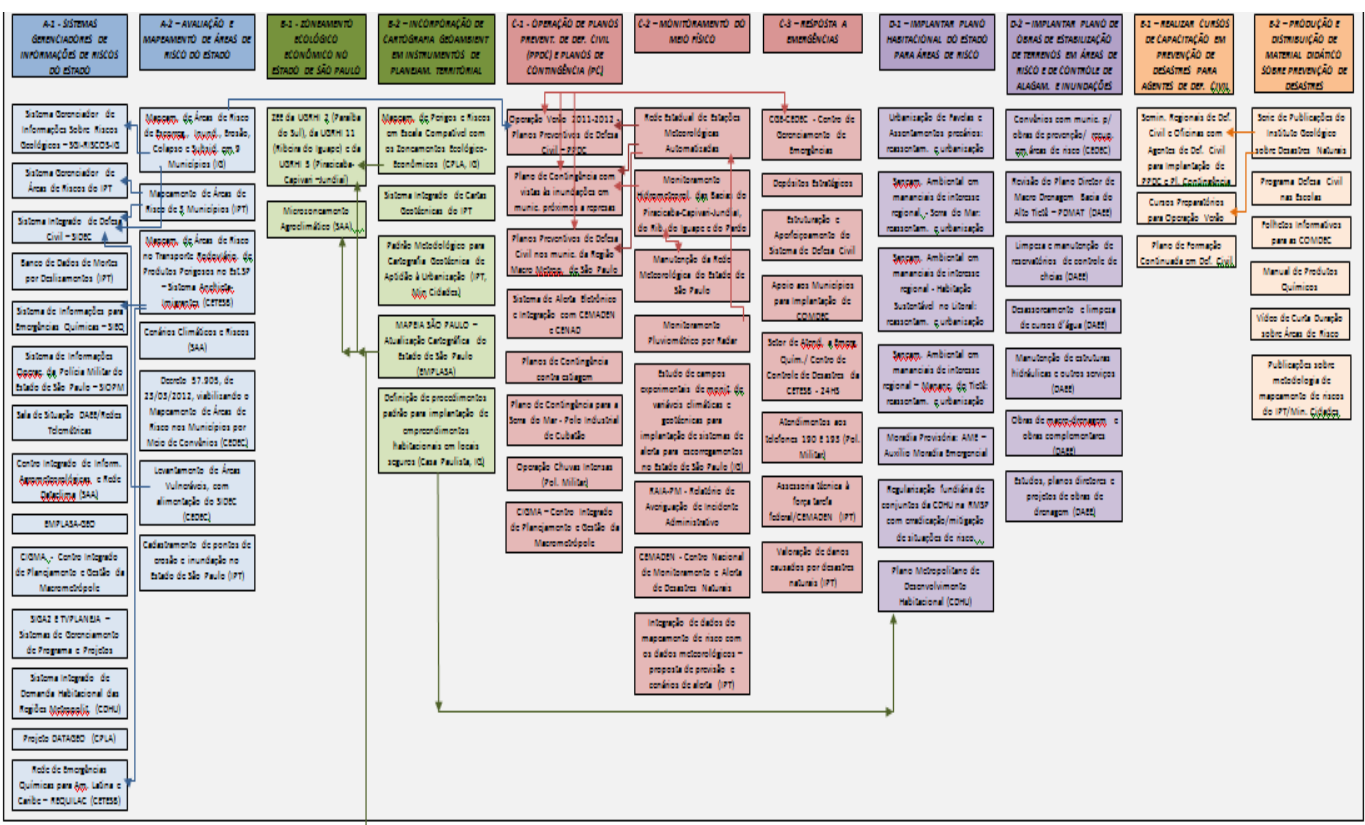

FIG. 13 Fluxograma de ações, fases e agentes do PDN. 
Instituído pelo Decreto Estadual no 57.512 de 2011, tem como premissa articular ações, programas e projetos das Secretarias de Governo e das Instituições Públicas que atuam com o tema desastres naturais e riscos geológicos. Em diagnóstico preliminar, a Coordenadoria Estadual de Defesa Civil realizou, em 2010, levantamento expedito em todos os municípios estaduais chegando a 3690 áreas de risco em todo o estado. Buscou-se construir uma estratégia de integração a partir de instrumentos de gestão pública, articulando ações já existentes - envolvendo a Coordenadoria Estadual de Defesa Civil (CEDEC), da Casa Militar; Instituto Geológico (IG), Coordenadoria de Planejamento Ambiental (CPLA), e Companhia Ambiental do Estado de São Paulo (CETESB), da Secretaria do Meio Ambiente; Secretaria da Habitação; Instituto de Pesquisas Tecnológicas (IPT), da Secretaria do Desenvolvimento; Departamento de Águas e Energia Elétrica (DAEE) e Companhia de Saneamento Básico São Paulo (SABESP), da Secretaria de Saneamento e Energia - e estabelecendo novas ações, articuladas à proposta do Programa à Política Estadual de Mudanças Climáticas (PEMC) - Lei no 13.798, de 9 de novembro de 2009.

O decreto de 2011 definiu um Comitê Deliberativo, composto por Secretários das pastas envolvidas, e um Grupo de Articulação de Ações Executivas (GAEE), de caráter técnico, composto por representantes das secretarias e instituições com ações ligadas a gestão de riscos e desastres. Desde a sua criação até 2016, o GAEE produziu 4 boletins técnicos ${ }^{67}$, traçou cenário de referência dos riscos no Estado de São Paulo (tipos de riscos e instrumentos existentes) e estabeleceu 5 linhas de ação do Programa, com atividades articuladas a órgãos correlatos:

A. Ações de diagnóstico: proposição de sistema de informação e gerenciamento de informações das áreas de risco (a cargo do IPT e IG) alimentado por diversos órgãos, e ações de avaliação e mapeamento dessas áreas;

B. Ações de planejamento: zoneamento econômico ecológico no estado que incorpore a cartografia geoambiental a instrumentos de planejamento territorial;

C. Ações de monitoramento e resposta a emergências, com estabelecimento de operações e planos preventivos de defesa civil e planos de contingência específicos (como os planos de contingência C23 para controle de inundações em municípios próximos a represas, alguns analisados em casos da parte 2), desenvolvimento e integração de monitoramento, e ações emergenciais;

D. Intervenção/erradicação/mitigação, com proposta de ações habitacionais do Estado para áreas de risco, de plano de obras para estabilização de encostas controles de alagamento e inundações;

E. Ações de capacitação, informação e comunicação para situações de risco.

Estas ações acompanham um fluxograma de articulação dos diversos agentes envolvidos. As ações de articulação do programa, propriamente, a cargo da Secretaria de Meio Ambiente, foram enfraquecidas ao longo dos últimos anos, e a produção de uma plataforma (SGI-RISCOS-IG) de informações sobre riscos não avançou, mas houve importante sistematização de informações para o Estado no período.

\footnotetext{
${ }^{67}$ Um deles na RMSP, de 2016, analisado dos estudos de caso na parte 2.
} 

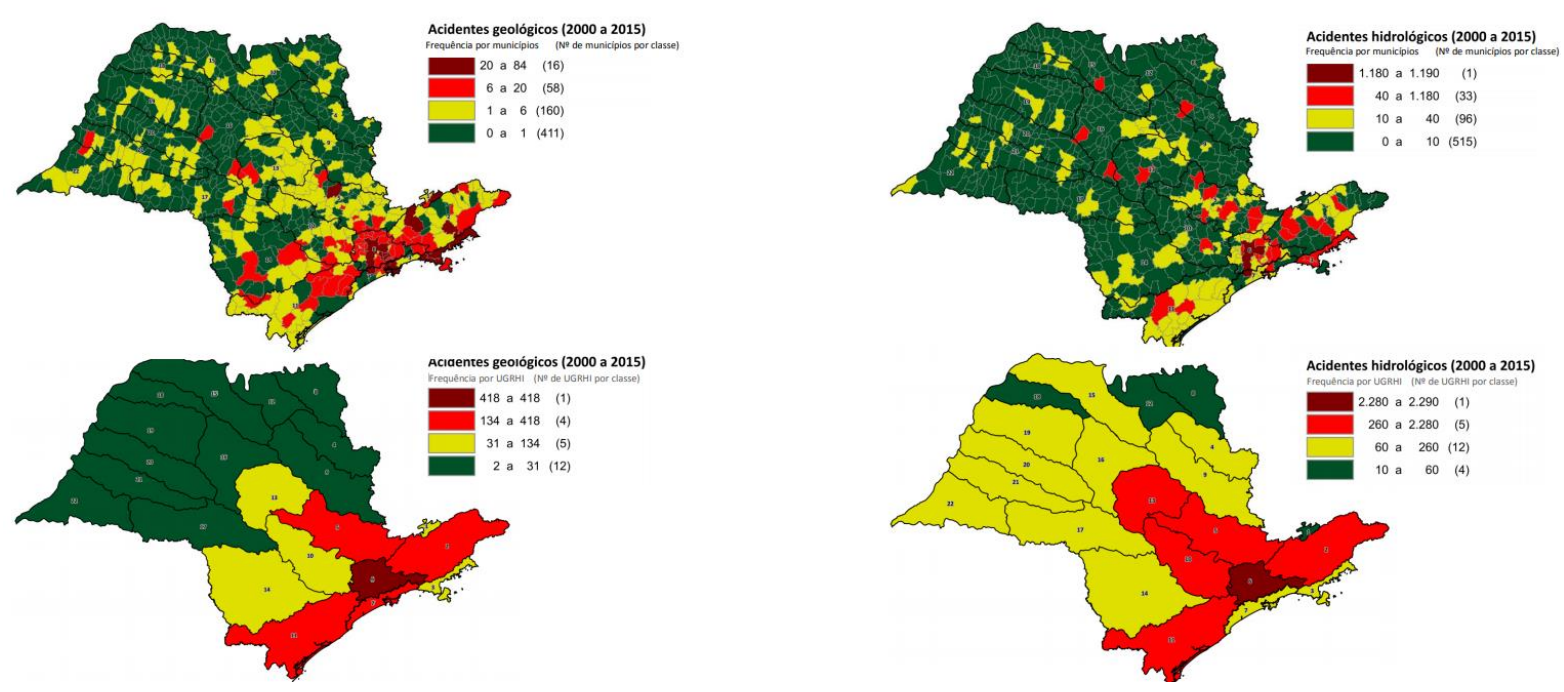

FIG. 14 Espacialização das ocorrências geológicas. À esquerda, por município e por UGRHI, e ocorrências hidrológicas; à direita. Um dos produtos de mapeamento das ocorrências do Boletim 67, (IG, 2016).

O Boletim 27 do IG, de 2012 (BROLLO, 2012), apresenta sistematizações e mapas dos atendimentos realizados pelo PPDC no Estado, e algumas sistematizações preliminares quanto a instrumentos de identificação de riscos nos municípios. O Boletim 67 do IG, lançado em 2016 (BROLLO e FERREIRA, 2016), apresenta um sistema de indicadores para o Estado, a partir do cadastro de eventos da entidade. São dois grupos de indicadores: relativos às ocorrências (ocorrências, óbitos, afetados, edificações afetadas) e relativos ao desenvolvimento dos instrumentos de risco nos municípios. São informações organizadas para a abrangência do Estado e por UGRHI, não desagregadas por município, e para as quais foram gerados mapas para cada indicador desagregados também por tipo de ocorrência ${ }^{68}$.

Além desses estudos, em 2017 foi lançado o "Sistema de Classificação Unidades Territoriais Básicas" - UTB" do Estado de São Paulo, e cinco produtos derivados para abrangência do estado: Mapa de Perigo de Escorregamento e Inundação; Mapa de Vulnerabilidade de Áreas do tipo Residencial/Comercial/Serviços; Mapas de Riscos de Escorregamento e Inundação das Áreas do tipo Residencial/Comercial/Serviços, do Estado de São Paulo, todos compatíveis com a escala de análise 1:50.000, melhor descritos a seguir; e o cadastro de Eventos Geodinâmicos, Acidentes e Desastres de 50 municípios da Região Metropolitana de São Paulo, Baixada Santista e Litoral Norte.

\footnotetext{
68 Nos capítulos 4 e 5, fizemos uso desse banco de dados, que permite a desagregação de informações, para gerar sistematização de indicadores para a abrangência da RMSP, por município.
} 


\section{A10. Mapeamento de vulnerabilidade, perigos e riscos para o Estado de São Paulo do Instituto Geológico}

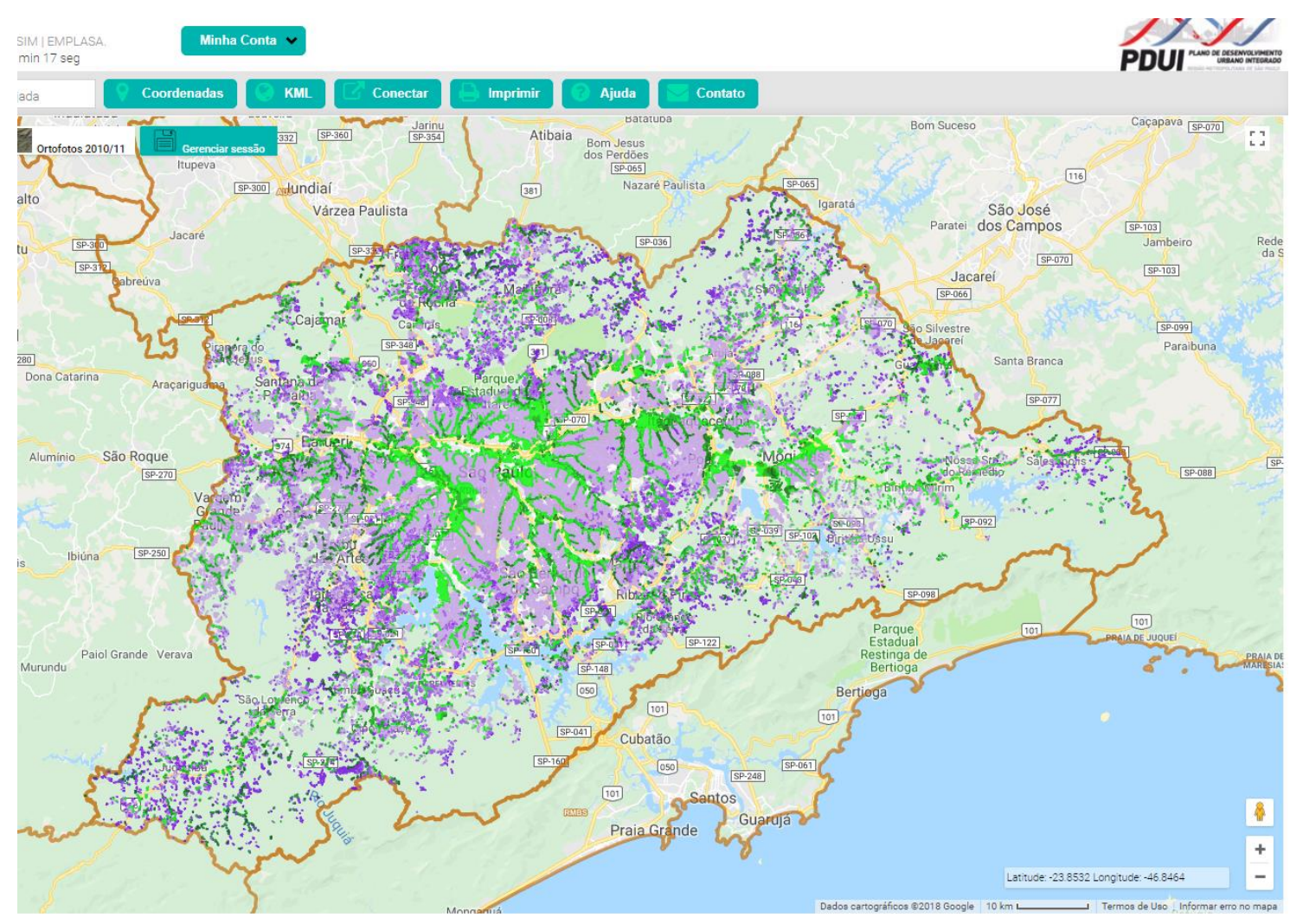

FIG. 15 Mapa síntese de riscos geológicos e hidrológicos a partir de informações do IG com incorporação das manchas de inundação do PDMAT3, incorporados ao SIM. Há também informações espacializadas de perigos e vulnerabilidade.

Esses mapeamentos foram produzidos no âmbito do PDN. Os mapas de risco consideram a identificação e caracterização das variáveis que compõem a equação do risco, que incluem: perigo (similar à suscetibilidade), vulnerabilidade (relacionada ao padrão de ocupação) e dano potencial. Além dos fatores de análise que têm influência direta sobre os processos, foram aplicadas ponderações como fórmulas, regras e pesos aos fatores considerados para a estimativa dos índices simples e compostos de cada variável da equação de risco. Os mapeamentos do IG foram incorporados à plataforma SIM, da Emplasa, no âmbito do PDUI, e ainda está em avaliação como cruzar camadas de informação desta fonte com demais fontes a fim de gerar o zoneamento metropolitano com restrições. A Escala dos mapas é 1:50.000.

O Cadastro georreferenciado de eventos geodinâmicos de 50 municípios das regiões metropolitanas de São Paulo, Baixada Santista e Litoral Norte, no período 1993-2013 é um dos produtos do contrato Projeto de Transporte Sustentável de São Paulo, Componente 3 - Gestão de Riscos de Desastres, um exemplo de articulação de interesses setoriais para promover informações amplas e compartilhadas, relevantes à gestão de riscos. 


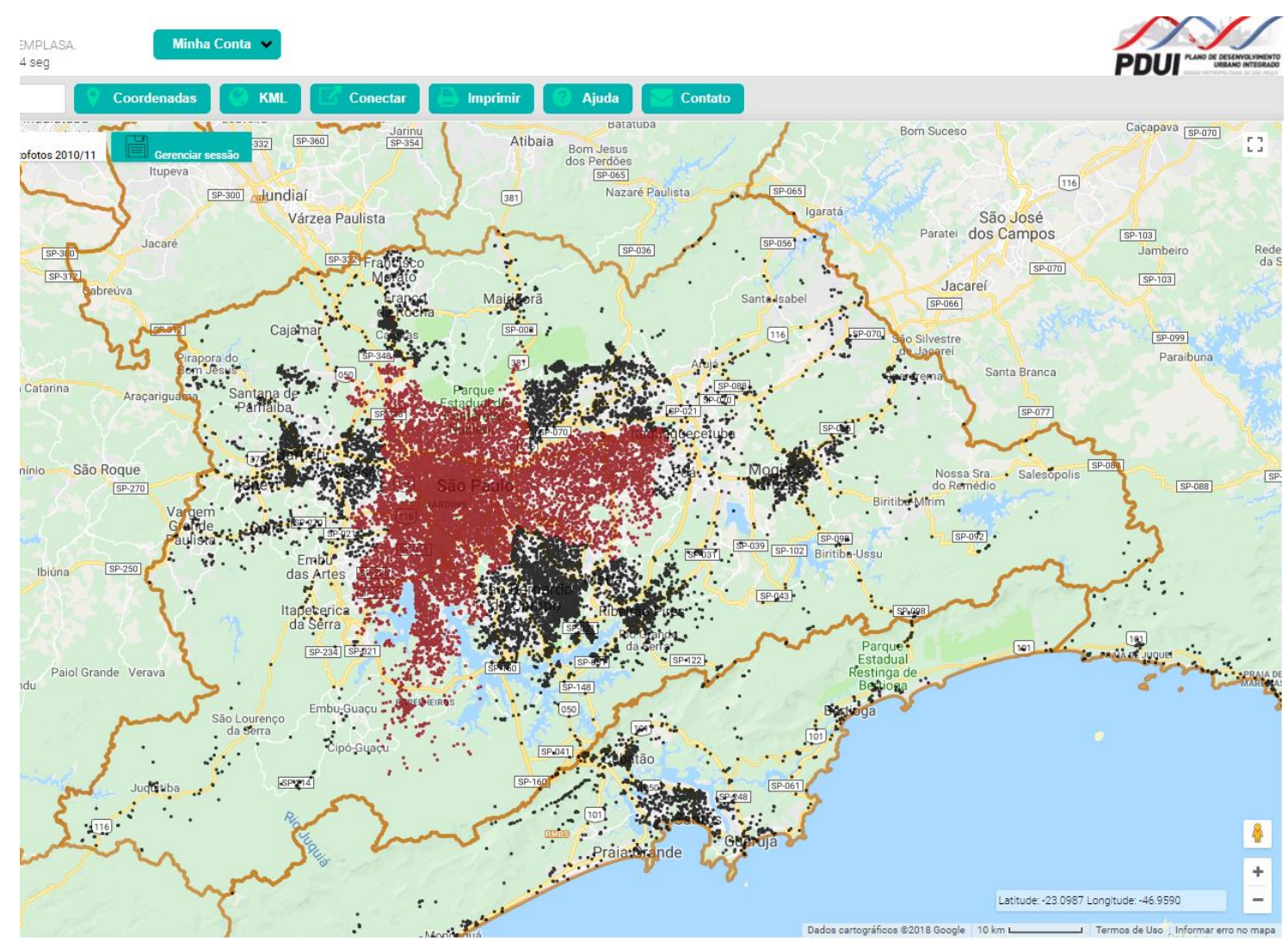

FIG. 16 Espacialização das ocorrências (1993-2013) do cadastro do IG (em preto) e espacialização das ocorrências (2013-2017) do COMDEC-SP (em marrom). As duas fontes foram incorporadas ao SIM e podem ser analisadas conjuntamente, mas correspondem a períodos diferentes.

O projeto tem como objetivo incorporar parâmetros e atributos da gestão de risco de desastres a eventos geodinâmicos nos planos estratégicos, gerenciais e operacionais do Setor de Logística e Transporte. O Cadastro foi desenvolvido com base nas fontes: a) Notícias veiculadas na mídia impressa e eletrônica; b) Bancos de dados e/ou cadastros (formato digital ou não) disponíveis em instituições públicas e privadas, em particular de órgãos estaduais e municipais de defesa civil, operadoras e concessionárias das rodovias estaduais e federais; c) Interpretação de produtos de sensoriamento remoto de alta resolução. Estas informações estão georreferenciadas. No entanto, não foi esta a base utilizada para as análises dos capítulos 4 e 5 , pois 0 município de São Paulo não está no escopo do contrato do serviço do cadastro. As análises foram feitas para o Cadastro de Eventos e Desastres do IG, que conta com fontes de notícias e bancos de dados das defesas civis, sem maiores detalhamentos de informações privadas e concessionárias, e não estão georreferenciadas. Uma vantagem na utilização deste Cadastro foi permitir análise de série histórica para todos os municípios da RMSP até o ano de 2017, e não apenas até 2013.

A11. Rede de monitoramento do CGE: O Centro de Gerenciamento de Emergências (CGE) é o órgão da Prefeitura de São Paulo responsável pelo monitoramento das condições meteorológicas na Capital. As informações meteorológicas são associadas à comunicação em tempo integral com as equipes da Companhia de Engenharia de 
Tráfego (CET), Defesa Civil, Secretaria das Prefeituras Regionais, Corpo de Bombeiros. Entre os mecanismos utilizados no monitoramento estão: radar meteorológico do Sistema de Alerta de Inundações do Estado de São Paulo (SAISP), operado pela Fundação Centro Tecnológico de Hidráulica (FCTH), instalado em Salesópolis; rede telemétrica (medição de chuvas e nível de rios e córregos - SAISP/FCTH); estações meteorológicas automáticas do CGE distribuídas nos principais pontos da cidade; pluviômetros instalados em 31 prefeituras regionais; imagens de satélite (Master/IAG, Cptec, etc.); modelos numéricos de previsão; radiossondagem (Comando da Aeronáutica); metar (código internacional sobre as condições meteorológicas nos aeroportos); radares auxiliares: do Comando da Aeronáutica; radares integrados de Bauru e Presidente Prudente (Unesp); radar SOS Chuva - Vale do Paraíba (CPTEC/INPE) e radar do Sistema Meteorológico do Paraná (Simepar); dados instantâneos e climatológicos do Instituto Nacional de Meteorologia (Inmet); sistema integrado de rádio; observadores locais (agentes da CET, funcionários das prefeituras regionais e Defesa Civil, etc.) (informações obtidas no site do CGE). Dado o impacto de ocorrências de alagamentos em vias de tráfego principais, a maior parte dos dados de observação local são relacionados a problemas causados ao trânsito; por isso, ao se trabalhar com registros de impactos de eventos do CGE há uma clara tendência a maior quantidade de registros em vias de tráfego importantes, podendo enviesar priorizações.

A12. Sistema de Alerta a Inundação de São Paulo (SAISP): Operado pela Fundação Centro Tecnológico de Hidráulica (FCTH), gera boletins sobre as chuvas e suas consequências na cidade de São Paulo a cada 5 minutos. O monitoramento hidrológico (vazão nos corpos hídricos) é feito pela Rede Telemétrica de Hidrologia do Departamento de Águas e Energia (DAEE), Rede telemétrica do Alto Tietê (28 postos distribuídos na bacia do Tietê à montante do Pinheiros, 13 telemétricos e 15 pluviométricos), e pelo radar Meteorológico de São Paulo, adquirido em convênio de pesquisa com a Fapesp. O SAISP emite os seguintes produtos: mapas de chuva observada pelo radar na Ponte Nova, leituras de pontos da Rede Telemétrica na Bacia Alto Tietê, em Cubatão, Registro e Piracicaba, mapas de previsão de inundação para a cidade de São Paulo

A13. Rede de pluviômetros automáticos do CEMADEN: O CEMADEN é o Centro Nacional de Monitoramento e Alerta a Desastres Naturais associado ao Ministério da Integração Nacional, criado em 2011 na esteira do processo de institucionalização da PNDEC. O projeto "Pluviômetros Automáticos" tem como objetivo ampliar e complementar a rede de monitoramento pluviométrico no Brasil e subsidiar a emissão de alertas de desastres naturais. São instalados pluviômetros em locais próximos a áreas de risco nos municípios, com o propósito de medir a quantidade e a intensidade das chuvas que possam deflagrar deslizamentos de terra, inundações e enxurradas. Para essa instalação, são estabelecidos convênios entre o CEMADEN e os municípios, que devem ter um mapeamento de suas áreas de risco, e passam a se encarregar dos cuidados e manutenção dos equipamentos. Os pluviômetros automáticos se conectam aos servidores do Cemaden e transmitem dados dos acumulados de chuva a cada 10 minutos. São processados e disponibilizados para a Sala de Situação do CEMADEN, 
que associa essas informações aos mapas de risco fornecidos pelos municípios conveniados.

Algumas premissas definiram a escolha de municípios para monitoramento de pluviômetros do CEMADEN, e algumas situações levaram à adesão voluntária: estar inserido na lista de 821 (atualmente 827) municípios prioritários do Plano Nacional; ter áreas de riscos mapeadas e estudo de demandas de instrumentação; apresentar demandas registradas voluntariamente pelos municípios por meio de agentes de Defesa Civil e demais interessados; ter mapeamento das áreas de risco realizado por parceiros interinstitucionais; ter cobertura de sinal GPRS; ter disponibilidade de espaço físico adequado para instalação do equipamento, (normalmente cedido por instituição parceira em local público municipal ou estadual); ter histórico de desastres naturais no município registrado pelo Atlas de Desastres Naturais e pelo sistema S2iD; apresentar critérios relacionados a dados censitários dos municípios.

Os dados dos equipamentos ficam disponíveis na plataforma do Cemaden, são acompanhados em tempo real na Sala de Situação do Centro e, juntamente com outras informações, embasam a decisão pela emissão de diferentes níveis de alerta. Para emissão de alertas, o protocolo de comunicação prevê que sejam repassados ao CENAD/MI, que os repassa para os órgãos de Defesa Civil Estadual e Municipal (informações do site do CEMADEN). Esse é um fator que recebe críticas, pois o processo de comunicação não é direto com os municípios. Na RMSP, em muitas situações, os sistemas de monitoramento do município de São Paulo e do DAEE acabam subsidiando a comunicação com outros municípios metropolitanos, com comunicação mais ágil que a do CEMADEN.

\section{A14. Programas de Monitoramento da CETESB}

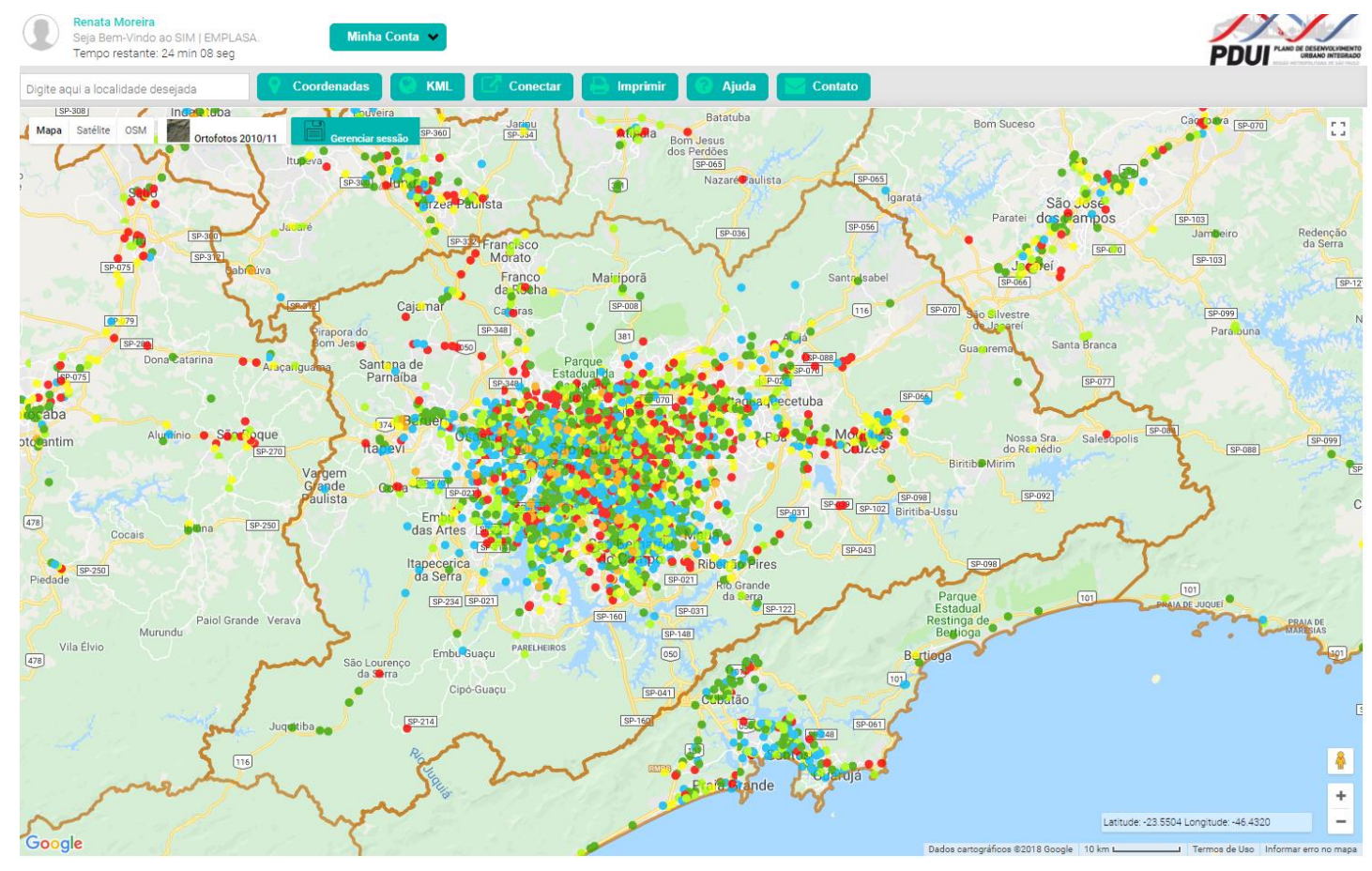

FIG. 17 Mapa de áreas contaminadas na RMSP - CETESB 2017, incorporadas ao SIM Emplasa. 
A CETESB iniciou em 1974 a operação da Rede de Monitoramento de Qualidade das Águas Interiores do Estado de São Paulo. As informações obtidas permitem conhecer parâmetros de qualidade nos principais rios e reservatórios das 22 UGRHIs do Estado. Em 2006 os programas de monitoramento de qualidade dos rios e reservatórios totalizaram 356 pontos de amostragem. Os principais objetivos das redes de monitoramento gerenciadas pela CETESB são para o público técnico (Secretarias de Estado / Cômites de Bacias Hidrográficas / Empresas de Saneamento): avaliar a evolução da qualidade das águas doces; levantar áreas prioritárias para o controle da poluição das águas; identificar trechos de rios onde a qualidade d'água mais degradada exija ações preventivas e de controle da CETESB, como a construção de ETEs (Estações de Tratamento de Esgoto) por parte do município responsável pela poluição ou a adequação de lançamentos industriais; subsidiar o diagnóstico da qualidade das águas doces para enquadramento de seu uso (abastecimento público e outros); dar subsídio para a elaboração dos Relatórios de Situação dos Recursos Hídricos, realizados pelos Comitês de Bacias Hidrográficas. Para o público em geral, a rede de monitoramento informa condições de balneabilidade, qualidade das águas de abastecimento dos mananciais (água bruta), e de proteção da vida aquática.

Não existem medidas estabelecidas entre os controles de qualidade da água CETESB e ações de defesa civil, a não que se estabeleçam processos similares ao APELL em alguma localidade. Para os controles de risco, a rede de monitoramento da CETESB relaciona-se, principalmente, aos sistemas de abastecimento e controles de riscos tecnológicos e de áreas contaminadas. As informações da CETESB que foram incorporadas ao SIM tratam das emergências químicas e de áreas contaminadas.

\section{A15. Plano de contingência para abastecimento de água da Região Metropolitana} de São Paulo: o Plano de contingência, elaborado no cenário de crise hídrica de 2014 a 2016 no sistema produtor Cantareira, contempla ações de Defesa Civil emergenciais, associadas a níveis de alerta, em seu anexo 2. O Plano tem, sobretudo, medidas de ordem técnica setorial, estruturais e não estruturais, para mitigação dos efeitos da escassez de água nos sistemas. As atribuições pertinentes aos órgãos de defesa civil estabelecem os procedimentos para a Coordenadoria Estadual de Defesa Civil e os órgãos Regionais e Municipais abrangidos pelo Sistema Produtor Cantareira.

No nível de atenção, o plano propõe que sejam identificadas e mapeadas as áreas e equipamentos no âmbito municipal para serem empregados como pontos de apoio na distribuição de água à população em caso de redução severa no fornecimento, bem como catalogados os recursos materiais e humanos a serem empregados em conjunto com as empresas concessionárias. No nível de alerta, foi previsto o apoio para garantir segurança às equipes técnicas das concessionárias em campo, por meio dos órgãos de segurança pública municipal e de defesa civil, em articulação com a Polícia Militar. No nível de emergência, foi prevista a implantação de áreas e/ou equipamentos públicos de apoio que serão usados como pontos estratégicos locais de distribuição de água à população, medida para a qual a defesa civil participa com apoio logístico (síntese extraída do plano, $\mathrm{CCH}, 2015)$. 
A16. Planos de bacias locais: a noção de "bacia" é ampla e variável, visto que toda bacia comporta uma sub-bacia e é também parte de uma bacia maior. Aqui, não se trata da denominação de bacia hidrográfica correspondente às UGRHIs ${ }^{69}$, para as quais existem os planos de recursos hídricos e de macrodrenagem, mas de bacias que correspondam à escala de bacia municipais (ainda que não necessariamente, pois sua delimitação pode extrapolar limites administrativos municipais), conforme planos de bacias de drenagem como proposto para a Prefeitura de São Paulo - Plano de Manejo das Águas Pluviais Urbanas (FCTH, 2012). Não existe uma regulamentação ou metodologia elaborada para planos de prevenção e mitigação de risco por meio de planos de bacias, mas, em função do artigo $4^{\circ}$ da Lei 12.608 , muito se discute nos ambientes de gestão de riscos sobre a delimitação de bacia como a primeira medida que permite promover um olhar mais integrado para a gestão de riscos. O artigo 4ํㅜ estabelece que adotar a "bacia hidrográfica como unidade de análise das ações de prevenção de desastres relacionados a corpos d'água" é uma diretriz da política, mas não define a qual abrangência ou classe de bacia isso se refere. Em outras passagens da lei, o termo "bacia" aparece associado a bacias do sistema hídrico nacional, relativas ao Plano Nacional de Proteção e Defesa Civil, e à escala estadual, relacionadas ao Plano Estadual de Proteção e Defesa Civil.

Em geral, a visão que se tem nos debates, é que um plano de bacia de escala local, próxima à ordem de grandeza da escala de um bairro ou região municipal, permitiria desenvolver análises mais detalhadas das formas da ocupação, desenvolver procedimentos de modelagens mais precisos para sistemas setoriais diversos, integrando informações detalhadas sobre alterações no uso do solo ao estabelecer cenários de transformação, e construir processos participativos, de educação para o risco e governança local.

Uma política assim organizada, precisaria de um nível anterior que estabelecesse critérios para definir bacias onde ações desse tipo são prioritárias, e também que estabelecesse metas e resultados esperados nas diversas áreas de interesse que integram o plano: riscos geológicos, de melhoria da qualidade das águas, da salubridade e condições de precariedade, ampliação e regularidade dos serviços, ou seja, metas para avaliação de uma qualificação ambiental ampla. Tanto a Política Municipal de Drenagem, articulada ao saneamento, como a Política de Controle Urbano, articulada à política habitacional e planos diretores, podem constituir o nível anterior que ordena o desenvolvimento de planos de bacias locais. Os processos de escala regional que cruzam a escala local das bacias também devem ser devidamente endereçados, e informar níveis superiores de gestão de situações de risco, ou, no sentido contrário, indicar razões para priorizar análises em determinadas bacias.

No município de São Paulo, está em experiência inicial um piloto de plano para controle de riscos na bacia do Jaguaré. Os Planos de Bacia são instrumentos transversais, que aparecem também como instrumento de planejamento urbano ambiental e de

\footnotetext{
${ }^{69}$ Cabe observar, ainda, quanto à delimitação das UGRHIs, que nem sempre sua demarcação corresponde rigorosamente ao conceito de bacias hidrográficas. Há UGRHIs que correspondem a frações de bacias maiores (como a própria BAT) ou combinação de trechos de diferentes bacias (como o PCJ). Ou seja, a delimitação de bacia, como definição genérica, nem sempre pode encontrar contextos de bacias já delimitadas que sejam funcionais para fins de controle e prevenção de riscos.
} 
planejamento setorial, sobretudo do setor de drenagem. No entanto, apesar de permitirem um olhar local integrado substantivo, não se pode dizer que a delimitação de bacia, que corresponde à organização os fluxos por gravidade, seja por princípio a ideal para orientar análises de risco e medidas preventivas, pois nem todos os riscos se distribuem apenas por meio dos fluxos de gravidade. Os processos de poluição do ar, dispersões e condições atmosféricas, e mesmo alguns processos de contaminação do solo e águas subterrâneas, não necessariamente respondem a uma delimitação desse tipo. Para esses casos, metodologias do tio APELL podem ser mais apropriadas. Também é preciso considerar que certas áreas que exigem abordagem detalhada podem escapar à delimitação de bacias locais, como a faixa de planície aluvial do Tietê, a zona de amortecimento do rio cuja bacia é de classe (nível) superior. Ou seja, nem todos os riscos podem ser expressos em processos de planejamento organizados por delimitação de bacias locais.

\subsubsection{Instrumentos de planejamento urbano e ambiental em relação ao controle dos riscos}

Os instrumentos de planejamento urbano e ambiental não carecem de maiores apresentações. Por isso, serão aqui discutidos em ordem crescente de escala de abrangência, e de acordo com a potencialidade que possuem para que se integrem e funcionarem como instrumentos de gestão de riscos.

Algumas atividades pontuais de manutenção urbana (ver B1 na tabela ${ }^{70}$ ), negligenciadas tanto em termos de ação como de planejamento, são importantes deflagradores de efeitos secundários, como as quedas de árvores. Em contextos já agravados por chuvas e alagamentos, a queda de árvores interrompe linhas de tráfego e mesmo condições de socorro e salvamento. Podem interromper a transmissão de eletricidade, causando panes que desencadeiam outros processos. Uma indicação importante dessa avaliação é a de que os planos de manejo e podas de árvores deveriam se integrar a avaliações das redes elétricas e logística de emergência.

Ações pontuais de mitigação de riscos - projetos de contenção de pequena escala, execução de galerias (B2) em pontos de alagamento recorrentes - podem representar medidas negativas, perpetuadoras de precariedade, se não estiverem articuladas a visões mais amplas e análises dos fatores de risco, que devem ser mitigados por ações mais complexas, de ataque tanto às causas e condições do meio como das condições de vulnerabilidade. Por exemplo, projetos de urbanização integrados de assentamentos precários (B3) e planos integrados de bacias (B4) são instrumentos de ação que permitem elaborar saídas de mais longo prazo, associar medidas estruturais e não estruturais, e combinar ações de estruturação urbana de diversas áreas conjuntamente. São oportunidades para se trabalhar localmente a integração de diversos setores e disciplinas que atravessam um território, e associar à avaliação de certos riscos.

No caso dos projetos de urbanização integrada (B3 e B4), a integração é possível não somente pelos trabalhos objetivos de compatibilização de temas e disciplinas técnicas

\footnotetext{
${ }^{70}$ Os códigos entre parêntesis que acompanham o texto têm correspondência na tabela 4, p. 80.
} 
nos projetos para resolver situações de precariedade e risco já instalados. O caso do município de São Paulo é um exemplo em que há integração de recursos do saneamento para soluções habitacionais de áreas precárias e qualificação de bacias municipais críticas. Conforme previsto no contrato de concessão dos serviços de água e esgoto com a Sabesp, parte das receitas da concessionária podem constituir um fundo para urbanizações, que são nós cujo equacionamento é de interesse da concessionária. Os planos de bacia (B4) pertencem a um nível de equacionamento acima de projetos de urbanização de áreas precárias (B3), e integram visão conjunta dos fluxos por gravidade, permitindo equacionar no nível local nós de drenagem e de esgotamento sanitário relacionando diversas medidas de ordenamento do uso do solo, como definição de taxas de ocupação, destinação de áreas verdes com funções ambientais específicas, desocupação de várzeas (B11) e áreas frágeis e suscetíveis a riscos.

Os planos diretores regionais (B5), desenvolvidos no município de São Paulo, podem ser entendidos como um detalhamento do Plano Diretor e, em certo sentido, sua função é concorrente com a dos planos de bacias (B4). Os Planos Regionais correspondem à divisão administrativa do município em distritos, ou subprefeituras, mas as delimitações de bacias poderiam ser o âmbito em que se detalha o zoneamento das diretrizes gerais do município, desde que reagrupadas para não gerar grandes incompatibilidades com as delimitações administrativas.

Os Planos Diretores Municipais (B6) e seus produtos derivados (zoneamento B7 e instrumentos de cotas ambientais B9) podem se articular a um enfrentamento amplo dos riscos nos aspectos difusos, definindo: restrições à ocupação e controle do adensamento por certos parâmetros edilícios, zonas prioritárias para ações de urbanização integrada e para implantar empreendimentos que ataquem o déficit habitacional (as ZEIS), confirmar funções de proteção definidas em níveis de planejamento territoriais hierarquicamente superiores (como as áreas de Proteção de Mananciais B13), além de algum grau de flexibilidade para estipular, em âmbito municipal, a destinação de proteção de determinada função municipal. Os Códigos de Obras (B8) já incorporam aspectos de controle das edificações frente ao risco de incêndios e recentemente incorporam novos instrumentos com a premissa do controle difuso da impermeabilização e da drenagem, pela discussão de restabelecer, no lote, a vazão de pré-desenvolvimento por meio de mini reservatórios de detenção de água de chuva (piscininhas) ${ }^{71}$. Não foram estabelecidos, ainda, em códigos de obras, restrições específicas para edificações em terrenos de encostas, embora parte das restrições a terrenos de alta declividades já sejam controladas nas leis de parcelamento. E, com todos os mecanismos existentes de controle-comando sobre como ocupar a cidade, é forçoso considerar que ocupações que ampliam a vulnerabilidade das edificações ocorrem apesar de, e mesmo por causa dos controles. Pois as áreas que seriam mais custosas de ocupar, em função das restrições, acabam configurando o mercado urbano fora das normas, ilegal e precário. As leis específicas de mananciais (B13) são exemplo disso, muito embora instrumentos recentes de detalhamento dessas leis tentem

\footnotetext{
${ }^{71}$ As piscininhas partem do princípio da vazão de pré-desenvolvimento, que é o de que os lotes retenham, nos picos de chuva, certa quantidade de água como se fosse um terreno não ocupado.
} 
contornar de forma mais criativa a ocupação já consumada, e integrar parâmetros técnicos de controles ambientais à permissão para regularizar ocupações existentes.

Os planos ambientais que definem áreas de conservação e de proteção e os zoneamentos econômico-ecológicos (B12, B13, B14) constituem escala e nível mais distante de ordenamento territorial que, por princípio, é a escala que deve lidar com mecanismos de proteção das funções regionais. No entanto, essa escala distante pode não alcançar conflitos locais que venham a interferir nas funções regionais, e promover certos riscos tanto de escala local como de impactos mais abrangentes, que exigem compreensão e equacionamento mais detalhado do que grandes delimitações. Os planos na escala das metrópoles (os PDUls, 0 ) poderiam articular essas duas escalas. Ou seja, além de indicar restrições da escala regional a serem carregadas aos processos de ordenamento local (representado nos Planos Diretores) - um processo que já acontece independentemente da existência de PDUls - o plano na escala metropolitana poderia diagnosticar e indicar lugares onde a dinâmica da escala local entra em conflito com a dinâmica das funções regionais, e promove riscos potenciais. Os Planos de Adaptação a Mudanças Climáticas (B15), que tendem a entrar em voga e constituir novo modo de elaborar instrumentos de planejamento, também deveriam incorporar diagnósticos multiescalares e multifuncionais. Os casos desenvolvidos na parte 2 procuram exemplificar essas lacunas, e propõem abordagem que permite desdobrar metodologias para análises de risco integradas.

Por fim, os Planos Habitacionais podem ser considerados como planos de ação, que têm relação direta com diagnósticos de riscos, tanto na escala municipal (B16) como na escala estadual (B17). Já incorporam, em suas formulações, algumas quantificações de riscos como composição do déficit. Porém, assim como apontado para os PMRRs, não consideram dinâmicas geradoras de risco e aspectos tendenciais que poderiam ser controlados, remodelados ou desfavorecidos pela oferta de soluções habitacionais organizadas a partir do interesse público. Sobretudo as escalas metropolitanas e estadual seriam as mais efetivas para identificar dinâmicas de ocupação indesejadas que extrapolam os controles município e direcionar saídas de escala mais apropriada.

\subsubsection{Instrumentos de planejamento setoriais em relação ao controle dos riscos - possíveis integrações}

Os sistemas de infraestrutura urbana setoriais seguem protocolos e normativas firmados em contratos de concessão e instrumentos de outorga de direito de uso, e por protocolos de segurança que, em geral, analisam os sistemas de forma segmentada.

$\mathrm{Na}$ menor escala, da operação e gestão de dispositivos e pontos específicos dos sistemas, existem resoluções operacionais $(\mathbf{C} 1)$ e planos de contingência que podem se articular com a escala local (C2), como os planos de contingência para as manobras do reservatório para abastecimento de água Paiva Castro (e outros reservatórios do Sistema Cantareira) ${ }^{72}$, onde são acordados limiares para tomada de decisão de abertura das comportas, definidas as áreas de impacto e estabelecido protocolo de

\footnotetext{
72 Esses planos de contingência são parcialmente analisados em casos da parte 2.
} 
comunicação com defesa civil e município; ou como os planos de contingência para operação de dispositivos de drenagem (como sistemas de bombeamento de piscinões) que podem ou não estar articulados a planos contingência de dispositivos de outros setores. Ainda considerando a escala local, é importante destacar ações e soluções pontuais, que utilizam recursos de obras emergenciais para serviços como canalizações, execução de galerias (C3), ou soluções pontuais de execução de redes de esgoto (C4), não articuladas a planos mais amplos, algo bastante comum sobretudo em municípios em franca ampliação da área urbana por expansão precária. Há, também, ações preventivas pontuais, de limpeza de córregos, que antecedem período de chuvas, em alguns casos feitas em mutirão com a comunidade (C5), que funcionam como ações educativas.

Em nível municipal, um instrumento que pode ser significativo para integrar aspectos setoriais a dinâmicas dos territórios urbanos municipais são os planos de saneamento (C6). Com a ampliação do escopo de serviços na definição de saneamento trazida pela Lei 11.455 de 2007, o saneamento engloba, além dos serviços de abastecimento de água e de esgotos, os serviços de drenagem e a gestão de resíduos sólidos. A lei estabelece a obrigatoriedade de Planos Municipais de Saneamento para vinculação a recursos federais e como parte dos contratos. Os planos municipais de saneamento podem ser integrados ou elaborados por atividade, segmentado: um para o serviço de abastecimento de água, outro para esgotamento, outro para drenagem e outro para gestão de resíduos.

No plano municipal de saneamento de São Paulo, elaborado em conjunto com a concessionária, em linhas gerais, se reproduz o plano de investimento da Companhia, sem aporte de contribuições significativas por parte do município, que poderia ser, por exemplo, um diagnóstico qualitativo da rede e do serviço elaborado pelo município a respeito dos serviços ofertados, mediante apoio de informações do regulador. Isso não foi feito, mas há um elemento importante a se destacar no Plano, porque integrado a aspectos de gestão territorial urbana. Ao se delimitar a área abastecível de São Paulo, termo reiterado no contrato firmado entre município e concessionária com anuência do regulador ARSESP (C7), foi definido não apenas um perímetro contínuo, uma delimitação da mancha urbana à qual a concessionária seria obrigada a atender, mas áreas não formalizadas e precárias dentro da mancha urbana, que definem perímetros de ação integrada, onde o atendimento deveria ser realizado mediante ação conjunta da concessionária e da secretaria de habitação do município, e para os quais haveria um fundo criado com destinações de parte das receitas obtidas pela concessionária com o município. Medida de gestão que equaciona alguns nós espaciais em pelo menos 3 frentes do saneamento: água, esgotamento e drenagem, e na frente habitacional, permitindo enfrentar alguns contextos de riscos.

O Contrato de 2010 indica, também, a necessidade de plano de contingência (C8) para situações adversas no abastecimento de água que, somente na crise hídrica de 20142015, foi realizado. O CHESS Crise Hídrica, Estratégias e Soluções Sabesp (SABESP, 2015) - que se desdobrou no Plano de Contingência para Abastecimento da RMSP (CCH, 2015) (A15), de ação articulada com a defesa civil, área de saúde e educação apresenta aspectos de abrangência, regional e macrometropolitana da ameaça meteorológica e aspectos técnicos da crise que cabem à Sabesp, bem como de 
assuntos a serem gerenciados em conjunto com municípios. Assuntos de responsabilidade das entidades gestoras de recursos hídricos - o controle de gerenciamento da água bruta e outros usos outorgados tanto do sistema estadual como do sistema nacional - não são abordados no plano, a não ser como fatores externos, ou condicionantes do contexto: os limites de retirada exigidos em meio à crise pelo DAEE e ANA. Algumas das medidas estabelecidas no plano são: os investimentos na interligação entre sistemas produtores, com criação de redundâncias para criar maior flexibilidade e permitir socorro de uma região a outra, e diminuir dependência do Sistema Cantareira; medidas difusas na rede e no consumo, como as medidas de redução da pressão na rede (que pressupõe que todas as edificações tenham caixas d'água, para garantia da regularidade) e a política de incentivo à redução do consumo, com bônus à redução e multas ao aumento de consumo; a intensificação dos investimentos em programas de controle de perdas na rede; e o uso das reservas técnicas dos reservatórios. Parte das soluções trazidas por este plano de contingência já tinham sido levantadas como um conjunto de ferramentas no Plano Diretor de Recursos Hídricos da Macrometrópole Paulista (C10b).

Ainda no que diz respeito a saneamento, mas relacionado a outra atividade, a estruturação de ações em drenagem urbana, embora aparentem ser tecnicamente menos complexas que outras atividades do saneamento organizadas por redes de capacidades hierarquizadas (produção, distribuição principal e secundária), é bastante complexa, pelas interações diferentes que as funções de macro e microdrenagem estabelecem com o território.

De um lado, a macrodrenagem compreende o estabelecimento de soluções hidráulicas de acordo com vazões mínimas e máximas definidas para os corpos hídricos nos planos diretores de macrodrenagem (C9) para as UGRHIs, e se relaciona diretamente com as regulamentações dos sistemas nacional e estadual de recursos hídricos. Esse arcabouço normativo pertence à territorialidade da água, e parte do princípio da água como recurso, e de sua exploração para usos diversos: abastecimento urbano, industrial e agrícola (controles de retirada e lançamento), geração de energia, transporte, lazer e segurança hídrica. Arbitrar o conflito pelo uso do recurso é o princípio que rege a gestão integrada de recursos hídricos no Brasil e no Estado de São Paulo, e que orienta os Planos Estaduais de Recursos Hídricos (C10), garantindo a manutenção do recurso em quantidade e qualidade adequada aos interesses pelo seu uso na bacia.

Do estabelecimento desse princípio básico, para o caso de São Paulo, já se delineiam dois órgãos diferentes que controlam a concessão dos direitos de uso do recurso: para avaliação da quantidade, o DAEE; e para avaliação da qualidade, a CETESB. Definições de vazão de referência, retirada do recurso e condições para lançamento, estabelecimento da necessidade de grandes dispositivos para armazenamento em depressão (piscinões), dispositivos de controle da vazão no curso d'água que dependem de gestão operacional (barragens), implementação de sistemas de medição da vazão e da qualidade da água, de radares hidrometeorológicos, e associação com sistemas de alerta e controle são os aspectos mais usuais do controle da macrodrenagem na escala 
regional (da Bacia hidrográfica) ${ }^{73}$. Para isto, além dos Planos de Macrodrenagem (C9) e de Recursos Hídricos (C10), a Política de recursos hídricos prevê outros instrumentos, como as outorgas de retirada e lançamento (C11) e o enquadramento dos corpos hídricos em classes de qualidade da água (C12), que se relacionam diretamente com o concessionário no planejamento dos serviços de saneamento (pelos planos de saneamento C6), mas podem se relacionar, também, com aspectos da gestão territorial e com a gestão de riscos relativos à qualidade das águas.

De outro lado, as funções de microdrenagem compreendem o traçado de redes, condutos e galerias, sistemas ambientais de absorção e mesmo retenção em pequena escala, que relacionam o manejo de águas pluviais urbanas com aspectos da gestão de uso do solo municipais, formalmente organizadas em:

- canalizações e redes em associação com traçado, abertura e adequação de vias (geralmente definidos pelas secretarias de obras) e controle da manutenção e operação de alguns dispositivos da rede (estes também realizados pelas Subprefeituras) para as quais são utilizados os chamados Planos Diretores de Drenagem (C15), que são apenas projetos detalhados para o orçamento de determinado ano;

- definição de usos do solo relacionados a funções urbana e de sistemas ambientais (SVMA, praças, parques e áreas municipais de proteção), estabelecidas nos planos diretores e planos de parcelamento;

- controles do uso do solo: ações de promoção de certos usos, controles de aprovação e fiscalização, adequação das construções, definição de diretrizes de ocupação por meio dos planos diretores e lei de zoneamento.

Diferentemente das demais funções de saneamento, as redes de microdrenagem não se relacionam exclusivamente com pontos de consumo, com usuários finais, e não configuram claramente um serviço sobre o qual poderia incidir tarifas. É um serviço em rede de consumo coletivo, difuso e disperso. Guias, sarjetas, bueiros, enterramento de canalizações (somente aceito em condições específicas), redefinição de cursos d'água por canalização, transposições, galerias, são aspectos de rede mais usuais e diretos. Todos aqueles relativos ao controle do uso do solo são ações indiretas sobre a drenagem, cuja responsabilidade é atribuída aos municípios pela Constituição Federal.

Complicador extra a essa miríade de instituições afeitas à função de drenagem, relacionadas à territorialidade da água e do controle do uso do solo, a atividade "drenagem e manejo de águas pluviais urbanas" passou fazer parte, formalmente, do saneamento urbano integrado. Os diversos aspectos institucionais da drenagem apontados até aqui - funções de macrodrenagem e segurança hídrica, ligada à gestão dos recursos hídricos; funções de microdrenagem, ligadas à transformação e controle da ocupação e uso do solo; ou ao entendimento da drenagem e manejo de águas

\footnotetext{
73 No monitoramento, são importantes a rede estadual da CETESB (A13), de avaliação da qualidade da água, a rede de monitoramento SAISP (C14) e (A12), que avalia chuva e vazão (quantidade) na escala municipal e a rede de monitoramento da ANA (C22) de vazão e nível dos reservatórios que compartilham do Sistema Nacional de Recursos Hídricos.
} 
urbanos como parte do saneamento básico integrado - poderiam se associar a partir do conhecimento compartilhado e gestão preventiva de risco de inundações, mas não é o caso. Inundação e alagamento, inclusive, constituem conceitos técnicos distintos ${ }^{74}$ : a primeira, relativa a transbordamento de vazões fluviais (cheias) - macrodrenagem; a segunda, relativa a falhas ou limites nos sistemas e redes de microdrenagem. Enquanto que para o usuário, tanto o alagamento como a inundação significam apenas água onde ela não deveria estar. Por isso, os Planos Municipais de Drenagem (C16), ou Planos Municipais de Manejo de águas Pluviais - como um dos instrumentos dos Planos de Saneamento - poderiam ser mais um elemento oportuno para integrar ações que devem estar entre a escala da macrodrenagem e a escala da microdrenagem, mediante associação de aspectos de gestão de riscos, como estabelecimento de medidas preventivas, e integração de medidas estruturais e não estruturais. Do ponto de vista da drenagem, os Planos ou Programas de Bacias Locais (C17 - já mencionados anteriormente como instrumento de gestão de riscos A15 e de planejamento urbano B3) deveriam orientar contratações relativas a serviços de projetos integrados, envolvendo serviços de modelagem hidráulico-hidrológica de escala mais detalhada, previsão de cenários tendenciais de crescimento e simulações de eventos críticos que levem em conta tanto propostas de soluções hidráulicas estruturais como soluções urbanísticas, com associação entre medidas estruturais e não estruturais. Pode-se dizer que os Programas de Bacia seriam o nível mais elementar de uma ação de GRD - Gestão de Risco de Desastre - para inundações e alagamentos.

Para qualquer pretensão política de integração de ações setoriais no território, a escala local - municipal - é imprescindível; é nesta escala que a gestão e monitoramento de contratos de manutenção e execução de sistemas pode acontecer com agilidade e eficácia, e para a qual é preciso arranjo institucional que garanta controles de eficiência e desempenho. A soma dos diversos planos de bacias na escala da Região Metropolitana poderia equacionar grande parte dos riscos de inundações, e mesmo geológicos, por meio de medidas de prevenção, controle e alerta, ações de mitigação, e resolver parte de problemas de integração entre ações setoriais e de controle urbano. No entanto, mesmo a soma de todas as bacias "resolvidas" internamente não representaria a resolução de todos os problemas de integração setorial. Nem representaria método para, em tese, equacionar todos os riscos gerenciáveis. Pois existem processos que atravessam a escala local, cujo controle, arbitragem de interesses e conflitos de decisões estão acima da escala local.

Conflitos com potenciais riscos entre capacidades produtoras dos diferentes sistemas são típicos de níveis de decisão da instância federativa dos estados. Nesse nível, os instrumentos da gestão de recursos hídricos (C9), tanto estaduais como federais, e os protocolos estabelecidos entre os agentes usuários do recurso $(\mathbf{C} 18, \mathbf{C 1 9}, \mathbf{C 2 0}, \mathbf{C 2 1})$ são determinantes, e, inclusive, orientados por controles e monitoramentos de sistemas de informação de nível superior, como a rede de monitoramento mantida pela ANA, (C22). Isso não quer dizer que os controles, instrumentos e mecanismos de gestão das diferentes escalas apresentados aqui sejam independentes e autônomos entre si, nem

\footnotetext{
${ }^{74}$ Os conceitos de inundação e alagamento em nossas leis reproduzem aqueles da Diretiva Quadro Européia.
} 
que devam ser relacionados apenas hierarquicamente, como determinações de restrições regionais às decisões locais, que se desdobram em cascatas de comando. Para lidar com contextos complexos, é importante reconhecer que há situações, e sobretudo contextos de risco potencial, em que as escalas se cruzam em um lugar e exigem um ataque ao problema que alcance, ao mesmo tempo, a grande e a pequena escala. Estas situações devem ser, por excelência, situações de interesse de uma gestão na escala metropolitana.

Um exemplo de estudo que cruza as escalas regional e local, definindo diretrizes regionais a partir do nível local, é o estudo técnico que embasou as Resoluções operacionais para manutenção do volume de espera em reservatórios de abastecimento (C23), elaborado a partir de 2010 em virtude dos riscos associados a períodos de cheias e as necessidades de manobras nas comportas dos reservatórios de abastecimento. A partir desse estudo, foram definidas regras operacionais para que os reservatórios de abastecimento do Sistema Cantareira pudessem atuar também como amortecimento de cheias no período de chuvas. 
PARTE II - Contexto dos riscos na RMSP e estudos de caso 


\section{Capítulo 4 - Aspectos metodológicos e as informações sobre}

\section{desastres}

Tendo a premissa de que os métodos usuais de análise de riscos possibilitam que riscos nas interfaces entre sistemas setoriais sejam tratados como desprezíveis, de baixa probabilidade, ou baixo impacto dentro de determinado sistema de gestão de riscos ao qual pertence

E a hipótese:

Em contextos urbanos densos e complexos, sob ameaças extremas, riscos cruzados, entre sistemas ou em suas interfaces, devem ser considerados fator de agravamento dos impactos individuais de cada ocorrência. A soma de seus efeitos pode definir categorias de riscos mais altos e potencialmente catastróficos a partir de riscos tidos como baixos pelo sistema setorial que o gerencia.

1. Como investigar a hipótese tendo como recorte de análise a RMSP?

2. O problema envolve qual abrangência espacial?

3. A que conclusões, em termos de ações para a gestão metropolitana, a confirmação dessa tese nos leva?

Este capítulo tenta responder à primeira pergunta e levantar os elementos de análise para responder às duas últimas perguntas. E, sobretudo, caracterizar um objeto ainda pouco pesquisado em termos de gestão de riscos: aquele que toca funções de sistemas setoriais e de grandes dispositivos de infraestrutura e seus limites críticos dentro do arranjo metropolitano. Existem suscetibilidades desenhadas nas localidades, entre as dinâmicas municipais e sistemas setoriais pela presença de certos elementos sistêmicos, e existem vulnerabilidades dos sistemas, internas (limites dos próprios sistemas) e externas, provocadas na interação com a escala local. Falhas em cascata, envolvendo ocorrências com efeitos intersetoriais são, em geral, pouco conhecidas, o que justificaria uma abordagem do ponto de vista urbanístico, em tese, mais abrangente.

Quais situações de análise escolher na RMSP, por que, e como escolher foram questões sempre presentes no desenvolvimento da pesquisa. Para um pesquisador não treinado em gestão de riscos, o caminho mais lógico e imediato para identificar o agravamento dos impactos por fatores associados aos riscos residuais e nas interfaces de grandes sistemas urbanos parecia ser, primeiro, avaliar quantitativamente, dentro do universo de danos e consequências causados por desastres em meio urbano, quais eventos geraram maiores consequências para, num segundo momento, avaliar se, associadas a esses eventos, existiriam questões relativas a falhas e interfaces críticas entre sistemas setoriais urbanos e suas respectivas medidas de gestão de risco.

\subsection{As informações sobre desastres}

O primeiro passo desse caminho, de buscar as bases de dados quantitativos sobre desastres, já levou a inúmeras questões metodológicas, revelando que a simplicidade da tarefa é aparente quando se trata de dados sobre ocorrências de desastres e avaliação dos riscos. Pois nas sistematizações existentes, a caracterização e tipificação 
do universo de danos e consequências são mal representadas, sendo os danos causados possivelmente o conjunto de informações menos consistentes.

Há uma série de problemas na produção das informações sobre desastres. O primeiro é relativo ao contexto de produção de informação. A subnotificação é o principal fator a ser apontado, que resulta em pouca confiabilidade e baixa consolidação de dados, exigindo tarefas de validação de informações ao se trabalhar com elas. As notícias de jornal continuam sendo uma fonte importante na alimentação dos bancos de dados sobre desastres, pois elas compensam parcialmente a ausência de notificação oficial dos eventos ou a falta de alimentação cruzada entre os agentes que produzem as notificações e os sistemas de informação. A falta de uma rede que permita fluxos de informação resulta da desarticulação entre instituições responsáveis pela resposta ao desastre e instituições que deveriam lidar com a prevenção dos riscos urbanos, e pela própria incipiência das ações de prevenção nas instituições responsáveis pelo desenvolvimento e controle urbano.

Nossos sistemas de informações em desastres também apresentam problemas na forma de disponibilização dos dados, na forma de agregação de informações e pela incompletude das séries históricas. A base de dados internacionais, EM-DAT, é uma plataforma de dados sobre desastres mantida pelo Centre for Research on the Epidemiology of Disasters (CRED), criada pela Organização Mundial de Saúde e pelo governo Belga e alimentada com informações oficiais dos diferentes países. O Brasil alimenta o EM-DAT a partir das informações do S2iD.

Conforme visto no capítulo 3, o S2iD sistematiza somente dados dos processos de reconhecimento federal de situação de emergência ou de estado de calamidade pública. Embora também tenha registros de ocorrências além dos reconhecimentos federais, não são contabilizados, e apenas oferecidos na forma de arquivos digitais de imagem. As sistematizações dos dados do S2iD foram trabalhadas pela Universidade Federal de Santa Catarina e disponibilizadas em análises por estados (com algumas desagregações por municípios, mas que não completam a série histórica da última década) nos Atlas Brasileiros de Desastres Naturais (CEPED-UFSC, 2012), e em estudos recentes sobre perdas (CEPED-UFSC, 2016), também com dados agregados por estados. Não é possível acessar banco de informações desagregadas.

Para São Paulo, existem também os bancos de dados do IPMET (Centro Meteorológico de Bauru - Unesp), baseado em informações de notícias de jornal, e uma limitação para sua utilização é o fato do lançamento da informação de ocorrência ser desmembrado por processo, sendo raros os dados mais precisos das localidades. O IPT mantém desde 1988 um banco de dado de mortes por deslizamentos, catalogando eventos de movimentos de massa com fatalidade a partir de notícias de jornal. As limitações para utilização desse banco é o corte pelo tipo de processo.

O Cadastro de Eventos do Instituto Geológico (IG) mostrou-se o banco de dados que oferecia melhores condições para um estudo quantitativo na Região Metropolitana de São Paulo. É um banco de dados de ocorrências em todo o Estado, alimentado tanto por fontes de notícias como por dados do Sistema SIDEC, de acesso restrito. Contém informações desde 1994 até 2018, cadastradas por bacia hidrográfica e município, o que facilita a filtragem para a RMSP, e por tipos de ocorrência. Além desse Cadastro, o 
IG atualizou recentemente as informações de localização das ocorrências, permitindo o trabalho georreferenciado com dados, mas nessas informações mais recentes constam atualizações somente do período 1993-2013 (o que deixaria de fora períodos de dois dos estudos de caso propostos), e não contempla o município de São Paulo (que estava fora do escopo de contratação). Os dados de ocorrência do COMDEC MSP são georreferenciados e poderiam complementar os do IG, mas o período de abrangência (2013-2017) não permite uma série histórica contínua. Por fim, o uso exclusivo dos dados dos atendimentos feitos pelo PPDC não cobririam uniformemente toda a RMSP, e estão incorporados no Cadastro do IG.

\section{Quadro 05. Síntese dos sistemas de informações em desastres}

\begin{tabular}{|c|c|c|c|}
\hline $\begin{array}{l}\text { Sistema } \\
\text { ou Banco } \\
\text { de dados }\end{array}$ & Abrangência & Fontes & $\begin{array}{l}\text { Limitações de uso para esta } \\
\text { pesquisa }\end{array}$ \\
\hline EM-DAT & Global & $\begin{array}{l}\text { Informações oficiais } \\
\text { dos países. O Brasil } \\
\text { alimenta com dados } \\
\text { do S2iD }\end{array}$ & As mesmas do S2iD. \\
\hline S2iD & $\begin{array}{l}\text { Brasil. Informações } \\
\text { agregadas por ano, } \\
\text { estado e município. }\end{array}$ & $\begin{array}{l}\text { Processos de } \\
\text { reconhecimento } \\
\text { oficial. Outras } \\
\text { entradas (notícias e } \\
\text { outros documentos) } \\
\text { não sistematizadas. }\end{array}$ & $\begin{array}{l}\text { Reconhecimentos oficiais } \\
\text { apresentam série histórica } \\
\text { desde } 2003 \text {, mas não contém } \\
\text { informações sobre danos. } \\
\text { Informações sobre danos em } \\
\text { relatórios por municípios, mas } \\
\text { somente a partir de } 2013 \text {. } \\
\text { Informações sobre ocorrências } \\
\text { além dos processos de } \\
\text { reconhecimento oficial não } \\
\text { lançados em base de dados } \\
\text { (somente arquivos pdf). }\end{array}$ \\
\hline IPT & Estado de SP & Notícias de Jornal & $\begin{array}{l}\text { Somente para eventos com } \\
\text { óbitos, e processos de } \\
\text { deslizamentos }\end{array}$ \\
\hline IPMET & Estado de SP & Notícias de Jornal & $\begin{array}{l}\text { Informações sobre localidades } \\
\text { é incipiente }\end{array}$ \\
\hline IG & Estado de SP & $\begin{array}{l}\text { Notícias de Jornal, } \\
\text { IPMET, SIDEC }\end{array}$ & $\begin{array}{l}\text { Boa aplicação para a pesquisa } \\
\text { na RMSP (classificação por } \\
\text { bacia e município, grande } \\
\text { variedade processos nas } \\
\text { ocorrências cadastradas, série } \\
\text { histórica mais completa) }\end{array}$ \\
\hline
\end{tabular}




\subsection{As exigências do objeto desta pesquisa}

Além dos aspectos tratados anteriormente, há complexidades metodológicas relativas ao objeto da pesquisa. Enquanto os procedimentos usualmente utilizados (e normatizados) em gestão de riscos propõem a identificação e conhecimento dos riscos a serem gerenciados dentro de um sistema (um universo determinado pelo tipo de ameaça, por delimitação espacial ou por escopo de atividade sob risco, no caso de uma organização setorial ou empresa), para esta pesquisa sobram questionamentos: quando o objeto trata dos efeitos de riscos residuais, nas interfaces e lacunas entre sistemas, como observar o universo entre sistemas? Qual o ponto de partida, qual recorte? A delimitação metropolitana, por si, é suficiente para definir um sistema integral a ser analisado? A metrópole deve ser entendida como uma soma de porções territoriais diversas, seja de delimitações administrativas, seja de bacias e sub-bacias, conforme sugere a Lei Federal? Ou a metrópole deve ser entendida como uma composição de sistemas diversos? Os sistemas setoriais a serem analisados alteram os limites metropolitanos? De quais sistemas se trata?

Bacias e sub-bacias certamente oferecem uma noção mais clara de territorialidade associada a riscos de inundação e de secas, e mesmo para a gestão de riscos geológicos. Mas não dão conta de outras interconexões, como efeitos de secas e cheias distantes, ou como as do sistema elétrico, seja nos arranjos de distribuição e transmissão, seja nas interferências hídricas - as vazões necessárias - para sua geração. As falhas em cascata e efeitos de segunda ordem entre sistemas tendem a definir territorialidades distintas daquelas já estabelecidas para a gestão setorial.

O objeto - definido como o agravamento das situações de desastre pelo encadeamento entre riscos menores ou externos a diferentes sistemas metropolitanos (riscos residuais e riscos na interface), e/ou pela falha de seu gerenciamento - é necessariamente confrontado com uma qualidade inerente aos métodos quantitativos e intrínseca à organização de dados numa tabulação: a segmentação em categorias.

Ao se organizar informações por uma classificação prévia de causas e/ou consequências - seja essa classificação a codificação Cobrade ${ }^{75}$ ou qualquer outro critério que se estabeleça, e entendendo por causa e consequência a ameaça e o dano, e não as condições de vulnerabilidade - tem-se como resultado a segmentação de um contexto. A leitura das consequências geradas por um evento pode ficar muito simplificada, dificultando a identificação de possíveis casos-problema de interface e dos nexos causais. Por exemplo, as situações em que um único fator gera outros fatores e desencadeia variadas e amplas consequências, seriam contextos que poderiam indicar problemas de interface, mas há casos em que seu registro é segmentado em várias entradas por categoria de evento, local ou mesmo data, e, a depender do filtro aplicado às informações, a relação entre fator inicial e impacto decorrente se perde: há uma soma de registros, e cortes de entrada podem negligenciar conexões importantes a serem observadas. Há casos em que as consequências são, ao contrário, aglutinadas em uma única entrada sem maiores pistas para desagregação: nesse caso, a mera contabilização do evento (em um registro) não representa bem sua amplitude. Nos dois

\footnotetext{
${ }^{75}$ Conforme apresentado na Parte 1, cap. 1.2.1
} 
casos - e é comum um banco de dados apresentar ao mesmo tempo e aleatoriamente os dois tipos de critério de tabulação do registro de ocorrência - procurar pela evidência de casos de interfaces problemáticas a partir da quantidade de registros de entrada, conexões recorrentes, ou pela magnitude e/ou amplitude das consequências geradas, torna-se uma tarefa que exige muitas mediações, pois não é possível fixar as variáveis de entrada. Tudo varia: o intervalo e período (tempo), a tipificação da causa, o local (espaço), os tipos de consequências. Há, também, nos registros, uma mistura de entradas classificadas ora por ameaças (causas), ora por efeitos causados (consequências).

São quatro as variáveis que estão presentes com mais regularidade nas diferentes fontes de informação sobre desastres: tempo (agregadas por ano ou abertas por data do evento); espaço (em agregações por estados, municípios ou por pontos de ocorrência); tipo de ocorrência (em geral, seguindo a grande classificação Cobrade); número de mortes. Número de desabrigados, desalojados e afetados não é uma informação cujo registro é uniforme ou redundante, nem é facilmente trabalhável nos diferentes bancos de dados. A partir dessa constatação, e optando por utilizar o banco de dados mais recente e com maior viabilidade para aplicação de filtros (IG), se tentou agregar e desagregar informações, exercício que permitiu desdobrar algumas análises gerais sobre o perfil dos riscos na RMSP (apresentadas no capítulo 5).

O trabalho com o cadastro de eventos revelou mais questões metodológicas para o objeto de interesse desta pesquisa. Com relação a variável tempo, surgem duas questões para que os contornos da amplitude e magnitude das consequências e a identificação de contextos de riscos de interface sejam bem definidos:

- como saber se dois eventos de mesma data são eventos isolados ou interrelacionados? O que excluir e incluir na contagem de um mesmo intervalo de tempo depende da compreensão das interações entre eventos (causa-causa) além da relação causa-consequência, interações que ocorrem tanto no tempo como no espaço. Depende de reestabelecer nexos no tempo e no espaço, onde deve haver um olhar técnico, de avaliação qualitativa.

- onde começar e terminar um intervalo de análise, como estabelecer recortes dos registro de um evento que é contínuo, mas está segmentado em várias entradas? Nem sempre o início do evento deflagrador define bem a data que deve marcar o início de uma análise integrada, pois pode haver, entre os dados, fatores pré-existentes predisponentes, observáveis ou não, que podem estar associados à geração de consequências, e que deveriam ser incluídas na quantificação de danos. A depender do caso, o que se inclui pode até atribuir nova magnitude ao problema. Como método e regra geral, qualquer evento deflagrador (chuva, abalo sísmico, ciclone) ocorrido em um dado intervalo é ainda uma suposição de causa não submetida à análise qualitativa de risco: somente ao se reestabelecer os nexos, é possível identificar se ele é agravante, decorrência, ou deflagrador de fato. Pode-se concluir que uma ameaça registrada como geológica é, na verdade, um efeito de uma ameaça tecnológica. O mesmo raciocínio pode ser feito para os eventos posteriores, com interferências na magnitude e amplitude do caso, exigindo inclusão de outras 
situações. É preciso considerar que se um intervalo de tempo é definido à priori, pode sofrer variação no decorrer da análise.

Fixar a variável espaço a uma delimitação para a qual se analisa um contexto de ameaças, suscetibilidades e vulnerabilidades (diagnóstico das componentes do risco), e as soluções de mitigação em uma área piloto, é um recurso utilizado por alguns métodos de gestão de risco para áreas críticas (o método APPEL ${ }^{76}$, por exemplo), sobretudo para avaliar a incidência de ameaças múltiplas. Podem ser muito coerentes para a gestão de riscos locais, pois realizam diagnósticos e soluções possíveis a um determinado espaço físico. No entanto, fixar a localidade pode ser uma das variáveis mais traiçoeiras para proceder às análises quantitativas e qualitativas de risco do objeto desta pesquisa, que procura por riscos na interação entre sistemas e nas funções comuns (FPICs). Pois o simples fato de identificar resultados expressivos (recorrentes) de eventos e consequências por determinado bairro, ou mesmo município, pode estabelecer cortes arbitrários que excluem inter-relações estabelecidas pelo funcionamento regional das estruturas urbanas e sistemas setoriais integrados metropolitanos e macro metropolitanos - energia, água, abastecimento, trânsito, mobilidade, habitação - e os possíveis riscos e oportunidades encadeados que se estabelecem entre eles. Ou seja, fixar a localidade pode induzir à falsa compreensão de vulnerabilidades e ameaças localizadas, que, na verdade, podem estar integradas e inter-relacionadas.

Ainda, e por outro lado, nem sempre um evento e as consequências geradas num mesmo município têm o mesmo processo desencadeador, ou estão inter-relacionados. Podem ocorrer no mesmo limite espacial, mas serem eventos independentes. Somente uma análise qualitativa que busque religar os nexos dos eventos e identificar os elementos que definem o funcionamento de uma localidade - portanto, com uma visão ampla e com delimitação física aberta, de acordo com funções relacionadas - pode estabelecer a real abrangência espacial de um evento, sua amplitude e magnitude. Voltaremos a essa questão metodológica nas análises qualitativas, ao identificar problemas de risco metropolitanos cuja abrangência espacial extrapola a própria delimitação metropolitana.

Outra forma de análise, de fixar a variável do tipo de ocorrência, consiste no método mais convencional das avaliações de risco. Parte-se de um processo relativo a um campo do conhecimento, uma disciplina que define o que é externo e interno a seu universo de perícia e controle, para os quais são dirigidas soluções igualmente categorizadas. A partir dessa visão, algumas conclusões sobre consequências e danos recorrentes em função dos tipos de processos já estão consolidadas no campo de gestão de riscos. No Estado de São Paulo, riscos hidrológicos (enxurradas, alagamentos, inundações) e riscos geológicos (erosões e movimentos de massa) caracterizam o perfil de riscos no Estado, igualmente representados, com maior intensidade, na Região Metropolitana de São Paulo. Nesse perfil de riscos ${ }^{77}$, os riscos

\footnotetext{
${ }^{76}$ Abrodado na parte 1, Capítulo 3.2.1

77 Embora estas conclusões sejam apresentadas no Atlas de Desastres, na formulação da política e em divulgações científicas, não é possível identificar nas publicações e sistemas a base de dados desagregada, nem dados das consequências (perdas e danos) ou como elas se relacionam com os tipos de eventos. A
} 
geológicos estabelecem alta correlação com o número de óbitos, enquanto que os riscos hidrológicos, maior correlação com o número de desalojados e desabrigados. As mortes causadas por processos hidrológicos, em geral, estão relacionadas às enxurradas, quando a velocidade e vazão das águas se tornam um fator de periculosidade.

Mas para se trabalhar com o objeto em questão, quais processos interessam? Naturais ou tecnológicos? Se naturais, geológicos, hidrológicos, meteorológicos ou climatológicos? Como enquadrar os agravantes em questão, no caso, as atividades produtivas e operacionais das infraestruturas urbanas? Tais riscos residuais são tecnológicos? Quais bancos de informações estão disponíveis, em quais prestadores pesquisar estatísticas de sinistros e falhas nas infraestruturas? CETESB, DAEE, EMAE, Sabesp? Cabe lembrar que o Atlas dos desastres e os sistemas de informação em construção recente tratam, apenas, dos desastres naturais stricto sensu ${ }^{78}$. Interessa segmentar as análises e escopo deste trabalho por processos? O ponto de vista do urbanismo acrescentaria algo de novo e relevante se permanecesse na análise segmentada por tipo de ocorrência ou setor? Segmentado, seria uma contribuição melhor que as análises de especialistas das demais disciplinas relacionadas com a gestão de risco podem oferecer?

É quase certo que não. A visão de um urbanista acrescenta na medida em que busca pela integração. Pois o desastre não é sempre apenas natural (ainda que se considere a atividade antrópica na definição dos cenários de risco de desastres naturais) ou apenas tecnológico. Na maioria das vezes (e os eventos da Região Serrana do Rio de Janeiro, por exemplo, são exceção) tende a ser uma combinação entre os dois, e é a combinação entre áreas que interessa a um olhar urbano, e que, inclusive, alimenta os debates entre os conceitos de mudança climática ${ }^{79}$ e mudança ambiental. As perguntas persistem e se acumulam.

Uma das variáveis de informações sobre consequências mais consistente é o número de mortes, seja porque há notificação a partir das defesas civis ou porque são casos que recebem maior atenção da imprensa. As mortes representam inquestionável indicador de impacto do evento, e a gravidade do impacto é um critério importante ao objeto desta pesquisa, que procura identificar se riscos residuais, de interface entre sistemas e falhas em seu gerenciamento, são agravantes importantes em situações de risco, e como agravam essas situações. A interpretação da abrangência dos impactos (se locais ou regionais - metropolitanos ou extra metropolitanos) foi possível pelas

\footnotetext{
ausência de dados trabalháveis impede de retraçar o caminho que levou a essas conclusões, e sugere que são conclusões oriundas de análises qualitativas, não apenas quantitativas.

${ }^{78}$ Conforme apresentado no capítulo 3.2.1, sobre a construção das informações sobre riscos ambientais urbanos no sistema SIM da Emplasa, há a discussão de associar informações de áreas contaminadas, disponíveis na plataforma DataGeo a partir de dados da CETESB. Mas não houve incorporação de outros riscos tecnológicos.

${ }^{79}$ As discussões sobre mudança climática têm uma visão mais voltada à transformação das ameaças. Mudança ambiental (SUGUIO, 2010) é um termo que busca pelas interações entre a transformação das ameaças e do meio físico, da geologia do quaternário. Aos estudos urbanos, o mais interessante seria desenvolver uma 'ciência dos efeitos no urbano', uma avaliação sistemática das consequências das ameaças nos territórios e a relação com as formas de organização existentes.
} 
análises qualitativas e descrição dos casos, com a formulação de matrizes de risco com discriminação destas abrangências.

O trabalho sobre o banco de dados do IG tinha como intuito identificar e levantar as situações de maior impacto para análise qualitativa posterior de possíveis problemas de falhas e interfaces, e respondeu apenas parcialmente a esta necessidade, deixando claro, como discutido pelas questões metodológicas colocadas anteriormente, que a segmentação quantitativa de ocorrências mantém algumas situações críticas ocultas. Outro intuito foi o de definir o contorno geral dos riscos na metrópole, construir um perfil de riscos metropolitanos a partir de dados brutos, e o cenário de contexto para os estudos de caso que mostraram necessidade de serem estabelecidos a priori.

Para trabalhar o banco de dados do IG a partir das 4 variáveis mencionadas (tempo, espaço, tipo de ocorrência, mortes), foi possível levantar 4 critérios para analisar a variação de impacto de períodos e eventos:

1. Quantidade (absoluta): de registros de ocorrências e de mortes, com seleção de piores anos e piores dias, piores localidades e caracterização por tipos de ocorrências.

2. Dispersão espacial dos eventos: a amplitude ou extensão dos efeitos (quantidade de localidades com registro de ocorrências em um período) e a magnitude ou intensidade dos efeitos (quantidade de registros de ocorrência em uma mesma localidade em um período) puderam ser observadas a partir da distribuição espacial das ocorrências em dado período, permitindo identificar anos e dias piores, ou críticos.

3. Dispersão temporal dos eventos: a partir da distribuição temporal de registros nas localidades, foi possível identificar a criticidade de localidades $^{80}$ sob situações de ocorrências crônicas (recorrentes) ou agudas (concentradas), ou as duas qualidades simultaneamente.

4. A apreciação do indicador de letalidade dos eventos - relação entre mortes e total de registros de ocorrências - permitiu melhor resposta para as variáveis de tempo (piores anos e dias). Em termos espaciais, permitiu avaliar quão relativo é o peso do município de São Paulo no arranjo metropolitano, e comparar com outros indicadores que permitam compreender essa relativização.

A partir do trabalho com os dados e das reflexões metodológicas, foi possível concluir que a análise quantitativa permite apenas uma aproximação preliminar do objeto. Com todas as ressalvas já feitas, a análise pode indicar apenas anos e dias mais críticos em

\footnotetext{
${ }^{80}$ Nas análises de concentração espacial e temporal, entende-se por localidade o limite administrativo dos municípios, pois esta era a menor desagregação espacial constante dos dados brutos utilizados. Há informações mais detalhadas de localidades (bairros, ruas), mas não é uma informação aplicada uniformemente a todas as entradas, e não permitiria uma espacialização mais precisa. O maior problema deste recurso é a consideração do Município de São Paulo como uma única localidade, sem subdivisão em sub-regiões. A tentativa em desagregar o município de São Paulo por subprefeituras, mais comparáveis com as dimensões e dinâmicas dos outros municípios metropolitanos, mostrou-se possível e desejável, porém demandaria tempo fora do cronograma e condições de produção possíveis para esta pesquisa. Este é, sem dúvida, um ponto para desdobrar pesquisa. A relativização do peso do município de São Paulo será trabalhada parcialmente na seção 5.2.4.
} 
termos de registros de eventos e mortes; e pelas recorrências temporais, indicar algumas abrangências espaciais (por agrupamentos regionais da RMSP) que se destacam. Mas é o estudo em detalhe dos nexos entre ameaça e efeitos existentes nessas situações de destaque que permite identificar exemplares de riscos de interface, como veremos no capítulo 6 , realizado a partir de leitura contínua dos fatos noticiados. O que as reflexões apresentadas até o momento deixam claro é que a definição de situações concretas a observar deve ser simultânea, e não decorrente das análises quantitativas. A análise quantitativa pode, apenas, confirmar a validade dessas situações.

\subsection{Novo ponto de partida: definir os casos}

Como ponto de partida, foram selecionados 3 contextos que sugeriam problemas e conflitos relacionados a riscos residuais, aqui apresentados na ordem em que foram definidos ao longo da pesquisa:

1. Inundações persistentes e de longa duração no extremo leste da Região Metropolitana, e região do Jardim Pantanal no município de São Paulo, especialmente no período de 2009-2010, considerado, inicialmente, como possível risco residual das medidas de controle de macrodrenagem na barragem da Penha ${ }^{81}$, entrada da porção central da Bacia do Alto Tietê.

2. As operações de manobra para segurança do Reservatório Paiva Castro e consequências no município de Franco da Rocha e outros municípios da região Norte da RMSP em 11 e 12 de março de 2016, situação considerada inicialmente como risco residual das manobras de segurança desse ponto de afluência ao sistema hídrico metropolitano.

3. A contaminação hídrica e morte de peixes no município de Salto em 29 de novembro de 2014, gerando toneladas de resíduos neste município, considerado, inicialmente, como risco residual da operação de abertura dos descarregadores do reservatório de Pirapora do Bom Jesus, do controle hidráulico na saída da bacia de macrodrenagem na porção central da Bacia do Alto Tietê. Esta situação evidencia mais claramente os riscos e oportunidades em cadeia, com a interação entre o descarregador em Pirapora e a operação das estruturas existentes no canal do Rio Pinheiros.

A identificação da situação tempo-lugar do primeiro estudo de caso foi possível pela contextualização geral dos riscos no Estado (Atlas de desastres) e na RMSP (capítulo 5). O ano 2009-2010, e com menor intensidade, o ano 2010-11, concentram registros de ocorrências, com grande incidência na porção leste da RMSP - nos municípios de Guarulhos, Itaquaquecetuba, Mogi das Cruzes, Suzano e Ferraz de Vasconcelos, incluindo, nestes anos, municípios de pouca recorrência, como Guararema, Santa Isabel e Salesópolis. O ano é de grande impacto para toda a metrópole, mas, neste período, concentra registros nessa região, que apresenta ocorrências recorrentes também em períodos em que houve menor impacto. A maior quantidade de ocorrências

\footnotetext{
${ }^{81}$ O papel que a barragem desempenhou no evento não foi um fator agravante, como será melhor explicado nos capítulos 6 e 7.
} 
na metrópole no ano de 2009-2010 está no município de São Paulo, espalhadas por toda a cidade e com alguma concentração nas zonas oeste e leste ${ }^{82}$.

O segundo estudo de caso foi selecionado a partir da leitura do Boletim do Grupo de Articulação de Ações Executivas (GAEE), formado no âmbito do PDN, e do último Informe Técnico ${ }^{83}$ (n. 04) produzido pelo mesmo Grupo. Do grupo de 4 documentos disponibilizados pela Defesa Civil do Estado como produtos do PDN (Programa Estadual de Prevenção a Desastres Naturais), este era o único relativo a casos na RMSP. O documento relata a ocorrência de chuva extrema na região Norte da RMSP em março de 2016, e as situações geológicas e hidrológicas decorrentes com grande número de óbitos. Apesar do documento não mencionar as medidas operacionais adotadas na manobra do Reservatório Paiva Castro, que agravou a situação de inundação no município de Franco da Rocha, ao se investigar o caso constatou-se que a medida foi adotada na mesma data, reiterando o interesse e relevância dessa data e lugar como caso para estudos de riscos residuais. Este evento também motivou algumas ações institucionais posteriores, como o desenvolvimento de Planos de Ação Emergencial (contingências) para Inundações em Franco da Rocha e para o Sistema Cantareira (disponibilizados pela Defesa Civil do Estado em seu site na categoria "planos"), que serão abordados no desenvolvimento do caso. O ponto de partida para a análise foi buscar por possíveis agravos e interações entre as ocorrências geológicas e hidrológicas, apontadas no documento, e as operações de manobra, ou outros fatores intervenientes relativos aos dispositivos do sistema hídrico e de produção de água implantados nas localidades atingidas.

O terceiro estudo de caso foi de mais difícil detecção, com presença discreta no universo de notícias e em período (ano) de ocorrências que não é o de maior impacto. Para sua seleção, foi importante o apoio na revisão bibliográfica, a partir de artigo técnico e científico da Revista Saneamento e Engenharia ${ }^{84}$. Este artigo confirma os dois casos anteriores ( 1 e 2) como localidades problemáticas ${ }^{85}$, com interfaces mal resolvidas entre sistemas hídricos, e aponta uma nova região para estudo: a região oeste, fazendo referência à conflito que se estabelece entre a porção central da bacia e o ponto de controle hidráulico na saída da BAT, em Rasgão e Pirapora, com problemas de inundação na região de Itu e dependência da capacidade de reversão do rio Pinheiros:

\footnotetext{
${ }^{82}$ Foi feita contagem das ocorrências para as diferentes regiões do município de São Paulo para o ano crítico de 2009-10. A análise das informações revelou que há grande incidência de registros em vias de grande circulação, aumentando a quantidade de entradas para a região Oeste do município. Este possível viés dos registros foi mais um dos motivos para considerar que a desagregação das informações de ocorrência em São Paulo para reintegrar às sub-regiões metropolitanas contíguas poderia trazer distorções às análises espaciais. Para este ano foram contadas: 82 ocorrências na Zona Leste, 97 na Zona Sudoeste, 41 na Zona Sudeste, 59 na Zona Sul e 65 no Centro.

${ }^{83}$ Foram produzidos apenas 4 informes técnicos pelo GAEE, o primeiro refere-se a ocorrências em Cubatão, o segundo em São Sebastião, o terceiro trata de procedimentos para atendimento habitacional emergencial e o quarto, dos eventos na Região Norte da RMSP.

${ }^{84}$ COSTA, J.; NUCCI, N. e SILVA, R.T, (2012). Recursos hídricos, saneamento e gestão metropolitana: os novos desafios. Revista Engenharia, n. 609, 2012.

${ }^{85}$ Embora o artigo seja de 2012, anterior ao evento a ser analisado na manobra do Paiva Castro, ele já aponta a região norte metropolitana como um ponto crítico para controle de inundações (página 107).
} 
“Essas vazões são referências de planejamento e projeto tanto para as medidas de detenção a aplicar nas bacias contribuintes como para a capacidade nominal da calha do Rio Tietê ao longo da Bacia. Não obstante a capacidade da calha atingir quase $1500 \mathrm{~m} 3 / \mathrm{s}$ em Pirapora, as vazões máximas transitadas para 0 Médio Tietê/Sorocaba não devem ultrapassar $700 \mathrm{~m}^{3} / \mathrm{s}$ sob pena de inundar Itu e região. A diferença fica retida nos reservatórios Rasgão e Pirapora, para descarga diferida, nos limites admissíveis a jusante. Configura-se, nesses termos, uma relação também delicada no extremo oeste da Bacia (e da RMSP), que aumenta a criticidade no trecho central." (SILVA et al, 2012: 106).

$\mathrm{Na}$ busca por notícias de ocorrências em Itu e Região, foi localizado o evento selecionado em Salto, associado à operação em Pirapora. Apesar de Salto não ser um município dentro dos limites da RMSP, o interesse é investigar interações entre ocorrências e medidas tomadas na RMSP que possam ter interferência mesmo em limites além da metrópole.

O artigo que conduziu à seleção do caso propõe a análise da desarticulação entre sistemas, e das potencialidades no desenvolvimento de novas articulações sistêmicas. Importante destacar o que, desta visão, pode ser incorporado às discussões sobre gestão de riscos e governança de riscos: existem vulnerabilidades dos sistemas urbanos de infraestrutura, sobretudo da articulação entre eles, que precisam ser incorporadas às análises de vulnerabilidades e de riscos urbanos, e os atores envolvidos na gestão e operação dessas estruturas devem participar da governança dos riscos.

A partir dessa abordagem e da busca de uma visão sistêmica para o desenvolvimento de análises de riscos, que alcancem riscos de interface, foi possível sintetizar esquematicamente a posição de cada um dos casos-problema no sistema hídrico metropolitano, não só considerando a função de macrodrenagem, mas algumas interferências funcionais entre os sistemas de produção de água (Cantareira) e de qualidade da água (as questões de poluição hídrica), desdobradas em análises sobre mobilidade e sistema habitacional.

Assim, o caso 1 está localizado no ponto da BAT que exerce o controle hidráulico de montante da porção central da bacia, cujo funcionamento crítico pode ter interferências com a Estação de Tratamento de esgotos de São Miguel e conflitos na forma de ocupação da várzea (sistema habitacional). O caso 2 trata de um problema de macrodrenagem municipal, com agravamento da gestão de risco local quando associado a contingências da estrutura final de reservação do maior sistema produtor de água da RMSP, um ponto de afluência de água ao sistema hídrico metropolitano. $\mathrm{O}$ caso 3 está localizado no ponto de controle hidráulico na saída da BAT, e seu funcionamento deve ser articulado com o pleno funcionamento da reversão do canal do Pinheiros em períodos de chuva, para alívio da vazão na calha do Tietê. Não se trata, entretanto, de um corte para estudo de casos no sistema hídrico metropolitano ou por categoria de ocorrências hidrológicas, pois o interesse da pesquisa é identificar possíveis interferências entre categorias de risco que possam definir maior magnitude de consequências. 

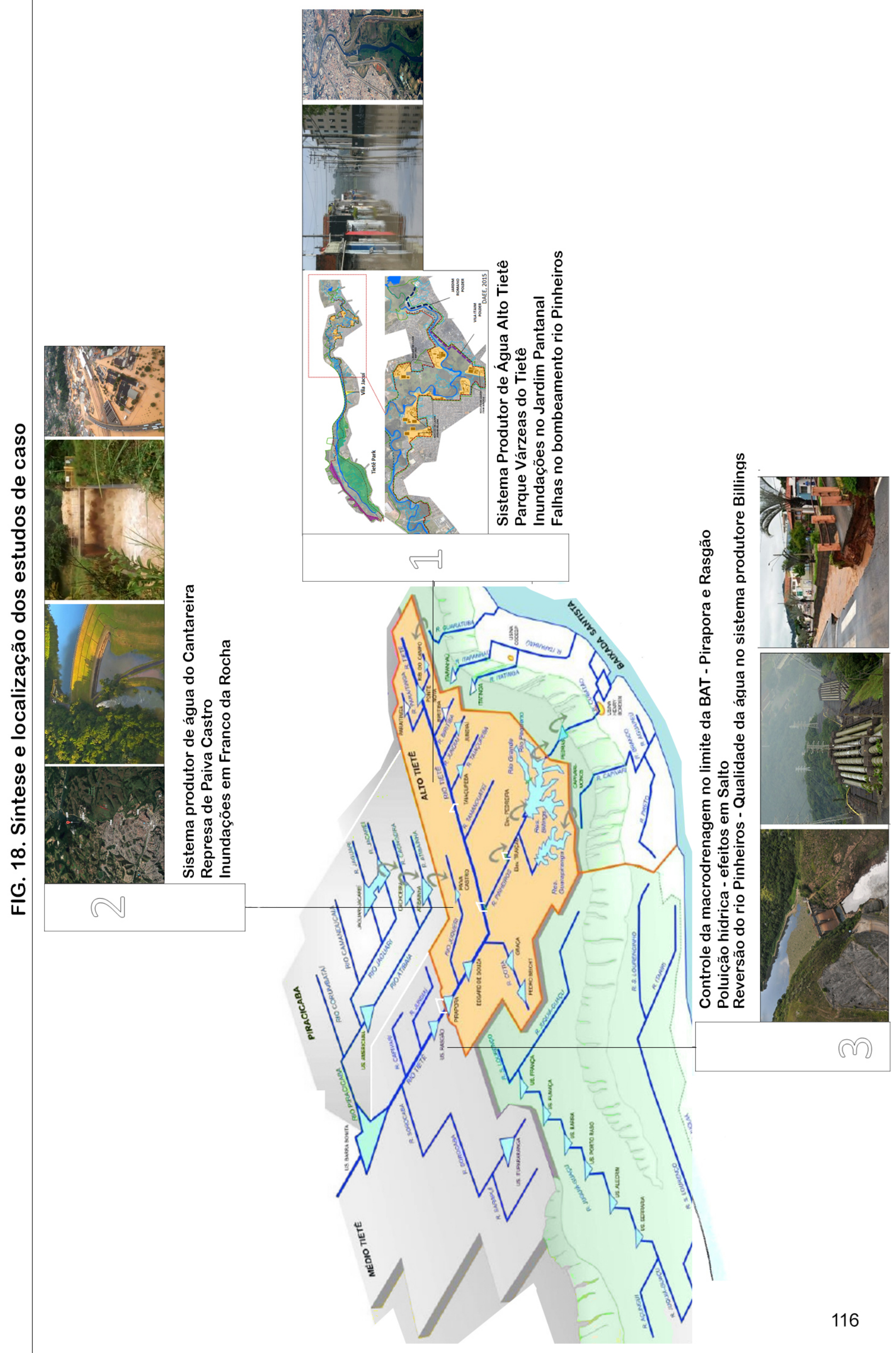


\section{Cap. 5 - Contexto geral dos riscos metropolitanos: análise quantitativa das ocorrências na RMSP a partir do Cadastro Geral do Instituto Geológico - 2006-2017}

\subsection{Aspectos gerais da contagem e organização dos dados}

A opção por utilizar o banco de dados "Cadastro de Eventos Geodinâmicos e Desastres" do Instituto Geológico se deu por esta ser uma fonte de informações que incorpora os registros de outros bancos já levantados (como do IPMET e SIDEC, da CEDEC, de acesso restrito) e é complementado por alimentação diária de notícias de jornal, com entradas consolidadas até o ano de 2017. Por este cadastro, foi possível proceder à análise para o período da última década (11 anos), de 2007 a 2017, para toda a RMSP.

Recentemente, em dezembro de 2017, o Instituto Geológico lançou um cadastro mais detalhado, com as entradas validadas, classificação de confiabilidade, e complementações e detalhamentos de informações feitas para diversos municípios através de administrações ou setores de defesa civil municipais. Esses dados são a fonte dos mapeamentos de vulnerabilidade e risco lançados na mesma data. No entanto, a contratação para realização deste cadastro detalhado exclui o município de São Paulo, o que exigiria mesclar informações não uniformes para analisar toda a RMSP. Por isso, para as análises de dados desta seção, a opção foi utilizar o cadastro geral, e não o cadastro detalhado.

A primeira contagem (quadro 06 , a seguir) e análise foi feita com base: nos municípios dos limites metropolitanos, no ano calendário (de janeiro a dezembro), e pelas 4 entradas de tipo de ocorrências: geológicos, hidrológicos, meteorológicos e climatológicos. Na classificação Cobrade, geológicos envolvem movimentos de massa, erosões, emanação vulcânica e terremoto; hidrológicos envolve inundações, enxurradas e alagamentos; meteorológicos envolve sistemas de grande escala (ciclones, frentes frias), tempestades, temperaturas extremas e climatológicos envolve estiagem, seca, incêndio florestal e baixa umidade do ar. No cadastro analisado, as entradas de ocorrências geológicas referem-se a variados processos de movimentos de massa e erosões (deslizamento, erosão continental, subsidência e colapso, corrida de massa, erosão de margem fluvial; queda, tombamento e rolamento); as entradas hidrológicas a alagamentos, inundações e enxurradas; as entradas meteorológicos a raios, granizos, chuvas intensas e vendavais, temporal e tornado; e as entradas climatológicas referemse a estiagem, seca, baixa umidade, ondas de calor, incêndio florestal.

A análise preliminar já permite indicar anos com maiores impactos, ou críticos: considerando a quantidade de registros de ocorrências, os anos de 2010 e 2015 têm maior expressividade; para o total de mortes, o ano crítico é 2009, seguido de 2016; considerando a letalidade dos eventos, o ano de 2009 é o que teve, proporcionalmente, ocorrências mais graves (mais ocorrências com mortes), seguido de 2016. O ano de 2016 está em primeiro em termos de gravidade (ocorrências com maior proporção de mortes) de ocorrências geológicas, mas o ano 2009 houve mais que o dobro de ocorrências com mortes por este motivo. 


\begin{tabular}{|c|c|c|c|c|c|c|c|c|c|c|c|c|c|c|c|c|c|c|c|c|c|c|}
\hline & \multicolumn{12}{|c|}{ Registros } & \multicolumn{6}{|c|}{ letalidade das ocorrências } & \multicolumn{4}{|c|}{ taxas do tipo de ocorrência } \\
\hline & total de registro (a) & & $\begin{array}{l}\text { geológico } \\
\text { RMSP (b) }\end{array}$ & $\begin{array}{l}\text { hidrológico } \\
\text { RMSP (c) }\end{array}$ & $\begin{array}{l}\text { Meteorológico } \\
\text { RMSP (d) }\end{array}$ & $\begin{array}{c}\text { climatológico } \\
\text { RMSP (e) }\end{array}$ & $\begin{array}{l}\text { mortes totais } \\
\text { (f) }\end{array}$ & & $\begin{array}{c}\text { morte } \\
\text { geo }(g)\end{array}$ & $\begin{array}{l}\text { morte } \\
\text { hidro (h) }\end{array}$ & $\begin{array}{l}\text { morte } \\
\text { met (i) }\end{array}$ & $\begin{array}{l}\text { morte } \\
\operatorname{clim}(j)\end{array}$ & \multicolumn{2}{|c|}{$\begin{array}{l}\text { taxa morte total } \\
(f / a)\end{array}$} & $\underset{\substack{\text { tx morte geo } \\
(\mathrm{g} / \mathrm{b})}}{\mid}$ & $\mid \begin{array}{c}\text { tx morte hidro } \\
(\mathrm{h} / \mathrm{c})\end{array}$ & 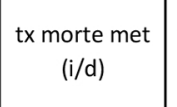 & $\begin{array}{c}\text { tx morte clim } \\
\text { (i/e) }\end{array}$ & $\left|\begin{array}{l}\text { taxa ocorrências } \\
\text { geológicas }(b / / 2)\end{array}\right|$ & $\begin{array}{c}\text { taxa ocorrências } \\
\text { hidrológicas (c/a) }\end{array}$ & $\begin{array}{l}\begin{array}{l}\mathrm{t} \times \text { ocorr } \\
\text { met }(d / \mathrm{d}) \mathrm{a}\end{array} \\
\text {. }\end{array}$ & $\begin{array}{l}\text { tx ocorr } \\
\text { clim (e/a) }\end{array}$ \\
\hline 2017 & $\square$ & 254 & & 115 & & & 枹 & 11 & 2 & 3 & & 0 & 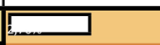 & $2,76 \%$ & $2,86 \%$ & $2,61 \%$ & $8,70 \%$ & $0,00 \%$ & $27,56 \%$ & $45,28 \%$ _ & $27,17 \%$ & $0,00 \%$ \\
\hline 2016 & {$[5$} & 545 & 35 & 257 & 241 & $12 \mid$ & - & 35 & 22 & 5 & 4 & 4 & & $6,42 \%$ & & $1,95 \%$ & $1,66 \%$ & $33,33 \%$ & $6,42 \%$ & $47,16 \%$ & $44,22 \%$ & $2,20 \%$ \\
\hline 2015 & & 647 & ${ }^{49}[$ & 365 & 231 & & $\square$ & 16 & 10 & 1 & 5 & 0 & $\square$ & $2,47 \%$ & $20,41 \%$ & $0,27 \%$ & $2,16 \%$ & $0,00 \%$ & $7,57 \%$ & $\quad 56,41 \%$ & $35,70 \%$ & $0,31 \%$ \\
\hline 2014 & 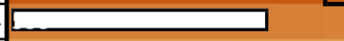 & 541 & 37[ & 345 & 159 & & $\square$ & 15 & 1 & 5 & 9 & 0 & 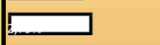 & $2,79 \%$ & $2,70 \%$ & $1,45 \%$ & $5,66 \%$ & $0,00 \%$ & $6,88 \%$ & $64,13 \%$ & $29,55 \%$ & $0,00 \%$ | \\
\hline 2013 & 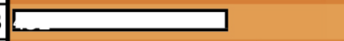 & 458 & $39^{2}$ & 292 & 116 - & & $\square$ & 14 & 6 & 4 & 4 & 0 & $\equiv$ & $3,10 \%$ & $15,38 \%$ & $1,37 \%$ & $3,45 \%$ & $0,00 \%$ & $8,63 \%$ & $64,60 \%$ & $25,66 \%$ & $2,43 \%$ \\
\hline 2012 & & 522 & 50 & 319 & 133[ & & a & 6 & 1 & 0 & 3 & 0 & $\square$ & $1,17 \%$ & $2,00 \%$ & $0,00 \%$ & $3,76 \%$ & $0,00 \%$ & $9,73 \%$ & $62,06 \%$ & $25,88 \%$ 口 & $3,89 \%$ \\
\hline 2011 & 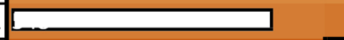 & 572[ & 911 & 352 & 128 & & & 27 & 21 & 3 & 3 & 0 & & $4,93 \% \mathrm{~L}$ & $23,08 \%$ & $0,85 \%$ & $2,34 \%$ & $0,00 \%$ & $16,61 \%$ & $64,23 \%$ & & $0,18 \%$ \\
\hline 2010 & 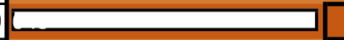 & 660 & 80 & 430 & 149 & & $\square$ & 25 & 20 & 3 & 2 & 0 & $\square$ & 3,89\% & $25,00 \%$ & $0,70 \%$ & $1,34 \%$ & $0,00 \%$ & $12,44 \%$ & $66,87 \%$ & & $0,16 \%$ \\
\hline 2009 & 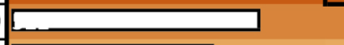 & 531 & 83 & 352 & 94 & & & 45 & 24 & 11 & 10 & 0 & & $8,62 \%$ & $28,92 \% 6$ & $3,13 \%$ & $10,64 \%$ & $0 \%$ & $15,90 \%$ & $\frac{67,43 \%}{1}$ & $18,01 \%$ & $0,38 \%$ \\
\hline 2008 & $\square$ & $423^{2}$ & 12 & 310 & 89[ & & & & & 2 & 4 & 0 & $\square$ & $1,65 \%$ & $8,33 \%$ & $0,65 \%$ & $4,49 \%$ & $0,00 \%$ & $2,82 \%$ & 72,94\% & $20,94 \%$ & $2,82 \%$ \\
\hline 2007 & $\square$ & 242 & 11 & 163 & 50 & & $\square$ & 14 & 0 & 3 & 11 & 0 & & $5,81 \%$ & $0,00 \% \Gamma$ & $1,84 \%$ & $18,64 \%$ & $0,00 \%$ & $4,56 \%[$ & $67,63 \%$ & $24,48 \%$ & \begin{tabular}{|l|}
$3,73 \% \%$ \\
\end{tabular} \\
\hline & 5395 & 5395 & $\begin{array}{r}557 \\
1030 \%\end{array}$ & $\begin{array}{r}33000 \\
61717 \%\end{array}$ & $\begin{array}{r}14468 \\
2721 \%\end{array}$ & & & & & & & & & & & & & & & & & \\
\hline
\end{tabular}

total de ocorrências por ano civil

mortes totais por ano civil

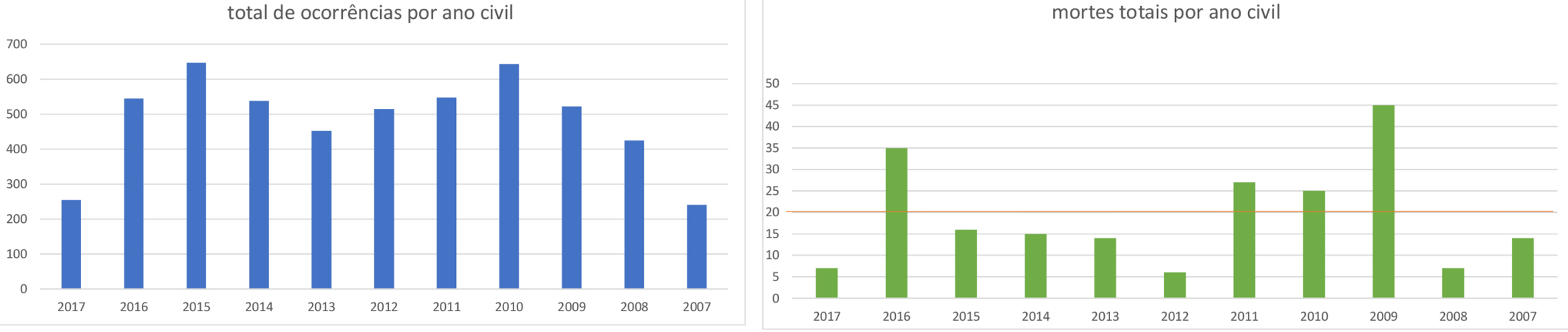

Elaboração: da autora
Dados: Cadastro de Eventos Geodinâmicos e Desastres do Estado de São Paulo - INSTITUTO GEOLÓGICO 
A proporção entre os tipos de ocorrência (taxas do tipo de ocorrência) revela maior participação da categoria hidrológicos, com mais de $61 \%$ do total da última década, seguida das categorias meteorológicos, com mais de $27 \%$, e geológicos, com $10,25 \%$. A categoria climatológica tem pouca representatividade, com 1,3\% do total.

Algumas questões sobre o registro dos dados, no entanto, levaram a refazer o trabalho de contagem utilizando outras agregações. A primeira delas é que os eventos chuvosos que ocorrem numa mesma estação, com maior concentração de novembro a março, ficavam contabilizados em anos separados, podendo gerar distorções para a contagem geral e análise da letalidade, pois alteram o total de eventos de um período contínuo, e este total define a taxa de morte ou o indicador de letalidade. A contagem dos registros de ocorrências e mortes foi refeita, então, para anos hidrológicos, considerando o período que vai de 01 de outubro a 30 de setembro na totalização da contagem.

Outra questão refere-se às duplicações de registros identificados no procedimento de contagem, que se relaciona também com a escolha dos tipos de eventos a serem considerados.

Dentre os 4 tipos de entradas para as ocorrências neste banco de dados - hidrológicos, geológicos, meteorológicos e climatológicos - as ocorrências na categoria climatológicas foram desprezadas por apresentarem uma quantificação inexpressiva frente ao universo de análise, podendo trazer mais distorções do que qualificar a análise, e também por revelarem incompatibilidade de conceitos em relação aos aplicados na tabela. No banco de dados, além dos registros de baixa umidade, as ocorrências climatológicas para a RSMP se distinguem das ocorrências meteorológicas principalmente pelo registro de ondas de frio. No entanto, na tabela Cobrade, onda de frio é um fenômeno associado à subcategoria "temperaturas extremas" da categoria "meteorológicos". Portanto, dentre as poucas ocorrências climatológicas do cadastro do IG, há dúvidas sobre a validação dos conceitos de categorização, e constatação de que são eventos de menor interesse para a análise desta pesquisa (mais relacionados a vulnerabilidade de formas de ocupação muito precárias - moradores de rua - e pouco relacionados ao espaço urbano e a configuração de sistemas em rede e suas interfaces). Além disso, há irregularidade visível nos registros - anos mais recentes trazem aumento de lançamentos de ocorrências nessa categoria, provavelmente pela mais ampla aceitação de contextos de extremos climáticos. Assim, optou-se por desconsiderar os dados relativos a esta entrada.

Um pouco mais complicada foi a decisão aplicada à categoria de ocorrências meteorológicas. Na análise da primeira contagem, as ocorrências meteorológicas aparentavam distorcer o registro total, pois elas apresentavam muitas entradas repetidas, principalmente em relação a eventos hidrológicos, além de alguns eventos geológicos e climatológicos. O trabalho de filtragem das repetições analisou as ocorrências registro a registro, e indicou que não seria adequado desprezar integralmente essa categoria. Seria importante utilizar parcialmente os dados de ocorrências meteorológicas na contagem global, pois havia situações relevantes que não de repetição.

Alguns critérios foram estabelecidos para a filtragem a partir da análise dos registros. Em muitas entradas, um evento hidrológico (inundação) é registrado também como 
meteorológico (chuvas intensas), mas isso não era uma regra que permitisse dividir o total das duas categorias ao meio, ou simplesmente desprezar a contagem meteorológica. Primeiro, porque há situações em que há apenas a entrada hidrológica (com ou sem desdobramentos do tipo de efeito, como inundação + alagamentos) sem referência a registros meteorológicos de chuva. Há situações em que um mesmo evento hidrológico tem ao menos mais duas entradas do tipo meteorológico, como chuvas fortes, vendavais, granizo etc. Há, também, situações em que um evento é registrado apenas como meteorológico, mas, na verdade, traz informações para ser enquadrado como hidrológico (com inundação e ou alagamento) sem estar presente nessa entrada. E há, também, situações em que um evento é registrado como meteorológico, com impactos e efeitos importantes (como mortes por raio, quedas de árvores, interrupção de energia, desabamentos de casas que não por processos geológicos, desprendimento de placas com mortes, interrupção do sistema ferroviário ou de aeroportos) sem estar associado a registros de alagamentos e inundações de mesma data, indicando que há efeito importante, não hidrológico, que deve entrar na contagem.

Ainda, dependendo da abrangência espacial, o registro aparece multiplicado por várias localidades de ocorrência, tanto por efeitos hidrológicos em vários pontos como por ameaças meteorológicas em vários pontos. Ou seja, uma chuva intensa que tenha atingido 10 bairros com alagamentos e inundações pode, por exemplo, ter mais entradas para a ocorrência de pancadas de chuva ou granizo, ou registros de alerta de ameaça desses fenômenos, sem que isso, necessariamente, tenha relação com efeitos negativos no espaço urbano.

Consideramos que, para o objeto da pesquisa, é mais importante focar na quantidade dos efeitos das ocorrências concretizadas no espaço urbano do que na quantidade das ameaças $^{86}$. A análise registro a registro mostrou, por exemplo, que a entrada meteorológica possui diversas ocorrências que são apenas informações de alerta, dissociados de qualquer consequência ("uma forte chuva atingiu determinado bairro, município" ou "a frente fria desloca-se para tais regiões com risco de chuvas intensas"). Todos os registros dessas situações não foram contabilizados.

Isso traz uma questão subjacente para a qual a disciplina do urbanismo pode contribuir: sobre como seria possível melhorar os registros de ocorrências para que sejam mais efetivos para direcionar ações de prevenção e de adaptação das estruturas urbanas.

As informações da categoria meteorológicos foram consideradas nas contagens da seguinte forma:

- desprezados totalmente os registros (chuva, raios, ventos ou granizo) que não apresentavam informações de efeitos no espaço urbano. Por efeitos entende-se: referência a congestionamentos, panes elétricas, desabamentos, quedas de árvores, fechamento de aeroportos, interrupção de trens, mortes por afogamentos em

\footnotetext{
86 Tendo como referencial os sistemas meteorológicos, a precipitação de chuva ou granizo pode ser entendida como efeito de processos meteorológicos atmosféricos, mas, tendo como referencial o espaço urbano e seus sistemas, ela é uma ameaça que pode ou não resultar em efeitos negativos no espaço urbano. Nos interessam os registros que resultam em efeitos materiais no espaço urbano.
} 
enxurradas, desabrigados, entre outros acidentes ou efeitos a serem enquadrados nas outras categorias computadas.

- desprezados os registros cujos efeitos (inundação e ou alagamento, movimentos de massa) já estivessem devidamente contabilizados na categoria "hidrológicos" ou "geológicos" para aquela data e localização (eliminação de duplicações).

- migrados de "meteorológicos" para "hidrológicos" os registros mal categorizados (referentes a inundações e ou alagamentos) que tinham entrada somente como "meteorológicos".

Ainda sobre a duplicação, surgiram outros critérios de filtragem em função das fontes de alimentação do banco de dados. Uma das fontes do cadastro geral do IG, o banco do IPMET, lança a informação de ocorrências desmembrada por processo. Portanto, uma única ocorrência pode ter entradas para: alagamento, inundação, vendaval, chuva intensa, enxurrada, granizo. No entanto, as ocorrências não são desmembradas por localidades. As fontes da defesa civil (SIDEC) e de notícias têm suas entradas desmembradas por localidades afetadas (por exemplo, enumerando todos os bairros dos municípios atingidos e desmembrados em processos). Em alguns casos, há entrada tanto do IPMET como da defesa civil e notícias, mas há outros em que só há entrada de dados do IPMET. Dessa forma, os critérios para contabilização foram os seguintes:

- se associados a efeitos no espaço urbano, a entrada deveria ser contada tantas quantas fossem as localidades afetadas, e desprezadas as duplicações de entradas gerais, se fosse o caso. Se um evento tem 10 entradas "hidrológicas" de localidades afetadas por alagamentos e inundações por fonte de notícias, e mais 4 entradas pela fonte do IPMET, as 4 entradas adicionais seriam contabilizadas apenas se fizessem menção a efeitos não indicados pelas outras entradas (por ventos, por exemplo, com indicação mais comum de destelhamentos ou outros efeitos).

- geralmente, entradas "hidrológicas" e "geológicas" foram integralmente contadas, e desprezados registros mais genéricos de mesma data, sem novas informações de efeitos, considerados como de duplicação.

Com isso, para a contabilização, foram geradas as seguintes colunas por tipo de ocorrência, que entendemos ser uma classificação de efeitos, e não de ameaças: efeitos geológicos (com um total original de 530 registros, e 7 registros eliminados na filtragem), efeitos hidrológicos (com um total de 3244 registros, e 101 registros acrescidos na filtragem), e efeitos de ameaças meteorológicas (com 1344 registros, e 936 registros eliminados na filtragem). No total, da quantidade original de 5186 registros, 910 foram eliminados. Os efeitos de ameaças meteorológicas, num total de 408, foram nomeados na nova contagem com o termo "chuva", pois foi checado que em nenhuma situação havia casos de ventos ou raios não associados também a chuvas. Há também uma coluna que soma efeitos hidrológicos e efeitos de chuvas, para proceder a algumas análises. 


\subsection{Análise geral de ocorrências - período de 2007-2017}

\subsubsection{Análise da variável tempo: anos hidrológicos}

Os resultados da segunda contagem (ver quadro 07) alteram parcialmente a indicação de piores anos, pois revelam o ano hidrológico 2009-10 com quantidades de eventos (781 registros, representando mais de $18 \%$ da década) consideravelmente maior que a indicação de piores anos na contagem anterior. Na nova contagem, o período 2014-15 apresentou 477 registros $(11,15 \%$ do período total analisado - coluna a/i), enquanto que, na contagem anterior, o ano 2015 (642 registros), que estava em segundo lugar, mostrava quase o mesmo número de registro que o ano em primeiro lugar, de 2010 (660 registros).

Na nova contagem, o ano 2010-11 aparece em segundo lugar em termos de quantidade de eventos (532 ou 12,4\% do total - coluna a/i). Isso indica que há comportamento similar entre esse período e o de 2009-2010 que não estava sendo percebido pelo corte de ano-calendário. A contagem geral de eventos também indica algum ponto crítico com possível descontinuidade entre o período de 2014 a 2016, já que, na nova contagem, o período 2015-16 (que contém parte do segundo pior ano na contagem anterior) apresenta uma participação de mediana a baixa no total de registros do período (309 ou $7,2 \%$ do total - coluna a/i).

Outro fator a ser considerado nesses resultados é que, com a aplicação dos critérios da nova contagem, foi possível perceber que poucas ocorrências dos anos 2009-10 foram descartadas após a filtragem dos dados de ocorrência, já que havia pouca duplicação e muitas entradas meteorológicas com indicação de efeitos mais críticos. A filtragem não só confirmou os maiores impactos do ano de 2010, como revelou importante continuidade desses impactos no ano de 2009. O ano de 2009 teve apenas 23 filtragens, num total de 531 registros originalmente, e o ano de 2010 apenas 59 filtragens em um total original de 660 registros. A título de comparação, o ano de 2014 teve 136 dados filtrados, de um total original de 541 registros.

Com relação às mortes, a indicação de ano de mais e maiores impactos se confirmou 45 mortes indicavam o ano 2009 como crítico, reiterado pelas 46 mortes no ano hidrológico 2009-10. Mas a nova contagem revela uma melhor distribuição dessa criticidade, com aumento das mortes também nos anos hidrológicos imediatamente anteriores e posteriores, 2008-09 e 2010-11. A análise da taxa de letalidade coloca 0 período 2015-16 (10,68\% - coluna e/a) em primeiro lugar, e em segundo lugar, o ano 2008-09 com praticamente a mesma taxa do ano 2015-2016 (8,12\%-coluna e/a). Anteriormente, o ano de 2016 aparecia em segundo lugar com 6,42\%, e o ano de 2009 em primeiro, com $8,47 \%$.

A taxa de letalidade para toda a década foi de 4,79\% (coluna e/a) de ocorrências com mortes para o total de ocorrências, sendo que ficaram acima desta média, em ordem decrescente, os períodos: 2015-16 (10,68\%); 2008-09 (8,12\%); 2009-10 (5,89\%); 200607 (4,82\%); 2016-17 (4,74\%); e 2010-11 (4,51\%). Ficaram abaixo da média, em ordem decrescente, os períodos: 2012-13 (3,61\%); 2014-15 (3,56\%); 2013-14 (2,30\%); $2007-$ $08(1,93 \%)$ e $2011-12(1,51 \%)$. Os períodos acima da média indicam que é preciso compreender melhor: os impactos dos eventos ocorridos em 2009 e 
Quadro 7. Sistematização e contagem dos dados de ocorrência por ano hidrológico - 2006-2017

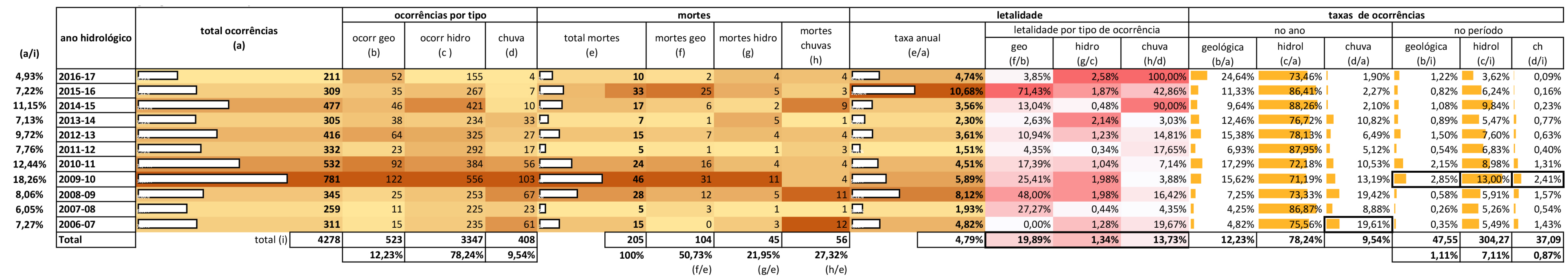

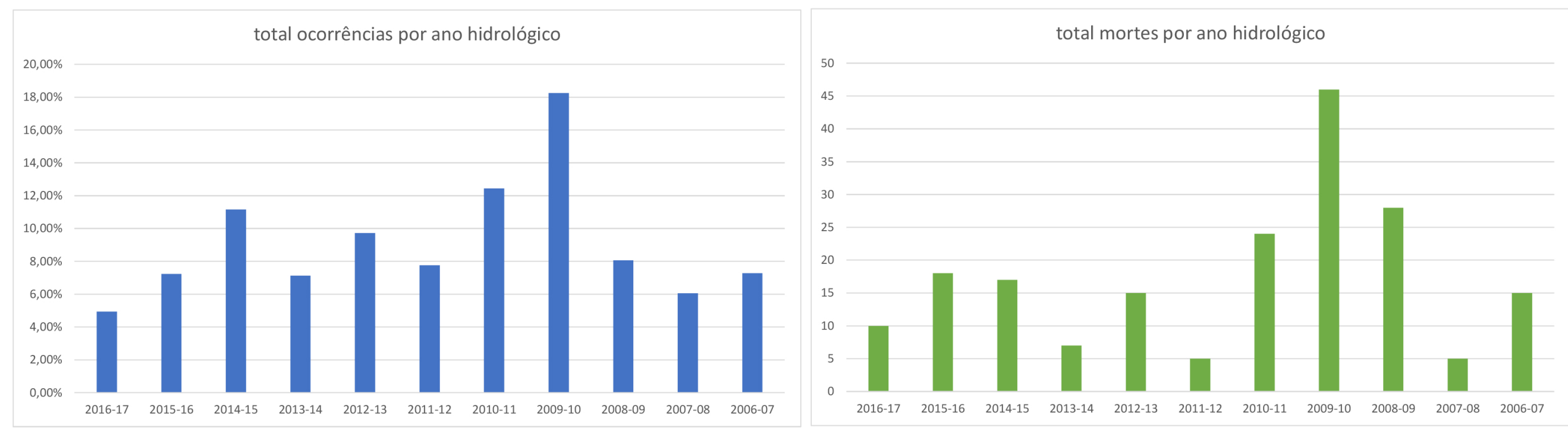


possíveis continuidades entre os anos hidrológicos 2008-09 e 2009-10 (pior ano em termos de quantidade de registros); o ano 2015-16, com proporcionalmente poucos registros em relação ao total $(7,22 \%$ - coluna a/i), mas apresenta eventos letais, sobretudo no ano de 2016, para ocorrências geológicas, principalmente, concentradas em apenas dois dias.

\subsubsection{Análise da variável categoria}

Considerando todo o período, a maioria dos registros é de ocorrências de tipo hidrológico, representando 78,24\% (taxa de ocorrências no ano, coluna c/a) do total de ocorrências. Em seguida estão as ocorrências geológicas, com 12,23\% do total (coluna b/a), e de chuvas, com 9,54\% do total (coluna d/a). As ocorrências hidrológicas, entretanto, mostram-se menos letais se comparadas com as demais: a participação das mortes por ocorrências hidrológicas no total de mortes do período é de $21,95 \%$ (g/e), e apenas $1,34 \%$ do total de registros hidrológicos têm indicação de morte (letalidade hidrológica total, g/c). As mortes nas ocorrências geológicas participam de 50,73\% (f/e) do total de mortes no período, e têm uma taxa de letalidade de média (percentual de ocorrências com mortes na categoria para o período total) de 19,89\% (total da coluna $\mathrm{f} / \mathrm{b}$ ). Os registros de mortes em ocorrências de chuva participam de $27,32 \%$ do total de mortes (h/e), com uma taxa de letalidade de $13,73 \%$ (total da coluna $\mathrm{h} / \mathrm{d}$ ). No caso das ocorrências tipo chuva, deve-se ter cautela na análise da taxa de letalidade pois, nesta contagem, como mencionado antes, foram selecionados para a categoria "chuvas" apenas os registros do cadastro geral do IG classificados como "meteorológicos" com indicação de efeito ou consequência. Sendo assim, já se fez um corte de ocorrências mais críticas, sendo possível que essa decisão tenha enviesado a amostra desse dado. É preciso considerar que esses registros não têm como considerar efeitos indiretos dessas ocorrências, como mortes no trânsito por visibilidade de chuva, agravos no funcionamento das emergências ou decorrências de doenças, como a leptospirose. Mas uma análise qualitativa de riscos deve buscar por esses efeitos.

Ao se analisar a proporção de ocorrências em cada ano (taxa anual dos tipos de ocorrência), o ano 2016-17 é o que apresenta maior participação de ocorrências geológicas no total de registros no ano $(24,64 \%$ do total de registros deste ano são geológicos - coluna b/a), seguido dos anos 2010-11 (17,29\% - coluna b/a) e 2009-10 $(15,62 \%$ - coluna b/a), reiterando que a proporção destas ocorrências no período total analisado é de $12,23 \%$.

O ano de 2014-15 é o que apresenta maior relação entre ocorrências hidrológicas e o total de registros desse ano $(88,26 \%$ dos registros totais deste ano são hidrológicos coluna c/a), seguido do ano 2011-12 (com 87,95\%) e dos anos 2007-08 e 2015-16, respectivamente com $86,87 \%$ e $86,41 \%$ - reiterando que a proporção destas ocorrências no total do período analisado é de $78,24 \%$.

Os anos com maior relação entre ocorrências de chuva e o total de registros anuais são 2006-07 (19,61\% - coluna d/a), seguido de 2008-09 (19,42\%) e 2009-10 (13,19\%), reiterando que a proporção destas ocorrências no período total analisado é de $9,54 \%$. 
Ao considerar a participação de cada tipo ocorrência de cada ano sobre o total do período analisado, é possível confirmar o ano 2009-10 como o pior ano em todas as categorias: ele possui simultaneamente a maior taxa de registros geológicos $(2,85 \%$ coluna b/i), hidrológicos (13\% - coluna c/i) e de chuvas $(2,41 \%$ - coluna d/i) da última década; seguido do ano 2010-11, com 2,15\% geológicos, 8,98\% hidrológicos e 1,31\% de chuvas. As taxas médias por categoria para o total do período analisado são de $1,11 \%$ para ocorrências geológicas; $7,11 \%$ para hidrológicas; e 0,87\% para chuvas.

Com relação à letalidade, na categoria geológica, ficaram acima da média para o total do período analisado (taxa de letalidade geológica de 19,89\% - coluna f/b) os anos de: 2015-16 (71,43\%), 2008-09 (48\%), 2007-08 (27,3\%) e 2009-10 (25,41\%) - lembrando que este último período é o primeiro em números absolutos para mortes por este motivo (31). Na categoria hidrológicos, ficaram acima da letalidade média para o total do período analisado (taxa de 1,34\% - coluna g/c) os anos de: 2016-17 (2,58\%), 2013-14 (2,14\%), 2009-10 e 2010-11 (ambos com 1,98\%). O ano de 2016-17 apresenta poucos óbitos nessa categoria (4) se comparado ao pior ano na análise dos valores absolutos (11 óbitos em 2009-10). A alta taxa se deve à menor ocorrência total no período, podendo indicar que, apesar de haver poucos registros, as ocorrências foram mais críticas - os 4 óbitos referem-se a enxurradas em duas datas e localidades diferentes.

$\mathrm{Na}$ categoria chuvas, ficaram acima da letalidade média do período total analisado (taxa de 13,97\% - coluna h/d) os anos de: 2016-17 (100\%), 2014-15 (com 90\%), 2015-16 (42,86\%), 2006-07 (19,7\%), 2011-12 (17,65\%), 2008-09 (16,4\%), e 2012-13 (14,8\%). Convém notar que a letalidade por chuvas parece estar distribuída na ordem inversa da letalidade hidrológica, ou complementá-la (por exemplo, o pior ano em termos de quantidades de ocorrências, mortes e letalidade hidrológica, 2009-10, é um dos que apresenta menor taxa de letalidade por chuvas $-3,88 \%$ ). Isso pode ter relação com a filtragem, que desconsiderou na contagem eventos meteorológicos de menor impacto (ou sem ocorrências) dos anos que tiveram ocorrências de menor gravidade, e manteve mais eventos de chuva nos anos mais críticos, quando esses eventos estão associados a ocorrências não letais, mas com efeitos consideráveis, aumentando o total de ocorrências de chuvas e interferindo no total para cálculo da taxa de letalidade de chuva. Ainda assim, parece importante levar em consideração os períodos 2016-17 e 2008-09 que mantém simultaneamente alta taxa de letalidade hidrológica e de chuvas (na análise desses efeitos somados, obtivemos, respectivamente, 5,03\% e 5\% - valores não apresentados na tabela).

Para os 3 piores anos em termos de letalidade das chuvas, no ano de $2016-2017$, os casos de óbito por chuvas estão relacionados a raios (2 óbitos) e efeitos de segunda ordem (1 óbito por raio associado à vulnerabilidade da edificação e 1 óbito associado a contato com fiação elétrica da rede pública sob situação de chuva). Para o ano de 201516, 1 óbito queda de muro, e 2 por ventos com quedas de árvores. Para o ano de 201415 , os efeitos de segunda ordem aparecem em 2 óbitos que se referem à vulnerabilidade da edificação, com queda de muro; 1 óbito pela queda de árvore e 1 óbito pelo alagamento de um cômodo de residência cujo morador tinha problemas de locomoção. Ainda neste período, 5 óbitos foram devidos a raios, além de uma ocorrência não contabilizada, pois o registro do COBOM informava que a causa da morte foi infarto, e não a descarga de raio - mas são indícios de alguma anormalidade meteorológica com 
tantas consequências e ocorrências por raios. Embora não tenham a maior taxa de letalidade por chuva, os anos de 2008-09 e 2006-07 apresentam o maior número de mortes por chuvas (ambos com 11), sendo a maioria dos motivos indicados o desabamento de edificações, raios e quedas de árvores.

\subsubsection{Análise da dispersão espacial}

Na contagem discriminada por município (ver quadro 8), São Paulo aparece com valores de magnitude predominante em relação aos demais municípios da RMSP, tanto para o total de registros (2473, ou $58 \%$ do total) como para o total de mortes no período ( 75 , ou $37 \%$ do total). Essa predominância também é confirmada em alguns subtotais por tipos de ocorrências do período para o município de SP em comparação com o total para a RMSP ${ }^{87}$ : hidrológicas, 2154, representando $64 \%$ do subtotal da RMSP; chuvas, 217 ou $53 \%$ do subtotal da RMSP. As mortes por esses mesmos tipos de ocorrência repetem a predominância (18 por motivos hidrológicos e 31 por chuva representando, respectivamente, participação de $50 \%$ e $55 \%$ de subtotais de mortes nessas categorias na RMSP).

No entanto, os registros de ocorrências geológicas mostram menor discrepância entre São Paulo e os demais municípios da RMSP. São Paulo apresentou, no período total analisado, 103 registros de ocorrências geológicas (21\% do total), enquanto Mauá apresentou 56 registros (10,7\% do total), seguido por Francisco Morato com 37 (7\%) e Ribeirão Pires com 35 (ou 6,7\% do total). São Paulo apresenta um total de 21 mortes por ocorrências geológicas (participando em $21 \%$ das mortes por este motivo), seguido de 13 mortes em Mauá (13\%), 11 mortes em Mairiporã e Francisco Morato (11\%) e 9 mortes em Itapecerica da Serra (9\%). Com relação às mortes por ocorrências geológicas, o que marca o diferencial do município de São Paulo é que as mortes são constantes ao longo dos anos, crônicas, enquanto que em outros municípios as situações são agudas, com números mais altos de mortes em algumas ocorrências.

\footnotetext{
${ }^{87}$ Temos os seguintes valores em segundo lugar: total de registros hidrológicos - Guarulhos (119); total de chuvas - Guarulhos (26); total de mortes e participação nas mortes por evento hidrológico Guarulhos (5 ou 13,5\%) e Osasco (5 ou 13,5\%); total de mortes por chuva e participação nas mortes por chuva - São Bernardo do Campo (6 ou 10,7\%).
} 
QUADRO 8. Contagem de corrências e mortes para o período 2006-07 a 2016-17 por tipo de ocorrência e por localidade

\begin{tabular}{|c|c|c|c|c|c|c|c|c|}
\hline \multirow[b]{2}{*}{ Municípios da RMSP } & \multicolumn{4}{|c|}{ total de registros } & \multicolumn{4}{|c|}{ total de mortes } \\
\hline & total & geo & hidro & ch & total & geo & hidro & ch \\
\hline Arujá & 14 & 6 & 7 & 1 & 1 & 1 & 0 & 0 \\
\hline Biritiba-Mirim & 0 & 0 & 0 & 0 & 0 & 0 & 0 & 0 \\
\hline Ferraz de Vasconcelos & 75 & 7 & 61 & 7 & 2 & 0 & 2 & 0 \\
\hline Guararema & 20 & 6 & 11 & 3 & 4 & 4 & 0 & 0 \\
\hline Guarulhos & 159 & 13 & 120 & 26 & 11 & 0 & 7 & 4 \\
\hline Itaquaquecetuba & 99 & 15 & 77 & 7 & 2 & 0 & 2 & 0 \\
\hline Mogi das Cruzes & 84 & 11 & 60 & 13 & 1 & 0 & 0 & 1 \\
\hline Poá & 39 & 2 & 34 & 3 & 0 & 0 & 0 & 0 \\
\hline Salesópolis & 10 & 7 & 0 & 3 & 0 & 0 & 0 & 0 \\
\hline Santa Isabel & 15 & 4 & 10 & 1 & 0 & 0 & 0 & 0 \\
\hline Suzano & 88 & 23 & 60 & 5 & 2 & 1 & 0 & 1 \\
\hline Caierias & 31 & 10 & 19 & 2 & 0 & 0 & 0 & 0 \\
\hline Cajamar & 18 & 5 & 10 & 3 & 2 & 2 & 0 & 0 \\
\hline Francisco Morato & 78 & 37 & 37 & 4 & 11 & 11 & 0 & 0 \\
\hline Franco da Rocha & 43 & 16 & 25 & 2 & 2 & 0 & 1 & 1 \\
\hline Mairiporã & 16 & 8 & 6 & 2 & 11 & 11 & 0 & 0 \\
\hline Barueri & 17 & 5 & 9 & 3 & 0 & 0 & 0 & 0 \\
\hline Carapicuíba & 42 & 9 & 28 & 5 & 1 & 0 & 1 & 0 \\
\hline Itapevi & 58 & 20 & 36 & 2 & 6 & 6 & 0 & 0 \\
\hline Jandira & 5 & 4 & 1 & 0 & 0 & 0 & 0 & 0 \\
\hline Osasco & 92 & 13 & 60 & 19 & 16 & 7 & 5 & 4 \\
\hline Pirapora do Bom Jesus & 3 & 0 & 3 & 0 & 0 & 0 & 0 & 0 \\
\hline Sanatana de Parnaíba & 13 & 8 & 4 & 1 & 7 & 7 & 0 & 0 \\
\hline Diadema & 29 & 3 & 18 & 8 & 2 & 0 & 0 & 2 \\
\hline Mauá & 103 & 56 & 40 & 7 & 15 & 13 & 1 & 1 \\
\hline Ribeirão Pires & 68 & 35 & 27 & 6 & 3 & 2 & 0 & 1 \\
\hline Rio Grande da Serra & 12 & 9 & 3 & 0 & 0 & 0 & 0 & 0 \\
\hline Santo André & 156 & 32 & 102 & 22 & 2 & 1 & 0 & 1 \\
\hline São Bernardo do Campo & 64 & 8 & 47 & 9 & 10 & 3 & 1 & 6 \\
\hline São São Caetano do Sul & 101 & 2 & 93 & 6 & 1 & 0 & 0 & 1 \\
\hline Cotia & 25 & 7 & 16 & 2 & 1 & 1 & 0 & 0 \\
\hline Embu & 15 & 6 & 8 & 1 & 2 & 1 & 1 & 0 \\
\hline Embu-Guaçu & 7 & 0 & 5 & 2 & 2 & 0 & 0 & 2 \\
\hline Itapecerica da Serra & 34 & 9 & 21 & 4 & 10 & 9 & 1 & 0 \\
\hline Juquitiba & 20 & 5 & 14 & 1 & 0 & 0 & 0 & 0 \\
\hline São Lourenço da Serra & 5 & 0 & 3 & 2 & 1 & 0 & 0 & 1 \\
\hline Taboão da Serra & 127 & 13 & 109 & 5 & 2 & 1 & 1 & 0 \\
\hline Vargem Grande Paulista & 21 & 6 & 10 & 5 & 0 & 0 & 0 & 0 \\
\hline São Paulo & 2473 & 103 & 2154 & 216 & 75 & 21 & 22 & 32 \\
\hline total & 4279 & 523 & 3348 & 408 & 205 & 102 & 45 & 58 \\
\hline
\end{tabular}

Elaboração: da autora/ Dados: Cadastro de Eventos Geodinâmicos e desastres do IG 

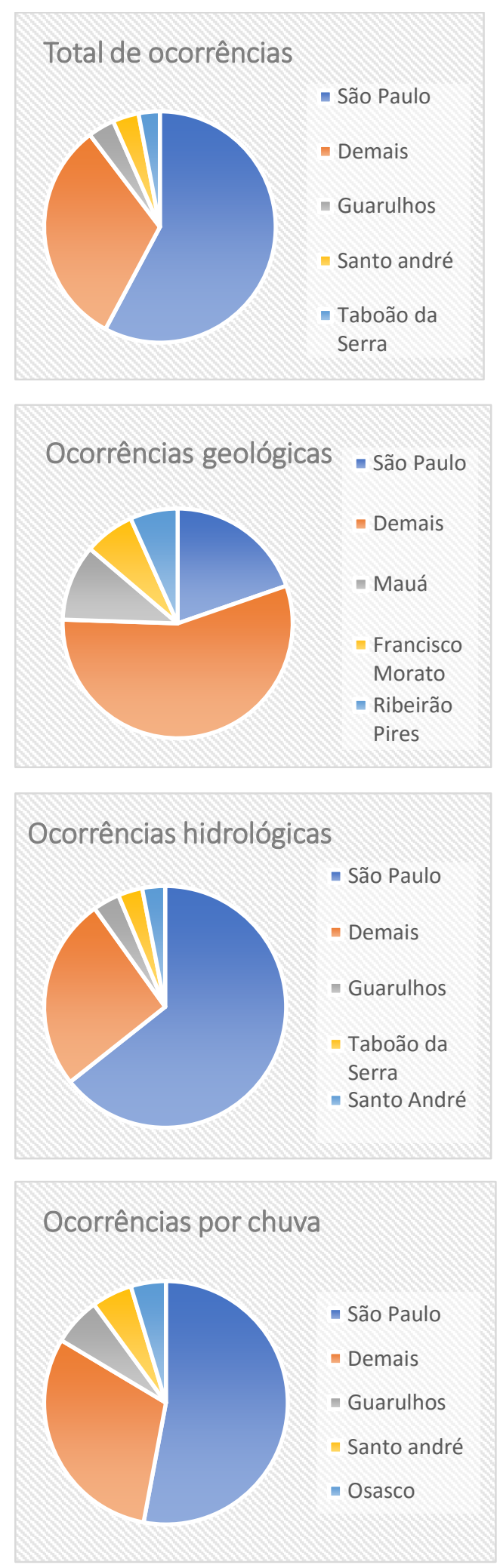
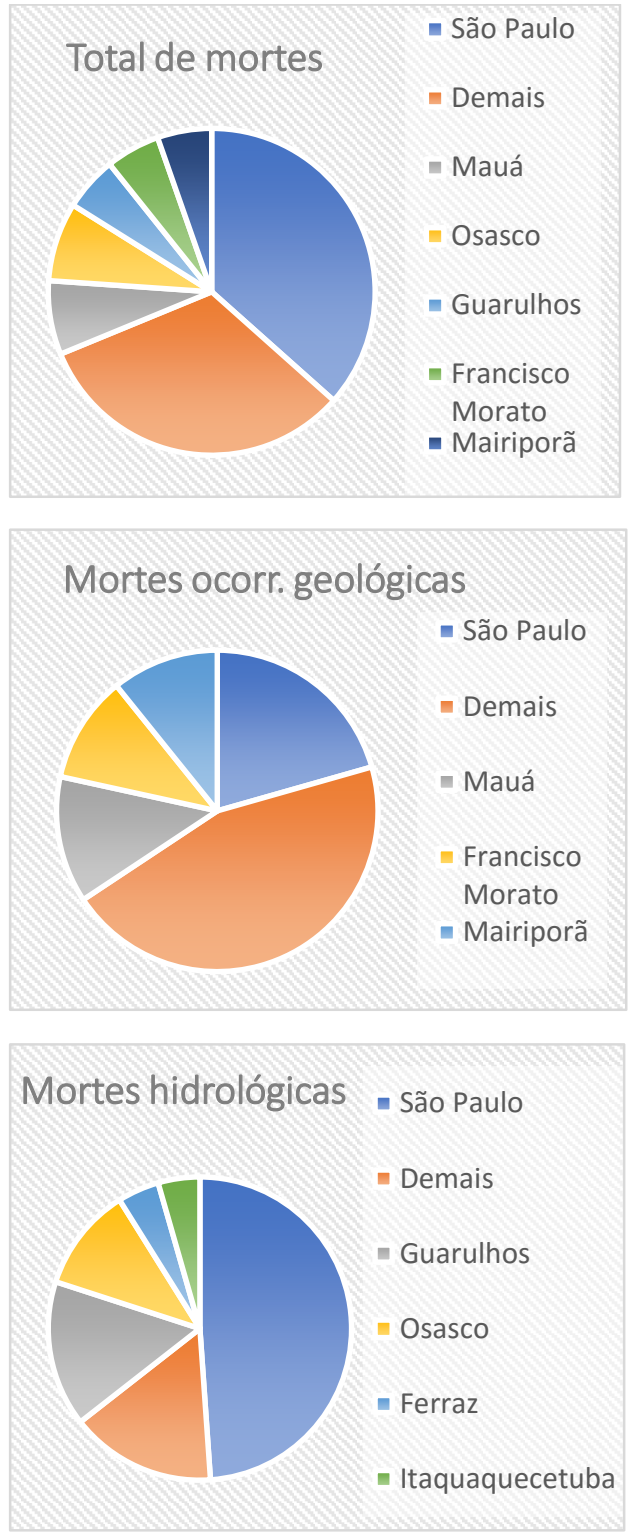

Mortes ocorr. chuva

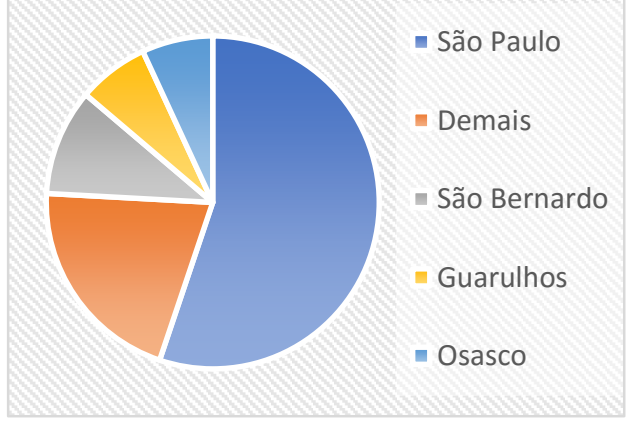

FIG. 19 - Quantidade de ocorrências por tipo e localidade. Elaboração: da autora/ Dados: Cadastro de Eventos Geodinâmicos e desastres do IG 


\section{Amplitude e intensidade}

Aplicar gradientes aos dados como feito nos quadros apresentados ao longo das próximas seções, mostrou-se um recurso mais eficiente do que a produção de gráficos, e mesmo mapas, para realçar a extensão e magnitude dos impactos em cada ano, e proceder às comparações.

Primeiro, organizando as entradas de ocorrências e mortes dos municípios em ordem decrescente nas colunas dos anos (ver quadro 9) e aplicando gradiente de cor às entradas, foi possível ler a distribuição dos registros e identificar contextos que tiveram maior amplitude e intensidade. Cada coluna representa um ano hidrológico e cada célula corresponde ao registro em um município distinto. Ao serem justapostas (excluindo células de municípios sem ocorrência) por ordem decrescente de quantidade de registros de cada localidade, o comprimento das colunas determina maior ou menor quantidade de localidades com registros, e permite ler a amplitude dos efeitos das ocorrências no espaço metropolitano: quanto mais longas as colunas abaixo, significa que mais localidades foram atingidas naquele ano, quanto mais longas as colunas acima, significa que mais localidades tiveram registros de óbitos. A cor das células foi atribuída por gradiente de acordo com a quantidade de registros em um lugar (ou em cada célula) naquele ano. Quanto mais escuras as células, maior a concentração de ocorrências ou de mortes naquele ano em determinada localidade, maior a intensidade do impacto. $O$ ano com maior amplitude de ocorrências (mais localidades atingidas) é 0 ano 2009-10, seguido de 2010-11 e 2014-15. O ano 2009-10 também apresenta maior amplitude de mortes, seguido dos anos de 2015-16 e 2012-13. O ano com ocorrências de maior intensidade (mais registros por localidade) repete o ranking da amplitude, destacando também os anos de 2012-13 e 2013-14. Em termos de óbitos, é possível notar que a maior intensidade de mortes do ano de 2009-10 é concentrada em uma localidade, e em duas localidades em 2010-11. Chama a atenção, também, a intensidade de mortes dos anos 2008-09 e 2015-16, sendo que neste último a intensidade também corresponde a maior amplitude. 
Quadro 9. Amplitude e intensidade dos efeitos das ocorrências na RMSP por ano hidrológico (2006-2017)

\begin{tabular}{|c|c|c|c|c|c|c|c|c|c|c|c|}
\hline total & 15 & 5 & 28 & 46 & 24 & 5 & 15 & 7 & 17 & 33 & 10 \\
\hline 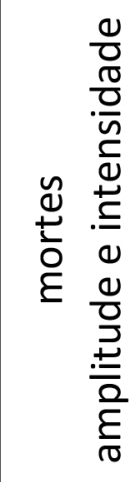 & $\begin{array}{r}1 \\
1 \\
1 \\
2 \\
10\end{array}$ & & $\begin{array}{r}1 \\
1 \\
5 \\
5 \\
5 \\
7 \\
9\end{array}$ & $\begin{array}{r}2 \\
2 \\
3 \\
3 \\
3 \\
4 \\
4 \\
5 \\
5\end{array}$ & $\begin{array}{r}1 \\
1 \\
1 \\
1 \\
9 \\
11\end{array}$ & $\begin{array}{l}1 \\
1 \\
3\end{array}$ & $\begin{array}{l}1 \\
1 \\
1 \\
1 \\
2 \\
6\end{array}$ & $\begin{array}{l}1 \\
1 \\
1 \\
2 \\
2\end{array}$ & $\begin{array}{l}1 \\
2 \\
2 \\
2 \\
3 \\
3 \\
4\end{array}$ & $\begin{array}{r}1 \\
1 \\
1 \\
1 \\
2 \\
4 \\
5 \\
8 \\
10\end{array}$ & 3 \\
\hline ano & 20062007 & 20072008 & 20082009 & 20092010 & 20102011 & 20112012 & 20122013 & 20132014 & 20142015 & 20152016 & 20162017 \\
\hline 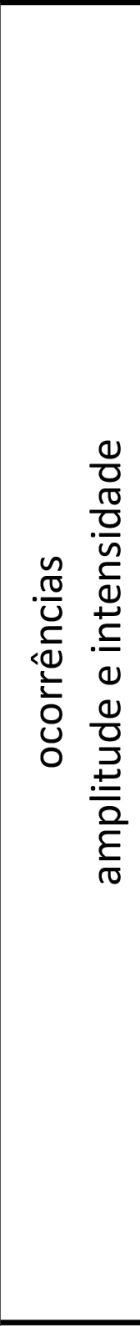 & $\begin{array}{r}236 \\
11 \\
10 \\
10 \\
9 \\
7 \\
6 \\
5 \\
4 \\
3 \\
2 \\
2 \\
2 \\
1 \\
1 \\
1 \\
1\end{array}$ & & $\begin{array}{r}260 \\
14 \\
10 \\
6 \\
6 \\
6 \\
5 \\
4 \\
4 \\
3 \\
3 \\
3 \\
2 \\
2 \\
2 \\
2 \\
2 \\
2\end{array}$ & $\begin{array}{r}412 \\
49 \\
35 \\
29 \\
25 \\
19 \\
18 \\
17 \\
16 \\
15 \\
12 \\
11 \\
11 \\
11 \\
10 \\
10 \\
9 \\
8 \\
7 \\
7 \\
6 \\
6 \\
5 \\
5 \\
5 \\
5 \\
4 \\
4 \\
3 \\
3 \\
2 \\
2\end{array}$ & $\begin{array}{r}279 \\
52 \\
29 \\
25 \\
20 \\
15 \\
15 \\
13 \\
13 \\
10 \\
9 \\
7 \\
7 \\
5 \\
5 \\
4 \\
4 \\
3 \\
3 \\
3 \\
2 \\
1 \\
1 \\
1 \\
1 \\
1\end{array}$ & $\begin{array}{r}233 \\
20 \\
18 \\
17 \\
9 \\
7 \\
7 \\
5 \\
4 \\
3 \\
3 \\
2 \\
1 \\
1 \\
1 \\
1\end{array}$ & $\begin{array}{r}212 \\
32 \\
26 \\
24 \\
16 \\
15 \\
10 \\
9 \\
9 \\
9 \\
9 \\
7 \\
7 \\
5 \\
4 \\
3 \\
3 \\
3 \\
3 \\
2 \\
2 \\
2 \\
2 \\
1 \\
1\end{array}$ & $\begin{array}{r}122 \\
31 \\
22 \\
20 \\
16 \\
15 \\
8 \\
8 \\
8 \\
7 \\
7 \\
7 \\
5 \\
5 \\
4 \\
4 \\
3 \\
3 \\
3 \\
2 \\
1 \\
1 \\
1 \\
1 \\
1\end{array}$ & $\begin{array}{r}25 \\
23 \\
21 \\
20 \\
19 \\
19 \\
16 \\
14 \\
9 \\
9 \\
9 \\
9 \\
7 \\
6 \\
5 \\
5 \\
5 \\
5 \\
4 \\
4\end{array}$ & $\begin{array}{r}149 \\
23 \\
16 \\
13 \\
11 \\
11 \\
8 \\
8 \\
7 \\
7 \\
7 \\
7 \\
6 \\
6 \\
6 \\
4 \\
4 \\
3 \\
3 \\
3 \\
2 \\
2 \\
1 \\
1 \\
1\end{array}$ & $\begin{array}{c}10 \\
24\end{array}$ \\
\hline total & 311 & 259 & 345 & 781 & 532 & 332 & 416 & 305 & 477 & 309 & 211 \\
\hline
\end{tabular}

Elaboração: da autora

Dados: Cadastro de Eventos Geodinâmicos e Desastres do Estado de São Paulo - INSTITUTO GEOLÓGICO
- cada célula corresponde a um município

- os números correspondem a registros em cada município - amplitude = comprimento da coluna

- intensidade $=$ intensidade de cor 
Para as informações de mortes, uma mesma escala de gradiente foi aplicada a todas as entradas, incluindo as do município de São Paulo. Para as informações de registros de ocorrências, foi aplicado uma escala de gradiente para as células de maior quantidade de registros (em geral São Paulo está nas células mais próximas ao centro) e outra para os demais totais. Se fosse aplicado um único gradiente a todas as células, as que se referem às ocorrências de São Paulo assumiriam protagonismo de intensidade, não permitindo revelar concentrações nos outros municípios.

Desmembrando o gradiente de ocorrências anuais por tipo de ocorrência (quadro 10), o ano de 2009-10 confirma que os efeitos amplos e intensos se fazem presentes em todos os tipos de ocorrência. Cabe destacar a grande quantidade e a espacialização ampla de ocorrências geológicas neste ano. As colunas dos demais anos indicam que o perfil de riscos na RMSP é de ocorrências geológicas mais concentradas, com amplitude significativamente menor que a amplitude das ocorrências hidrológicas. Em 2009-10, a amplitude desses dois diferentes tipos de ocorrências praticamente se igualou.

Acompanhando, ainda, o gradiente anual por tipo de ocorrência, é possível perceber quantidade um pouco maior das localidades com registros hidrológicos para o ano 201415 se comparada à quantidade de registros totais. Este ano ultrapassa em amplitude de ocorrências hidrológicas o segundo pior ano na análise geral, 2010-11. Ao considerar a intensidade de mortes por motivos geológicos dos demais anos, destaca-se o ano de 2015-16, que apresenta alta concentração de mortes por ocorrências geológicas em relação ao total de ocorrências no período, sugerindo alguma anormalidade a ser compreendida. Destaca-se, também, o alto número de mortes por chuva em anos que apresentam menores impactos na análise geral: 2006-07, 2008-09 e 2014-15.

Para estes gradientes desmembrados por tipo de ocorrência, foram utilizadas escalas de gradiente da mesma forma descrita anteriormente: uma escala separada nas ocorrências em maior quantidade (que, em geral, correspondem ao município de São Paulo), e uma única escala para as mortes. No caso das ocorrências geológicas também foi aplicada uma única escala para toda a RMSP, uma vez que não há grande discrepância entre os números do município de São Paulo e demais municípios. No ano de 2012-13, por exemplo, mais de um município da RMSP teve maior quantidade de ocorrências geológicas que o município de São Paulo. 
Quadro 10. Amplitude e intensidade dos efeitos das ocorrências na RMSP por ano hidrológico e por tipo de ocorrência (2006-2017)

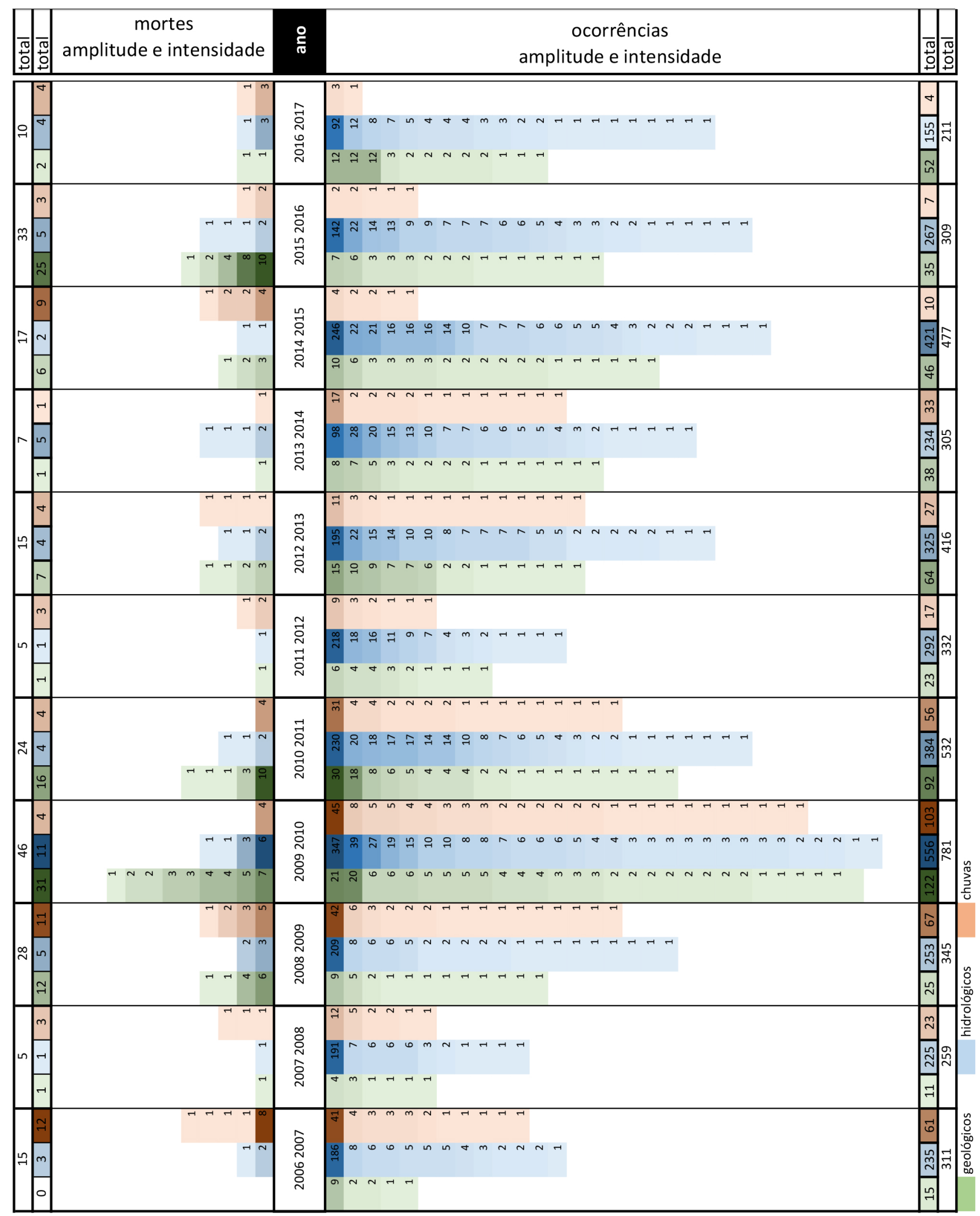




\section{Situações crônicas e agudas}

Ao se organizar as entradas em ordem decrescente nas linhas dos municípios e aplicar gradiente de cor (quadro 11), foi possível ler o comportamento das ocorrências no espaço, e identificar localidades com efeitos mais estendidos no tempo dessa série histórica (crônicas) ou mais concentradas no tempo (agudas), ou os dois simultaneamente. Quanto mais longa a linha, mais crônicos são os efeitos na localidade. Quanto maior a concentração de cor escura, mais agudos são os efeitos dos eventos (maior concentração de ocorrências naquela localidade em algum ano). Os dois contextos ao mesmo tempo indicam que a localidade sofre frequentemente com ocorrências, e em alguns anos os registros ocorrem em maior quantidade. As análises de ocorrências por localidade aplicaram um mesmo gradiente para todos os municípios da RMSP com exceção de São Paulo, que se mostra como município com quantidade de registros muito acima dos demais. Com relação às mortes, aplicou-se o mesmo gradiente a todos.

Seguindo o critério de regionalização da Emplasa (figura 20), na análise dos valores absolutos do quadro 11, as regiões leste e sudeste da RMSP aparecem como localidades com problemas mais crônicos, seguidas das regiões oeste e norte, e a região menos crônica é a sudoeste. As localidades mais crônicas contêm, também, registros mais agudos. Os gradientes revelam que há maior concentração de ocorrências nas regiões Leste. Na região leste, o município de Guarulhos revela ter problemas crônicos, que se agudizam em alguns anos, e os municípios de Itaquaquecetuba e Mogi são os que tiveram registros mais agudos de ocorrências. $\mathrm{Na}$ região Sudeste, Santo André e São Caetano aparecem como os municípios com problemas mais crônicos, sendo que Santo André revela também situações agudas. Mauá destaca-se como município com situações muito agudas. Apesar de estar em último lugar como região crônica e aguda, é importante destacar, na região sudoeste, o município de Taboão da Serra, com importante concentração de ocorrências que, nos quadros 8 e 12, se mostram como predominantemente hidrológicas. Na Região Norte, cabe destacar o município de Francisco Morato, que aparece como o mais crônico e agudo da região; e na região oeste, os municípios de Osasco (crônico e relativamente agudo) e Itapevi (agudo). A análise das mortes confirma algumas situações de impacto já apontadas: Guarulhos, Osasco e Mauá apresentam destaques de concentração e, sobretudo, recorrência de mortes. Ou seja, as mortes são mais crônicas nessas localidades e, em determinados anos, se agudizam. Mas dentre todos, os municípios mais agudos, em termos de mortes, são Francisco Morato e Mairiporã. 


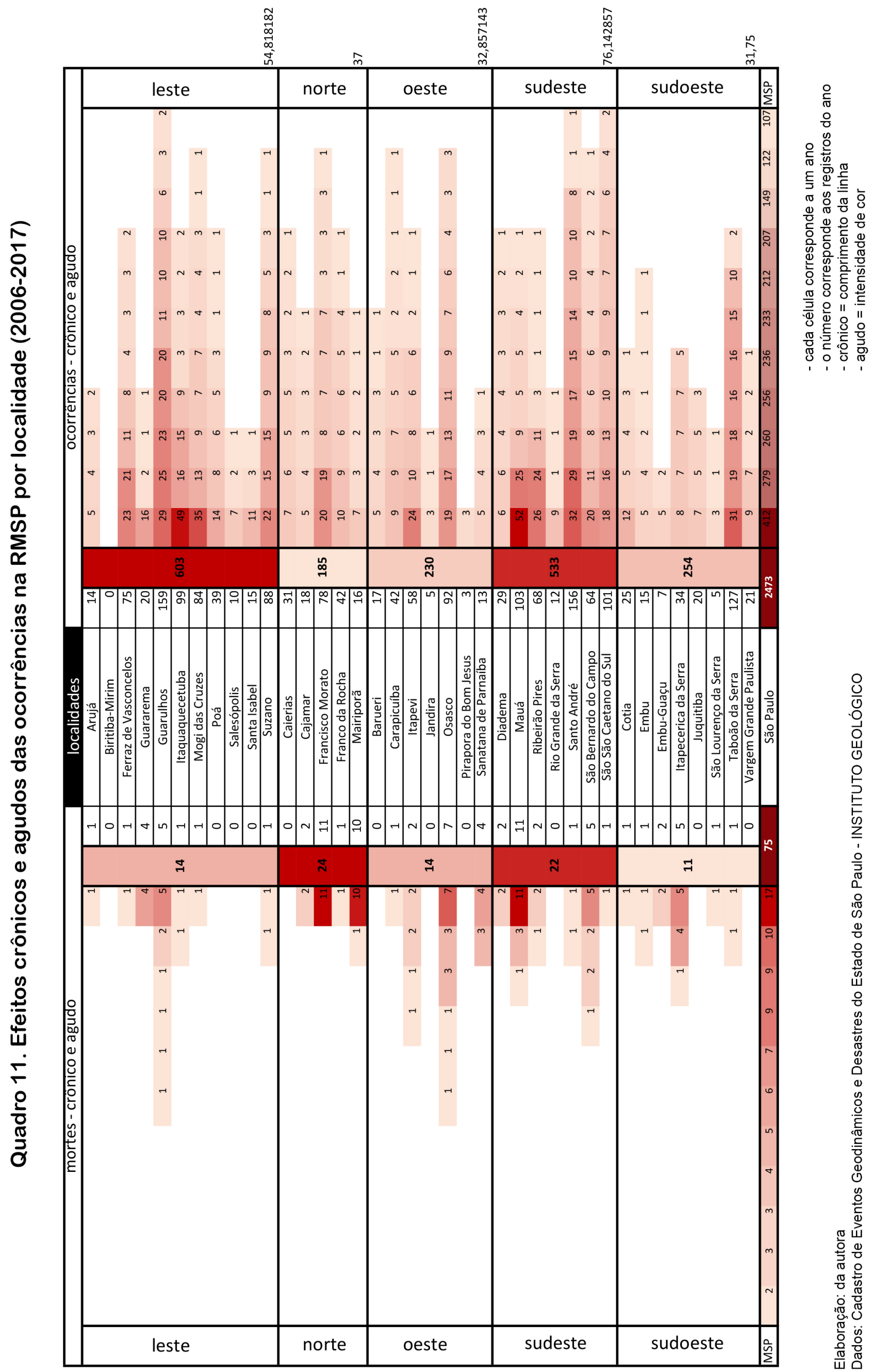




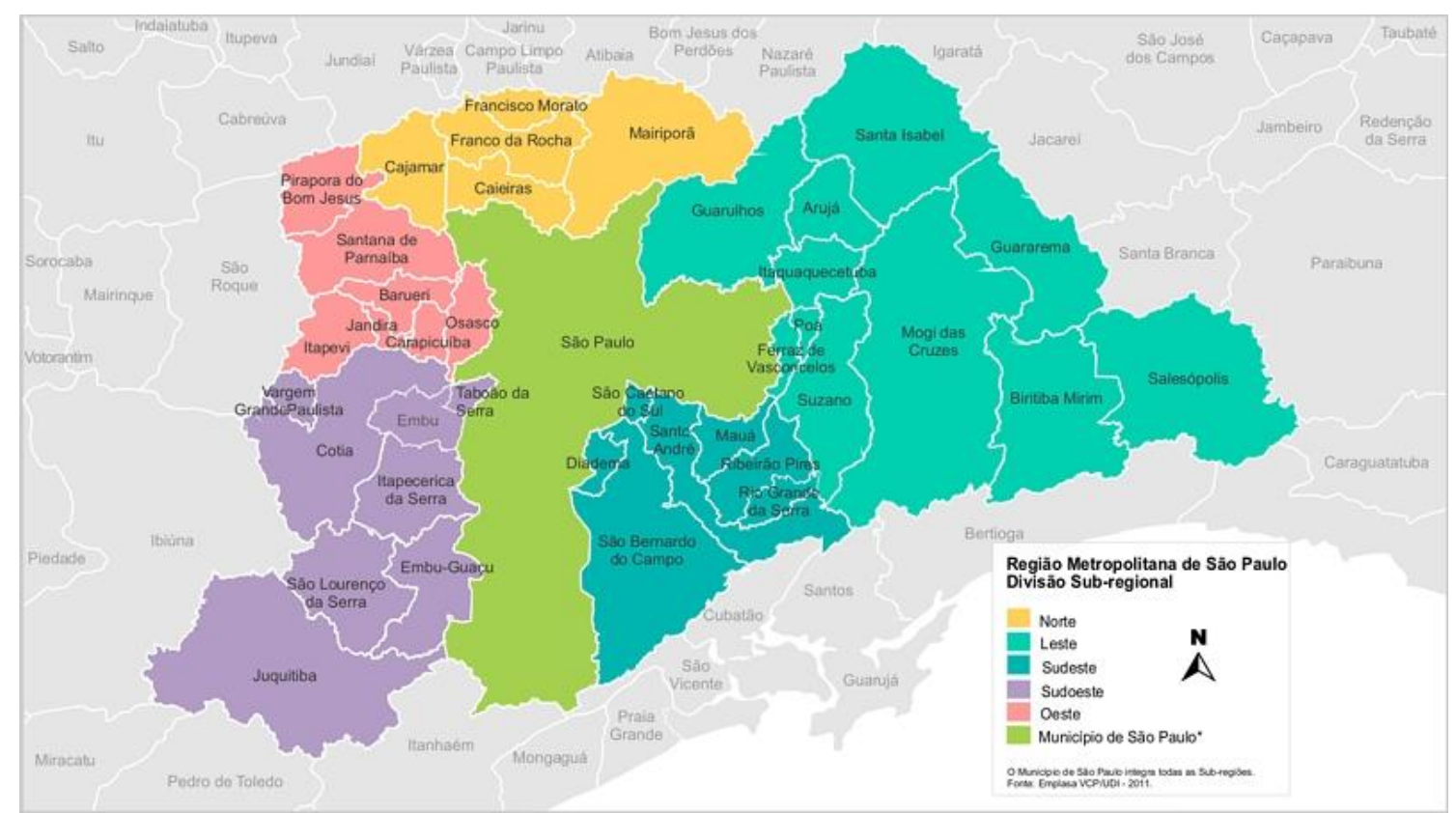

FIG. 20 - Regionalização Emplasa - disponível em https://www.emplasa.sp.gov.br/RMSP

A desagregação dos mesmos gradientes em tipos de ocorrência (ver quadro 12) indica que, na região Leste, há predominância de ocorrências de tipo hidrológicas, e mortes associadas a esse tipo de ocorrência. Na região sudeste, ocorrências hidrológicas e de chuvas são também predominantes, mas as ocorrências de tipo geológico e mortes associadas têm alta incidência se comprada a outras regiões. Na região Norte, se se considera a média de ocorrências geológicas, a quantidade de mortes por esse tipo de ocorrência também é alta, proporcionalmente. Com relação às mortes por ocorrências geológicas, cabe destaque aos municípios de Mauá, Francisco Morato e Mairiporã, com contextos de mortes agudos; Itapecerica da Serra, com contexto relativamente crônico e agudo - sobretudo se comparado com um número não tão elevado de registros de ocorrências na região; e Itapevi, com o contexto de mortes mais crônico. No total, exceto São Paulo, a região com maior número de mortes é a Sudeste, seguida da Norte. A região com mais mortes por motivos hidrológicos é a leste; geológicos, a norte; e por chuva, a sudeste. As mortes por chuva se concentram em municípios maiores e mais populosos - Guarulhos, Osasco, São Bernardo do Campo, São Paulo - sugerindo alguma correlação entre mortes por chuva e população ou densidade demográfica. Como nos gráficos anteriores, para as informações de mortes, os gradientes de uma mesma escala foram aplicados a todas as entradas, incluindo São Paulo. Para as informações de registros de ocorrências, foi aplicada uma escala de gradiente para São Paulo e outra para os demais municípios. 
Quadro 12. Efeitos crônicos e agudos das ocorrências na RMSP por localidade e por tipo de ocorrêcia (2006-2017)

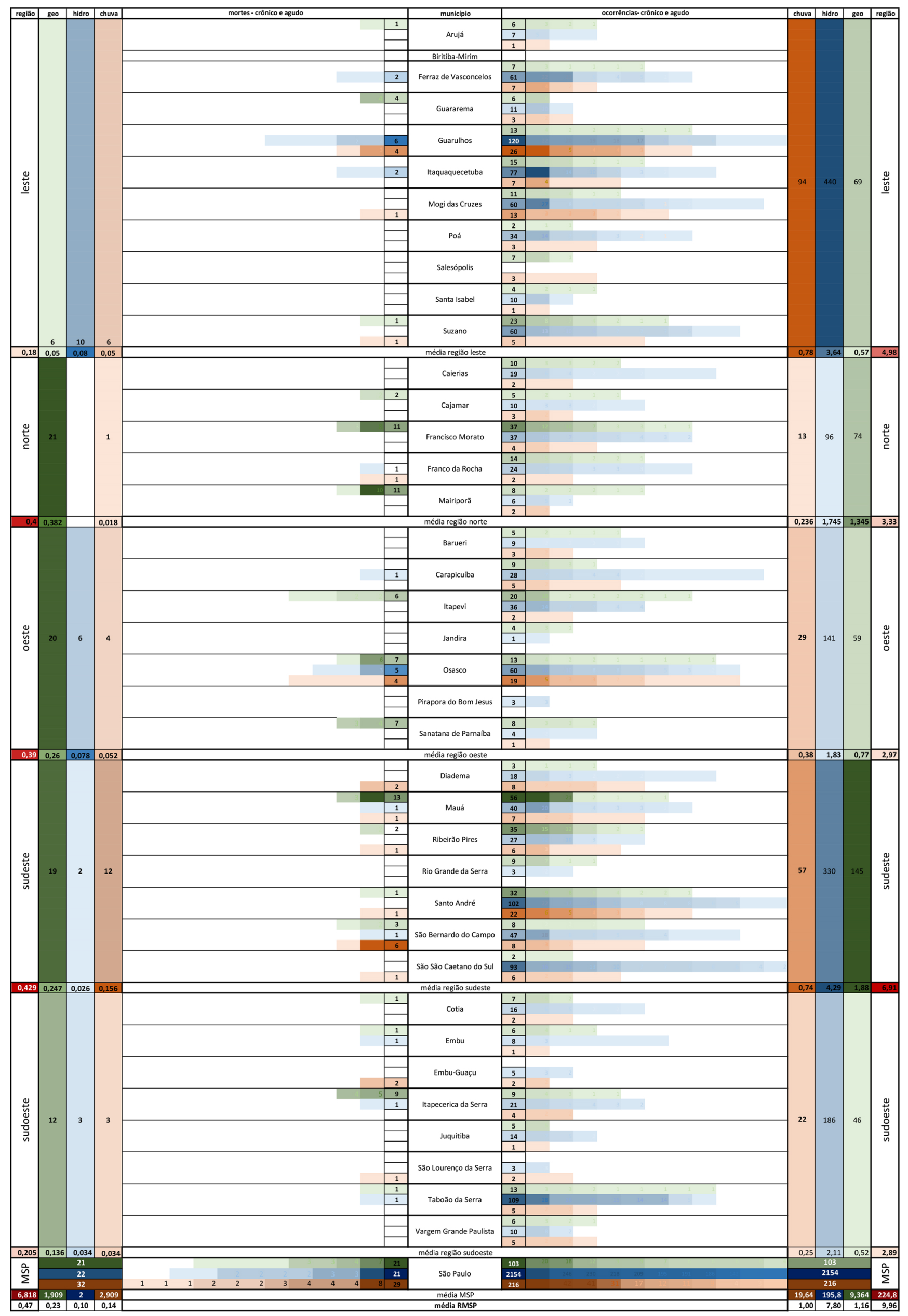


Ao se observar a distribuição simultânea no espaço e no tempo dos gradientes totais de ocorrências e mortes (quadro 13), é possível perceber os anos nos quais os efeitos foram mais amplos (colunas mais preenchidas) e mais intensos (cor mais intensa das células, ou mais ocorrências por localidades). Nota-se as colunas dos anos 2009-10 e 2010-11 mais preenchidas, com concentração de cor nas regiões Leste e Sudeste. Simultaneamente, a variação da concentração de cor ao longo das colunas indica em qual localidade os efeitos foram mais intensos naquele ano. Este quadro sobrepõe intensidade e situações agudas. O ano 2009-10 aponta para situação aguda sobretudo da região Leste: não só ela foi a região com maior intensidade de efeitos desse ano como esse foi o ano o que trouxe mais e mais amplos efeitos à região. A região sudeste, diferentemente, apresenta outros anos em situação crítica: além de 2010-11, o ano de 2012-13.

As localidades com efeitos crônicos aparecem nesse quadro como aquelas com maior proporção de células preenchidas e mais células de cor intensa em anos diferentes (situação aguda recorrente). Distribuindo essa contagem de células por sub-região pela quantidade de municípios nas sub-regiões, a região Sudeste aparece como a mais crônica: os efeitos são mais amplos (mais de $75 \%$ das células preenchidas, na maioria das localidades e na maioria dos anos), com constância da alta intensidade (média de 7 ocorrências por município por ano). A Região Leste revela situação crônica (mais de $52 \%$ das células preenchidas), com alta intensidade (média de 5 ocorrências por município por ano), diluídas principalmente pela presença de municípios como Biritiba Mirim (sem ocorrências) e Salesópolis, com ocorrência somente nos anos de 2009-10 e 2010-2011, além de outros municípios de menor densidade demográfica, como Santa Isabel e Arujá. A Região Leste apresenta, no entanto, a maior concentração de eventos para o ano mais crítico de 2009-10, podendo ser considerada como mais vulnerável em contextos de ameaças extremas. A terceira região mais crônica é a Norte, com $66 \%$ das células preenchidas e média de 3,35 ocorrências por município por ano. 
Quadro 13. Gradiente geral de ocorrência e mortes - Distribuição por ano hidrológico e por localidade da RMSP entre 2006-2017
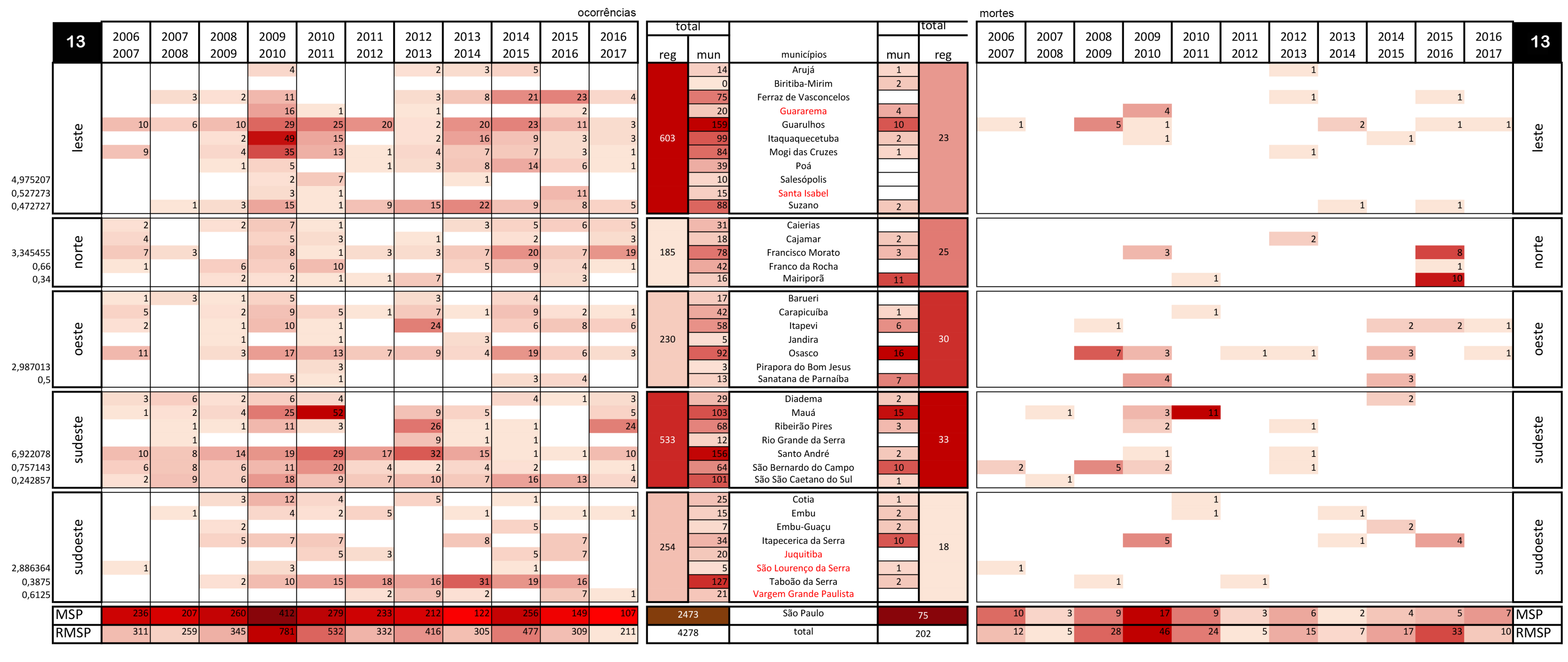

Elaboração: da autora

Dados: Cadastro de Eventos Geodinâmicos e Desastres do Estado de São Paulo - INSTITUTO GEOLÓGICO 
Outros contextos com maior intensidade de registros, ou dos efeitos, podem ser observados nas linhas e agrupamentos de regiões, ou seja, é possível buscar outros anos críticos, além de 2009-10, para as diferentes localidades. Para a região leste, há amplitude e intensidade notáveis também nos anos de 2013-14 e 2015-16; na região norte, parece haver intensificação de efeitos em anos recentes, sobretudo a partir de 2014-15, com maior quantidade de ocorrências neste ano; para a região oeste, destacase os anos de 2012-13 e 2014-15; para a região sudeste, os anos de 2012-13 e 201314; e para a região sudoeste, os anos de 2013-14 e 2015-16. Para o município de São Paulo, além de 2009-10 e 2010-11, destaca-se o ano de 2014-2015.

Com relação às mortes, desconsiderando-se o município de São Paulo (75 mortes no período total analisado), as ocorrências de desastres mataram mais na região sudeste (33 mortes), seguida da região oeste (30 mortes). A região leste aparece em quarto lugar, com 22 mortes, que se concentram nos anos críticos de 2009-10 e 2010-11. A região sudeste apresenta mortes também mais concentradas nos dois piores anos, 2009-10 e 2010-11, e a região oeste apresenta as mortes um pouco mais intensas e distribuídas ao longo de anos recentes, com aumento da intensidade sobretudo pela participação dos municípios de Itapevi, Osasco e Santana de Parnaíba. A região norte, em terceiro lugar, com 25 mortes, apresenta alguma anormalidade no ano de 2015-16, fora dos piores anos, com 10 mortes em Mairiporã e 8 em Francisco Morato. A região sudoeste apresenta maior intensidade de mortes nos piores anos e no ano de 2015-16.

Ao se observar simultaneamente a distribuição espaço-tempo dos gradientes de ocorrências e mortes desagregados por tipo de ocorrência (quadros 14, 15 e 16), é possível confirmar maior amplitude e intensidade de ocorrências geológicas na região sudeste nos dois piores anos e também no ano de 2012-13, com elevado número de mortes em 2009-10, e aumento na amplitude de ocorrências geológicas na região norte em anos recentes, com alta intensidade de mortes em 2015-16. Com relação às ocorrências hidrológicas, confirma-se as regiões leste e sudeste com problemas crônicos, a concentração de situações agudas na região leste no pior ano, além de maior intensificação de efeitos sugerida também para os anos de 2013 a 2016. É a região com maior número e maior dispersão de mortes por motivos hidrológicos. Na região sudoeste, destaca-se o município de Taboão da Serra, com problemas hidrológicos crônicos e intensidade evidenciada no ano de 2013-14. Com relação às chuvas, as ocorrências se concentram no pior ano (2009-10), sobretudo nos municípios mais populosos. É interessante notar, entretanto, que o ano crítico de 2009-10 não é o que possui maior distribuição de mortes por chuva; neste ano elas se concentraram (4 óbitos) somente no município de São Paulo. 


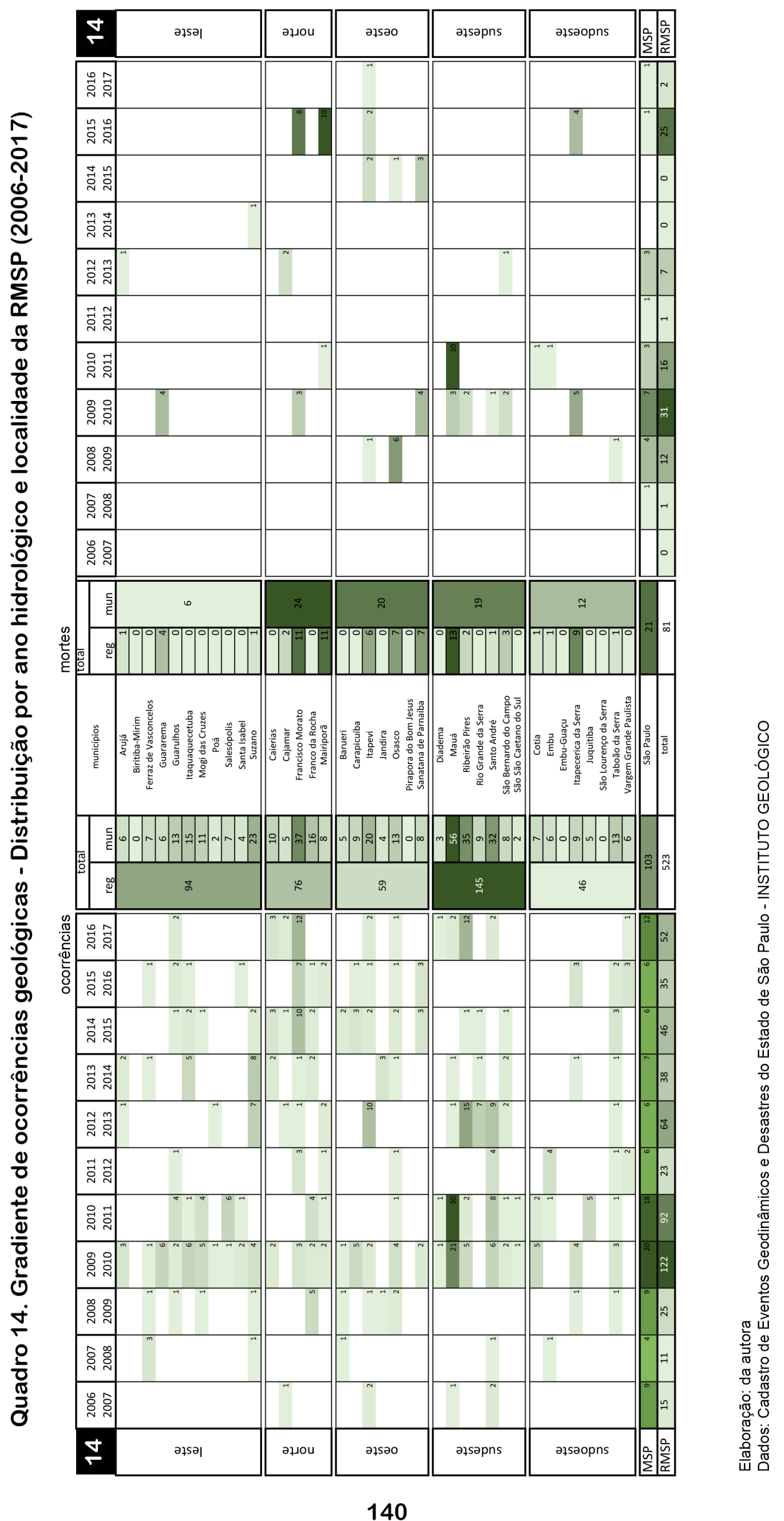




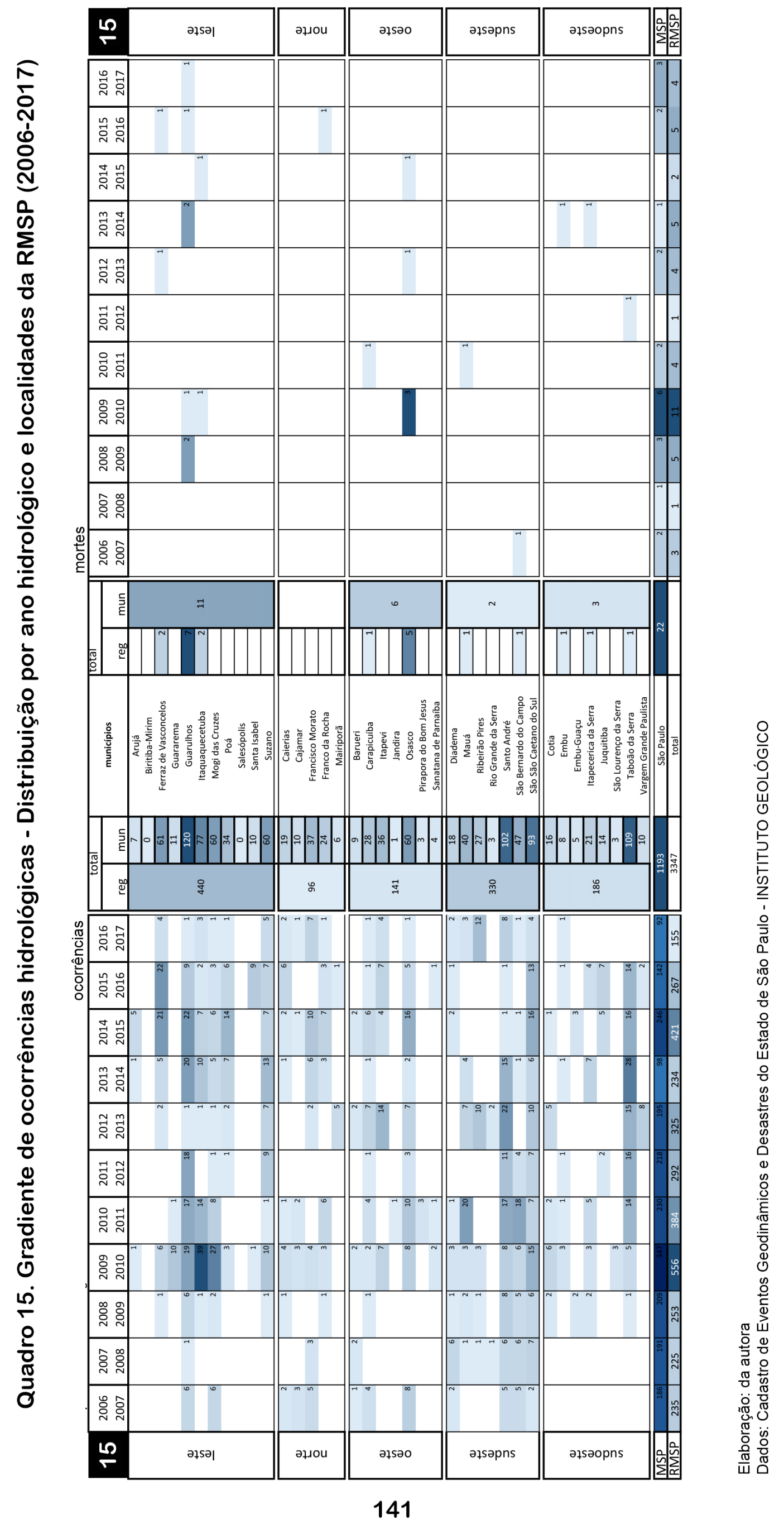




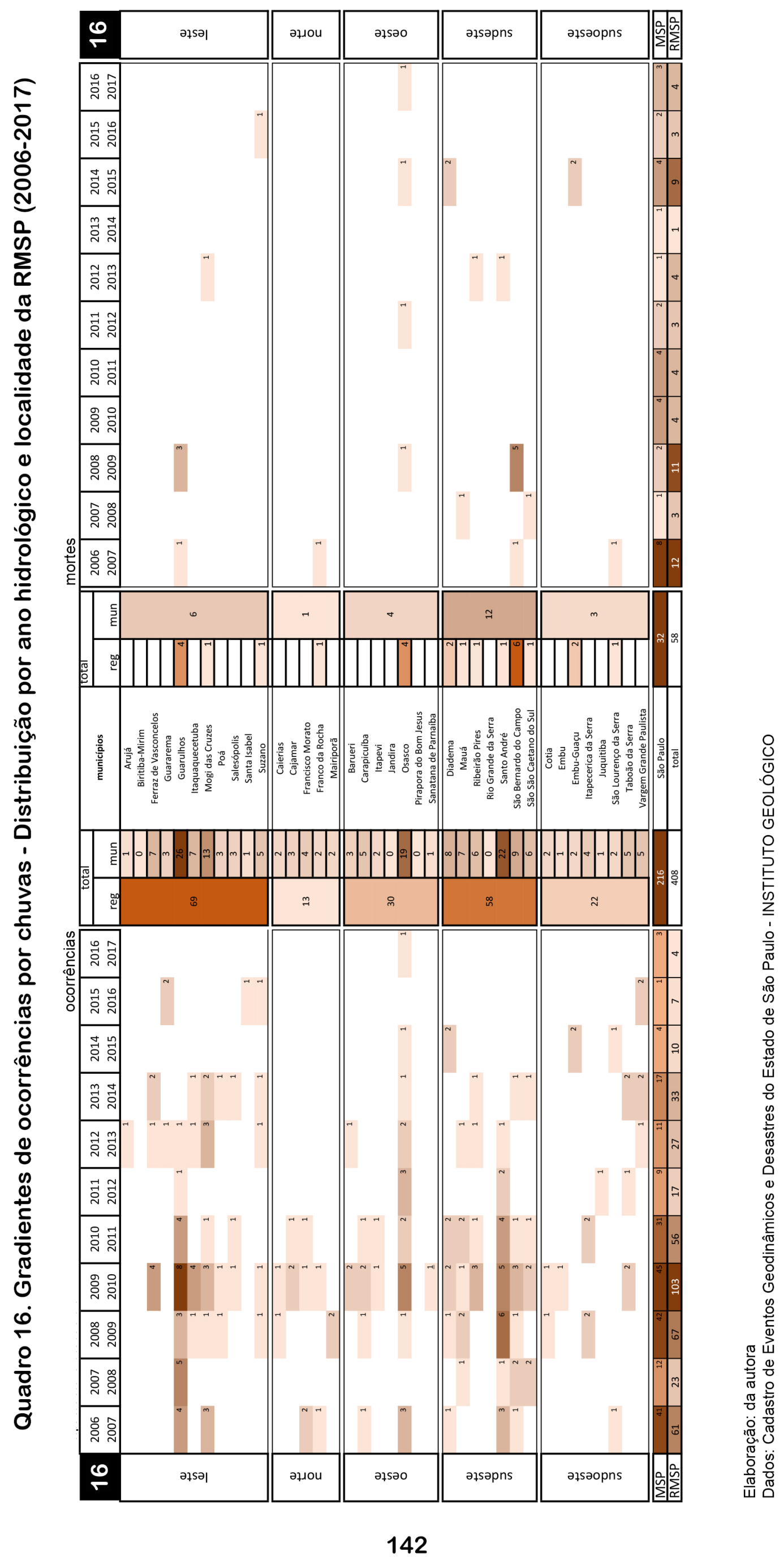




\subsubsection{Indicadores de letalidade por localidade e registros por número}

\section{de domicílios: relativização do peso do município de São Paulo}

As atividades aqui desenvolvidas sobre os dados do Cadastro do IG são novas para os estudos urbanos, e exigiriam maiores desdobramentos e testes de correlação. Uma primeira tarefa, parcialmente discutida anteriormente, seria produzir um melhor tratamento dos dados para o município de São Paulo, desdobrando contagens por subprefeituras ou bairros, e buscar viabilidade dos registros para fazê-lo, já que nem sempre o dado bruto permite esse desdobramento facilmente ${ }^{88}$. Muitos outros indicadores e correlações, além daqueles aqui ensaiados, merecem maior investigação, que poderia revelar diretrizes para um futuro tratamento diferenciado das informações, da forma registros e sistematizações, e de sua disponibilização para setores da gestão urbana, de modo que possam ser melhor apropriados pelas atividades de planejamento e mais efetivos para fins de prevenção e adaptação das estruturas urbanas.

Dentre os indicadores trabalhados, alguns permitem mostrar que, apesar de reunir o maior número de ocorrências e de mortes, a predominância do município de São Paulo pode ser relativizada em relação aos demais municípios. Ao se analisar a relação entre mortes por ocorrências registradas (taxa de letalidade) e a proporção de eventos e mortes por número de domicílios (PNAD), a presença do município de São Paulo se mostra diluída.

Como pode ser visto no quadro 17 , no cálculo da taxa de letalidade do período para cada município (total de mortes/total de registros), o indicador do município de São Paulo (3\%) fica abaixo da média geral para a RMSP $(4,8 \%)$. O município que aparece em primeiro lugar é Mairiporã (68,75\%), seguido de Santana de Parnaíba, (53,85\%) e Itapecerica da Serra $(29,41 \%)$. Ao se analisar a taxa de letalidade apenas dos registros geológicos, os mesmos 3 municípios aparecem em destaque: Mairiporã com 137,5\%, Itapecerica com $100 \%$, e Santana de Parnaíba com $87,5 \%$. Isso porque as ocorrências geológicas mais críticas causam num mesmo local - em geral uma residência - a morte de vários membros da mesma família. Por isso seria possível taxas de letalidade de $200 \%$ para apenas 2 registros, por exemplo, no caso de 4 pessoas de uma mesma família mortas em uma única ocorrência. As ocorrências geológicas têm maior taxa de letalidade em quase todos os municípios, com exceção daqueles sem mortes por este motivo e dos seguintes municípios, para os quais a letalidade de eventos hidrológicos ou de chuvas supera a dos eventos geológicos: Suzano (letalidade geológica de 4,35\% contra $20 \%$ de letalidade de chuva); Ribeirão Pires (letalidade geológica de $5,71 \%$ contra $16,7 \%$ de letalidade de chuva); e Santo André (letalidade geológica de 3,13\% contra $4,55 \%$ de letalidade de chuva). Para o total da Região Metropolitana, a maior letalidade geológica se confirma, com 19,50\% de taxa para as ocorrências geológicas.

Os municípios com maior taxa de letalidade hidrológica são Embu (12,5\%), Osasco $(8,33 \%)$ e Guarulhos (5,83\%). Para a Região Metropolitana, a taxa de letalidade hidrológica é de $1,34 \%$ de mortes para o total de ocorrências hidrológicas. Os únicos

\footnotetext{
88 É importante esclarecer que o acesso a esse banco de dados ocorreu na fase de elaboração final desta tese, e todas as contagens e análises aqui realizadas tiveram que ser feitas no prazo de um mês.
} 


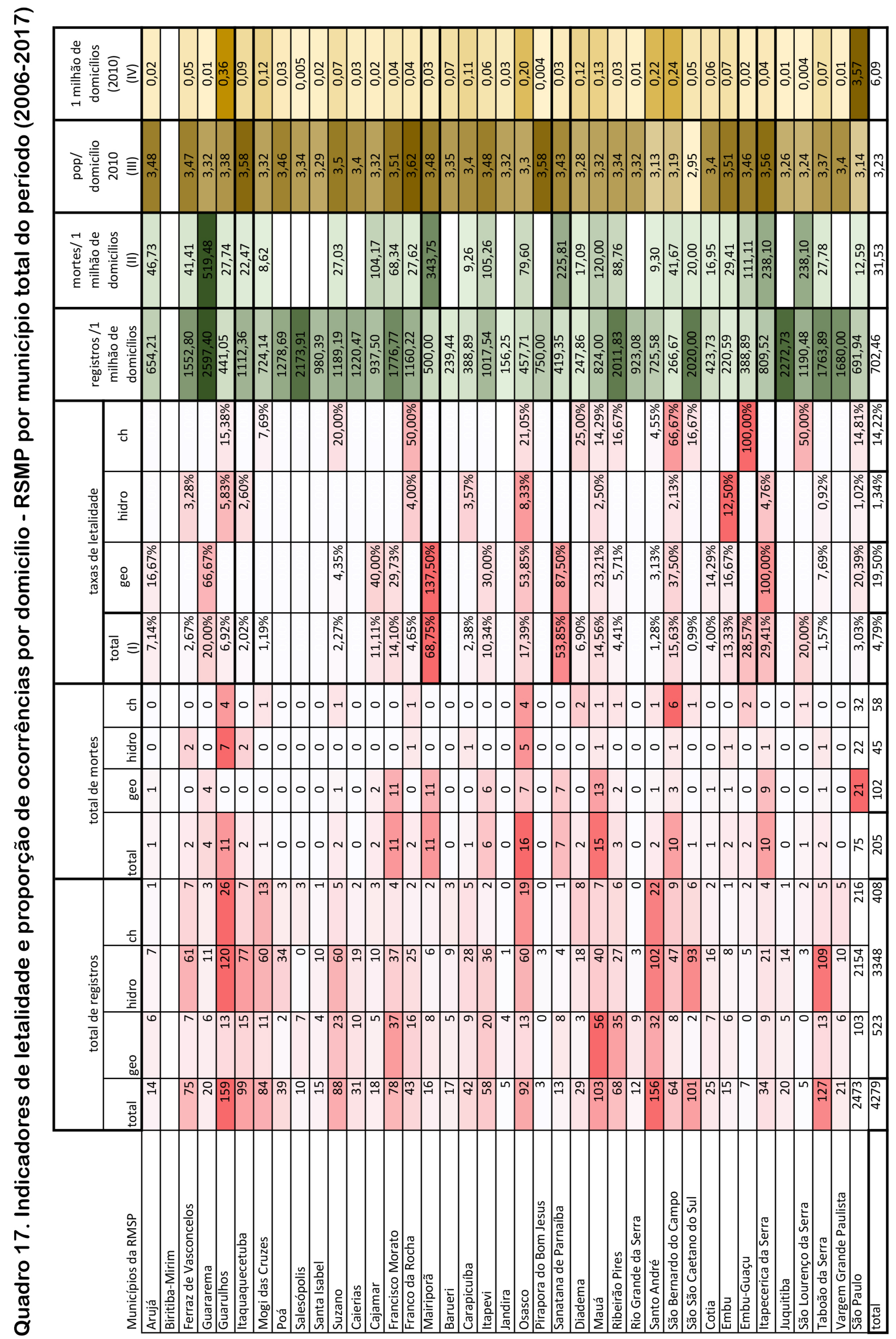

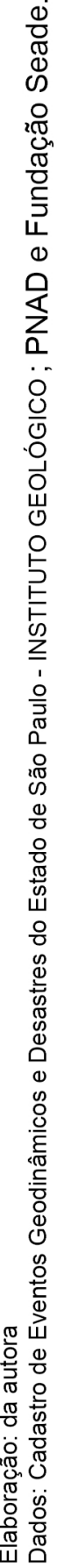


municípios que ficam abaixo dessa taxa (além daqueles com taxa zero) são São Paulo, com $1,02 \%$ e Taboão da Serra, com $0,92 \%$.

Ou seja, provavelmente por apresentarem muitos registros hidrológicos, as ocorrências expressam menor letalidade. Isso pode ser por um maior número ocorrências que estão sob controle; como pela 'super-notificação' em relação a outros municípios, quando a identificação das ocorrências se dá apenas para situações muito críticas; ou da combinação entre os dois. De toda forma, o número absoluto de mortes por motivos hidrológicos em São Paulo é alto: 22 mortes em todo o período analisado.

Os municípios com a maior taxa de letalidade de chuvas são Embu-Guaçu (100\%), São Bernardo do Campo (66,7\%) e Franco da Rocha (50\%). Para a Região Metropolitana, a taxa de letalidade de chuva é $14,22 \%$, sendo que o município de São Paulo praticamente repete essa taxa (14,81\%). Apenas os municípios de Mogi das Cruzes (7,69\%) e Santo André (4,55\%) estão abaixo da taxa da RMSP, além daqueles que não apresentam mortes por este motivo. É de se destacar que a taxa de letalidade por chuva é de média a alta em municípios com média populacional maior (como Guarulhos, Osasco, Diadema e São Bernardo do Campo), podendo sugerir que o maior adensamento (e impermeabilização) corresponda a ameaças de chuvas mais intensas, pelo fenômeno das chuvas convectivas.

A letalidade mostrou ser um indicador que funciona melhor para analisar a variável tempo do que a variável espaço, provavelmente porque as localidades apresentam muitas diferenças na prática de registros. Municípios menores tendem a registrar somente as ocorrências mais graves, e município maiores, principalmente SP, com sistemas de monitoramento e alerta implantados, tendem a produzir mais registros, mais discriminados em diversas entradas de bairros, ruas, etc, o que aumenta o volume de registros de ocorrências menos críticas e interfere na relação de letalidade. Assim, um indicador baixo para São Paulo acaba por esconder que há grande quantidade de mortes, e, para mortes, o valor absoluto pode ser mais revelador de criticidade da situação do que a relação entre mortes e ocorrências. Uma medida importante para confirmar a validade ou não do indicador para análise espacial da criticidade seria desagregar o município de São Paulo em subprefeituras ou regiões, a fim de ter comparações espaciais mais similares, com ordens de grandezas parecidas. A contagem teste feita para o município de São Paulo no ano de $2009-10^{89}$ mostra grande quantidade de registros na região central e em grandes vias de circulação, onde há mais monitoramento, o que é um fator de diluição da letalidade dentro do próprio município. Ainda assim, foi possível identificar que as mortes por motivos hidrológicos estão concentradas na zona leste (em São Miguel, Itaquera e São Mateus, 4 no total) além de outras 3 sem especificação de bairros. As mortes por motivos geológicos, neste ano em que as ocorrências desse tipo foram generalizadas, concentram-se na zona sul (3), além de duas (2) ocorrências em regiões consolidadas (Pompéia e Butantã) e duas (2) ocorrências sem especificação de bairros. As mortes por chuva (3) não contêm especificação. A desagregação da letalidade por bairros poderia revelar dinâmicas diferenciadas na cidade.

\footnotetext{
${ }^{89}$ Tarefa não ampliada em virtude do cronograma e porque não é possível uniformizar a sistematização da contagem por subprefeituras.
} 
Outros parâmetros dos municípios foram testados para verificar a validade do indicador de letalidade: área, densidade, população e domicílios. Estão apresentados e desdobrados apenas os indicadores relacionados a domicílios, que pareceram mais promissores para as análises. O dado de domicílio foi usado como um proxy de população, que abrange melhor diferenças relativas ao congestionamento domiciliar, gerando indicadores de ocorrências por número de domicílios e mortes por número de domicílios. O quadro 17 permite algumas comparações. É possível perceber que o indicador de letalidade (coluna I) varia em alguma correspondência com a variação do indicador de morte por número domicílio (coluna II - para 1 milhão de domicílios). É apenas uma sugestão que explica pouco: municípios menores (coluna IV) apresentam maior número de mortes por número de domicílio (e isso pode ter explicação matemática, pelo menor divisor), mas apresentam também uma maior taxa de letalidade, o que não deveria ter correspondência com número de domicílios, já que letalidade é a relação entre ocorrências com mortes e ocorrências totais. Isso pode sugerir que quanto menos populoso o município, menos ocorrências são registradas e noticiadas: somente as mais críticas. Pode sugerir, também, que quanto menor o município, maior o número de ocorrências geológicas, cujo perfil é de maior letalidade. Osasco, Mauá e São Bernardo do Campo fugiriam a essa regra, já que têm um índice populacional médio a alto, e médio a alto índice de letalidade geológica.

Por isso, foi investigado, também, se haveria alguma correspondência entre a letalidade e o indicador de congestionamento domiciliar (população/domicílio - coluna III). O mais alto indicador de letalidade (Mairiporã) apresenta a relação de registros por número de domicílio abaixo da média da RMSP e do Município de São Paulo, mas relação de mortes por número de domicílio muito acima da média. O perfil de ocorrências geológicas e a possível subnotificação justificam esses valores, e o índice de congestionamento domiciliar em Mairiporã (coluna III) é entre médio e alto, sugerindo que as condições de habitabilidade correspondem à maior frequência do tipo de ocorrência geológica, e o perfil mais letal deste tipo de ocorrência eleva a letalidade das ocorrências na localidade. Esse padrão de correspondência se repete nos dois municípios a seguir no ranking de letalidade: Santana de Parnaíba e Itapecerica da Serra. O mais alto indicador de congestionamento domiciliar é no município de Franco da Rocha (3,62 habitantes por domicílio), com registros e mortes por domicílio acima da média, mas letalidade não tão alta, por não haver registros de mortes por ocorrências geológicas. Dentre as taxas de letalidade hidrológicas e por chuvas, Franco da Rocha apresenta valores de médio a alto.

Ainda no quadro 17, analisando a correspondência entre o indicador de congestionamento domiciliar (população por domicílio, coluna III) e as relações entre ocorrências e mortes por número de domicílios (colunas I e II), ao se eliminar do ranking os municípios menores (com até 10 mil habitantes - Guararema, Salesópolis, Rio Grande da Serra, Juquitiba e São Lourenço da Serra), que podem distorcer o ranqueamento, a correspondência das colunas I e II com a coluna III ficam mais evidenciadas, destacando-se a correspondência nos municípios: Itaquaquecetuba, na sub-região leste; Franco da Rocha, Francisco Morato e Mairiporã, na sub-região norte; Itapevi e S. de Parnaíba, na sub-região oeste; Embu-Guaçu, Embu, Itapecerica da Serra e Taboão da Serra, na sub-região sul; e Ribeirão Pires na sub-região sudeste. Na sub- 
região sudeste, destaca-se como exceção o município de São Caetano do Sul: apesar do baixo indicador de congestionamento domiciliar, possui uma alta relação de registros por número de domicílios. Esta exceção bem pode confirmar a explicação da regra: de que municípios com melhores indicadores de habitabilidade podem ter melhor estrutura e registrar mais ocorrências, e não apenas as mais letais.

Desdobrando os indicadores de letalidade (quadro 18) e registros de ocorrências e mortes por número de domicílios (quadro 19) nos quadros que distribuem variáveis de tempo e localidade simultaneamente, e agrupam regiões para o período total analisado, também foi possível observar poucas correspondências com indicadores do quadro 17.

O quadro 18 mostra o desdobramento das taxas de letalidade no tempo e no espaço, e foi aplicado o mesmo gradiente para todos os municípios. Se comparado com o quadro 13, que mostrava os valores absolutos de registros e mortes, os gradientes indicam concentrações muito diferentes, diluindo sobretudo a participação do município de São Paulo (com letalidade média a baixa, e constante em todos os anos). Localidades que parecem ter problemas crônicos e agudos (alta concentração de células ao longo do tempo e alto gradiente de cor) são confirmadas como localidades com ocorrências mais letais, como: Mairiporã, Osasco, Mauá, Ribeirão Pires, São Bernardo e, mais moderadamente, Ferraz de Vasconcelos e Francisco Morato. Outras localidades exibem o maior contraste, se comparado aos resultados do quadro 13, quando se aplica o gradiente ao indicador da letalidade: Cajamar, Itapevi, Santana de Parnaíba, Embu e Itapecerica da Serra. Quando se aplica o gradiente à letalidade das sub-regiões, encontramos mais respostas. As regiões Norte e Oeste apresentam ocorrências mais letais, enquanto que no quadro 13 - com gradientes aplicados aos valores absolutos - 0 município de São Paulo aparecia em primeiro, seguido das regiões Leste e Sudeste para ocorrências, e das regiões Oeste e Sudeste, para mortes. A comparação com este indicador aponta para o fato de que não é porque há menos registros em uma localidade que isso signifique que foram menos graves, pois há lugares em que as ocorrências são mais letais (provavelmente pela menor quantidade de notificações).

O quadro 19 mostra o desdobramento dos registros de ocorrências e mortes por número de domicílio no tempo e no espaço, considerando a variação no total de domicílios em cada ano (projeções SEADE da PNAD). Ao comparar com o quadro 13, a participação do Município de São Paulo aparece mais diluída. Localidades que antes apareciam com baixa concentração, destacam-se com gradientes muito altos: Guararema, Salesópolis, Pirapora do Bom Jesus, R. Grande da Serra, Juquitiba, S. Lourenço da Serra, Vargem Grande Paulista. Isso sugere que análises desse tipo talvez devessem ser feitas por grupos com ordem de grandeza populacional semelhantes. Descartando esses municípios de menor população da avaliação do quadro 19, os gradientes relacionados com o total de domicílios aumentam o contraste de localidades que, no quadro 13, apareciam com concentrações médias discretas no total de ocorrências, como é o caso dos municípios: F. Morato, Itapevi, Mauá e Ribeirão Pires. Na soma sub-regional, a região Norte tem a maior concentração, tanto de mortes como de ocorrências, em relação ao total de domicílios - enquanto, no quadro 13, era a sub-região com menor concentração absoluta de ocorrências, e a terceira na concentração dos valores absolutos de mortes. 


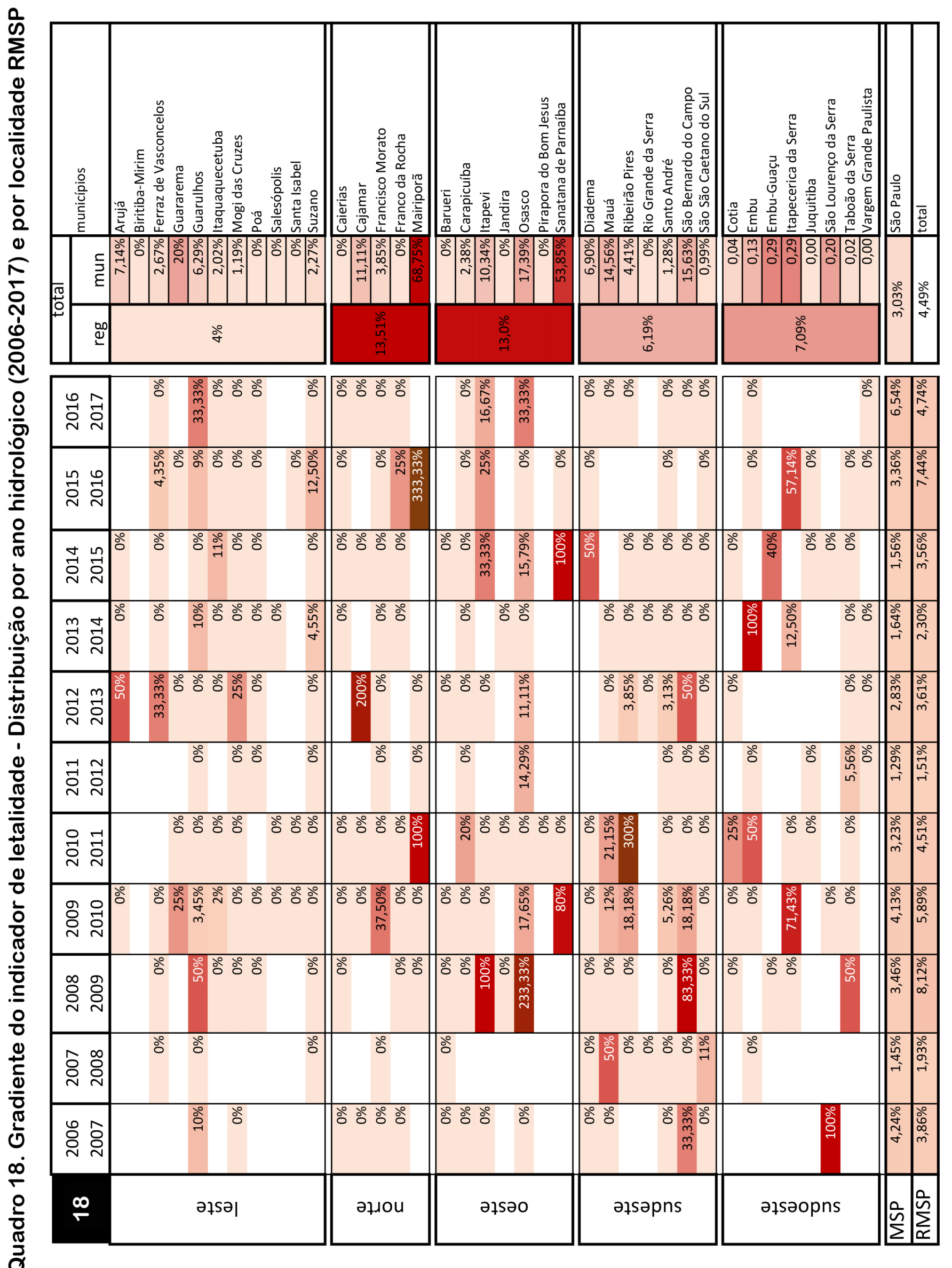

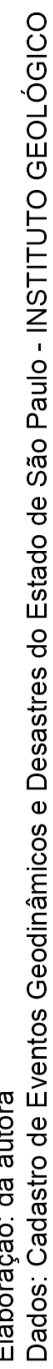


Quadro 19. Gradientes do indicador de ocorrência por domicílio - Distribuição por ano hidrológico e localidade RMSP (2006-2017)

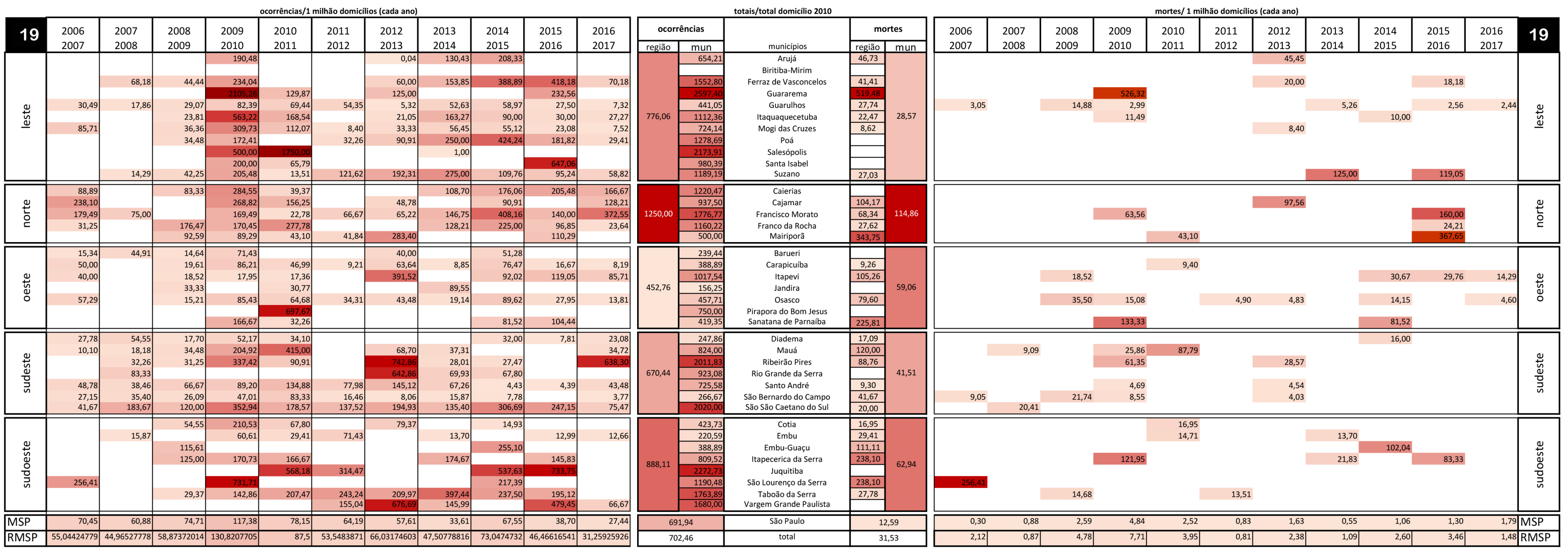

Elaboração: da autora
Dados: Cadastro de Eventos Geodinâmicos e Desastres do Estado de São Paulo - INSTITUTO GEOLÓGICO; PNAD 2010 e projeções SEADE para demais anos. 


\subsubsection{Análise de piores dias}

Para o objeto desta pesquisa, interessa o intervalo de tempo que possa expressar simultaneidade. Assim, além das análises relativas às variáveis tempo (ano hidrológico), tipos de ocorrência e variações nas localidades do espaço metropolitano, é interessante identificar os piores dias de cada período. Foram utilizadas 3 variáveis para identificar piores dias: quantidade de registros em um dia (dias mais agudos), quantidade de mortes em um dia (dias mais agudos) e quantidade de localidades diferentes atingidas em um dia (dias com efeitos de maior amplitude).

A seleção de pior dia de registros (Quadro 20) indica que estão contidos nos piores anos (2009-10 e 2010-11): os dias 08/12/2009 e 21/01/2010, ambos com 45 ocorrências, e o dia 10/01/2011, com 48 ocorrências. Em terceiro lugar está o dia 06/04/2017, com 37 ocorrências, um dia atípico para o período, pois representa mais de $17 \%$ das ocorrências daquele ano. No caso dos anos mais críticos, o pior dia representa, respectivamente, $5,76 \%$ e $9 \%$ do total daqueles anos. Dentro do universo de análise de dias com maior número de ocorrências, alguns dos dias piores também tiveram mais mortes: 21/01/2010 e 10/01/2011. No entanto, a série não apresenta uma variação linear entre quantidade de ocorrências e de mortes. Apenas é possível perceber que, a partir de um volume maior de ocorrências, os óbitos são certos. Na seleção destas datas é possível identificar, apenas, que os piores anos apresentam com mais regularidade dias com grande número de ocorrências.

Quando selecionados os piores dias em relação a óbitos (Quadro 21), não houve repetição de datas com nenhum dos piores dias com relação a registros, à exceção das datas dos anos críticos já mencionadas. Isso parece sugerir que deve haver um limiar a partir do qual o aumento de ocorrências corresponde ao aumento de óbitos, a que os anos mais críticos dessa série analisada podem ter atingido. O dia com mais mortes no ano 2010-11 - 10/01/2011 - teve 8 óbitos, e é também o dia com mais registros nesse ano. Igualmente, em 2009-10, o dia 21/01/2009 reaparece como pior dia, também com 8 óbitos. Chama a atenção mais duas datas nesse universo: no ano 2008-09, o dia 08/09/2009 teve 12 óbitos. É o pior dia desta série histórica, e o número de mortes desse dia corresponde a $42,86 \%$ do total de mortes deste ano, a maior porcentagem dentre este universo, apesar do total de ocorrências do dia não ser tão alto (22) nem tão disperso espacialmente (3 municípios). Isto sugere que o número de mortes e número 

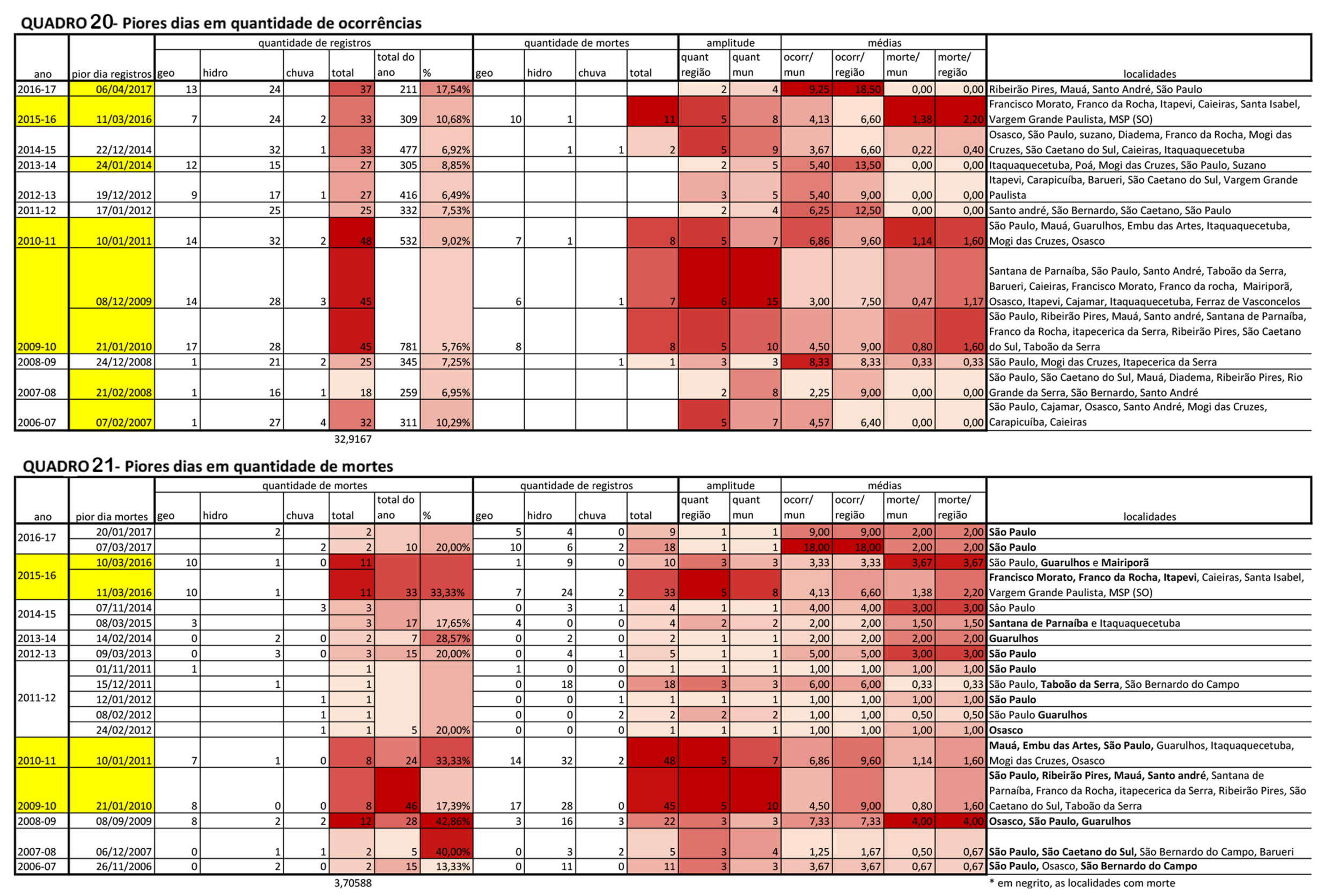

QUADRO 22- Piores dias em quantidade de localidades atingidas

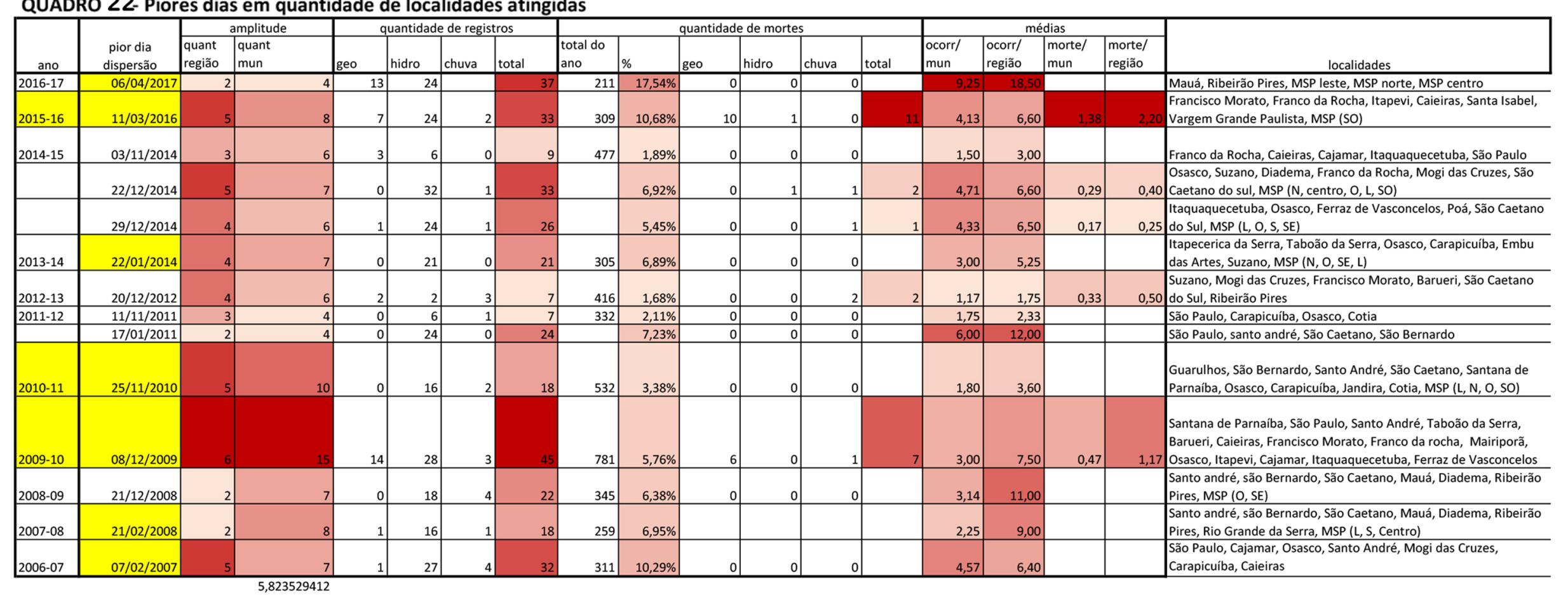


de ocorrências não correspondem a uma regra linear, e que é possível que alguma anormalidade no comportamento do ano hidrológico 2009-10 tenha se iniciado já no final do ano hidrológico 2008-09, já que a ocorrência é do mês de setembro, e o corte do ano hidrológico foi estabelecido em 01 de outubro. Este nexo será investigado nos estudos de caso. O segundo dia com mais mortes é de 2015-2106, na verdade, dois dias seguidos com alto número de mortes: 10/03/2016 e 11/03/2016, com 11 óbitos cada um, bastante alto sobretudo se somados, totalizando 22 óbitos. O dia 11/03 apresenta uma grande abrangência, com 8 municípios atingidos em 5 diferentes regiões. Para os anos mais críticos 2009-10 e 2010-11 (que não são os piores anos em termos de óbito, mas estão na segunda posição), a abrangência espacial das ocorrências é grande: 10 e 7 municípios, respectivamente.

A fim de compreender se a dispersão espacial das ocorrências poderia estar relacionada com agravamento de consequências e aumento de mortes, foram selecionadas datas a partir da terceira variável: quantidade de localidades atingidas em um dia. Os anos que aparecem no topo da lista (Quadro 22) como piores anos são, novamente, 2009-10 e 2010-11, respectivamente com 10 e 15 municípios com ocorrências registradas num mesmo dia, porém, só uma data ranqueada como pior, nos critérios anteriores, reaparece entre eles: o dia 08/12/2009. Para o ano 2010-11, a pior data é o dia 25/11/2010, com 10 municípios atingidos, mas esta data não é a que apresenta maior número de ocorrências deste ano (18), e não apresenta óbitos. Outras datas selecionadas como piores pelo critério da maior dispersão também repetem datas de pior dia pelo critério da quantidade de ocorrências: os dias 06/04/2017, 22/01/2014, 21/02/2008 e 07/02/2007, mas essa regularidade não surpreende, considerando que a quantidade de registros tem relação com a quantidade de locais atingidos. O dia 11/03/2016, com 8 municípios atingidos em 5 diferentes regiões, seria a única data que repete como pior dia do ano pelos 3 critérios - amplitude, óbito e quantidade de ocorrência. É ainda mais crítico se analisado o nexo com o dia 10/03/2016 para o ano 2015-16. Esta data faz parte de um dos estudos de caso selecionados previamente.

$\mathrm{Na}$ seleção de piores anos por dispersão temporal e espacial das ocorrências (Quadro 23), os anos 2007-08 e 2008-09 chamam atenção por possuírem proporcionalmente poucos dias com situação de grande amplitude, sendo a grande maioria das ocorrências concentradas no município de São Paulo. A partir de 2009-10, as ocorrências possuem maior dispersão pelo território metropolitano, à exceção do ano 2011-12. O ano crítico 2009-10, além de possuir o dia com mais ocorrências da série e o segundo dia com mais óbitos da série, possui vários dias com grande dispersão das ocorrências, acima de 6 municípios atingidos (indicado na contagem como 22 dias com mais de 4 municípios atingidos, ou $28,2 \%$ do total de dias com ocorrência tiveram mais que 4 municípios com registros), e grande continuidade temporal de dias com ocorrências (78 dias). Outro ano em que, proporcionalmente, muitos dias possuem dispersão de ocorrências acima de 4 municípios atingidos é o ano 2014-15, em que 19,3\% do total de dias com ocorrências tiveram mais que 4 municípios com registros. Esse ranking se repete quando considerada a incidência de dias com mais ocorrências em cada período: em 2009-10 20,5\% dos dias com ocorrência têm 18 ou mais ocorrências registradas, e no ano 2014-15, 14\% dos dias com ocorrência têm 18 ou mais ocorrências registradas. Com relação à quantidade de dias com mortes, o ranking entre valor absoluto e relativo 

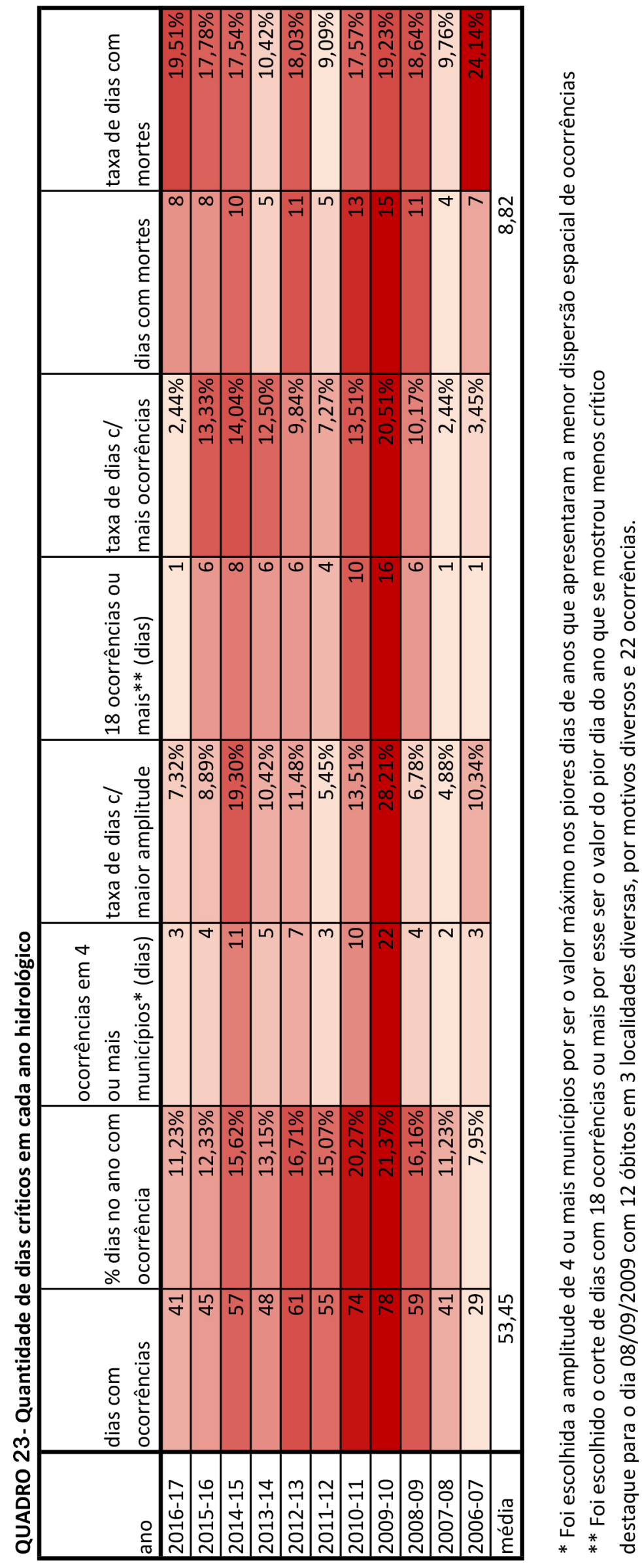

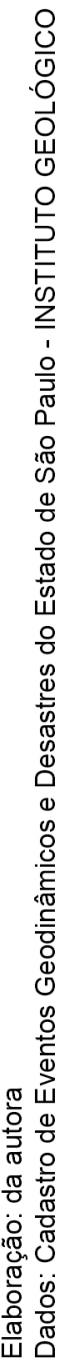


divergem. Os anos 2006-07 e 2016-17 apresentam mais dias com mortes proporcionalmente ao total de datas com ocorrências (respectivamente, $24,14 \%$ e $19,5 \%$ dos dias com ocorrência têm registros de morte), maior que a proporção nos anos críticos. Se analisados os valores absolutos, o ranking confirma o ano 2009-2010 como o pior ano. E, ainda, se as contagens do dia 08/09/2009 fossem consideradas no ano seguinte, considerando outro corte hidrológico, isso reforçaria claramente o ranking do ano 2009-10 em todos os quesitos, pois este dia contém 12 óbitos em 3 localidades diversas (é o dia com mais óbitos em toda a série analisada), apresenta motivos de ocorrências diversos, e reúne um total de 22 ocorrências.

\subsection{Síntese geral das ocorrências metropolitanas como contexto para os estudos de caso selecionados}

Considerando os estudos de caso previamente selecionados (abaixo), é possível traçar seu contorno baseado nas análises feitas a partir dos registros de ocorrências na RMSP.

1. Inundações persistentes e de longa duração no extremo leste, região do Jardim Pantanal, no ano de 2009-2010

2. Operações de manobra no Reservatório Paiva Castro e consequências no município de Franco da Rocha e outros municípios da região Norte da RMSP em 11 e 12 de março de 2016

3. Operação das barragens de Pirapora do Bom Jesus para controle da macrodrenagem da BAT, com consequências no município de Salto em 29 de novembro de 2014

O Primeiro estudo de caso representa claramente a localidade metropolitana com efeitos mais crônicos e amplos em termos de ocorrências de inundações, e o ano mais crítico (mais ocorrências) da série histórica analisada, com os efeitos mais agudos deste ano nesta localidade. A desproporção das variáveis (registros totais, mortes e dispersão) e dos indicadores (dias com mais ocorrências, mais dias com dispersão considerável e mais dias com mortes) para este ano em relação aos demais anos aponta para a necessidade de identificar os fatores de anormalidades dos eventos neste período, seja pela caracterização de ameaças naturais atípicas, outros fatores não naturais, agravantes, bem como a característica de vulnerabilidade a ameaças das localidades mais atingidas.

A análise do banco de ocorrências do IG não permite traçar os nexos necessários para compreender esses fatores, sendo necessário lançar mão de outros recursos, como a leitura contínua de notícias de jornal do período e, posteriormente, entrevistas com moradores e representantes comunitários, agentes da defesa civil locais, e atores institucionais envolvidos nas questões levantadas a partir do reestabelecimento dos contextos. Este estudo de caso tem seu contorno de relevância claramente desenhado a partir dos números analisados nas seções anteriores, e pode partir da constatação de que a região leste, com problemas crônicos, evidencia a criticidade do ano crítico. As 
datas 8/12/09 e 21/01/10 são as mais críticas, e o início de sua análise deveria avaliar a inclusão do dia 08/09/09, no período imediatamente anterior.

O ano 2015-2016 apresenta o segundo número mais alto de mortes por ocorrências geológicas, e o segundo pior ano em mortes se considerado o total de ocorrências. A taxa de letalidade deste ano é a mais alta $(10,68 \%)$, e se considerada a letalidade das ocorrências geológicas (71,43\%), supera em muito a do segundo ano mais crítico (48\%). O período torna-se ainda mais relevante ao se considerar que boa parcela dessa criticidade se deu concentrada em apenas dois dias.

Com relação à análise dos piores dias, o ano 2015-16 apresenta uma proporção de média a alta $(17,8 \%)$ de dias com mortes (8 dias com mortes) em relação ao total de dias com ocorrências (total de 45 dias com ocorrências), e é o único ano com reincidência de data entre os 3 critérios de piores dias: mais ocorrências, mais mortes (11) e maior dispersão - o dia 11/03/16, que deve ser analisado juntamente com o dia que o antecede, também com 11 óbitos.

A análise espacial das ocorrências sugere que em anos recentes (2014 a 2017) pode estar se formando um contexto crônico de ocorrências geológicas na região norte, com maior número de ocorrências em Francisco Morato desde 2014, exacerbado no número crítico de mortes em 2015-16. São indícios de que a região pode estar ampliando sua vulnerabilidade a esse tipo de ocorrência, e de algum fator que pode ter agravado as consequências nas datas críticas de 2015-16.

Mais difícil é, a partir das análises quantitativas no contexto metropolitano analisado, explicar a relevância para último caso. As evidências de relevância parecem estar ocultas.

$\mathrm{Na}$ análise dos gradientes por anos e tipos de ocorrência, no quadro 10, o ano 2014-15 aparece como o segundo ano com maior dispersão espacial de ocorrências hidrológicas; o segundo ano se considerada a intensidade desse tipo de ocorrência; e segundo, também, no total dessas ocorrências e no total delas para o município de São Paulo. Com relação às ocorrências geológicas, aparece em terceiro lugar, perdendo apenas para os dois anos mais críticos. Na análise dos piores dias, para o ano de 201415, o dia com maior quantidade de registros é 22/12/2014, com 33 ocorrências, um valor médio para alto. O dia com mais número de mortes é 07/11/2014, com 3 mortes (médio), e os dias com maior dispersão de ocorrências são: 03/11/2014 (6 municípios com registros), 22/12/2014 (7 municípios com registros) e 29/12/2014 (6 municípios com registros), que apresentam dispersão considerável, média para alta, mas não são críticas.

Nenhuma dessas datas coincide com o dia levantado inicialmente para estudo de caso, 29/11/2014, mas indicam contextos críticos imediatamente anteriores. Seria necessária uma análise alargada dos meses de novembro e dezembro para ter uma visão contínua desses eventos e investigar possíveis tomadas de decisão operacionais para controle da drenagem na porção central da bacia (onde o município de São Paulo ocupa a maior parte) que resultaram nos efeitos que justificam o caso. $O$ ano apresenta, ainda, a segunda maior taxa de dias com 4 ou mais municípios atingidos (19\%, abaixo apenas do ano mais crítico, com $28,2 \%$ ) e a segunda maior taxa (14\%) de dias com mais 
ocorrências (18 ou mais), novamente, perdendo apenas para o ano mais crítico, 200910. O total de dias com ocorrência neste ano é de 57 , correspondente a $19 \%$ do ano, a segunda maior taxa. Ou seja, é um ano com grande intensidade e homogeneidade de ocorrências, sobretudo hidrológicas. Cabe lembrar, o ano que marca o início do período em que São Paulo passou pela maior estiagem de sua história, com a crise hídrica.

No cadastro geral do IG não constam registros para estiagem. Também não foram encontradas ocorrências para o dia 29/11/14, mas os dias 25 e 26 de novembro têm entradas de ocorrências hidrológicas e meteorológicas para Osasco, MSP (zonas sudeste, norte, sul, sudoeste, leste e centro) e Diadema. Para o município de Salto, não há nenhum registro de ocorrência no cadastro, que abrange todo o estado.

O contexto deste estudo de caso, portanto, está oculto, e somente a análise das notícias do período ou relativas a esta localidade e evento, e o levantamento de contexto com agentes operadores das barragens, EMAE, e do sistema de macrodrenagem (DAEE) podem desenhar melhor seu contorno, problemática e relevância. Este caso exige da análise qualitativa que se busque efeitos diferidos e cumulativos. 


\section{CAPÍTULO 6 - ANÁLISE DO TEMPO: NOTÍCIAS DE JORNAL DOS MOMENTOS CRÍTICOS NA RMSP}

Dentre as atribuições próprias de cada disciplina envolvida na análise de risco, ao urbanista é fundamental compreender os efeitos que as ameaças geram. Quais são, como se relacionam, o que é resíduo não gerenciado, e como os desenhos do ambiente construído (planejado ou não) podem estar implicados em determinadas consequências. Uma vez que as análises quantitativas dos efeitos são muito difíceis, dada a indisponibilidade de dados sobre efeitos de desastres, resta proceder à análise qualitativa, neste caso, recorrendo sistematicamente a fontes de notícias, e, a partir delas, documentos, planos relacionados e complementação de informações por entrevistas.

Uma das primeiras atividades da pesquisa empírica, antes do trabalho com os dados de ocorrências, foi realizar o levantamento de notícias de jornal sobre consequências geradas para datas indicadas pelo Plano Diretor de Macrodrenagem da Bacia do Alto Tietê (PDMAT3) - eventos pluviométricos críticos, usados para calibração e simulação de cenários na modelagem hidráulico-hidrológica. Foi consultada sistematicamente apenas uma fonte de notícias, os arquivos do Jornal Folha de São Paulo ${ }^{90}$, inicialmente para as datas e períodos que constam da lista abaixo.

Para essas datas ${ }^{91}$, foram encontradas as seguintes quantidades de consequências para a RMSP no conjunto de notícias:

23 a 26 de maio $2005-2$

05 a 12 de fevereiro $2005-7$

18 a 21 de dezembro $2007-8$

6 a 10 de setembro $2009-13$

21 de novembro a 19 de dezembro 2009 - 46

20 a 22 de janeiro $2010-14$

01 de janeiro a 01 de fevereiro de $2011-18$

Complementaram essas datas os períodos e dias críticos levantados a partir da sistematização do cadastro do IG, e períodos alargados para as datas dos 3 estudos de caso - ou conforme sugerido pelas próprias notícias.

Fez-se a opção de apresentar, neste capítulo, apenas a leitura dos períodos relacionados aos estudos de caso (2009-2010, 2014-2015 e 2015-2016), com

\footnotetext{
${ }^{90}$ Optou-se por utilizar apenas uma fonte de jornal porque interessava compreender a variação dentro de um período. Mais de uma fonte poderia trazer variações de ênfase e alinhamento editorial dos diferentes veículos para a análise, o que não é de interesse. Parte-se do princípio de que o fato noticiado não varia substancialmente entre os diferentes veículos, apenas a ênfase a determinados aspectos.

91 Datas selecionadas para calibração das modelagens e simulações do plano, relativas a ocorrências de transbordamento da calha do Tietê.
} 
referências a períodos de outros anos somente quando necessário, para salientar continuidades, semelhanças ou diferenças.

O ano crítico 2009-2010 contém um universo completo de variedade de consequências com interações críticas entre sistemas urbanos que esta pesquisa analisa. Os mesmos problemas revelados nesse período reaparecem nos períodos críticos posteriores analisados, mas apresentam ênfases diferentes. Desta forma, serão mais detalhadas no primeiro caso, e recuperadas para os casos seguintes.

\subsection{O ano crítico 2009-2010 e inundações duradouras no Jardim Pantanal}

Conforme apresentado no capítulo 5 , com base na análise do cadastro geral do IG, o ano de 2009-10 é o mais crítico da série: com 781 ocorrências na RMSP, mais de 18\% de todo o período de analisado, recorde em ocorrências geológicas (122), em mortes (46) e em quantidade de municípios atingidos (amplitude de 31 municípios, 29 para ocorrências geológicas e 30 para ocorrências hidrológicas). Se somadas as ocorrências de setembro de 2009, esses números sobem para 816 no total de ocorrências e 56 no total de mortes.

A primeira decisão para reestabelecer a sequência de acontecimentos, possíveis nexos perdidos e elementos residuais de análise, foi incorporar as notícias a partir do dia 09 de setembro (relativa a eventos do dia 08/09/09) no entendimento do ano de 2009-2010, pois foi verificada continuidade na caracterização da ameaça desta data em diante, para os efeitos do ano 2009-10. Este dia foi crítico na categoria "mais mortes" para o ano hidrológico 2008-09, com 12 mortes.

$\mathrm{Na}$ caracterização geral deste período destacam-se:

1) referências a um comportamento meteorológico atípico, não apenas com chuvas intensas fora do período esperado, mas a indicação de um fenômeno espacialmente abrangente e duradouro. As informações apontam também para uma ameaça fora dos padrões pela grande continuidade temporal, que mudou o padrão da resposta do ambiente urbano, ou seja, o padrão das consequências.

2) menções diversas a panes em sistemas de infraestrutura (além das panes normalmente previstas e gerenciáveis), não apenas como consequências, mas como agravantes das situações de emergência e das consequências. São panes que expõem fragilidade dos sistemas para tal magnitude de ameaça, e revelam interdependências críticas: panes telefônicas, elétricas, de sistemas de bombeamento, dos sistemas de alerta, dos sistemas de socorro e organização para resposta, e exposição de condições críticas de elementos dos sistemas para abastecimento de água.

3) a localidade do Jardim Pantanal, na porção leste da Metrópole, como manifestação concentrada da desordem diante da ameaça extrema. 
4) as datas em que mais e maiores impactos são relatados referem-se a ocorrências nos dias: 08/setembro/2009, 08/dezembro/2009, 21/janeiro/2010.

Os três primeiros aspectos, pontuados pelas datas mais críticas (ponto 4), orientam a análise descritiva das notícias do período.

\subsubsection{Um período de ameaça atípica}

Com relação à caracterização do fenômeno, as notícias apresentam opiniões e abordagens diferentes entre o final de 2009 e o início de 2010. A partir de janeiro, as notícias passaram a fazer referência a um comportamento meteorológico atípico, iniciado por chuvas intensas fora do período esperado, espacialmente abrangente e duradouro. Simultaneamente aos eventos de setembro, foram noticiados fortes vendavais desde a Região Sul (principalmente do Estado de Santa Catarina) e interior do estado de São Paulo, e contextos críticos de inundação no sul. Mas as opiniões dos especialistas em meteorologia colocavam as ameaças do sul e do sudeste como fenômenos independentes (09/09/09: C6), assim como consideravam a seca recorde de agosto seguida da chuva recorde em $24 \mathrm{~h}$ do dia 08/0992 fenômenos independentes:

“... tanto a baixa umidade do ar quanto de chuva não podem ser explicados por fenômenos climáticos como el Ninõ, la Niña ou pelo aquecimento global. 'Essas relações levam anos para ser comprovadas e ainda assim, são muito polêmicas'." (09/09/09: C5).

Em janeiro, foram noticiados eventos catastróficos em Angra dos Reis e São Luís do Paraitinga. Entre os dias 2 e 26 de janeiro, mais de 34 páginas foram dedicadas a esses desastres, 7 páginas somente no dia 03 de janeiro. A partir destes eventos, as informações passaram a apresentar menos argumentos meteorológicos e mais argumentos da climatologia, de uma ameaça fora dos padrões pela associação entre os fenômenos El Ninõ (de escala global), fenômenos de escala local típicos da temporada - uma zona de convergência de umidade no sudeste - e do microclima decorrente do excesso de impermeabilização em São Paulo (22/01/10: C5 e 28/09/10: C4).

"A Região Metropolitana de São Paulo, não bastasse a umidade acima da média que chega até ela, tem mais um agravante (...). Por causa da impermeabilização (...) as chuvas aqui têm ocorrido de forma mais rápida e concentrada. O calor que emana do concreto paulistano joga mais calor na atmosfera. Isso engorda as nuvens, que descarregam água de forma mais violenta. Os radares (...) mostram claramente essa situação (...) 'nuvens de até $18 \mathrm{~km}$ de altura'." (28/09/10: C4)

No início de janeiro, as notícias discutiam divergência entre dados (sobre os recordes batidos ou não) e incipiência das séries históricas para fazer afirmações.

\footnotetext{
${ }^{92}$ As reportagens indicam $70 \mathrm{~mm}$ de chuva em um dia, frente à estimativa para o mês entre 42 e $86 \mathrm{~mm}$, e que o acumulado nos 8 dias do mês foi de $141 \mathrm{~mm}$ (13/09/09 p. C3).
} 
"Não faltam pesquisadores, nem tecnologia. Falta um maestro que organize essas variáveis [a respeito da ausência de dados para estudos climáticos na região costeira] ." (10/01/10: C6).

"A quantidade de chuvas registradas por dois institutos diferentes em São Paulo coloca o atual mês de janeiro entre os mais chuvosos de que se tem notícia. $O$ problema é que o país tem séries históricas relativamente curtas, o que deixa essa contextualização prejudicada. Segundo os dados da USP, o atual janeiro já é o mês mais chuvoso registrado, com $577 \mathrm{~mm}$ até ontem. As medições (...) no Parque do Estado começaram em 1933. Para o INMET, que faz medições no Mirante de Santana, o mês atual está na terceira posição da série histórica deles, que começa em 1943. Na zona norte, até ontem, havia chovido 426,8mm. Os dois primeiros colocados do ranking são os meses de janeiro dos anos de 1947 (481,4mm) e de 1987 (442,3mm)." (28/01/10: C4).

“'De qualquer forma, não haveria quebra de recorde', afirma (...) meteorologista do INMET. Segundo outras duas medições, da USP e CGE, nunca choveu tanto em um janeiro em São Paulo como neste ano." (01/01/10: C4).

Além de incertezas, também há registros de limites nos serviços de previsão meteorológica em interagir com outras áreas, como defesas civis e outras conhecedoras das vulnerabilidades das ocupações, para evitar consequências mais graves.

"'A gente não sabia qual rio poderia transbordar ou em que morro haveria deslizamento. Mas pela previsão, dava para saber que muita chuva ia cair na região (...) e que haveria problemas."' (12/01/10: C3).

Ao fim da temporada, em fevereiro, parecia haver maior consenso a respeito das características da ameaça no período:

"Não é só o volume de chuvas que impressiona e está acima da média. A quantidade de vezes que choveu em São Paulo em janeiro também reforça a existência de um fenômeno climático atípico. 'A chuva toda foi distribuída pelo mês. Nos 28 dias que choveu nas medições da USP, as precipitações foram entre fraca e intensa, com poucas exceções'“. (01/02/10: C6).

Esse foi um padrão de ameaça semelhante ao do ano seguinte, 2010-11. Janeiro de 2011 bateu o recorde de chuva da série histórica, com 491,5mm - o recorde de 1947 era $481,4 \mathrm{~mm}$ ). O pior dia (acumulado de chuva em 24h) da temporada 2010-11 teve $88,6 \mathrm{~mm}$ de chuva na média, enquanto na temporada $2009-2010$ foi de $90,4 \mathrm{~mm}$. Em 2011 também houve chuvas concentradas em determinadas localidades, com 102mm no bairro da Penha, em 23/01/11. Os argumentos meteorológicos e climatológicos em janeiro de 2011 caracterizavam um cenário de chuvas intensas concentradas em determinadas localidades, com aumento da média das chuvas ao longo de todo o mês (duração), cenário motivado pelo aquecimento global, microclima ${ }^{93}$ e sazonalidade típica do verão (16/11/2011: C2), resultando em solos saturados ao fim das temporadas.

\footnotetext{
93 "Os dados do climatologista do Inpe, Carlos Nobre mostram mudanças no padrão de chuvas que a mudança climática causou (...). As ilhas de calor explicam por que, apesar de aumentos nas precipitações intensas terem ocorrido em todo Sudeste nos últimos 80 anos (...) na região metropolitana de São Paulo o crescimento foi 3,5 maior que a média." (13/01/11: C6).
} 
Entretanto, o período 2010-11 apresentou menos notícias de consequências que o período 2009-10, e menor criticidade (duração das inundações) no Jardim Pantanal.

Ao analisar as consequências, a percepção de que o período 2009-10 não foi típico fica reforçada, quando as notícias trouxeram muitas discussões e especulações sobre a forma da cidade na interação com a ameaça. Desde o debate sobre a configuração das Marginais imediatamente após as obras para sua ampliação - "não deveriam existir", "a impermeabilização das marginais é desprezível para a contribuição no Tietê", "é preciso religar a cidade com o rio, e não bloquear essa interligação pelo fluxo de carros" (10/09/09 p. C4) - até argumentos de ordem hidráulico-hidrológicos propriamente - "é preciso aumentar a velocidade da água em Osasco e Barueri" (09/09/09: C8), "O cenário do nível de segurança das obras das marginais mudou" (09/09/09: C6).

A discussão sobre a impermeabilização do solo foi a que se fez mais presente, desde os argumentos sobre sua importância na absorção e diminuição do escoamento superficial até as questões relacionadas à interferência na característica das ameaças (conforme citado anteriormente, o microclima que produz nuvens mais densas e chuvas convectivas). Os argumentos abordam não somente a capacidade de absorção, mas a contribuição de desenhos apropriados difusos por toda a cidade, não concentrados em grandes estruturas:

“(...) todos os municípios da Bacia do Alto Tietê deveriam exigir que novas edificações fossem capazes de reter ou armazenar a mesma quantidade de água de chuva que seria retida naquele espaço se ele estivesse coberto de vegetação ${ }^{94 "}$. (22/12/09: C1).

"Parques lineares, calçada verde e recuperação de áreas degradadas são as apostas da Prefeitura de São Paulo para combater enchentes." (23/01/10: C4).

Os relatos das consequências no decorrer do período, entretanto, iam indicando que os argumentos a favor de medidas não estruturais em drenagem eram limitados para a magnitude do problema da temporada. Foram noticiadas ocorrências geológicas em bairros de São Paulo onde esses eventos não são recorrentes, e onde as ocupações não são precárias (Perdizes e Lapa). Foram apontados que novos pontos de alagamento, sem recorrências anteriores, estavam sendo registrados. O sistema de drenagem estava no limite e o solo estava no limite:

"O Secretário das subprefeituras (...) disse que a cidade entrou no período de chuvas com o sistema de drenagem - galerias, bocas de lobo, córregos e piscinões - com $100 \%$ de sua capacidade. (...) O solo estava mais encharcado porque vem chovendo acima da média desde o segundo semestre do ano passado." (09/01/10: C1).

O Parque Ibirapuera estava com permanentes alagamentos, e também o Zoológico e Jardim Botânico, em zonas altas da cidade de São Paulo. Foi registrado o dobro de

\footnotetext{
${ }^{94}$ Em estudos feitos para a prefeitura de São Paulo em 2014 para revisão do Código de Obras e Edificações, a utilização desse critério, de restituição da vazão de pré-desenvolvimento no lote, levou a volumes de reservatórios em torno de $480 \mathrm{~m} 3 / \mathrm{há}$. Em um lote mínimo de $5 \times 25 \mathrm{~m}$, isso resultaria em um volume $6 \mathrm{~m} 3$, ou um tanque de $2 \times 2 \times 1,5 \mathrm{~m}$. Posteriormente, essas discussões foram substituídas pelo instrumento da Cota Ambiental.
} 
quedas de árvore em relação a outros anos, e indicada relação com o comportamento do solo (04/02/2010).

A constatação da grande continuidade temporal das chuvas no período, que mudou o padrão da resposta do ambiente urbano, trouxe novos argumentos à discussão da permeabilidade do solo, restituindo à discussão um aspecto importante das características do meio físico da RMSP:

"Os solos de São Paulo, devido à sua natureza silte-argilosa, têm uma permeabilidade muito baixa, e a água tem dificuldade para atravessá-los (...). Com mais de 20 dias seguidos de chuvas, o solo acaba se saturando. Para piorar as coisas, o volume de poros no solo é pequeno e os poros não se comunicam entre si. Todas as colinas de São Paulo (...) têm essa composição argilosa. (...) Não sou contra essas medidas [não estruturais, de aumento da permeabilidade], mas o nosso solo não é grande coisa na capacidade de absorver água. A eficiência no aumento da impermeabilização não é o que se espera. Contar com o aumento da permeabilidade para resolver o problema das enchentes não faz sentido, porque o solo embaixo é impermeável. Vai ser como um mataborrãozinho numa pia de granito." (Entrevista com geólogo Arnaldo Kutner, 29/01/10: C3).

Estávamos diante de dois anos com ameaças semelhantes, cujas consequências demonstravam que tínhamos chegado aos limites das estruturas para detenção e fluxo da chuva e do solo. Mas as consequências em 2009-10 foram diferentes e mais críticas (com mais mortes) que em 2010-11.

\subsubsection{Principais consequências e as panes como agravantes}

Foram 6 páginas do jornal apenas para o dia 09/09. No dia 08/09, havia chovido $70 \mathrm{~mm}$ em um dia, dentro de uma estimativa média do mês estabelecida entre 42 e $86 \mathrm{~mm}$. Nos oito dias anteriores no mês de setembro, já havia chovido $141 \mathrm{~mm}$. Há destaque de notícia para uma pane telefônica que dificultou o trabalho de emergências, impedindo a realização de chamadas para a polícia e defesa civil. Em um dia de primavera, a chuva fora das estatísticas resultou em 86 pontos de alagamento em toda a Região Metropolitana, com paralisação de trânsito (152 km de lentidão), e 7 mortes relatadas nos estados de São Paulo e Santa Catarina (no bairro de Itaquera, em Osasco e Guarulhos, números que aumentaram nas edições seguintes, e totalizaram 12 mortes pelo cadastro do IG). Aeroportos, linhas de trens e vias de circulação importantes foram paralisadas, o Ceagesp perdeu mais de 300 toneladas de frutas devido a alagamentos. Neste cenário, a falta de telefones agravou a situação (09/09/09: C7):

"A Polícia Militar informou que os telefones de emergência 190 (para solicitação de policiamento) e 193 (para casos de incêndio, busca e salvamento) ficaram inoperantes durante 1 hora e 20 minutos (...). Ao menos 3 ocorrências graves (desabamento, soterramento e pessoas ilhadas em enchentes) foram comunicadas com atraso, de acordo com a PM'.

"A Defesa Civil informou que também o seu telefone, 199, não funcionou pela manhã, e prejudicou o atendimento de ocorrências como queda de árvores e 
deslizamentos. À tarde, o serviço da Defesa Civil recebia chamadas referentes a casos ocorridos às $6 h . "$

“Outro serviço prejudicado foi o da CET, no telefone 1188. Por este número, o motorista pode alertar sobre a presença de semáforos apagados na cidade, ou informar sobre ocorrências de trânsito. O número ficou inoperante até as 16h."

As notícias relatam que não era a primeira pane da companhia telefônica no mesmo ano, porém a informação divulgada posteriormente, em 10/09/09 (10/09/09: C5), indica que houve uma situação de falha em cascata: uma empresa terceirizada da Telefônica informou que três equipamentos, responsáveis por direcionar chamadas, foram danificados em virtude das descargas elétricas do temporal. Situação que revela condição de vulnerabilidade desses sistemas e, principalmente, dos sistemas de emergência, dependentes de sistemas de comunicação frágeis.

As notícias registram eventos de tornados e chuvas persistentes na região sul de setembro a novembro, com alto número de mortes, e à combinação de fenômenos como o El Niño, frentes frias vindas da Patagônia e massas tropicais da Amazônia.

Em São Paulo as chuvas persistiram em novembro, com relatos, ao fim do mês, de mais panes elétricas (principalmente por quedas de árvores) e um blecaute no dia 23/11/2009 devido a problemas menores e simultâneos, como o rompimento de um cabo de transmissão e outras falhas não esclarecidas na saída de uma subestação elétrica.

Dias antes desse blecaute local, em 10/11/09, o Brasil teve um dos maiores blecautes devido a uma falha em uma subestação de Itaberá $^{95}$ (SP), atingindo mais de 18 estados das regiões sul, sudeste e centro-oeste. Segundo apuração da ONS (notícia de 04/12/09: C10), a falha ocorreu devido ao mau funcionamento de isoladores sob condição de chuva, atingindo outras 3 linhas de $750 \mathrm{kV}$ que saem de Foz do Iguaçu para o fornecimento regional, e são as de maior tensão da América Latina. A reportagem indica que o problema de perda de capacidade dos isoladores sob chuva havia sido diagnosticado em 2007, e medidas para troca foram tomadas, mas não integralmente concluídas.

Coincidência ou não, um mês depois, em 09 de dezembro, os jornais noticiaram um dos piores contextos de desastre na Região Metropolitana de São Paulo, como consequências das chuvas dos dias 07 e 08 de dezembro de 2009 e de uma pane elétrica em uma das bombas do Rio Pinheiros.

\footnotetext{
95 Segundo pesquisa (ZOLNERKEVIC, 2017), este foi um dos maiores apagões do Brasil, e começou com a falha na subestação em Itaberá. "O problema desencadeou uma cascata que levou ao desligamento da hidrelétrica de Itaipu e afetou estados inteiros do Sudeste e do CentroOeste, além do Paraguai. Houve um efeito de amplificação. A desconexão de Itaipu, que produzia $20 \%$ da energia elétrica do país, induziu outras partes da rede, indiretamente ligadas à usina, a também se desconectarem, e o blecaute afetou cerca de $40 \%$ da demanda no território nacional."
} 


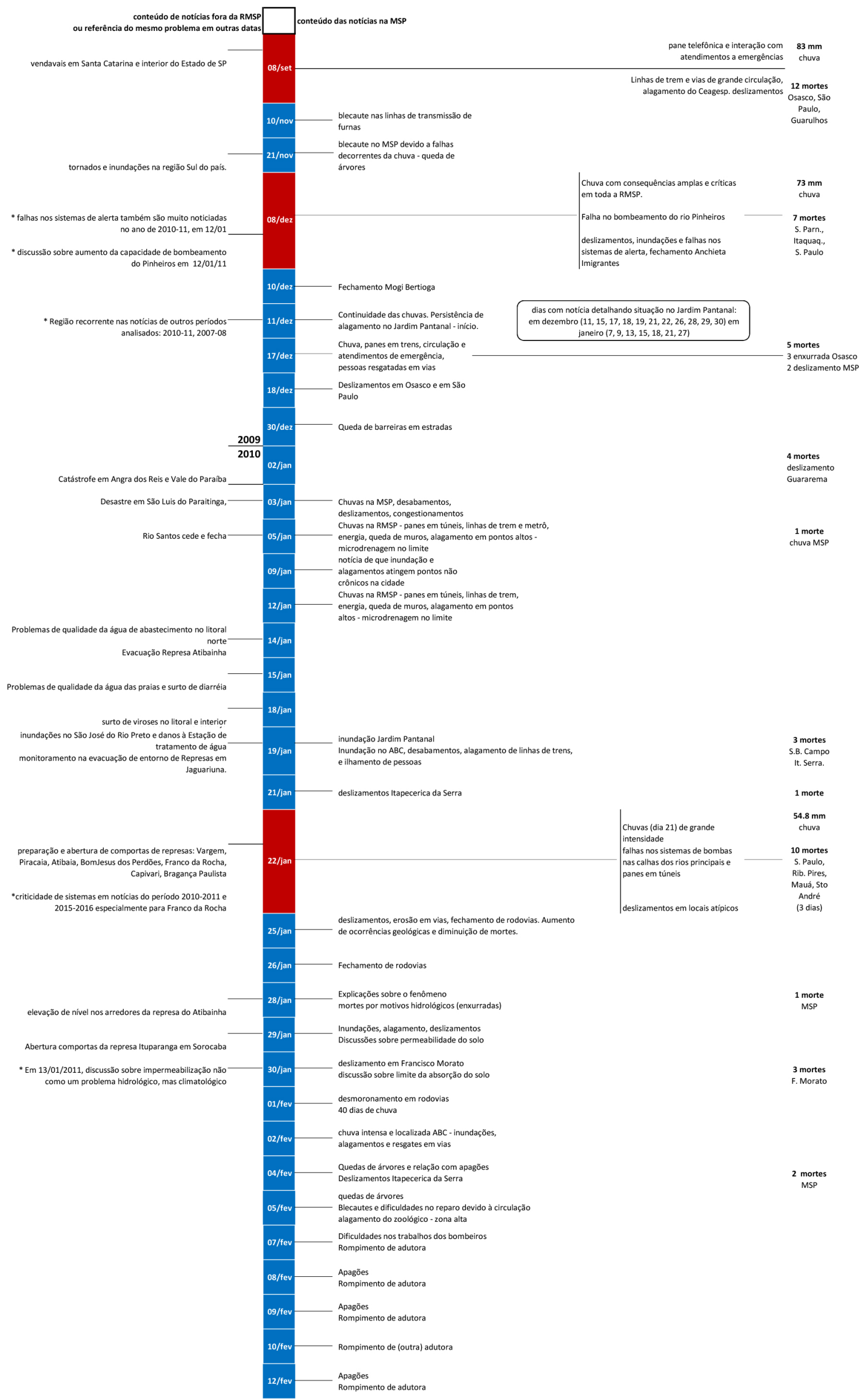
"As mortes indicadas nas noticias foram cotejadas com dados do cadastro geral do IG, corrigidas ou acrescentadas às noticias. Do cadastro, constam mortes para dias sem notícias
e não listados na linha do tempo: 06/out (1); 01/dez (1); 04/dez (7 - It. Serra, Mauá, MSP); 27/dez (1); 13/jun (1). 
Para efeitos de controles de inundação, a contribuição da bacia do rio Pinheiros para o rio Tietê é considerada (e deve funcionar como) "nula, devido ao sistema implantado que permite o isolamento da bacia pela Estrutura de Retiro, e a transferência das vazões para o Reservatório Billings, por meio de bombeamento nas Usinas Elevatórias de Traição e Pedreira" (PDMAT3 - R11/ SÃO PAULO-ESTADO: 6). Em 1992, em função da baixa qualidade das águas do rio Pinheiros - por lançamentos de esgotos e cargas difusas - e devido à necessidade de controlar a poluição para preservar as funções de abastecimento da Billings, o bombeamento contínuo foi proibido, mantendo-se a reversão somente para controle de cheias, quando é esperado que a calha do Pinheiros funcione como um grande reservatório.

No dia 08/12/2009, uma das quatro bombas existentes sofreu uma pane elétrica que afetou este funcionamento hidráulico, comprometendo $25 \%$ da capacidade de bombeamento do rio Pinheiros e, consequentemente, o escoamento na calha do Tietê. A falha da bomba não evitaria as cheias, mas diminuiria as consequências vividas na metrópole nesse dia.
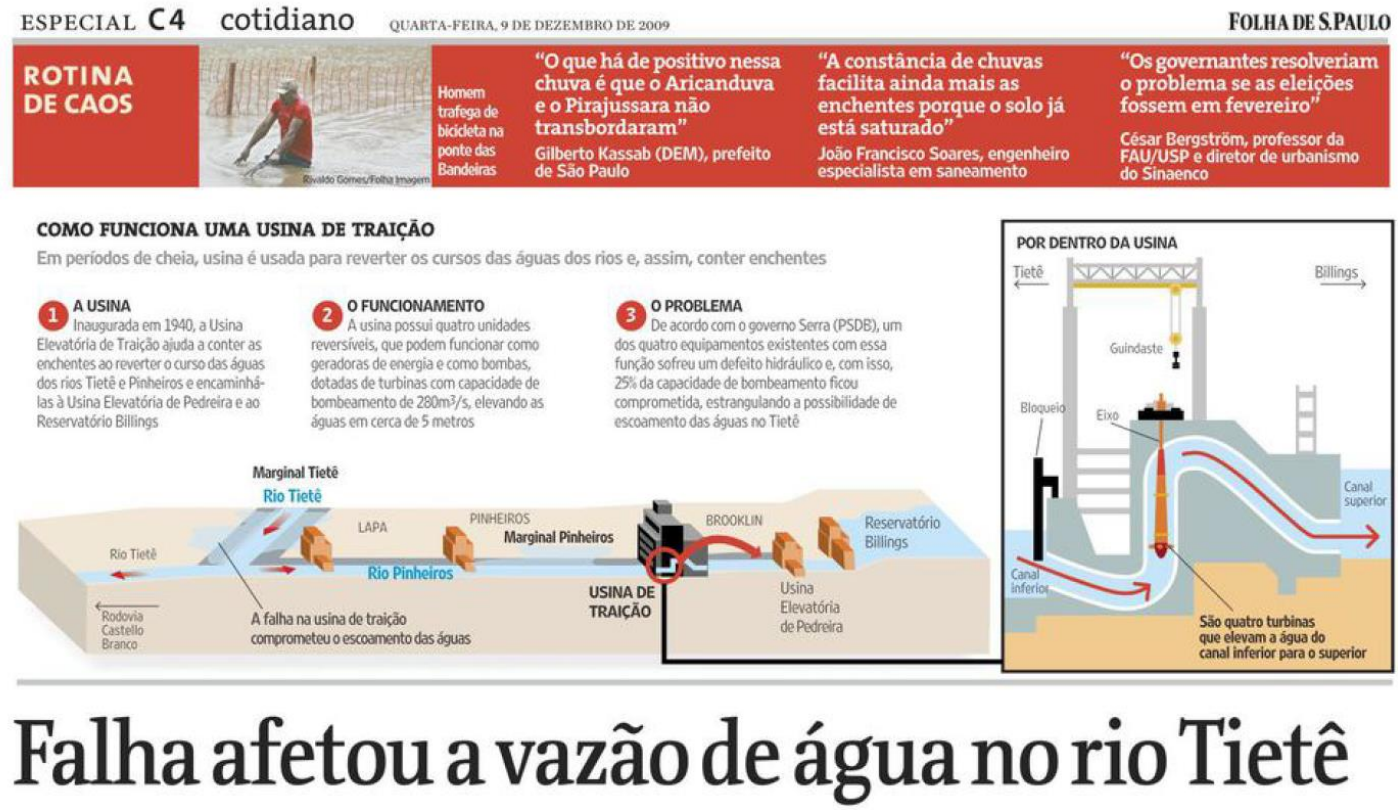

Defeito em uma das quatro bombas usadas para esvaziar o Pinheiros e aliviar o Tietê acabou prejudicando a operação

FIG. 21 - Falha no bombeamento do rio Pinheiros. Arquivos Folha de São Paulo, 09/12/2009:C4.

Foram nove páginas do jornal dedicadas ao evento, e mais cinco no dia seguinte. Relatados 105 pontos de alagamento com inundação do Ceagesp e mais de $127 \mathrm{~km}$ de congestionamento. A rodovia Anhanguera foi bloqueada completamente pela manhã e o transporte ferroviário na linha 7 (Luz-Francisco Morato) interrompido por mais de 10 horas entre Caieiras e Jundiaí, revelando que a porção Norte da Metrópole possui uma estrutura de mobilidade bastante vulnerável ${ }^{96}$. Além desta, outras duas linhas foram

96 O fechamento da Rodovia Anhanguera e da linha 7 é uma constante nesse período e em vários outros
períodos pesquisados nas notícias. Nas reuniões de grupos de trabalho do PDUI e nas audiências públicas
dos dois últimos anos ( 2017 e 2018), representantes da região norte e do Consórcio Cimbaju são
fortemente engajados nas questões de ampliação da mobilidade da região, muito embora representem
esse interesse recusando soluções racionais de controle da hierarquização viária proposta no plano, 
prejudicadas. Mais de mil desabrigados, ao menos 7 mortes, e muitas pessoas ilhadas em casas ou no trânsito.

O Tietê subiu sete metros e o Pinheiros, quatro. O CGE (Centro de Gerenciamento de Emergências) emitiu alerta de transbordamento dos rios Tietê e Pinheiros somente depois que ambos já tinham transbordado, às 5:55h da manhã.

"Se o alerta do CGE tivesse chegado com antecedência, vias que seriam alagadas poderiam ter sido interditadas, emissoras de rádio poderiam informar a população, e as concessionárias poderiam avisar motoristas em estradas que chegam à cidade para evitar as Marginais, por exemplo" (11/12/09:C1).

"Vendo a quantidade da chuva e que o nível do rio já tinha subido, a gente poderia decretar o alerta antes do rio transbordar. Mas é muito difícil. E se a gente decretar um estado de alerta, que é grave, e a coisa não acontecer? Aí o nosso trabalho perde o crédito." (11/12/09: C1).

Diferentemente do sistema do SAISP (Sistema de Alerta de inundações da FCTH), que trabalha com medição da vazão em alguns rios, o sistema de alerta do CGE trabalhava com limiares de chuva associado a uma previsão (velocidade) de subida do nível de água dos rios dentro de um comportamento padrão da vazão. Não contava com a elevação do nível do rio em velocidade maior devido à falha de bombeamento. A falta de comunicação de risco decorrente, em parte, da desconexão entre os diferentes sistemas de monitoramento, também é um agravante nesse contexto.

Incomum a outras datas, as imagens das notícias desse dia passam a ideia de um caos completo: pessoas presas dentro de ônibus por horas, caminhões de lixo fazendo resgate de pessoas ilhadas, e veículos (em torno de 50) invadindo o estacionamento do Complexo do Anhembi:

"A água estava subindo, mas os seguranças não deixavam a gente entrar. Aí o motorista de um caminhão quebrou o portão e todos entraram." (09/12/09: C2).

A inundação do quartel de bombeiros na Ponte do Limão também pode ser considerada como uma falha na estruturação de um sistema de resposta (09/12/09: C2):

"O que ninguém imagina, é que em dias de enchente, como ontem, aumentam os chamados de incêndio. 'As casas mais antigas, que não têm laje, têm muito curto-circuito. Os fios entram em contato com a água'."

"Dos 33 modelos de carros da corporação para salvamento, só alguns, como as motos, conseguiram sair na manhã de ontem. Ainda assim, houve bombeiros que tiveram de nadar, com a enchente na altura do peito, para chegar ao local da ocorrência e apagar o incêndio com baldes enchidos com a água da chuva".

“'A água chegou ao para-brisa do carro. Não teve jeito, abri os braços e fui embora. O problema maior foi não poder nos locomovermos, ficarmos ilhados', disse o Capitão (...) do Quartel da Casa Verde, de onde era possível chegar de bote inflável no rio Tietê".

defendendo a conexão direta da malha urbana com vias de Classe 0 e 1 e recusando a proposta de indução de novas vias intra-urbanas. Esta questão da mobilidade está presente nos estudos espaciais do caso 2. 
Esses tipos de problema aumentaram no final da longa temporada chuvosa:

"O principal problema das equipes tem sido chegar aos locais de ocorrências. $O$ trânsito e a água nas ruas atrasam e até impedem a chegada do resgate. Para a população, uma dificuldade extra: conseguir linha para comunicar as emergências." (07/02/2010: C6).

Essas informações mais sutis sobre as variadas consequências de uma grande ameaça são detalhes fundamentais para criar repertório sobre quão vulnerável pode ser uma cidade, que tipos de vulnerabilidades existem, e quais cenários a mente de um urbanista deve frequentar quando reflete sobre resiliência urbana frente a ameaças extremas.

As consequências relacionadas a deslizamentos são mais apreensíveis às análises urbanísticas, porque mais graves e noticiadas, reconhecidas. As soluções para sanar vulnerabilidades a acidentes geológicos também são bastante difundidas no campo dos estudos urbanos - o que não significa que as soluções sejam implementadas porque se conhece o problema e as soluções, nem que o choque causado anualmente por mortes devido a deslizamentos sirva como alerta para a implementação de políticas habitacionais mais responsáveis. $O$ fato é que os outros cenários de risco ilustrados pelas reportagens nesse período são pouco problematizados na prática projetual e de planejamento, e podem ser agravantes de situações de risco já conhecidas, evitáveis por um bom planejamento das localizações de bases estratégicas de resposta e comunicação, e da estrutura de circulação de seu entorno. Esta situação vivida por uma família vítima de deslizamento de terra no Tremembé, de janeiro de 2011, ilustra o problema:

"Desesperados, seus familiares correram para ajudar. No quarto, sob os escombros, Claudia gemia. Emanuela não dava sinais de vida. Enquanto aguardavam o resgate, tentaram em vão remover a terra e pedaços de alvenaria que estavam sobre a mulher. O resgate chegaria uma hora depois do acidente. Claudia não resistiu." (12/01/11: C3).

No dia 09/12/09, as notícias relatavam as primeiras mortes referentes a deslizamentos (Santana de Parnaíba, Itapevi e Cajamar) e desabamentos de residências sobre córregos ou edificações precárias (barraco). Há menção a uma morte em Cajamar causada pela velocidade da água em um escadão. Dias depois, em 11/12/09, as notícias passaram a relatar a persistência dos alagamentos na região do Jardim Pantanal, localidade que prevaleceu nas edições até o fim do período, em fevereiro de 2010 (e que será descrito em mais detalhes na seção 6.1.3 e no capítulo 7).

Quedas de barreiras em estradas e o fechamento de complexos rodoviários - AnchietaImigrantes e Mogi-Bertioga - foram noticiados no final de dezembro e início de janeiro, quando Angra dos Reis e São Luiz do Paraitinga sofreram graves consequências das chuvas. No início de janeiro, há relatos de paralisação de linhas de trem e metrô (por quedas de árvores e alagamentos) e de alagamento de zonas altas, indicativos de que o sistema de micro drenagem trabalhava no limite. Ao final do período (fim de janeiro e início de fevereiro) as ocorrências de deslizamentos e desabamentos passaram a aparecer com mais frequência, mesmo em partes de urbanização menos precária, embora com diminuição do número de mortes. Pelas notícias, é possível compreender 
o aumento dessas ocorrências como consequência da saturação do solo após tantos dias de chuva, mas não é possível afirmar se as mortes diminuíram por uma melhor mobilização na resposta a emergências após um período tão longo, ou se a resposta a emergência em situações urbanas mais bem estruturadas (sobretudo em termos de circulação) funciona melhor.

A terceira data emblemática no período foi o dia $\mathbf{2 1}$ de janeiro. Assim como nas outras duas datas críticas (8 de setembro e 8 de dezembro), neste dia as inundações foram amplas em toda a metrópole, 112 áreas com alagamento e 10 mortes. Os rios Tietê e Pinheiros transbordaram e deslizamentos de terra causaram 7 das mortes noticiadas. A média acumulada de chuva deste dia, entretanto, foi um pouco menor que a dos outros dias críticos, $54,8 \mathrm{~mm}$. Os piscinões Sharp (na bacia do Pirajussara) e Pedreira (na bacia do Aricanduva) transbordaram porque já estavam com sua capacidade esgotada e, segundo as notícias (22/01/10: C5), por insuficiência no bombeamento. $O$ transbordamento dos rios Tietê e Pinheiros provocaram efeito em cascata no trânsito, afetando a circulação nas estradas que chegam à cidade. O DAEE declarou que esses efeitos eram decorrentes de uma chuva intensa incidindo sobre um solo totalmente encharcado e sobre estruturas já na capacidade limite após 30 dias contínuos de chuva. O Engenheiro Aluísio Canholi declarou que "os pontos de alagamento principais na Marginal Tietê têm diques de proteção, tanques e bombas. Provavelmente estes sistemas não estão funcionando a contento" ${ }^{\prime 2}$.

Situação confirmada de falha no sistema de bombeamento da drenagem foi noticiada em outra localidade, nos túneis Tribunal de Justiça e Ayrton Senna, no Itaim:

"O problema começou à 1:35h, quando uma falha elétrica causada pela chuva fez com que as bombas de drenagem parassem. Minutos depois, antes que 0 gerador começasse a funcionar, o painel eletrônico que comanda o sistema já estava coberto pela água. Se a água tivesse atingido o teto do túnel, poderia haver um curto-circuito no sistema de iluminação." (...)

"A água deixou submerso também o sistema de ventilação do Túnel Ayrton Senna, que fica a poucos metros do Túnel Tribunal de Justiça e foi sobrecarregado pela interdição no vizinho. Com isso, a fumaça dos veículos que trafegavam no início da manhã começou a incomodar os motoristas. O tempo para percorrer o túnel, de $1,7 \mathrm{~km}$, chegou a 2 horas. Segundo técnicos, o recomendável é que a permanência dentro de um túnel não ultrapasse meia hora". (...)

"No Tribunal de Justiça, funcionários do Metrô, da Eletropaulo e de empresas privadas foram escalados para retirar a água. Levaram 12 horas para descobrir como fazer a sucção". (22/01/10: C4).

"Tudo bem, entrou uma quantidade grande de água, faltou energia, o gerador não ligou. Mas um quadro elétrico não pode ficar em uma área ao alcance da água. E, numa situação dessa, é preciso que exista um plano de contingência

\footnotetext{
97 Dentro dos períodos analisado, também em 03/12/2005 foram apontadas falhas de bombeamento nas Marginais.
} 
também, que determine as ruas que serão fechadas e por onde o trânsito será desviado." (23/01/2010: C4).

A reportagem aponta registro de alagamento do túnel em 1998, também pelo mau funcionamento do gerador elétrico para uso em caso de queda de energia. Outro túnel problemático na cidade, o Anhangabaú, foi fechado quatro vezes, no período 2009-10: nos dias 08/09 em 2009, e nos dias 25/01, 27/01 e 02/02, em 2010. Na década analisada, também consta fechamento em 09/02/2007 e em 10/01/2011.

Já no fim do período, além do aumento do número de deslizamentos e das panes em bombas, a metrópole passou a enfrentar aumento das panes elétricas e falta de energia generalizadas, problemas de rompimento de adutoras e necessidade de executar operações de manobras nas represas para evitar transbordamentos com danos ainda maiores.

No dia 08/02/10 houve rompimento de uma adutora localizada na zona Sul de São Paulo, que leva água do alto da Boa Vista para as regiões oeste e sul da cidade, e para os municípios de Cotia, Carapicuíba, Embu e Taboão da Serra. O evento interrompeu fornecimento de água para mais de 750 mil pessoas, abrindo uma cratera de mais de $5 \mathrm{~m}$ de diâmetro no local. O reparo levou mais de 24 horas. Os motivos não são apresentados nas matérias, mas é provável que seja devido à saturação do solo.

A partir de 04 de fevereiro de 2010, as notícias de quedas de árvores e panes elétricas passaram a aparecer com mais frequência. Nessas matérias, as concessionárias alegavam que o trânsito e pontos de alagamento dificultavam o deslocamento das equipes para efetuar reparos e manutenções. Em 13/02/10, uma interrupção mais grave na região central de São Paulo apresentou motivos de panes mais complexos: o rompimento de dois cabos subterrâneos no dia 10/02/10 após um curto circuito, possivelmente por problemas de manutenção e estanqueidade. No mesmo dia, o país sofria, novamente, um dos maiores apagões pelo desligamento de uma linha de transmissão no Tocantins, que atingiu 11 estados das Regiões Norte e Nordeste. 0 motivo para problema de tal magnitude foi, também, queda de árvore.

Por fim, o período expôs condições críticas de elementos dos sistemas para abastecimento de água. Em 14 de janeiro, antes do terceiro dia mais crítico do período (21/01/2010), era noticiado um plano de emergência para evacuação de localidades na área de influência das manobras das represas do Sistema Cantareira, sob controle da Sabesp, devido à iminência de riscos de transbordamento. A situação vinha sendo monitorada desde setembro, e em janeiro foi dada ordem para retirada de pessoas das áreas de alto risco, ou seja, na influência do canal a jusante das barragens, cabendo à Sabesp e aos municípios organizar planos de contingência.

"No município de Bom Jesus dos Perdões, um condomínio praticamente inteiro, chamado Nova Veneza, nas margens da rodovia $D$. Pedro, poderá ser inundado se o volume de chuva sobre as represas continuar grande até o fim do mês.

Mais perto da capital, Franco da Rocha também pode ser atingida. Inclusive, estradas que passam pela região tendem a ficar intransitáveis se 0 transbordamento for grande." (14/01/2010: C1). 


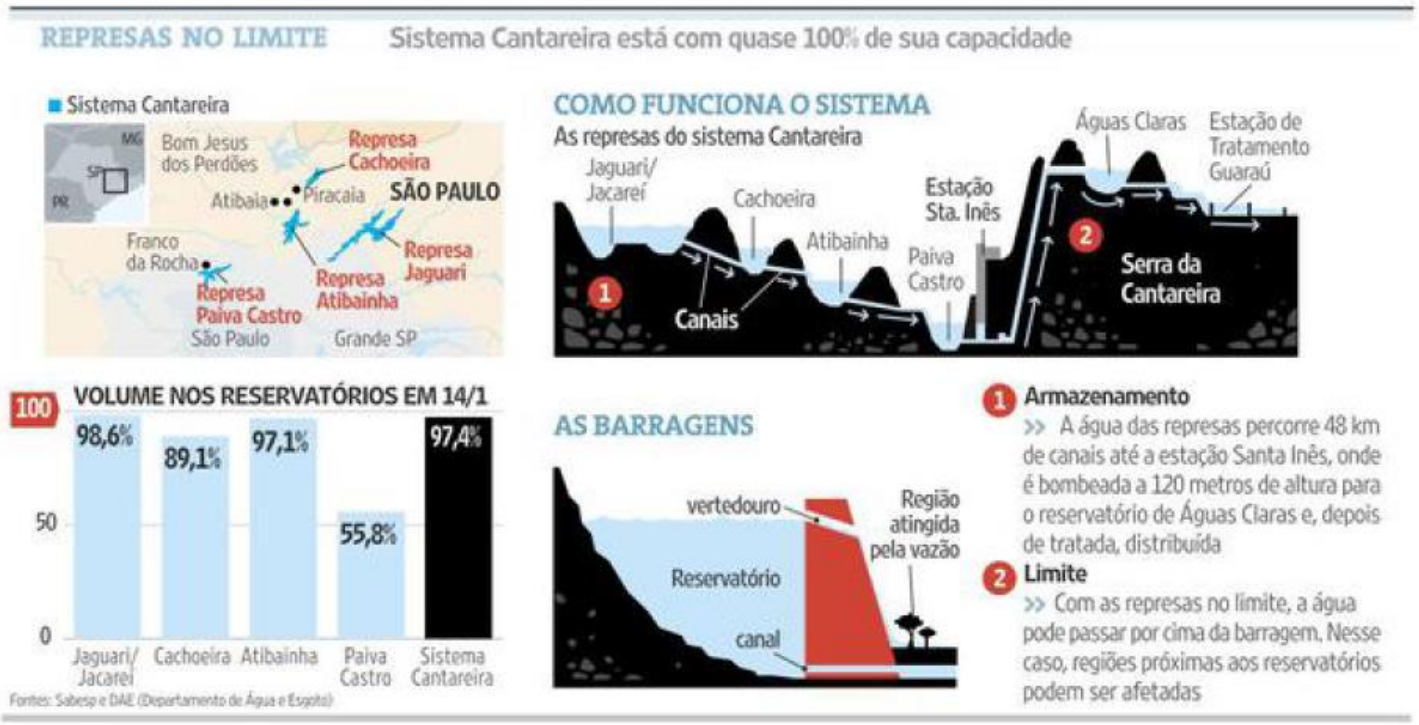

Fig. 22 - Limite de armazenamento do Sistema Cantareira. Arquivos Folha de São Paulo, 15/01/10: C3.

Além destes, também estavam no plano os municípios de Atibaia, Vargem, Nazaré Paulista e Piracaia, no rio Atibaia, e Jaguariúna, Pedreira, Amparo e Bragança Paulista, no Jaguari-Jacareí. Tratava-se de um plano de comunicação, apenas, pois o risco material para as casas era inevitável. O que traz preocupações a respeito do regramento urbano produzido por esses municípios, pois são relatadas tanto situações de ocupações anteriores à construção da represa, como de ocupações informais, rurais, e de ocupações formalizadas posteriormente, ainda que essas ocorrências tenham um tempo de recorrência observado próximo ao prazo de revisão de planos diretores:

"Desde 1973, quando o sistema de abastecimento de água ficou pronto, duas vezes a água passou por cima da barragem. Uma em 1985 e outra em 1999. A recorrência desse fenômeno tem sido de 12 anos." (14/01/10: C1).

"Só o aumento de fluxo do rio, pela abertura controlada das barragens, seria suficiente para provocar enchentes. 'Nos últimos anos, por causa da estiagem, as várzeas dos rios acabaram ocupadas'." (15/01/10: C1).

“(...) Secretário de obras da cidade diz que uma decisão judicial de cinco anos atrás regularizou o condomínio, que começou, segundo ele, com ocupações irregulares, sem licença dos órgãos devidos (como a Cetesb). 'A Justiça decidiu que o local era regular, então fornecemos os documentos'. (...) Já o Prefeito diz que (...) 'sempre foi regular'.' (15/01/10: C3).

Foram noticiados casos de resistência de moradores e prefeitos para a retirada antecipada das famílias. Em 22 de janeiro, após o terceiro dia crítico do período, e com a subida do nível d'água um metro acima do normal em Atibaia, devido a procedimentos de manobra, finalmente as famílias passaram a ser removidas:

"Segundo o Município [Bom Jesus dos Perdões], a quantidade de água liberada dos reservatórios é maior do que a anunciada. (...) A Sabesp diz que as represas estão mantendo água de maneira controlada e que as comportas estão sendo abertas desde o mês de dezembro." (22/01/10: C6). 
Não é pequena a magnitude dos riscos residuais envolvidos por essas medidas de segurança. Para evitar catástrofes maiores, um risco residual passa a ser gerenciado, e nesse caso, representa aproximadamente 900 famílias desabrigadas pela cheia do rio Atibaia, e mais 400 pelas cheias do rio Jaguari.

"O medo é que o rio, que já entrou mais de um metro nas moradias mais próximas, suba aos próximos dias os dois metros a mais que a Defesa Civil diz serem inevitáveis. 'Próximas' é maneira de dizer. No Parque dos Coqueiros, também de classe média, o rio passa normalmente a mais de 300 metros das casas." (28/01/10: C6).

Os conflitos entre interesses de municípios e funções setoriais de grandes dispositivos de infraestrutura, nesses casos, são evidentes. Há as questões do assoreamento dos rios, que antes da implantação das represas têm maior vazão, e após a construção das represas - e em situação de normalidade do fluxo de saída - têm sua vazão de base mantida muito baixa. Isso ocasiona assoreamento que, em situação de manobra de abertura da comporta, pode aumentar a mancha de inundação prevista. Quando a represa está com os níveis controlados, as questões permanecem em torno do conflito pela água.

"O vice-prefeito de Atibaia (...) diz que o tema em torno do sistema Cantareira, nos últimos anos, vinha sendo a seca. 'A gente reclamava que nossa região estava sendo drenada para abastecer São Paulo de água. Em uma circunstância como essa é difícil tomar a decisão de jogar água fora'." (28/01/10: C6).

Para o período analisado, estes conflitos não apareceram somente no sistema produtor de águas ao norte. Também no município de Cubatão havia preocupação de que a manobra da Billings, com descida de água pela Serra, poderia causar transbordamentos do rio Cubatão, não apenas assoreado, mas com risco de outras contaminações:

“(...) uma área com água poluída com pó da China está perto do rio Perequê. Se o rio subir, afirmou a prefeita, as duas águas se misturarão." (30/01/09: C3)."

Apesar da avaliação de que o período de recorrência dessas manobras é de aproximadamente 12 anos, no ano seguinte, o segundo ano crítico das análises de quantidades absolutas, 2010-201198, as comportas das represas tiveram que ser abertas novamente em Atibaia, e Paiva Castro, em Franco da Rocha, causando inundação severa à região central deste município. Cinco anos depois, novamente em Franco da Rocha, mais uma vez houve manobra da represa com extensos danos, sugerindo que esses tempos observados de recorrência das manobras podem estar ficando menores.

Destes municípios, apenas Franco da Rocha faz parte da Região Metropolitana de São Paulo. Mas não se pode dizer que, porque os riscos residuais do sistema de abastecimento metropolitano estão fora da delimitação metropolitana, não sejam espaços de interesse de uma análise de riscos metropolitana. Estes riscos representam funções setoriais, e estes contextos expressam, com muita clareza, as lacunas deixadas pelo método de delimitar espacialmente uma área para analisar apenas os riscos

\footnotetext{
98 Mesmo ano em que ocorreram as catástrofes na Região Serrana do Rio de Janeiro.
} 
internos; ou mesmo a lacuna deixada pelos métodos de delimitação setorial, um sistema técnico que gerencia seus riscos internos. Algum agente desvinculado de delimitações espaciais e de delimitações setoriais deve identificar o risco residual de grandes dispositivos de sistemas setoriais, e equacionar os conflitos. Este tema é retomado na apresentação do caso 2, no item 6.2.

\subsubsection{Concentração da desordem no Jardim Pantanal}

A partir do dia 11 de dezembro de 2009 (3 dias após o segundo evento chuvoso de consequências críticas na temporada, que apresentou falha nas bombas do rio Pinheiros), o Jardim Pantanal passou a ser assunto frequente das notícias (ver p.179).

A persistência do nível d'água em diversos bairros da Várzea do Tietê (Vila Seabra, Vila da Paz, Jardim São Martinho, Vila Aimoré, Vila Itaim e, sobretudo, Jardim Romano), com cerca de 10 mil pessoas, associado ao vazamento de esgotos da Estação de Tratamento de São Miguel, foi o fato inicial que motivou tanta atenção (29 páginas com notícias em 25 dias, entre 11 de dezembro de 2009 e 9 de fevereiro de 2010). Mas os fatos noticiados não são constituídos apenas pelas consequências geradas e pelas reiteradas subidas de nível da água nos bairros a cada chuva. A falta de estrutura de resposta e de contingências para uma área sabidamente crônica diante da situação crítica, bem como os conflitos gerados pela apresentação imediata de uma solução de projeto para área, com desarticulação entre os setores habitacional, ambiental e de gestão de recursos hídricos, e muito mal comunicada à população, também compõem boa parte dos conteúdos noticiados.

Com relação ao comportamento de estruturas urbanas agravantes da situação, eram noticiadas panes e falhas da ETE São Miguel e conflitos entre ocupação e a Barragem da Penha.

"Sobre o vazamento de esgoto, a nota informa que isso ocorreu devido ao alagamento das estações elevatórias que atendem a região e diz que 'o sistema voltará a funcionar plenamente após o escoamento das águas'." (11/12/09: C3)

"Ontem, uma comissão de deputados (...) descobriu que, no Jardim Pantanal, desta vez, dizer que as pessoas estavam alagadas por esgoto não era figura de expressão. A ETE (...) São Miguel ficou parada durante oito dias - desde a chuva do dia 8. (...) Um fluxo de 450 litros de esgoto por segundo, produzido por casas e indústrias da zona leste, deixou de receber qualquer tratamento. 'O destino do esgoto acabou sendo o próprio Tietê'. E, por consequência, toda a região que está alagada até hoje pelas águas do rio. Como oito dias contém 691.200 segundos, durante o período em que as bombas pararam, um total de 311 milhões de litros de esgoto (... 124 piscinas olímpicas) foi despejado 'in natura' no principal rio da cidade." (17/12/09: C1).

“(...) a estação, localizada na margem esquerda do rio Tietê, viu a água subir mais de metro. A central de comando perdeu computadores, houve princípio de incêndio na telefonia (cujos fios correm junto ao chão) e, o pior, todas as bombas de esgoto foram inundadas e pifaram [sic]." (17/12/09: C1). 
O nível d'água alto do rio Tietê foi fator determinante para a persistência dos alagamentos no Jardim Pantanal, mantido mesmo durante dias sem chuvas. Somente com o rebaixamento do nível do Tietê, foi possível adotar medidas para drenar a área. A subida crítica do nível do Tietê em $\mathbf{0 8 / 1 2}$ pode ser explicada como efeito agravado pela pane no bombeamento do Pinheiros em Traição nesta data. Embora possa explicar a duração, o fator agravante não explica por que essa região alaga. O que explica "por que ali?" é a configuração de sua ocupação.

Moradores, em protesto, chegaram a tentar quebrar as comportas da Barragem da Penha com marretas ${ }^{99}$, considerando que seu fechamento era o responsável pela duração dos alagamentos à montante.

"Em nota, Secretaria de Saneamento e Energia, DAEE e Sabesp também negaram que as comportas da Barragem da Penha estivessem fechadas, o que poderia ter causado a inundação, segundo alguns moradores." (11/12/09: C3)

Realizando o levantamento das cotas de implantação das ocupações nesses bairros e cotejando com as cotas da barragem (indicadas no PDMAT 3), foi possível constatar que o nível d'água do Tietê à jusante da Barragem da Penha é $720 \mathrm{~m}$, e a cota do vertedouro da barragem é $722,8 \mathrm{~m}$. Todos os bairros citados nas reportagens têm cota acima de $732 \mathrm{~m}$, ou seja, não é a barragem que interfere nas cheias acima do nível $722,8 \mathrm{~m}$. A causa de alagamentos é atribuída à configuração da região, um espaço natural de amortecimento de cheia do Tietê e que recebe contribuição de diversos outros afluentes. A ocupação irregular se dá muito próxima à zona de amortecimentos (ou sobre ela) e, em alguns pontos, abaixo das cotas de amortecimento do rio.

"O rio Tietê é muito sinuoso naquele trecho, e por isso a água se move de maneira lenta. Ajuda também o fato da declividade ser baixa, ou seja, a água não ganha velocidade. Sem contar que a região habitada está mais ou menos alinhada com o rio. [A demora em baixar o nível] é um processo natural de retenção da bacia. Leva um tempo até passar essa onda de cheia. Essa zona marginal é o leito maior do rio, ou seja, a área que o rio ocupa em período mais chuvoso. O problema não é a impermeabilização. É que o solo já está saturado, já absorveu muita água, e fica difícil absorver mais. Isso leva tempo. Diminui alguns centímetros por dia. Se vier outra chuva forte, pode piorar." (Entrevista com engenheiro Mario Thadeu Leme de Barros, 15/12/09: C3).

Ainda, em entrevista com os engenheiros Luís Orsini e Orlando Natali, para complementação de informações técnicas, há relato de que, nos meandros próximos ao Jardim Romano, há um afloramento rochoso no fundo da calha que se comporta como um ponto de controle hidráulico natural do rio, promovendo efeitos de uma mini barragem.

O assoreamento do leito à montante da Barragem da Penha foi um tema polêmico que também apareceu na pauta dos moradores e nas notícias:

\footnotetext{
99 Esta informação não consta das notícias do período, mas foram informadas em entrevistas diretas com representantes do bairro envolvidos nessas manifestações.
} 
"Nunca vi obra no leito aqui, diz responsável pela Barragem da Penha (...) um conjunto de seis comportas capazes de segurar as águas do Tietê antes que elas entrem pela seção do rio que foi retificada. Ontem ele disse à comissão de deputados: 'Nos 12 anos que trabalho aqui, nunca vi uma máquina trabalhando para desobstruir o leito do rio daqui pra cima'. O rio acima da barragem é onde fica o Jardim Pantanal. Para baixo, o Tietê tem dragas e rebaixamento do leito". (17/12/09: C1).

Em algumas reuniões recentes na região (no segundo semestre de 2017), foi possível acompanhar técnicos do DAEE confirmando para moradores e representantes a contratação para serviços de desassoreamento do Tietê à montante da barragem.

Em 22/12/09 foi noticiado o bombeamento das águas e esgotos de algumas ruas de volta para o rio Tietê.

"Após 14 dias de alagamento, a água baixou nas casas e ruas do Jardim Romano. (...) A decisão de fazer o bombeamento foi tomada depois que o nível da água da várzea diminuiu. 'Antes a água que estava na várzea se encontrava no mesmo nível da rua. Agora que ela baixou, podemos tirar a água e despejar na várzea. (...) depois de retirar toda a água, o entulho da rua terá de ser levado para um aterro, e as galerias de esgoto deverão ser limpas'. À tarde, nos locais onde não havia água, era grande a quantidade de entulho. Em apenas um deles, havia ao menos três ratos mortos. Em uma casa, os bombeiros encontraram uma enguia." (22/12/12: C8).

Apesar da aparente melhora da situação, com a persistência das chuvas, há notícias de que o nível d'água voltava a subir em $27 / 12 / 09$, resultado de fortes chuvas localizadas na região de Guarulhos, e posteriormente, em 07/01/10 e 26/01/10, atingia níveis e áreas antes não atingidos, como o bairro Chácara 3 Meninas.

"Com a chuva de ontem, a água que já cobria o bairro chegou na altura do peito dos moradores. Na rua Capachós, os carros que antes tinham água pela metade ficaram completamente submersos. No cruzamento das ruas Cachoeira Cairugaçu e Curimatã, a força da água formou correnteza." (27/01/10: C4).

Com relação à falta de estruturação da resposta a emergências e de contingências, as notícias traziam um cenário de descaso na organização de abrigos e atendimento emergencial, no auxílio financeiro a desabrigados e no atendimento de saúde:

"Os moradores (...) reclamaram do descaso. Muitos disseram que perderam seus bens e não receberam nenhuma ajuda de nenhum governo. A reportagem percorreu as ruas do Jardim Romano e não se deparou com nenhum assistente social, agente de saúde ou membro da Defesa Civil. Os únicos agentes públicos vistos foram policiais militares. No local, a população (...) fazia o que podia para driblar a água. Um garoto transformou um capô de perua Kombi em jangada para transportar os moradores que não podiam contar com transporte público." (11/12/09: C3)

Cerca de 9.000 pessoas foram afetadas com a chuva, e grande parte delas adaptou seu cotidiano ao contexto do alagamento duradouro, em geral, mudando-se para o andar superior das casas, construindo pontes, tampando privadas com pesos para reduzir a 
entrada de esgotos, ou indo para a casa de parentes, num esforço sobre-humano para manter a rotina, não faltar ao trabalho, se recuperar de doenças trazidas com a cheia e proceder à limpeza das casas quando o nível d'água baixava. Até a reportagem do dia 11/12, apenas 1.200 famílias haviam sido cadastradas como 'afetadas' pela defesa civil, e uma pequena parte fora encaminhadas para 3 escolas e uma igreja. Há notícias de falta de limpeza nos abrigos e demora de mais de $12 \mathrm{~h}$ para provisão de comida (10/12/09: C3). A água para consumo nas casas era distribuída pela Sabesp por caminhões pipa (11/12/09: C3).

No sistema de saúde, aumentou a procura por serviços para atendimento de sintomas típicos de contato com água de chuva e esgotos, como diarreia, vômitos e dermatites, e mesmo de contato com animais peçonhentos de toda ordem que surgiram nas águas. Mas não havia preparo para esse aumento de demanda - “(...) só havia um pediatra na UBS do Jardim Romano" (15/12/09: C3). As filas de atendimento levavam mais de 4 horas. No primeiro caso de morte por suspeita de leptospirose, alegava-se negligência no atendimento de saúde que, ainda que tenha ocorrido dentro dos protocolos, sugeriu a volta do paciente para uma casa que estava alagada com esgotos há mais de 13 dias:

“O garoto (...) foi liberado por um médico da AMA Jardim Romano 31 horas antes de morrer anteontem no Hospital santa Marcelina com suspeita de leptospirose. Segundo (...) o pai, no sábado, o médico (...) receitou remédios para dor e vômitos, e recomendou que ele voltasse em 3 dias." (22/12/09: C8).

Outros casos reforçam a carência de estrutura de saúde:

"Com pneumonia e carregando o filho de 3 anos, que está com diarreia há 10 dias, (...) disse que a van da prefeitura, que deveria prestar socorro, não tinha nem termômetro - além disso, ela teve que ir buscar soro para o filho. (...) $\grave{A}$ tarde, a van estava trancada, e o motorista estava sendo procurado por funcionários da prefeitura, já que o terreno em que ela estava estacionada seria utilizado para construir uma base de apoio da Defesa Civil. As pessoas que tiveram contato com a água suja devem procurar um médico. A água misturada ao esgoto pode provocar doenças capazes de levar à morte, como febre tifoide e a leptospirose. 'Quem teve contato com essa água deve fazer a profilaxia com um antibiótico que evita a leptospirose'. (...) Outras doenças comuns nessa situação são hepatite, diarreias infecciosas e erisipela (...)”. (18/12/2009: C5).

"Medo da água, ela diz não ter. Mas, de tanto enfrentá-la, acabou doente e nem tratamento pode ter. Foi barrada na AMA Jardim Romano porque não tinha R.G. Perdeu-o na enchente." (18/12/09: C4).

Em 15/12/09 foi noticiada, pela primeira vez, uma proposta de solução definitiva para a região: o prefeito anunciava antecipação, em dois anos, da retirada das famílias. Isso seria feito até fevereiro daquele ano para implementação do Parque Várzeas do Tietê (PVT). A proposta foi divulgada sem que houvesse uma solução de remanejamento habitacional claramente elaborada. A solução anunciada previa a remoção de um número entre 3.500 e 7.000 famílias, projeto do Governo do Estado de São Paulo em convênio com a prefeitura, e apoio do BID. 
"'A situação das chuvas mostrou que temos que antecipar a retirada dessas pessoas. Vamos iniciar a ação já no dia de hoje, com o cadastramento das famílias que deverão ser transferidas para outros locais', disse o prefeito em visita à região. (...) 'Em um primeiro momento, as famílias serão retiradas de suas casas sem ter uma nova moradia, mas com uma bolsa-aluguel paga pela prefeitura, ainda sem valor definido (...)'. “(15/12/09: C3).

Em 18/12, reportagem (18/12/09: C5) informava que era definido o valor da bolsaaluguel em $R \$ 300,00$ e os seguintes critérios para os benefícios, conforme informações de cadastro: moradores de casa alugada receberiam bolsa aluguel por até 36 meses; indenizações de até $R \$ 60$ mil para moradores de casa própria (até então, sem anunciar que isso seria válido somente para casas regulares), oferta de cem apartamentos da CDHU às famílias em situação mais grave (a defesa Civil contabilizava ao menos 300 famílias). Mais do que não ser uma solução, essa política era mal comunicada aos moradores.

Inicialmente, o cadastramento para atendimento habitacional teve baixa adesão - 15 famílias cadastradas das 3.000 pretendidas. Nem todos os atingidos estavam em áreas passíveis de remoção pelo projeto, segundo a Defesa Civil.

No início de fevereiro, uma reportagem indicava mais de 6.000 famílias cadastradas, e apontava falhas graves nos procedimentos de comunicação com a população:

"O cadastramento não é feito diretamente por funcionários municipais. A prefeitura contratou duas empresas de 'gerenciamento social', a Cobrape e a Diagonal, para fazer o serviço. Nos 3 postos visitados (...) eram temporários das duas empresas (...) que explicavam o funcionamento do auxílio-aluguel. 'A prefeitura entendeu que vocês precisam de um atendimento para sair da casa que está alagada. Vocês então vão ter o atendimento seis meses provisório (sic). Aí vocês vão poder retornar para suas casas quando a chuva passar, quando a enchente passar'. (...). Não poderá. A via onde vivem está dentro do perímetro do parque que será construído". (4/02/10: C4).

"[À reportagem a prefeitura] reiterou que não poderão, que as casas dentro do parque serão demolidas. Quem estiver dentro da área do parque e for proprietário regularizado receberá uma indenização (como em qualquer desapropriação). Essa indenização se somará à quantia recebida a título de auxílio-aluguel. Famílias de alagados vivendo em área invadida receberão só o auxílio aluguel." (4/02/10: C4)

"após dois dias de fila, 19 horas no total, a família tinha conseguido fazer 0 cadastro junto à Prefeitura de São Paulo para receber, de uma tacada só, um cheque de $R \$ 2.000,00$. (...). São seis meses de auxílio-aluguel no valor de $R \$$ 300,00, mais uma ajuda de $R \$ 200,00$ para mudança." (4/02/10: C4)

Na proposição divulgada, há uma clara confusão - ou uma sobreposição intencional entre os auxílios financeiros do processo de remoção para projetos habitacionais municipais, para implementação do Parque, e os auxílios que deveriam existir para suprir uma situação emergencial. 
As informações sobre as propostas variavam. Em meados de dezembro de 2009, há menções a projetos de moradias novas em terrenos da Cohab em Guaianazes, Itaim Paulista e Cidade Tiradentes, além do oferecimento de apartamentos da CDHU para atendimento emergencial; estudos para compra de imóveis pelo Fundo de Habitação Social; ocupação de imóveis desocupados na área central; alteração do zoneamento para adensamento associado ao projeto do parque; e oferta de cadastramento e abrigo como solução de atendimento (19/12/09: C8). Uma semana depois (24/12/09), há uma nota que afirma que, à medida que os atendimentos fossem concretizados e as famílias retiradas, as casas seriam demolidas. Em 29 de dezembro (29/12/09: C6), era noticiado que o prefeito anunciava a construção de 3250 moradias, assinava decretos de desapropriação das áreas para sua construção, que as casas seriam construídas em 6 meses e entregues até 2012, período em que as famílias beneficiárias poderiam usufruir do auxílio aluguel.

Todas essas informações acabavam por gerar reação no mercado de aluguéis na região:

"'Peguei o cheque da prefeitura e fui checar o contrato com a proprietária. Mas foi só eu dizer que o dinheiro viria do bolsa-aluguel e a mulher disse que um parente ia ocupar o imóvel. Descobri que ninguém confia em que a prefeitura vá continuar pagando depois do primeiro cheque.' O subprefeito garante que pagará até quando for necessário. No Jardim Noêmia, (...) conseguiu mudar-se com as duas filhas para a casa de um tio. Só ele topou a insegurança da situação'." (13/01/10: C7).

As matérias apresentam o discurso oficial culpabilizando as ocupações informais e, ao mesmo tempo, apontam como contradição que boa parte das ocupações naquele território foram consentidas, e mesmo incentivadas por benfeitorias públicas, com aumento do valor de mercado dos imóveis na planta genérica de valores. No Jardim Romano, há um CEU implantado, cuja piscina era usada pelas crianças durante as enchentes - ainda que parcialmente tomada por água das cheias. Na mesma rua, há um conjunto Habitacional financiado pela CEF, que também ficou alagado em janeiro:

“(...) a valorização do metro quadrado se deve ao fato de a região ter recebido investimentos públicos, como uma estação da CPTM, quatro Unidades Básicas de Saúde, três assistências médicas ambulatoriais (AMAs), além do CEU'. (18/12/09: C3).

"Moradores dos térreos perderam móveis e tiveram que limpar a lama até de madrugada. Eles pagam por mês cerca de $R \$ 300,00$ do arrendamento com a CEF e R\$ 129 de condomínio. 'Não deviam ter vendido isso. Quem foi o engenheiro que aprovou? Ele não viu o rio?." (9/01/10: C4)

Essas incoerências associadas ao que se descreveu sobre o despreparo para a situação de emergência, e à comunicação pouco transparente das decisões a respeito das soluções e direitos envolvidos, ampliava a tensão da situação, e levou a população a reagir com diversas manifestações. Em 28/12/09 ocorreu a primeira manifestação, que acabou em confronto com a polícia: 
"Cerca de cem manifestantes atearam fogo em móveis (...). A aposentada (...) foi impedida por PMs de jogar almofadas no fogo, o que irritou o filho dela (...). Ele acabou sendo algemado e detido por desacatar os policiais. A mulher [dele] (...) tentou impedir a saída do veículo policial, e quatro PMs tiveram de retirá-la à força. Os moradores, então, disseram que, se a polícia iria levar (...), teria que levar todos." (28/12/09: C4)

Em 9 de janeiro, o prefeito foi hostilizado em visita à área. Em 16 de janeiro, o CEU foi saqueado. Os próprios moradores também tinham medo de abandonar suas casas, com medo de saques. Em 18 de janeiro, novo protesto, em razão da persistência dos alagamentos e contra as propostas de bolsa-aluguel, aconteceu pelas ruas do bairro. Em 27 de janeiro, com considerável aumento do nível de água no bairro, após chuva concentrada na região de Guarulhos, os moradores decidiram fechar a rodovia Ayrton Senna por cerca de uma hora (27/01/10: C4). Em 9 de fevereiro, os moradores fizeram protestos na prefeitura.

As reações não aconteceram somente no Jardim Pantanal. Em outras partes da cidade também ocorreram protestos em razão dos efeitos das chuvas. Em 07 de janeiro, moradores da Brasilândia, na zona norte de São Paulo, protestaram pela inundação junto ao córrego Canivete, local recém urbanizado que recebia aumento recente no valor do IPTU. Em 8 de janeiro, moradores fecharam a avenida Sapopemba para manifestar contra as enchentes. Em 19 de janeiro, moradores da zona sul protestavam contra a falta d'água, que os impedia de limpar as casas que haviam sido alagadas.

No ano hidrológico seguinte, 2010-2011, também crítico em números de ocorrências e mortes na RMSP, os efeitos no Jardim Romano não foram tão intensos. Em 12 de janeiro de 2011 a região voltou a ficar alagada, mas a duração do alagamento não se comparou à do ano anterior. Apesar da construção do dique do Jardim Romano, a menor duração dos alagamentos deveu-se, provavelmente, ao melhor controle do escoamento na calha do Tietê, que falhou em 2009-10. O dique do jardim Romano, mesmo para efeitos locais, mostrou ter eficácia bastante limitada, à jusante e à montante:

“'A obra adiantou só para o Jardim Romano. O dique só protegeu o CEU, que é obra principal da prefeitura' [morador da Vila Itaim]. (...) Já em Itaquaquecetuba, pessoas se alimentavam de peixes achados na água que chegava ao joelho, por onde também circulavam sanguessugas. Lá, moradores diziam que a obra do Jardim Romano piorou a situação para eles. Isso porque o dique construído pela prefeitura - uma espécie de mureta que barra as águas do rio Tietê - estaria impedindo a passagem da água para o lado de SP, 'represando' a água em Itaquaquecetuba." (12/01/11: C4).

A análise sugere que, além da construção do dique, algum fator do período 2009-2010 foi diferente em 2010-2011, que fez com que os alagamentos no Jardim Pantanal não fossem duradouros como no ano anterior. 
Quadro 25 - Linha do tempo das notícias do período crítico 2009-2010 no Jardim Pantanal

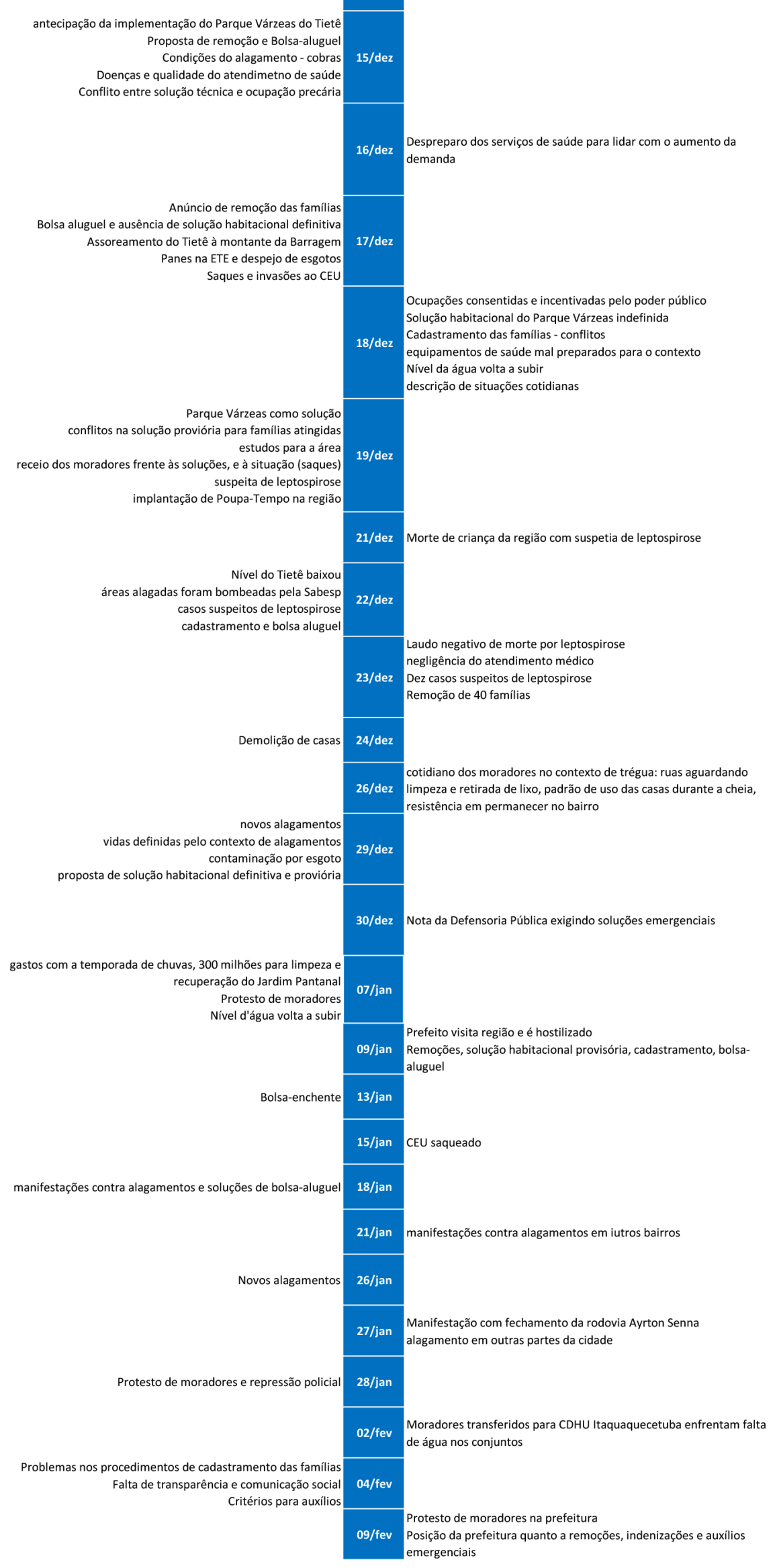

persistência das inundações contaminação por esgoto risco de doenças

abertura da Barragem da Penha

bairros afetados

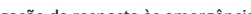

Despreparo dos serviços de saúde para lidar com o aumento $d$ demanda Várzeas indefinida

Nível da água volta a subir

Dez casos suspeitos de leptospirose limpeza e retirada de lixo, padrão de uso das casas durante a che

emergenciais 


\subsection{Março de 2016: criticidade da região norte e operações de manobras em represas}

Ao contrário do período anteriormente analisado, as ocorrências críticas do ano 20152016 - segundo no ranking de pior ano pelo total de mortes, e ano com maior intensidade de mortes (mais mortes em uma mesma região da metrópole) - não exigem a observação de toda a temporada, pois tratou-se de uma ameaça de chuva bastante incomum: localizada, concentrada, intensa e duradoura. A chuva foi contínua no intervalo de uma noite, entre os dias 10 e 11 de março do ano de 2016. O que choveu nessa noite em uma única região, quase chegou à média estimada para o mês.

É necessário mencionar, entretanto, que dias antes do fato noticiado, as matérias davam conta do decreto de fim da crise hídrica de 2014-2015 em São Paulo.

No dia 12 de março de 2016, os jornais noticiaram a morte de 18 pessoas no estado: 4 em Mairiporã, 8 em Francisco Morato, e 2 em Itapevi, por deslizamentos de terra; 1 em Guarulhos e 1 em Cajamar, por afogamento - 16 na Região Metropolitana, no total - e 2 em Itatiba, por afogamento. No dia seguinte, o número de mortes subiu com mais uma morte por deslizamentos em Mairiporã, além de 5 pessoas desaparecidas (que dias depois vieram a ter a morte confirmada, subindo para 10, o total em Mairiporã), e uma morte em Franco da Rocha por afogamento.

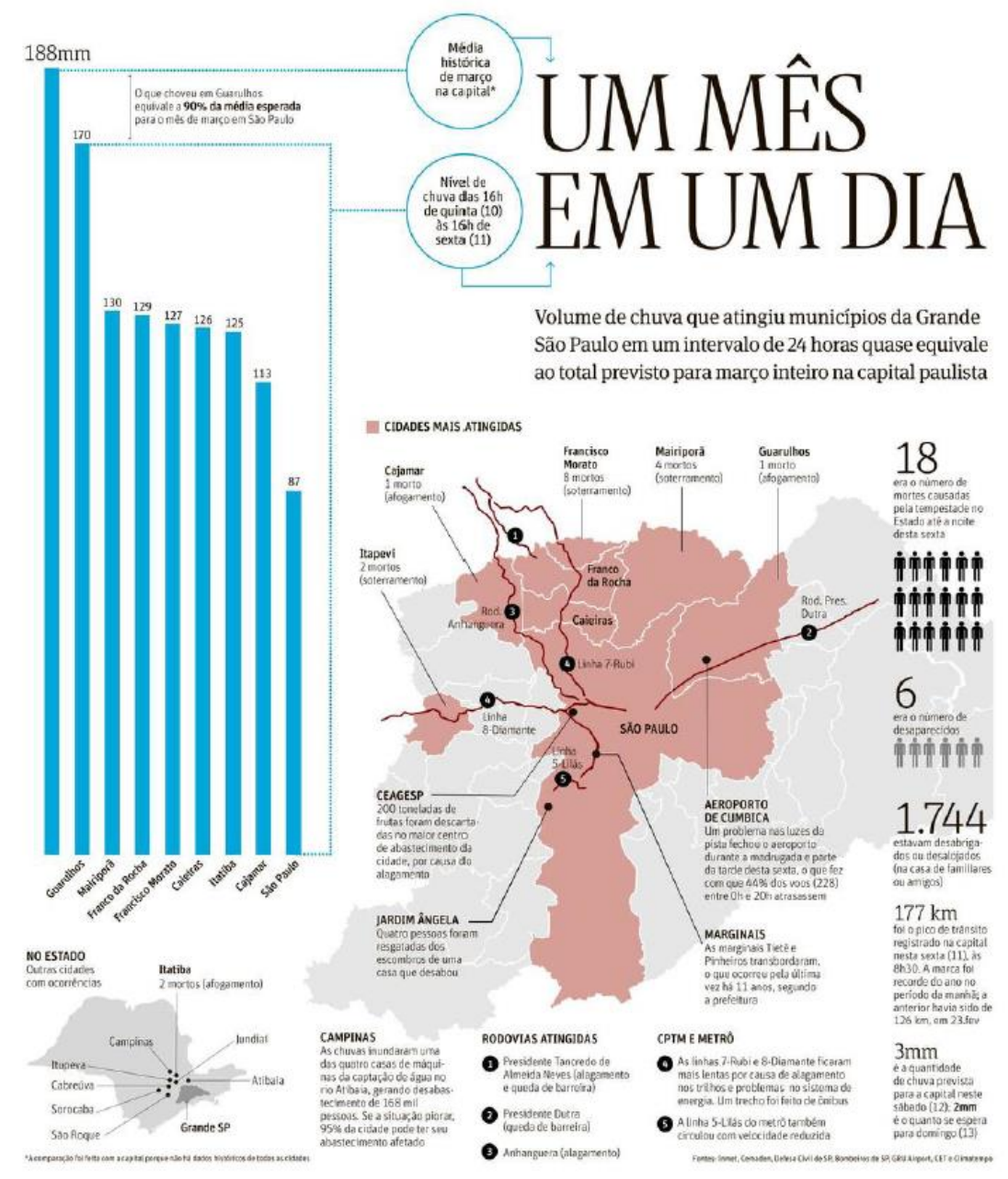

FIG. 23 Infográfico: ocorrências na RMSP nos dias 10 e 11 de março de 2016 
O evento deixou, ainda, 2.965 pessoas desabrigadas ou desalojadas em todos os municípios já mencionados onde ocorreram mortes, além dos municípios de Atibaia, Cabreúva, Caieiras, São Roque e Santa Isabel. Foi anunciada a liberação de recursos federais para os municípios atingidos após sobrevoo da Presidente pelas áreas ${ }^{100}$.

A chuva foi tão intensa que a represa de Paiva Castro passou rapidamente de $35 \%$ para 99\% de sua capacidade, e precisou de manobra imediata: as comportas foram abertas para evitar o galgamento do maciço da barragem, que poderia trazer consequências catastróficas. No caso de rompimento da barragem, 7,5 bilhões de litros de água escoariam sem controle. Há, também, uma subestação elétrica à jusante da represa, que esteve sob risco, tema não abordado pelas notícias ${ }^{101}$. A abertura controlada das comportas ampliou a vazão na calha do rio Juqueri na confluência com o Ribeirão Euzébio, agravou a inundação nas cidades à jusante da barragem, Franco da Rocha e Caieiras, e também prejudicou o escoamento das áreas de montante que já estavam inundadas, em Franco da Rocha e Francisco Morato.

"Para se ter uma ideia, das $18 \mathrm{~h}$ de quinta até as $6 \mathrm{~h}$ de sexta, a represa recebeu 125 mil litros de água por segundo devido às chuvas. O pico foi à $1 \mathrm{~h}$, quando 0 fluxo de entrada de água na represa chegou a 219 mil litros por segundo. Para efeito de comparação, isso é quatro vezes o volume de água consumido pela grande São Paulo [sic]. Com a represa cheia, as comportas tiveram que ser abertas. A Sabesp passou a liberar água ao ritmo de 20 mil litros por segundo em média (o pico foi às $13 \mathrm{~h}$ de sexta, quando a empresa liberou 50 mil litros por segundo). A água escoou em direção às cidades de Franco da Rocha e Caieiras, que já sofriam com enchentes. A represa funcionou como uma esponja, e absorveu 5 bilhões de litros de água." (12/03/16: B6).

Três aspectos relativos às manobras do Paiva Castro aparecem nas notícias deste e de outros períodos:

1) além da função de reserva de água para abastecimento, a represa funciona também como reservatório de amortecimento de cheias (essa função residual é argumento também presente nas notícias de manobras em outros reservatórios e em outros períodos, conforme descrito do item 6.1.2);

2) são apresentados conflitos entre Sabesp e municípios relativos à comunicação da manobra e protocolos de ação;

3) são descritas as localidades atingidas pela mancha de inundação quando, pela manobra, o reservatório deixa de desempenhar a função de amortecer as cheias - no caso de Franco da Rocha, o centro da cidade.

Com relação aos dois primeiros aspectos, as informações das notícias de 12 e 13 de março não permitem compreender o que, além da chuva e da maior vazão do afluente Juqueri, entra na definição de 'fluxo de entrada na represa', ou, melhor dizendo, se havia afluência de outros volumes de água oriundos do sistema Cantareira na ocasião, e até que momento. Alguns meses depois, em junho do mesmo ano, uma notícia do Jornal o

\footnotetext{
${ }^{100}$ Cabe lembrar que, diferentemente do período estudado anteriormente, em 2016 a lei da Política Nacional de Proteção e Defesa Civil já estava sancionada, e que a administração municipal era do PT. ${ }^{101}$ Este foi um ponto levantado a partir de entrevistas com funcionários da defesa civil local.
} 
Estado de São Paulo apresentava uma explicação que permite esclarecer melhor essa dúvida:

"Após 5 dias seguidos de chuva (...) a Sabesp decidiu aumentar em 50\% a produção de água do Sistema Cantareira (...) para evitar o enchimento da represa Paiva Castro e enchentes na cidade de Franco da Rocha, como ocorreu em março deste ano. Segundo a estatal, o reservatório amanheceu nesta segunda feira com $70 \%$ da capacidade máxima e recebendo uma vazão de 36 mil litros por segundo, nove vezes maior do que a vazão média para o mês de junho. Por isso, afirma, a produção de água para abastecer a população da capital foi ampliada de $22 \mathrm{mil} \mathrm{l/s}$ para $33 \mathrm{mil}$ l/s. O objetivo é evitar que a Paiva Castro encha rapidamente a ponto de obrigar a abrir as comportas. Na ocasião, a entrada pelo rio Juqueri foi de 125 mil l/s." (O Estado de São Paulo, 06 de junho de 2016, versão online).

Ou seja, alterações no procedimento operacional de entrega de água para tratamento também permitem manejar o volume total da represa em situação crítica, além da alternativa da manobra. Para a gestão desse risco, seria necessário que os agentes dessa governança compreendessem estas interações e os protocolos relacionados ${ }^{102}$, o que é difícil, pela complexidade técnica envolvida.

A função de amortecimento de cheias desempenhada pelos reservatórios de água para abastecimento cria falsa percepção de segurança nas localidades próximas a eles, pois essa não é sua função primordial. Sob essa aparente segurança, áreas são ocupadas ou tem seu uso intensificado e consolidado. Quando essa função cessa, por exigências de segurança do próprio dispositivo, designado para outros fins, a dependência e a carência de controles de macrodrenagem nas localidades próximas a reservatórios para armazenamento de água de abastecimento são expostas.

"Deveria ter um investimento de reservatórios [piscinões] para que em momentos como esse a gente tenha uma capacidade de resiliência maior. E esse investimento é impossível que a prefeitura financie." (12/03/16: B6)

A matéria do dia 12 de março de 2016 aponta para um elemento que desdobrou em maior investigação: a existência de um protocolo de ação da empresa para comunicação à defesa civil e prefeito, e para abertura das comportas, que o prefeito alegava não ter sido seguido. Apesar do protocolo operacional, não havia plano de contingência municipal para as áreas. De fato, na página da defesa civil do Estado de São Paulo, os planos de contingência para o Sistema Cantareira e o reservatório Paiva Castro são datados de setembro de 2016, posteriores a este evento, apesar de neles estar apontado que a produção de tais planos era exigência do DAEE desde 2008.

Os planos de contingência de 2016 se articulam a outros protocolos para acionamento das bombas de 2 reservatórios de detenção (para controle da macrodrenagem) no ribeirão Eusébio, que corta Franco da Rocha junto à linha de trem da CPTM, e é afluente do rio Juqueri. Estes dois reservatórios, junto com um parque para acomodar a mancha

102 Os protocolos seguem vazões e limites de segurança estabelecidos nos termos de outorga e outros documentos técnicos que, desde 2009, vêm ampliando a compreensão de impactos no entorno, a complexidade das tomadas de decisão e dos processos de comunicação. Mais detalhes no capítulo 7.2. 
de inundação durante as manobras, foram construídos posteriormente ao evento de 2016, e podem ter sido motivados ou aceleradas a partir do conflito midiático na ocasião.

Por fim, a descrição das localidades atingidas é de onde se pode extrair pistas para a questão colocada por esta pesquisa para este caso: se haveria alguma relação de agravo entre a manobra realizada na represa e o impacto decorrente do evento. Além do agravo óbvio aos alagamentos, especialmente, se haveria interferência no alto número de mortes por deslizamentos nessa mesma região.

"Em uma ribanceira de mais de 100 metros [em Mairiporã] estão as cinco pessoas que, até a conclusão desta edição, ainda estavam desaparecidas após as chuvas fortes na Grande São Paulo. Para encontrá-los, os bombeiros terão de fazer uma escavação profunda. Os desaparecidos pertenciam a duas famílias que moravam de aluguel na edificação, típica das periferias de São Paulo, com três lajes. Atrás do imóvel, há um morro desmatado, apenas com bananeiras plantas que encharcam a terra. Uma das famílias estava de mudança, mas ficou mais tempo por ali justamente por causa do temporal. 'Eles deviam ter saído na quarta-feira (9). O caminhão [de mudança] só não chegou por causa da chuva'." (13/03/2016: B11).

Teriam sido menos cinco mortes.

A leitura das notícias não foi conclusiva, mas sabe-se que no dia 11/03 o centro de Franco da Rocha ficou inundado. Para compreender os impactos da manobra na cidade e na região a partir das notícias, a manobra no período 2010-2011 pareceu ilustrar melhor o cenário de consequências:

"O poder público em Franco da Rocha (...) está submerso. Após chuvas intensas que começaram na noite de segunda e que se repetiram na madrugada de terça para quarta-feira, a enxurrada engoliu todo o paço municipal. Prefeitura, Câmara Municipal, fórum, delegacia de polícia, duas escolas, um ginásio de esportes, uma igreja, parte dos trilhos da CPTM e até um edifício da Sabesp ficaram sob as águas. A cidade decretou estado de emergência e o prefeito (...) despachará em uma escola. (...) Além da perda de instalações, carros de polícia, ambulâncias e um ônibus (...), processos arquivados no fórum também se perderam." (13/01/2011: C7).

"O delegado usa um posto de gasolina como seu quartel, e as ocorrências são encaminhadas para outras cidades. 'Estou provisório numa creche, mas ninguém sabe onde é. Então fico nesse posto, que é perto da delegacia.' Anteontem, os policiais entraram na delegacia 'com água no peito' para resgatar mais de 20 armas e cerca de 40 caixas de munição. A prefeitura também foi parar numa creche. A secretaria (...) se transformou no gabinete do prefeito. (...) O Hospital Municipal Praça da Saúde também ficou parcialmente alagado." (14/01/2011: C7).

É evidente a vulnerabilidade de uma cidade para atuar nas emergências se seus centros de comando são passíveis de alagamento, sobretudo quando a recorrência desses eventos se torna cada vez mais frequente. Embora as ocorrências geológicas graves do dia 11 de março de 2016 não tenham ocorrido em Franco da Rocha, ocorreram em 
municípios de suas imediações e circuitos de acesso. Seria possível, portanto, investigar vulnerabilidades da estrutura urbana da região às sabidas manobras do Paiva Castro, e sua relação com as ações emergenciais realizadas. Além disso, que riscos a forma da ocupação impõe ao sistema produtor de água. A ser apresentado no capítulo 7 .

\subsection{Novembro de 2014: efeitos da crise de estiagem no sistema hídrico no Médio Tietê}

Nas análises do cadastro geral do IG para o ano 2014-2015, os piores dias em termos de quantidade de ocorrências estão no mês de dezembro; em termos de amplitude, em novembro e dezembro, e em termos de morte (3 mortes) o dia 07 de novembro é o mais crítico. Embora tenha sido o segundo ano em número de ocorrências hidrológicas (421, perdendo apenas para as 556 do ano 2009-10) e tenha tido a segunda maior abrangência para este tipo de ocorrências (24 localidades municipais com ocorrências no cadastro), as notícias dos anos de 2014 e 2015 são predominantemente caracterizadas pela discussão sobre a severa estiagem e a crise hídrica nos sistemas que abastecem a Região Metropolitana de São Paulo - que interferem indiretamente neste caso - e quase não trazem informações de consequências negativas das chuvas neste período. Por isso, para análise deste caso, recorreu-se à leitura sistemática de mais de uma fonte de notícias, a fim de complementar informações.

$\mathrm{O}$ primeiro fato noticiado encontrado relativo ao caso $(27 / 11 / 2014: \mathrm{C} 1)$ refere-se à ocorrência de águas pretas desde o dia 26 nas quedas d'água do Tietê que cortam a cidade de Salto, e grande mortandade de peixes. Eram apresentadas avaliações diferentes quanto à gravidade do problema: de um lado, afirmações de que o fato nunca acontecera antes; de outro, de que era frequente quando a vazão está baixa e ocorre chuva intensa próximo à Capital. Meses antes, em matéria que apontava a perda gerada para as atividades turísticas em função da estiagem, um morador de Salto afirmava: "Quando a cidade de São Paulo inunda, a queda d'água fica uma beleza!" (Folha de S. Paulo, 20/07/2014).

Um dia depois (dia 28) apareceram também espumas densas vindas pelo rio e algumas especulações: que as barragens de Pirapora haviam sido abertas para evitar alagamentos em São Paulo; que haveria transferência de sedimentos de outras partes do rio, da RMSP para Salto, provavelmente de sedimentos acumulados em barragens.

Neste mesmo dia, a Cetesb havia divulgado nota confirmando que se tratava de um:

"fenômeno natural, decorrente das fortes chuvas que promoveram 0 carreamento de resíduos dispostos no solo, em corpos d'água afluentes e no próprio leito do rio pela correnteza. Trata-se de um processo recorrente quando ocorrem chuvas intensas, especialmente após longos períodos de estiagem." (28/11/2014 - UOL 18h10).

A empresa informou ter feito análises de quantidade de sólidos sedimentáveis na área, obtendo resultado de 75 a $80 \mathrm{ml}$ por litro de amostra coletada, menos de $10 \%$ do verificado em episódio anterior, 12 anos antes, quando as comportas das barragens de Santana de Parnaíba e Pirapora do Bom Jesus, administradas pela EMAE, foram 
abertas causando problemas em Salto. Na ocasião comparada, a quantidade de sedimentos era de $900 \mathrm{ml} / \mathrm{l}$, e a EMAE foi autuada pelo Ministério Público.

Um dia depois da nota divulgada em 2014, as notícias davam conta de um aumento expressivo no número de peixes mortos no córrego Ajudante, um contribuinte do Tietê em Salto. Foram mais de 40 toneladas de peixes mortos, que levou em torno de dois dias para serem retirados do manancial por retroescavadeiras (informações de 29/11/2014 nos veículos G1, UOL Notícias e R7). A EMAE afirmava, em nota, que realizou as operações nas comportas de acordo com as regras, e o município, de que não foi comunicado (Agência Estado 01/12/2014).

“'A maior parte da população ficou assustada. O rio é nosso cartão de visita'. (...) 'O que estamos passando aqui é desleixo de São Paulo pra cá.' (...) a cidade, de 113 mil habitantes, trata o esgoto de 100 mil deles, e, em junho, havia limpado o leito do rio de olho no turismo. 'Sabíamos que estávamos enxugando gelo'." (Folha de S. Paulo, 01/12/2014).

Após o dia 01/12/2014, as notícias sobre esta ocorrência cessaram, e somente seis meses depois, ressurgiram notícias de espumas no Tietê, em Santana de Parnaíba e Pirapora do Bom Jesus (G1, 05/07/2015). Em 22/07/2015, um novo posicionamento da Cetesb em relação ao caso passou a ser divulgado:

"A Cetesb apontou que a EMAE (Empresa Metropolitana de Águas e Energia) e - DAEE (Departamento de Águas e Energia Elétrica), ambos órgãos da administração estadual, foram responsáveis pela mancha negra que causou a mortandade de 40 toneladas de peixes em um afluente do rio Tietê em Salto em novembro passado. (...) a mortandade foi causada pela abertura irregular de barragens nas represas de Pirapora e Rasgão (...) administradas pela EMAE. (...) Já o DAEE foi multado 'por deixar de remover o lodo acumulado nas barragens das represas, ocasionando carregamento de sedimentos para as águas do rio Tietê, causando poluição das águas e provocando mortandade de grande quantidade de peixes no córrego do Ajudante, em Salto'." (UOI, 22/07/2015).

Além de multas, a empresa exigiu do DAEE o desenvolvimento e implementação de um plano de desassoreamento, já que o órgão não descartava que o fenômeno pudesse voltar a ocorrer. A EMAE justificava ter agido dentro das regras operacionais, a fim de evitar enchentes na RMSP.

Entretanto, ao buscar de notícias entre 24 e 27/11/2014, as únicas relativas a chuvas em São Paulo indicam o dia 25/11/14 como crítico - a segunda maior chuva do ano com $23,2 \mathrm{~mm}$ ( $16 \%$ da média prevista para o mês), concentrada no bairro da Lapa, em São Paulo, e ocasionando 20 pontos de alagamento. Não são indícios de que teria sido um dia tão crítico para a Região Metropolitana. No cadastro de eventos do IG, constam 9 entradas para este dia, todas por motivo hidrológico. Nos relatórios fluviométricos e de 
chuva do SAISP também não há indicativos de problemas graves e extravasamentos de calha ${ }^{103}$.

O município de Salto fez denúncia ao Ministério Público, que arbitrou favoravelmente ao município e aplicou multa muito maior que a da Cetesb à empresa e ao órgão. Em setembro de 2015, matérias jornalísticas sobre o aumento da mancha de poluição no Tietê apontam algumas causas para o retrocesso na meta:

- lançamentos diretos de esgoto pelos municípios de Guarulhos e Mogi das Cruzes

- fim do programa Córrego Limpo, na capital,

- estiagens e eventos extremos das últimas temporadas.

Sobre este último fator, são apontadas as estiagens, pela diminuição da capacidade de diluição dos lançamentos; e com relação aos eventos extremos, apontado, especificamente, o caso de Salto como "um golpe inesperado" (Estadão, 23/09/2015) pela quantidade de contaminação dos sedimentos, com metais pesados, bactérias e matéria orgânica com alta demanda bioquímica de oxigênio.

"O impacto dessa operação resultou nos mais graves danos ambientais do rio Tietê desta década e na mortandade de mais de 40 toneladas de peixes no município de Salto. Destacamos que desde 2006 não foram registradas ocorrências de morte de peixes no Médio Tietê, fato que voltou a ocorrer em novembro de 2014. (...) Os custos diretos desse impacto ambiental, com a retirada dos peixes mortos, de toneladas de lixo e lama contaminada foram assumidos exclusivamente pela Prefeitura Municipal de Salto (...)." [sobre relatório da ONG SOS Mata Atlântica]. (Estadão, 23/09/2015).

Um ano após o evento, nem a obra nem o plano para desassoreamento haviam sido feitos. Em meados de 2017, a espuma branca voltou a aparecer no município de Salto, novamente após abertura das comportas da EMAE.

A barragem de Pirapora foi projetada e construída pela Light, e entrou em operação pela primeira vez em 1956. Seu objetivo era armazenar afluências (sobretudo do rio Juqueri) e a elevação dos níveis do Tietê para reverter até Henry Bordem e produzir energia. Com o esvaziamento dessa função, seu principal objetivo passou a ser o controle de níveis: controle das cheias do Alto Tietê e evitar vazões acima do limite para o Médio Tietê, e controle de níveis para os aproveitamentos na Usina de Rasgão. Nos relatórios

103 “A formação de uma Zona de Convergência de Umidade provoca precipitação moderada em toda a faixa leste do estado de São Paulo. O registro da chuva teve inicio às 12:35 (GMT) do dia 26/11, passou por um horário de pico às 20:10 (GMT) do dia 26/11 e terminou às $13: 35$ do dia 27/11. A chuva acumulada nos postos da Rede Telemétrica do Alto Tietê variou entre 0.00 e 43.40 mm (Córrego Poá Foz). Na rede telemétria do Alto Tietê, foram observadas mudanças de níveis de alerta nos rios. ALERTA: Ribeirão dos Couros - Vila Rosa, Ribeirão dos Meninos - Clube São José, Córrego Pirajuçara Sharp, Córrego Poá Foz. ATENÇÃO: Rio Aricanduva RAR3, Córrego Taboão - Ford Fábrica, Ribeirão dos Couros FORD. O CGE/PMSP registrou 16 pontos de alagamento." - DAEE-FCTH, 2014. Relatório fornecido pelo SAISP. 
do PDMAT 3, consta descrição sobre esse ponto hidráulico como ponto crítico da rede hídrica e seus limites em função do assoreamento:

"O reservatório de Pirapora (...) tem boa capacidade de laminação de cheias, reduzida de $30 \%$ nos últimos anos devido ao assoreamento dos braços e do fundo do canal, e limitação de vazão descarregada a $700 \mathrm{~m} / \mathrm{s}$, para evitar inundações na cidade Pirapora de Bom Jesus e na Estrada dos Romeiros." (PDMAT3 - R11/ SÃO PAULO-ESTADO, 2014:13).

Além de Pirapora, também são descritos os problemas de assoreamento na Barragem da Penha:

"Os dois reservatórios no rio Tietê com capacidade expressiva de amortecimento de cheias são os formados pelas barragens da Penha, na região de montante da $B A T$, e de Pirapora, próxima ao limite de jusante da BAT. O assoreamento desses reservatórios nas últimas décadas reduziu a capacidade de laminação de cheias, em função da diminuição do volume útil pela deposição de sedimentos.

Verifica-se que o assoreamento na Penha ocupou quase que totalmente $2 \mathrm{~m}$ do fundo do reservatório, entre as cotas 720 e $722 \mathrm{~m}$, resultando numa perda de cerca de 50\% do volume. Em Pirapora, além do assoreamento expressivo do fundo, houve também reduções significativas do volume em cotas mais elevadas, o que está relacionado à deposição de sedimentos nos braços do reservatório. O volume atual de Pirapora é menor do que $60 \%$ do volume projetado. No reservatório da Penha, observou-se que com o volume de reservação de projeto [original] ocorre um retardamento de aproximadamente 3 horas nas vazões descarregadas (...), além de um amortecimento no pico de $10 \%$. Com isso, o nível d'água [da mancha de inundação modelada] nas proximidades da barragem rebaixou cerca de $0,5 \mathrm{~m}$. Apesar da redução de vazão (...) os impactos decorrentes são sentidos apenas localmente. (...) Os impactos para montante da Penha também são limitados. A redução de cerca de 0,5 $\mathrm{m}$ no nível d'água se estende até a foz do rio Baquirivu, que é o trecho do rio Tietê inserido no Parque Ecológico, margeado pelas pistas da Rodovia Ayrton Senna, onde a ocupação é praticamente inexistente (...). O desassoreamento do reservatório da Penha poderia ser uma medida compensatória às alterações do uso do solo a montante, de forma a não modificar as vazões descarregadas pela barragem. A mesma comparação foi realizada com o desassoreamento hipotético do reservatório de Pirapora, respeitando a restrição de $700 \mathrm{~m} / \mathrm{s}$ da cidade a jusante. A laminação do hidrograma de cheias obtida foi levemente mais eficiente com o reservatório desassoreado, porém a redução nas vazões e nos níveis máximos foi pouco expressiva, próxima de 5\%. (...) Cabe ressaltar que atualmente não é possível rebaixar o nível d'água do reservatório de Pirapora até a cota 689, $15 \mathrm{~m}$ (...) tendo em vista que o assoreamento em algumas seções está acima desta cota. Recomenda-se a realização de estudos posteriores mais detalhados deste trecho, visando à identificação de outras ações de manutenção e adequação das estruturas existentes, para subsidiar o estudo de regras operativas mais eficientes no controle de cheias, aproveitando a elevada 
capacidade de reservação do lago formado pela barragem de Pirapora". (PDMAT3 - R11/ SÃO PAULO-ESTADO, 2014: 56).

Trata-se de uma análise direcionada pelo ponto de vista e interesse de controle da quantidade, e não da qualidade das águas. E, deste ponto de vista, as análises indicam que o benefício do desassoreamento não vale o custo.

Enquanto os casos 1 e 2 trazem, respectivamente, contextos de falhas e risco residual em sistemas de infraestruturas como agravadores de consequências internas e externas à RMSP, o caso 3 trata de um risco residual de impactos externos. Nos dois casos anteriores, os fatores espaciais de agravo e de vulnerabilidade das localidades são passíveis de análise, gerenciamento e solução localizadas - ainda que não sejam soluções simples e envolvam conflitos complexos. No caso 3, apesar de ser caracterizado por consequências bastante localizadas, os fatores espaciais que levam ao risco residual não são facilmente determináveis. O problema é composto por fatores espaciais difusos: embora não haja entradas de estiagem no cadastro do IG para este ano, é preciso considerar que o período de seca também contribuiu para os efeitos da ocorrência em questão; e a poluição hídrica, um fator difuso, sem dúvida, é causa e agravante do contexto.

\section{Quadro 26 - Esquema analítico dos sistemas envolvidos nos estudos de caso}

\begin{tabular}{|c|c|c|c|}
\hline Caso & \multirow{2}{*}{\begin{tabular}{|l} 
sistema \\
RMSP
\end{tabular}} & \multirow{2}{*}{$\begin{array}{l}\text { Tipologia dos } \\
\text { riscos } \\
\text { Ameaça extrema } \\
\text { (chuvas } \\
\text { duradouras) + } \\
\text { falhas + risco } \\
\text { residual } \\
\text { agravamento } \\
\text { (duração } \\
\text { abrangência das } \\
\text { consequências) }\end{array}$} & \multirow{2}{*}{$\begin{array}{l}\text { Fator espacial } \\
\text { Gerenciável } \\
\text { (delimitar problemas } \\
\text { melhorar vulnerabilidade das } \\
\text { áreas atingidas) }\end{array}$} \\
\hline 1 & & & \\
\hline 2 & $\begin{array}{l}\text { Sistema } \\
\text { Produtor de } \\
\text { Água - } \\
\text { Cantareira } \\
+ \\
\text { RMSP }\end{array}$ & $\begin{array}{l}\text { Ameaça extrema } \\
\text { (chuvas } \\
\text { localizadas e } \\
\text { intensas) + risco } \\
\text { residual = } \\
\text { agravamento dos } \\
\text { riscos locais }\end{array}$ & $\begin{array}{l}\text { Gerenciável } \\
\text { (delimitar problemas e } \\
\text { melhorar vulnerabilidade das } \\
\text { áreas atingidas) }\end{array}$ \\
\hline 3 & $\begin{array}{l}\text { Estruturas } \\
\text { hidrálucas } \\
\text { da BAT }\end{array}$ & $\begin{array}{l}\text { Ameaça extrema } \\
(\text { seca })+\text { risco } \\
\text { residual }= \\
\text { consequências } \\
\text { externas à RMSP }\end{array}$ & $\begin{array}{l}\text { Fator espacial difuso } \\
\text { (melhorar índice de } \\
\text { tratamento de esgotos, } \\
\text { controlar emissão de } \\
\text { sedimentos, controle do uso } \\
\text { do solo) }\end{array}$ \\
\hline
\end{tabular}


Nenhum dos atores envolvidos no conflito do caso 3 errou em suas atuações.

O município de Salto é a vítima, portanto não errou ${ }^{104}$, e procedeu defendendo seus interesses como usuário do recurso hídrico.

A EMAE priorizou o controle da segurança frente a inundações - e a exposição de todas as consequências metropolitanas apresentadas no primeiro caso exemplificam por que essa posição é justificável e pode ter sido priorizada com justeza.

O DAEE é responsável pelo desassoreamento, mas como pode ter errado sobre priorizar ou não este ponto sobre outros pontos da rede hídrica? O reservatório Paiva Castro, do caso 2, também está consideravelmente assoreado, assim como a calha do Tietê, à montante da Penha, do caso 1 . E em diversos outros pontos de controle, no canal do Pinheiros, em diversos afluentes, toda a rede hídrica de São Paulo sofre com assoreamento. Por que o DAEE deveria priorizar este ponto sobre os outros, frente a um risco residual (danos em Salto) que parece economicamente suportável no tempo? A implementação de medidas de controle de sedimentos na fonte geradora é uma ação que pode ser mais efetiva para solucionar definitivamente o problema, mas depende de um longo caminho de amadurecimento de elaboração, processos e colaboração de diversos atores, sobretudo de controle de uso do solo e de fiscalização. Uma atuação difusa. O controle da poluição difusa, a implantação de redes de esgoto e seu tratamento, também são fatores que compõem o problema que o DAEE tem sob sua responsabilidade nesse caso. Outras medidas de despoluição a posteriori (como o teste de flotação no Rio Pinheiros, abordado no próximo capítulo) exigem contexto favorável e a articulação de vários agentes.

A Cetesb não errou ao aplicar as multas e as sanções, muito embora saibamos que ações punitivas, ou a mera responsabilização judicial do agente operador, não resolvem problemas cuja natureza exige um controle difuso, e responsabilidades difusas.

Para os casos de fatores difusos e contextos complexos, seria importante e mais efetivo, buscar maneiras de envolver os atores positivamente na solução do problema: quem poderia extrair benefícios de determinadas medidas? Como implementar incentivos para que as ações sejam realizadas com cooperação e efetividade? Que articulações podem ser feitas, ou outros atores envolvidos? Seria possível desenvolver soluções para diluir, concentrar e trocar riscos e responsabilidades da mesma maneira com que as seguradoras diluem seus riscos, ou como os fundos de investimentos montam seus portfólios de negócios? Quais caminhos se abrem ao posicionar-se metodologicamente desta outra forma e incluí-la numa agenda que busca encontrar soluções de complexidade para problemas urbanos complexos?

\footnotetext{
${ }^{104}$ Em entrevista com técnicos da EMAE, foi levantado o fato de que, no córrego Ajudante, para onde os peixes fugiram da mancha de poluição, havia uma adutora implantada, que impedia a sua passagem, levando à mortandade. Esta adutora estaria implantada irregularmente, já que o córrego se encontra em área de proteção natural. Esta informação não consta em nenhuma matéria de jornal analisada.
} 


\section{CAPÍTULO 7 - ANÁLISE DO ESPAÇO: DIAGNÓSTICO DOS CONTEXTOS CRÔNICOS NA RMSP}

\subsection{O Jardim Pantanal}

\subsubsection{Caracterização geral: riscos e interfaces}

Conforme visto anteriormente, diante de uma ameaça extrema, o contexto de inundação no Jardim Pantanal sofreu agravos em 2009 e 2010 em função do vazamento de esgotos da ETE São Miguel e do nível elevado do rio Tietê que, devido a falha de bombeamento no Rio Pinheiros, fez com que a duração do alagamento mudasse a natureza do problema e a forma como esse risco é costumeiramente gerenciado em São Paulo. A quantidade de atingidos na ocasião era maior que nas outras ocorrências vividas na várzea, e o cotidiano durante a cheia, extremamente problemático. Naquele momento, a tolerância com uma ocupação por princípio equivocada - ainda que tolerada, consentida e consolidada pelo próprio poder público - expôs uma questão sempre adiada na cidade. $O$ desastre se transformou em oportunidade.

A estimativa de população sujeita a risco de inundação na várzea (baseado nas manchas de alta e média suscetibilidade do CPRM, conforme fig. 24 e dados na próxima página) é de 168.604 habitantes.

Embora o número de mortes na região tenha sido de apenas 1 no ano crítico 2009-10105, os dados de leptospirose indicam que houve aumento de contaminações. A leptospirose pode ser considerada como efeito de segunda ordem das ocorrências hidrológicas, um indicador importante nas políticas de gestão de risco. No período entre os anos de 2009 e 2017, os anos de 2009 e 2010 foram os que apresentaram mais mortes de leptospirose para o Município de São Paulo, respectivamente com 47 mortes e 301 casos confirmados, e 39 mortes e 265 casos confirmados, (dados do CVE - Casos confirmados para o Estado de São Paulo 2009-2018, fonte SINANW e SINANNET, SÃO PAULOESTADO, 2018). A média do período $2009-2018$ na cidade foi de 216 casos confirmados e 29 óbitos ${ }^{106}$. Sobre a distribuição dos casos na cidade:

"A campeã de doentes de leptospirose no último verão foi a Subprefeitura de São Miguel Paulista. (...) 30 pessoas adoeceram (em 2011) de leptospirose, segundo estatísticas da prefeitura. No verão anterior (2010) foram sete. (...) Em São Miguel Paulista, segundo a secretaria, não houve mortes - moradores dizem que foram orientados sobre os sintomas da doença, o que pode ter evitado que os casos se agravassem." (Folha de São Paulo, 16 de janeiro de 2011).

\footnotetext{
105 Para todo o período analisado no cadastro geral, existem mais 4 mortes por motivos hidrológicos em que é possível identificar o município de São Paulo como localização, mas sem identificação do bairro. Uma delas é no período 2009-10.

${ }^{106} \mathrm{Na}$ RMSP, a média do período foi de 418 casos confirmados e 52 mortes.
} 
FIG. 24 - Contagem de população suscetível a inundação na Várzea Tietê - Leste

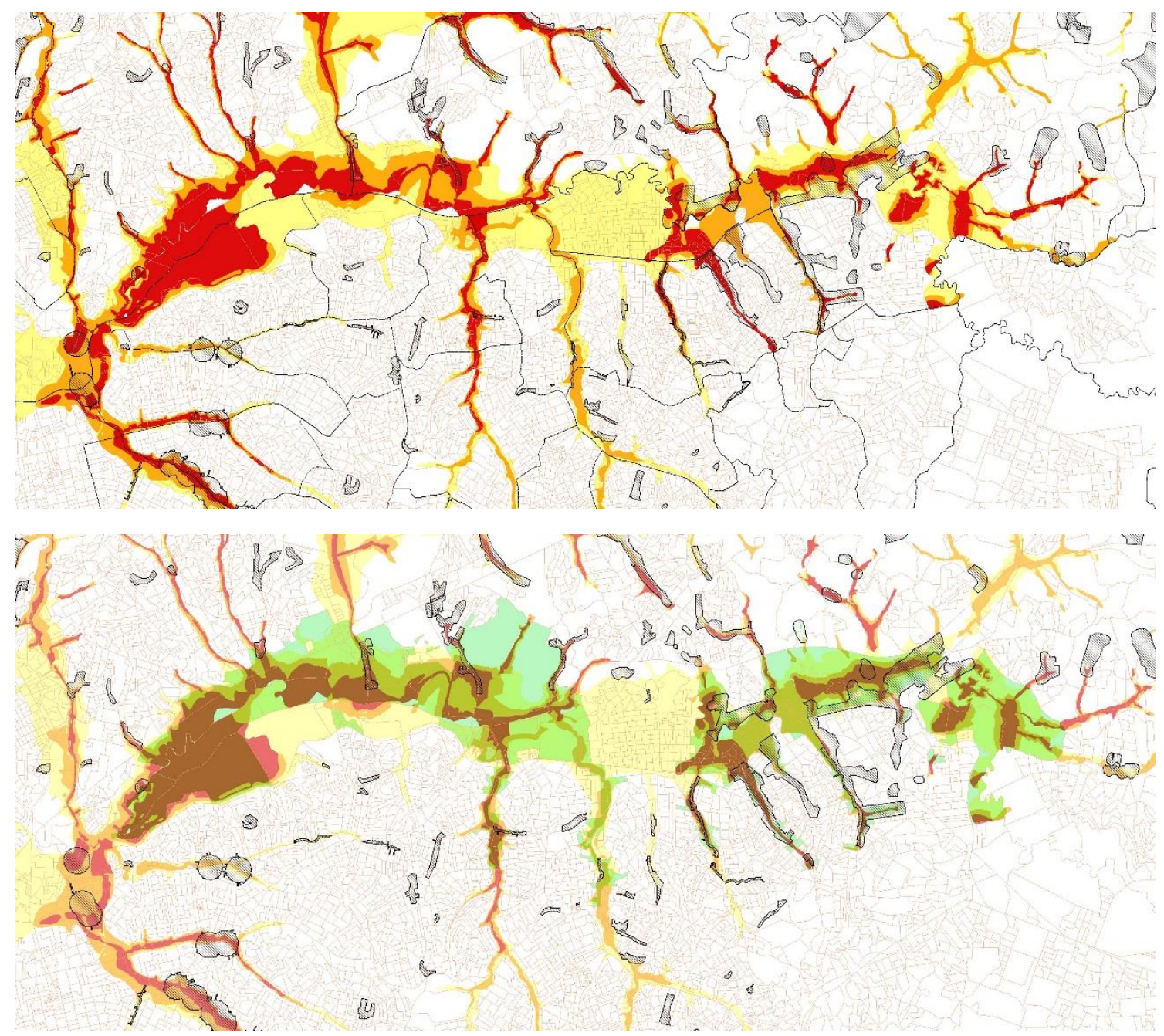

\begin{tabular}{|c|c|c|c|}
\hline $\begin{array}{l}\text { mun/distr } \\
\text { (total: 168.504) }\end{array}$ & Pop & $\begin{array}{l}\text { suscet. } \\
(A+M)\end{array}$ & $\begin{array}{l}\% \\
\text { pop }\end{array}$ \\
\hline Cangaíba & 136.550 & 81 & -- \\
\hline Jd. Helena & 134.979 & 40.347 & $29 \%$ \\
\hline S.Miguel & 91.835 & 10.972 & $12 \%$ \\
\hline V. Jacuí & 142.313 & 27.871 & $19 \%$ \\
\hline Erm. Matarazzo & 113.525 & 6.708 & $6 \%$ \\
\hline Itaim Paulista & 223.950 & 36.085 & $16 \%$ \\
\hline Vila Curuçá & 148.879 & 11.013 & $7 \%$ \\
\hline Guarulhos (outros) & \multirow{2}{*}{1.221 .979} & 7.681 & \multirow[b]{2}{*}{1,7} \\
\hline $\begin{array}{l}\text { Pres. Dutra } \\
\text { Guarulhos }\end{array}$ & & 13.685 & \\
\hline Itaquaquecetuba & 321.384 & 14.161 & 4,4 \\
\hline
\end{tabular}

Os perímetros das populações em áreas de risco do IBGE (BATER - hachuras em preto) para a região não coincidem com as áreas suscetíveis a inundação na várzea. O BATER é recurso importante para quantificar populações em risco, pois faz adequação entre a delimitação (perímetro) de setor censitário e a delimitação (perímetro) de setorizações de risco. Mas não foram trabalhados uniformemente para diferentes fontes de informação sobre riscos. Por exemplo, nas franjas periféricas da RMSP os perímetros BATER foram trabalhados principalmente ao risco geológico, somente nas áreas centrais, junto a vias principais, estão aplicados e coincidem a riscos hidrológicos. Para uma estimativa de população em risco na região da várzea, foram cruzadas as manchas de alta e média suscetibilidade do CPRMIPT (não foi possível obter shapefile da mancha do PDMAT3) com os setores censitários. Foram selecionados setores ora além do perímetro da suscetibilidade, ora aquém. Nos mapas, do amarelo ao vermelho, baixa, média e alta suscetibilidade a inundação; em verde, no mapa abaixo, os setores censitários apontados para a contagem, consolidada na tabela ao lado.

Base: RMSP-Terraview-CEM. Fontes: IPT-CPRM (suscetibilidade); IBGE (2010 e 2018). Elaboração: da autora. 
Em relação ao agravante das falhas nas bombas do Pinheiros, foi levantado estudo técnico desenvolvido pela EMAE para implantação de redundâncias elétricas em diversos pontos dos dispositivos de controle na calha do Tietê e Pinheiros:

Quadro 27 - Controles da calha Tietê-Pinheiros analisados no estudo EMAE

\begin{tabular}{|l|l|l|l|}
\hline & ESTRUTURA & PROPRIETÁRIO & OPERADOR \\
\hline 1 & U.Elevatória Pedreira & EMAE & EMAE \\
\hline 2 & U.Elevatória Traição & EMAE & EMAE \\
\hline 3 & Barragem do Guarapiranga & EMAE & EMAE \\
\hline 4 & Estrutura de Retiro & EMAE & EMAE \\
\hline 5 & Barr. Reg. Billings - Pedras & EMAE & EMAE \\
\hline 6 & Barragem Móvel & DAEE & EMAE \\
\hline 7 & Barragem da Penha & DAEE & EMAE \\
\hline 8 & Est. Bomb. Eduardo Yassuda & PMSP & EMAE \\
\hline 9 & Polder Ponte das Bandeiras & PMSP & PMSP \\
\hline 10 & Polder Ponte Casa Verde & PMSP & PMSP \\
\hline 11 & Polder Ponte Anhanguera & PMSP & PMSP \\
\hline
\end{tabular}

O documento aponta em suas conclusões que as Usinas de Pedreira e Traição estavam atendendo aos critérios de segurança dos circuitos elétricos, e que havia necessidade de reforço de segurança em todos os outros dispositivos. As propostas não indicam custos altos para a implementação de melhorias na segurança desses sistemas $(R \$$ $375.000,00$ para todos os sistemas, a preços de 2010) ${ }^{107}$. Mas a questão do bombeamento do Pinheiros, e mesmo a falha na ETE São Miguel, não extinguem nem explicam os riscos a que está sujeita a ocupação da várzea, nem os riscos que a ocupação da várzea representa para os sistemas. São, no mínimo, quatro interfaces envolvidas no problema:

- interfaces, falhas e riscos inerentes ao sistema de macrodrenagem - a várzea tem uma função de zona de amortecimento nesse sistema, cujo desempenho entra em conflito com as ocupações residenciais. Ocorrências na interface macrodrenagemhabitação podem ser consideradas como um risco residual do sistema de macrodrenagem da BAT, pois a solução geral prescinde de uma zona de amortecimento e os controles hidráulicos estabelecidos priorizam a segurança da parte central da bacia, cujos efeitos se materializam nessa região. Esses riscos não são apenas muito prováveis, eles são inerentes ao sistema. O contexto pode ser entendido também pelo risco que a ocupação proporciona para que os controles hidráulicos funcionem de acordo com seus propósitos - controlar vazões e nível do Tietê a jusante da barragem

107 EMAE, 2010. “Melhora da Confiabilidade da Alimentação Elétrica das Estruturas para Controle de Cheias da RMSP". Informações posteriores da Secretaria de Energia e Mineração (2015) dão conta de que os reforços foram executados. 
da Penha. Ou seja, a ocupação é um fator de vulnerabilidade do sistema. Além disso, as ocorrências no Jardim Pantanal na data crítica avaliada podem ser entendidas como local onde se manifestou o agravamento por falhas dos controles de macrodrenagem. As falhas são riscos menos prováveis e gerenciáveis por manutenção continuada e implementação de sistemas redundantes para segurança elétrica.

- interfaces, riscos e falhas relativos à Estação de Tratamento de Esgotos - os riscos da ETE (cujo alcance é regional e metropolitano) para a região do Jardim Pantanal envolvem contextos de falha nesse sistema. Qualquer falha na ETE associada a contexto de cheia pode impactar rapidamente a população do entorno. No entanto, a contaminação por esgotos não é ocorrência provável apenas se a ETE falhar. A estruturação da ocupação, que exige bombeamento para coleta de seus esgotos, é um problema em si nos momentos de inundação. A contaminação na data crítica, pela falha, é uma situação aguda. O que torna o problema do Jardim Pantanal crônico é a falha do sistema habitacional. A falha do sistema habitacional dificulta as funções regionais da ETE ao impedir a implementação de coletores tronco (o que permitiria ampliar a quantidade de esgotos tratados nessa capacidade instalada), permitindo que redes coletoras locais e lançamentos a céu aberto descarreguem no sistema de drenagem.

- interfaces e riscos relativos aos sistemas produtores de água - os níveis de segurança das represas dos sistemas produtores do Alto Tietê (SPAT) são maiores que os do Paiva Castro no Sistema Cantareira, até mesmo pela interligação com outras represas, pelo contexto de ocupações menos densas (Mogi, Suzano) e porque, originalmente, os reservatórios do SPAT tinham por finalidade principal o controle de cheias. No entanto, ao se preparar para ameaças extremas, é importante ponderar que as ocupações da várzea, já vulneráveis a processos de inundação, possam ter como agravante o aumento das vazões decorrente da necessidade de manobras dessas represas em afluentes do rio Tietê. Em conversa com moradores, alguns afirmavam que no episódio de 08/12/2009, uma das datas mais críticas, as comportas de Jundiapeba, em Mogi, foram abertas enquanto a barragem da Penha estava fechada ${ }^{108}$. A interferência na várzea é um risco, como regra, internalizado ao gerenciamento do sistema, e mitigado quando estabelecidos volumes de espera dos reservatórios. Em situações extremas, quando excedidos os volumes de espera, as descargas tenderão a inundar as várzeas ocupadas. Ainda que de baixa probabilidade, deve ser mais um risco a ser considerado para as ocupações. Trata-se de duas interfaces: macrodrenagem-sistemas produtores de água e sistemas produtores de água-habitação. No caso mencionado, a barragem da Penha nada teria a ver com a inundação da várzea, como comentado mais adiante. Mas o vertimento, possivelmente sim.

- interfaces e falhas do controle ambiental - a delimitação da APA da Várzea do Tietê exige um conselho gestor que dê conta do manejo da área e gerencie as ocupações já existentes. Deve ser uma premissa reconhecer as ocupações que existem. Ao mesmo tempo, as próprias restrições ambientais impedem a resolução de uma série de conflitos causados pelas ocupações, sobretudo na execução de obras necessárias para saneamento e regularização da área. Interface controle ambiental-habitação.

\footnotetext{
108 Informação obtida do representante 'Gonzagão', em atividade de grupos de discussão promovida pelo Consórcio Vizca e Sinergia Consultoria em dezembro de 2017.
} 
- interfaces, riscos e falhas relativas ao sistema habitacional - as restrições ambientais dificultam a regularização das ocupações no Jardim Pantanal. Regularização em sentido amplo - não apenas fundiária, mas no acesso a serviços de infraestrutura urbana. Há dificuldades técnicas na implantação de redes sanitárias (de água, pelas restrições ambientais, e de esgoto pelas mesmas, além do custo de soluções técnicas de bombeamento). Há riscos consideráveis de contaminação cruzada entre esgoto e água, uma vez que as redes de água são clandestinas ${ }^{109}$. As falhas do sistema habitacional são de várias ordens: desde a falta de oferta pública e de mercado acessíveis, até falta de controle do uso do solo (áreas junto aos braços do Tietê continuam recebendo ocupações recentes, como pôde ser verificado em visitas e entrevistas com moradores). As consolidações promovidas pelo poder público não articulam soluções abrangentes e estruturadas para a regularização da região, nem fazem uma avaliação ampla dos riscos que geram e aos quais estão submetidas. Como veremos, a seguir, há desarticulação entre esferas envolvidas nas propostas para a área. Falta, sobretudo, clara delimitação no zoneamento municipal que determine a área como de interesse especial para a gestão de riscos das redes metropolitanas de infraestrutura, funções de interesse comum na metrópole. Essa poderia ser uma indicação no ordenamento metropolitano, com caráter vinculante ao plano diretor, e associada a programas específicos de gestão de riscos.

\section{Quadro 28. Matriz dos riscos identificados para a região do Jardim Pantanal*}

\begin{tabular}{|c|c|c|c|c|}
\hline & \multicolumn{3}{|c|}{ Impactos } \\
\hline & & $\begin{array}{l}\text { impacto local } \\
\text { (bairro, micro-região) }\end{array}$ & $\begin{array}{l}\text { impacto local severo e } \\
\text { impacto metropolitano } \\
\text { difuso }\end{array}$ & $\begin{array}{l}\text { severos impactos } \\
\text { metropolitanos e locais }\end{array}$ \\
\hline \multirow{5}{*}{$\begin{array}{l}\frac{0}{0} \\
\frac{\pi}{0} \\
\frac{0}{\overline{0}} \\
\frac{0}{\pi} \\
\frac{0}{0} \\
\frac{0}{2}\end{array}$} & baixíssima & & $\begin{array}{l}\text { * níveis críticos das } \\
\text { represas do SPAT }\end{array}$ & \\
\hline & baixa & & & $\begin{array}{l}\text { * falhas operacionais do } \\
\text { sistema de } \\
\text { macrodrenagem } \\
\text { (bomba do Pinheiros) }\end{array}$ \\
\hline & média & & * falhas na ETE São Miguel & \\
\hline & alta & & $\begin{array}{l}\text { * falhas dos controles } \\
\text { ambientais }\end{array}$ & \\
\hline & altíssima & $\begin{array}{l}\text { * contaminação cruzada } \\
\text { água x esgoto devido à } \\
\text { irregularidade das redes }\end{array}$ & $\begin{array}{l}\text { * inundação do Jardim } \\
\text { Pantanal } \\
\text { * falhas do sistema } \\
\text { habitacional }\end{array}$ & \\
\hline
\end{tabular}

${ }^{*}$ A matriz de risco é uma forma expedita e simplificada de classificar riscos, considerando probabilidade e impacto: quanto mais alta probabilidade e maior impacto, mais alto o risco (campos em vermelho), quanto menor a probabilidade e a escala do impacto, mas baixo o risco (em verde). Os impactos foram classificados aqui entre de escala local ou metropolitana (impacto amplo e difuso, não apenas os diretamente afetados).

${ }^{109}$ Em reunião da frente Parlamentar de Inquérito, representante da Sabesp informou que a companhia faz redução de pressão na rede para preservar redes clandestinas de rompimentos e diminuir riscos de contaminação. 


\subsubsection{Soluções, limitações, potencialidades}

Existem duas soluções urbanísticas que deveriam ser complementares e são concorrentes na área do Jardim Pantanal: a implementação do Parque Várzeas do Tietê e a implementação do projeto para o perímetro de ação integrada Água Vermelha 2, do Programa de Urbanização Integrada Renova São Paulo da Prefeitura de São Paulo. Ambas tratam o território de forma fragmentada, seja pelas delimitações espaciais estabelecidas, seja pela segregação de funções e responsabilidades relacionadas a elas. Há sobreposições de perímetros e atribuições, há confluência de algumas proposições, mas falta articulação adequada entre os dois projetos. Essa desarticulação prejudica a tomada de medidas duradouras para prevenção e mitigação de riscos, e também a comunicação com a população moradora sobre qual e como será a transformação na região, bem como a adequada integração entre os recursos públicos empregados nessa transformação.

A proposta do Parque Várzeas do Tietê faz parte de um antigo ideário urbanístico de configuração da Metrópole, consolidado na proposta de Rui Othake para preservação ambiental e uso paisagístico das várzeas do rio Tietê: a montante da barragem da Penha até a nascente em Salesópolis, e a jusante de Pirapora, até Barueri, nos limites da mancha urbana de São Paulo. Originalmente elaborada em 1977, foi parcialmente executado no Parque Ecológico do Tietê, inaugurado em 1982, composto pelos núcleos: Engenheiro Goulart e Vila Jacuí, na Zona Leste de São Paulo, e Ilha do Tamboré, em Barueri. Para a continuidade da proposta na várzea leste, um elemento conceitual importante de projeto ${ }^{110}$ é a construção de uma perimetral, a Via Parque, que estabelece o limite entre as ocupações e a zona de várzea a ser preservada. A concepção original argumenta que, se no passado se pretendia que a ocupação urbana da região de São Miguel e municípios adjacentes à várzea do Tietê fosse limitada pela linha férrea, dada a configuração presente, este limite deveria ser reestabelecido por algum outro forte elemento de projeto.

A via parque é apresentada pelo autor como um edifício linear contínuo e subterrâneo (fig. 25), uma galeria por onde passam as redes de infraestrutura de capacidade secundária, como interceptores de esgoto, adutoras e cabeamentos da rede elétrica. Em intervalos determinados, essa linha contínua se liga a estações, ou dispositivos das redes nos bairros, na transição entre distribuição local e a capacidade secundária: estações de tratamento, reservatórios regionais de água, subestações elétricas. Apesar do sentido primordial do projeto ser preservar funções de macrodrenagem (ao preservar as margens), a Via Parque não incorpora soluções para problemas que ela mesma traria ao funcionamento da drenagem dos bairros. Para que a água dos bairros flua para a várzea e o rio, a Via Parque deveria ser interrompida em sua continuidade, ou ser transposta de alguma forma. A ideia da Via Parque permaneceu na concepção do Parque Várzeas do Tietê (PVT) como o limite entre as ocupações e a área do parque, a ser compatibilizado com a mancha de inundação prevista no PDMAT (atualizada para a mancha do PDMAT 3), e que recebe um programa funcional de ciclovia.

\footnotetext{
${ }^{110}$ Argumento confirmado com o próprio arquiteto, em atividades para formulação de proposta o Fehidro, para detalhamento da Via Parque.
} 


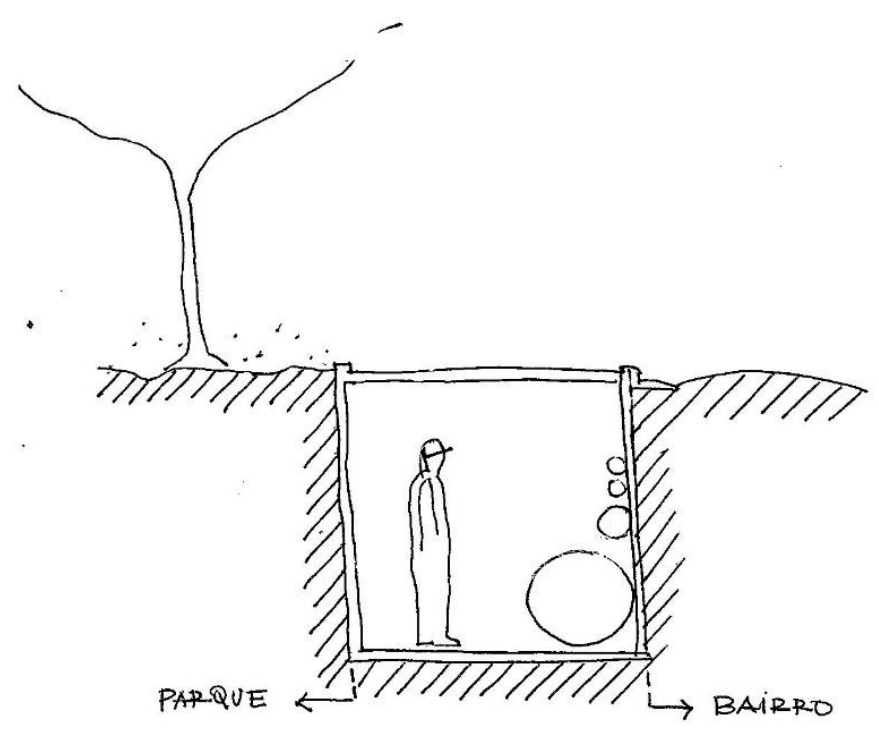

FIG. 25 Corte esquemático - conceito da proposta da Via Parque (elaborado com base em desenho de Ruy Otahke).
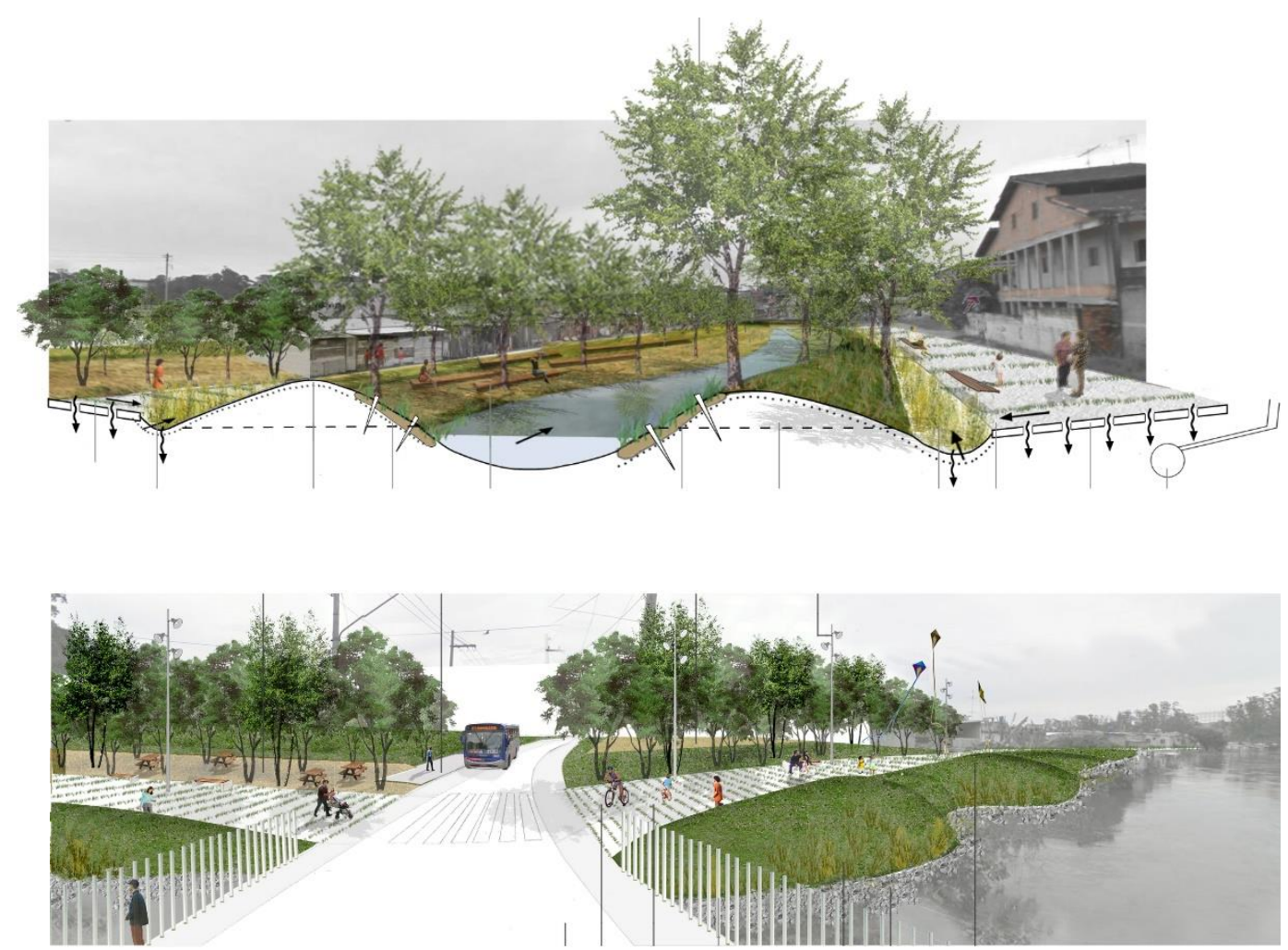

FIG. 26 Desenho de soluções ambientais propostas no projeto vencedor do Renova SP Água Vermelha. 
Ao final do ano de 2016, foi possível acompanhar alguns encontros do grupo ZL Vórtice, que se reunia para formular e pleitear recursos do fundo Fehidro com o intuito de detalhar a proposta da Via Parque de Ruy Ohtake, e promover ações locais de mobilização da população para a produção de espaços mais sustentáveis e resilientes. A proposta foi elaborada apenas para um bairro da várzea, o Jardim Lapena, como piloto. O agente facilitador das discussões do grupo era ligado a uma importante entidade local que promove ações sociais na região, a Fundação Tide Setúbal ${ }^{111}$. Participaram dos encontros, além dos responsáveis pela proposta, representantes da fundação e moradores do bairro, o arquiteto Ruy Ohtake, interessado na possibilidade de desenvolver detalhamentos da Via Parque, o arquiteto responsável pelo desenvolvimento do projeto do Renova São Paulo, e representantes da Sabesp responsáveis pela ETE São Miguel - o Jardim Lapena é uma ocupação adjacente à ETE.

A participação nesses encontros expôs o quão desarticulado estavam as propostas para a região. O representante da Sabesp afirmava ser a primeira vez que tomava contato com o conceito completo da Via Parque, e que se isso se concretizasse seria 'um sonho' para resolver os problemas de coleta e transporte de esgotos para a várzea. Os representantes da fundação e os responsáveis pela elaboração da proposta ao Fehidro pediam para que o arquiteto responsável pelo projeto do Renova São Paulo ampliasse o alcance das propostas de urbanização para aquele bairro, e apresentasse as soluções desenvolvidas, uma costura entre o tecido urbano e o parque por meio de elementos de infraestrutura verde, presentes na proposta vencedora (ver fig. 26 e 28). Os moradores pediam para que o perímetro da Via Parque e a delimitação do PVT fosse alterada em função da consolidação das ocupações, ainda que não participasse da reunião nenhum gestor do projeto do PVT. Os dois arquitetos demoraram a se dar conta de que as duas distintas concepções de infraestrutura que apresentavam eram inconciliáveis para compor uma mesma proposta, pois enquanto uma previa radical separação entre várzea e ocupação, a outra propunha elementos de retenção da drenagem entremeado no tecido urbano, num desenho de conexão desses fluxos com a várzea. As propostas de educação ambiental na região propunham conciliação de ações artísticas e construções piloto de pisos drenantes, sem considerar que a baixa capacidade de absorção em solos de várzea tende a comprometer a eficácia desse tipo de solução.

Ainda assim, o projeto obteve recursos para implementação, e tem apoio de laboratórios da FAU-USP e Poli-USP para seu desenvolvimento. Embora seja um elemento marginal nos processos de transformação da região, tanto em termos de recursos como de resultados, ilustra bem o grau de desarticulação conceitual dos agentes.

O projeto do Parque Várzeas do Tietê é um programa do Governo do Estado cujo executor é o DAEE. O programa, preparado em 2009-2010, é parcialmente financiado pelo Banco Interamericano de Desenvolvimento - BID, que trabalha com as frentes de ação propostas pelo PDMAT e visa:

"recuperar, para efeito de amortecimento de picos de ondas de cheias, as várzeas remanescentes na bacia do Alto Tietê a montante da Barragem da Penha, assim como a atenuação dos efeitos de sua ocupação desordenada e

\footnotetext{
${ }^{111}$ A região possui duas importantes fundações promotoras de ações sociais na região da várzea: a Fundação Tide Setúbal e o Instituto Alana.
} 
dos consequentes problemas ambientais, urbanísticos e sociais, ensejando obter, de forma progressiva, a gestão integral de toda a várzea e a melhoria da qualidade de vida da população no entorno urbano da área de intervenção. Para tanto, o Programa prevê várias obras específicas, além da implantação de Núcleos com equipamentos de esporte, cultura e lazer e de uma Via Parque e Ciclovia para o acesso a esses Núcleos." (HOLTZ, 2015: 7)

A gestão do programa é bastante complexa. Foram firmados protocolos de intenção entre o Governo do Estado de São Paulo, Prefeituras de São Paulo, Guarulhos e demais municípios inseridos na área do PVT, Convênio de Habitação entre a então Secretaria de Estado de Saneamento e Energia - SSE (atual Secretaria de Estado de Saneamento e Recursos Hídricos - SSRH), a Secretaria de Estado da Habitação - SH, a Secretaria Municipal de Habitação - SEHAB, o Departamento de Águas e Energia Elétrica - DAEE e a Companhia de Desenvolvimento Habitacional e Urbano - CDHU, e convênios de execução e termo de cooperação com município de Guarulhos, para reserva 600 unidades habitacionais do Programa Minha Casa Minha Vida que atendesse às famílias vinculadas ao PVT. Além dos protocolos de cooperação institucional, há extensa produção de documentos de acompanhamento por exigência do BID, e documentos que estabelecem procedimentos de ação: um Manual Operacional do Programa, Plano Diretor de Reassentamento e Planos de Execução do Reassentamento, Manual de Trabalho Técnico e Social, Relatórios de Gestão Ambiental e Social, Manual Ambiental de Construção, entre outros documentos derivados. Certamente são salvaguardas para obter financiamentos em um cenário de muitas inseguranças, não só do contexto da ocupação informal:

"Na ocasião da preparação do Programa, no período que foi até a assinatura do contrato de empréstimo com o BID, a maior parte dos projetos estava elaborada e pronta no nível de projeto básico. No entanto, no que se refere a projetos com informações suficientes para ir à licitação, só o projeto da ciclovia e via parque estavam elaborados, mas assim mesmo, incompletos. (...) Por exemplo, os núcleos de lazer tinham "projetos básicos" que não continham os elementos necessários para se licitar.

Assim sendo, foi necessário licitar os projetos executivos que estão sendo entregues neste momento para serem submetidos a não objeção do Banco e posterior licitação das obras. (...) Os atrasos do Programa são resultado dessa falta de projetos e outras razões, como (i) reassentamentos, que não estavam equacionados; (ii) desapropriações (que inicialmente não constavam do orçamento do Contrato de Empréstimo), para as quais não foram viabilizados recursos pelo Governo do Estado e (iii) indefinição quanto à execução de obras de Macrodrenagem que, de acordo com o cronograma do Programa, seria iniciada após finalização do Contrato de Empréstimo". (HOLTZ, 2015: 32)

Apesar das exigências e complexidade do acompanhamento, acordos e decisões estabelecidos para a área ainda não estão resolvidos satisfatoriamente. Um dos riscos classificados como "alto" na matriz do programa (SSRH e DAEE, 2015: anexo 3) referese à disponibilidade de unidades habitacionais incompatível com o cronograma de obras. A solução habitacional é condição necessária não só para o financiamento, mas 
para um processo de comunicação e trabalho social respeitoso, essencial para envolver no programa uma população cuja ação de resistência e reocupação pode drenar todos os esforços e recursos empregados na mitigação de riscos. Talvez seja o elemento mais difícil de ser equacionado na proposta. No arranjo do reassentamento, entretanto, essa responsabilidade foi consideravelmente repassada ao município de São Paulo:

"Embora o Convênio Geral da Habitação, de 2010, estimasse o atendimento a 5.000 famílias oriundas do município de São Paulo, a atualização de demanda realizada pela SEHAB em São Paulo demonstrou a necessidade de alteração nos números das previsões: de 5.000 famílias para 7.115, a serem beneficiadas com atendimento habitacional nas áreas de intervenção do PVT, em São Paulo. Nos termos do ajuste celebrado com vistas ao reassentamento habitacional do PVT - 1ª Etapa e os dados atualizados de demanda, à SEHAB do município de São Paulo cabe prover habitação para 3.557 famílias e à SH do Estado de São Paulo, 3.558 famílias oriundas do município de São Paulo. Das 7.115 famílias, 2.661 foram removidas por conta das inundações do verão de 2009/2010, sendo que 340 foram encaminhadas para imóveis da CDHU (em 2010), 203 para imóveis sob a responsabilidade da SEHAB (em 2012 e 2013) e 2.118 continuam a receber Auxílio Moradia, cujos custos estão divididos igualmente entre GESP/SH - CDHU e PMSP/SEHAB. Por acordo comum entre os partícipes do Convênio no 2010/22/00186.7, essas famílias atendidas na calamidade foram consideradas como demanda habitacional do PVT e, portanto, deverão ter atendimento prioritário em relação às demais famílias a serem removidas. Além das famílias acima listadas, outras 4.454 famílias continuam a residir no perímetro do Parque. $O$ atendimento habitacional da demanda oriunda do município de São Paulo não faz parte do Contrato de Empréstimo com o BID (Contrato $n^{\circ}$ 2500/OC-BR) para a implantação da $1^{\text {a }}$ Etapa do PVT, firmado em 13 de julho de 2011, mas é condição necessária para a realização de serviços $e$ obras do PVT neste município". (SSRH e DAEE, 2015:106)

$\mathrm{Na}$ preparação do programa ficou estabelecido que as obras e a gestão social dos reassentamentos no município de São Paulo seriam executadas pela CDHU e a Prefeitura Municipal de São Paulo, e não seriam parte do financiamento. Também as obras do "Polder Jardim Romano", cuja construção permitiria menor número de reassentamentos, ficaram de fora do contrato. Toda a demanda habitacional do município de Guarulhos (originalmente estimada em 500 e posteriormente adequada a 675), bem como o trabalho social de reassentamento, fazem parte do Contrato de Empréstimo, e se apoiam no Termo de Cooperação para as 600 unidades do MCMV deste município.

Em entrevista com moradores e representantes dos bairros da várzea, foi informado que muitas famílias que recebem auxílio aluguel voltaram a suas casas ou iniciaram novas ocupações em áreas de risco, pela própria dificuldade do mercado já indicada na análise das notícias, no capítulo 6 .

A fim de avaliar quanto tem custado essa prática de gerenciar financeiramente os riscos, houve grande dificuldade em obter informação específica para a área no histórico de benefícios concedidos com auxílio aluguel pela Prefeitura de São Paulo. Na listagem 
disponível ${ }^{112}$, com informações de beneficiários ativos, subprefeitura e data de início do benefício, foi possível discernir apenas as seguintes informações para as subprefeituras que compõem a várzea:

- total de benefícios vigentes em 2018 - 28.407, dos quais 443 em subprefeituras que compõem a várzea (todas as moradias no limite da subprefeitura, ou seja, não se pode extrapolar considerando que esses benefícios correspondem a moradias na várzea);

- Subprefeitura de Itaim Paulista - total de 105, dos quais: 64 desde 2011; 27 desde 2012; 4 desde 2014; 5 desde 2015 e 7 desde 2017;

- Subprefeitura de Ermelino Matarazzo - total de 13, dos quais: 4 desde 2011, 9 desde 2013, 1 desde 2015;

- Subprefeitura de São Miguel - total de 325, dos quais: 72 desde 2010, 101 desde 2011, 8 desde 2012, 8 desde 2013, 1 desde 2014, 1 desde 2015, 119 desde 2017 e 16 em 2018.

Em consulta à Sehab, foi informado que não é possível identificar nos registros históricos entrada diferenciada por localidades e categoria de atendimentos, sobretudo por subcategorias (motivos) de emergências, vulnerabilidades ou riscos. Foi possível apenas levantar categorias em relação ao total do município para 2017, sem discriminar localidade: dos 29.199 atendimentos ativos em 2017, 2.463 pertenciam à categoria "emergência", 4.879 à categoria "remoção por obra", 7.299 à categoria "remoção por risco", 1.838 à categoria "remoção por risco e obra", e 52 à categoria "vulnerabilidade"113.

Utilizar o mesmo recurso para situações de emergência e em contextos de soluções de regularização habitacionais de diversas ordens revela a ausência de mecanismos financeiros específicos para lidar com riscos urbanos, e a ausência do desenvolvimento de instrumentos próprios e lógica própria para gestão de riscos nos órgãos responsáveis pelo planejamento urbano. Os contextos de risco são colocados num pacote único de carências urbanas.

Apesar das solicitações por meio da Lei de Acesso à Informação, não foram fornecidos mais dados sobre procedimentos e situação de implementação do Programa Renova São Paulo no Perímetro Água Vermelha 2. No entanto, as informações conhecidas e disponíveis são suficientes para identificar os pontos de desarticulação entre os programas de urbanização Municipal e Estadual para a região.

Enquanto a delimitação do PVT é uma faixa contínua ao longo do rio, e considera as questões habitacionais apenas parcialmente dentro do perímetro do parque (ou seja, as interferências internas à delimitação da Via Parque), o perímetro do Renova São Paulo PAl-Água Vermelha 2 associa um amplo tecido de favelas, loteamentos irregulares e núcleos urbanizados aos trechos correspondentes do rio Tietê e braços (Flg.27).

\footnotetext{
112 Os dados são disponíveis apenas em arquivos pdf - mais um fato constatado a ser considerado em processos de estruturação das informações necessárias à gestão de riscos.

http://www.habitasampa.inf.br/atendimento/atendimentos-realizados/programa-acoes-de-habitacao/ 113 Informações fornecidas pela Sehab, não discriminados por subprefeitura, categorias de acordo com a Portaria 131/SEHAB/2015.
} 

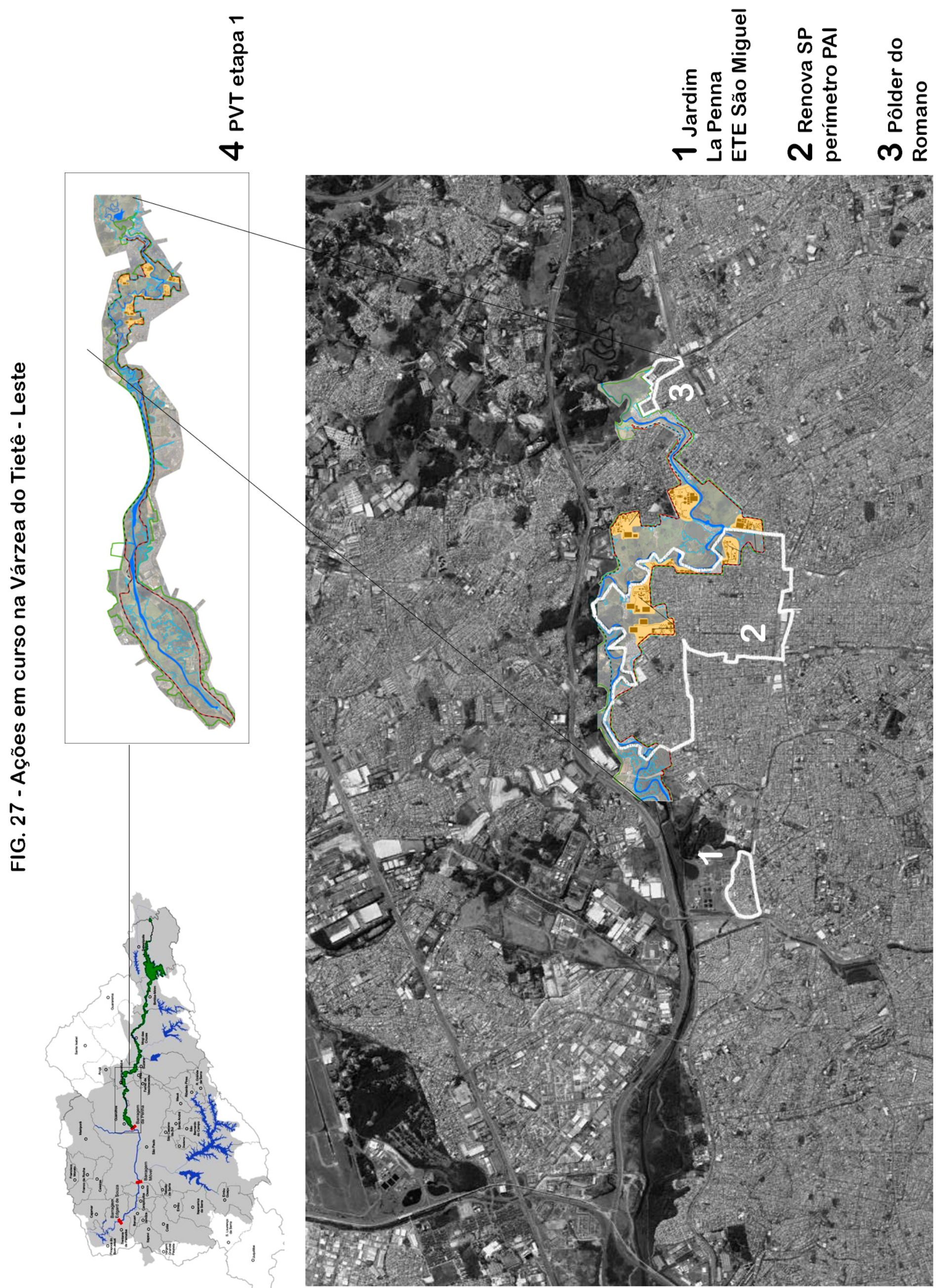


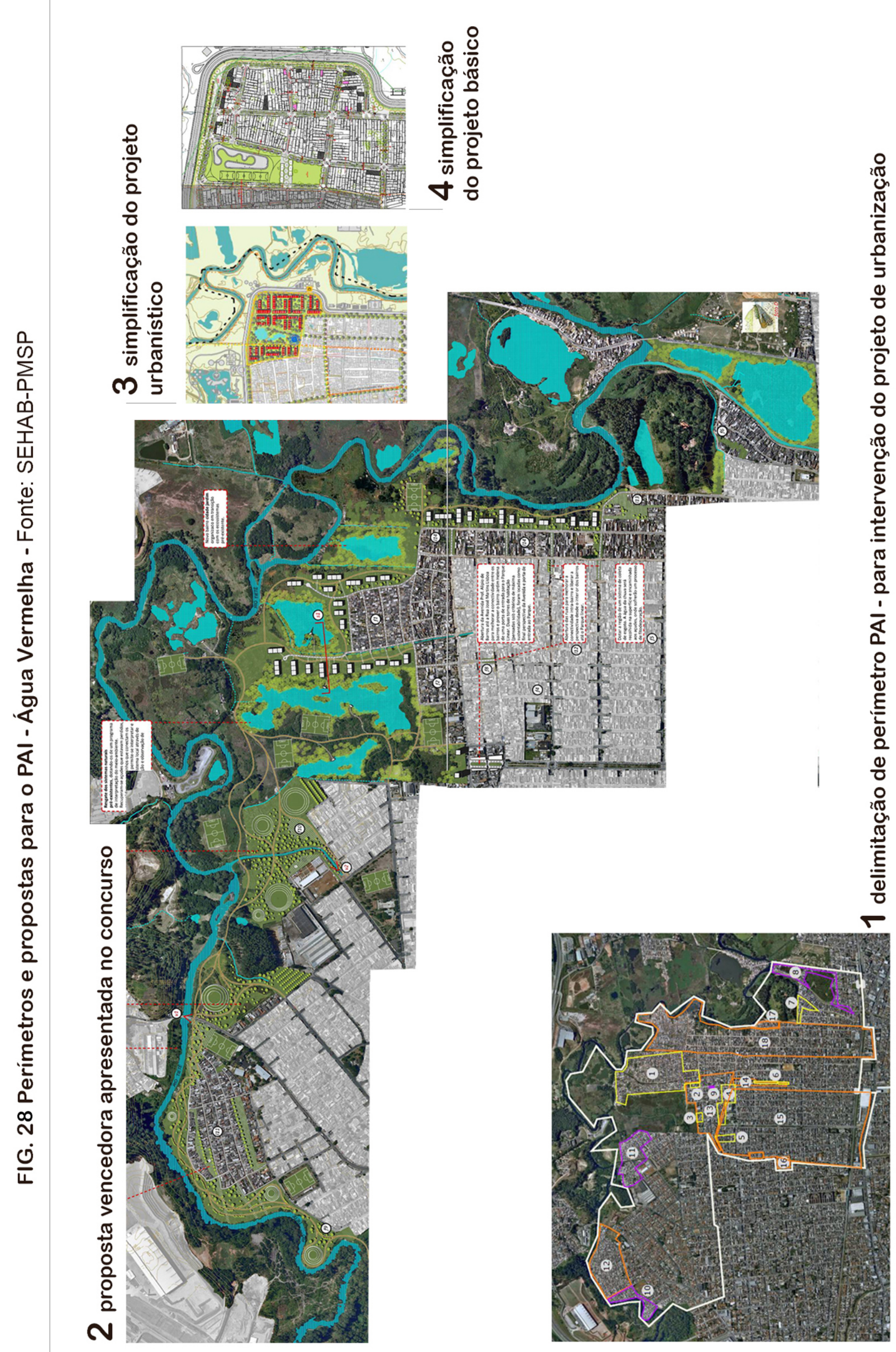


O projeto vencedor, em seu conceito original (Fig. 28, página anterior), é uma proposta mais ampla de resolução do conflito habitacional e que integra funções hidrológicas em seu desenho. Porém, não ampla o suficiente para abarcar os problemas habitacionais da várzea entendida como totalidade. O Jardim Lapena e Jardim Romano, por exemplo, estão fora do PAI, embora expressem conflitos similares aos da área delimitada. Isso ocorre porque o Programa não foi formatado para solucionar os problemas específicos desta localidade, como uma região contínua, mas para dar conta de um problema de ocupações informais generalizado na cidade, através de perímetros parciais.

O Programa Renova São Paulo é parte de uma estratégia da gestão municipal de 2010 que previa utilizar recursos do Fundo Municipal de Saneamento Integrado, FMSAI, na urbanização de assentamentos precários no município em longo prazo. Este fundo, criado em 2010, é composto pelo repasse ao município de $4,5 \%$ das receitas brutas da Sabesp, provenientes das tarifas de água e esgoto, e destinado a obras municipais não exclusivas de saneamento, mas exclusivas para urbanização de áreas precárias abastecíveis. Os recursos do fundo podem ser utilizados para: regularização fundiária e parcelamento, despoluição limpeza e canalização de córrego, obras viárias, provisão habitacional, drenagem e obras geotécnicas de controle de riscos, desapropriações, conservação de mananciais, parques lineares e piscinões.

Os perímetros PAI foram elaborados justamente para definir, além das áreas urbanas regulares, quais áreas não regulares seriam abastecíveis para efeito do contrato firmado entre o município e a Sabesp. O repasse de 4,5\% da receita (além de 13\% a ser decidido por um comitê gestor do contrato sobre investimento nas obras municipais exclusivas de saneamento) é parte do contrato firmado em 2009 entre município e a prestadora.

A opção de inserir o projeto habitacional para a Várzea do Tietê como mais um PAl entre outros estabeleceu uma indistinção para os problemas desta localidade, equalizou os riscos metropolitanos aí representados com outros riscos cujo equacionamento poderia se dar em escala local. Colocou uma zona de riscos crônicos em situação de disputa por recurso com outras localidades. Além do FMSAI, era previsto que o Programa contasse com recursos federais do PAC Urbanização de Favelas e do MCMV, mas, ao fim do ano de 2015, com a crise de financiamentos federais, as obras de urbanização de assentamentos precários em São Paulo estavam recorrendo principalmente, e de forma não estruturada, aos recursos do FMSAI ${ }^{114}$. Isso tem reflexos no andamento do outro programa na região: relatórios de implementação do PVT apontam que a dependência de outros órgãos envolvidos em aquisição de terrenos, remoção e reassentamento das famílias residentes no território do Parque (em situação regular ou irregular) são as maiores dificuldades para a execução do contrato de empréstimo.

A compreensão desses processos em andamento na área permite destacar dois problemas fundamentais, que são pontos importantes para estruturação de propostas que se pretendam como de gestão de riscos, e têm sido empecilhos para sua implementação na várzea:

\footnotetext{
${ }^{114}$ Conforme balanço apresentado pelas representantes do Conselho Gestor do FMSAI, Luciana Royer e Ana Gabriela Akaishi, em grupo de pesquisa na FAU-USP, em outubro de 2016.
} 
- é preciso dar tratamento institucional específico aos contextos de risco, principalmente com relação ao financiamento das soluções, e garantir estabilidade sobretudo à gestão de riscos que envolvem a dimensão metropolitana;

- é necessário desenvolver procedimentos de comunicação social muito bem estruturados;

Em diferentes ocasiões ${ }^{115}$ foi possível acompanhar a falta de informação sobre as ações na área e os problemas de comunicação institucional e de trabalho social. Em encontro de Frente Parlamentar na região, a Sehab apontava o regulamento da APA como empecilho para o desenrolar do projeto de urbanização, com necessidade de revisar o plano de manejo. Os relatórios da implementação do Parque apontavam a falta de solução de reassentamento em São Paulo como um elemento de atraso do programa. Em reunião solicitada por moradores à Secretaria Municipal de Habitação, representantes da Sehab apresentavam o andamento de tratativas de atendimento apenas para moradores da região do Polder do Romano e queixas sobre comunicação dos processos em andamento na área por parte do DAEE. Na reunião dos representantes do Comitê da Várzea, uma agenda extensa e organizada de questões levantada pelos moradores demandava respostas que, naquele momento, poderia ter a Frente Parlamentar como oportuna, apesar da consciência do clientelismo político que é suscitado pela condição precária e crônica da região - "É sempre assim, vai chegando perto do ano eleitoral e eles voltam a falar de regularização. Não sei se dá pra acreditar, mas tem que aproveitar essa oportunidade da Frente, porque é a única chance de se comunicar que a gente tem." (representante da AMOJAP).

E os moradores têm mesmo que aproveitar porque, sem ir atrás, as demandas são muitas e as informações são escassas. Por exemplo, a respeito de como serão atendidas as famílias já removidas - se se trata de atendimento a situação de emergência, dispensadas de participação financeira, conforme regramento do MCMV ${ }^{116}$, ou se haverá participação financeira dessas famílias; sobre quem deve sair e por qual motivo (se está no perímetro do parque ou na área de intervenção da Sehab). De todas as situações acompanhadas, a mais reveladora foi a reunião do trabalho de educação ambiental do Programa do Parque com representantes de moradores: enquanto estes buscavam informações sobre viabilidade de regularização dos imóveis, plano de remoções do projeto, custo-benefício da implementação de infraestruturas, elementos de acompanhamento que pudessem conferir transparência ao processo de transformação do lugar, a consultoria apresentava o resultado de oficinas com discussões de fomento ao desenvolvimento de espírito coletivo absolutamente descoladas dos projetos. Ficou claro como falta aos responsáveis pela implementação

\footnotetext{
${ }^{115}$ Além das reuniões do grupo ZL Vórtice e de algumas entrevistas semi-estruturadas com representantes de moradores da AMOJAP (Associação Amigos do Jardim Pantanal), foi possível participar de: 1. encontro da Frente Parlamentar de Inquérito formada para obter esclarecimentos sobre processos de regularização e implementação do parque (com representantes do legislativo estadual, de moradores e de órgãos públicos envolvidos nos programas para a área e Sabesp) em julho de 2017; 2. reunião do Comitê da Várzea (entre representantes de moradores) em agosto de 2017; 3. reunião de representantes de moradores com a Sehab, para informações sobre reassentamentos; 4. encontro das atividades de comunicação social e educação ambiental com representantes de moradores promovidas pelo Consórcio Vizca-CRA, contratados pelo programa PVT.

116 Lei 11977 , artigo 6으, par. 3ㅇ, inciso III.
} 
compreenderem que nenhum interesse coletivo pode ser fomentado sem informação séria e segura sobre permanência ou não no lugar. Tratava-se de um desastre em termos de comunicação.

Em síntese, do ponto de vista da gestão urbana, é possível concluir que o Programa PVT é um avanço ao trabalhar toda a frente fluvial e associar com programa habitacional, mas delega parte importante das remoções referentes ao perímetro do parque sem a devida articulação e sem integrar esforços à devida comunicação social. Não está associado a um programa amplo de regularização da região, que ocorra para além da linha da Via Parque. Considerando o âmbito municipal, o programa Renova São Paulo é um avanço ao associar saneamento ambiental integrado com propostas de habitação. Porém, um programa na área em questão deveria ter caracterização especial e diferenciada em relação aos demais perímetros da cidade, por se tratar de uma região cujos riscos são peculiares e envolvem funções regionais. Um mesmo programa para toda a cidade leva à partilha de recursos com outras áreas, inclusive de bolsa aluguel, sem o devido tratamento específico que deveria ser dispensado a atendimentos financeiros emergenciais. A demarcação dessa área ocupada como zona específica de riscos regionais seria uma medida importante para elaborar e aplicar instrumentos de planejamento metropolitanos. Nessas áreas deveriam ser atribuídas diretrizes de programas específicos, não apenas espacialmente, mas financeiramente, e ações de comunicação social de risco permanente.

Enquanto os riscos forem apenas ônus a ser vivenciado por uma população socialmente vulnerável, que pode ser explorada politicamente de tempos em tempos, e a solução econômica for recorrer a fundos e dotações orçamentárias emergenciais, quando não a fundos habitacionais não específicos, não haverá interesse nem econômico e nem político em sua resolução. Um aspecto potencial poderia estar, justamente, no cruzamento dos riscos de elementos da infraestrutura regional. Uma boa identificação de sistemas que participam do contexto de riscos poderia revelar articulações de interesses e benefícios mútuos, possíveis arranjos de custos e benefícios e investimentos. Como os riscos em cada sistema são avaliados? São bem avaliados, mensurados, precificados? Pode não ser interessante a determinado agente sob risco ter essa condição avaliada, mas interessaria à arena política apontá-los, se ela puder vislumbrar ganhos decorrentes dessa avaliação. Pois riscos mensurados e direcionados a responsáveis podem promover interesses pelo seu gerenciamento. Entretanto, na forma como os entes estão implicados neste caso, não parece haver um regulador claramente identificado que possa assumir o papel de mensurar riscos e benefícios envolvidos. As únicas atividades reguladas são da Sabesp, e, diferentemente do caso 2, os riscos envolvidos são fracamente incorporados (internalizados) em seus sistemas.

O empréstimo internacional (financiamentos específicos) tal como resolvido no Programa PVT parece ser uma saída mais apropriada. Mas não a articulação entre diferentes âmbitos da administração pública: seria importante que os critérios de priorização em função do interesse público que cada ator envolvido no equacionamento do problema defende estivessem bem balanceados. No arranjo proposto, está claro que - Governo do Estado ganha em flexibilidade e segurança aos seus sistemas de macrodrenagem. Mas para a prefeitura de São Paulo o equacionamento desse caso é prioritário? É possível mensurar se sua participação está bem balanceada? 
Para além do investimento público, é possível elucubrar algumas possibilidades de investimento privado. O cenário de uma grande ocupação submetida a inundações crônicas, com população que resiste à mudança e consolida cada vez mais sua permanência na área, sugere também um contexto possível para desenvolver pilotos de microsseguros com possíveis cruzamentos que garantam a diluição desses riscos, e reinvestimento orientado a ampliar a resiliência urbana. Por exemplo, cruzando a aposta da proteção financeira dos riscos com alguns ganhos: de uma eventual renovação urbana, de maior segurança às infraestruturas, ou entre casos similares nas diversas áreas em diferentes regiões metropolitanas - o que exigiria um plano nacional de diluição de riscos, e estudos sobre possíveis emissões de títulos, até mesmo no formato de CATbonds. Importante esclarecer que a referência ao termo 'renovação urbana' não necessariamente envolve transformações na escala do desenho urbano. Um bom exemplo são iniciativas privadas que já existem na área ${ }^{117}$, de assistência técnica e financiamentos populares para reforma de edificações de baixa renda, que poderiam lidar diretamente com melhoria de aspectos da resiliência das edificações, e vincular essa intervenção e seus produtos financeiros a produtos de microsseguros.

\subsection{Municípios ao norte da RMSP}

\subsubsection{Caracterização geral: riscos e interfaces}

O segundo caso trata de problemas que envolvem várias cidades na região Norte da RMSP, ou da Bacia do Juqueri: Franco da Rocha, Francisco Morato, Mairiporã e Caieiras. O foco da pesquisa foi aplicado a Franco da Rocha. As funções regionais implicadas neste município envolvem o Sistema de Abastecimento de Água Cantareira - especialmente o controle na barragem Paiva Castro; estruturas de controle da drenagem (piscinões); equipamentos de segurança pública; e estruturas da rede de distribuição de energia. Em todos os municípios, o contexto é de um território altamente suscetível a movimentos de massa e escorregamentos, sobretudo pela declividade, e em uma região com limitações dos sistemas de circulação. Na pesquisa de populações vulneráveis IBGE, 2018, há dados de população vulnerável para os municípios de Mairiporã (3.635 domicílios vulneráveis, 12.775 habitantes em risco sobre um total de 80.956 habitantes, ou 15,7\% da população) e Francisco Morato (8.694 domicílios, 30.479 habitantes em risco sobre um total de 154.472 habitantes, ou $19,7 \%$ da população). O total populacional dos 4 municípios da região é de 424.814 habitantes e, caso se considere o mesmo padrão de risco e vulnerabilidade dos outros municípios (15\%), uma estimativa de população vulnerável total na região de 64 mil habitantes.

\footnotetext{
${ }^{117}$ A iniciativa empresarial Programa Vivenda, que oferece pacotes populares de financiamentos para reformas, acompanhamento de obra e assessoria técnica para melhorar a qualidade habitacional de moradias de baixa renda, recentemente, passou a emitir títulos na forma de debêntures de impacto social para financiar sua atividade. O produto financeiro foi desenvolvido por uma seguradora Gaia. A abertura para o mercado, com os títulos emitidos pelo Private Bank Itaú, ocorreu no mesmo momento em que se associou à frente de desenvolvimento territorial da Fundação Tide Setúbal (da família Setúbal), que tem grande inserção na região da várzea, e passou a focar suas ações no local, indicando que já há iniciativas privadas que enxergam a região como um mercado bastante específico.
} 
Franco da Rocha apresenta especificidades que conferem diversidade e peculiaridades a seu perfil de riscos. A primeira delas, comum à região, se relaciona à geomorfologia e forma de ocupação: as ocupações mais antigas, que surgiram associadas às paradas da ferrovia, localizam-se no ponto mais baixo da cidade, na várzea, e são sujeitas a alagamento; as ocupações mais recentes ocorreram nos morros, em áreas de alta declividade. Ou bem a ocupação está numa área de várzea, suscetível a inundação, ou bem está em área suscetível a escorregamento. Os trechos de várzea são estreitos e entrecortados por morros, configurando uma ocupação com conexão e circulação precária, interrompida entre as várias zonas. A cidade é distribuída em duas porções, nos dois lados da ferrovia. O eixo viário paralelo à ferrovia, ao longo do córrego Eusébio, é importante eixo de circulação intra-urbana, mas o eixo da Rodovia Tancredo Neves é o principal na região, servindo não somente Franco da Rocha como também os municípios de Caieiras e Francisco Morato. Ao Sul, a rodovia dos Estados interliga a Rodovia Tancredo Neves a Mairiporã (fig. 29).

A circulação de um lado a outro do município de Franco da Rocha é altamente dependente do eixo ao longo do córrego Eusébio. No ponto mais baixo da cidade, esse eixo é suscetível a inundações e extravasamento da própria calha do córrego (com contribuições desde Francisco Morato) e da calha do Juqueri, na confluência entre esses dois rios. Além dele, toda a rodovia dos Estados, paralela ao rio Juqueri, desde a saída do Paiva Castro, é tomada por água durante os procedimentos de manobra da represa. No evento de março de 2016, a mobilidade mal resolvida neste município tornou a logística do auxílio às emergências de escorregamento fora do centro mais difíceis. Nesta data, nas cidades da região, foram computadas 19 mortes: $10 \mathrm{em}$ Mairiporã, 8 em Francisco Morato e 1 em Franco da Rocha.

Os riscos a que Franco da Rocha está submetido, entretanto, não se restringem às características de sua geomorfologia e ocupação, ou a ameaças peculiares de eventos climáticos críticos. Franco da Rocha está submetido a uma série de fatores relativos ao convívio com elementos da infraestrutura urbana de alcance metropolitano e macrometropolitano, que se localizam dentro de seus limites e podem se encadear em situações críticas. O contexto de ocupações vulneráveis a movimentos de massa fora da zona central, e submetidas a inundações na zona central por extravasamento dos rios locais, é agravado quando submetido ao fluxo de água das operações de manobra da represa de Paiva Castro. Importante lembrar que, nos diagnósticos do PDMAT 3, Franco da Rocha e Francisco Morato são as regiões da BAT que tem previsão de maior taxa de impermeabilização para os próximos 15 anos.

Além disso, e de acordo com relato da chefe da Defesa Civil em Franco da Rocha, a existência de unidades prisionais neste município, que exigem o bloqueio de telefonia celular e tornam o sinal mais difícil na região, também é fator de dificuldade no contexto de emergência, pois inviabiliza alguns processos de comunicação via SMS. O fluxo da manobra atinge também os equipamentos do sistema prisional e deixa em alerta máximo uma subestação elétrica de abrangência importante para a região, cuja pane agravaria ainda mais a situação de gestão da crise. 


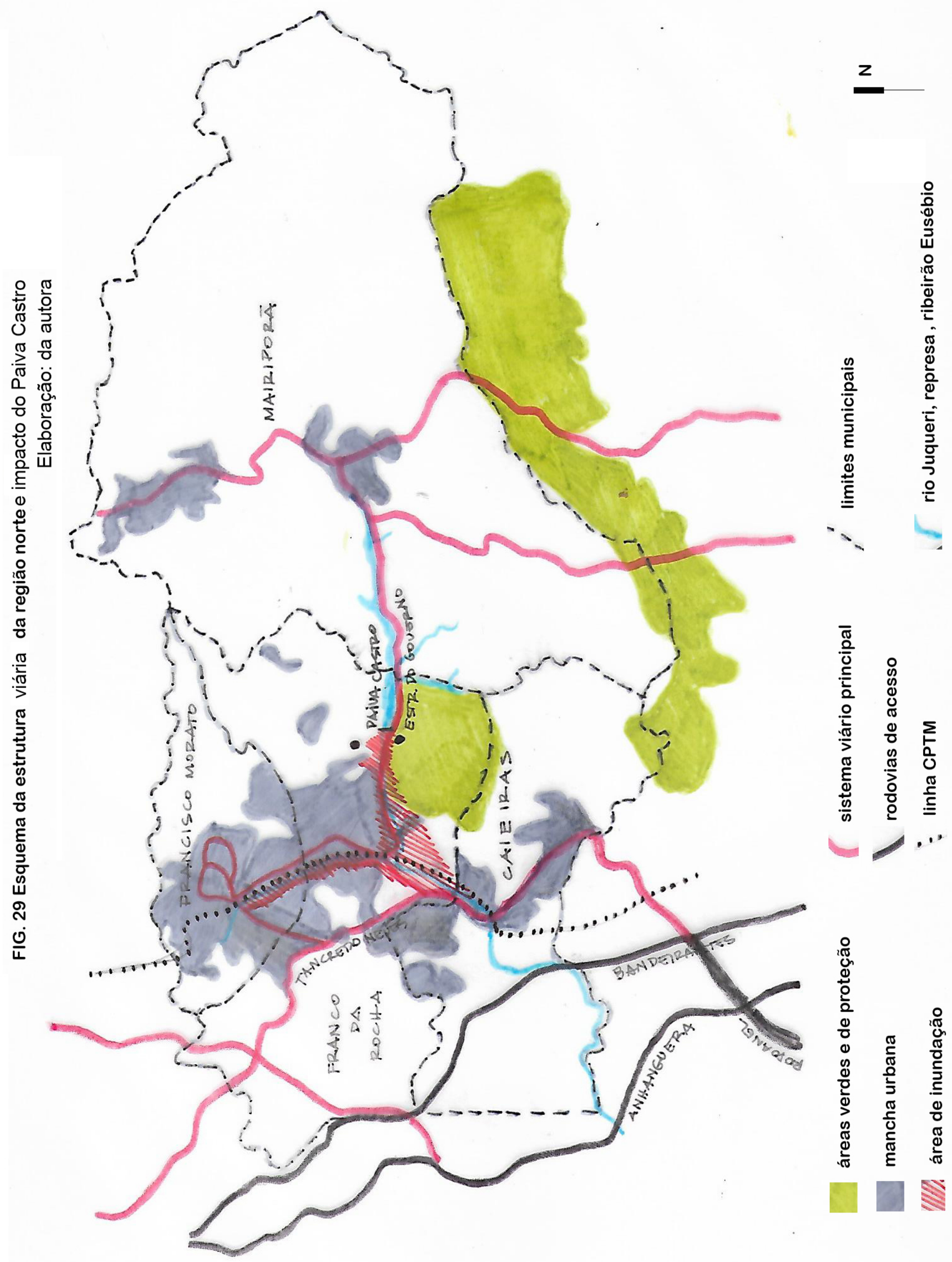


A região é constituída, portanto, pelos seguintes riscos e interfaces:

- interfaces e riscos relativos aos sistemas produtores de água - as ocupações urbanas nas proximidades de um elemento do sistema produtor de água de escala regional, como o Cantareira, estão sob risco e, ao mesmo tempo, incorporam riscos ao sistema, impondo necessidade de variações operacionais. Nas normas operacionais da Sabesp, a Represa de Paiva Castro é gerenciada para manter o reservatório no nível mínimo operacional sempre que possível, a fim de regularizar vazões e amortecer picos de cheia no rio Juqueri. Isso significa fechar o túnel 5 e bombear a afluência pela Elevatória de Santa Inês para o Reservatório de Águas Claras, que encaminha o fluxo para a Estação de Tratamento (fig.30). No entanto, durante um evento crítico, essa operação nem sempre é possível. Quando o nível da Represa de Águas Claras sobe, impossibilita o funcionamento da Elevatória de Santa Inês, fazendo com que o nível do Paiva Castro suba rapidamente ${ }^{118}$. Nas situações em que o nível da represa atinge os limites de segurança para 10.000 anos (SABESP-HIDRO, 2009), ela precisa ser extravasada, causando danos na escala local e agravando as situações de inundação que já ocorrem pela configuração urbana e geográfica. Caso a manobra não seja feita, a extrapolação do limite da barragem da represa representa um risco de proporções e consequências incalculáveis, com destruição local e panes catastróficas a sistemas de produção e distribuição de água e distribuição de energia de alcance metropolitano. A grande dependência da metrópole em relação ao Sistema Cantareira, e a pressão a que é submetido por ocupações neste vetor norte da metrópole, permite pouca flexibilidade e saídas alternativas em situações críticas. As interfaces problemáticas, neste caso, se relacionam com o sistema de drenagem dos municípios do entorno e o ordenamento do território urbano, sobretudo em Franco da Rocha.

- riscos e interfaces relativos à macrodrenagem na região - os objetivos de implantação dos piscinões em Franco da Rocha (cujas obras foram parcialmente finalizadas após o evento crítico de 2016) são resolver o conflito entre as cheias e o sistema de circulação ferroviário e viário principal na cidade, entre outros objetivos de macrodrenagem da bacia do Médio Juqueri e da Bacia do Alto Tietê que ultrapassam as necessidades do município. A implantação incompleta do sistema de reservatórios previstos nos PDMATs resulta em um sistema de macrodrenagem insuficiente, e exige função complementar do sistema de produtor de água, conforme exposto anteriormente. Nas manobras do Paiva Castro em 2011 e em 2016, as comportas da represa foram abertas quando a cidade já estava inundada ${ }^{119}$. No Plano de Contingência do Reservatório Paiva Castro, a mancha de inundação de suas vazões de descarga não leva em consideração os cenários de inundação a jusante (cheias por extravasamento do ribeirão Euzébio ou alagamentos devido à rede local de microdrenagem), induzindo o município a uma previsão de impacto menor do que realmente ocorre. A interface entre esses dois sistemas não expõe apenas a necessidade de soluções para os problemas de drenagem, mas a necessidade de melhor integrar contingências entre os dois sistemas (abastecimento de água e controle de cheias) para a combinação de diversos cenários críticos nas ações emergenciais e de resposta.

\footnotetext{
118 Procedimentos descritos no Parecer Técnico IC n. 1410900000024/16 MPSP e CAEx.

${ }^{119}$ Fatos descritos no documento Parecer Técnico IC n. 1410900000024/16 MPSP e CAEx.
} 

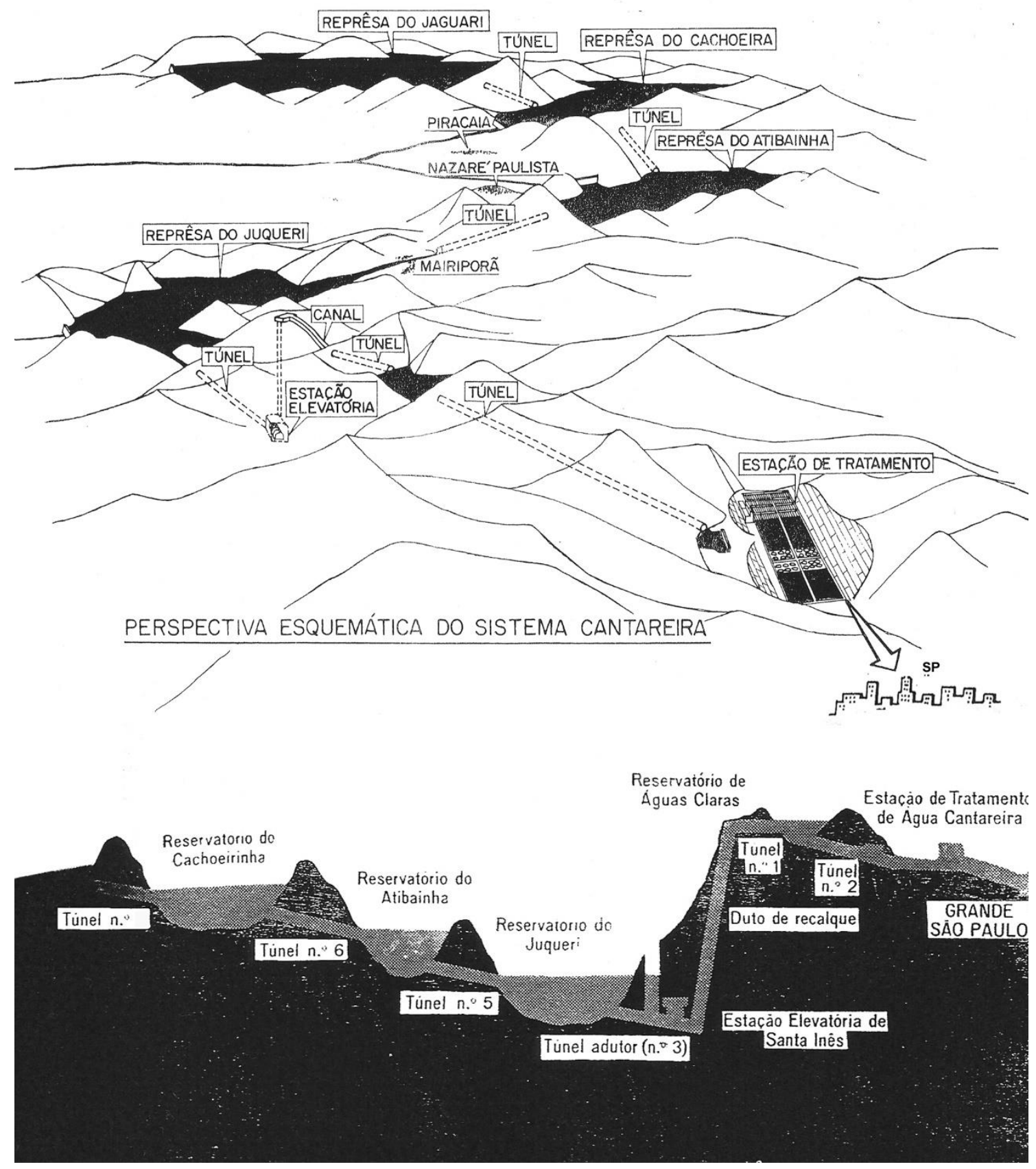

FIG. 30 - Perspectiva e corte esquemático do Sistema Cantareira. O Reservatório Juqueri corresponde ao Paiva Castro. Fonte: COMASP, 1970. 
- interfaces e riscos relativos a falhas nas diretrizes de ordenamento urbano - a área suscetível a alagamento na cidade e a agravamento pela manobra do Paiva Castro consiste no centro de comando da cidade - prefeitura, posto da defesa civil, delegacia de polícia - e no principal nó de distribuição da circulação - principal via de acesso e cruzamento entre porções leste e oeste do município, cruzamento com linha férrea, e interligação com outros municípios (fig.29). A mobilidade dificultada durante contextos de manobra prejudica medidas de socorro a emergências em zonas vulneráveis, que, do ponto de vista da gestão local de riscos, carecem de programas habitacionais adequados para sua mitigação. O ordenamento urbano do município falha ao não elaborar instrumentos de controle e adequação de uso e ocupação das áreas sujeitas à inundação e aos impactos de manobra no município, bem como na implementação de soluções adequadas para lidar com esses impactos - faixas lindeiras à rede hídrica e parques lineares para controle de enchentes - e com os riscos geológicos.

- interfaces e riscos relativos a equipamentos do Sistema de Segurança Pública - o município de Franco da Rocha conta com 5 equipamentos do sistema Penitenciário do Estado. Junto à várzea do rio Juqueri, entre a barragem da Represa Paiva Castro e a confluência com o Ribeirão Euzébio, estão localizados três deles. Na margem esquerda do rio Juqueri ao longo da rodovia estadual SP-023, que acessa Mairiporã, estão o CDP feminino de Franco da Rocha e o Centro de Progressão Penitenciária de Franco da Rocha (regime semi-aberto). Para além do aumento das ocorrências de pequenos delitos nos chamados "dias de saidinha" do CPP, a que o município está sujeito, há riscos nas situações de manobra das comportas, quando medidas operacionais de exceção são necessárias para manter a integridade física dos detentos e internos e o adequado funcionamento desses equipamentos, como entrada e saída de funcionários e fluxo de suprimentos alterados pela cheia. Ainda na várzea do Juqueri, do outro lado da rodovia SP-023, há também o Hospital de Custódia e tratamento Psiquiátrico II de Franco da Rocha, localizado numa cota mais baixa e na confluência de um afluente do Juqueri. Durante o período de manobra, as águas desse afluente não conseguem fluir pela calha do Juqueri, extravasando e inundando a área do Hospital, exigindo procedimentos específicos para manter sua operação. Para além da implantação dos edifícios, outra dimensão de amplificação do risco encadeados pela presença de equipamentos desses sistemas é a dificuldade de comunicação via SMS. Os bloqueadores de celular para controlar a comunicação dos internos causam problemas de comunicação nos canais principais da defesa civil em situações de crise.

- interfaces e riscos relativos a dispositivos de distribuição de energia elétrica - a subestação elétrica Melhoramentos da concessionária Elektro (138kw) está implantada na rodovia de acesso ao município de Franco da Rocha a jusante da zona central da cidade, na divisa com Caieiras, em cota abaixo da rodovia e junto à várzea do rio Juqueri. Dada a sua cota de implantação $(738 \mathrm{~m})$, tanto inundações na calha do Juqueri, como inundações decorrentes das manobras da represa, são riscos para a operação da subestação, que abastece diversos municípios da região norte metropolitana e alimenta as bombas dos reservatórios de detenção recém implantados, R1 e R2. No evento de março de 2016 (fig. 31) o nível da água chegou muito perto das chaves secionadoras da subestação, que só não foram desligadas porque a Sabesp suspendeu a descarga. Em futuros eventos, uma pane nesta subestação pode complicar ainda mais o cenário 
de crise nos municípios afetados, dificultando o funcionamento dos dispositivos de controle da macrodrenagem, e ações de resposta e socorro às vítimas. Esta situação levanta uma análise necessária e possível de ser experimentada para toda a RMSP, sobre a vulnerabilidade de localização das subestações elétricas (fig. 32), bem como a área de abrangência de seu atendimento.
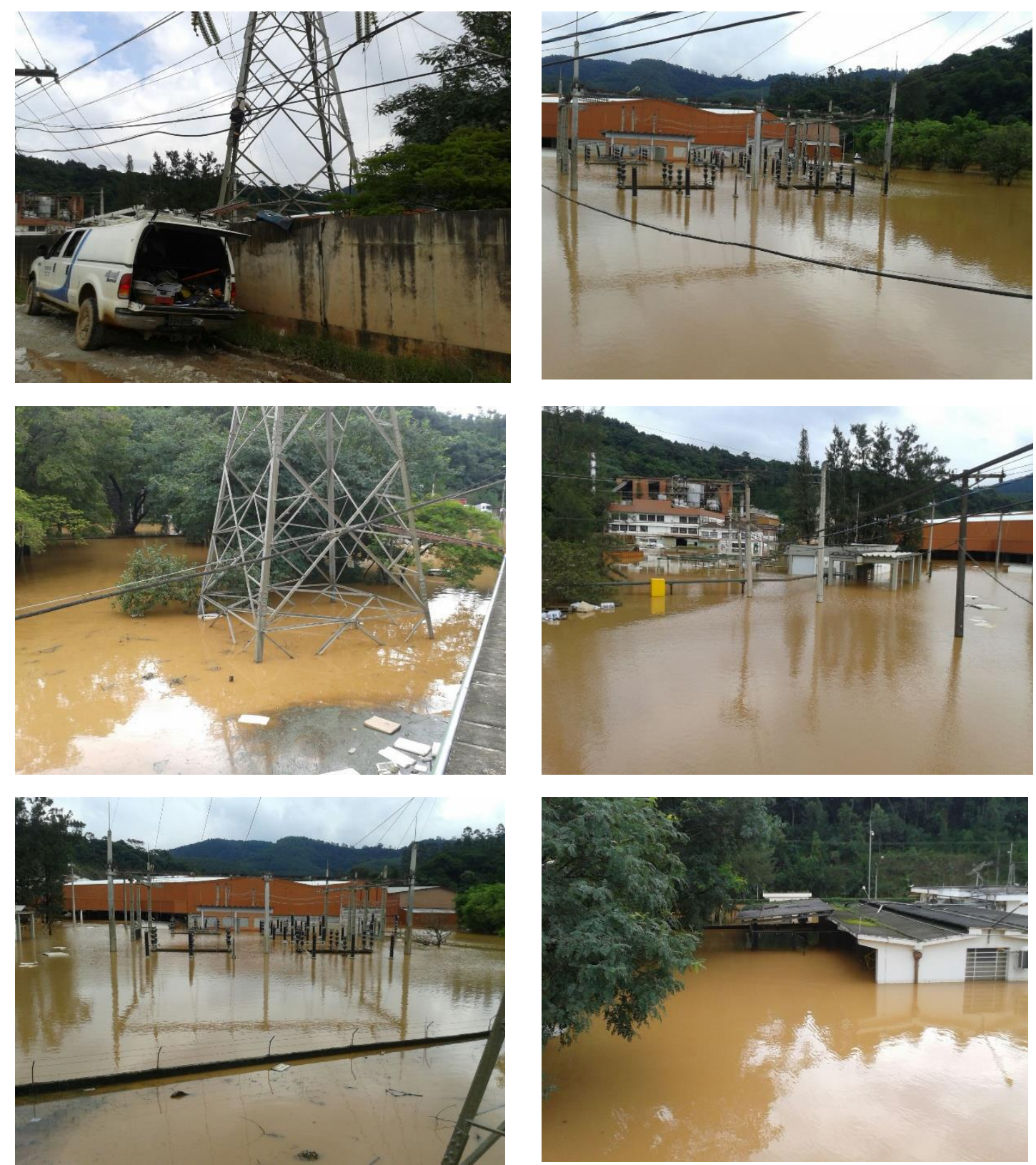

FIG. 31 - Conjunto de fotos da ocorrência na SE Melhoramentos, situada na cidade de Franco da Rocha, área de concessão da Elektro. Documentos da Secretaria de Energia e Mineração do Estado de SP. 


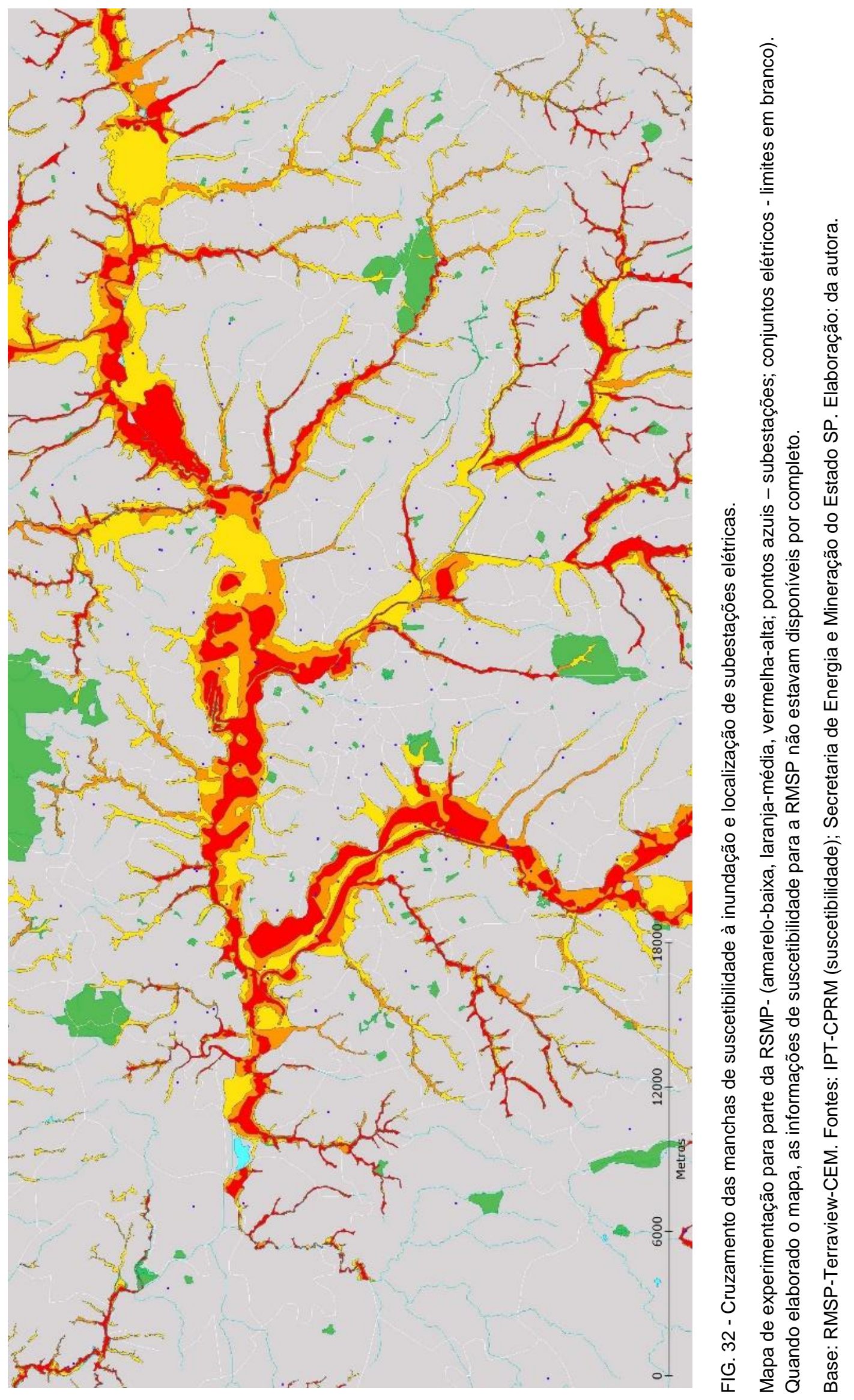


- interfaces e riscos relativos a impactos das obras do Rodoanel - junto à subestação Melhoramentos, está sendo realizada deposição de solo das obras do rodoanel, autorizada pela CETESB, na várzea do rio Juqueri. Segundo denúncia do município (Ofício n. 23/2017), esse acúmulo de terra ocasiona dificuldade na dissipação do fluxo do rio, gerando problemas a montante e problemas de sedimentação a jusante.

\section{Quadro 29. Matriz dos riscos identificados para o município de Franco da Rocha}

\begin{tabular}{|c|c|c|c|c|}
\hline & \multicolumn{3}{|c|}{ impactos } \\
\hline & & $\begin{array}{l}\text { impacto local } \\
\text { (bairro, micro- } \\
\text { região) }\end{array}$ & $\begin{array}{l}\text { impacto local severo e } \\
\text { impacto metropolitano } \\
\text { difuso }\end{array}$ & $\begin{array}{l}\text { severos impactos } \\
\text { metropolitanos e locais }\end{array}$ \\
\hline \multirow{5}{*}{ 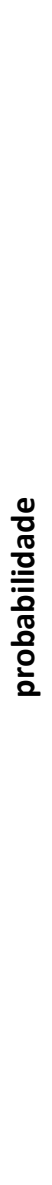 } & baixíssima & & & $\begin{array}{l}\text { * ruptura da barragem } \\
\text { de Paiva Castro }\end{array}$ \\
\hline & baixa & $\begin{array}{l}* \text { impactos dos } \\
\text { aterros do } \\
\text { rodoanel sobre a } \\
\text { rede hídrica }\end{array}$ & & \\
\hline & média & & & \\
\hline & alta & & $\begin{array}{l}\text { * Manobras da Represa } \\
\text { Paiva Castro } \\
\text { * falhas operacionais do } \\
\text { sistema de macrodrenagem } \\
\text { (implantação incompleta ou } \\
\text { falha nas bombas) }\end{array}$ & $\begin{array}{l}\text { * impactos na } \\
\text { distribuição de } \\
\text { eletricidade } \\
\text { * falhas nos } \\
\text { equipamentos de } \\
\text { Segurança Pública }\end{array}$ \\
\hline & altíssima & $\begin{array}{l}\text { *paralisação do } \\
\text { sistema viário } \\
\text { principal }\end{array}$ & $\begin{array}{l}\text { * variações operacionais do } \\
\text { S. Cantareira para atenuar } \\
\text { pico de cheia do entorno } \\
\text { * paralisação do sistema } \\
\text { ferroviário } \\
\text { *falha no ordenamento } \\
\text { territorial }\end{array}$ & \\
\hline
\end{tabular}

\subsubsection{Soluções, limitações, potencialidades}

Por ocasião das entrevistas com agentes da Defesa Civil em Franco da Rocha, em agosto de 2017, o município não apresentava instrumentos de identificação de riscos recentes, apenas uma setorização de risco de 2006 produzido pelo IG e recente adesão ao monitoramento do CEMADEN (embora no site do CEMADEN constasse apenas o município de Francisco Morato). Naquele momento, estavam sendo elaboradas cartas de suscetibilidade pelo IPT e Cartas de aptidão pela UFABC, com recursos do Ministério 
das Cidades ${ }^{120}$. A base de setorização do IG de 2006 mostrava riscos geológicos e hidrológicos bastante distribuídos por todo o município, em 136 setores nas porções leste e oeste da linha de trem. A estes setores, tinham sido incorporados, desde 2013, mais 71 setores de risco vistoriados pela equipe que integrava a defesa civil municipal, atualizações exigidas pelo Ministério das Cidades quando o município pleiteou recursos do PAC para mitigação de riscos. Esses recursos permitiram algumas ações pontuais de remoção por riscos geológicos (349) e produção de novas unidades (1160 UH), além de suprir parte dos recursos de bolsa aluguel. No entanto, o município não contou com investimentos em processos mais amplos de urbanização integrada de assentamentos precários, seja com recursos do PAC, estaduais ou municipais, indicando a falta de solução habitacional estruturada que complemente o atendimento pontual às ocupações em áreas de risco. As equipes da defesa civil são distribuídas com responsáveis por zonas de risco da cidade, setorização que, em contextos de alerta, orienta o deslocamento prévio para a proximidade de áreas de responsabilidade, tendo em vista a dificuldade de locomoção.

Além dos instrumentos de identificação de risco mencionados, no site da defesa civil é possível acessar na entrada para o município de Franco da Rocha, os arquivos relativos ao "Plano de Ação Emergencial Para Inundações na Região de Franco da Rocha", o "Plano de Contingência da Sabesp para Cheias da Represa Paiva Castro", e os anexos relativos a questões operacionais dos Reservatórios de acumulação de cheias R1 (pôlder do Juqueri) e R3 no córrego Eusébio. Todos esses materiais são datados de setembro de 2016, posteriores ao evento de março de 2016.

No relatório de danos e prejuízos do evento de $2016^{121}$, constam: impactos no Paço Municipal (sede da prefeitura e vias públicas da área central), unidades municipais de educação, cultura, esporte e lazer (4 escolas, centros de cultura e a sede da secretaria de educação, Ginásio de Esportes), sede da Câmara Municipal, unidades básicas de atendimento à saúde, hospital de custódia e equipamentos de apoio à saúde, centros de referência de assistência social e residências.

Embora não conste nos documentos analisados, funcionários da Defesa Civil informaram que, após o evento crítico de março de 2016, foi implantado um parque junto ao Ginásio de Esportes, no ponto de maior alagamento da cidade durante as cheias da represa, com desenho desenvolvido pela prefeitura com a finalidade de adequar espaços urbanos e facilitar a manutenção para o caso de manobras da represa. Essa obra teria sido feita em acordo de cooperação com a Sabesp.

Após os eventos de manobra de 2011 e 2016, foram instaurados inquéritos civis para apurar "responsabilidade ambiental decorrente de omissão administrativa em face da inexistência ou insuficiência de planos de contingência, comunicação eficaz e evacuação para o Município de Franco da Rocha" (IC 1410900000024/16).

Tanto pelos documentos do inquérito como por meio de entrevistas a técnicos da Sabesp, foi possível constatar que os procedimentos de abertura das comportas da

\footnotetext{
${ }^{120}$ As cartas de suscetibilidade foram finalizadas no início de 2018 e o trabalho das cartas de aptidão está em processo de finalização.

${ }^{121}$ Fornecido pela chefe da Defesa Civil de Franco da Rocha.
} 
represa são medidas normatizadas, e que são realizadas de acordo com procedimentos aprovados pela ANA e DAEE e consentidas nos Comitês de Bacia. As medidas de comunicação e contingência, entretanto, como a própria decisão do Inquérito Civil aponta, possuem muitas falhas e insuficiências.

Com relação ao aproveitamento dos reservatórios para controle de cheias e os limites para manobras de descargas a jusante, foi levantado que, ao menos desde a outorga do Cantareira de 2004, o mesmo nível máximo de operação normal é definido para o Paiva Castro, na cota 745,61m. No entanto, no documento da outorga de 2004 não foi definida uma norma operacional para chuva e volumes de espera ${ }^{122}$ nos reservatórios. $\mathrm{Na}$ nota técnica - Parte C - da resolução conjunta ANA e DAEE de 2004, explicita-se, com relação a volumes de espera, que "não foram consideradas restrições nas acumulações máximas para proteção contra enchentes das comunidades de jusante, devendo estas serem consideradas na operação mensal' (ANA, DAEE, 2004:17).

Em entrevistas com funcionários, entretanto, foi informado que sempre existiram protocolos internos para procedimentos de interrupção de transferências e redução de cota de operação para evitar elevação de nível indesejado nas represas, acionados conforme previsão de dias ou semanas com chuva. No entanto, a partir das chuvas de 2009-10, quando os sistemas ficaram na iminência de extravasamento e manobra em barragens de diversos municípios, foram desenvolvidos estudos mais específicos para avaliar volumes de espera, definir manchas de inundação nas regiões a jusante das represas, redefinir protocolos internos e protocolos de comunicação articulados com planos de contingência.

Esse movimento de revisão operacional teve início pouco antes das cheias críticas de 2009-2010. Começou com a revisão dos estudos de volume x cota x vazão dos reservatórios, em 2008, para análise de assoreamento, após eventos críticos de chuva em 2007 causarem vítimas em Franco da Rocha. Consolidada a avaliação dos reservatórios, foram realizados estudos hidrológicos para redefinição dos volumes de espera dos reservatórios do sistema Cantareira, considerando aspectos de segurança hidrológica das barragens e restrições a jusante, finalizados em $2009^{123}$.

Nesses estudos, são apresentados dados de entrada das modelagens (caracterização física e da ocupação das bacias, definição de $\mathrm{CN}$, análise da frequência de chuvas) e realizadas simulações: 1. para operação de cheia dos reservatórios considerando período de retorno de 1.000 e 10.000 anos (decamilenar), como verificação de limites de segurança hidrológica das barragens; 2. para operação de cheias considerando período de retorno de 50 e 100 anos, a fim de mensurar a capacidade de controle de espera de cada reservatório a variadas vazões de restrição que garantam segurança a jusante dos reservatórios; 3. delimitadas as manchas de inundação das descargas dos reservatórios dentro de limites que não causem impacto às ocupações (no caso de Franco da Rocha, para vazões entre 20 e $50 \mathrm{~m} 3 / \mathrm{s}$, posteriormente definidas em $10 \mathrm{~m} 3 / \mathrm{s}$, em resolução conjunta da ANA e DAEE n. 614). Foram feitas, também, análises das áreas fora dos controles dos reservatórios, a fim de verificar a contribuição das sub-

\footnotetext{
${ }^{122}$ Volume de espera é o volume vazio a ser deixado no reservatório a fim de amortecer cheias previstas para determinado período.

${ }^{123}$ SABESP-HIDRO, 2009.
} 
bacias e afluentes a jusante para período de retorno de 50 e 100 anos, mas não foram geradas manchas de inundação dessas contribuições (apenas hidrogramas), e não foram associadas às manchas causadas pelas descargas definidas como não geradoras de impacto. Para o rio Juqueri, o relatório conclui que:

"Na área urbana de Franco da Rocha, as sub-bacias da área não controlada geram hidrogramas cujas vazões de pico superam significativamente os limites de impacto de 20 e 50m3/s. A margem direita do rio Juqueri na região urbana de Franco da Rocha sofrerá inundações decorrentes dos hidrogramas das subbacias independentemente das vazões de restrição do aproveitamento. Desta forma, a operação de controle de cheias não será eficiente para evitar as inundações e imapctos no rio Juqueri à jusante do aproveitamento Paiva Castro." (SABESP, HIDRO, 2009: 101).

Tabela 30. Vazões limite de impacto e vazões de pico geradas nas sub-bacias ao longo do rio Juqueri

\begin{tabular}{|l|l|l|l|l|}
\hline Seção & $\begin{array}{l}\text { Distância } \\
\text { acumulada } \\
\text { (m) }\end{array}$ & $\begin{array}{l}\text { Vazão ou limite } \\
\text { de } \\
\text { (m3/s) }\end{array}$ & $\begin{array}{l}\text { Vazão de Pico } \\
\text { impasto sub-bacias } \\
\text { (m3/s) }\end{array}$ & $\begin{array}{l}\text { Vazão máxima } \\
\text { (m3/s) }\end{array}$ \\
\hline Barragem & 0 & 50 & 0 & 50 \\
\hline Pc1 & 1.158 & 50 & 0 & 50 \\
\hline Pc2Pc3 & 2.248 & 20 & 90 & 90 \\
\hline S1PONTE & 3.290 & 50 & 90 & 90 \\
\hline S2Ponte & 3.375 & 50 & 90 & 90 \\
\hline Pc4 & 3.811 & 50 & 90 & 90 \\
\hline Pc5 & 4.299 & 50 & 97 & 97 \\
\hline S3PONTE & 5.488 & 50 & 97 & 97 \\
\hline Pc6 & 6.181 & 50 & 97 & 97 \\
\hline Pc7 & 7.279 & 50 & 243 & 243 \\
\hline Posto 3E-109 & 7.678 & 50 & 243 & 243 \\
\hline & Indica que a área estará inundada independemente da vazão de restrição \\
\hline
\end{tabular}

(SABESP-HIDRO, 2009:119)

O cenário pode ser ainda pior do que a tabela revela. É possível que esses valores estejam abaixo das vazões que podem ocorrer no contexto atual, pois para avaliação das contribuições, nas bacias em Franco da Rocha foram considerados CN de áreas rurais (70) para a realidade de áreas consideravelmente ocupadas e impermeabilizadas.

A partir dessas análises, o procedimento estabelecido para operação de chuva considerou que a operação de cheia dos reservatórios do Cantareira deve garantir a vazão de restrição (vazão limite na saída do reservatório estabelecida para condições normais, que no Paiva Castro é de $1 \mathrm{~m} 3 / \mathrm{s}$ ) até determinado limite, quando passa a entrar em modo de segurança para garantir a integridade da barragem. Assim, em contexto de subida de nível e previsão de elevação de chuva, todas as decisões operacionais são tomadas para que o reservatório mantenha volume necessário para garantir a vazão de restrição para ocorrência de cheia T100. Ultrapassando certo limite, o procedimento muda, e as operações são feitas para manter o nível com segurança para uma chuva de período decamilenar (T10.000). Abaixo, a representação esquemática desse procedimento, com as cotas estabelecidas para o Paiva Castro e, como comparação 


\section{Quadro 31. Esquema do método para determinar a cota de restrição para absorver o hidrograma com período de retorno de 10.000 anos}

\begin{tabular}{|c|c|c|c|}
\hline & & $\begin{array}{l}\text { Paiva } \\
\text { Castro }\end{array}$ & Cachoeira \\
\hline $\begin{array}{l}\text { cota da crista de coroamento } \\
\text { da barragem }\end{array}$ & & 750,24 & 827,67 \\
\hline Borda livre de $1 \mathrm{~m}$ & Volume de segurança & 749,24 & 826,67 \\
\hline $\begin{array}{l}\text { cota da restrição para } \\
\text { absorver cheia decamilenar }\end{array}$ & $\begin{array}{l}\text { Volume para armazenamento da } \\
\text { cheia } \mathrm{T} 10.000\end{array}$ & 745,36 & 823,34 \\
\hline Nível máximo normal & $\begin{array}{l}\text { Volume p/ armazenamento da cheia } \\
\text { T100 e garantir vazões de restrição }\end{array}$ & 745,61 & 821,88 \\
\hline
\end{tabular}

(elaboração: da autora baseado na fonte: SABESP-HIDRO, 2009: 128 e 129).

para o reservatório Cachoeira. Pode-se notar que, para o reservatório Cachoeira, há uma diferença de nível de quase $2 \mathrm{~m}$ entre o nível operacional máximo normal e a cota de restrição para a cheia decamilenar. No reservatório Paiva Castro, o nível operacional máximo normal $(745,61 \mathrm{~m})$ é maior que o nível de segurança da cheia decamilenar $(745,36)$, exigindo operação para reduzir volumes em período de cheia, com vazões eventualmente superiores às vazões de impacto calculadas.

Esse estudo de 2009 embasou a Resolução Conjunta ANA e DAEE n. 614 de novembro de 2010, e a definição de vazões de restrição da Nota Técnica do DAEE de outubro de 2010. Na Portaria do DAEE, são estabelecidas as vazões de restrição adotadas para o rio Juqueri: $1 \mathrm{~m} 3 / \mathrm{s}$ na fase de preparação (final da estiagem) e na fase de controle de cheia; vazão limite de impacto: 10m3/s (o estudo indica entre 20 e 50m3/s). O documento aponta, ainda, a formação de um grupo de trabalho para reavaliar essas vazões de restrição, e a contratação de serviços de desassoreamento que permitam aumentar a vazão de restrição no rio Juqueri. Na Resolução Conjunta, está definido que a Sabesp deve realizar estudos para alocar volumes de espera em operações de cheias, a serem deliberados pela ANA, DAEE e Comitês de Bacia. Neste documento, é reiterado para o Reservatório Paiva Castro o nível máximo normal em 745,61m; o nível de água máximo operacional em $745 \mathrm{~m}^{124}$; e as vazões de restrição de julho a novembro (em $1 \mathrm{~m} 3 / \mathrm{s}$ ) e de dezembro a agosto (em 10m3/s). A outorga de 2017 define vazão mínima do Juqueri em $1 \mathrm{l} / \mathrm{s}$, mantém as cotas e limites estabelecidos nos documentos anteriores, e mantém estas resoluções operacionais ativas.

No Plano de Contingência da Sabesp (2016), ficou estabelecido que, no momento em que o reservatório atingisse a cota 745,25m e chuvas com tendência de elevação, seria acionado o fluxo de comunicação do plano de contingência, que lista apenas a Defesa Civil do Estado CEDEC e uma designação geral de 'empresas afetadas' (a CPTM é uma delas, como pôde ser constatado pelos fatos relatados). A partir da cota $745,55 \mathrm{~m}$, as comportas passam a ser abertas, descarregando $10 \mathrm{~m} 3 / \mathrm{s}$ inicialmente até o limite de

\footnotetext{
${ }^{124}$ Nível de água máximo normal é a cota máxima de operação do reservatório em situação normal, sem elevação de nível e previsão de chuva. Nível de água máximo operacional é a cota máxima do reservatório que deve ser mantida para manutenção do volume de espera, usado no amortecimento de cheias.
} 
$80 \mathrm{~m} 3 / \mathrm{s}$. Antes de atingir a primeira cota de descarga, o túnel 5 deve ser fechado ${ }^{125}$. Caso a vazão de descarga já esteja no limite máximo e a cota do reservatório ultrapasse o nível 745,80m, é decretada situação de máxima gravidade às autoridades. O nível máximo maximorum da represa é $746,60 \mathrm{~m}$.

Na leitura do inquérito civil instaurado após evento de 2016, é possível compreender que houve falha na comunicação entre CEDEC e NUDEC de Franco da Rocha (ver quadro 32, a seguir, com síntese dos relatos prestados ao Ministério Público pela Sabesp e pelo NUDEC), embora o parecer técnico de fevereiro de 2017 não aponte a falha de comunicação como uma de suas conclusões, e não solicite que a CEDEC preste maiores esclarecimentos a esse respeito.

O parecer conclusivo do mesmo documento aponta que a cidade inundou antes mesmo da manobra da represa, que a Sabesp cumpriu todos os procedimentos estabelecidos no protocolo e no plano de contingência, e que essas medidas amortecem os picos de cheia e mitigam efeitos negativos à jusante da barragem. No entanto, alerta para o fato de que, em virtude da capacidade limitada deste reservatório para trabalhar com volumes de espera, e as ameaças de chuva terem sido de precipitação intensa e rápida nas últimas duas ocorrências de manobra (2011 e 2016), o tempo que o município tem para organizar a resposta ao evento tem sido muito curto. Para essas circunstâncias, o plano de contingência existente é limitado e ineficaz para reduzir danos materiais e riscos à população, pois prevê apenas que a Sabesp comunique à CEDEC e se comprometa e emprestar um caminhão e um barco a remo para auxiliar na emergência.

O parecer sugere que a Sabesp deva participar efetivamente nas ações de comunicação de risco quando as comportas são abertas. Além disso, aponta que as manchas de inundação apresentadas pela Sabesp apenas para a descarga do reservatório são insuficientes. De fato, elas têm uso muito limitado, não apenas porque não incorporam as manchas das demais contribuições, mas porque mostram diversas incompatibilidades. Há trechos em que a mancha foi desenhada acima de morros. É possível identificar, pela metodologia do estudo, que o modelo de terreno utilizado para a geração das manchas foi feito a partir da base do IBGE em escala 1:50.000, ou seja, uma escala muito imprecisa para poder proceder um cadastro das edificações atingidas.

Com relação ao NUDEC, o parecer conclui que há falha pela não elaboração de cadastro completo das edificações afetadas na mancha da Sabesp, e trabalho preventivo com plano de comunicação nessas áreas. Essas áreas não estão integradas ao PPDC (Plano Preventivo da Defesa Civil) e este não incorpora em seus procedimentos o Plano de Contingência do Paiva Castro. Ao município e DAEE, o parecer aponta, sobretudo, a necessidade de implantar medidas contra enchentes, com

\footnotetext{
125 Tanto no estudo da Sabesp para definição de volumes de espera como no plano de contingência, não foi possível encontrar maiores informações sobre as decisões operacionais para o túnel 5, que transfere vazões para o Paiva Castro. Sabe-se apenas que, antes de atingir a cota para início da descarga de jusante em Franco da Rocha, o túnel 5 já deve estar fechado, mas não há definição clara nos documentos analisados sobre a partir de quais limiares ele deve ser fechado. Também não foi possível identificar mais informações, ou mesmo parâmetros operacionais (sobretudo os limites para funcionamento) a respeito das vazões recalcadas para a Elevatória de Santa Inês.
} 


\begin{tabular}{|c|c|c|c|c|}
\hline dia & hora & relato Sabesp & relato NUDEC & observações \\
\hline \multirow{11}{*}{ 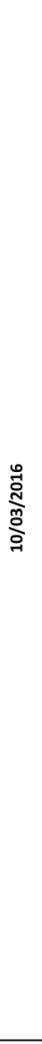 } & $6: 40 \mathrm{~h}$ & $\begin{array}{l}\text { indice pluviométrico nulo no período de } 24 \mathrm{~h} \text {, nível do } \\
\text { reservatório em } 744,48 \text {, túnel } 5 \text { com vazão de } 19,1 \mathrm{~m} 3 / \mathrm{s}\end{array}$ & & \\
\hline & 12:50h & $\begin{array}{l}\text { redução da vazão do túnel } 5 \text { para } 9,55 \mathrm{~m} 3 / \mathrm{s} \text {, para manter } \\
\text { nivel operacional normal. Nivel do reservatório } 744,50 \mathrm{~m}\end{array}$ & & $\begin{array}{l}\text { (nivel máximo operacional, de acordo com } \\
\text { resolução ANA/DAEE n. } 614 \text { nov/2010, é } \\
\text { 745,00m. Nível máximo operacional é aquele } \\
\text { a ser mantido entre outubro e abril a fim de } \\
\text { obter volumes de espera). }\end{array}$ \\
\hline & 15:03h & & $\begin{array}{l}\text { Registro de pancada de chuva fraca a } \\
\text { moderada, com pontos fortes, sem } \\
\text { problemas causados ao município. }\end{array}$ & \\
\hline & $17: 17 \mathrm{~h}$ & & $\begin{array}{l}\text { Aviso de chuvas fortes vindas da região de } \\
\text { Jundiaí. }\end{array}$ & \\
\hline & 19:23h & & $\begin{array}{l}\text { Chuvas fortes vindas da região de Guarulhos } \\
\text { e permanência em Mairiporã, com potencial } \\
\text { para atingir Franco da Rocha. }\end{array}$ & \\
\hline & $20: 30 \mathrm{~h}$ & $\begin{array}{l}\text { Fechamento total do túnel 5, nível do reservstório } \\
\text { 744,59. Descarga de jusante 20l/s. Nível do córrego } \\
\text { Eusébio alto (fotos do ponto de medição fluvial) }\end{array}$ & & $\begin{array}{l}\text { indice pluviométrico entre as } 18 \mathrm{~h} \text { do dia } \\
10 / 03 \text { e as } 18 \mathrm{~h} \text { do dia } 11 / 03 \text { foi de } 120,7 \mathrm{~mm} \text {. } \\
\text { Maiores pontos de acumulação nas } \\
\text { cabeceiras dos córregos Eusébio e Itaim, } \\
\text { contribuintes do Juqueri. Momento em que } \\
\text { se decide fechar o túnel } 5 \text {, município já } \\
\text { poderia ser comunicado sobre possível } \\
\text { operação. }\end{array}$ \\
\hline & 21:00h & & $\begin{array}{l}\text { NUDEC aciona o Plano Preventivo de Defesa } \\
\text { Civil - Alertas de riscos - e realiza vistorias em } \\
\text { áreas de risco municipais (sobretudo } \\
\text { geológicos). }\end{array}$ & \\
\hline & $21: 30 \mathrm{~h}$ & & $\begin{array}{l}\text { Sistema de Alerta - viatura passa informando } \\
\text { sobre possivel inundação, elevação do nível } \\
\text { dos córregos. }\end{array}$ & \\
\hline & $22: 20 \mathrm{~h}$ & & $\begin{array}{l}\text { CEDEC declara Estado de Atenção no } \\
\text { município, PPDC, equipes designadas para } \\
\text { vistorias preventivas em áreas de risco. }\end{array}$ & $\begin{array}{l}\text { atingido limiar de chuva para nível de } \\
\text { atenção - } 95 \mathrm{~mm} \text {. Acumulado de precipitação } \\
\text { em } 15 \mathrm{~h} \text {. }\end{array}$ \\
\hline & $22: 30 \mathrm{~h}$ & & $\begin{array}{l}\text { Chuvas generalizadas e pancadas fortes. } \\
\text { Nivel do córrego Eusébio sobe, fica ni limite } \\
\text { de extravazamento. }\end{array}$ & \\
\hline & $22: 55 \mathrm{~h}$ & $\begin{array}{l}\text { Represa de Águas Claras com quase } 100 \% \text { do volume } \\
\text { útil, operação passa de } 2 \text { bomas para } 1 \text { bomba na ESI. } \\
\text { Córrego Eusébio transborda. }\end{array}$ & & \\
\hline \multirow{15}{*}{ 总 } & $0: 40 \mathrm{~h}$ & $\begin{array}{l}\text { ESI é desligada. Fotos mostram cidade inundada, quase } \\
\text { no mesmo nível do córrego Eusébio. }\end{array}$ & & \\
\hline & 2:30h & $\begin{array}{l}\text { Acionado plano de contingência: Sabesp entra em } \\
\text { contato com CEDEC, informando possivel operação de } \\
\text { manobra. Nivel } 745,25 \mathrm{~m} \text {. }\end{array}$ & & \\
\hline & $2: 40 \mathrm{~h}$ & CPTM interdita linhas, que já estavam alagadas. & & \\
\hline & $2: 45 \mathrm{~h}$ & & $\begin{array}{l}\text { CEDEC informa municipio sobre possivel } \\
\text { manobra. }\end{array}$ & defasagem de 15 minutos \\
\hline & $3: 00 \mathrm{~h}$ & & $\begin{array}{l}\text { NUDEC comunica CEDEC que município } \\
\text { estava em nível de Emergência pelo PPDC. } \\
\text { Área central da cidade inundada pelo } \\
\text { córrego Eusébio e rio Juqueri. }\end{array}$ & \\
\hline & $4: 34 \mathrm{~h}$ & $\begin{array}{l}\text { Detesa Civil Municipal entra em contato com Sabesp, } \\
\text { informando falta de comunicaçäo com CEDEC desde as } \\
2: 45 \mathrm{~h} \text {. }\end{array}$ & & \\
\hline & $4: 40 \mathrm{~h}$ & $\begin{array}{l}\text { Sabesp aciona CEDEC sobre falta de comunicação com } \\
\text { município a respeito dos procedimentos de descarga do } \\
\text { plano de contingência }\end{array}$ & & \\
\hline & 5:50h & $\begin{array}{l}\text { Município entra em contato com Sabesp solicitando } \\
\text { informações sobre a descarga. Sabesp informa iminência } \\
\text { de descarga de } 10 \mathrm{~m} 3 / \mathrm{s} \text { nas próximas horas. Nivel do } \\
\text { córrego Eusébio baixa, mas cidade permanece alagada. }\end{array}$ & & \\
\hline & 6:40h & $\begin{array}{l}\text { Início das descargas de } 10 \mathrm{~m} 3 / \mathrm{s} \text {. Nivel do reservatório } \\
745,55 \mathrm{~m} \text {. }\end{array}$ & & \\
\hline & 8:00h & $\begin{array}{l}\text { Vazão de descarga aumentada para } 20 \mathrm{~m} 3 / \mathrm{s} \text {. Nivel } \\
\text { eservatório } 745,60 \mathrm{~m} \text {. }\end{array}$ & & \\
\hline & 9:09h & & $\begin{array}{l}\text { Municipio recebe comunicado da CEDEC } \\
\text { sobre inicio da operação no Paiva Castro. }\end{array}$ & Defasagem de $2 \mathrm{~h}$ e $24 \mathrm{~min}$ \\
\hline & 10:52h & & $\begin{array}{l}\text { Chuvas de intensidade moderada a forte } \\
\text { permanecem. }\end{array}$ & \\
\hline & 11:20h & $\begin{array}{l}\text { Vazão de descarga aumentada para } 35 \mathrm{~m} 3 / \mathrm{s} \text {. Nível } \\
\text { eservatório } 745,70 \mathrm{~m} \text {. }\end{array}$ & & \\
\hline & 13:06h & & $\begin{array}{l}\text { Aviso de deslocamento de chuvas } \\
\text { moderadas a fortes para a região. }\end{array}$ & \\
\hline & 13:20h & $\begin{array}{l}\text { Vazão de descarga aumentada para } 50 \mathrm{~m} 3 / \mathrm{s} \text {. Nivel do } \\
\text { reservatório } 745,74 \mathrm{~m} \text {. }\end{array}$ & & \\
\hline \multirow{7}{*}{ 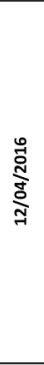 } & 14:00h & $\begin{array}{l}\text { Redução da vazão de descarga para } 20 \mathrm{~m} 3 / \mathrm{s} \text {. Nível do } \\
\text { reservatório } 745,23 \mathrm{~m} \text {. Indices pluviométricos } \\
\text { insignificantes. }\end{array}$ & & \\
\hline & 14:02h & & $\begin{array}{l}\text { Aviso de pancadas de chuva de moderadas a } \\
\text { fortes na região. }\end{array}$ & \\
\hline & 14:15h & & $\begin{array}{l}\text { Aviso de pancadas de chuva de moderadas a } \\
\text { fortes na região. }\end{array}$ & \\
\hline & 15:00h & & $\begin{array}{l}\text { Aviso de deslocamento de chuvas } \\
\text { moderadas a fortes para a região. }\end{array}$ & \\
\hline & $16: 15 \mathrm{~h}$ & & $\begin{array}{l}\text { Aviso de chuvas isoladas, de moderadas a } \\
\text { fortes, na região }\end{array}$ & \\
\hline & 16:40h & $\begin{array}{l}\text { Descarga totalmente fechada. Nível do reservatório } \\
745,16 \mathrm{~m} \text {. }\end{array}$ & & \\
\hline & 20:00h & $\begin{array}{l}\text { Reaberta descarga em } 5 \mathrm{~m} 3 / \mathrm{s} \text { para ajuste de nivel do } \\
\text { reservatório, até } 9: 30 \mathrm{~h} \text { do dia seguinte. }\end{array}$ & & \\
\hline 04/20 & $9: 30 \mathrm{~h}$ & $\begin{array}{l}\text { Nivel do reservatório em } 745 \mathrm{~m} \text {, comunicado à CEDEC } \\
\text { fim do acionamento do plano de contingência. }\end{array}$ & & \\
\hline
\end{tabular}

*Quadro de informaç̃̃es sistematizadas a partir do Inquérito Civil IC 1410900000024/16. Em vermelho, identificação das falhas de comunicação, não avaliadas no aprecer do inquérito. 

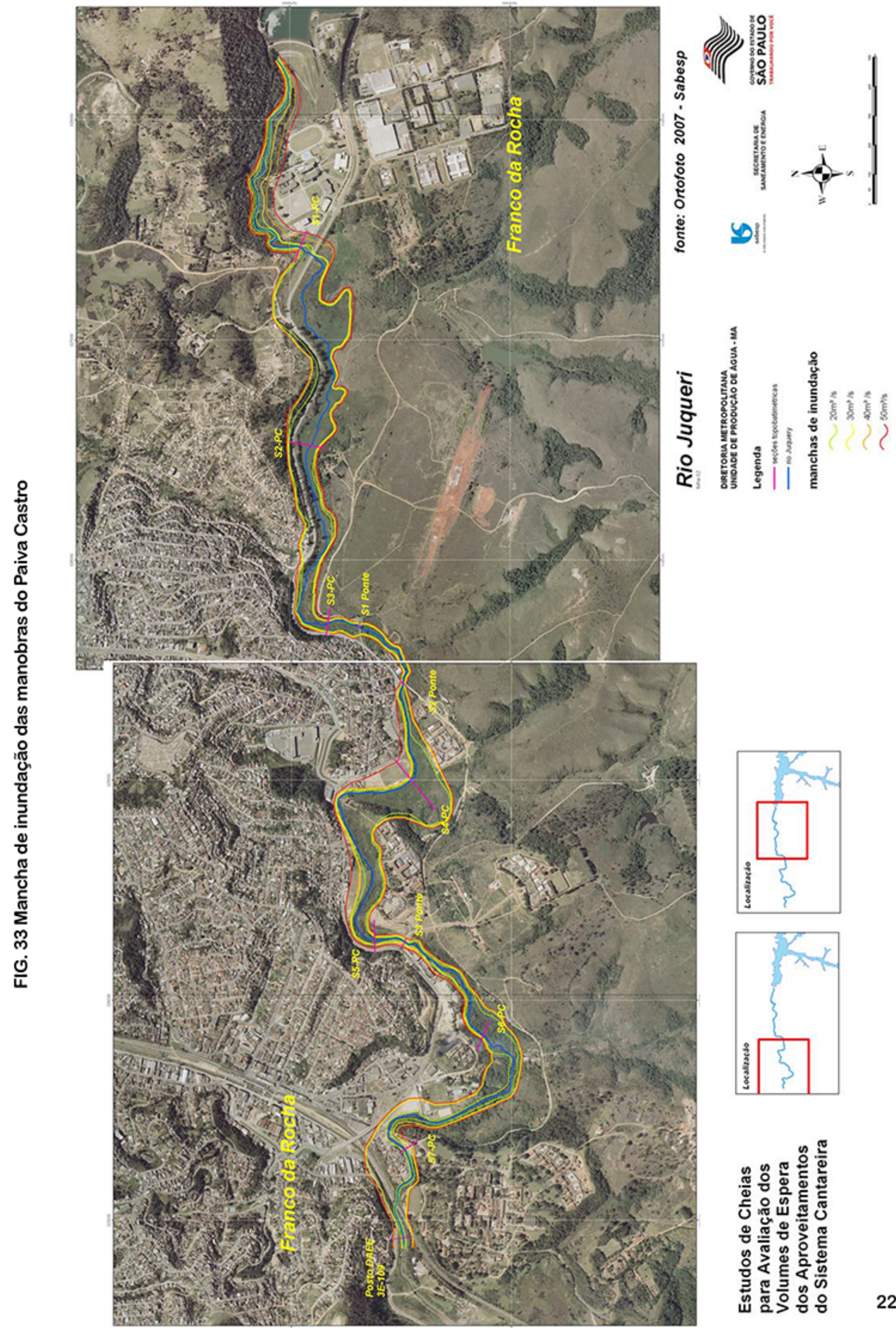
implantação das obras do plano de macrodrenagem e parques lineares previstos, e desenvolvimento de estudos mais completos e detalhados das manchas de inundação.

A Sabesp cumpre papel além das funções estritas de seu dispositivo como sua atribuição por força das obrigações da outorga. Avalia tecnicamente riscos além de suas funções a serem incorporados ao seu sistema, e os limites (a segurança decamilenar) a partir dos quais não consegue incorporá-los e mitiga-los por seus sistemas. Avaliou e produziu mapas, ainda que limitados, do limite físico em que as manobras não causam impacto, e avaliou o limite do sistema Cantareira em que a operação de cheia pode ocorrer com segurança da demanda de abastecimento, ao incorporar as curvas de aversão ao risco no estudo de avaliação dos volumes de espera.

Em tese, cumpriu o papel de trabalhar dentro de limites que não causem impacto. Ocupações urbanas dentro desse limite devem ser controladas pelas prefeituras e, em não sendo, é responsabilidade da prefeitura trabalhar na preparação dos ocupantes dessa mancha. No Paiva Castro, a Sabesp assume que a partir de $20 \mathrm{~m} 3 / \mathrm{s}$ o rio extrapola a calha, e que a partir de $50 \mathrm{~m} 3 / \mathrm{s}$, sua manobra causa danos - como, por exemplo, durante o período de 2011 em que a vazão manobrada chegou a $80 \mathrm{~m} 3 / \mathrm{s}$. O DAEE diminuiu esse limite para $10 \mathrm{~m} 3 / \mathrm{s}$. Agindo estritamente pelo princípio da normativa estabelecida, a partir da descarga de $10 \mathrm{~m} 3 / \mathrm{s}$, a empresa deveria se envolver na responsabilidade de comunicação de risco, nas fases preventiva e emergencial, pois esse é um risco presumido da atividade.

As prefeituras têm como tarefa integrar as informações fornecidas pela Sabesp aos efeitos de inundação a que estão submetidas as bacias de contribuição sob suas jurisdições. Para que isso ocorra, é preciso um trabalho de avaliação de riscos, prevenção e mitigação, a ser desempenhado em âmbito metropolitano e municipal. Em âmbito metropolitano, seria fundamental designar a região como suscetível a riscos residuais de dispositivos dos sistemas setoriais. Aplicando os princípios do Estatuto da Metrópole, essa designação obrigaria os municípios a definirem diretrizes diferenciadas em seus planos diretores para essas áreas, necessariamente atreladas a programas de gestão de risco. Para esse caso específico, a designação poderia apontar, ainda, que a vulnerabilidade da mobilidade dos municípios da região é um fator de amplificação dos riscos a que são suscetíveis, e exigir diretrizes direcionadas ao equacionamento dessa vulnerabilidade.

Para este caso analisado, é possível ir além, e apontar necessidades de um programa com ações de gestão de riscos conduzido pelo município (ou conjunto de municípios) sobre as quais a Sabesp não deveria ter qualquer responsabilização:

1. produção de modelagens hidráulico-hidrológicas (mancha de inundação) considerando as contribuições superficiais e dos afluentes das microbacias a jusante da barragem, para cenários com e sem (numa eventual situação de falha) os dispositivos de controle de cheias implantados, e com acréscimo da vazão de descarga de $10 \mathrm{~m} 3 / \mathrm{s}$;

2. identificação, no zoneamento municipal, das áreas sujeitas a riscos de inundação e agravamentos pelas manobras das represas, nas quais deve incidir maior restrição no uso e ocupação do solo, priorização de ações de mitigação, e adequação de diretrizes do plano diretor; 
3. proposição de medidas preventivas para não adensamento e para desadensamento dessas áreas;

4. promoção de trabalho continuado de comunicação de risco, planos de alerta e ações para situação de emergência que atendam a população já instalada nessas áreas. Deve incluir comunicação ampla a todo o município sobre logística e mobilidade durante cenários críticos, para informar amplamente aos munícipes sobre como receber informação e agir de forma a não se colocar em risco durante cenários críticos.

Além dessas ações, e considerando que a partir da liberação de vazão na barragem do Paiva Castro acima de $10 \mathrm{~m} 3 / \mathrm{s}$ há um risco de impacto que é presumido pela companhia Sabesp, seria uma medida de boa governança que a empresa disponibilizasse recursos para o trabalho continuado da última ação descrita, a comunicação de riscos. O tempo curto de resposta imposto pelos limites de armazenamento do Paiva Castro e pela característica das ameaças extremas que têm sido observadas exige um trabalho preventivo muito bem feito.

Além disso, deveria ser incluído na responsabilidade que cabe à Sabesp:

5. incorporar às manchas de inundação do município (primeiro item apontado acima) os impactos da vazão de descarga acima de $10 \mathrm{~m} 3 / \mathrm{s}$;

6. desenvolver informação e preparação para aqueles riscos apresentados no Plano de Contingência como de "Máxima Gravidade", ou seja, quando parâmetros operacionais passam a ser determinados dentro dos níveis de segurança decamilenar, ou vazões acima de $80 \mathrm{~m} 3 / \mathrm{s}$,

7. reapresentar as informações da mancha de inundação das vazões manobradas em escala mais apropriada para que o município proceda devidamente os seus cadastros.

Uma medida para a participação da empresa nas ações de comunicação poderia ser avaliada pelo quanto a companhia ganha, em termos de flexibilidade para seus sistemas, com um melhor manejo urbano de seu entorno. Seria possível colocar valor nesses ganhos, a fim de avaliar o quanto (em termos de quantidade de recursos) a empresa estaria disposta a empregar nessa governança? Os Comitês de Bacia são instâncias apropriadas para arbitrar esses conflitos, ou é necessária uma esfera específica para arbitragem de riscos? Esse poderia ser um fator a ser submetido a algum controle pelo ente regulador da atividade desempenhada pela empresa.

\subsection{Controles de quantidade e qualidade da água a oeste}

\subsubsection{Caracterização geral: riscos e interfaces}

Apesar das inundações em Salto serem as consequências mais claramente localizadas e pontualmente definidas dentre os 3 casos analisados, a situação em risco, nesse caso, não envolve a análise de uma localidade, pois não se trata de um conflito entre usos de escala local e funções da escala regional, mas de riscos cruzados, agravos e conflitos entre os sistemas setoriais na escala regional. Não é necessário compreender nenhum aspecto da configuração urbana de Salto, ou dos programas em curso nesse município, para compreender o risco a que está submetido e as vulnerabilidades a ele associadas. 
A melhoria da condição vulnerável não depende da reorganização urbana local. A análise dos riscos urbanos e ambientais desse caso exige maior compreensão das causas, cruzamentos e agravos por uma observação regional.

O controle de inundações nas UGRHIs do Médio Tietê e Sorocaba está associado aos controles da BAT. A vazão de restrição colocada entre os limites das bacias define uma descontinuidade à vazão do rio Tietê. Esta descontinuidade seria resolvida, conforme proposta do PDMAT3, por meio de soluções de grande impacto, como túneis escavados entre a foz do Tamanduateí - ou alternativamente, na foz do Juqueri - até o mar, no intuito de descarregar a vazão que excede a restrição, já que, mesmo com todos os piscinões implantados e ampliação da calha do Tietê, as modelagens mostraram que, para as chuvas críticas dos últimos anos, não havia capacidade de reservação possível para manter o escoamento na bacia ${ }^{126}$ dentro dos limites da restrição. A conexão entre as UGRHIs BAT e Médio Tietê é feita pelos reservatórios de Pirapora e Rasgão, com vulnerabilidades tanto relacionadas à qualidade da água como no controle da quantidade - a vazão do rio Tietê no ponto de Pirapora é da ordem de $1500 \mathrm{~m} 3 / \mathrm{s}$, e o limite de descarga para não inundar a cidade de Pirapora é da ordem de $700 \mathrm{~m} 3 / \mathrm{s}$. A única alternativa já existente para direcionamento das vazões de cheia, que não as descargas acima da restrição ao Médio Tietê, é o direcionamento das vazões para Cubatão, por meio da reversão do curso do rio Pinheiros para controle de cheias, realizada no complexo hidro energético da Usina Henry Borden.

FIG. 34. Sistema hidroenergético de Henry Borden - hidrografia e dispositivos. Elaboração: da autora.

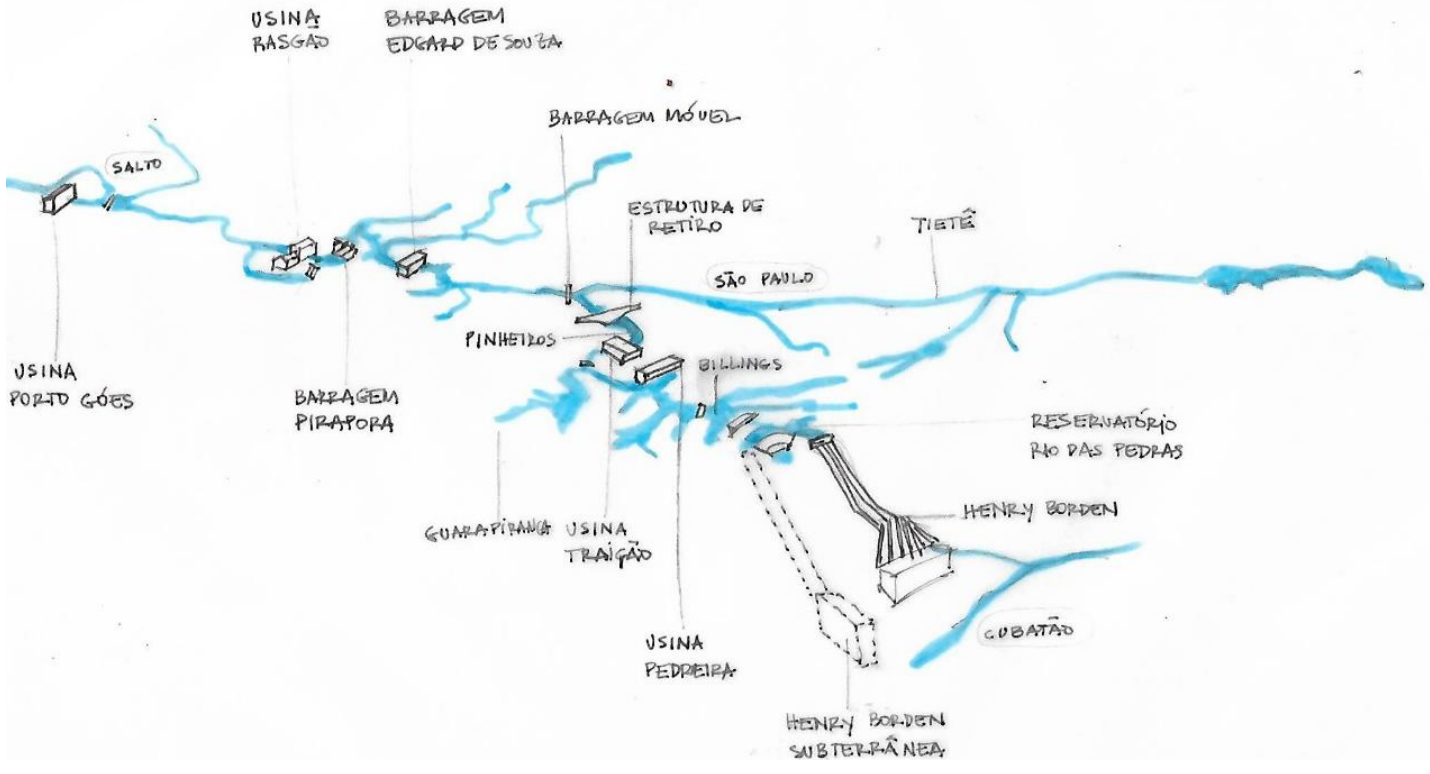

${ }^{126}$ No relatório R11 do plano são apresentadas as soluções estruturais mencionadas. Apesar do volume (R10), que apresenta soluções não estruturais, apontar propostas para controle da vazão no lote (pequenos reservatórios), não foram modelados cenários hipotéticos em que essas soluções pudessem ser implantadas. Por exemplo: se todos os lotes da cidade adotassem pequenos reservatórios, se metade dos lotes da cidade, se lotes a partir de determinada área, etc. Isso poderia definir outros CN de cenário para as modelagens, que um urbanista poderia auxiliar a desenvolver. Essas simulações poderiam ser úteis ao permitir avaliar os impactos dessas pequenas soluções e seus custos em comparação com a possibilidade de reduzir a magnitude das grandes obras. Se houvesse financiamentos para obras de drenagem nos lotes particulares, e recursos para fiscalizar a realização das mesmas, quanto custaria e qual seria seu impacto? 


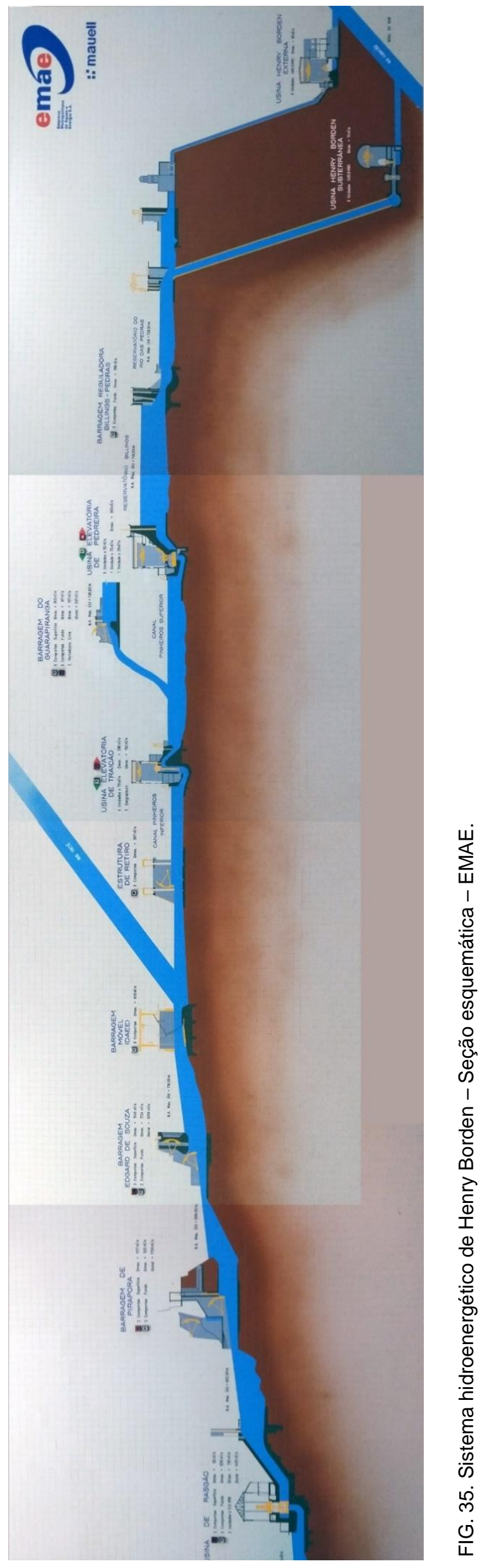


Uma medida sistêmica que poderia reduzir cargas poluentes às UGRHIs Médio Tietê e Sorocaba também se relaciona com a reversão do Pinheiros, pois, ao reverter parcialmente as águas do Tietê, sua vazão afluente a jusante de Pirapora é reduzida junto com toda a carga poluente a ela associada. A utilização da reversão associada a medidas de despoluição locais, como a proposta piloto do projeto de flotação do rio Pinheiros - entre outras possíveis soluções que podem ser abordadas em planos de bacias municipais, partindo de uma visão integrada das águas urbanas - seria uma decisão cujos resultados a longo prazo minimizariam riscos de contaminação transferidos a outras bacias, e obrigariam à resolução da poluição na própria bacia.

A reversão se relaciona também, no aspecto quantidade, a interesses de ampliação da disponibilidade de água para abastecimento da RMSP, aumentando a afluência às represas Billings e Guarapiranga, e para a própria geração de energia em Henry Borden - importante para suprir a demanda energética metropolitana em períodos de pico, uma das usinas mais produtivas do Brasil na relação entre volume turbinado e potência gerada - usina instalada e operável.

Com relação à ampliação de disponibilidade para abastecimento, a reversão é, no mínimo, contraditória: em termos de quantidade, pode ser uma afluência importante, mas em termos de qualidade, traz um aporte de cargas poluentes considerável às represas. Novamente, pensar a reversão como solução é uma medida que coloca como necessidade tomar medidas de despoluição na bacia, cuja melhora paulatina pode atuar na diluição das cargas que promovem a eutrofização nas represas. É uma decisão que não resolve todos os problemas no momento em que é tomada, mas impõe obrigações para o futuro, com estabelecimento de metas graduais, ajustáveis no tempo. Raciocínio semelhante foi proposto por Saturnino de Brito, no Plano de Abastecimento para São Paulo de 1905 e em sua revisão, em 1925: prever a utilização de águas poluídas no abastecimento (no caso, a proposta era de utilização de poços perfurados na várzea do Tietê para abastecer zonas baixas) cria, ao sistema, a necessidade de implementar controles de poluição ${ }^{127}$.

O conflito do caso oeste, portanto, pode ser expresso pontualmente pelos conflitos a respeito da função de reversão do rio Pinheiros, e pela necessidade de soluções estruturais e não estruturais para despoluição. A expressão difusa desse caso está no descontrole urbano, que faz parte da gestão das águas urbanas: contaminação hídrica pela falta de saneamento, produção de sedimentos, ocupação de mananciais.

O sistema metropolitano em questão envolve, basicamente, duas grandes interfaces, e a probabilidade de ocorrência dos problemas é certa ou quase certa:

- riscos, falhas e interfaces dos controles da quantidade do recurso hídrico:

- vazões de restrição para controle da macrodrenagem, operação dos controles entre a saída da BAT e Médio Tietê;

${ }^{127}$ BRITO, 1943, vol. 3: 60-61. 
- alocação do recurso para abastecimento de água - redução da dependência do Cantareira pela ampliação de outros sistemas produtores ${ }^{128}$, que impõe associar qualidade e quantidade;

- regularização e reversão para aproveitamento energético - interação positiva com controle da drenagem, mas limitada pelos controles de qualidade da água.

- riscos, falhas e interfaces dos controles (ou falta de controles) da poluição hídrica:

- fatores difusos que implicam em prejuízos à qualidade da água - falta de coleta de e tratamento de esgotos, falta de controle urbano;

- ameaças meteorológicas e climatológicas que ampliam problemas da qualidade da água em geral - estiagem severa;

- fatores que ampliam problemas da qualidade da água nos mananciais de abastecimento - reversão para controle de cheias, reversão para aproveitamento energético;

- limites dos controles ambientais para soluções alternativas - o caso da flotação do Rio Pinheiros.

\section{Quadro 33. Matriz dos riscos identificados - sistema hidráulico do rio Pinheiros}

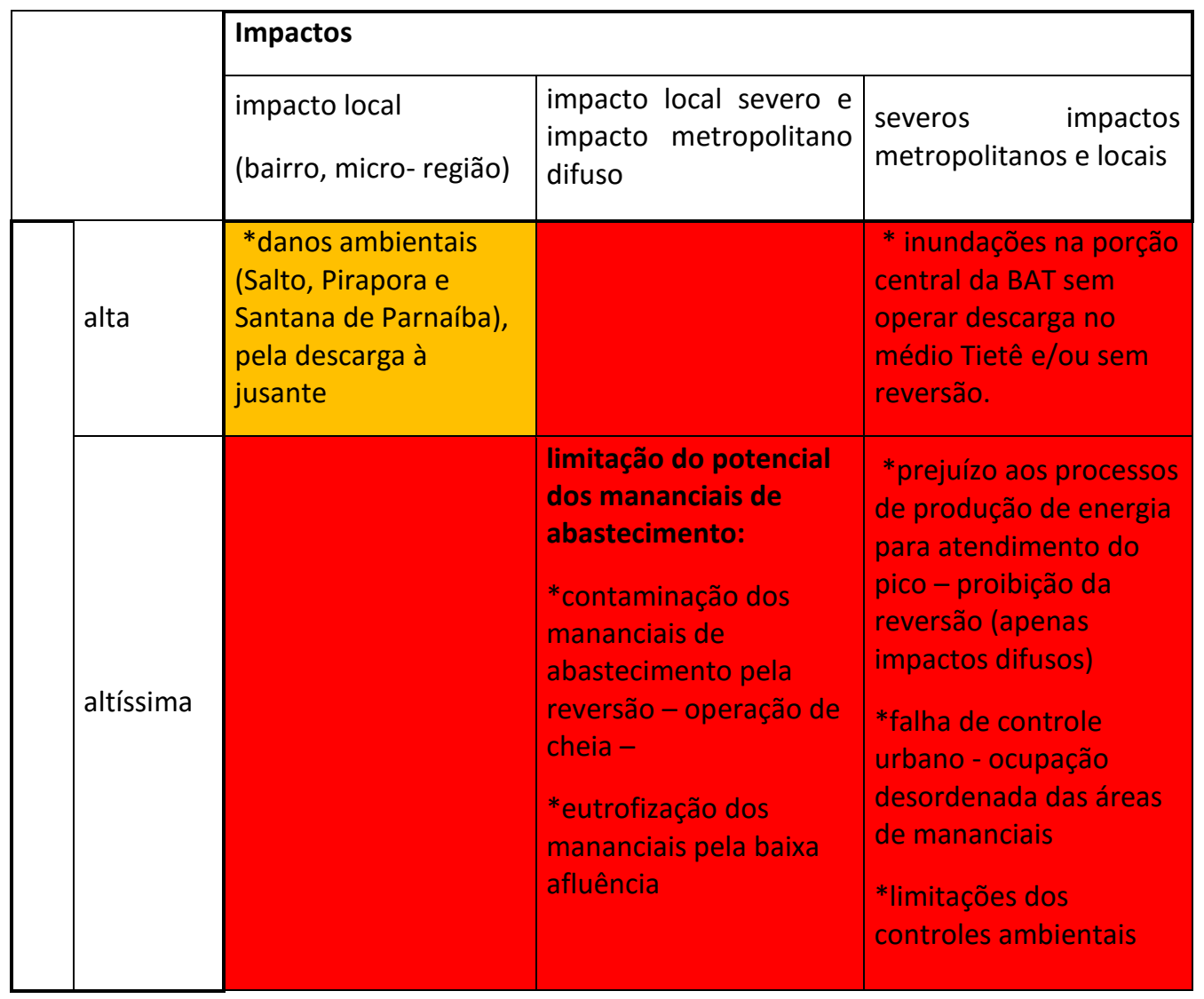

${ }^{128} \mathrm{O}$ aproveitamento de vazões despoluídas no reservatório Billings é a única resposta objetiva com que a UGRHI Alto Tietê conta para atender exigência expressa do acordo de outorga do Sistema Cantareira quanto a redução de dependência das águas revertidas da UGRHI PCJ para o abastecimento da Região Metropolitana de São Paulo. 


\subsubsection{Soluções, limitações, potencialidades}

A EMAE opera diversas barragens nos rios Tietê e Pinheiros, e controla os níveis desses corpos hídricos para variadas funções: controle de cheias, geração de energia e mesmo transporte fluvial - como a passagem de balsas à ilha do Bororé e balsas de dragagem do DAEE. Os protocolos operacionais seguidos pela EMAE para operação em Henry Borden e demais usinas seguem as regras do Operador Nacional do Serviço (ONS), estabelecidas no contrato de concessão, e as Medidas Provisórias para Regime de Cotas. Nas operações de Controle de Cheias, segue também os protocolos operacionais regulados por Resoluções Conjuntas SMA/SSE.

Por ocasião da ocorrência da descarga em Pirapora com consequências de alta carga poluidora em Salto, os técnicos da EMAE alegam ${ }^{129}$ que a chuva relativamente intensa posterior ao longo período de estiagem em 2014 provocou tais efeitos. Durante a seca, as barragens operaram por muito tempo apenas à vazão turbinada, ou seja, vazão dirigida aos dispositivos para geração de energia, e não pelos dispositivos das comportas, havendo depósito de sedimentos nessas estruturas. Com a chuva, além da contaminação de primeira chuva muito alta, devido à estiagem, ao se manobrar as comportas, o sedimento acumulado foi carregado de uma vez.

Além das questões decorrentes da imposição dos limites de vazão e da poluição no ponto de controle entre bacias regionais (BAT e Médio Tietê), e conforme discutido anteriormente, nos itens 7.3.1 e 6.3, com base nos diagnóstico e propostas do PDMAT3, a utilização da reversão do Rio Pinheiros é uma medida essencial e estratégica tanto para o aproveitamento energético como para o controle de inundações na BAT, quando sua contribuição ao Tietê passa a ser zero.

Nas Operações de Cheia do rio Pinheiros, nem sempre as condições exigem o bombeamento para o Reservatório Rio das Pedras, que encaminha para geração de energia em Cubatão. Muitas vezes, até certo limiar, é possível controlar integradamente os níveis do canal do Pinheiros sem o bombeamento. O canal é dividido em 2 trechos separados pela Usina elevatória de Traição: até a estrutura de Retiro (o trecho inferior) e até a Usina Elevatória de Pedreira (o trecho superior). O modo de Operação Controle de Cheias no rio Pinheiros é acionado quando ocorre sobrelevação natural de $30 \mathrm{~cm}$ no canal do rio Pinheiros inferior até a Usina de Traição, e no Tietê, até a estrutura de Retiro. Neste cenário - e depois de desprezadas as águas de primeira chuva, com alto teor de contaminação - as descargas em Traição são interrompidas e a Estrutura de Retiro (na confluência com o rio Tietê) é fechada. Posteriormente, se inicia o bombeamento em Traição, com 2 máquinas; seguido de Pedreira, com 2 máquinas. Caso as chuvas persistam, os níveis continuem subindo, e o Canal Inferior atinja níveis acima do nível do Rio Tietê, o bombeamento nas elevatórias passa ao máximo: outras máquinas entram em operação até se atingir a vazão máxima para o reservatório Billings $385 \mathrm{~m} 3 / \mathrm{s}$ em Pedreira. Acima disso, passam a ser avaliados limiares para acionamento de protocolos de situação de emergência, que os técnicos relatam nunca terem visto ser acionados.

\footnotetext{
${ }^{129}$ Informações obtidas em entrevista com José Luppi Jr., Mario Luiz Oliveira e Julio Pinfari, da EMAE.
} 
A usina Henry Borden, localizada em Cubatão, aproveita o recurso armazenado no Reservatório Billings-Rio das Pedras pelo desnível da Serra do Mar. Com uma das maiores produtividades do país para geração de energia (relação de 5,6MW por m3/s), capacidade para uma vazão de $157 \mathrm{~m} 3 / \mathrm{s}$, e vazão mínima de 22,6m3/s para seu funcionamento na geração de energia, o aproveitamento, cujo bombeamento teve início em 1940, depende da reversão da vazão dos rios Tietê e Pinheiros. Durante a estação seca, a vazão no Rio Pinheiros é da ordem de $10 \mathrm{~m} 3 / \mathrm{s}$, baixa para as necessidades de geração de energia. Por isso, em torno de 50 a 150m3/s do Tietê, no período seco, eram aproveitados no arranjo.

O aumento da carga poluidora lançada no reservatório Billings, tanto pela ocupação da área de manancial protegida da bacia no entorno do reservatório, como pelo aumento da poluição dos rios Tietê e Pinheiros conduzidas pela operação de reversão, levou a qualidade das águas no reservatório a níveis limite para o aproveitamento no abastecimento de água na década de 1980. Diante desse cenário, na Constituição do Estado de São Paulo de 1989, no artigo 46 do ato das Disposições Transitórias, foi estabelecido que: "no prazo de três anos, a contar da promulgação desta Constituição, ficam os Poderes Públicos Estadual e Municipal obrigados a tomar medidas eficazes para impedir o bombeamento de águas servidas, dejetos e de outras substâncias poluentes para a represa Billings." As resoluções posteriores - Resolução Conjunta SMA/SES 03/92 e Resolução SEE-SMA-SRHSO-I de 13/03/96, modificada pela Resolução Conjunta SMA/SSE-002 de 19/02/2010 - estabeleceram a interrupção do bombeamento contínuo dos rios Pinheiros e Tietê para fins de geração de energia.

Com isso, o bombeamento do Rio Pinheiros para o Reservatório Billings pela Estação Elevatória de Pedreira passou a ser feito somente para o controle de cheias ${ }^{130}$, diminuindo a capacidade de produção de energia do complexo e a afluência ao reservatório Billings.

A operação no período de cheias é necessária para o controle da vazão não só para o médio Tietê, mas para a própria bacia do rio Pinheiros, pois a retificação do canal do Pinheiros, com eliminação de seus meandros, foi pensada com o funcionamento da reversão. Sem ela, a capacidade de vazão da calha, no sentido da foz natural, é limitada a cerca de $40 \mathrm{~m} 3 / \mathrm{s}$. Na operação controle de cheias, apesar da maior diluição das cargas poluentes, a carga poluidora ainda é bastante considerável aos reservatórios, sobretudo se consideradas as cargas difusas de primeira chuva. À medida que transitam as cheias de maior vazão, a carga poluente cai devido à diluição (FCTH, 2010).

A partir do ano 2000, foi implantada transferência de água do Reservatório Billings para - Reservatório Guarapiranga, no braço do rio Taquacetuba, com a finalidade de aumentar a disponibilidade de água para abastecimento captada pela Sabesp na Guarapiranga, reiterando as três finalidades da Billings: geração de energia, controle de cheias e abastecimento. No mesmo ano, um projeto conjunto entre as empresas responsáveis pelo abastecimento, geração de energia e controle ambiental (Sabesp,

\footnotetext{
${ }^{130} \mathrm{E}$ também para controle de espumas que ocorrem em Pirapora, em virtude da poluição concentrada do rio Tietê, e para controle do bloom de algas nos reservatórios, que ocorre, entre outros fatores, também pela baixa afluência.
} 
EMAE e Cetesb, respectivamente), em parceria com a Petrobrás, propôs a implantação de um protótipo piloto para tratamento direto das águas no canal do Pinheiros ${ }^{131}$.

Por meio de flotação das águas (processo de floculação seguido de injeção de ar), o protótipo propunha testes para o tratamento de $10 \mathrm{~m} 3 / \mathrm{s}$ durante bombeamento em regime seco, correspondendo a aproximadamente $20 \%$ da capacidade prevista para 0 objetivo de implantação final do sistema.

"No futuro, a implantação do sistema completo, aliado a medidas complementares de controle de poluição, permitirá a reversão de $50 \mathrm{m3} / \mathrm{s}$ para o Reservatório Billings e, conseqüentemente, um aumento médio de $280 \mathrm{MW}$ na produção de energia na usina de Henry Borden. Isto significa que a produção média poderá passar dos $128 \mathrm{MW}$ brutos atuais (vazão média de $23 \mathrm{~m} 3 / \mathrm{s}$ ) para 408 MW (vazão média de 73m3/s)." (FCTH, 2010: 7).

O intuito do projeto era restituir a possibilidade de reversão em períodos secos, proibida nas resoluções da década de 90, considerando que o financiamento para implementação e operação dessa proposta para tratamento pudesse ter as despesas cobertas pelo adicional de energia gerado.

Em 2001, os testes do piloto implantado foram paralisados por Ação Civil do Ministério Público, demandada por movimentos ambientalistas. O projeto foi retomado em 2007, após acordo judicial que estabeleceu parâmetros para o tratamento compatíveis com as exigências da Classe 2, estabelecida pela Resolução Conama:

"III - classe 2: águas que podem ser destinadas: a) ao abastecimento para consumo humano, após tratamento convencional;

IV - classe 3: águas que podem ser destinadas: a) ao abastecimento para consumo humano, após tratamento convencional ou avançado" (Resolução Conama 357).

"Classe 3 poderia também ser uma exigência aceitável para a oferta de abastecimento desde que o tratamento - para distribuição de água potável fosse avançado." (SILVA, 2011: 95).

O projeto foi retomado em 3 fases, entre 2007 e 2009, com os seguintes objetivos de monitoramento:

- avaliar a eficiência do processo de flotação do Rio Pinheiros em remover os principais poluentes monitorados

- avaliar o impacto do bombeamento das águas flotadas do Rio Pinheiros nos Reservatórios Billings e Guarapiranga no período seco, com o acompanhamento da variação de variáveis de qualidade da água

- estudar efeitos do bombeamento das águas flotadas nos Reservatório Billings para a simulação de diferentes cenários de flotação e de geração de cargas de poluentes afluentes ao lago, com a aplicação de modelo matemático de qualidade da água.

${ }^{131}$ FCTH, 2010 e Relatório Final, Volume 1; SILVA, 2011. 
As conclusões da última fase de operação do protótipo (FCTH, 2010: 80) apontam basicamente 3 pontos:

1. que houve remoção de fósforo superior a $90 \%$, valor próximo do esperado para esse tipo de processo, mas que não atende às exigências da Classe 2; a remoção de outros poluentes também foi razoável, com destaque para a redução de $\mathrm{DBO}$, indicador importante para diminuir o processo de eutrofização;

2. que a operação do protótipo para a vazão de $10 \mathrm{~m} 3 / \mathrm{s}$ não produziu impacto negativo detectável no reservatório Billings. Nas simulações do modelo de qualidade, para o cenário do padrão atual de lançamento de cargas difusas e esgoto no entorno do reservatório, variando-se a vazão flotada entre 10 a $50 \mathrm{~m} 3 / \mathrm{s}$, foram observados impactos positivos significativos na qualidade da água da Billings apenas em uma pequena área do reservatório. Para cenários com uma grande redução das cargas afluentes pelas sub-bacias no entorno do reservatório - simulando melhorias sanitárias e ambientais nessas sub-bacias - o modelo demonstrou que a flotação impacta positivamente também apenas uma pequena região da Billings, independentemente do padrão de lançamento de cargas no entorno do reservatório. Ou seja, a contaminação existente no reservatório é resiliente.

3. Entretanto, é destacado que para o bombeamento de $50 \mathrm{~m} 3 / \mathrm{s}$, o modelo mostrou que existe influência direta na melhora da qualidade da água do Rio Pinheiros, e que, posteriormente ao ponto de controle da análise, o fluxo é misturado a outras fontes de contaminação. Existem pontos de controle da análise em que a eutrofização ocorre no período de verão mesmo nos cenários com redução de cargas poluentes afluentes pelas sub-bacias, sugerindo que o reservatório seria favorecido com maior volume para diluição dos nutrientes que alimentam esse processo. A troca de água do reservatório com mais frequência favoreceria a mistura de poluentes. Ou seja, novas políticas de turbinamento (aumento da frequência de turbinamento em Henry Borden) poderiam contribuir ao reduzir o tempo de detenção e melhorar as condições de mistura de poluentes no reservatório.

"Uma extensa e detalhada análise comparativa para os cenários simulados com a primeira calibração já foi apresentada no primeiro relatório do Projeto QAPB (CESP, EMAE e FCTH, 2008), onde foi observado que um aumento da vazão característica afluente por Pedreira, e um conseqüente aumento da vazão utilizada para a geração de energia na Usina Henry Borden, causa um decréscimo do tempo de detenção da água no interior do reservatório e melhora a qualidade da água neste." (FCTH, 2010: 68)

Este terceiro ponto é um argumento que possibilita uma visão mais ampla da eficiência da proposta. Manter ativo um projeto de despoluição gradual poderia permitir ganhos entre os diversos sistemas: as interfaces entre controle de inundações, geração de energia e abastecimento de água poderiam justificar um custo partilhado entre os diversos interessados.

A gradação de metas e, inclusive, a gradação da implementação dos próprios mecanismos de controle, é um princípio fundamental da política de recursos hídricos. $O$ estabelecimento de parâmetros de classe muito elevados pelos órgãos de controle 
ambientais, e nos posicionamentos de movimentos ambientalistas, dificulta o exercício de metas graduais como projeto e como plano. Por se tratar de sistema complexo, com integrações múltiplas, regiões distintas, instituições governamentais distintas e de resposta lenta, e por depender de pactos entre interessados com grau de conscientização e conhecimento distintos sobre o processo, os diversos instrumentos da política de recursos hídricos preveem desenvolvimento gradual.

Contextos como o das regiões metropolitanas, onde se concentram conflitos no uso dos recursos hídricos, tendem a ter sistemas de gestão mais desenvolvidos, maior aplicação de instrumentos e sistemas de informação. No caso da RMSP, o desenvolvimento mais intenso dos instrumentos se depara com novas fronteiras. As leis específicas de Proteção dos Mananciais Billings e Guarapiranga, de 2006 e 2009, aplicam princípios de desempenho, com cargas metas de carga poluidora de acordo com a capacidade de diluição e saturação dos compartimentos da represa, associados a parâmetros de controle ambiental e urbanos não homogêneos para toda a APM. É um exemplo de sofisticação na aplicação do instrumento.

O desafio aqui apontado pelo estudo de caso, coloca como fronteira a resolução integrada para melhoria da segurança entre as interdependências dos sistemas, e na superação de falhas e lacunas nas interfaces entre os sistemas. As conclusões do Parecer Técnico sobre a mortandade de peixes em 2014 (FCTH, 2018) corroboram na percepção deste desafio:

"(...) considerando a diversidade de Instituições que se relacionam com os recursos hídricos da região, cada uma atuando de forma independente, com objetivos diferentes, é quase impossível identificar tecnicamente um ou mais responsáveis pelo ocorrido. Somente com uma política de gestão integrada se poderá efetivamente mudar este quadro de degradação da bacia hidrográfica e estabelecer níveis de responsabilidade gerencial/operacional no rio.

(...) levando em consideração o parágrafo $2^{\circ}$ do artigo 225 da Constituição Federal, que diz que aquele que causar danos ambientais deverá recuperar 0 meio ambiente degradado, de acordo com a solução técnica exigida pelo órgão público competente, acredita-se que a indenização não irá recuperar o ambiente degradado. Um estudo detalhado do sistema complexo do rio Tietê, tendo como objetivo avaliar a influência das operações dos reservatórios e usinas no meio ambiente e a otimização de tais operações, realizado por uma equipe de pesquisadores e profissionais de diferentes formações e com participação dos multistakeholders envolvidos (CETESB; Ministério Público; concessionárias de saneamento e de energia; prefeituras; etc), assim como a implantação das medidas propostas (...) [de monitoramento tático da qualidade da água na bacia] constitui a verdadeira reparação do dano causado e a prevenção de outros danos semelhantes que possam ocorrer no futuro" (FCTH, 2018: 47).

Apesar dos avanços desde a instituição da lei, os espaços de representação da política de Recursos Hídricos, nos Comitês de Bacia, estão em franca decadência. Assim como nos dois casos anteriormente analisados, a melhora da comunicação social e institucional permitiria, também neste caso, recuperar o sentido dos comitês, não como espaço genérico de representação da sociedade civil, apartada do conhecimento das 
soluções técnicas em jogo, mas como espaço de consulta e negociação dos interesses de agentes informados, apoiados por uma sociedade civil igualmente informada dos processos em questão.

Riscos cruzados e interdependências entre sistemas é uma pauta que deveria se fazer presente e com total transparência nas decisões sobre os sistemas regionais, assim como os sistemas regionais deveriam ser incorporados nas discussões sobre gestão de riscos. A vulnerabilidade urbana não é um fator a ser analisado apenas do ponto de vista do uso e da ocupação do solo, com predominância das funções residenciais. Existem fragilidades dos sistemas urbanos de infraestrutura, sobretudo da articulação entre eles, que precisam ser incorporadas às análises de vulnerabilidades e de riscos urbanos. Existem riscos inerentes a essas atividades, e seu resíduo deve ser incorporado nas análises como um elemento da suscetibilidade de um local. A gestão de riscos deveria operar em escala local, ou em agrupamentos de bacias, arbitrando soluções de nível local e compreendendo as escalas regionais que atravessam esse território. Mas deve haver, também, um nível de decisão que compreenda a integração, e não a mera soma, de territórios. 


\section{PARTE III - Conclusões}




\section{Cap. 8 - Interfaces de escala e escopo: transversalidade em construção}

Esta tese propõe umaabordagem metodológica inovadora, que pode promover avanço significativo na execução da ação prioritária 1 do Marco de Sendai - "Compreender o risco de desastres", desdobrado nas metas 2 e 3 - fortalecer a governança e investir em resiliência. Este é o ponto de partida de um posicionamento epistemológico, dos limites que estão colocados ao conhecimento sobre o tema, e é também o ponto de chegada, ao tentar produzir uma contribuição tangível à gestão urbana.

Tem como foco um contexto extremamente desafiador e complexo, que é o das grandes regiões metropolitanas, trabalhado para a situação específica da Região Metropolitana de São Paulo. Assim, nesta pesquisa, foram testados os primeiros ensaios de uma avaliação intersetorial de riscos urbanos, procurando abranger: diversas dimensões e aspectos da vulnerabilidade, da capacidade física, organizacional e financeira em lidar com ameaças, da exposição ao risco e caracterização das ameaças, analisando, especialmente, danos e interrupção de serviços básicos em infraestruturas nos contextos de desastres, seus desdobramentos e efeitos diferidos, bem como riscos que podem ser proporcionados às localidades pela presença, e não ausência, de infraestruturas. No referencial de boas práticas que decorre do Marco de Sendai (tratado no capítulo 2), predomina o foco nas experiências de escala local, e na melhoria da resiliência e redução da vulnerabilidade pelo enfoque da organização comunitária. Ao propor metodologias para lidar com complexidades e fatores que impactam a grande escala, este trabalho pode representar um avanço na ação prioritária 1 do Marco de Sendai, alinhado sobretudo com a meta $D$ deste documento - de reduzir danos a infraestruturas e interrupções de seus serviços em contextos de desastres.

Ao se deparar com limitações e incompletudes das fontes de informações, o trabalho formulou um método apoiado na busca de relações entre três naturezas de informações - sistematização e análise quantitativa dos dados sobre ocorrências, leitura sistemática dos eventos na mídia, e entrevistas locais e com agentes técnicos envolvidos nos contextos selecionados para análise, que indicaram fatos e rumos para investigar documentos necessários à melhor compreensão dos quadros analisados nos 3 estudos de caso. A partir dos casos, foi possível desenhar uma percepção geral das falhas interconexas no contexto metropolitano de São Paulo.

\section{Mudanças de rumos e o contexto da pesquisa}

A motivação original da pesquisa foi compreender o desenvolvimento da gestão de riscos e de uma possível organização preventiva de grande escala nas cidades brasileiras em comparação com cenários internacionais, e como, em cenários com distintas ameaças, os princípios de gestão de riscos são incorporados aos instrumentos de planejamento e gestão urbanas.

A primeira resposta com a qual a pesquisa se deparou foi a de que estamos em plena transformação de contexto. Principalmente após os eventos de 2011 na Região Serrana do Rio de Janeiro, com a tramitação da lei da Política Nacional de Prevenção e Defesa 
Civil (PNPDEC, de 2012, tratada no capítulo 3) - e também eventos anteriores, como o de Angra e São Luís do Paraitinga, em 2010, eventos recorrentes na região Sul, e do recente acidente em Mariana, em 2016 - paulatinamente, o tema dos riscos e adaptação a mudanças climáticas foi estimulado nas discussões e agenda da gestão urbana no Brasil e em São Paulo. No entanto, o arcabouço de informação e sistematização de dados ainda não é suficientemente consolidado, e, principalmente, não é coordenado de maneira adequada para lidar com esses estímulos. A primeira constatação foi perceber que se estava lidando com um tema em transição e em movimento acelerado, em construção. Portanto, e por isso, foi necessário assumir uma posição com o desenvolvimento da pesquisa: de que as investigações deveriam dialogar com o objeto de análise por meio de contribuições práticas.

Dessa forma, ainda que a investigação tenha acompanhado as atualizações no cenário nacional e internacional, a análise foi dirigida mais sistematicamente a um único contexto: a Região Metropolitana de São Paulo. A partir daí as perguntas que orientaram a investigação passaram a ser: quais seriam os riscos mais significativos e próprios da escala metropolitana? Como é e como deveria ser o rebatimento desses riscos nos instrumentos de planejamento em construção? Quais são as lacunas? O que pode ser aprimorado?

Essas perguntas exigiram formulações conceituais (capítulo 1) para subsidiar uma abordagem integrada e de coordenação à complexidade de setores e funções que compõem uma grande aglomeração metropolitana. As noções de falhas, riscos residuais e interface entre sistemas se mostraram mais promissoras do que a decomposição analítica de partes submetidas a ameaças crescentes. Nas interfaces e riscos residuais estão contidas as falhas da cidade, entendida como expressão máxima da natureza segunda, de uma natureza transformada. A natureza segunda configura suscetibilidades, não apenas vulnerabilidades; gera riscos, não apenas é suscetível a eles. Processos dessa segunda natureza resultam de interações complexas entre meio técnico, espaço social e espaço natural. Existem desastres cujos processos são de natureza urbana, transformada, e exigem o entendimento de funcionamentos, normalidades, falhas, e interações complexas dos sistemas urbanos frente a ameaças.

Em termos práticos, a participação nas reuniões da Câmara Temática de Gestão de Riscos Ambientais e Urbanos - CTM-GRAU, que vem discutindo a proposta de Plano e Política Metropolitana de Gestão de Riscos Ambientais Urbanos como parte das estratégias do PDUI (Plano de Desenvolvimento Urbano Integrado) - contribuiu na consolidação de diversos conceitos, e confirmou a aposta da pesquisa na abrangência metropolitana (capítulo 3). A proposta discutida na Câmara, de associar aspectos da gestão de riscos a desastres naturais à gestão de riscos tecnológicos, é um avanço à própria formulação do marco legal PNPDEC.

O consenso construído nesta Câmara entre as contribuições de representantes de diversas áreas e esferas - com alguma predominância da área de gestão de riscos geológicos e de esferas municipais - representou a soma de processos de diversos campos de atuação já experimentados na gestão de riscos geológicos, hidrológicos e tecnológicos, e alguma ênfase na educação para o risco. Representou, também, o interesse em identificar vulnerabilidades e riscos no território metropolitano, justapondo 
contextos a serem mapeados homogeneamente e incorporados em um sistema de informação integrado, com atualização constante. O sentido maior, nas propostas desenvolvidas, foi o de criar cooperação entre localidades para atuar na prevenção e resposta, por meio de instrumentos de informação semelhantes e uniformes.

Entretanto, foi incipiente, nestas mesmas discussões, a abordagem sobre quais funções de sistemas setoriais e de infraestrutura devem ser consideradas e tratadas em contextos específicos por uma política de Gestão de Riscos Metropolitana. Não se desenvolveu, naquela oportunidade, o entendimento de que o fato metropolitano implica uma abordagem qualitativa da escala, e não apenas uma delimitação física, que resulta da justaposição de territórios administrativos ou bacias, ou da soma de uma quantidade maior de riscos no universo metropolitano. O contorno de um limite metropolitano não é suficiente para definir as funcionalidades de um sistema metropolitano integral a ser analisado. Não é suficiente compreender a metrópole apenas como um acumulado de porções territoriais, pois ela resulta da interação entre sistemas funcionais e setoriais diversos, que, por vezes, alteram os próprios limites metropolitanos.

Existem riscos peculiares e próprios da escala metropolitana, e, a depender da escala espacial, a qualidade dos problemas se altera e exige novas respostas. Não foi possível organizar argumentos e subsídios para integrar este aspecto na discussão da Câmara. Na urgência de prazo para consolidação do PDUI, não se desenhou clara distinção entre riscos que devem ser gerenciados na escala local e riscos para os quais é imprescindível a gestão na escala metropolitana, nem se definiu quais seriam eles. Em determinado momento, o desenvolvimento desta pesquisa mostrou-se oportuno para construir estes argumentos com mais rigor, e incorporar reflexões a um processo de formulação de instrumentos de gestão pública ainda em aberto.

Essa constatação fortaleceu o interesse em desenvolver um estudo: que permitisse ilustrar e retratar riscos relacionados a funções dos sistemas setoriais; que não fizesse recorte disciplinar a alguma tipologia de riscos, mas que tratasse do cruzamento das categorias de riscos; que reforçasse a relevância do tratamento dos riscos na escala metropolitana para cenários em que há probabilidade de escalada de riscos frente a ameaças extremas. Assim, nos casos trabalhados buscou-se, principalmente, caracterizar os aspectos em risco relacionados a sistemas de infraestrutura e sistemas setoriais, e distingui-los dos aspectos que podem ser considerados como risco de gestão local, conforme apresentado nas matrizes síntese no capítulo 7.

Dessa forma, a hipótese trabalhada se confirma nestas conclusões, com direcionamentos à gestão metropolitana:

Em contextos urbanos densos e complexos, sob ameaças extremas, a gestão metropolitana deve considerar que riscos cruzados - entre sistemas ou em suas interfaces, e entre processos das escalas local e regional - são prováveis fatores de agravamento dos efeitos das ocorrências. Esses riscos imprimem qualidade diferente ao entendimento e enfrentamento de futuras ameaças na escala metropolitana. A soma dos efeitos de riscos cruzados pode definir categorias de riscos mais altos e potencialmente catastróficos mesmo que, quando analisados individualmente, possam ser considerados de baixo impacto ou residuais do ponto de vista setorial. 


\section{Métodos utilizados, limitações de informações e desdobramentos}

A fim de avaliar se casos de eventos que envolvem grandes dispositivos e funções de sistemas setoriais têm relevância no contexto dos riscos metropolitanos - qual o seu impacto, ou se estão associados a contextos de gravidade - foi desenvolvido estudo quantitativo das ocorrências (capítulos 4 e 5), buscando identificar anos críticos a partir da leitura de amplitude e intensidade dos efeitos, e localidades críticas caracterizadas por efeitos crônicos ou agudos. Posteriormente (capítulo 6), foram avaliados, em termos qualitativos se, em anos e localidades críticas, existiriam contextos de risco envolvendo problemas em grandes dispositivos e funções setoriais, e quais seriam. Três contextos emblemáticos foram detalhados no capítulo 7. O conjunto dos 4 capítulos da parte II busca relacionar 3 diferentes naturezas da informação - quantitativa, análise de notícias (mídia) e entrevistas locais.

O estudo quantitativo das ocorrências na RMSP da última década (capítulo 5) só foi desenvolvido porque o conhecimento sobre desastres é matéria ainda em construção. Caso as informações já estivessem trabalhadas para a abrangência metropolitana, bastaria a referência a um arcabouço constituído, relacionado a fatores do processo urbano por meio de indicadores orientados à gestão urbana.

A experimentação com análises quantitativas indica que ainda há muito trabalho pela frente. Há elementos analisados que merecem desdobramentos e determinados aspectos dos registros de ocorrências que podem ser melhorados ou associados a outras fontes de dados, para que sejam mais efetivos aos fins de preparação e adaptação das estruturas urbanas a cenários de ameaças extremas.

No trabalho com dados de ocorrências realizado para a RMSP, uma lacuna importante foi a desagregação para cidade de São Paulo. As informações do cadastro geral do Instituto Geológico exigiriam inserir nova classificação por sub-prefeitura para melhor adequar as análises e contagem ao cenário metropolitano. Este é um aspecto prático que merece ser desdobrado em agenda de pesquisa subsequente.

Tal necessidade fica evidente, por exemplo, pelo trabalho com indicadores de letalidade, que revela ocorrências mais letais nos municípios menores. Um resultado que pode tanto ser devido à mera expressão da subnotificação e pouca divulgação de eventos que não levam a óbito nesses locais, ou, de fato, devido à maior precariedade no processo de ocupação desses municípios - neste caso, terras que sobram à população mais pobre no processo de produção imobiliária: mais distantes, nas bordas da bacia sedimentar, suscetíveis a processos de inundação ou geológicos, e retiradas do mercado pelas restrições do regramento dos parcelamentos, ou pelo custo que uma ocupação com controle técnico maior exigiria, implicando em ocupações mais vulneráveis a processos perigosos. Na outra face deste mesmo indicador, em municípios maiores, mais consolidados e com maior estrutura dos mecanismos de monitoramento e gestão de ocorrências (como São Paulo), há mais notificação, e é provável que por este motivo o peso das ocorrências com óbitos se mostre diluído.

Apesar do indicador de letalidade e da relativização pela proxy de domicílios suavizarem o peso e gravidade das ocorrências no Município de São Paulo dentro do universo metropolitano, é importante considerar que a incidência de mortes relativamente alta e 
constante na capital pode sugerir que a expansão periférica da cidade seja tão ou mais precária que as de outros municípios da Grande São Paulo, e pode estar em continuidade com processos de expansão periférica. Por isso, o desdobramento das análises desagregado por subprefeituras seria importante, e permitiria compreender processos urbanos associados a ocorrências dentro de ordens de grandeza similares.

Outros desdobramentos sugeridos pelo estudo exigiriam agenda de pesquisa mais estendida, a fim de testar novas correlações e indicadores que relativizassem o peso dos valores absolutos de ocorrências e mortes, e que permitissem associar o estudo das ocorrências a determinados processos de desenvolvimento urbano: como a evolução e concentração das ocorrências se relaciona com a forma de crescimento populacional, com o desenvolvimento da mobilidade, de centralidades, fluxos migratórios intra e extra metropolitanos, fluxos imobiliários, implementação de políticas habitacionais para áreas precárias, condições de habitabilidade, qualidade da infraestrutura, entre tantos outros. E, pelo enfoque das estruturas e sistemas funcionais, se acessíveis os dados sobre sinistros, seria possível investigar: como os contratos de concessão dos serviços tratam os riscos das atividades e a interdependência entre sistemas, e riscos cruzados entre funções urbanas em geral e sistemas - de fornecimento de água, energia elétrica, gás, etc - conflitos no uso de recursos e insumos comuns aos sistemas setoriais, efeitos dos riscos sobre aspectos da atividade econômica do sistema setorial em questão.

O interesse pela identificação de riscos associados a determinadas funções compartilhadas e seus funcionamentos exigiu um enfoque teórico (capítulo 1) menos catastrofista - pelo qual as ameaças seriam inevitáveis e nossas estruturas despreparadas - e mais pragmático, focado em compreender como é a normalidade dos sistemas, seus limiares, como essa normalidade entra em suspensão diante das ameaças, o que entra em falha e o que a falha desencadeia, pontos de vulnerabilidade e interdependências. Os três casos trabalhados qualitativamente (capítulos 6 e 7) ilustram e explicitam riscos nas funções de sistemas setoriais.

\section{III. casos: percepção geral das falhas interconexas no contexto metropolitano}

Os casos revelam certas fragilidades dos sistemas. O caso 1 , sobre as inundações crônicas e críticas na várzea do Tietê, expõe principalmente os limites do arranjo de macrodrenagem existente. O caso 2, que envolve o Reservatório Paiva Castro sobretudo no conflito em Franco da Rocha, expõe os limites da capacidade do sistema de abastecimento para operar simultaneamente o controle de cheias, fator que se torna ainda mais complexo se considerada a alta dependência da RMSP no consumo de água do sistema Cantareira. No caso 3, que relaciona os controles hidráulicos no sistema hídrico oeste da RMSP, interligados pelo canal do Pinheiros, a poluição hídrica se mostra como limitadora da potencial integração entre funções e sistemas - a reversão do Pinheiros poderia ser mais bem aproveitada e útil, simultaneamente, à macrodrenagem, à produção de água e à geração de energia, se as metas de despoluição fossem gradualmente ajustadas e fossem permitidos testes e ensaios de medidas para seu cumprimento. 
Os casos revelam também vulnerabilidades das localidades. Não se tratam de vulnerabilidades exclusivamente locais, mas de vulnerabilidades que interagem com funções sistêmicas, metropolitanas. No caso 1, a ocupação residencial na várzea não apenas submete a população à precariedade sanitária - inundações constantes, impossibilidade legal e dificuldade técnica em implantar redes de abastecimento e coletoras, dificuldade em regularizar a informalidade - como fragiliza os sistemas, principalmente ao sistema de macrodrenagem (no amortecimento da várzea), mas também dos sistemas de esgotamento e abastecimento de água.

No caso 2, em Franco da Rocha, as ocupações da região norte, vulneráveis a processos geológicos e de inundação, têm seus contextos de riscos locais agravados pela dificuldade de mobilidade durante as manobras da represa, além do agravo direto no processo mesmo de inundação. O problema não se resume à vulnerabilidade das ocupações suscetíveis à mancha de inundação da manobra da Represa. O que ocorre é uma interação entre vulnerabilidades. Há que se destacar o papel que a carência de uma estrutura de mobilidade adequada na região desempenha nessa interação. Uma boa estruturação da circulação deveria levar em consideração, no seu desenho, tanto a necessidade programática de conexão, como as condições de suscetibilidade dos territórios que serve, e de sua própria implantação como ampliação de suscetibilidades proporcionadas pelos grandes dispositivos existentes no entorno. No caso de Franco da Rocha, estes são não só a represa de Paiva Castro, mas também, os equipamentos do sistema prisional, que dificultam a comunicação nas emergências, subestações elétricas entre outras possíveis futuras implantações, cujo funcionamento deve ser considerado em planos preventivos. Trata-se de situação que limita o desenvolvimento dos municípios da região, e poderia motivar discussão sobre mecanismos metropolitanos de compensação por serviços infraestruturais prestados.

No caso 3, o aspecto de vulnerabilidade revelado através do dano ambiental fora da delimitação urbana, no município de Salto, esconde outras ordens de conflitos, do tipo local x regional, metropolitanos, implicados na situação. A ampla difusão no território metropolitano de uma combinação de ausência de controle do uso do solo em interação com a ineficiência na cobertura sanitária é exposta por esse caso, na forma de uma sequência de problemas encadeados. A situação crítica de controle da quantidade da água em períodos de cheia, ou seja, as necessárias descargas de águas poluídas operadas pelo reservatório de Pirapora no Médio Tietê, poderiam ser aliviadas pela reversão do Rio Pinheiros. E em operação de cheias o são, acarretando aumento de vazões com alta carga poluidora para os reservatórios metropolitanos de abastecimento de água. A proposta de despoluição das vazões revertidas poderia ser uma medida para viabilizar o uso de uma função estratégica já instalada: tanto do ponto de vista do controle de inundações, como do aumento da disponibilidade de água para abastecimento e para geração de energia. No entanto, um outro aspecto local, ainda, é ponto de conflito. Pois não se trata apenas de controlar a poluição oriunda da reversão das águas do Pinheiros e Tietê, mas de controlar a carga poluidora à Represa Billings decorrente, em grande medida, das ocupações nesta bacia.

A análise dos casos revela, ainda, que as respostas da gestão urbana e comunicação institucional nas localidades estudadas não consideram as especificidades de riscos, e de riscos que decorrem processos regionais naqueles contextos. Esse reconhecimento 
exigiria instrumentos apropriados de gestão de riscos urbanos e, ainda mais complexo, instrumentos de gestão de riscos metropolitanos, pois os contextos envolvem funções de interesse comum, ou relativas a sistemas setoriais.

No caso 1, soluções habitacionais e ambientais concorrentes enfrentam problemas entre as esferas de implementação distintas: a municipal e a estadual. A esfera estadual propôs arranjo institucional e de financiamento mais próximo de uma solução de gestão de risco metropolitano. No entanto, delegou boa parte de um elemento essencial ao projeto - o reassentamento - ao município, sem estabelecer um acordo que despertasse interesse positivo do município em priorizar ações naquela área ou o compromisso permanente. O município ofereceu uma solução habitacional nessa área indistinta em relação às que foram propostas nas demais áreas que compõem o déficit habitacional da cidade. O que agrava o conflito é que as duas esferas falham na comunicação: tanto na comunicação institucional como, principalmente, na transparência do processo com os moradores.

No caso 2, apesar de todos os protocolos operacionais estabelecidos e dos planos de contingência desenvolvidos recentemente, a comunicação também é um ponto falho. Além da falha objetiva na situação de resposta, há falha na comunicação entre município e população em risco, e entre município e agente responsável pelo dispositivo de infraestrutura, sobretudo nas etapas de prevenção. As informações sobre operação das estruturas da Sabesp e possíveis agravos aos riscos já instalados no município não são compreendidas como restrições a serem transferidas aos planos diretores, incorporadas na reorganização de funções chave da cidade, nem como condições para um trabalho permanente de comunicação de risco com a população. Apesar da bem estruturada equipe da Defesa Civil local em Franco da Rocha, e do trabalho continuado em setores de risco geológico reconhecidos, as consequências das manobras da represa são efeitos que somente a partir de 2010 começaram a ser debatidos tecnicamente pela Sabesp em diálogo com os municípios, e em 2016 ainda não estavam nas rotinas municipais de preparação das populações em risco.

No caso 3, para se construir uma solução integrada que melhore a segurança nas interdependências entre sistemas, que permita superar falhas e lacunas e trabalhar positivamente as interfaces entre sistemas, falta um melhor trabalho de comunicação institucional entre agentes usuários de recursos hídricos e instâncias reguladoras. A melhor comunicação entre agentes operadores e controladores permitiria uma arbitragem mais bem informada dos interesses em jogo, apoiada por uma sociedade civil igualmente informada dos processos em questão.

Falar em gestão urbana - e da gestão de riscos como um elemento da gestão urbana sem levar em conta os recursos para implementação de propostas significa repetir procedimentos existentes: de medidas à posteriori, apoiadas em reservas orçamentárias anuais, em que a própria população afetada arca com parte dos prejuízos dos eventos, e os entes responsáveis pelo planejamento não se apropriam dos reais custos envolvidos nas situações de anormalidade. Por isso, o desenvolvimento de informações e dados sobre efeitos das ocorrências é tão necessário a uma agenda de gestão de riscos. 
O que o desenvolvimento dos casos revela é, sobretudo, a ausência de mecanismos e políticas de proteção financeira específicos para lidar com riscos urbanos. Os estudos sugerem, por outro lado, que as implicações regionais poderiam orientar algumas saídas de arranjos financeiros, uma percepção inovadora mesmo ao contexto do Marco de Sendai.

No caso 1, do Jardim Pantanal, recursos emergenciais de bolsa aluguel às famílias não foram suficientes para impedir reocupações vulneráveis e novas exposições ao risco. Isso evidencia a importância em dar tratamento institucional específico aos contextos de risco, principalmente com relação ao financiamento das soluções, no intuito de garantir estabilidade e continuidade às ações. Sobretudo quando os riscos interferem nas funções metropolitanas - que tendem a potencializar impactos negativos - a estabilidade e continuidade do investimento para soluções é importante, pois envolve decisões de planejamento de estruturas articuladas ao tratamento de amplas demandas por serviços, e em mais longo prazo.

A alternativa de empréstimo internacional (com financiamento específico), tal como resolvido no Programa Parque Várzeas do Tietê, se mostra uma saída apropriada, assim como a articulação entre diferentes âmbitos da administração pública. Mas encontrou obstáculos porque os ganhos de cada agente no equacionamento do problema não estavam bem balanceados. No arranjo proposto, o investimento do Governo do Estado seria recompensado pela flexibilidade e segurança aos seus sistemas de macrodrenagem, mas o investimento da prefeitura de São Paulo não estava ancorado em retornos de mesma ordem. No desenho da cooperação institucional, faltou o compromisso para que o município se engajasse na proposta e estabelecesse prioridade independentemente da afinidade política das gestões.

Ainda no caso 1, o cenário de grande ocupação submetida a inundações crônicas, com população que resiste à mudança e que consolida cada vez mais sua permanência na área, sugere um contexto possível para desenvolver pilotos de microsseguros e elaborar desenhos de cruzamento que garantam a diluição desses riscos, com reinvestimento orientados a ampliar a resiliência urbana. Por exemplo, cruzando a aposta da perda com alguns ganhos: de uma eventual renovação urbana, de maior segurança às infraestruturas, ou entre casos similares de diversas áreas em diferentes regiões metropolitanas - este último implicaria em articular um plano nacional de diluição de riscos, e desenvolver as discussões sobre o tema da diluição de riscos no país, com possíveis emissões de CAT-bonds. Iniciativas privadas que já existem na área, de financiamentos populares para reforma de edificações de baixa renda, poderiam lidar diretamente com a melhoria de aspectos da resiliência das edificações, e vincular essa intervenção e seus produtos financeiros a produtos de microsseguros.

Nos outros dois casos, a questão da proteção financeira implica principalmente desenvolver propostas de balanceamento da participação dos atores na governança dos riscos, considerando interesses econômicos de concessionárias e dos municípios.

Quanto maior o desenvolvimento de políticas de proteção financeira, melhor deve ser a sistematização de informações sobre riscos, danos, ocorrências e sinistros. Os casos confirmam que os impactos causados por desastres recorrentes, e mesmo nas situações de agravos e encadeamentos, são perdas cumulativas subestimadas e 
mesmo não avaliadas pelas gestões. Sobretudo quando difusos nos usos residenciais, há muito recurso em recuperação investido pela população afetada que não é contabilizado. Faltam procedimentos de avaliação de danos em geral, sobretudos de danos ocorridos em situações menos graves. Conforme descrito nos capítulos 2 e 3 , procedimentos dos processos para liberar acesso a fundos pós desastre no Brasil, que prejudicam a homogeinização das informações, pois limitam casos contabilizados aos disponibilizados no sistema nacional integrado. Daí a importância em desenvolver estudos que contribuam na melhoria do conhecimento e desenvolvimento de informações sobre ocorrências de desastres, que avaliem lacunas na disponibilização de dados e entraves a seu potencial analítico.

\section{Uma agenda de gestão de riscos metropolitana que considere processos da natureza segunda}

Dada a magnitude das consequências que as falhas em funções de sistemas regionais podem proporcionar, preparar cidades para enfrentar contextos de ameaças cada vez mais extremas exige abordar funções regionais, interdependências estabelecidas entre diferentes funções setoriais, e o agravo que seu mau funcionamento pode desencadear aos processos de risco já instalados localmente. É imperativo que as discussões sobre riscos cruzados sejam incorporadas à pauta dos sistemas regionais, e que os sistemas regionais sejam incorporados às discussões sobre gestão de riscos.

A vulnerabilidade urbana não é um fator a ser analisado apenas do ponto de vista do uso e da ocupação do solo, com predominância das funções residenciais. Existem fragilidades dos sistemas urbanos de infraestrutura, sobretudo da articulação entre eles, que precisam ser incorporadas às análises de vulnerabilidades e de riscos urbanos. Existem riscos inerentes a essas atividades, seu resíduo deve ser incorporado às análises como um elemento da suscetibilidade de um local. A gestão de riscos que opera em escala local, ou agrupamentos de bacias menores, deve compreender as escalas regionais que atravessam tal porção do território. Mas, além disso, deve haver um nível de decisão que compreenda a integração, e não a mera soma, de territórios.

As conclusões deste trabalho - que reconhece a duplicidade da natureza urbana frente aos riscos como vulnerável e como geradora de risco simultaneamente - apontam para elementos de uma agenda de pesquisa urbana como campo que pode conferir visão integradora e de coordenação ao tema da gestão de riscos:

- desenvolver estudos que facilitem aos processos de planejamento urbano inserir em suas premissas: instrumentos, métodos, princípios dos 3 momentos e das 5 fases de controles dos riscos (prevenção, planejamento da preparação, mitigação e resposta); investigações interdisciplinares e identificações de risco amplas; atualização de parâmetros de segurança já estabelecidos frente a cenários de mudanças climáticas;

- desenvolver estudos sobre contextos geradores de risco urbano, por meio da compreensão de processos que produzem vulnerabilidades e exacerbam riscos em cenários tendenciais e dinâmicos, considerando componentes técnicas, sócio- econômicas e institucionais relacionadas à produção do espaço urbano; 
- multiplicar estudos sobre a coordenação de interfaces complexas e aspectos transdisciplinares dos funcionamentos e fluxos do e no espaço urbano, e os riscos associados, pela identificação permanente de interfaces não trabalhadas entre sistemas;

As conclusões apontam, também, para uma agenda de gestão urbana que inclua determinados elementos relacionados à gestão de riscos, como:

- integrar e identificar instrumentos de gestão urbana que possam incorporar medidas de gestão de riscos, e elementos de gestão de riscos que possam ser articulados com instrumentos de gestão urbana, ou gerar novos;

- desenvolver sistemática e rede que permita disponibilizar informações variadas sobre sinistros, ocorrências, emergências, reconstrução, danos e investimentos empregados, de forma a alimentar decisões de planejamento e prevenção;

- desenvolver programas para comunicação de risco de nível institucional, entre agentes, de forma a promover a percepção de risco amplamente e fomentar a disponibilidade para implementar redes de ação e informação para gestão de riscos, conforme proposta mencionada acima;

- no âmbito de uma política metropolitana de gestão de riscos, a articulação de instrumentos de planejamento urbano com foco no controle dos riscos deveria considerar além da somatória de demarcação e identificação de zonas vulneráveis a processos que merecem desenvolvimentos específicos nos planos diretores de cada município. Deveriam apontar os contextos específicos que afetam e/ou são afetados por sistemas setoriais, implicando riscos de ordem funcional e operacional nesses sistemas, o que interfere no planejamento e desenvolvimento de longo prazo;

- no âmbito nacional, a regulamentação da PNPDEC deveria buscar melhor articulação dos propósitos de gestão de risco com o arcabouço institucional da gestão de recursos hídricos e o sistema de gestão e instrumentos já existentes: comitês de bacia, planos de recursos hídricos (dos quais derivam planos de outros aproveitamentos, como planos de saneamento, regionais e municipais), planos de macrodrenagem, metas de enquadramento, bem como incorporar os riscos tecnológicos;

- para além da gestão de riscos no nível local, e o planejamento para distribuição de recursos nos níveis nacional e estadual sugeridos na política nacional PNPDEC, deve haver um nível de decisão que compreenda a integração de funções e o diálogo de especificidades entre aspectos regionais e locais. Isso difere da mera soma de territórios ou quantificação de ocorrências para planejamento de financiamentos regulares que em geral são reservados para serem acionados posterior aos eventos. Para isso, se faz necessária uma política ampla e efetiva de comunicação de riscos, localmente, com populações afetadas, e, sobretudo, entre agentes regionais.

- desenvolver programas de proteção financeira a desastres, de forma a melhorar o direcionamento e eficiência na destinação de recursos para mitigação dos riscos ou adaptação das estruturas urbanas. 


\section{REFERÊNCIAS BIBLIOGRÁFICAS}

ABNT-ISO (2009). ABNT-ISO 31000: 2009. Gestão de Riscos: Princípios e Diretrizes.

ACSELRAD, H. (2002). "Justiça ambiental e construção social do risco". Desenvolvimento e Meio Ambiente, n. 5, jan/jun.

ANGOTTI. T. (2013). "Who Benefits, Who Pays and Where is the Long Term Planning?" In: Progressive Planning, Nova lorque, n. 194. New York, Winter.

BANCO MUNDIAL (2012a). Cidades e Inundações: um guia para a Gestão Integrada do Risco de inundação Urbana para o século XXI. Um resumo para formuladores de políticas.

Washington DC, 2012. Disponível em:

https://www.understandrisk.org/page/publica\%C3\%A7\%C3\%B5es

BANCO MUNDIAL (2012b). O Relatório Sendai: gerenciando riscos de desastres para um futuro resiliente. GFDRR, Washington DC, 2012. Disponível em:

https://www.understandrisk.org/page/publica\%C3\%A7\%C3\%B5es

BANCO MUNDIAL (2012c). Lidando com perdas: opções de proteção financeira contra desastres no Brasil. GFDRR, Washington DC 2012. Disponível em: https://www.understandrisk.org/page/publica\%C3\%A7\%C3\%B5es

BANCO MUNDIAL; Governo do Estado de Santa Catarina (2012). Avaliação de perdas e Danos: Inundações bruscas em Santa Catarina - novembro de 2008. Brasilia, 2012. Disponível em: https://www.understandrisk.org/page/publica\%C3\%A7\%C3\%B5es

BANCO MUNDIAL; Governo do de Alagoas (2012). Avaliação de perdas e Danos: Inundações bruscas em alagoas - junho de 2010. Brasilia, 2012. Disponível em:

https://www.understandrisk.org/page/publica\%C3\%A7\%C3\%B5es

BANCO MUNDIAL; Governo do Estado de Pernambuco (2012). Avaliação de perdas e Danos: Inundações bruscas em Pernambuco - junho de 2010. Brasilia, 2012. Disponível em: https://www.understandrisk.org/page/publica\%C3\%A7\%C3\%B5es

BANCO MUNDIAL; Governo do Estado do Rio de Janeiro (2012). Avaliação de perdas e Danos: Inundações e deslizamentos na Região Serrana do Rio de Janeiro - janeiro de 2011. Brasilia, 2012. Disponível em: https://www.understandrisk.org/page/publica\%C3\%A7\%C3\%B5es

BECK, U. (2011). Sociedade de Risco: rumo a uma outra modernidade. Editora 34, São Paulo.

BERTAZZO et ali. (2013). Revisão da literatura acadêmica brasileira sobre a gestão de operações em desastres naturais com ênfase em logística humanitária. In: Revista TRANSPORTES v. 21, n. 3 (2013) p. 31-39.

BITAR, O. (2015). Guia Cartas Geotécnicas: orientações básicas aos municípios. Omar Yazbek Bitar, Carlos Geraldo Luz de Freitas, Eduardo Soares de Macedo. São Paulo: IPT Instituto de Pesquisas Tecnológicas do Estado de São Paulo.

BRASIL (2012). Classificação e Codificação Brasileira de Desastres. Ministério da Integração. Disponível em: http://www.integracao.gov.br/documents/3958478/0/Anexo+V++Cobrade com+simbologia.pdf/d7d8bb0b-07f3-4572-a6ca-738daa95feb0

BRASIL - MMA (2007). Plano Nacional de Prevenção, Preparação e Resposta Rápida a Emergências Ambientais com Produtos Químicos Perigosos - P2R2. Brasília, 2007.

BRITO, S. (1943). Obras Completas de Saturnino de Brito. Vol. 3. Rio de Janeiro: Imprensa Nacional. 
BROLLO, M. J.; TOMINAGA, L. K. (2012). Desastres naturais e riscos geológicos no Estado de São Paulo: cenário de referência - 2012. Boletim no 1 - Grupo de Articulação de Ações Executivas (GAAE) / Organizadores: Maria José Brollo, Lídia Keiko Tominaga - $1^{\text {a }}$ ed. - São Paulo: Coordenadoria Estadual de Defesa Civil.

CABALLERO, C. (2005). Organização Político-Institucional frente aos riscos da modernidade: o caso brasileiro. Dissertação de mestrado Programa de Pós Graduação das Ciências da Engenharia Ambiental. Escola de Engenharia de São Paulo. EESC, Centro de Recursos Hídricos e Ecologia Aplicada, CRHEA. Universidade de São Paulo. São Carlos.

CARVALHO, C. (1996). Gerenciamento de riscos geotécnicos em encostas urbanas uma proposta baseada na análise de decisão. Tese de doutorado apresentada à Escola Politécnica - USP. São Paulo.

CASTRO, A. (2003ª). Manual de Desastres. Ministério da Integração Nacional e Secretaria Nacional de Defesa Civil. Brasília.

CASTRO, A. (2003b). Glossário de Defesa Civil, Estudos de Riscos e Medicina de Desastres. Ministério da Integração Nacional e Secretaria Nacional de Defesa Civil. Brasília.

CCH (2015). Plano de Contingência para o abastecimento de água da RMSP. Comitê Crise Hídrica - CCH, 19/11/2015.

CEDEC-SP. S/ data. Plano Preventivo da Defesa Civil. Apostila.

CEPED-UFSC (2012). Atlas Brasileiro de desastres naturais 1991-2010. Volume Brasil. Florianópolis. Disponível: http://150.162.127.14:8080/atlas/Brasil\%20Rev.pdf

CEPED-UFSC (2016). Relatório de Danos Materiais e Prejuízos decorrentes de desastres naturais no Brasil 1995-2014. CEPED-UFSC, World Bank, GFDRR, Florianópolis.

CLARKE, D. (2014). "Worth your money? What risk models and economic models tell us about the development impact of insurance and financial protection". In: Understanding Risk, 2014: producing actionable information - proceedings from the 2014 UR Forum.

COSTA, J.; NUCCI, N. e SILVA, R.T, (2012). "Recursos hídricos, saneamento e gestão metropolitana: os novos desafios". Revista Engenharia, n. 609.

CPRM (2014). Cartas de suscetibilidade a movimentos gravitacionais de massa e inundações 1:25.000. Nota Técnica Explicativa. IPT-CPRM.

DAEE-FCTH (2014). Relatório de evento de chuva de 26/11/2014 12:40(GMT) até 27/11/2014 11:40. São Paulo, documento arquivo digital.

DI GIULIO, G. M. (2012). Risco, ambiente e saúde: um debate sobre comunicação e governança de risco em áreas contaminadas. São Paulo: Anablume.

DI GIULIO et al. (2015). "Percepção de risco: um campo de interesse para a interface ambiente, Saúde e Sustentabilidade”. Saúde e Sociedade (USP. Impresso), 2015 - no prelo.

DOUGLAS, M. WIDALVSKY, A. (1982). Risk and Culture: an Essay on the Selection of Technological and Environmental Dangers. Berkeley: University of California Press.

DOUGLAS, M.; THOMPSON, M.; VERVEIJ, M. (2003) Is Time running out? The case of global Warming. Daedalus, 132 (2):98-107.

DUTRA, A.; DALCIN, K. E FERNANDES, L. (2018). "Preparação de comunidades para emergências locais: o Programa APELL e a experiência de Caraguatatuba". In: Revista O Social em questão - Ano XXI n. 40 - jan/abr/ 2018. 
EMAE (2010). Melhora da Confiabilidade da Alimentação Elétrica das Estruturas para Controle de Cheias da RMSP. Empresa Metropolitana de Água e energia. Documento técnico.

EMPLASA (2018). Plano de Desenvolvimento Urbano Integrado da Região Metropolitana de São Paulo - Caderno de Propostas. Disponível em: https://www.pdui.sp.gov.br/rmsp/?p=5039

FCTH (2010). Avaliação do Sistema Pinheiros-Billings com o protótipo de flotação. Relatório Final, Volume 1. Arquivo digital.

FCTH (2014). Parecer Técnico sobre a Mortandade de Peixes. Arquivo digital.

FEMA (1986). A unified national program for flooplain management. Federal Emergency Management Agency. FEMA 100/march 1986.

FRANCO DA ROCHA - município (2017a). Ofício n. 23/2017. Documento impresso.

FRANCO DA ROCHA - município (2017b). Relatório de danos e prejuízos do evento de 2016. Documento impresso.

GRAHAM, S. Disrupted Cities: infrastructure disruptions as the Achilles Heel of urbanizes societies. In: Disaster, infrastructure and society: Learning from the 2011 Earthquake in Japan n. 3 12/2011, p. 12- 26. Disponível em: http://hdl.handle.net/10086/25363

GUIDDENS, A. (1999). "Risk and responsibility". The Modern Law Review Limited, 1999. (MLR 62:1, January).

GUIVANT, J. S. "A trajetória das análises de risco: da periferia ao centro da teoria social". Revista Brasileira de Informações Bibliográficas, Anpocs, 46:3-38.

GUIVANT, J. S. (2004) "A governança dos riscos e os desafios para a redefinição da arena pública do Brasil”. In: Ciência, Tecnologia+Sociedade. Novos modelos de governança. Brasília, 06 a 11 de dezembro, 2004. World Wide Web Adress:

http://www.nisra,ufsc, br/pdf/A\%20governa\%5B1\%D...pdf

HANNIGAN, J. A. (1995). Environmental sociology - a social constructive perscpective. Routledge, London.

HANSCOM, G. (2014). Flood Pressure: Climate disasters drown FEMA's insurance plans. 13/01/2014. Disponível em: <http://grist.org/cities/flood-pressure-how-climate-disasters-putfemas-flood-insurance-program-underwater/>

HOLTZ, A. C. (2015). Programa Parque Várzeas do Tietê - Relatório de Avaliação Intermediária - Produto 3/ RAI PVT. 18 de maio de 2015.

IBAMA (2002). GEOBRASIL - Perspectivas do Meio Ambiente no Brasil. Brasília-DF: Edições IBAMA - Instituto Brasileiro do Meio Ambiente e dos Recursos Naturais Renováveis. Disponível em: http://www.ibama.gov.br/sophia/cnia/site cnia/geo brasil 2002.pdf

IBGE (2014). Perfil dos Municípios Brasileiros 2013. Pesquisa de Informações Básicas Municipais. Rio de Janeiro.

IBGE (2018). Populações em áreas de risco no Brasil. IBGE e CEMADEN. Rio de Janeiro, 2018.

BROLLO, M. e FERREIRA, C. (2016). Gestão de Riscos de Desastres devido a fenômenos geodinâmicos no Estado de São Paulo: cenário 2000-2015. Boletim do Instituto Geológico no 67/ Maria José Brollo, Cláudio José Ferreira - São Paulo : IG-SMA, 72p. 
IG-SMA (2016). Acidentes ocorridos entre 10 e 11 de março na Região Metropolitana de São Paulo. Informe Técnico 04/2016, Boletim GAEE. Eduardo Andrade e Lídia Keiko Tominaga (IGSMA).

JERONIMO, H. M. (2014) "Riscophrenia and 'animal spirits': clarifying the notions of risk and uncertainty in environmental problems". Sci. stud, vol 12, n.spe.

KEUCHEYAN, R. (2014). "Quando as finanças se conectam com a natureza". Le Monde Dipplomatique Brasil, março 2014, p.34-6.

LEFEBVRE, Henri (2000). La production de l'espace. Paris: Anthropos.

LEWIS, M. (2007). "In Nature's Casino". The New York Times, Agosto 26, 2007. Disponível em: http://www.nytimes.com/2007/08/26/magazine/26neworleans-t.html?pagewanted=all

LITTLE, R.G. (2010). "Managing the risk of cascading failure in complex urban ifrastructure". In: GRAHAM, S. (ed.) Disrupted Cities: when infrastructure fails. New York: Routledge, e-book location: $979-1334$.

MACEDO, L. e BRESSANI, L. (2013). Diretrizes para o zoneamento da suscetibilidade, perigo e risco de deslizamentos para planejamento do uso do solo. São Paulo, ABGE/ABMS.

MARCONDES, C. C. R. (2003). Defesa Civil: Orientação e legalizações nas emergências, mapa de ameaças múltiplas, preparação para os desastres e responsabilidade dos agentes. São Paulo: Imprensa Oficial, 120p.

MARCUSE, P. (2013). Sandy, Housing, the Market and the State's Planning Response. Artigo eletrônico disponível em: http://pmarcuse.wordpress.com/2013/03/06/blog-28-sandy-housingthe-market-and-the-states-planning-response-2/. Em 15/08/2013.

MARSH (2017). Apostila do curso Programa de Seguros e Garantias para Infraestrutura. MARSH e EduCorp Abdib, São Paulo, 2017. Arquivo digital.

MOMM, S; TRAVASSOS, L.; GRISA, G e FALCÃO, K. "Análises comparativas em planejamento e governança em um cenário de mudanças climáticas". In: Anais do XVII ENANPUR.

MPSP (2016). Parecer técnico IC n. 1410900000024/16 MPSP e CAEx - Franco da Rocha. Documento impresso.

MUIR-WOOD, R. (2014). "Models make markets: how catastrophe risk models facilitate new systems of risk transfer, risk pooling and risk reduction". In: Understanding Risk, 2014: producing actionable information - proceedings from the 2014 UR Forum.

MUNICH-RE (2017). "Natural catastrophes 2016: Analyses, assessments, positions - 2017 issue". In: TopicsGeo Magazine. Munique, março de 2017.

NATIONAL RESEARCH COUNCIL (2015). Affordability of National Flood Insurance Program Premiums: Report 1. National Research Council of the National Academies. National Academy Press, Washington DC.

NOGUEIRA, F. e CANIL, K. (2017). "Cartas Geotécnicas de Aptidão à Urbanização: instrumento de planejamento para prevenção de desastres e para gestão do uso do solo". In: Anais do XVII ENANPUR.

PNUMA. Programa das Nações Unidas para o Meio Ambiente. (1988). APELL: A Process for Responding to Technological Accidents. Disponível em:

<http://apell.eecentre.org/Modules/GroupDetails/UploadFile/APELL Handbook 2016 -

Publication.pdf>. Acesso em: 09 out. 2017 
RIBEIRO, M. (2007). Gestão de Riscos Operacionais - GRO para um Sistema de Abastecimento de Água: ênfase no risco de escorregamentos no processo de distribuição. Dissertação de Mestrado apresentada ao Instituto de Pesquisas Tecnológicas do Estado de São Paulo - IPT. Orientador: Dr. Eduardo Soares de Macedo. São Paulo.

SABESP - PMSP (2010). Contrato de Prestação de Serviços Públicos de abastecimento de água e Esgotamento Sanitário. Contrato Firmado entre Companhia de Saneamento Sabesp e Município de São Paulo.

SABESP e HIDRO (2009). Estudo de cheias para avaliação dos volumes de espera dos aproveitamentos do sistema Cantareira. Relatório Final, outubro de 2009 - v.2.

SABESP (2015). CHESS Crise Hídrica, Estratégia e Soluções da Sabesp para a Região Metropolitana de São Paulo. 30/04/2015. Disponível em:

http://site.sabesp.com.br/site/uploads/file/crisehidrica/chess crise hidrica.pdf

SABESP (2016a). Gestão de Riscos Corporativos. Documento, 12 de maio de 2016.

Disponível

em:http://www.sabesp.com.br/Calandraweb/CalandraRedirect/?temp=0\&proj=investidoresnovo \&pub=T\&db=

SABESP, DAEE, CEDEC (2016b). Plano de Ação Emergencial Para Inundações na Região de Franco da Rocha. Governo do Estado de São Paulo, Casa Militar, Coordenadoria Estadual da Defesa Civil, Setembro de 2016.

SABESP (2016c). Plano de Contingência da Sabesp para Cheias da Represa Paiva Castro. Setembro, 2016.

SABESP (2018d). 22a Emissão de Debêntures Simples. Documento, 8 de fevereiro de 2018. Disponível em:

http://www.sabesp.com.br/Calandraweb/CalandraRedirect/?temp=0\&proj=investidoresnovo\&pu $\underline{b=T \& d b}=$

SÃo PAULO - Município (2010). Plano Municipal de Saneamento do Município de São Paulo.

SÃo PAULO - Município (2012). Plano Municipal de Gestão do Sistema de Águas Pluviais de São Paulo: detalhamento das ações de desenvolvimento institucional - Relatório Final RF4. FCTH, julho de 2012.

SÃO PAULO - Estado (2010). Termos de referência para elaboração do terceiro plano diretor de macrodrenagem da bacia do Alto Tietê. São Paulo: Secretaria de Saneamento e Energia.

SÃO PAULO - Estado (2014). Plano Diretor de Macrodrenagem da Bacia Hidrográfica do Alto Tietê - PDMAT 3. Engecorps/Cobrape. Volumes consultados: R8, R10, R11.

SÃO PAULO - Estado (2018). Leptospirose - Casos confirmados por região e ano no Estado de São Paulo 2009-2018. CVE/SP Secretaria Estadual de Saúde. Disponível em: http://www.saude.sp.gov.br/resources/cve-centro-de-vigilancia-epidemiologica/areas-devigilancia/doencas-de-transmissao-por-vetores-e-zoonoses/dados/lepto/lepto0918 regiao.pdf

SEHAB-PMSP (2018). HabitaSAMPA - Relação de Munícipes no Auxílio Aluguel - benefícios de bolsa aluguel vigentes em 2018. Documento. Acessível em:

http://www.habitasampa.inf.br/atendimento/

SHIMBO \& CABALLERO (1989). "Análise de variáveis na segurança contra incêndios e pânico". São Paulo: Geociência de Riscos ITSEMAP, ano IV, n. 15, 1989.

SIEBERT, C. (2017). "Mudanças Climáticas e Desastres Naturais em Santa Catarina: Impactos Socioterritoriais e Avaliação das Políticas Públicas". In: Anais do XVII ENANPUR. 
SILVA (2011). "Integration of Hydraulic infrastructure in metropolitan São Paulo". In: Geographica Helvetica. Heft 2, 2011, 66 Jahrgang. ASG-GEGZ, Zürich.

SIMS, B. (2010). "Disoriented Cities: infrastructure, social order and the Police response to Hurricane Katrina". In: GRAHAM, S. (ed.) Disrupted Cities: when infrastructure fails. New York: Routledge, e-book location: 979-1334.

SPINK, M. J. (2014). "Viver em áreas de risco: tensões entre gestão de desastres ambientais e os sentidos de risco no cotidiano". Ciência \& Saúde Coletiva, 19(9):3743-3754.

SSRH, DAEE (2016). Relatório Semestral de Acompanhamento do Programa Várzeas do Tietê/ PVT-RS 08 - Julho a dezembro de 2015. Secretaria de Saneamento e Recursos Hídricos, Departamento de Águas e energia, UGP Várzeas, fevereiro de 2016.

SUGUIO (2010). Geologia do quaternário e mudanças ambientais. São Paulo: Oficina de Textos.

SULAIMAN, S. (2014). De que adianta? O papel da educação para a prevenção de desastres naturais. Tese da Faculdade de Educação da Universidade de São Paulo. Pedro Jacobi, orientador. São Paulo.

SWISS-RE (2012). Revista Sigma n. 2/2012.

THE CITY OF NEW YORK (2007). PLANYC 2030: A Greener, Greater New York. NYC Mayor's Office Recovery \& Resiliency. New York City. Disponível em:

http://www.nyc.gov/html/planyc2030/html/publications/publications.shtml

THE CITY OF NEW YORK (2011). PlaNYC 2030: A Greener, Greater New York - Full Report Update - April 2011. New York City. Disponível em:

http://www.nyc.gov/html/planyc2030/html/publications/publications.shtml

TOMINAGA, L.; SANTORO, J. e AMARAL, R. (2015). Desastres naturais: conhecer para prevenir. São Paulo: Instituto Geológico.

UNISDR (2009). UNISDR Terminology on Disaster Risk Reduction. United Nations International Strategy for Disaster Reduction. Disponível em: www.unisdr.org/publications e www.preventionweb.net

UNISRD (2004). Terminology: Basic terms of disaster risk reduction. United Nations International Strategy for Disaster Reduction. Disponível em: https://www.unisdr.org/files/7817 7819isdrterminology11.pdf

UNISRD (2005). Hyogo Framework for Action 2005-2015: building the resilience of nationa and communities to Disasters. United Nations International Strategy for Disaster Reduction. Disponível em: https://www.unisdr.org/2005/wcdr/intergover/official-doc/L-docs/Hyogoframework-for-action-english.pdf

UNISDR (2015). Marco de Sendai para redução de riscos de desastres 2015-2030. United Nations International Strategy for Disaster Reduction. Disponível em:

http://www1.udesc.br/arquivos/id submenu/1398/traduzido unisdr novo sendai framework for disaster risk reduction 20152030 portugues versao 31mai2015.pdf

US GAO (2002). Catastrophe insurance risks: the role of risk-linked securities and factors affecting their use. Report to the Chairman, Committee on Financial Services, House of Representatives. GAO-02-941, United States General Accounting Office. Washington D. C, Setembro de 2002.

VALENCIO, N. (org.) (2010). Sociologia dos Desastres: Construção, Interfaces e Perspectivas no Brasil. Vol. I e II. São Carlos: Rima Editora. 
VALÊNCIO, N. (2009). "O Sistema Nacional de Defesa Civil (Sindec) diante das mudanças climáticas: desafios e limitações da estrutura e dinâmica institucional”. In: Sociologia dos desastres. M. Siena, V. Marchezini e J. Gonçalves (orgs). São Carlos, Rima Editora, pp. 03-18.

VALÊNCIO et al (2003). "Gestão de Desastres no Brasil: considerações sociais acerca das políticas de emergência ante os perigos hidrometeorológicos". In: Uso e Gestão de Recursos Hídricos no Brasil, Martins \& Valêncio (orgs). São Carlos: Rima editora, pp 223-238.

WILKINSON, E. (2014). "Changing the paradigm: reducing losses and exploiting opportunities". In: Understanding Risk, 2014: producing actionable information - proceedings from the 2014 UR Forum.

ZOLNERKEVIC, I. (2017). "O comportamento dos apagões: modelos matemáticos ajudam a entender como sucessão de falhas causam blecautes em redes elétricas". In: Revista Pesquisa Fapesp, n. 254, Abril de 2017.

\section{LEGISLACÃO CONSULTADA:}

BRASIL (1942). Decreto Lei n. 4.098 de 13 de maio de1942. Define, como encargos necessários à defesa da Pátria, os serviços de defesa passiva anti-aérea.

BRASIL (1967). Decreto Lei n.200 de 25 de fevereiro de 1967. Dispõe sôbre a organização da Administração Federal, estabelece diretrizes para a Reforma Administrativa e dá outras providências.

BRASIL (1969). Decreto Lei n.950 de 13 de outubro de 1969. Institui no Ministério do Interior o Fundo Especial para Calamidades Públicas (FUNCAP) e dá outras providências.

BRASIL (1970). Decreto n.66.204 de 13 de fevereiro de1970. Regulamenta o Fundo Especial para Calamidade Públicas - FUNCAP - e dá outras providências.

BRASIL (1979). Decreto n.83.839 de 13 de agosto de 1979. Dispõe sobre a estrutura básica do Ministério do Interior e dá outras providências.

BRASIL (1988). Decreto n. 97.274 de 16 de dezembro de 1988. Dispõe sobre a organização do Sistema Nacional da Defesa Civil - SINDEC e dá outras providências.

BRASIL (1994). Decreto n.1.080 de 8 de março de 1994. Regulamenta o Fundo Especial para Calamidades Públicas (Funcap) e dá outras providências.

BRASIL (1995). Medida Provisória n. 913 de 24 de fevereiro de 1995. Cria, na estrutura organizacional do Ministério da Justiça, o Conselho Federal de que trata o artigo 13 da Lei ${ }^{\circ}$ 7.347, de 24 de julho de 1985, altera os artigos 4ํㅜ $39,82,91$ e 98 da Lei $n^{\circ} 8.078$, de 11 de setembro de 1990, e dá outras providências.

BRASIL (1998). Lei n.9.649 de 27 de maio de 1998. Dispõe sobre a organização da Presidência da República e dos Ministérios, e dá outras providências.

BRASIL (1999). Medida Provisória n.1911-8 de 29 de julho de1999. Altera dispositivos da Lei no 9.649, de 27 de maio de 1998, que dispõe sobre a organização da Presidência da República e dos Ministérios, e dá outras providências.

BRASIL (2001). Lei n.10.257 de 10 de julho de 2001. Regulamenta os arts. 182 e 183 da Constituição Federal, estabelece diretrizes gerais da política urbana e dá outras providências.

BRASIL - CONAMA (2005). Resolução Conama n. 357 de 17 de março de 2005. Dispõe sobre a classificação dos corpos de água e diretrizes ambientais para o seu enquadramento, bem como estabelece as condições e padrões de lançamento de efluentes, e dá outras providências. 
BRASIL (2007). Lei 11.455 de 05 de janeiro de 2007. Estabelece as diretrizes nacionais para o saneamento básico e para a política federal de saneamento básico.

BRASIL (2009). Lei n.11977 de 7 de julho de 2009. Dispõe sobre o Programa Minha Casa, Minha Vida - PMCMV e a regularização fundiária de assentamentos localizados em áreas urbanas; altera o Decreto-Lei no 3.365, de 21 de junho de 1941, as Leis nos 4.380, de 21 de agosto de 1964, 6.015, de 31 de dezembro de 1973, 8.036, de 11 de maio de 1990, e 10.257, de 10 de julho de 2001, e a Medida Provisória no 2.197-43, de 24 de agosto de 2001; e dá outras providências.

BRASIL (2010). Decreto n.7.257 de 4 de agosto de 2010. Regulamenta a Medida Provisória no 494 de 2 de julho de 2010, para dispor sobre o Sistema Nacional de Defesa Civil - SINDEC, sobre o reconhecimento de situação de emergência e estado de calamidade pública, sobre as transferências de recursos para ações de socorro, assistência às vítimas, restabelecimento de serviços essenciais e reconstrução nas áreas atingidas por desastre, e dá outras providências.

BRASIL (2012). Lei n. 12.593 de 18 de janeiro de 2012. Institui o Plano Plurianual da União para o período de 2012 a 2015.

BRASIL (2012). Lei n.12608 de 10 de abril de 2012. Institui a Política Nacional de Proteção e Defesa Civil - PNPDEC; dispõe sobre o Sistema Nacional de Proteção e Defesa

Civil - SINPDEC e o Conselho Nacional de Proteção e Defesa Civil - CONPDEC; autoriza a criação de sistema de informações e monitoramento de desastres; altera as Leis nos 12.340, de 10 de dezembro de 2010, 10.257, de 10 de julho de 2001, 6.766, de 19 de dezembro de 1979, 8.239, de 4 de outubro de 1991, e 9.394, de 20 de dezembro de 1996; e dá outras providências.

BRASIL (2015). Lei n. 10257 de 12 de janeiro de 2015. Institui o Estatuto da Metrópole, altera a Lei no 10.257, de 10 de julho de 2001, e dá outras providências.

SÃO PAULO - Governo do Estado (1989). Constituição Estadual de 5 de outubro de 1989.

SÃO PAULO - Estado (1997). Lei Estadual 9866, de 28 de novembro de 1997. Dispões sobre diretrizes e normas para a proteção e recuperação das bacias hidrográficas dos mananciais de interesse regional do Estado de São Paulo.

SÃO PAULO (2006). Lei n. 12.233, de 16 de janeiro de 2006. Define a área de proteção e recuperação dos mananciais da bacia hidrográfica do Guarapiranga, e dá outras providências correlatas.

SÃO PAULO - Governo do Estado (2009). Lei no 13.798, de 9 de novembro de 2009. Institui a Política Estadual de Mudanças Climáticas - PEMC.

SÃo PAULO (2009A). Lei 13.579, de 13 de julho de 2009. Define a área de proteção e recuperação doa mananciais da bacia hidrográfica do Reservatório Billings - APRMB.

SÃO PAULO - Governo do Estado. Secretaria do Meio Ambiente e Secretaria de Saneamento e Energia (2010). Resolução Conjunta SMA/SSE-002 de 19 de fevereiro de 2010. Trata de procedimentos a serem adotados em casos de emergência na operação do sistema hídrico da bacia do Alto Tietê e bacias a ela interligadas.

SÃo PAULO - Município (2009). Lei n. 14.934, de 18 de junho de 2009. Autoriza o Poder Executivo a celebrar contratos, convênios ou quaisquer outros tipos de ajustes necessários, inclusive convênio de cooperação e contrato de programa, com o Estado de São Paulo, a Agência Reguladora de Saneamento e Energia do Estado de São Paulo - ARSESP e a Companhia de Saneamento Básico do Estado de São Paulo - SABESP, para as finalidades e nas condições que especifica; cria o Fundo Municipal de Saneamento Ambiental e Infraestrutura; e dá outras providências. 
SÃO PAULO - Município (2015). Portaria 131/SEHAB/2015. Dispõe sobre Concessão de atendimento Habitacional Provisório.

DAEE (2004). Portaria DAEE n. 1213 de 06 de agosto de 2004. Determina concessão das vazões máximas médias mensais e autorização administrativa para fins de abastecimento público do Sistema Cantareira.

ANA-DAEE (2010). Resolução Conjunta da ANA e DAEE n. 614/2010. Dispõe sobre as condições de operação dos reservatórios do Sistema Cantareira no período de controle de cheias.

DAEE-DPO (2010). Nota Técnica do DAEE n. 01/2010 de 28 de outubro de 2010. Define as vazões de restrição para descargas dos aproveitamentos do Sistema Cantareira para jusante.

ANA - DAEE (2017). Resolução Conjunta ANA-DAEE n. 925, de 29 de maio de 2017. Dispõe sobre as condições de operação para o Sistema Cantareira.

ANA-DAEE (2017). Resolução Conjunta ANA-DAEE n. 926, de 29 de maio de 2017. Dispõe sobre a outorga à Companhia de Saneamento Básico do Estado de São Paulo - Sabesp do direito de uso das vazões máximas médias mensais do Sistema Cantareira.

\section{SITES CONSULTADOS:}

PREFEITURA DE SÃO PAULO

http://www.capital.sp.gov.br/cidadao/seguranca/servicos/operacao-chuvas-de-verao

CGE Centro de gerenciamento de emergências https://www.cgesp.org/v3/

SISTEMA DE ALERTA A INUNDAÇÕES DE SÃO PAULO - SAISP

https://www.saisp.br/estaticos/sitenovo/home.xmlt

CENTRO NACIONAL DE ALERTAS E MONITORAMENTO DE DESASTRES NACIONAL CEMADEN https://www.cemaden.gov.br

SECRETARIA DE HABITAÇÃO DO MUNICÍPIO DE SÃO PAULO - SEHAB-PMSP

http://www.habitasampa.inf.br/atendimento/

SUPERINTENDÊNCIA DE SEGUROS PRIVADOS - SUSEP http://www.susep.gov.br/

EMPRESA PAULISTA DE PLANEJAMENTO METROPOLITANO - EMPLASA. Sistema de Informações Metropolitanas - SIM. http://sim.emplasa.sp.gov.br

\section{FONTES DOS DADOS UTILIZADOS:}

Bases Centro de Estudos da Metrópole para RMSP-Terraview-CEM

IPT-CPRM - dados de suscetibilidade

Secretaria de Energia e Mineração do Estado SP- localização subestações e conjuntos elétricos

Sistema Nacional de Informações em Desastres - S2iD http://s2id.mi.gov.br

INSTITUTO GEOLÓGICO - Cadastro de Eventos Geodinâmicos e Desastres do Estado de São Paulo. Instituto Geológico, Secretaria do Meio Ambiente: Estado de São Paulo. Planilha Online. Disponível em: http://goo.gl/8UjEi2 - último acesso em nov/2018.

EM-DAT - Plataforma internacional de dados sobre desastres

IPMET-Unesp. Instituto Meteorológico de Bauru. Cadastro de desastres do Estado. 
Arquivos do Jornal Folha de São Paulo - consulta sistemática às edições impressas dos períodos:

- maio 2005

- fevereiro 2005

- dezembro 2007

- 6 de setembro 2009 a 22 de janeiro 2010

- 01 de janeiro a 01 de fevereiro de 2011

- 01 de novembro de 2014 a 31 de janeiro de 2015

- 01 de março a 31 de março de 2016

Notícias online que não constam das edições impressas:

FOLHA DE SÃo PAULO (2011). Com enchentes, leptospirose avança em São Paulo. Edição de, 16 de janeiro de 2011, Caderno Cotidiano.

O ESTADO de SÃO PAULO (2016). "Região Oeste da Grande São Paulo é o novo gargalo do “abastecimento'”. Edição de 06 de junho de 2016, versão online.

FOLHA DE SÃO PAULO (2014). "Seca faz cidade cancelar rafting e boia cross no interior Paulista”. Edição de 20/07/2014, Seção Cotidiano, atualizado 15h57. Disponível em: https://www1.folha.uol.com.br/cotidiano/2014/07/1488618-seca-faz-cidade-cancelar-rafting-eboia-cross-no-interior-paulista.shtml

UOL (2014). "Morte de peixes por poluição revolta moradores de Salto (SP)". Notícia de 28/11/2014 - UOL Araçatuba 18h10. Disponível em: https://noticias.uol.com.br/ultimasnoticias/agencia-estado/2014/11/29/morte-de-peixes-por-poluicao-revolta-moradores-de$\underline{\text { salto.htm }}$

G1 (2014). "Morador registra milhares de peixes mortos em córrego de Salto". Notícia de 29/11/2014 - G1 Sorocaba e Jundiaí 15h27. Disponível em: http://g1.globo.com/saopaulo/sorocaba-jundiai/noticia/2014/11/morador-registra-milhares-de-peixes-mortos-emcorrego-de-salto.html

UOL Notícias (2014). "Morte de peixes por poluição revolta moradores de Salto". Notícia de 29/11/2014 - Agência Estado - Araçatuba, 15h30. Disponível em:

https://noticias.uol.com.br/ultimas-noticias/agencia-estado/2014/11/29/morte-de-peixes-porpoluicao-revolta-moradores-de-salto.htm

AGÊNCIA ESTADO (2014). "Salto retira $40 \mathrm{t}$ de peixes mortos por poluição no Tietê". Notícia de 01/12/2014 - Estadão Conteúdo - Chico Siqueira, especial para Agência Estado,

8h28.Disponível em: https://www.estadao.com.br/noticias/geral,salto-retira-40-t-de-peixesmortos-por-poluicao-no-tiete, 1600482

G1 (2015). "Ambientalista aposta em mudança na lei para combater espuma nos rios". Notícia de 05/07/2015 - G1 Sorocaba-Jundiaí 13h50. Disponível em: http://g1.globo.com/saopaulo/sorocaba-jundiai/noticia/2015/07/ambientalista-aposta-em-mudanca-na-lei-paracombater-espuma-nos-rios.html

UOL (2015). "Mortandade de peixes no rio Tietê em 2014 gera multa à Emae e ao DAEE". Notícia de 22/07/2015 - UOL Ribeirão Preto, 21h39. Disponível em:

https://noticias.uol.com.br/cotidiano/ultimas-noticias/2015/07/22/mortandade-de-peixes-no-riotiete-em-2014-gera-multa-a-emae-e-ao-daee.htm

AGÊNCIA ESTADO (2015). "Mancha de poluição no rio Tietê dobra em 1 ano e 'invade' o interior". Notícia de 23/09/2015 - Fábio Leite para O Estado de S. Paulo, 7h00. Disponível em: https://sustentabilidade.estadao.com.br/noticias/geral,poluicao-no-rio-tiete-dobra-em-1-ano-einvade-interior, 1767220 


\section{GLOSSÁRIO DE SIGLAS}

ABIQUIM Associação Brasileira da Indústria Química

ABNT Associação Brasileira de Normas Técnicas

AID Associação Internacional de Desenvolvimento

AMA Ambulatório Médico Assistencial

AMOJAP Associação dos Moradores do Jardim Pantanal e Várzea do Tietê

ANA Agência Nacional de Águas

APA Área de Proteção Ambiental

APM Área de Proteção aos Mananciais

APELL Awareness and Preparedness for Emergencies at Local Level

ARSESP Agência Reguladora de Saneamento e Energia do Estado de São Paulo

AVADAN Formulário de Avaliação de Danos

BAT Bacia do Alto Tietê

BATER Base Territorial Estatística de Áreas de Risco

BID Banco Interamericano de Desenvolvimento

BIRD Banco Internacional para Reconstrução e Desenvolvimento

CAT-DDO Catastrophe Deferred Drawdown Option - Linha Contingente de Crédito

CAT Bonds Catastrophe Bonds - Títulos de Catástrofe

CDHU Companhia de Desenvolvimento Habitacional e Urbano do Estado de São Paulo

CDP Centro de Detenção Provisória

Ceagesp Companhia de Entrepostos e Armazéns Gerais de São Paulo

CEDEC Coordenadorias Estaduais de Defesa Civil

CEF Caixa Econômica Federal

CEM Centro de Estudos da Metrópole

CEMADEN Centro Nacional de Monitoramento e Alerta a Desastres Naturais

CENAD Centro Nacional de Gerenciamento de Riscos e Desastres

CEPED-UFSC Centro de Pesquisa em Desastres - Universidade Federal de Santa Catarina

CEPETEC Centro de Previsão de Tempo e Estudos Climáticos

CET Companhia de Engenharia de Tráfego

CETESB Companhia Ambiental do Estado de São Paulo

CEU Centro de Educação Integrada

CGE Centro de Gerenciamento de Emergências

CHESS Crise Hídrica, Estratégias e Soluções Sabesp (Plano)

CIMBAJU Consórcio Intermunicipal dos Municípios da Bacia do Juqueri

COBOM Centro de Operações do Corpo de Bombeiros

COBRADE Classificação e Codificação Brasileira de Desastres

COHAB Companhia Habitacional do Município

COMDEC Comissões Municipais de Defesa Civil 
CORDEC Coordenadorias Regionais de Defesa Civil

CN Coeficiente de Permeabilidade

CPLA Coordenadoria de Planejamento Ambiental

CPP Centro de Progressão Penitenciária

CPRM Serviço Geológico do Brasil

CPTM Companhia Paulista de Trens Metropolitanos

CRED Centre for Research on the Epidemiology of Disasters

CTM-GRAU Câmara Temática de Gestão de Riscos Metropolitanos

CVE Centro de Vigilância Epidemiológica

DAEE Departamento de Águas e Energia Elétrica

DBO Demanda Bioquímica de Oxigênio

DPE Department for Professional Employees

EIRD-ISDR Estratégia Internacional para Redução de Desastres - International Strategy for Risk Reduction

EMAE Empresa Metropolitana de Águas e Energia S.A.

EM-DAT Plataforma de dados internacionais sobre desastres

Emplasa Empresa Paulista de Planejamento Metropolitano S.A.

ETE Estação de Tratamento de Esgotos

FCTH Fundação Centro Tecnológico de Hidráulica

Fehidro Fundo Estadual de Recursos Hídricos

FEMA Federal Emergency Agency - Agência Federal para Emergências

FESR Fundo de Estabilidade do Seguro Rural

FIDE Formulário de Informação do Desastre

FMSAI Fundo Municipal de Saneamento ambiental Integrado

FONDEN Fundo Nacional de Desastres - México

FPIC Funções Públicas de Interesse Comum

FUNCAP Fundo Nacional para Calamidades Públicas

GAEE Grupo de Articulação de Ações Executivas

GECAP Grupo Especial para Calamidades Públicas

GESP Governo do Estado de São Paulo

GRD Gestão de Risco de Desastres

IAG Instituto de Astronomia, Geofísica e Ciências Atmosféricas

IBGE Instituto Brasileiro de Geografia e Estatística

IG Instituto Geológico

IPMET Centro de Meteorologia de Bauru

INMET Instituto Nacional de Meteorologia

INPE Instituto Nacional de Pesquisas Espaciais

IPCC International Panel on Climate Change - Painel Intergovernamental de Mudanças Climáticas das Nações Unidas 
IPPUR Instituto de Pesquisa e Planejamento Urbano e Regional

IPT Instituto de Pesquisas Tecnológicas

IPTU Imposto Predial Territorial Urbano

IRB Instituto de Resseguros do Brasil

ISO International Organization for Sandartization

MCMV Minha Casa Minha Vida

MUNICH-RE Companhia de Seguros e Resseguros Alemã

NASA National Aeronautics and Space Administration - Administração Nacional da Aeronáutica e Espaço.

NFIP National Flood Insurance Program - Programa Nacional de Seguros contra Inundações

NOPRED Formulário de Notificação Preliminar de Desastres

NUDEC Núcleos Comunitários de Defesa Civil

ONS Operador Nacional do Sistema Elétrico

ONU Organização das Nações Unidas

PAC Programa de Aceleração do Crescimento

PAI Perímetro de ação Integrada

PDMAT Plano Diretor de Macrodrenagem da Bacia do Alto Tietê

PDN Programa Estadual de Prevenção de Desastres Naturais e de Redução de Riscos Geológicos

PDUI Plano de Desenvolvimento Urbano Integrado

PEMC Política Estadual de Mudanças Climáticas

PFD Proteção Financeira aos Desastres

PIB Produto Interno Bruto

PM Polícia Militar

PMA Perda Anuam Média

PMSP Prefeitura de São Paulo

PMRR Plano Municipal de Redução de Risco

PNAD Pesquisa Nacional por Amostragem de Domicílios

PNPDEC Política Nacional de Prevenção e Defesa Civil

PPCV Plano Preventivo Operação Chuvas de Verão

PPDC Plano Preventivo da Defesa Civil

PVT Parque Várzeas do Tietê

P2R2 Plano Nacional de Prevenção, Preparação e Resposta Rápida a Emergências Ambientais com Produtos Perigosos

RMSP Região Metropolitana de São Paulo

RRD Redução de Risco de Desastres

SABESP Companhia de Saneamento Básico do Estado de São Paulo

SAISP Sistema de Alerta de Inundações do Estado de São Paulo

SEADE Fundação SEADE

SEDEC Secretaria Especial de Defesa Civil 
SEHAB Secretaria Municipal de Habitação

SES Secretaria de Estado da Saúde

SIDEC Sistema Integrado de Defesa Civil - Estado de São Paulo

SIM Sistema de Informações Metropolitanas

SINDEC Sistema Nacional de Defesa Civil

SMA Secretaria do Meio Ambiente

SPAT Sistemas Produtores do Alto Tietê

SPE Sociedade de Propósito Específico

SRHSO Secretaria de Recursos Hídricos, Saneamento e Obras

SSE Secretaria de Estado de Saneamento e Energia

SSRH Secretaria de Saneamento e Recursos Hídricos

SUSEP Superintendência de Seguros Privados

SWISS-Re Swiss Reinsurance Company

S2iD Sistema Integrado de informações sobre Desastres

UFABC Universidade Federal do ABC

UGRHI Unidade Hidrográfica de Gerenciamento de Recursos Hídricos

UNDP United Nations Development Program

UNISDR United Nations Office for Disaster Risk Reduction - Escritório das Nações Unidas para Redução de Riscos a Desastres

USACE The U.S. Army Corps of Engineers - Corpo de Engenheiros do Exército dos Estados Unidos

USP Universidade de São Paulo

UTB Unidades Territoriais Básicas

VGBL Vida Garantidor de Benefício Livre - modalidade de seguro

ZEIS Zona Especial de Interesse Social 